THE ARCHAEOLOGY OF WILSON'S PROMONTORY

P.J.F. Coutts

Volume 1

This thesis was submitted in partial fulfilment of the requirements for the degree of Master of Arts in the Australian National University,

May 1967 
All sources used in this thesis have been acknowledged and the thesis is my own composition.

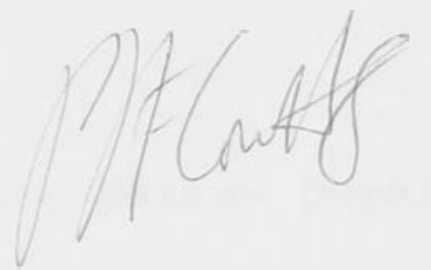

P.J.F. Coutts 


\section{AC KNOWLEDGEMENTS}

To all those people mentioned below I wish to extend my sincere thanks for their assistance and participation in this project.

\section{Specialists}

(a) Geologists and Geomorphologists

Dr J, Talent (Department of Mines, Melbourne) for rock identification and general advice. Mr W. Tuddenham (Geography Department, Sydney University), Mr B. Joyce (Geology Department, Melbourne University) and Mr V. Gostin (Research Scholar, Geology Department, A.N.U.) for general discussions on the area and advice and assistance in the field.

\section{(b) Botanists}

Mr B. Parsons (Research Scholar, Botany Department, Melbourne University) for carrying out and writing up a field project in the region of Site 9A. Also Mr M. Gill (Research Scholar, Botany Department, Melbourne University) for general advice. Dr S. Duigan (Botany Department, Melbourne University) for her report on pollen samples from the peat.

\section{(c) Conchologists}

Mrs H. Black, formally Miss Hope Macpherson

(National Museum, Melbourne) for making the journey to the Promontory and identifying species and habitats. Also for advice and identification in the laboratory.

(d) Zoology

Dr J. Warren (Zoology Department, Monash University) for identifying and writing a report on the bone material 
(e) Soils

Mr F。 Gibbons (Soil Conservation Authority, Victoria) for arranging for numerous soil samples to be ana 1 ysed.

(f) Laboratory Tests

Mr G. Grant (State Laboratories, Victoria) for arranging to have the pitch samples analysed and Mr C, Key for his report on polished stone axes.

\section{(g) Artists and Photographers}

Miss E。 Scott, Mr B. Jorgenson and Miss V, Mumford for drawings of artifacts. Mr Jorgenson was also the photographer on the first few expeditions. Mr R, Lyth was the photographer on later expeditions.

(h) Surveying

Mr B. Jorgenson, Mr Jo Coomes (National Mapping, Melbourne), Mr B, Sandy (Swinburne Technical College, Melbourne) and Mx Jo Pollitt (formerly of Melbourne Technical College, Melbourne). Professor Fulton Smith (Surveying Department, Melbourne University) for loaning the expedition surveying equipment,

(i) Special Projects

Mr R, Pryor (Geography Department, Melbourne University) for conducting and analysing the augering project on Site 9A. Miss C, Donavon (Geologist, B.H.P.) for assisting in the augering project. Miss $M$, Opthorpe (Geologist, B.H.P。) for notes on the morphology of Site 9D。

\section{(j) Supervisors}

Mr J, Pollitt (formerly of the Royal Melbourne Institute of Technology) and $M x \quad J$. Trompf (formerly of the History Department, Monash University). 
(k) Archaeologists

Mr J, Golson and Mr J.D. Mulvaney (both of the Archaeology Department, A.N.U.) for advice.

(1) Computers and Mathematics

Professor W, Ewens (formerly of the Statistics Department, A.N.U.) for statistical advice and for devising various statistics, Mr N, Tuckwell (statistics Department, A.N.U.) for programming and statistical advice, and for writing several programs. Mr G, Achmaty (formerly of the Mathematics Department, A.N.U.) for several programs.

(m) Paleotemperature Measurements

Dx F, Dorman, C.S.I.R.O., David-Rivett Laboratories, Monash University.

(n) Calcite-Aragonite Measurements

Dr R.A. Eggleton for his advice and for allowing the author to use the departmental X-ray diffractometer. Mr B. Gulson for some preliminary measurements.

\section{Lay Projects}

(a) Miss C. Champion, Mr and Mrs J, Taylor, Mrs E. Henderson, Mrs S. Slater, Mrs D, Cato and Mrs A Crossley for working on various shell projects.

(b) Mr J, Taylor and Miss J, Lang for conducting various field projects associated with shell studies.

(c) Mr K. Simpson (Eden), Mrs C, Harris (Broulee), Mr H. Pilgrim (Shell Harbour), Mr K, Thorpe (Ulladulla), and Miss M. Crossley (Ricketts Point, Victoria) for taking measurements of sea temperatures throughout $1965-6$.

(d) Laboratory Analysis. Special thanks to Mr and Mrs K. Crossley for making their house available on Tuesday nights, A fine work group consisting of Mrs A Crossley, Mrs L. Curr, Mrs S, Slater, Mrs D, Cato, Mr and 
Mrs J. Taylor, Mr P. McGann, R. Dundas, Mr M. Binderman, Mrs E. Henderson, Mrs K. Moffatt and Mr R. Glen assisted with this work.

(d) Transport. Mr K. Crossley and Mr D. Debenham (Foster) for supplying Landrovers. Mr Debenham also provided storage space on his property and some equipment for the various expeditions. Mr C. Cowling (Fisheries and Games Department, Victoria) arranged the transport of heavy equipment to the Promontory.

(e) Cooks. Miss S. Munro and Miss J. Anderson.

(f) Historical Information, Miss D, Rose and Miss S. Jago were responsible for collecting local historical data.

(g) Typing. Special thanks to Mrs N. Young of the A.N.U. Typing Pool for oxganising the several drafts of this thesis. Also Mrs E, Ballestrin for typing the final draft. Mrs B, Calderwood and Mrs B. Muller for the offset printing,

\section{Excavating and Field Teams}

The following personnel were engaged in field work at the Promontory on various expeditions:- D。 Rose,

S. Jago, S. Monsborough, C, Champion, A. Rubbo,

T. Kandiah, A. McDonald, A. Scott, G, Allen, B. Clarkson,

D. Skiotis, M. Harris, J. Wilson, K。 Every, I, Every,

N. Gregory, D。 Woodruff, B. Millex, L, Scott, J, Brush, C. Fowler, D, Gilbert, S, Heenan, Dr E. Shaw, A.R.F. Dowling, D. Dungan, S, Slater, J。 Taylor, Joy Taylor, L. Curx, A. Crossley, K. Crossley, D, Cato, N. Butler, H, Coutts, S, Longmuix, F, McDonald, C. Reseigh, J, Howell, P. Mosig, R. Clarkson, D, Thomson, C. Garnaut, L。 Drulin, To Pryor, Do Curtis, J, Byard, G, Douglas, D, Hoban, W. Pate, D. Jones, G. Parkenson, 
M. Tyre11, L. Anderson, B. Ridland, G. Tahan, G, Rolph,

M. Zidan, T. Willoughby, F, Dykstra, J. McMann,

E. Barrow, G. Breen and M, Redding.

4. Other

Mr J, Allen for proof reading. Tents were

borrowed from the Army through Captain D'Burn (Victoria Barracks)。

Last1y, I would like to thank the A.N.U. for

financial support, The University contributed up to two thirds of the total cost of the project, and much of the analytical work was carried out under an A.N.U. research grant. 


\section{VOL UME 1}

2. 3 Yanakie West Sites

2. 4 Yanakie East Sites

2.5 Wilson's Promontory West Sites

2.6 Wilson's Promontory East Sites

2.? Tasmanian Connections

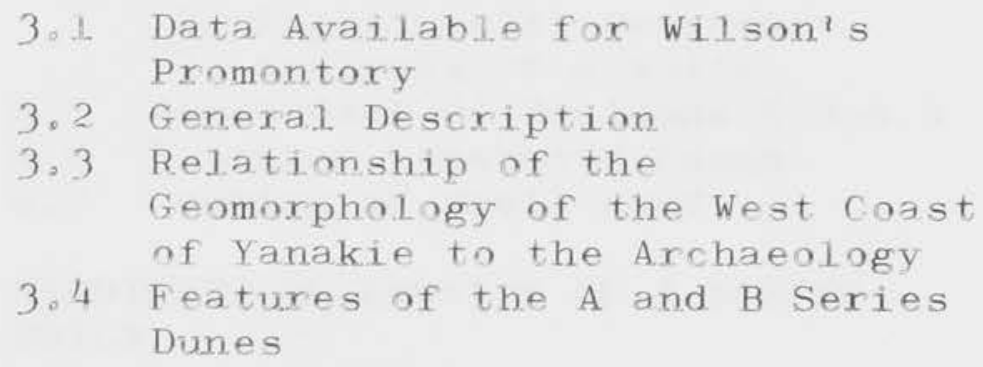

3.2 General. Description

3. 3 Relationship of the Geomorphology of the West Coast of Yanakie to the Archaeology

3. 4 Features of the A and B Series Dunes

CHAPTER 4 SITES 9, 10 AND II; THE GENERAL ARCHAEOLOGY OF THE YANAKIE AREA

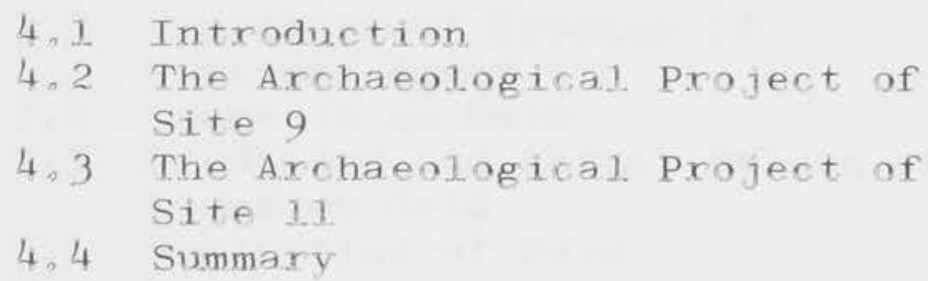

CHAPTER 5 ANALYSIS OF FAUNAL MATERTAL FROM THE EXCAVATIONS AT WILSON'S PROMONTORY, PART I

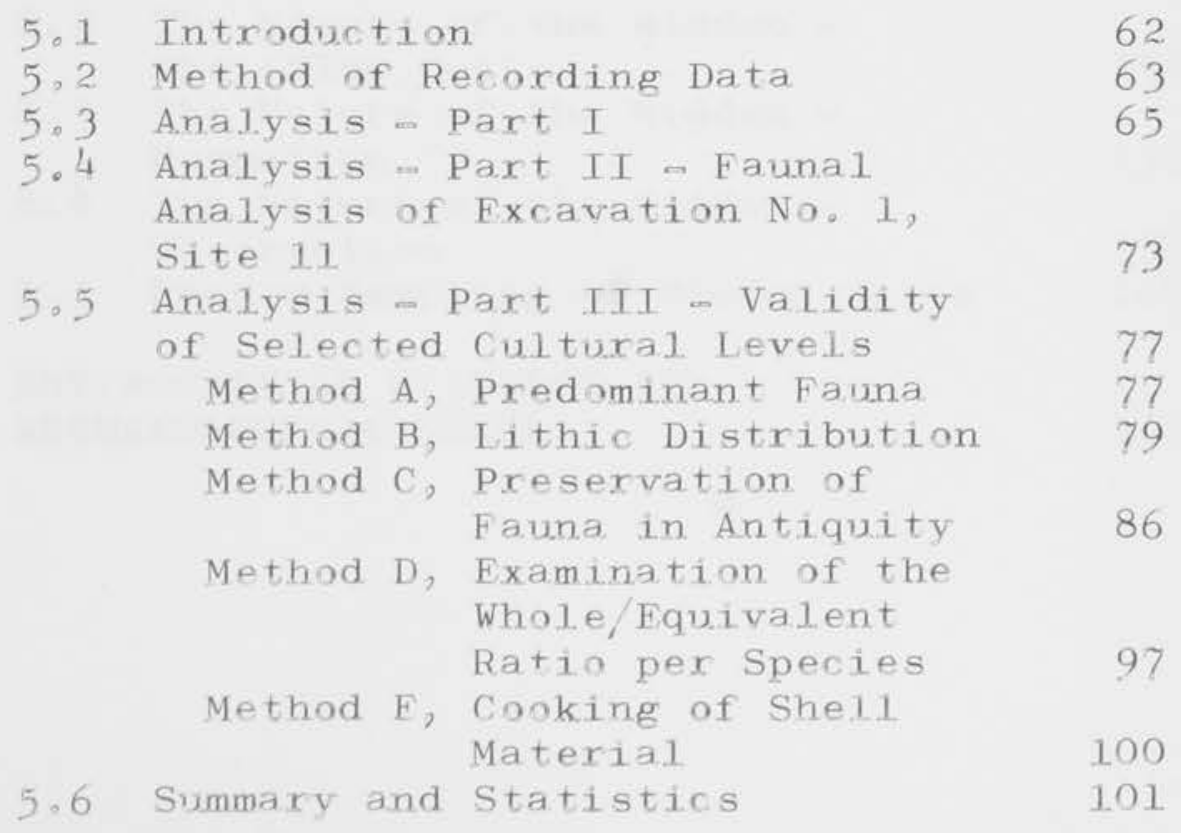


CHAPTER 6 ANALYSIS OF FAUNAL MATERIAL FROM THE EXCAVATIONS AT WILSON'S PROMONTORY, PART II

6.1 Selection of Occupational Flooxs 103

1. Excavation No. 1, Site 9A

2. Excavations Nos. 3 and 5, Site $9 \mathrm{~A}$

3. Excavation. No, 6, Site 9A

6.2 Correlation of Other Peak Ratios 111

1. Excavations Nos, 3 and 5, Site 9A

2. Excavation No, 6, Site 9A

6.3 Examination of the $W / E$ Ratio per Species

1. Excavation Nos. 3 and 5, Site 9A

2. Excavation No. 6, Site 9A

6.4 Experiments Carried Out to Ascertain the Degree of Shell Movement in the Present Environment

1. Introduction

2. Experimental Procedure

118

3. Analysis of Results

6.5 Assessment of Sections 6.3-6.4

120

6.5 Assessment of Sections $6.3-6.4$

121

6.6 B Series Excavated Fauna

125

6.7 Cooking of She11 Food

132

132

CHAPTER 7 HYPOTHETICAL EROSION OF A SERIES SOILS

7.1 Introduction 134

7.2 Determining the Degree of

7.3 Hypothetical Exosion of Uneroded Areas

7.4 Comments on Data

7.5 Predicted and Actual Values of Fauna on Grid

7.6 Evaluation of Data

7.7 Summary

CHAPTER 8 RANDOM SAMPLTNG OF MIDDEN SITES

8.1 Introduction

8.2 The Nature of the Midden The 'Blow Out'

8.3 The Nature of the Midden Formation

8.4 The Nature of the Midden Observation

8.5 Random Sampling of Midden Sites 


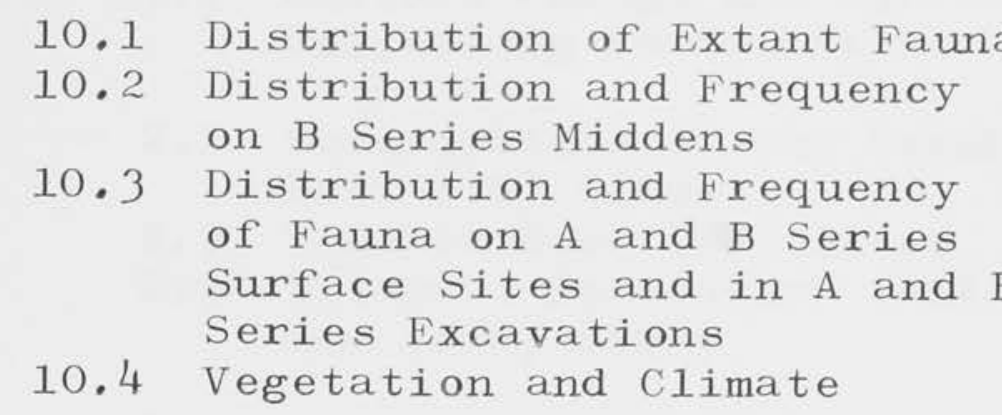

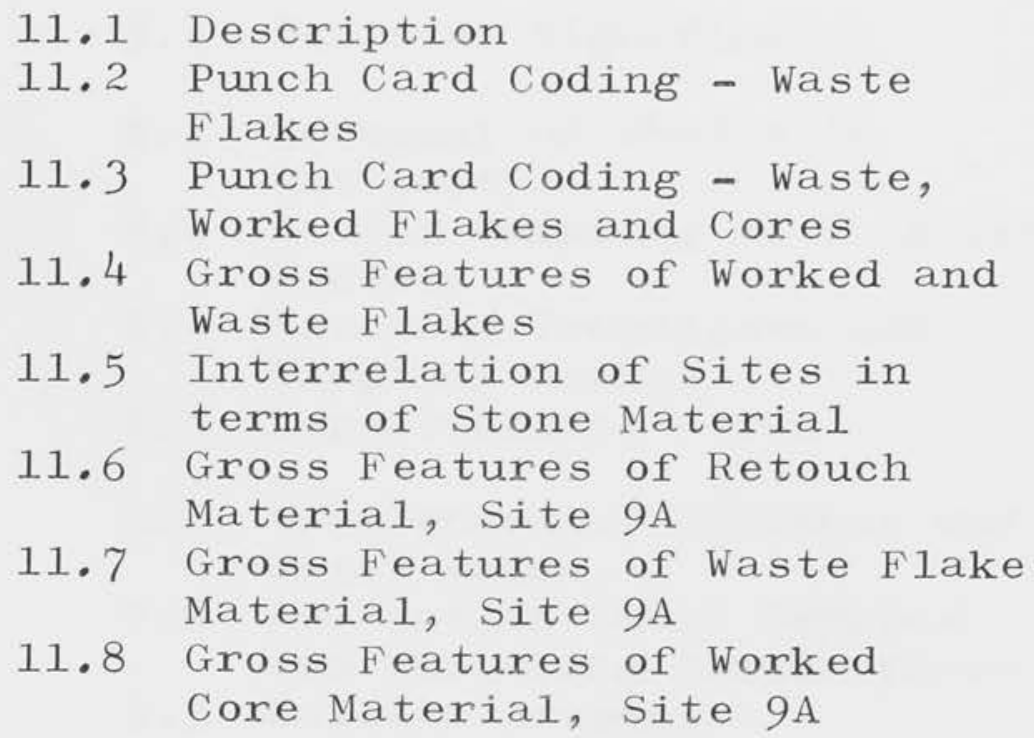

CHAPTER 13 THE ABORIGINES OF WILSON'S PROMONTORY 
APPENDICES 1.1 Culture Change and Surface Collecting in Australia

2.1 Descriptions of the Yanakie West (YW) Sites

2.2 Yanakie East (YE) Sites

2.3 Wilson's Promontory (WPW) and (WPE) Sites

4.1 Methods of Excavations

4.2 Method of Soil Analysis

xviii

xxyi

5.1 Tests of Significance

xxviii

8.1 Movement of Shells in Antiquity

$\operatorname{xxxii}$

8.2 Random Sampling of B Series Middens

8.3 Counting Techniques and Sampling Errors

8.4 Topographical Notes

9.1 Environmental Evidence and She11 Fauna

9.2 Collecting She11 Samples and Measuring Temperatures

9.3 Calcite Aragonite Determination by $\mathrm{X}$-ray Analysis

$\mathrm{x} \times \times \times i$ xxxxyiii

$1 \times x i i i$

$1 \times x v i$

10.1 Botanical Report on the Area in the Vicinity of Sites 9 to 11, by R.F. Parsons

$1 \times \times x$

10.2 Analysis of Pollen Samples from the Peat at Wilson's Promontory, Victoria, by Dr. S. Duigan

$1 \times x x i i$

11.1 Statistical Tests by

N. Tuckwe 11

$1 \times x \times v i$

11.2 Retouch and Utilization Indexes

$1 \times x \times i x$

12.1 Description and Characteristics of Some Standard Classes of A Series Tools

12.2 Classification Using a Computer

$1 \times \times \times x i$

12.3 Edge Ground Axes from Wilson's Promontory

12.4 Mineralogical Examination of Axes by C. Key

12.5 Zoological Report from Wilson's Promontory by J. Warren

12.6 Report on a Pitch Sample by J.C. Kennedy 
DIAGRAMS

PLATES

VOLUME 2

\section{TABLES}

LIST OF ABBREVIATIONS 


\section{INTRODUCTION}

Wilson's Promontory is Australia's southernmost land projection (Diagram 1.1). Detailed archaeological work began in this area in the summer of 1964 and was continued until January 1966. During this period excavations and surveys were conducted which eventually showed that the aborigines had occupied this area for at least 6500 years. This discovery in its own right is important enough to justify the original choice of the area as one suitable for field studies. However, several factors influenced the choice of Wilson's Promontory as a promising area to initiate field work.

(a) The Promontory is close to Melbourne, thus facilitating the transport of staff and supplies to and from the area. This must always be an important consideration when choosing a site where work is to be carried out over long periods.

(b) There is a need for a systematic survey of the archaeological sites of Victoria, carried out on a regional basis, and similar to the work carried out by Isobel McBryde in New England, New South Wales (Isobel McBryde 1962, p.12; 1963, p.64). ${ }^{1}$

\section{1}

As far as can be ascertained there have been no comprehensive field surveys in Victoria. Mulvaney has conducted investigations in the Glen Aire area, but his principal concern has been with excavating cave shelters (D.J. Mulvaney 1960a, p.2). The first regional survey has yet to be published for this state.

In South Australia and New South Wales there have been attempts to publish regional reports. The south Australian published accounts suffer generally from the following defects: (a) Relocation is poor. There are no datums or grid references given. (b) Vague descriptions of sites, with poor drawings and maps. A twenty year old drawing is of little use to the present 
Until this is done, the prehistory of Victoria

cannot be written. Because Wilson's Promontory is one of the few areas to escape extensive pillage by vandals and collectors, it is a suitable area from which to commence a regional survey in Victoria.

It was decided that the survey should extend across the land mass to the south of the northern boundary of Yanakie Isthmus.

(c) Several major archaeological considerations influenced the choice of the Promontory as a starting point for the survey.

1. In the past, writers have speculated on the origin of the Tasmanian and Australian Aborigines. ${ }^{1}$ It is recalled that the former

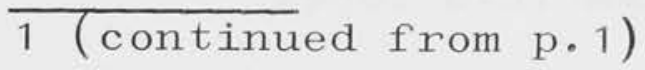

worker without datums, especially if the physiography of the landscape is changing. (c) Implements associated with a particular site are not named (T.D. Campbe11 and H.V.V. Noone, 1943a and 1943b, and T.D. Campbell, J.B. Cleland and P.S. Hossfeld, 1946 and regional reports of this nature). More recently Mulvaney has carried out a regional survey in the Glenelg area. Again he has been preoccupied with finding cave sites for the purposes of excavation, and his reports on the results of the survey are brief, and unillustrated (D.J. Mulvaney, 195.7, p.38). Thus South Australian field work also awaits a more scientific and detailed approach by its workers.

In New South Wales much the same comments apply. McCarthy has been responsible for most of the regional survey work and though more objective and stimulating in his interpretation of the surface material, his publications suffer from most of the defects listed above (i.e.F.D. McCarthy, 1941; 1943a and 1943b; 1947 etc). 1

This problem has been discussed and reviewed by many authors, some of whom are listed below. Those references which have an asterisk give more detailed accounts: A.W. Howitt 1904, pp.1-8; H. Basedow 1925, pp.52-60; R.H. Pulleine 1929, pp.296-8; F.W. Jones 1935, pp.5-7; D.S. Davidson* 1937; A.P. E1kin 1938, p.19ff; D.J. Mahony* 1943, p.9; N.W.G. Macintosh* 1963, p.250; R.M. \& C.H. Berndt 1964, p.2ff. A recent and the most comprehensive review is contained in N.W.G. Macintosh and B.C.W. Baker* 1965, pp.47-54. 
has been classified as Negroid and the latter as Australoid.

Out of the confused and conflicting evidence put forward in support of various theories, three schools of thought have emerged (T.B. Kemp 1963, p.245). The first proposed that the Tasmanians arrived in Tasmania by sea without contact with the Mainland Aborigines, i.e. 'the drifters' (F. Wood-Jones 1935, pp.5-7; W. G. Macintosh 1949, p.123ff, for discussion of this possibility). The second school proposed that they reached Tasmania from the Mainland by hopping from one island to the next, across Bass Strait (A.L. Merston 1935; 1936; 1949; 1956; D.J. Mahony 1943, p.12). Neither of these two schools then, supposed any great antiquity for the Tasmanian Aborigine. The other school suggested that they entered Tasmania over a Pleistocene land bridge from Continental Australia (D.S. Davidson 1937; J.B. Birdse11 1949, p.120; A. N. Lewis 1934, p.83).

Recent evidence has tended to favour the land bridge hypothesis. Starting with Gill in 1954, whose dates for the Keilor skul1 suggested Pleistocene occupation of the area (E.D. Gi11 1953a, 1953b, 1954a, 1955a, etc) other dates have come forth in the last three years to prove beyond doubt that man was in Australia during the Pleistocene (D.J. Mulvaney 1962, p.137; 1964a, p.42; 1964b, p.265). One must therefore assume that the Aborigine living in Australia at this 
time could cross from the Mainland to

Tasmania. 1 During the Pleistocene the granite peaks of Wilson's Promontory formed part of a range of mountains linking Tasmania and the Mainland. (The 'Bassian Isthmus', R.A. Keble 1946, p.113; J.N. Jennings 1959, p.54). This mountain chain bends south-eastward from the Promontory through the Hogan and Kent groups, through Flinders and Cape Barren Islands, swinging south-west to join north-eastern

Tasmania between Cape Portland and Eddystone Point. The ancient landscape and the flora and fauna are not entirely clear. It has been suggested that a peneplain existed between the Bassian and King Island ridges, and that some sort of river system carried the waters draining off the ridges westward across this peneplain, eventually emptying into the ocean. Keble describes the ancient landscape as follows:

1

Considerable confusion has arisen over the distance the sea fell during the last glacial. Some authors imply that Tasmania and the Mainland have not been connected since the second or third glacial period (A.B. Edwards 1941, p.256 - 120'-150' submerged shoreline; A.N. Lewis 1934, pp.83-4 - Lewis places migration into Tasmania in the Riss-Wurm interglacial. He suggests on purely eustatic evidence that there could have been no 1 and bridge since Mindel times. He therefore subscribes recent tectonic movement as the cause of submergence of the isthmus, an isthmus which he feels must have been in existence up to the last interglacial at least; D.J. Mahony 1943, p.22), i.e. the fall would have to be of the order of $180^{\prime}$ to complete the bridge ( J.N. Jennings 1959, see map facing p.50). Other workers maintain that the separation only took place in recent times, and that the fall in sea level during the last glacial far exceeded 180'. (R.A. Daly 1934, p.193, 75 metres fall, map of land bridge between Mainland and Tasmania, p.191; R.A. Keble 1946, p.116; 1947, p.64-i.e. 294' fal1). The situation is further complicated by tectonic movement (J.N. Jennings 1959, p.53). However if the sea

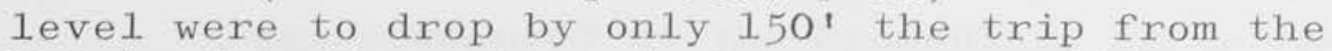
Mainland to Tasmania and vice versa could be achieved by a series of short sea journeys. 
Near the shore of the Tasman sea was the Bassian Ridge tending northeasterly from what is now Cape Portland in Tasmania to Wilson's Promontory in Victoria, and towards its western side was the King Island Ridge separating the middle reaches of the Tamar Major from its lower reaches. On both sides of the river flats was a gently rolling countryside covered with open forest; on the river flats was a deeper forest comparable to that of the Otway Peninsula or Gippsland, consisting of tall timber with strata of small trees and shrubs; but in places there were natural clearings with swamps and billabongs. In the open forest, the animal life was like that at present in a similar environment, and consisted of kangaroos (including the forester), wallabies, opossums, bandicoots, phalangers, native cats, echidnas, many kinds of reptiles.... (R.A. Keble, 1946, p.119).

Thus the plain was well watered and had plenty of game. At the end of the Pleistocene, however, as the waters breached the King Island Isthmus and encroached on the plain, if the Aborigines desired to cross from the Mainland to Tasmania they would have had to travel along the western foothills of the Bassian Ridge (R.A. Keble 1946, p.114).

It is unlikely that the Aborigines camped here during the Pleistocene, since the granite peaks would have held little attraction (except for water and perhaps shelter) for a hunting people. The plains would have been their main hunting grounds. Thus any evidence left in the foothills or in the mountains themselves along the Ridge would probably belong to the last phase of Pleistocene occupation in south-east Australia, to the era just preceding separation of the Mainland from Tasmania. Archaeological work 
some evidence of this last phase might be recovered.

2. Surface collecting in Victoria has had a long and infamous history. As early as 1918 Spencer noted that 'we have very few detailed accounts of any kitchen middens in Victoria' (Sir B. Spencer 1918, p.113). At this time the collecting of Aboriginal implements had not reached its height, but shortly afterwards many people had taken it up as a hobby. Thousands of Aboriginal implements found their way into private collections, most of them unlabelled and unidentified, ${ }^{1}$ while the practice of labelling the localities from which the implements were taken has only recently been impressed upon many collectors (A. Massola 1963, p.257). Societies were formed to implement more systematic and guided collecting. Within these societies, members participated in discussions of their finds and brought their discoveries to the attention of their fellow members. However, the fact remains that vast numbers of implements remain locked up in the dim archives of private collectors, unavailable for study and mostly unrecorded. As late as 1949 S.R. Mitchell could write: 'The locating and mapping of the camping sites of the Aborigine and the systematic collecting of relics from them is of the utmost urgency as so many of them are disappearing with the advance of settlement' (S.R. Mitche11 1949, pp.107-8) 
and this comment is equally true in 1967 .

'Systematic' should be emphasized. Labelling of implements with the site location and the selective collection of implements from these sites are not good enough. Selective collecting must be replaced with detailed collecting; every piece of stone from a site must be picked up and labelled. The lithic material must be collected and labelled on a fine scale - in carefully laid out grids with surveyed datums for purposes of re-location. It has been clearly demonstrated at the Promontory that a casual grid reference or the name of a site is not sufficient, and that positional errors of the order of 100 feet may change the entire archaeological significance of a site, Random collecting by we11-meaning amateurs must be discouraged. 1

A principal archaeological project at the Promontory has been to sort out lithic material found on surface sites and fix it culturally and chronologically. Here one is dealing with extensive middens which appear to have avoided the pilfering of collectors. This favourable situation is suggested, not only by the wealth of material still found in the area, but also

1

Mulvaney has also been careful to stress the essential nature of systematic surface collecting and the accurate record of sites (D.J. Mulvaney 1957, p.36; see also P.J.F. Coutts 1967b). However, he has also voiced his suspicions of field observations other than those arrived at by digging. His attitude is perhaps over cautious (D.J. Mulvaney 1964a, p.41). McBryde has said that 'systematic field studies still form the backbone of any archaeological programme' (I. McBryde 1962, p.12; 1963, p.64). Indeed, this will always be the case in Australia. 
by the fact that the area has received little or no mention in the literature. Visits by

A.S. Kenyon (1906), Sir Baldwin Spencer (1918; 1928 P $500 \mathrm{fig} .343$, VoL II), W.B Spencer and F.J.Gillen (ig27, p537. fig, $182, v i(i 1)$

182, vol. II; $1928,0.500$, fig. $343, \mathrm{vol}$. II)

and G. Nethercote (1920) are recorded; but no one since has attempted to elaborate on their comments. Indeed, Mitchell (1949) fails to mention the eight miles of middens on the west coast of Yanakie. Reasons why this midden series has been forgotten in recent times may be explained by two associated factors. Firstly, to reach Darby River in the early part of the century, one travelled along the beach from Shallow Inlet to Cottars Lake (or Darby River directly) or from here inland to Darby River depending on the state of the tide. This route proved dangerous and there were many instances of people being stranded by the incoming tide. Later an inland road was built to Darby River, so that coastal journeys were no longer attempted. Consequently the coastal midden series found obscurity. Secondly, entry onto the beach at Shallow Inlet had become treacherous (C. Daley 1925, p.205). The changing physiography of the beach front produced quicksand at this end of the beach, so that today, it is impossible to take a vehicle onto the beach at Shallow Inlet.

A review of field work carried out on midden sites shows how this aspect of Victorian prehistory has been neglected. Its contributors 
have been few. ${ }^{1}$ of these workers, Mitchell is to be commended for his effort in attempting to compile a comprehensive list of artifacts found at various sites, both along the coast and inland (S.R. Mitche11, 1949). However, his publication is not critical, and valuable as his work is for distributional purposes, he does not attempt to solve the cultural problems arising from the lithic material he so carefully describes. The archaeological project at Wilson's Promontory has been orientated towards defining cultural sequences rather than the description of sites and artifacts.

3. One of the most obvious and outstanding problems in Victorian (and Australian) prehistory is the relationship of Bondi points to geometric microliths. ${ }^{2}$ These implements occur on surface sites along the whole coast of Victoria and until recently had not been obtained in a stratified context in this state. It is to be regretted that no field worker has

1

A.S. Kenyon 1906, 1912, 1927; Sir Baldwin Spencer 1918, 1927, 1928; F. Chapman 1923; R.A. Keble 1928; S.R. Mitche11 1949, 1958, 1962; E.D. Gill 1953b, 1954a, 1955b; W.H.D. le Souef 1902, 1916; G. Horne 1921, are some of the contributors.

2

Hereafter referred to as backed blades (W. Wright 1964; W. Wright in Megaw 1966, p.29); their associations and chronology, to be more specific. Until Mulvaney excavated at Fromm's Landing, a similar problem existed in South Australia. Speculation in South Australia had reached the stage 'Where we can say no more than that the microliths are implements of an extinct aboriginal culture, and their use may have continued, in some areas, up to comparatively recent times' (T.D. Campbell and H.V.V. Noone 1943a, p.303). Mulvaney's excavations in South Australia have not completely clarified the relationship and much more archaeological work will need to be carried out in the future. Meanwhile up until 1964 little archaeological work of any cultural significance had been conducted in Victoria. 
attempted to exploit the evidence of surface sites to help place these implements in their correct context. At Wilson's Promontory, backed blades appear in midden deposits. It has been found that by carefully considering a midden's relationship to its geomorphological environment, important cultural information can be obtained from the area as a whole.

The distribution of geometric microliths in Australia has been partially described by Mulvaney (D.J. Mulvaney 1961, p.81) and brought up to date by the author. ${ }^{1}$ (Diagram 1.2). In south-east Australia, geometric microliths are found everywhere south of the Murray River, with the exception of most of the Northern District Plains and the most northerly portions of the Eastern Highlands.

In New South Wales they are found on the coast 100 or so miles north of the border of Victoria, and continue along the New South Wales coast to the Queensland border. The distribution extends inland as far as Parkes and Dubbo. In western New South Wales the distribution follows the Darling River system. Westwards from the Murray River in South Australia, the distribution of geometric microliths follow the coast to the eastern edge of Spencer's Gulf, and thence northwards to Lake Torrens and Lake Eyre, From other more sparsely distributed examples, it would appear

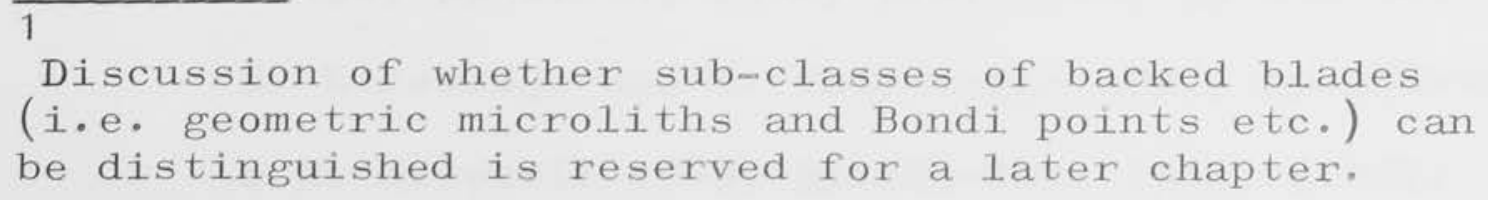


that geometric microliths have an even wider distribution - they have been found in Western Australia, the Northern Territory and southwest Queensland. Further field work may well show that this implement type has an Australiawide distribution.

The distribution of Bondi points is not as widespread as for geometric microliths (Diagram 1.3). In Victoria, Bondi points are found mainly along the coastal areas, south of the Great Dividing Range. They extend eastwards to Lakes Entrance and the Mitchell River, westwards to Cape Otway, north-west over the Great Divide to Dooen Swamp. Bondi points are found in South Australia on the coast at Kongorong; Mulvaney has excavated Bondi-like points at Fromm's Landing (D.J. Mulvaney 1960b, p. 79; 1964d, pp.488-91). They are found in the Woakwine Range (T.D. Campbell and H.V.V. Noone $1943 \mathrm{a}, \mathrm{p} .293 ; 1943 \mathrm{~b}, \mathrm{p} .378)$ and in Western Australia on Millstream Station (H.V.V. Noone 1943, p.275; F.D. McCarthy et. al 1946, p.34). In western New South Wales Tindale has found Bondi points at Lake Menindee (N.B. Tindale 1955, p.278), while McCarthy has found them to the north east at Cobar (F.D. McCarthy 1965b). In eastern New South Wales contributions by many field workers, in particular McCarthy, shows an extensive coastal distribution of Bondi points. (F.D. McCarthy 1943a, pp.145-9; 1943b, pp.221-4; 1948, p.9; 1964, pp.234-74; R. Etheridge and $T$, Whitelegge 1907, pp.238-40; S.R. Mitche1.1 1949, pp.183-202; 1962, p.467; 
F.D. McCarthy and F.A. Davidson 1943, pp.221-9). They are found rarely in Queensland. An isolated example has been noted by Gresser as far north as Hughenden in Central Northern Queensland (P.E. Gresser 1962, p.531). Mulvaney has obtained them in a stratified context at Kenniff's Cave in mid-west Queensland (D.J. Mulvaney 1965, table 3, p.172). However, these are the only two cases of their occurrence in Queensland as far as can be ascertained from present literature. Unfortunately, both the distribution maps and the carbon dates tell little. For example, these carbon dates (Table 1.1) when used in conjunction with the distribution maps suggest that the South Australian Aborigines made the first backed blades, and that Bondi points diffused around the coast of Victoria into New South Wales. Such a situation would require both implement types to have been developed locally. This idea is in contrast to the popular alternative which suggests that the techniques were brought into Australia from the north, diffusing southwards. Again it has been suggested that the techniques appeared suddenly, brought south by new waves of aboriginal. immigrants, supplanting or supplementing older techniques. Thus McCarthy, referring specifically to the Bondi point, may have been right when he commented: 'I prefer to regard these changes as being due to diffusion rather than to new waves of Aboriginal people' (F.D. McCarthy 1964, p.239). However, he prefers to 
think of diffusion from the north rather than from the south or west. He rejects diffusion from the west, because 'The point is not found in far western New South Wales' (McCarthy ibid). However, Tindale has found Bondi points at Lake Menindee; Mulvaney has found them at Fromm's Landing and McCarthy himself has noted them at Cobar. Thus further field work may show that an eastward diffusion of the point could have occurred. Until recently no dates were available for Bondi points in Victoria. Thus one objective of the archaeological project at Wilson's Promontory was to isolate and chronologically define the occurrence and associations of this implement. Because the Promontory is situated about half way between South Australia and New South Wales, and because it is Australia's southernmost 1 and mass, it might then be possible to comment on the direction and pattern of point diffusion.

4. The problem of geometric microliths and their relationship to the Bondi point is also complex. Their wide distribution is complemented by a wide date range wherever dates are available. Both Bondi points and Pirri points have been found stratigraphically in association with geometric microliths, The suggestion of Mulvaney (1960b, p.78; 1961, p.83) of an association of points and microliths in some dual function is not at all clear, because in every case where there is stratigraphic association of Bondi points and microliths, or Pirri points and microliths, the association 
never continues throughout the levels, the

implements becoming mutually exclusive (e.g. at Fromm's Landing (D.J. Mulvaney 1960b, p.79); at the Royal National Park in New South Wales (J.V.S. Megaw 1965, p.204)). On the other hand, it seems clear that one function of the Bondi point was as part of a weapon, probably as a composite spearpoint-barb. It has also been suggested that the Bondi point was used to extract the animal from its shell, while McCarthy claims that the Bondi point replaced the muduk as a detachable barb (F.D. McCarthy 1965a, p.79). But these ideas are based on supposition, and there is no evidence to support them. ${ }^{1}$ Thus the whole question of the function of these two implements remains very much an open one. Because they occur in such profusion on a large number of surface sites, there remains the possibility that the problem of 'function' may be solved 'on the surface' rather than 'beneath it' (F.D. McCarthy 1965a, p. 83) .

These then were the main reasons why the Promontory was chosen as a favourable area to commence field work. At the outset the main objectives of the research project may be summarized as follows:-

1. To locate and map all aboriginal sites on the Promontory.

2. To define the local cultural sequences.

1

See also T.D. Campbell, J.B. Cleland and P.S. Hossfeld 1946, p.471; F. McCarthy 1943a, p.149; 1964, p.202;

T.D. Campbe11 and H.V.V. Noone 19439, pp.294, 303 ;

D.J. Mulvaney 1960b, p.79; 1961, p.83. 
3. To develop techniques for processing both faunal (shell) and lithic material.

4. To place considerable emphasis on ecological studies.

5. To place the cultural material at the Promontory in its correct historical context when viewed in relation to excavations in other parts of Australia.

6. To study the ethnology and local history of the area.

In the space of three field seasons all of these objectives have been achieved. It remains to describe the results of this research. 


\section{CHAPTER 2}

\section{SURVEY OF ARCHAEOLOGICAL SITES}

\section{1 Introduction}

For purposes of locating and mapping the various archaeological sites the Promontory was divided into three areas - the western and eastern coasts of the Yanakie Isthmus and the east coast of the Promontory including the Singapore Peninsula. These divisions are arbitrary and were based on the ease with which these areas could be examined. For example the west coast sites were easily accessible because the main road runs approximately parallel to the coast as far south as Norman Bay while some of the east Yanakie sites could be reached by side roads leading to the beach. However, the Singapore Peninsula and other east coast sites are difficult to reach by 1 and and there are no suitable overland routes to the various coves and inlets over which large quantities of equipment and stores can be hauled. Thus these sites were surveyed with the aid of a boat.

\subsection{Site Numbering}

The area locally called Wilson's Promontory includes the main part of the Promontory and the sandy isthmus which joins the Mainland to the Promontory itself. The army carried out a survey of the area in 1941 and called the northern part of the Promontory (including the isthmus), Yanakie, and the southern part, Wilson's Promontory (Diagram 2,1). Although these maps are inaccurate they can be conveniently used as a basis for site location and numbering. When and if a new series of more accurate maps are issued it should be 
possible to locate precisely, and number all kboriginal sites in Victoria as described below. The Wilson's Promontory sites have been numbered and labelled in the hope that this system will be adopted for the rest of the state in the near future.

In accordance with the title of the map e.g., 'Yanakie', the first letter, capital 'Y' precedes the site number. Coastal sites are given numbers from the south to the north respectively and if the sites are located on the west, or east coasts the letter ' $W$ ' or 'E' (Capital), follows the letter ' $\mathrm{Y}^{\prime}$. Inland sites are identified by a small 'i' following the map letter. These should be numbered systematically from south to north and from west to east. New locations discovered after sites have been assigned numbers take the site number of the nearest numbered areabut with an (a) or a (b) to distinguish them, i.e. YEI7(a).

Few inland sites were found at the Promontory and the following comments are restricted to coastal sites. Coastal middens are usually situated on the face of dune 'blow outs'. Generally 'blow outs' are separated from each other by sand ridges which separate the midden deposits artificially. In these cases it is easy to assign a number to each site. In some instances the separation may be slight (e.g., by a low grassed sand ridge) in which case the entire area is given one site number but it is subdivided into sections (A), (B), (c), etc.

Each site examined and numbered on the Promontory was surveyed and located relative to an initial datum. Detailed notes were made of:

1. State of preservation of the faunal remains. 2. Distribution of the faunal remains over the site. 
3. Species of fauna.

4. The morphology of the site, including the presence and position of soil profiles, degree of stabilization of the blow out, presence or absence of old Leptospermum, size and progress of the 'blow' and so on.

5. The density, distribution and material of the implements and waste flakes. Collections were made in some areas and an attempt was made to estimate the fraction of the entire assemblage that had been collected. Collections were always random, no preference being given to worked or unworked tools.

\subsection{Yanakie West Sites (Diagrams 2.1-2.4)}

Aboriginal midden material is found all along the coast from Darby Beach to Shallow Inlet and beyond. All aboriginal sites have been located, mapped and numbered as far as Shallow Inlet, though the detailed plans and locations are only shown as far north as Cottars Lake in Diagrams 2.2-2.4. These maps were prepared by using air photos, the results of intensive field surveys and extant maps. Each map shows the location of various Aboriginal midden sites, e.g. Diagram 2.2 the full title for Site 1 is YW1.

Appendix 2.1 contains a brief description of the first twenty-five sites. They have not been described in detail as this Appendix was compiled with specific objectives in mind relating to Chapters 12 and 13 . Table 2.1 shows which species occur on each site.

\subsection{Yanakie East Sites (Diagram 2.5)}

These sites were examined by walking over the entire area. A base camp was set up at Shelter Cove where the field survey party was dropped by boat. 
Although a thorough examination was made of the area, very few middens were found. None of those located were of the 'blow out' variety.

Appendix 2.2 contains a brief description of each site.

Although rich in shell fauna the east coast of the Yanakie Isthmus failed to reveal any sign of aboriginal occupation. This dearth of midden evidence continues from the south-west corner of Corner Inlet to the northeast as far as Chinaman's Long Beach. There may be several explanations for this lack of material.

1. There is hardly any beach along this part of the coast, and at high tide most of this is covered up. Dense scrub comes down to the water's edge so that the Aborigine would have had nowhere to camp.

2. Diagram 2.7 shows that much of the east coast is swampy. No land fall could be made here as one sinks into the mud when attempting to walk along the shoreline at low tide. Similar porous loose mud flats are located along the coast between the Telegraph Swamp and Chinaman's Long Beach making land falls difficult,

3. Between the White and Telegraph Swamps a new dune sequence is being blown into Corner Inlet. Any ancient âboriginal remains situated along this part of the coast are likely to have been destroyed or covered by the moving sand dunes.

4. There are no streams or rivers in this area to provide drinking water.

In recent times the lack of midden evidence in the eastern Yanakie area (Singapore area) can be explained 
by the nature of the country itself. Inland the country is difficult to negotiate with thick scrub and heath barring progress. There are few perennial sources of drinking water and animals are not prolific. The Aborigines certainly came to the area by canoe but not over land (see Chapter 13).

\section{$2.5 \frac{\text { Wilson's Promontory West Sites }}{\text { (Diagrams } 2.1 \text { and } 2.6)}$}

Diagram 2.6 shows the location of the Oberon Bay sites and Appendix 2.3 contains brief descriptions of each site. While there is a plentiful fresh water supply along this part of the coast, and abundant marine fauna, access to the area is difficult except via the National Park's walking tracks. Off these tracks the bush is thick and virtually impenetrable. It is likely then, that the vegetation cover in preEuropean times was different from the extant situation.

Sites 8, 9 and 10 are shown in Diagram 2.1 and described in Appendix 2.3. The lack of sites between Oberon Bay and Darby River is surprising in view of the extensive midden remains located at Oberon Bay. Possibly the Aborigines reached the latter by an inland route, so that the paucity of midden remains along this portion of the coast would be explained.

\subsection{Wilson's Promontory East Sites (Diagram 2.1)}

Two sites producing evidence of sparse occupation are described in Appendix 2.3. Location of sites along this part of the coast is seriously hampered by a prolific vegetation cover which could be obscuring much of the evidence. 


\subsection{Tasmanian Connections}

None of these sites produced material evidence that could suggest a connection between Mainland and Tasmanian cultures. 


\section{GEOMORPHOLOGY AND PHYSIOGRAPHY OF YANAKIE ISTHMUS}

The survey of sites on the Promontory revealed that the richest archaeological material was situated on the Isthmus, so that attention will now be concentrated on this area (refer Diagram 2.7).

\subsection{Data Available for Wilson's Promontory}

\section{(a) Geology}

Little work has been carried out on this aspect of the Promontory. R.A.F. Murray (1876) looked at the area last century and his work forms the basis for the present geological map. The discovery of tin at Mount Hunter in the early twentieth century led to visits by other geologists, but they came with special purposes in mind. (T.B. Pritchard 1906; E.D. Dunn 1907; W.H. Ferguson 1909; A.J. Robertson 1913; J.P.L. Kenny 1921). Since then little has been written on the subject (see T.W.E. David 1950; K.J. Reed 1963).

\section{(b) Geomorphology}

The Geomorphological study is being carried out by Mr W. Tuddenham of Sydney University.

\section{(c) Surveying}

Air photos are available of Yanakie and the Promontory proper (1941 and 1966) and of the Promontory by itself (1958). Inaccurate army survey maps (1941) are also available and the south-west portion of the Promontory has been well surveyed as part of the preparation for a road to the lighthouse.

1. Except where specifically indicated the interpretation of the data and the ideas expressed in this chapter are those of the author. 


\subsection{General Description}

Geology and Physiography ${ }^{1}$

The Promontory consists of tall granite peaks (up to $\left.2,475^{\circ}\right)$ with sedimentary deposits situated in the valleys and pockets between them. In general these deposits are either swamp areas or dune ridges.

The isthmus which joins the Promontory to the Mainland has four main features:

(a) Pliocene gravels extend from the north in a tongue through the centre of the isthmus eastward of Shallow Inlet, reaching toward a granite outcrop west of Townsend Point. Tertiary gravel deposits can be seen on the north-east coast as the beach platform.

(b) The granite outcrops at Townsend Point. Cliffs of Silurian clay up to 100' high extend for a mile or so starting just north of Townsend Point. At Red Cliff a Silurian granite interface can be seen, while a granite shore platform and granite boulders are situated just off shore.

Because the Tertiary deposits come as far south as the granite, and because the lowest point on the Tertiary hillocks is approximately $50^{\prime}$ above HWM, ${ }^{2}$ then if one assumes a rise in sea level of $25^{\prime}$ at the beginning of the last glacial (W.R. Browne 1963, p.268), it is clear that the Mainland has been connected to Townsend Point for a considerable period of time, i.e. at least

A very general description is contained in R.F. Parsons $1966, \mathrm{pp} \cdot 320-5$. 
100,000 years - a period much longer than man's occupation in Australia. ${ }^{1}$

(c) Overlying the Tertiary gravels and between Townsend Point and the granite foothills of the Promontory itself there are extensive sedimentary deposits. Along the eastern coast these take the form of swamp deposits. These cannot be negotiated either inland or along the coast.

(d) The west coast of the isthmus consists of sand dunes and it is this area that is of archaeological interest. The dune system which fills the gap between the granitic Promontory and the Tertiary deposits further north is not simple. However it is clear that the Promontory has not been isolated from the Mainland within the present known chronology of man in Australia.

Twelve miles south of Yanakie township there is a large flat expanse to the east of the road which extends up to the granite and the foothills of the Vereker range. On Diagram 2.7 this flat area has been called a Sand Plain, and it is the remnant of the oldest series of dunes in the area. These older dunes collapsed to their present state through weathering and leaching. Remnants, however, can still be readily distinguished. The height of the plain above sea level varies between 50'-100', and there is no doubt of its great antiquity (W. Tuddenham 1966). Thus any rises in sea level in recent times would not have resulted in the isthmus being breached. discussed here. 


\subsection{Relationship of the Geomorphology of the West Coast of Yanakie to the Archaeology}

Two broad series of dunes, an older and a newer series, have been identified in this area. These are described below.

The best example of the older dunes may be seen at Darby River and have been described by several authors (i.e. G.B. Pritchard 1906, p.222; A.J. Robertson 1913, p.180; K.J. Reed 1964, p.50) 'in the vicinity of Darby River, there are considerable thicknesses of

Pleistocene dune limestones showing well developed cross bedding, which are overlain by the Recent dune sands' (K.J. Reed ibid). However, such a terminology should be used with caution for the upper levels of Reed's 'Pleistocene dune limestones' could be Holocene. Hence the terms 'Pleistocene' and 'Recent' need to be used with reservations.

The Darby River series of dunes exhibit at least four soil profiles in the eroded beach section. These soils are fairly mature and possibly indicate prolonged periods of dune stabilization. The lower three horizons do not contain Aboriginal material. ${ }^{1}$ However, the soil horizon that caps the whole sequence - a grey brown soil varying in depth from 0-4' - contains stratified Aboriginal material. The surface of the soil is strewn with the shell and stone that has been eroded out of the occupational soil.

Plate 3.1 shows a view of the west coast of Yanakie looking north from Site 1 (see Diagram 2.2). The Darby Beach older series dunes are clearly labelled

1

The lower soil horizons are of Pleistocene age. Radio-Carbon dating suggests that the lowest soil horizon is more than 40,000 years old ( $W$. Tuddenham 1966). 
and the dark line surmounting the sequence is the

occupational soil. Plate 3.2 is a close-up view of the cliff face illustrating the badly eroded nature of the dune series. Three soil profiles can be seen in this plate.

Reed's 'Recent sands' overlying the occupational horizons (Plate 3.1) have been called the B series, because they are more recent in age, and because they exhibit a fundamentally different physical character from the older dune series beneath them.

This older dune series (sealed by the occupational soil) is termed A series. ${ }^{1}$ The A series can be traced along the beach for four or five miles north of Darby Beach and it can be recognized by the occupational soil which seals it. At the north end of Darby Beach this soil runs off the A series into the beach and continues along the coast at approximately HWM as a peat layer. The peat is bedded and contains fresh water gastropods (Austrosuccinea australis). In places the peat is $2-3$ ' thick and protrudes onto the beach for 200-300 yards. There is no sign of aboriginal material in the peat itself, though material stratified in the occupational soil often continues to within 2-3' of the present HWM. ${ }^{2}$ At regular intervals along the beach the peat rises from beach level over another set of A series dunes

\section{1}

The exact relationship between the A series dunes and the sand plain further east has not been determined. Possibly the sand plain is contemporary with the A series. In Tuddenham's opinion the A series followed the sand plain dunes. Certainly the A series dunes east of Darby Beach appear to overlie the sand plain. 2

Comparison of Phosphorous percentages in the peat (Table 4.2) and occupational soils (Table 4.1) shows the latter to be much higher. These results support this field observation. 
(becoming the occupational soil), and drops off on the opposite side to become peat again. This is illustrated in diagrams $(2.2-2.4)$ which show the A series remnants along the beach with the peat outcropping in the swales. Plates 3.3 and 3.4 show a situation analagous to that at Darby Beach for the cliffs adjacent to Site 9C (Diagram 2.3). The remains of the occupational soil can be seen at the top of the Pleistocene dune series. At the south end of this sequence most of the occupational soil has been completely stripped off (Plate 3.4). However, as beach level is approached the soil colour changes from dark brown to black, eventually becoming the peat layer itself. Plate 3.6 shows the peat exposed at low tide between Sites $9 \mathrm{~A}$ and 10. Plate 3.6 shows a better example of the thick peat layer exposed at low tide. The view was taken from abreast of Site 15 (Diagram 2.4) looking south toward Darby Beach. The occupational soil can be seen stretching into the distance towards Site 11. Plates 3.7 and 3.8 are close-up photographs of the occupational soil showing the occurrence of stratified Aboriginal material in the soil.

Along the coast north of Cottars Lake the A series is almost completely absent. ${ }^{1}$ Remnants can be discerned in a few areas immediately north of the lake. However the A series is found further inland and to the north east. Tuddenham is of the opinion that A series

1

The A series occupational soil has been traced much further north. To the north-west of Cape Liptrap an extensive series of 'Pleistocene' dunes is capped by an occupational soil which appears to be the same as the uppermost A series soil of the 'Pleistocene' dunes on the west coast of Yanakie. Carbon dates confirm this. See P.J.F. Coutts 1967 a for a fuller discussion. 
dunes should continue right up to the granite southeast of Yanakie. The absence of A series outcrops along the present beach towards Shallow Inlet suggests that there has been a change in orientation of the beach fronting Waratah Bay in recent times - the change being due to 'sedimentation and the resulting adjustment to the wave refractive pattern' (w. Tuddenham 1966). Examination of Diagram 2.7 shows that in the area immediately south of Shallow Inlet there has been a tremendous build up of sand in recent times. About three quarters of a mile inland, and a little south of the inlet, large, badly eroded A series deposits lie exposed. This suggests that there has been differential erosion of the Pleistocene dune sequence from Shallow Inlet to Darby Beach. Sand deposits have since built up at the northern end of the beach covering up most of the A series dunes and building westward in front of an older shoreline thus protecting the A series dunes from further erosion. This outward building of the coast line reaches its maximum at Shallow Inlet and is negligible beyond Cottars Lake beyond where the coast line is being eroded back at a very fast rate. The exit to shallow Inlet was at one time much further south and in recent times the outward building of the coast line has almost blocked its exit to the sea.

\subsection{Features of the A and B Series Dunes}

1. Where an A series occurs, Aboriginal matter has been eroded out of the occupational horizons and lies strewn about on the soil surface.

2. Nearly all the A series exhibit soil profiles on their eroded beach front. 
3. Except for the occupational horizon, there is no obvious connection between exposed soil profiles in the various A series sections occurring along the beach. 1

4. Occupational debris continues up to the eroded edge of the A series cliff tops. This suggests that the physiographical conditions in which the A series Aborigines lived were different from those of today. Thus the A series dunes at one time extended further out to sea and in the course of time have been eroded back to the present standline. Aboriginal material within the occupational soil has been eroded out of it as part of this process. There is no satisfactory way of estimating

(a) how far the A series dunes extended out to sea,

(b) at what stage in the erosional process the A series Aboriginals camped in the area.

5. The thickness of the occupational soil varies according to the amount of erosion, but in every case the depth of occupation is defined by a debris layer (Plates 3.3 and 3.8). This layer consists of calcareous root nodules and limestone concretions, produced by leaching from higher levels in the soil. The debris layer does not appear to be the B horizon of the occupational soil (see Chapter 4). The very fragmented state of the nodules and limestone concretions suggest

A red-orange soil profile tends to occur periodically in the exposed A series faces at the lowest levels. Beneath the red-orange layer a white calcarenite layer is found which may be of some use in correlating profiles. 
an alternative explanation which can be supported by other field observations. There is the suggestion in several eroded cliff profiles that the present occupational soil was preceded by a terra R̂ossa soil. In the cliff faces adjacent to Sites 11 and 10B, the terra Rossa is in situ and immediately below the occupational soil. In both cases it appears to have been subjected to considerable erosion before the occupational soil built up. Thus the debris line may consist of material eroded from the B horizon of the older soil. The following gives a possible reconstruction of the soil sequence. Originally a nodule layer existed in the B horizon of a mature (Terra Rossa?) soil. (This soil may have been covered with a layer of unconsolidated dune sand and/or further fossil soils). Then for some undefined reason erosion occurred and any layers of sand and/or soils above this horizon were stripped off exposing the soil itself. Further erosion removed the A and part of the B horizon of the soil and as the calcareous material was exposed, erosion proceeded more slowly. Further erosion caused the root nodules to break off and fragment. Likewise, the limestone lumps were reduced to fragments and so a debris layer was formed. At some later stage aeolianite was deposited on the debris layer. Subsequent stabilization led to the formation of new A and B horizons. Today one observes the eroded A horizon of this latter sequence. ${ }^{1}$ The 
A series Aborigines began to camp in the area soon after redeposition began.

It can also be argued that the calcarenite layer is in the B horizon of the occupational soil. For example there is a no change of colour in the occupational soil above the nodule layer to suggest a higher and secondary B horizon. The soil begins to change colours above the debris layer and grades gradually from dark-grey-brown to buff suggesting that the buff layer (which also contains the debris layer) is the B horizon of the occupational soil. Small nodules do occur throughout the occupational soil, but there are no obvious depositional layers which could suggest a higher B horizon. The extant debris layer and the stratigraphy described above are widespread occurring in nearly all eroded profiles along the beach. Forty miles away the same occupational soil and debris layer caps an exposed coastal Pleistocene dune sequence situated between Cape Liptrap and Tarwin Meadows. Thus if one wished to explain the nodule layer by the erosion/redeposition process described above, one would need to postulate a fairly a very wide area. Such a process is unlikely. On the other hand the same area may have experienced a period of climate stability which could account for the great thickness of the occupational soil, its maturity and the debris line. Thus the nodule layer would be the result of precipitation in a B horizon of the occupational soil.

The A series occupational soil has been radio-carbon dated at site 9A. GAK-681 and 
GAK-683 make the soil older than $6550 \mathrm{BP}$ and not younger than about $3100 \mathrm{BP}$ (see Table 3.1).

GAK-681 is a charcoal date, approximately six inches above the nodule layer and buff horizon. The peat stratigraphy was examined in the area between Sites $9 \mathrm{~A}$ and 11. The top eighteen inches consisted of black, bedded, oily, sandy peat layers intermixed with organic and fresh water she11 material. A grey-brown sandy soil (?) continued beneath the peat for approximately seven inches. Over the next eighteen inches the profile graded from a grey-brown sandy soil (?) into a bright yellow sand at a depth of approximately fifty inches below the peat surface. Approximately three inches above the lowest extent of the bedded peat layers a wood sample was radio-carbon dated at approximately 5900 BP (GAK-969). This date confirms the stratigraphic observation that peat and soil are contemporary. Moreover the peat began to form contemporary with or soon after the occupational soil began to form. The grey-brown layer beneath the peat represents the first stages of soil formation prior to the formation of the peat. No nodules were found below the peat in this trench but between Sites 11 and 12 (Diagram 2.3) the peat directly overlies solid limestone. This stratigraphic situation supports the first hypothesis (see above), as a debris layer should underlie the peat if it belongs to the B horizon of an earlier soil.

Detailed soil analysis has not clarified this and other problems. If the nodule layer is indeed within a B horizon, the percentage calcium 
carbonate and the clay percentage should be greater in the lower layers. Diagrams 3.1 and 3.2 show the results of two soil analyses from two separate areas. The high peak for the percentage calcium carbonate for the uppermost spit of Excavation No. 6 may be discounted as the soil in this spit was mainly overburden and the sample was probably contaminated with B series sand. Neglecting this peak it can be seen that there is a fairly steady rise in percentage calcium carbonate in both analyses (10 per cent increase for Excavation No. 6 and 17 per cent for Excavation No. 11). Likewise one can say that there is a general tendency for the clay fraction to increase with increasing depth. However the clay fraction is too erratic to argue from, and the increase of the percentage of calcium carbonate with depth is not significant enough to be used as evidence to support the view that the nodule layer lies within a B horizon of the occupational soil. In fact the sudden increase in calcium carbonate and clay percentage in Spit 17 of Excavation No. 6 might be interpreted as evidence for the existence of a B horizon, belonging to a much older soil with different proportions of calcium carbonate.

The origin of the nodule layer will remain obscure until further field work is carried out.

6. The carbon dates indicate that both the soil and the peat deposits built up before, during and after what has been described as the Post Glacial Thermal Maximum (E.D. Gill 1965, p.300). If one accepts this geological period (see below) then 
some account must be taken of a possible ten foot rise in sea level during the formation of occupational soil. 1

If one subscribed to the hypothesis that stripping of an older A horizon had occurred then it is tempting to correlate the process with a major climate upset. The most recent such period would have been initiated prior to the Thermal Maximum .

Before setting out the evidence for such a climatic variation it is as well to point out several limiting factors that would be operative in any attempt to correlate the sparse Promontory evidence with a postulated climatic cycle.

(a) The ideas expressed above on the relationship of the debris layer to the occupational soil are not certain.

(b) That late quarternary climatology and geochronology are at the moment the subject of intense debate. (A single school's opinion is given below). Dates for the Post Glacial Thermal Maximum and following events are more widely accepted.

(c) Even if all factors associated with the Thermal Maximum were well known it is not necessarily valid to take a confined area such as the west coast of Yanakie, with limited evidence and try to fit it into a world wide climatic pattern. The following must be considered with these limitations in mind.

Gill has obtained evidence for the Post Glacial Thermal at Tidal River, Wilson's Promontory. Here he has radio-carbon dated raised shell beds at $6230 \pm 430 \mathrm{BP}$ (AC-12) (R.F. Parsons 1966, p.324). 
It has been suggested that the climate of Australia during this era consisted of very harsh summers with little or no rain, and winters which were wetter than those experienced at present (R.A. Keble 1947, p.36; E.D. Gill 1953b, p.55; $1955 \mathrm{c}, \mathrm{p} .205 ; 1964, \mathrm{pp} .9,12 ; 1965, \mathrm{p} .300)$. IIt was a period of increased dryness in western Victoria, causing the shallow lakes to dry up each summer and the dessicated lake-bed sediments to build up into dunes' (E.D. Gil1 1964, p.12). The period following the Thermal Maximum was wetter (W.R. Browne 1963, p.269). Gill has shown this by demonstrating that the Western District lakes held much more water after the Thermal Maximum than they do at present (E.D. Gill 1953b, p.55; W.G. Browne, ibid). Prior to the Thermal Maximum the climate improved from colder glacial conditions (at approximately 8000 BP) becoming warmer (E.D. Gill 1955, p.205). By 6000 BP climatic conditions became more stable and remained so for approximately 2000 years (Post Glacial Thermal Period). From this time there has been a degeneration as world wide temperatures dropped slightly, producing further climatic upsets. Returning now to the field situation at the Promontory it is possible to fit the soil building and stripping processes into this climatic sequence, The dates of the soil (approximately 3100-6500 BP) almost exactly overlap the era of the Thermal Maximum. The rate of build up of the soil - approximately 0.9 inches per hundred years suggests that there was little airborne material being deposited during this period, though the 
contribution of fine sand (50-60 per cent) which remains fairly constant throughout the soil buildup indicates that there was a source of aeolinite in the vicinity. Both the fine and coarse sand contributed very little throughout the history of the soil, suggesting that fairly stable conditions prevailed at the time. If one postulates that the soil was formed in slightly drier conditions then it is reasonable to expect little evidence of a nodule or calcaronite layer in the soil because there would be limited leaching from the upper horizons. That some leaching has occurred is indicated by the soil colour (dark brown - due to leaching of humus), by the fact that there is an increase in organic carbon from the top of the soil, and because numerous small nodules are found spasmodically throughout the soil.

It is clear that the fossil coastline was different from the present one. This is suggested firstly by the fact that stratified Aboriginal material can be seen in the eroded beach profile itself, and secondly by the way the peat is situated relative to the present strandline. The peat is coincident with the HWM, and at one time extended westward beyond the extant foredune. Since fresh water gastropods are found in the peat it must be assumed that the peat was once land locked. Preliminary investigations have revealed that the peat probably did not extend much further inland than the present foredune so that the fossil shoreline may not have been too far distant from its modern counterpart. Inter dune swamps are found a little way inland today and if it is 
valid to make analogies between past and present conditions, these ancient swamps were probably of no great size. On the other hand the distributions of peat along the beach shows that interdune swamps were once much more common than they are today. Nor did they appear and disappear irregularly. Some of the deposits are three feet thick with up to forty bedding layers so that swamps were probably consistent features of the landscape.

Although there is insufficient evidence to definitely attribute the formation of these interdune swamps to a period of higher sea level (during the Thermal Maximum), it is possible that a higher sea level caused them to form. The peat deposits are all situated in swales between Pleistocene dune ridges which run approximately at right angles to the modern foredune. Hence run off from these ridges would accumulate in the swales. Since the peat at present is situated (at its highest point) at the present high tide mark any increase in sea level would leave it below the HWM. Thus water trapped in the swales would have difficulty in draining away and would tend to produce swampy conditions.

7. Examination of the faunal and lithic material both in situ and being eroded from the occupational soil, revealed two interesting features. Firstly the fauna appeared to be exclusively rock platform species, predominantly Subninella and Cellana, while the lithic material fell into the backed blade class (see R. Wright 1963). This contrasted with the B series material. Here the predominant 
species appeared to be Plebidonax. The

differences in faunal distribution between $A$ and B series material is fully explored in a later chapter. At present it remains to be pointed out that there are at least two possible explanations for these differences. Firstly, there may have been a change in preference from rock platform to sandy beach species, and secondly, there may have been a change in coastline so as to produce a habitat suitable for Plebidonax. It will be seen presently that these two factors are probably interconnected.

The physiography of the present coastline suggests that it has not had its present form 1 ong. The rock platform areas along the coast - between Darby River and Cottars Lake - are all adjacent to eroded Pleistocene dune cliffs. In some cases, particularly with Black Rock (see Diagram 2.4), there are large exposed dune limestone remnants some hundreds of yards out to sea. Offshore soundings and enlarged aerial photographs show large concentrations of limestone reefs adjacent to the Darby River dunes and between Sites 9A and 17. These reefs are not exposed at low tide. It would seem then that seven thousand years ago the Pleistocene dune ridges (at the present time truncated with their eroded faces concurrent with the extant coastline) extended further out to sea. Many of the reefs that can only be discerned today in air photographs or soundings were possibly exposed and protecting the coastline from extensive exosion. Under these circumstances the ecology of the entire area must have been very 
different from its extant counterpart. The ancient habitat would be classed as 'Bay' in contrast with the present 'Sandy Beach' environment,

Further north there are few signs of inshore reef. Here severe erosion has occurred, for the A series dunes have been completely demolished for some distance out to sea. North of Cottars Lake backed blades are found in the $B$ series dunes and the entire midden series has Plebidonax as a predominant species. On the other hand backed blades are not found in the $B$ series dunes south of Cottars Lake. This suggests that there are at least two major B series dune sequences. An older sequence in the north was formed after or during severe erosion of the A series dunes in the area, and was probably contemporary with a well vegetated landscape south of Cottars Lake. As erosion proceeded (possibly initiated in the first instance by a slight rise in sea level) the stability of the landscape to the south was upset, and parallel dune ridges began to build up behind and at right angles to the beach front. Thus a second series of $B$ dunes was formed. Since many of the southern B dunes (since consolidated) are situated on ancient dune ridges (i.e. at Darby River) it is possible that the seaward areas of the older A dunes may have sloped more gently towards the sea so that sand could be trapped and accumulated more readily behind the foredune.

8. The B series includes (i) the modern foredune, (ii) windblown, destabilized (or stabilized) dunes situated on top of the A series, (iii) the dune 
sequence behind the foredune - overlying or east of the peat. In general the B series dunes are mobile or else in the process of destabilization. The sand supplying the B series comes from several sources including the beach, the foredune, from the erosion of the A series, and from other B series destabilized dunes. The percentage calcium carbonate for the beach and B dune systems is demonstrably the same (ranges from 23-28 per cent) but differs significantly from that of the A series occupational soil (above 35 per cent). The beach slopes gently away for some distance. One to two miles off shore the water depth is still only sixty feet deep; five miles off shore it is of the order 120 feet. Waratah Bay, which appears to be a main source of sand supply for the west coast of Yanakie, is only $40^{\prime}-50^{\prime}$ deep two to three miles off shore and still only $60^{\prime}$ deep five to six miles out. 1 On an average this represents a slope of $1^{\prime}$ in every $180^{\circ}$. A fast south easterly current (of the order three knots) runs parallel to the coast carrying sand from the floor of Waratah Bay and depositing it along the west coast of Yanakie. Once past Black Rock the water is noticeably shallower inshore and the ten fathom line bends outwards towards Shellback Island approximately three miles off the coast.

Midden material is frequently associated with these B dunes and is situated in blow outs. Such middens are a general feature of much of the 
Australian coastline, and have been classified by many authors (P.J.F. Coutts 1967b). For example 'It can be accepted that the most favoured and frequented open air camps were invariably situated on sand or loose sandy soil in close proximity to food, water, shelter, fuel and stone, the five essentials that made the life of such people tolerable' (S.R. Mitchell 1949, p.108).

However these $B$ series dunes often have immature soils and Aboriginal material is frequently exposed in situ in eroded soil profiles. The erosion of these sites makes interpretation of the cultural material difficult. A blow out may show evidence of several soil horizons. As a rule the cultural material found on the higher levels will be younger than other material found lower down. Erosion will cause material higher up on the blow out face to be scattered down to lower levels where it mixes with other midden debris. 9. Aeolian action can reduce a dune to the level of the local water table. When this has happened it is impossible to sort out the cultural material. Mitchell had noted this process (but not its significance) when he observed tThe light sand enclosing the heavier debris has been blown away awd deposits the debris o.j the underhyiug hard surface (ibid, picg) hard surface' (ibid, p.109).

10. South of Cottars Lake B series cultural material is always situated behind the foredune, never on or in the foredune or in eroded B series dune ridge faces which form a beach front. Thus the B series dunes correlate with the present coastline indicating their recent age. 
On the other hand, as one progresses north of Cottars Lake there are a number of cases of $B$ series middens which have been truncated by erosion. At Shallow Inlet B series middens are found only some distance inland. The reason for this is that the mouth of Shallow Inlet has been progressively migrating northward as sand dunes have built out east and southward. Consequently the older coastline (with its middens) is now some distance inland. 
THE GENERAL ARCHAEOLOGY OF THE YANAKIE AREA ${ }^{1}$

\section{1 Introduction}

Site 9 was selected for detailed archaeological work for several reasons (Diagram 2.3). Firstly, the area is accessible via an inland track over which supplies and equipment could be brought in. Secondly, there is a large expanse of exposed occupational soil (Plate 4.1) which is protected from violent on-shore breezes by low dunes to the south and west. Thirdly, an initial survey showed that there were sufficient quantities of faunal and lithic material to warrant a detailed investigation. Lastly, a large B series dune lay immediately to the north of the site which had both exposed occupational lenses and eroded midden material lying upon its surface.

Diagram 4.1 shows a detailed plan and survey of the area and should be studied in conjunction with Plate 4.1. The immediate area was divided into three sections:

(i) $9 \mathrm{~A}$ which includes all the exposed A series occupational soil east of the low dunes on the cliff top. That the area is badly eroded in places is shown in the detailed plan of the site (Diagram 4.2), for the nodule layer is exposed in the southern area of the site. The site is flanked further south by low B series dunes. All measurements were referred to the site datum (shown on Diagram 4.1),

Each excavation is described in Appendix 4.1. 
which is approximately 32 feet above HWM. Contour heights in this diagram have been referred to an arbitrary datum level (100.0' because there were no standard bench marks or trig points to which measurements could be referred). The datum peg is a stout $2 "$ x $1 \frac{1}{4} "$ peg driven some feet into the ground. Ground level slopes away to the north, dropping approximately six feet from north to south.

(ii) 9 C consists of the area of exposed A series occupational soil on the cliff face immediately west of $9 \mathrm{~A}$. This area is very badly eroded so that little occupational soil remains. Constant exposure to the wind has destroyed most of the occupational material eroded from the soil.

(iii) $9 \mathrm{~B}$ consists of the B series dune to the north of 9A. 9B consists mainly of unconsolidated aeolianite which is constantly moving. The southern face of the dune is littered with dead Leptospermum some of which still have their roots embedded in the sand. This would suggest that destabilization has occurred fairly recently. Two midden lenses, such as that shown in Plate 4.2, had been exposed, and material eroded from these lenses lay scattered down the dune slope. Other midden material was situated upon the surface further up the slope with no obvious point of origin. However, careful examination of an eroded section at the top of the dune suggested that an immature dune soil had once covered most of the dune. The soil was 
approximately two feet in depth and graded from a grey, sandy, firmly compacted soil, into looser buff coloured sand. Roots were still embedded in the soil, as was stratified midden material (Plate 4.3). A few feet of sand lay on top of the soil which had almost smothered the vegetation still rooted there. Traces of the soil could still be discerned down the slope of 9B. However, the soil had almost completely disappeared over most of the area and only these soil remnants and the dead Leptospermum remained as evidence of its previous existence.

For convenience the slope of $9 \mathrm{~B}$ was divided into four roughly defined areas (Diagram 4.1)

\subsection{The Archaeological Project at Site 9}

The following programme was adopted after completing the detailed survey of the area.

1. It appeared obvious that material was being eroded out of the A series occupational soil on 9A. The degree of erosion varied over the site but was most severe on the south side. To test this hypothesis and at the same time to investigate the concentration of the remaining stratified midden material, a test trench was put down as shown in Diagrams 4.1 and 4.2 . At this stage it was not certain how far 9B had originally extended over 9A, so that a small dune hillock on $9 \mathrm{~A}$ was taken to be

a remnant of 9B. Hence Excavation 1 (9A/1) was laid out so that half the hillock could be excavated. (It should be mentioned at this stage 
that the absence of dead Leptospermum on $9 \mathrm{~A}$ pointed to the long exposure of this surface).

A trench $15^{\prime} \times 3^{\prime}$ was laid out and dug to a depth of approximately two feet. The stratigraphy is shown in Diagram 4.3 and Plate 4.5. As the diagram shows, there is a clear erosion line underlying the unconsolidated sand and there is no diffused surface between sand and soil. Further, during excavation, shells were found to be lying on the surface of the soil which had clearly been eroded from it prior to the build up of the small dune hillock. The dune stratigraphy exhibited cross bedding and small shell fragments concentrated in irregular layers. This evidence suggests that the dune built up recently over the top of the eroded A series surface.

Digging continued into the A series soil until occupational material no longer appeared. At this stage the concretionary or calcareous nodule layer had been reached in the southern end of the trench. Table 6.1 and Diagram 6.1 show that the artifactual and faunal finds were disappointingly few. However, this excavation did establish that there was stratified aboriginal material in the soil, and that erosion was proceeding at different rates over the site. Only ten feet to the east of the excavation (refer to Diagram 4.2) the concretionary layer was completely exposed for some distance (P1ate 4.6).

2. Thus, in order to establish the intensity of occupation an excavation in an uneroded area of the A series occupational soil was required. It seemed best to look for such an area in the north 
of $9 \mathrm{~A}$ where erosion appeared to be at a minimum. Further, since the prevailing winds were blowing the sand of $9 \mathrm{~B}$ north and east of $9 \mathrm{~A}$ it could be assumed that the sands of $9 \mathrm{~B}$ were protecting the $\mathrm{A}$ series soil, and that if one was to dig down through 9B to the A series soil, an uneroded surface would be obtained.

A small area was cleared of sand and Excavation $3(9 \mathrm{~A} / 3)$ was commenced (refer Diagram 4.1 for location of the excavation). This excavation confirmed that the soil beneath 9B had not been eroded. No midden material was obtained at the soil-sand interface, and the first midden material appeared approximately four inches below the top of the humus.

The stratigraphy of the south wall is shown in Diagram 4.4 and Plate 4.7. Intermittent shel1 layers and charcoal were obtained in the course of excavation though the shell layers themselves were often hard to detect in the deposit. Occupation continued for some depth but disappeared before the concretionary layer was reached. Numerous shells and stone material were recovered. One could also conclude that the stratigraphic situation exhibited in this excavation exactly duplicated those of the eroded sections along the beach. It can be seen from Plate 4.7 that visual changes in the walls of the trench are almost nonexistent.

A second trench was driven southward from the wall of Excavation $9 \mathrm{~A} / 3$, separated by a six inch baulk. This trench was called Excavation $5(9 \mathrm{~A} / 5)$. The sand above the soil was removed on spits in 
order to look for wind blown material in the sand itself and to examine the soil-sand junction more carefully. For example, if the sand had been in situ for some time - assuming it was originally protected by a soil and vegetation cover - then one would not expect to find shell fragments in the sand (as was the case for Excavation 9A/1). Diagram 4.5 and Plate 4.8 show the stratigraphy of the excavation. A fragment layer was located just below the surface of the sand but this layer was situated well within the area of reworking and was assumed to be a recently covered shell fragment layer. Clear non-bedded yellow sand was situated between the soil and this layer, As the soil was approached the wall gradually darkened in colour.

The boundary between soil and sand was found to be diffuse, and there was no midden material in this boundary region.

Plate 4.8 shows three important features, two of which have been discussed above: (i) a distinct shell layer; (ii) the concretionary layer; (iii) a new feature which appears as a colour change in the wall of the trench. The soil colour changes in turn from dark grey-brown to a lighter brown then to dark brown. However, not enough information was obtained from this excavation to make any significant comment on this colour change.

Once again abundant shell and lithic material was recovered from the excavation.

Referring again to Diagram 4.5, Spit 9, Square 1 has been carbon dated at $3060 \pm 100 \mathrm{BP}$ 
(GAK-681) and spit 20 , Square 2 at $6550 \pm 100 \mathrm{BP}$ $\left(\right.$ GAK-683) ${ }^{1}$

The results of these excavations are summarized in Diagram 4.6 which represents a sketch profile of the site along an approximate north-south line. It shows increasing erosion of the surface of $9 \mathrm{~A}$ as one proceeds from north to south, with the concretionary layer exposed on the far south side of the site.

3. It was also important to determine the chronological relationship of the B series with the latest stages of the A series. ${ }^{2}$ Excavation 2 was undertaken primarily to investigate this problem (refer to Diagram 4.1 for the location). This excavation took place in a charcoal/shell lens which was only a few feet above the soil level (Diagram 4.7), A date from this lens of $1260 \pm 90$ BP $($ GAK-682) gave some idea of the hiatus between the end of the A series soil build up and the beginning of $B$ series build up on that part of the site (1800 years). What has happened in the intervening period is uncertain and the possibilities are numerous. For example, the sand may have been stabilized for a long period, but destabilization and erosion could have demolished all evidence of this soil; then a further period

1

Both dates were derived from charcoal samples and both levels were associated with occupational material. 2

Although $9 \mathrm{~A} / 2$ and $9 \mathrm{~A} / 4$ were both conducted in the $\mathrm{B}$ series dunes, they were not labelled $9 \mathrm{~B} / 1$ and $9 \mathrm{~B} / 2$ because these excavations form an intimate part of an argument which centres on the archaeology of Site 9A itself. Consequently, it was more convenient to label the excavations consecutively in terms of one site number. 
of dune building could have followed with subsequent occupation.

Diagram 4.8 and Plate 4.9 show the stratigraphy of the excavation. Lens thickness varied between six and nine inches. Shells were embedded in a matrix of charcoal and dark grey (charcoal stained?) sandy soil.

A similar lens was excavated further east (see Plate 4.2). Diagram 4.1 shows the location of the excavation (Excavation $4(9 A / 4)$ ) and Diagram 4.9 shows a location profile relative to the site datum. The lens is situated well above the soil level. Stratigraphically the excavation was similar to 9A/2 (Diagram 4.10 and Plate 4.10). In dunes adjacent to and down the slope from both these lenses, large numbers of shells 1 ay scattered on the surface of the sand and it seemed certain that they were being eroded out of these lenses and distributed down the slope of the dune. As the sand was blown away they collapsed still further until finally, when the occupational soil was reached, material from both the $A$ and the $B$ series lay mixed together.

These excavations helped to confirm a notable difference in the species of fauna in the $A$ and $B$ series. Examination of the fauna on $9 \mathrm{~B}$ showed a predominance of Plebidonax (sandy beach species) in contrast to the fauna on the surface of $9 \mathrm{~A}$ which had very few Plebidonax and where rock platform species predominated. Diagrams 4.8 and 4.11 show the faunal distributions for Excavations $9 \mathrm{~A} / 2$ and $9 \mathrm{~A} / 4$ respectively, and it can be seen 
the other hand not a single example of plebidonax came from Excavations $9 \mathrm{~A} / 3$ and $9 \mathrm{~A} / 5$. However, it is unsafe to argue solely from the evidence provided by such small excavations, and it must be stated that these results merely support

conclusions derived from wider observations on the distribution and nature of the surface deposits at Site 9. These observations have been summarized in Diagram 4.12 which shows the relationship of $9 B$ to $9 \mathrm{~A}$ in terms of stratigraphy and fauna.

4. In order to study the faunal species and distribution on $9 \mathrm{~A}$ a large grid system was laid out. (see Diagram 4.1 for the overall 1ocation of the grid relative to the excavations and Diagram 4.2 for a detailed plan and survey of the grid). The number of each species was determined for each grid square and all lithic material was carefully collected. (See Chapters 7 and 8 for a full description of the technique used in counting shells and collecting archaeological material). Diagrams 8.6 and 8.7 show histograms for the number of each species per square and Table 10.5 shows the overall number of each species for the area as a whole. It is clear from the table that $\underline{\text { Plebidonax is not a predominant species. From }}$ Diagram 8.6 it can be seen that the areas of greatest concentration of Plebidonax lie on the north side of the grid particularly in the area adjacent to Excavation $9 \mathrm{~A} / 2$. The reason for concentrations of Plebidonax in this region became clear, for they have derived from the erosion of the lenses in 9B (Diagram 4.8). Thus, the distribution of Plebidonax, as shown by Diagram 
8.6, gives some idea of how far $9 \mathrm{~B}$ originally extended over 9A. The small scatter of Plebidonax over the entire area of $9 \mathrm{~A}$ may be explained in one of two ways. Either they have been transported there from the $B$ dunes on the south side of $9 \mathrm{~A}$ or they have been eroded from the A series soil, in which case Plebidonax could not have been an important species in A series times.

A survey of the lithic material on the surface of $9 \mathrm{~A}$ revealed the presence of varieties of secondary retouched artifacts, best described generally as backed blades. It was therefore assumed that these backed blades formed part of the assemblage being eroded from the soil. It followed then that the assemblages recovered in Excavations $9 \mathrm{~A} / 1,9 \mathrm{~A} / 3$ and $9 \mathrm{~A} / 5$ should contain backed blades. However, this was not the case.

5. Excavation 6 was undertaken (i) to further investigate the colour changes in wall. stratigraphy noted in Excavation $9 \mathrm{~A} / 5$; (ii) to obtain a much larger sample of stone tools in order to be able to define the assemblages and to study their distribution through time; (iii) to further investigate the various shell horizons noted in Excavations $9 \mathrm{~A} / 3$ and $9 \mathrm{~A} / 5$; (iv) to carry out more detailed studies on the genesis of the soil itself; (v) to obtain a larger sample of the number and species of fauna in the various archaeological levels.

The Location of Excavation 6 is shown in Diagram 4.1. The stratigraphy is shown in Diagram 4.13 and Plates 4.1.1 and 4.12. A white layer is clearly shown in the photographs. However, this 
layer was hardly apparent while excavating. The band does not show up equally well on all the walls; it is most pronounced on the south wall while it is barely discernible on the west and north walls. Indeed it was not until the south wall had been exposed for some weeks that the colour change became so pronounced.

The colour change is probably caused by oxidation in conditions of reduced dampness. The south wall had no sand covering, while the other walls, particularly the west and north walls, stil1 had large quantities of sand directly behind and above them. The sand retained considerable moisture which helped to prevent these walls from drying out. At the same time, the east and west walls were more exposed to the sun than the other walls. However, precisely why this particular section of the wall should change in colour has yet to be established.

Soil samples were taken from every spit in Square $\mathrm{C} / 1$. The results of the soil analysis are shown in Diagram 3.1 and Table 4.1 and the method of analysis is set out in Appendix 4.2. The stratigraphic feature (the white layer) has been emphasized in the diagram.

Munse11 colours were determined for dry soil samples. It can be seen from Table 4.1 that the change in colour is not coincident with the stratigraphic feature shown in Diagram 3.1. Nor do the grain size analyses, organic carbon, calcium carbonate, or PH tests suggest an origin for the stratigraphic feature. 
Both the total shell density for this square (see Chapter 6 for definition) and the stone density (for $\mathrm{C} / \mathrm{I}$ and the squares immediately surrounding $\mathrm{C} / 1$ ) have been plotted as a function of depth in Diagram 3.1. Although the 1ithic and shell peaks correlate, they do not seem to relate in any way to the stratigraphic feature. 1 It would seem then that this feature has not been caused by occupation but has been produced by some undetermined geomorphological process.

Although there are no specific peaks of the organic carbon and phosphorous percentages which correlate with the shell density or the lithic peaks, in general, the various distributions corroborate each other. Phosphorous percentages are higher over the entire period of occupation (as indicated by the lithic and shell density peaks) and a similar tendency is apparent for the organic carbon percentages.

The north western corner of the excavation was dug down to the concretionary layer (Plates 4.13 and 4.14). Comparison of Diagrams $4.4,4.5$ and 4.13 show that there is approximately the same depth of soil above the concretionary layer.

Further, since a carbon date is available for spit 7, square C/4-3480 $\pm 90 \mathrm{BP}-(\mathrm{GAK}-970)$ it is possible to compare the rates of soil build up in these three excavations using the nodule layer as a datum. First of all, taking Excavation 9A/5

1 Note that for a particular square it is quite possible to have uncorrelated peaks. These would occur in areas where no stone was prepared (shell peaks only) or areas without shell peaks (1ithic peaks only). 
where dates are known for the upper and lower parts of excavation, and by using minus 8.75 feet as the datum level (corresponding to the first appearance of the concretionary layer) one can plot a graph of height above the nodule layer as a function of time (Diagram 4.14). Since the concretionary layer is not well defined (see Table 7.29) and because the charcoal for dating was taken from somewhere inside a spit of finite width, the error limits shown on the graph have been set at \pm 0.25 feet (corresponding to the approximate size of the spits taken out during excavation). For Square C/4, Excavation 9A/6, the nodule layer first appeared at a depth of minus 9.85 feet below the site datum. The carbon sample (for spit 7) was taken from somewhere between minus 7.22 feet and minus 7.46 feet. Allowing for an error of \pm 0.25 feet the shaded area on Diagram 4.14 represents the range of predicted dates for level 7 (3700 BP to $5100 \mathrm{BP})$. The predicted and actual dates for this level overlap when account is taken of the standard deviations for the three dates. One is able to conclude then, that the rates of build up of the soils in the two areas are approximately the same and that the dates for the two excavations corroborate each other.

The A series soil is not horizontal and it slopes upward from $9 \mathrm{~A} / 6$ to $9 \mathrm{~A} / 3$ and $9 \mathrm{~A} / 5$. For example the top of the soil begins at approximately minus 6.0 feet below the datum for the north wall of Excavation $9 \mathrm{~A} / 6$, compared with minus 4.0 feet for Excavation $9 \mathrm{~A} / 5$. 
Diagram 4.13 shows few stratigraphic features. However, it is apparent from the few shells that are exposed to view that there are concentrations at particular levels (for example, in the west wal1). Again, these levels are not horizontal but have a slight slope from south to north and seem to run approximately parallel to the soil surface. The stratigraphic feature behaves similarly indicating that it could be related in some way to the soil surface.

The faunal and lithic analyses of the material excavated from $9 \mathrm{~A} / 6$ are discussed in succeeding chapters. It is only necessary here to point out that these analyses confirmed the several hypotheses made on the basis of material examined from Excavations $9 \mathrm{~A} / 1,9 \mathrm{~A} / 3$ and $9 \mathrm{~A} / 5$, and on the surface of 9A. Backed blades are an important element in the excavated assemblage, and the marine fauna in the occupational soil is predominantly rock platform. A few Plebidonax were excavated in the top layers of 9A/6 (29 in a11) indicating that they were available in the area but these were not an important part of the aborigines' diet.

6. Having established the sequence at Site 9A the cultural material on $9 B$ was then studied. For this purpose all lithic material was collected from the four areas of $9 B$, Superficial examination of this material suggested that there were significant differences between the assemblages of $9 \mathrm{~A}$ and $9 \mathrm{~B}$. In particular, four observations were made: (i) the flake material of $9 B$ appeared to be larger and cruder than 9A; (ii) 
there appeared to be differences in materials.

For example at Site 9A, Quartzite, Quartz and

Flint were used extensively while at 9B, Flint and Quartz predominated; (iii) there were no backed blades in the B series assemblage; (iv) the density of lithic material was much lower in the $B$ series and retouched flakes were fewer.

\section{A working hypothesis}

On the basis of the foregoing it appeared that two cultural sequences were present at Site 9. The oldest assemblages mper be doseribed generatity senes dunes ind may be described geverally as consisting of backad as a backed blade industry and will hereafter be

blade widustries. The y will hereafter be referred to as YAwake $A$. Yavahie $A$ referred to as Yanakie $A$. The marine fauna

material is also associated with the northen sequence of $B$ series duwes (seo p-3q) ard wrth alssociated with this sequence are mainly Rock

Platform species, but with some Bay species on the

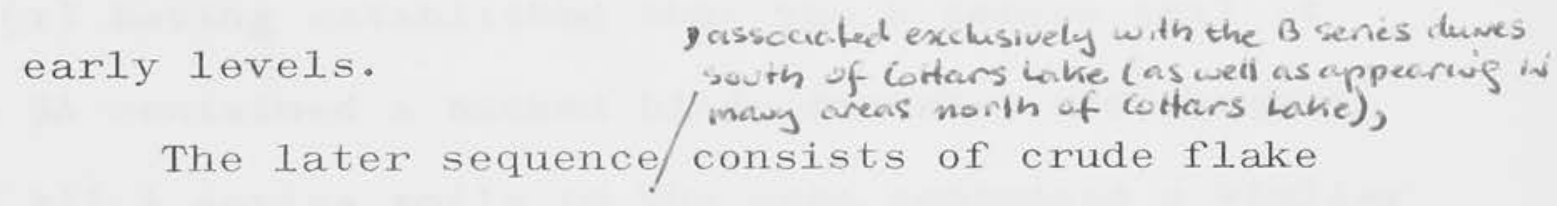
and large core tools and edge ground axes. The predominant marine fauna is Plebidonax, a sandy beach species. Hereafter this assemblage is referred to as Yanakie B.

\subsection{The Archaeological Project at Site 11}

Attention was given to another A series site north of Site 9 (see Diagram 2.3 for location relative to Site 9). Diagram 4.15 shows a detailed plan of the site. It can be seen that the southern section of the site is very badly eroded. The northern side slopes upward steeply and is covered by a high B series dune ridge which is well vegetated. The usual Pleistocene stratigraphy has been exposed by erosion on the seaward end of the dune ridge. Thus, badly weathered cliffs over 50 feet high stretch for some hundreds of 
yards northward along the beach to site 12. On the main part of Site 11 the A series occupational soil is badly eroded and towards the cliff edge the soil has been completely eroded. However, a little to the north on the cliff top itself, the soil is still largely intact and is accessible because the B series dune sands have been blown back a few yards from the cliff edge leaving the A series soil exposed. It was apparent from shell material lying on the A series surface that some of the soil had already been eroded away. This is not unexpected as the cliff top area is directly exposed to the prevailing winds and weather. Diagram 4.15 shows the precise location of Excavation 1 $(11 / 1)$.

There were several reasons for excavating at Site 11: (i) having established that the A series soil at Site 9A contained a backed blade industry one assumed that all A series soils in the area contained a similar industry. This was to be expected since the soil can be traced continuously from Darby Beach to Cottars Lake (see Chapter 3). Excavation $11 / 1$ was conducted to verify this assumption in another A series area; (ii) it was also designed to further investigate the stratigraphic feature noted in $9 \mathrm{~A} / 5$ and $9 \mathrm{~A} / 6$ and (iii) to obtain further data on shell densities and faunal species.

Diagram 4.16 shows the position of $11 / 1$ relative to the cliff edge. Excavation did not continue down to the concretionary layer because the occupational material had become too sparse before it was reached and further work was not warranted. Diagram 4.17 and Plate 4.15 show the stratigraphy of the excavation. Two observations can be made from this diagram: 
(i) shell/charcoal Lenses and (ii) the stratigraphic feature are again present. The stratigraphic break between soil and sand was clean and precise (compare with $9 \mathrm{~A} / 1$ ) indicating that redeposition of $\mathrm{B}$ series sands followed a period of erosion of the A series soil. This was further corroborated when shells were found immediately on top of and just embedded in the top layer of the A series soil.

The results of the soil analysis are shown in Diagram 3.2 and Table 4.1. However, the same comments apply here as were made for the soil analysis of $9 \mathrm{~A} / 6$. That is, the soil analysis does not solve the problem of the origin of the stratigraphic feature, and that both the phosphorous and organic carbon percentages increase over the main period of occupation (as indicated by shell density and lithic peaks).

Spit 3, Square $B / 5$ has been dated at $3920 \pm 90 \mathrm{BP}$ (GAK-968). This spit is 2.08 feet to 2.30 feet above the floor of the excavation or approximately 2.58 feet to 2.80 feet above the nodule layer (ascertained by sinking an exploratory hole in the floor of the excavation). Referring to Diagram 4.14, and allowing \pm 0.25 feet for spit width variation and inexact definition of the position of the nodule layer, the predicted date range for level 3 is $3500-4900$ BP. GAK-968 falls well within this range, indicating a similar rate of build up of the A series soils at Sites $9 \mathrm{~A}$ and 11 .

The problem of the stratigraphic feature remains unsolved. Although the top part of the occupational soil at $1 \perp / \perp$ has been eroded off, the stratigraphic feature is located at approximately the same distance below the extant surface as it is in Excavations $9 \mathrm{~A} / 6$ 
and $9 \mathrm{~A} / 5$. This observation would support the suggestion that the feature is somehow related to the surface. On the other hand, no such feature was observed for $9 \mathrm{~A} / \mathrm{I}$ - another eroded area - but it is possible that the stratigraphic feature was overlooked or indistinguishable for it could not be discerned in $9 \mathrm{~A} / 3$ and was often obscure in $9 \mathrm{~A} / 6$.

Analysis of the lithic material from $11 / 1$ confirmed that backed blades form an important part of the industry.

\subsection{Summary}

Excavation and surface studies have combined to reveal the probable existence of two cultural assemblages in the region of Sites 9 to 11 . Yanakie A consists of a backed blade industry and is associated with rock platform fauna. Yanakie B consists of a crude flake and large core industry with the edge ground axe and is associated with sandy beach fauna. The prevalence of the A series occupational soil over such a wide area enables all the cultural material contained within and eroding from this soil to be classed as part of the Yanakie A assemblage. Further, it was shown that approximate dates for in situ material (in the soil) may be obtained by measuring the height of the occupational level above the concretionary layer and using Diagram 4.14 to date the level.

The foregoing has outlined the general archaeological and geomorphological situation on the west coast of Yanakie. In the following chapters an attempt will be made to present more detailed evidence to support these views. In particular, considerable 
attention has been given to the ecology of the area so that the ancient climate, physiography, flora, population and culture traits all become focal points in this study. In the course of research into these topics, new techniques of handling data have been evolved and described in detail, so that the following dissertation must also be regarded as exploratory and experimental exercises in a methodological approach to archaeology. Thus, before the Yanakie A and B assemblages are defined a new type of approach to the typological analysis of lithic material is outlined. As well, considerable attention has been devoted to the study of surface sites. In particular, the surface material of 9A has been analysed in conjunction with the several control excavations nearby. The 200 or so retouched tools obtained from all the A series excavations were not enough to either define the Yanakie A assemblage or to enable reliable metrical work to be carried out on the assemblage. Thus tools collected from the surface of Site $9 \mathrm{~A}$ were used in these studies. This procedure was validated by demonstrating the relationship between the surface and excavated assemblages. 
$\frac{\text { ANALYSIS OF FAUNAL MATERIAL FROM THE }}{\text { EXCAVATIONS AT WILSON'S PROMONTORY }}$ PART 1

\subsection{Introduction}

In the last chapter it was apparent from the stratigraphic diagrams of each A series excavation that the trench walls were virtually featureless. This was to be expected since, except for the stratigraphic feature which does not appear to be due to human activity and the fact that the soil became more compact towards the bottom of the trench, no radical changes in colour or composition could be detected during these excavations. Without the help of visual changes in stratigraphy, it is difficult to place the cultural material in a useful sequence.

During excavations numerous shell horizons were detected. Some of these consisted of compact shell heaps, adjacent to, or interspersed with, charcoal concentrations and fragments. Operculum and Subninella and/or piles of shells of other species were often collected together on what appeared to be undisturbed living floors. Sometimes these floors were excavated as a whole but moxe often they were difficult to define and to trace in the confined area of a three feet wide trench, Because of breaks in floors (areas with no she11) or the time interval between excavating one trench and the next it was often difficult to make correlations between one square and the next while in the field.

These difficulties have led to the development of a method of redefining the floors in terms of the shell 
concentrations per spit. Once the floors have been established, the lithic material can be assigned to each floor and a sequence of industries established.

The first part of this chapter sets out to

describe a method of processing faunal data. Here, the shell floors have been assigned by plotting shell densities as a function of depth and considering the relationship between the peaks of the resulting distributions. The problem of whether these floors are authentic, and the degree of destruction of shell fauna on these floors has also been considered. Finally, some attempt has been made to relate the shell heaps on each floor to the maximum number of aborigines responsible for their deposition. Other subsidiary problems relating to the analysis have been discussed in the course of these investigations.

\section{PROCESSING FAUNAL DATA}

\subsection{Method of Recording Data}

All fauna from the several excavations at Wilson's Promontory was retained for analysis. The contents of each spit was examined and is summarized in Tables 5.1 and 5.2 .

\section{Explanation of Tables}

The shell fauna has been divided into three classes - Gastropoda (Table 5.1), Pelecypoda and Amphineura (Table 5.2) i.e. a pair of sheets was used for the primary recording of the fauna from each spit. ${ }^{1}$

1

All species mentioned in this and succeeding chapters were identified by $J$. Hope Macpherson formerly Conchologist at the National Museum, Melbourne, Victoria. The text used for this study was 'Marine Molluscs of Victoria' by J. Hope Macpherson and C.J. Gabriel (1962). 
The stratigraphic Iocation of the spit is recorded on the captions at the top of each sheet.

The left hand column records the various species found in the excavation. These were determined from a preliminary survey. The other columns are self explanatory. A distinction between fragments and whole shells was carefully maintained.

The equivalent number of shells was determined in the following manner. ${ }^{1}$ A large sample of each species (uncleaned and undried) was collected from the excavated material, i.e. whole shells. In some cases, as with Austrocochlea constricta, insufficient whole examples could be collected from the excavated material. Here, the sample was increased by collecting she11s from the surface site nearby. These shells had the same soil matrix adhering to them as the excavated shells, and were comparable with shells taken from the excavation, since shells lying on the surface have been eroded out of the same soil as that in which the excavations had been conducted. Table 5.3 summarizes the results of these determinations and, by using this table, the equivalent number of shells per species was computed for each spit.

Since no whole samples of Mytilus were available an equivalent value could not be calculated, so that Mytilus was compared by weight rather than by equivalent numbers. Poneroplax was recorded by noting the number of valves recovered. To obtain the number of Poneroplax (actual) the number of valves were

1

'Equivalent' number per species = total weight of whole shells plus fragments divided by the average weight of one shell of that species. 
divided by six. Recording of nodules was roughly formalized ${ }^{1}$ (see Table 5.2). They were divided into three groups:-

(a) Small (less than half an inch in diameter);

(b) Medium (half an inch to two inches in size);

(c) Large (greater than two inches).

If there were less than 50 in any one of these groups the number of nodules were counted. Each group of nodules was weighed and the weights were recorded.

\subsection{Analysis - Part 1}

The equivalent number of shells for each spit was then transferred on to new sheets (Tables 5.4 and 5.5). The three classes of fauna - Gastropoda (Table 5.4), Pelecypoda and Amphineura - were again retained ( Table 5.5). The species lists on each sheet have been set out in a special order. Austrosuccinea and Notocypraea are non-edible (i.e. NE) and have been grouped together. Austrosuccinea is a land or fresh water snail and was not eaten by the Aborigines and its appearance in midden deposits may or may not be associated with human occupation (see later). Notocypraea is very small usually less than three-eighths of an inch in diameter - and in the extant environment it is frequently found adhering to the shell of Cellana tramoserica. There is 1ittle doubt that its presence in the midden fauna can be attributed to the presence of considerable numbers of Cellana.

A distinction has been made between Bay or Muddy Bay, Sandy Beach and Rock Platform species of fauna

1

Nodules may be sand cemented by calcium carbonate, and/or root nodules formed by precipitation of calcium carbonate around a root structure. 
(i.e. B, S, R respectively). In most cases the

designation of a particular species to one of the three groups is clear. However, there are one or two

exceptions such as Polinices which can be $\mathrm{S}$ or $\mathrm{B}$, i.e.

SB. More will be said about the significance of these three groupings at a later stage. It will suffice to say at this stage that the different groups can assist in investigations of environmental and geomorphological changes.

Comparison of Tables 5.4 and 5.5 shows that the majority of fauna are Rock Platform. (The two nonedible varieties are also Rock Platform).

Operators assisting in the faunal analysis were trained to recognize various species of shell. However, many assistants had difficulty in remembering the proper name of each species. A simple code name was therefore given to each species to overcome this problem. To facilitate the recording of data, these code names have been placed alongside the proper name of each species.

Tables 5.4 and 5.5 are designed to summarize data from a single square.

There are 16 primary stages in the faunal analysis of each square. Each step is described below, with comments where necessary. For purposes of illustration, a full description of the analysis of part of Excavation No. 1 , Site 11 is included. The data from other excavations is too extensive to present here, so that summaries must suffice to display the results of the faunal analysis of these excavations. Likewise, presentation of all the raw data for Excavation No. 1 would also be too copious, so that only the full analysis of Square 2, Trench A is included below. 
Step $1(\mathrm{a})$ consisted of converting al1 weights to an equivalent number of shells and summarizing the results in Tables 5.4 and 5.5 (with the exception of Mytilus - see above).

In order to make comparisons between the contents of each spit, the number of each species had to be weighted according to the volume of each spit, i.e. the 'number of shells' had to be converted to 'shells per cubic unit' (Step 1(b)). Two dimensions of each square are constant, i.e. 3 feet $x 3$ feet. The only variable is spit depth and this can be used as a weighting factor. Spit depth is not constant over the square yard: that is the spits were not taken off horizontally. This necessitated computing a set of average spit depths for each square as described below:

(a) Average level diagrams were prepared for each excavation. As each spit was taken out, levels were noted for the corners of every square yard in the trench. In each square, an average level was obtained by taking the two left hand levels and averaging. The right hand levels were treated similarly and these two average values were then plotted on a scale diagram of the excavation. The process was repeated for each spit excavated. The resulting level diagrams represented the average spit depths for the excavation. All data has been plotted on these average level diagrams (see Diagrams 5.1 and 5.2 ).

(b) The average spit depth was computed by taking the depth of the spit (from the average level diagram) on either side of the square and averaging the two values. This figure 
(different from each spit per square) was used to weight the number of shells of each species in each spit per square, respectively (Table 5.6). Thus if the she 11 number is divided by the average spit depth, the final figure will be a shell density, i.e. shells per cubic unit, which is in turn proportional to shells per cubic inch, per cubic foot and so on.

If the number of shells per cubic unit is used, the shell densities are magnified by factors of the order 9 (shells per cubic foot) and 15,550 (shells per cubic inch). It will be seen presently that the midden material in the various spits cannot be regarded as dense (compared with New Zealand middens which are usually solid shell heaps). For example, a two inch spit $\left(0.16^{\prime}\right)$ with one shell per cubic inch would correspond to about 16,000 shells per cubic unit. The highest recorded shell densities in the Wilson's Promontory excavations are of the order 1,000-2,000 shells per cubic unit. After making allowances for shell losses in antiquity, this would correspond to an original density of approximately 2,000-4,000 she11s per cubic unit (see Chapter 6). That is, approximately 85 per cent of the spit volume consists of a soil and charcoal matrix.

Data on Tables 5.4 and 5.5 were converted into shell densities using the appropriate weighting factors shown in Table 5.6. The densities are recorded on forms identical to Tables 5.4 and 5.5 (Tables 5.7 and $5.8)$

Conversion to shell densities comprises stage two of the analysis. 
The total number per square for each species was computed by adding up each row of Tables 5.4 and 5.5 and placing the total in the extreme right hand column. This process was not repeated for Tables 5.7 and 5.8 , as the totals have no meaning. (An average shell density could be obtained by dividing the total number of shells of each species by an average spit depth computed for the whole square).

Three totals are required in the vertical addition on the Gastropoda sheets, i.e. when computing the total number of shells, including all species per spit. Obviously, in the vertical addition, both operculum and Subninella should not be included. Thus the first total adds whichever of the two groups (i.e. operculum and Subnine1la) contributes the highest number of shells. In most cases this will be operculum because they are virtually indestructable while Subninella are fragile and many have been destroyed. The second total adds only Subninella, and the third includes both Subninella and operculum. The vertical total does not include Austrosuccinea or Notocypraea.

Vertical additions are shown in Tables 5.7 and 5.8 and the totals have been worked out separately for Gastropoda and Pelecypoda. Tables 5.7 and 5.8 have provision for the grand total i.e. Gastropoda, Pelecypoda and Amphineura, and three totals are again required.

Stage 2 (Summary from above)

(a) The total number of Gastropoda/cubic unit for each spit was computed (excluding

Austrosuccinea and Notocypraea).

(b) The total number of Gastropoda was computed per square (excluding Austrosuccinea and Notocypraea). 
Table 5.9 is a special sheet which summarizes the processed data. Thus row one of Table 5.9 contains the results of $2(\mathrm{a})$. As pointed out above, the addition of the columns horizontally in Tables 5.7 and 5.8 is meaningless, so that $2(\mathrm{~b})$ - the total number of Gastropoda - is the absolute value taken from the addition of each column in Tables 5.4 and 5.5 horizontally and then adding these totals vertically.

\section{$\underline{\text { Stage } 3}$}

(a) The total number of Pelecypoda/cubic unit for each spit was computed.

(b) Per square (actual value). Computation was completed in identical manner to stage 2 . Results are placed in row 2 of Table 5.9.

Stage 4

(a) The total number of Amphineura/cubic unit was computed for each spit.

(b) Per square (actual value).

Computation was the same as in stages 2 and 3.

Results are placed in row 3 of Table 5.9.

Stage 5

(a) The total number of non-edible species per cubic unit was computed per spit.

(b) Per square (actual number).

Computation was the same as in Stages $2-4$. Results are placed in row 4 of Table 5.9 .

Stage 6

(a) The ratio of Pelecypoda to Gastropoda was computed per spit. (Reference to Tables 5.4 and 5.5 excluding Austrosuccinea and Notocypraea. The first total was used for this calculation).

(b) Per square.

Results have been inserted in row 5 of Table 5.9 . 
Stage 7

(a) The ratio of Sandy to Rock Platform species was computed for each spit (refer to Tables 5.4 and 5.5). The column labelled Type, as explained above, indicates which of the species to include in the additions, i.e. in this case $\mathrm{S} / \mathrm{R}$ ratio. The first total was used for this calculation.

(b) Per square.

Results have been inserted in row 6 of Table 5.9. Stage 8

(a) The ratio of Bay or Mud species to Rock Platform, i.e. B/R was computed for each spit (refer to Tables 5.4 and 5.5).

(b) Per square.

Results have been inserted in row 7 of Table 5.9. Stage 9

(a) The ratio of Sand to Muddy Bay or Bay species, i.e. S/B was computed for each spit (refer to Tables 5.4 and $5 \cdot 5$ ).

(b) Per square.

Results have been inserted in row 8 of Table 5.9. Stage 10

(a) Nodules. These were listed by weight - small, medium and large - see Table 5.5.

(b) Total weight of the three groups per spit see Table $5 \cdot 5$.

Stage 11

The occurrence of organic matter in any spit was noted. See row 9 of Table $5 \cdot 5$.

Stage 12

(a) The percentage of whole (actual shells as taken from column five of Tables 5.1 and 5.2) 
to the total equivalent number of shells (column 7 of Tables 5.1 and 5.2) was computed for each species per spit. The number of whole shells has been conveniently listed in Tables 5.10 and 5.11. These figures have then been divided by the corresponding total equivalent values set out in Tables 5.4 and 5.5. Note Tables 5.1 and 5.2 represent faunal data for one spit only. There are two similar sheets for every spit in the square.

(b) Per square.

Results have been inserted in Tables 5.12 and 5.13 as percentages.

\section{Stage 13}

The percentage of whole (actual) to total equivalent number of shells (as taken from the sum of columns 5 and 7 of Tables 5.1 and 5.2) was computed per spit for:

(a) Gastropoda - including firstly Subninella and operculum but excluding the non-edible species.

(b) Gastropoda - but excluding operculum.

(c) Pelecypoda - excluding Mytilus.

(d) Pelecypoda, and Gastropoda including both Subnine1la and operculum.

(e) Pelecypoda and Gastropoda but excluding operculum.

(f) Per square.

Results: 13(a), 13(b), 13(c), 13(d), 13(e) and $13(\mathrm{f})$ have been inserted in rows $10-14$ respectively of Table $5 \cdot 9$. 
(a) The ratio of burnt to unburnt shells was computed for each species per spit. (Figures were taken from columns 7 and 8 of Tables 5.1 and 5.2). The results are depicted in Table 5.14 .

(b) Per square.

Stage 15

(a) The ratio of burnt to unburnt shells was computed for the combined shells of each spit.

(b) Per square.

Results have been inserted in row 15 of Table 5.9. Stage 16

(a) The ratio of operculum to equivalent number of Subninella was computed for each spit (figures were taken from Table 5.4).

(b) The ratio was computed for the square as a whole.

Results have been inserted in row 16 of Table 5.9. Having dealt with the raw data in this manner, one is now in a position to extract useful information from it.

FAUNAL ANALYSIS OF EXCAVATION NO. 1 , SITE $11^{1}$

\subsection{Analysis - Part 2}

An attempt has been made below to determine the location of the living floors, by plotting shell density as a function of depth. Diagrams 5.3 and 5.14 depict both the shell density per species and the total

1

In order to facilitate recording of individual species, their names have frequently been abbreviated to a combination of the first letter in each of the species names. For example, Austrocochlea constricta would be written as AC. 
shell density as a function of depth. There is one diagram for each square. The data has been plotted on the average level diagrams (Diagrams 5.1 and 5.2). The mean spit depth, i.e. the depth of the spit in the centre of the square, has been taken as the ordinate increment. Spit numbers are shown at each level.

There are three parts to each sheet: (a) Gastropoda distribution; (b) non-edible and Pelecypoda distribution; and (c) total shell density distribution. The data was plotted from rows 1-4 of Table 5.9 (totals), and from Tables 5.7 and 5.8 (individual species). There were twelve squares ( 3 feet $x 3$ feet) in this excavation.

Each peak in the total shell density distributions was given a number 1, 2, 3 etc. and these are listed in Tables 5.15 and 5.16. Peaks may be located to within \pm half the error listed in these tables. The total shell density data was then taken, and plotted on a level diagram arranged in such a way that all the peaks could be viewed in relation to one another. These shell density values were first normalized by dividing through by the largest shell density $(2,225$ shells per cubic unit) and converting the ratios to percentages. Table 5.17 depicts the normalized data. ${ }^{1}$

The new values were plotted on a scale level diagram (5.15). These ordinate/abcissa scales were the same so that the diagram was an exact scale drawing of the excavation. The position of each spit (the average value) has been plotted on the left hand vertical axis of each square, and the normalized shell density scale 
was chosen so that its maximum value (100 per cent)

fell within the square. By plotting the data in this way the visual selection of correlations of shell peaks between squares was greatly facilitated and the living floors could be relocated. Diagram 5.15 can now be examined further.

The position of the shell peaks in both trenches suggests that there are at least four occupational floors. However, there are some lenses which do not seem to fit into this level scheme and cannot be assigned in any way possibly because of the limited nature of the excavation. 1 For example, Square 2 , Trench A, Level A3 could be drawn through either Peak 2 or Peak 3. However, when reference is made to the peak distribution in Square 2 of Trench B it appears that Peak 2 would be the best choice. This decision is supported by the distribution of the lithic peaks (discussed in the next section). However, regardless of which peak is chosen, one peak is left on its own. It is apparent from present day Aboriginal remains found amongst the dunes, that midden material tends to be concentrated in small heaps in localized areas. These lenses of Áboriginal material may be covered over by sand or overgrown by vegetation long before the next group of aborigines camp in the same area. Thus the extent of a living floor will depend upon:

(a) the number of aborigines visiting the area;

(b) the length of time spent in the area;

1 Referring to Tables 5.15 and 5.16 it can be seen that many peaks have low values. E.g. Trench A, Square 3, Peak 3; Square 2, Peak 5; Trench B, Square 4, Peak 1; Square 3, Peak 1. Eighteen shells per cubic unit corresponds to two shells per cubic foot which is a very low shell density. Consequently some of these minor peaks are not shown in Diagram 5.15. 
(c) the rate at which sand or soil accumulates over the deposit;

(d) the regularity of visits to the area;

(e) the nature of the floor itself, i.e. whether it is a sand or soil.

If, for example, the floor is soil, more extensive occupation of floors could be expected since the local topography would be better preserved for longer periods of time. A sandy floor will be associated with a shifting local topography. In such circumstances a considerable number of lenses may occur with no apparent correlation to any occupational floors. If the Aborigines were camping in a sandy environment (as opposed to a soil or stabilized environment) their deposits would be covered more rapidly because of the greater volume of air borne material associated with the destabilized environment.

At Site 11 the A series Aborigines were camping in a stabilized environment. Although occupational floors are expected, this does not mean that isolated lenses cannot occur. For this excavation, four occupational floors A1-A4 have been postulated and only two of these are extensive (A2 and A3). ${ }^{1}$ The living area of A1 covers the entire area of the excavation and how far it extends outside this area has not been determined. A4 extends the full length of the excavation in one trench but in the other there is little evidence of occupation in Squares 5 and 6 (Trench B). Of a total of 45 peaks,

1 The method of plotting the position of the occupational floors is as follows. Each peak position is transferred to the centre of the square (marked by crosses in Diagram 5.15). The floor positions are located by drawing lines through the crosses in adjacent squares. 
37 have been utilized to position the occupational

floors. In one case $(\mathrm{A} / 3)$, no peak occurs where a cultural level/has been drawn. However, the shell density is still quite high here and a level drawn through this point is consistent with the data in the other 11 squares. $^{1}$

\section{VALIDITY OF SELECTED CULTURAL LEVELS}

\subsection{Analysis - Part 3}

Some techniques are available for testing whether these cultural levels are reasonable propositions. The techniques were actually used in conjunction with the method just described to aid in selecting the most likely living floors.

\section{Method A - Predominant Fauna}

Table 5.18 lists those peaks used in determining the various cultural levels and the numbers of each of the main shell species contributing to them. The table was constructed by referring to Diagrams 5.3-5.12. These diagrams show which of the spits in each square contributed most of the shells to each of the peaks. Having determined these, the actual numbers of shells in each peak per species were derived from Table 5.14. The right hand part of Table 5.18 shows the fauna ranked in order of importance. This was done by giving each species in the peak a number one to five, according to their relative magnitudes, i.e. the species with the greatest number receives the number 'one'. Table 5.19 shows the data arranged per cultural

In other cases no peak and no occupational material may occur at an assigned level. This situation is interpreted as indicative of a sterile area on the living floor. 
level. 1 These ranked magnitudes indicate that the

levels may be separated in terms of dominant species.

A4 has Cellana as a clearly dominant species; A3 has a

predominance of Austrocochlea and Subnine1la; A2 has

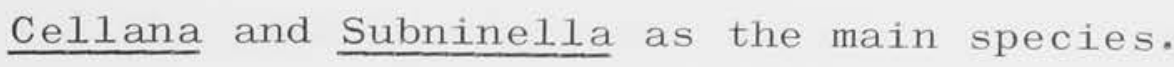

Alternatively, in Level A4, six squares out of ten have

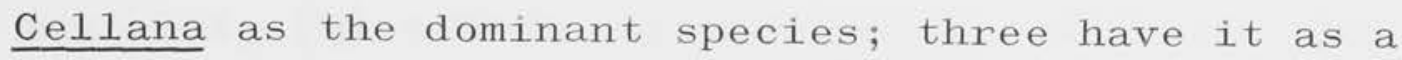

secondary species. For A3, five squares have

$\underline{\text { Austrocochlea }}$ as the dominant species, and another five squares have Subninella as the dominant species and so

on. In $\mathrm{A} 4$ and $\mathrm{A} 2$ the secondary species interconnect

the primary species, i.e. for A2, while five squares

have Cellana as the dominant species the six other

squares have it as a secondary species. On the other

hand, these six squares have Subninella as dominant

species, with Cellana secondary in the other five. The

peaks of A3 are related through a third species,

Cellana, which tends to be high in secondary importance.

This method of relating the peaks proves to be of

diminishing importance as the surface area increases.

Nevertheless over small areas it can be useful.

Concentrations of a particular species of fauna

such as those mentioned above, have been observed by

many field workers in open site contexts. ${ }^{2}$ On the

1

Taking Level A4 as an example, Table 5.19 should be interpreted in the following manner. Ten peaks (10) have been used to define A4. Of these ten peaks ten have no AA (rank 0), three have no AC (rank O), two have AC ranking first (rank 1), two have AC ranking second (rank 2), three have it ranking third (rank 3); six have CT as the predominant species (rank 1) and so on. 2

On the south eastern coast of Australia the most favoured shell fauna were Subninella undulata, Cellana tramoserica, Mytilus planulatus and Plebidonax deltoides, i.e. in South Australia at Lake Frome and Black Rock. sites - Turbo resp. (T.D. Campbell et. al., 1946, pp.458 \& 467); Cockle at Burrill Lake, New South Wales (W.W. Thorpe 1932, p.110); in Victoria: Mytilus middens (E.D. Gill 19549 p.249); Mytilus, Ostrea, Haliotł́s middens (G. Horn 1921, p.50). See also B. Smyth 1878, Vol. 1, p. xxxvi. 
basis of the foregoing, it is tempting to suggest that many of these open site concentrations are in situ.

Method B - Lithic Distribution

If the lenses are in situ, then one might expect (a) the peak occupational lenses - as depicted in the shell density diagrams - to contain most of the lithic material; (b) a high correlation of lithic and shell density peaks. Thus if lithic density is plotted as a function of depth for each square, the peaks of the lithic density distribution should coincide, or lie within the region of the peaks of the shell density distribution in each square. If there was enough variety and quantity of lithic material, it would be possible to carry out an analysis similar to that described above. The distribution and the concentrations of lithic material can also be some indication of how many separate occupations are associated with each floor.

Table 5.20 shows the distribution of lithic material through the spits for each square. No attempt has been made to separate the flakes into their material classes, though more will be said of this aspect presently. The table presents the total number of flakes in each spit, per square. These absolute values have been converted into lithic density, i.e. stones per cubic unit by dividing by the weighting factors in Table 5.6. The method of computation is identical to that described for the shell conversion. Table 5.21 shows the results of these calculations. No graphical presentation of these figures has been given because there is little difficulty in interpreting them from the table. 
The next step is to correlate the lithic peaks with those of the shell density distribution. Shortly, a more sophisticated method of correlating levels will be described while the method outlined below has been designed to explore a number of aspects of this particular correlation. Table 5.22 sets out in the second and ninth columns the various peaks of the shell density distribution. It will be recalled, that every square has been given a number from one upwards, where peak one is always the uppermost peak. This is a convenient way of recording the shell peaks in the various tables. If a shell peak corresponds to an occupational floor, the corresponding cultural level has been recorded in the seventh and fourteenth columns. Several grades of correlation have been considered. The most obvious is a one to one correlation, i.e. a lithic peak corresponding to a shell peak. In Table 5.22 this correlation has been called a ' 100 per cent correlation'. Zero correlations have also been noted. Consideration has also been given to the case where the lithic peaks do not exactly coincide with the shell peaks. The main criterion for a correlation is that the lithic peak must fall within the actual shell peak. These possibilities are presented in the table as 'inside peak - Iower' and 'inside peak - upper'. It is apparent from Table 5.21 that there are some isolated lithic peaks, i.e. spits where one or two flakes are found and which are isolated from the other levels with 1ithic material. It is doubtful whether these isolated and low density peaks should be treated in the analysis. However, when they are used they provide a much more rigorous test of level correlation. Correlation with Low density peaks has been written as 1 (L) instead of 1 . 
Thus two sets of correlation factors have been

calculated for comparison - the first with the isolated peaks included and the second excluding them. Using Diagram 5.15 and Table 5.21 the correlation factors were determined and recorded in Table 5.22. 1

Analysis of Table 5.22 gives the expected results which are summarized in Table 5.23. Thus there is a very high coincidence of lithic and shell peaks. Less than 50 per cent of the lithic peaks have one hundred per cent correlation. On the other hand zero correlation is negligible. Twenty two out of twenty seven 1ithic peaks are associated with occupational floors ( 80 per cent). 2

The results of this analysis indicate that the shell peaks are in situ, and that as a consequence the

\section{1}

At this stage a note is required on statistical. terminology. The term 'Correlation Factor' has been used and is quite distinct from the more standard 'Correlation Coefficient'. The Correlation Factor is a numerical measure of

(a) the degree of coincidence between discrete values of a particular variable (say peak shell density in this case) and discrete values of other variables.
E.g. Correlate
$\begin{array}{lll}0.1 & \frac{\text { Variables }}{0.1} & 0.1 \\ 0.1 & 0.1 & 0.7\end{array}$
Corr. Factor
0.1
0.1
0. 1
0. 1
0.1
0.5
0.9
0.66
0.2
0.20 .2
0.7
0.33
0.66

(b) an overall figure of merit for the degree of coincidence between all correlates (peak shell density) in a particular consideration, and other variables (discrete values only).

In the example above, the Correlation Factor is $1+0.66+0.33+0.66$ divided by $4(=0.66)$. That is, there seems to be a fair degree of correlation between the correlate and the other variables. The correlation Factor is a useful 'rule of thumb' figure and has been used to gauge the overall level of agreement between variables.

The Correlation Coefficient has been used in its standard form as defined by equation 12, M.R. Spiegel 1961, p.243. The coefficients have been calculated using the method described by Spiegel (p.254). 2

Note that there is little difference in the

Correlation Coefficients for the case 'with $L^{\prime}$ and

'without L'. 
living floors Al to $\mathrm{A}_{4}$ are also likely to be in situ. By using Tables 5.18 and 5.20 other deductions can be made. Diagram 5.16 represents a sketch plan of each living floor and from these tables the approximate shell and flake numbers belonging to each square per floor are shown in this diagram. Using the shell numbers as a guide, approximate contours of equal shell numbers have been drawn for each floor. Thus, there appears to be one major concentration of she11 on A4, three on A3 and two on A2.

Each concentration may have derived from single visits of a group of people to the area. But the possibility that the concentrations have accumulated over a much longer period of time should not be overlooked, for subsequent occasional visitors may have added to the shell heaps. However, the shell numbers in the heaps themselves do not suggest that they have accumulated over a long period of time.

A series of experiments were conducted in which European men lived for short periods of time on a shellfish diet. The species eaten were Cellana, Subnine1la, Ostrea, Brachidontes and Mytilus. The object of these experiments was to determine how many shellfish of each species would constitute a meal.

The subjects were given fresh shellfish of average size for their evening meal. They were either given a mixture of species, or a large number of a single species, and were asked to eat until they no longer felt hungry. ${ }^{1}$ At the end of each meal the empty shells were collected, dried, weighed and counted. Table 5.24

1

Some of the subjects required a supplementary meal later in the evening when they complained that they were hungry. 
shows the ranges of the number of shells per species required for a single meal. These figures are the results of 22 experiments on three subjects.

Ideally one would like to conclude that Aborigines eat similar numbers of shellfish per meal. It would then be possible to calculate the number of aborigines associated with each shell heap on each of the living floors using Table 5.24. However, there are a number of reasons why such an assumption cannot be made without some severe reservations. There is every reason to suppose that Aborigines could consume many more shells than a similar group of Europeans. In contrast to Europeans, shellfish are a natural part of the Aborigines' diet. Thus these experiments must have been biased by a psychological barrier to the consumption of a type of food unfamiliar to the European palate. The degree of inhibition depended partly on the species given to the subject. For example, they reacted favourably to ostrea and to the two mussel species, because they had already eaten these types of shellfish before. However, Cellana,

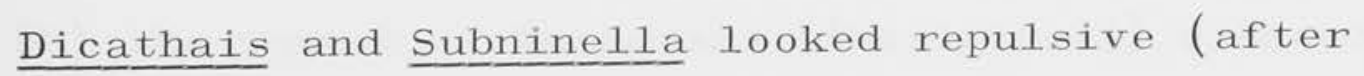
extraction from their shells) and consequently this may have effected the numbers eaten. As well some species, such as Cellana, were quite gritty and therefore tended to be less attractive. On the whole then, Europeans could be expected to consume far less shellfish per species than the Aborigines.

It is unlikely that the A series aborigines lived solely on shellfish. No evidence has been found in any of the excavations or in eroded profiles or on the older surface sites to suggest that they hunted other forms of fauna. Several small bone fragments were 
found in the A series excavations (Table 10.18)

indicating that bone material can survive in the highly alkaline soil, so that the absence of bone concentrations may be regarded as significant. Thus their shellfish diet was probably supplemented by organic foodstuffs. This factor would partly offset the error introduced when applying the figures in Table 5.24 to the midden data. Here the assumption is implicit that shellfish were being eaten exclusively. It would be too speculative at this stage to say more than that the figures of Table 5.24 are merely a basis for estimating the maximum number of Aborigines associated with the shell heaps on the living floors. ${ }^{1}$ Table 5.25 shows how the various shell concentrations are made up. Making the assumptions that these concentrations are due to single visits by a number of Aborigines, the maximum possible number of Europeans (Aborigines?) associated with the deposition of each heap has been calculated. That this is a reasonable assumption, is supported by (a) the small number of shells involved in the concentrations, and (b) the number of Europeans (borigines?) deduced in the calculations. Thus, if the concentrations had been very large so that the corresponding number of Aborigines may have been large such an assumption would be doubtful. On the other hand, small numbers are compatible with the concept of 'one visit'.

Applying Table 5.24 (the largest values in the various ranges) to the number of each species in each she11 concentration, Table 5.25 shows the estimated useful information on this aspect of Aboriginal diet. 
number of Europeans (Aborigines?) responsible for their deposition. In every case, the contour maps (Diagram 5.16) for each living floor are limited by the size of the excavation, so that no maps of a shell concentration are complete. Hence all the figures of Table 5.25 are minimal.

Because it is not really possible to envisage the camping habits of the ancient Aborigines many complications may arise in what at first appears to be a relatively simple problem. For example, all these shell concentrations may have accumulated at the one time during the visit of a single large tribe. Or there may have been several groups of the one tribe camping near each other, who threw their refuse on to different heaps. But even more important (as will be shown in Chapter 6), many shells have been broken and lost in antiquity, so that the shell numbers shown in Table 5.25 do not represent the original numbers of shells. 1 Fortunately, it is possible to derive correction factors for each species and to arrive at estimates of the original shell numbers. The recalculated population will still be a maximum estimate, referring only to the particular shell heaps on each floor, for there is no satisfactory way of studying the relationship (if any) between shell heaps on the same floor.

1 Several authors have commented on the movement and the fragmentation of shell material in exposed middens. For example, Horne and Le Souef have noted that the shell lenses collapse as the surrounding sand is blown away (G. Horne 1921, p. 48; D. Le Souef 1902, p.57), and Smyth detected evidence for shell movement (B. Smyth 1878, Vol. 1, p.205). 
Method C - Preservation of Fauna in Antiquity

So far, the possibility that there may have been movement of both lithic and shell material in antiquity has not been investigated, though it has been suggested that the cultural levels $\mathrm{A} 1-\mathrm{A} 4$ are in situ. This question will now be looked at in detail.

It is fortunate that Subninella is a predominant species in the A series fauna. It was pointed out previously, that although the shell of Subninella is perishable, its operculum is virtually indestructible. A count of the operculum will therefore be a reliable indication of the original number of Subninella.

For this study, a graph of the Subninella/operculum ratio $(\mathrm{s} / \mathrm{O})$, per spit per square, has been plotted (Diagram 5.17; see also Table 5.9 row 16). Likewise the ratio of whole to equivalent number of shells (W/E), with and without operculum, has been plotted in Diagram 5.30. (This ratio per species has been plotted on Diagrams 5.18-5.29. Diagram $5 \cdot 30$ was constructed by plotting values from rows 13 and 14 , Table 5.9). Two plots of the $\mathrm{W} / \mathrm{E}$ ratio are shown in Diagram 5.30 , because its magnitude is dependent on whether the actual number of Subnine1la or its operculum is used in calculating the ratio. By using operculum, the ratio tends to be much higher. If the actual number of shells is used, the ratio involves only perishable material which is a feature common to the other species, so that the second series of graphs is a much better indication of the condition of the shells in the excavation.

An in situ lens or level should have the following characteristics: 
(a) Concentrations of shells of the same species;

(b) In thick lenses, higher $\mathrm{W} / \mathrm{E}$ ratios are to be expected in the denser regions. When faunal material is not in situ, the $\mathrm{W} / \mathrm{E}$ ratio may be small because the shells will be more fragmented and can be blown around at random. But shells from an in situ lens may also be blown about. Consequently a small W/E ratio could indicate:

1. that the deposit is not in situ, or

2. that the deposit is in situ but with some of its material lost or reworked.

In cases of uncertainty, other sources of evidence must be used to determine which alternative is more likely. The $\mathrm{W} / \mathrm{E}$ ratio does not give any indication of the original number of shells, though it is a fair assumption that the smaller the ratio the greater the number of fragments, and hence the greater the probability that the material can or has been moved by the wind.

(c) Assuming that more human activity can be associated with the high shell density regions, a higher proportion of shells should be lost in these areas. However, the only gauge of this factor is the $\mathrm{S} / \mathrm{O}$ ratio. The degree of influence of human activity on shells will depend on:

1. the method of extracting the animal from its she11,

2. the density of each type of shell in the midden,

3. the size of the shells. 
For example, certain species may be smashed to extract the animal; large concentrations of a particular species increases the probability that a greater proportion of this species will be broken by trampage and other means. On the other hand, certain species are more robust, and can better withstand the damaging effects of man and the elements.

The $\mathrm{W} / \mathrm{E}$ ratio is a relative measure on all species, of the degree to which all these factors have been operative at each level in time. Plotted spit by spit, it is generally a good indication of the position of the original lenses (where the $\mathrm{W} / \mathrm{E}$ ratio has its peaks). However, because these factors are all unknowns and effect the various species differently, and also because the ratio does not take into account the number of shells in each spit, it must remain a rough method of locating in situ lenses. But used in conjunction with the $\mathrm{S} / \mathrm{O}$ ratio and the shell density peaks it becomes a powerful tool for this purpose. The $\mathrm{s} / \mathrm{O}$ ratio is a direct measure of the effect of these factors on Subnine1la, and should check with the W/E ratio. For an in situ lens, one should have larger W/E and $\mathrm{S} / \mathrm{O}$ ratios in areas where the greatest concentrations of shells occur. That is, more shells will be lost in these areas, but because of the larger shell concentrations, a proportionately higher number of whole shells can be expected in this region. On the other hand, the $\mathrm{S} / \mathrm{O}$ ratio does not take into account shell numbers either, so that both ratios must be used in conjunction with the total shell density peaks.

In this section, various correlations between the peaks of the shell density, $S / O$ and $W / E$ distributions 
are considered in detail, the object being to test each lens (as defined by the peak shell density) in terms of the above criteria, to see whether they are in situ.

In order to test the various correlations, a statistic has been devised which is fully described in Appendix 5.1. The reader is referred to this appendix before proceeding.

The peaks of Diagram 5.17 and 5.30 are considered in relation to Diagram 5.15, the shell density plot. Table 5.28 lists the shell density peaks per square (column 4). Other sets of peaks are shown alongside the shell density, For convenience, these sets have been given numbers and will be referred to below in the text, e.g. W/E (including operculum) has been called Set 5. 1 Thus it is possible to correlate sets 5, 6, 7, $8,9,10$ and 11 or combinations of these with the peak shell density (Set 4), or correlations may be made between any other combinations of variables. This is a useful and convenient way of recording the peaks. The $\mathrm{S} / \mathrm{O}$ ratio has been divided into four groups: (a) the continuous ratio ( $\operatorname{set} 7)$, (b) ratio equal to 1 (Set 8), (c) ratio greater than or equal to 1 ( Set 9), and (d) the $0 / \mathrm{s}$ ratio (Set 11$)$.

Table 5.29 considers the various correlations between variables. These include:-

1. Correlation between peak shell densities and peak W/E ratios including operculum (column 4, Table 5.29).

2. Correlation between peak shell densities and peak $W / E$ ratio excluding operculum (column 5, Table 5.29).

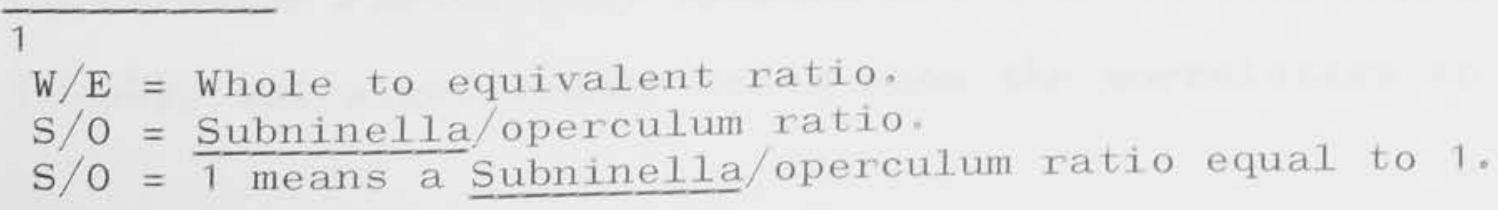


3. Correlation between peak shell densities and peak S/O ratios (column 6, Table 5.29).

4. Correlation between peak $W / E$ ratios excluding operculum and peak S/O ratio (column 7, Table 5.29).

5. Correlation between peak shell densities, peak $\mathrm{W} / \mathrm{E}$ ratios including operculum, peak $\mathrm{W} / \mathrm{E}$ ratios excluding operculum and peak $\mathrm{S} / \mathrm{O}$ ratios (column 8 , Table 5.29).

6. Correlation between peak shell densities and peak S/O ratios equal to 1 (column 9, Table $5.29)$.

7. Correlation between peak shell densities, peak S/O ratios and peak S/O ratios greater than or equal to 1 (column 10, Table 5.29).

8. Correlation between peak shell densities and peak 1ithic densities (column 11, Table 5.29).

9. Correlation between peak shell densities and peak 0/S ratio (column 12, Table 5.29).

10. Correlation between peak $\mathrm{W} / \mathrm{E}$ ratios, including operculum, and peak W/E ratio excluding operculum (see below).

Consideration of these correlations (Tables 5.29 and 5.30$)$ shows that the three postulated characteristics of an in situ lens are indeed present.

The Correlation Factors are all relatively high, indicating that of the peaks correlated with the peak shell density (set 4) a large number could be fully or partially correlated. Set 5 and set 6 both correlate with set 4, and significant tests (Table 5.30) indicate that the individual correlations are significant. The Correlation Factor ( $\mathrm{CF}$ ) between set 4 and set 7 is high $(0.64)$, but significance tests show the correlation to 
be insignificant. Here, one is endeavouring to correlate the $\mathrm{S} / \mathrm{O}$ ratio with the peak shell densities, and as pointed out above, one should not obtain significance in this correlation if the lens is in situ. The reason for such a high $\mathrm{CF}$ is explained by the large number of $\mathrm{S} / \mathrm{O}$ peaks (57) so that there is a greater probability of a correlation occurring.

On the other hand, correlation between peak shell densities (set 4), and peak $0 / \mathrm{S}$ or minimal $\mathrm{S} / 0$ ratios (Set 11), results in a high CF with positive significance. This was predicted in criteria $\mathrm{C}$ above. It is interesting to note, that many $\mathrm{S} / \mathrm{O}$ minimas, as they have been ranked in Table 5.28 (column 22), appear coincident with the peak $\mathrm{S} / \mathrm{O}$ ratios (column 7 ). The reason for this apparent anomaly is clear. Minimas closely follow peaks, and the separation in depth (time), is dependent upon the thickness of the peak. Thus in a narrow peak there may be little separation between the two - often less than $0.4^{\prime}$ - the theoretical spit depth. In these cases minima and maxima can appear coincident.

Negative significance results from correlations between set 4 and sets 6 and $7 \mathrm{~m}^{\circ}$. This is to be expected. In contrast, correlation between sets 4, 6 and 11 is high and positive. At first a significant correlation between sets $4,5,6$ and $7 \mathrm{~m}$ may seem a contradiction, particularly as the opposite case - a correlation between Sets 4, 5, 6 and 11 - is also significant. However, the significance formula becomes less sensitive as the numbers of columns increase, and low values of $W$ result. Bearing the previous comments in mind - that is, the insensitivity of maxima/minima separation and the fact that the number of peaks available for correlation in set 5, and particularly 
Set 7, exceeds the number of shell density peaks, significant correlation is not surprising. The important fact is that the correlation of shell density and any one or two sets may be sensitively tested by using the significance formula. Rejection in a one-one correlation, e.g. between sets 4 and 5, or Sets 4 and 6 , and so on, does not mean negative significance will result in a one-two or one-three correlation. But, rejection at the one-one level means the hypothesis must be rejected altogether.

$$
\text { Other results are (1) the set } 4,7_{\mathrm{m}}=1
$$

correlation has negative significance, This means that there is no identifiable relation between the in situ nature of the lens (and undisturbed lens), the $\mathrm{S} / \mathrm{O}$ peaks, and the peak shell densities. This result is also true for the opposite case, for the minima of the S/O ratio. (2) there is a positive significance for the case sets $7_{\mathrm{m}} \geqslant 1$ and also for $0 / \mathrm{s}$ ratio ( Set $11 \geqslant 1$. This means that the maxima of the $0 / \mathrm{s}$ distribution are usually greater than 1, while the minima are usually less than 1. These results are important for they indicate that the areas of greatest loss of shells are coincidental with the peak shell density (i.e. $0 / S \geqslant 1$ where the number of operculum is greater than the equivalent number of Subninella). (3) the correlation of the stone peaks with set 4 has positive significance.

The CF's for correlation between set 4 and the $\mathrm{W} / \mathrm{E}$ ratios including operculum $(0.64)$, the $\mathrm{W} / \mathrm{E}$ ratio excluding operculum $(0.58)$, the $\mathrm{W} / \mathrm{E}$ ratio including and excluding operculum $(0.78)$, all indicate high degrees of correlation. These correlations also have positive significance. However, the $\mathrm{CF}^{\prime} \mathrm{s}$ must be tested in order to see whether they are dependent on the 
magnitude of the peak shell densities. The CF between Sets 4, 5 or 6 and 11 were considered. A correlation between Sets 5 or 6 have been used, because greater sensitivity is obtained (more peaks are available for correlation).

Table 5.31 sets out the data. $X$ shows peak shell densities corresponding to the various shell peak numbers in each square. $Y$ is the derived CF. The Correlation Coefficient was calculated, and for a Type 1 error and forty five degrees of freedom the Correlation Coefficient is insignificant. This important result is supporting evidence for the in situ nature of deposits. Had the CF been magnitude dependent, it would have been tempting to postulate that the deposits were not in situ.

Returning now to a consideration of the $0 / \mathrm{S}, \mathrm{S} / \mathrm{O}$ ratios. Some of the comments made previously will now be re-emphasized. of $430 / \mathrm{s}$ peaks (a) 40 have a magnitude greater than 1, (b) 2 have a magnitude equal to 1, (c) one has a magnitude less than 1. That is, of 168 spits (the total number of spits taken out of the excavation), only nine (two plus the 7 minima or $7_{\mathrm{m}}=1$ peaks) have an $0 / \mathrm{S}$ or $\mathrm{S} / 0$ ratio equal to 1 , i.e. Iess than 6 per cent. On the other hand, 98 per cent of the 0/S peaks are greater than 1. Significance tests reveal that the set $4,11=1$ correlation is unimportant; on the other hand a set $4,11 \geq 1$ test is very significant (Table 5.30). One concludes then, that shells have been lost in antiquity.

The $0 / \mathrm{S}$ ratio has been computed for each living floor (Table 5.32(a)) and the results summarized in Table $5.32(\mathrm{~b})$. It can be seen that for each floor the $0 / \mathrm{S}$ ratio is greater than 1, and possibly increases with age. 
The shells were destroyed by one, or a combination, of three possible reasons.

1. Human activity. The Aborigines trampled on the shells, causing them to fragment and these fragments were blown away by the wind. Other shells were broken during extraction of the animals.

2. Animal activity. Trampling again caused fragmentation. This process has been observed on the $B$ series middens where marsupial fauna (including wallabies), foxes and cattle) have often been seen walking over the midden areas.

3. Weathering. The shells are blown about in exceptional winds and tend to fragment.

Before their effects become apparent, these factors need to be operative on the shell heaps for varying amounts of time.

If shells can be moved by the wind, it follows that many of the shells in the lenses may have arrived in their present situation from elsewhere. The amount of movement is governed to a greater or less extent by the degree of exposure of the area. Unless extremely exposed (an unlikely situation at the time of deposition) the undamaged shells are unlikely to move from the in situ position. Concentrations of shells of a particular species in the lenses support such an interpretation. In the disturbed case, the $\mathrm{W} / \mathrm{E}$ ratio is likely to be lower because movement will eventually damage the shells, increasing the number of fragments and thereby lowering the $\mathrm{W} / \mathrm{E}$ ratio. However, human and animal activity makes the biggest contribution to shell breakage, fragmentation and subsequent loss. Few 
really small fragments were obtained during the excavations, for these had already been dispersed by the wind. Thus the degree of contamination of the various lenses by shells from other sources is probably slight. Finally, most of the damaged shells showed the type of breakage one associates with human and animal activity. 1

The minima of the $\mathrm{W} / \mathrm{E}$ distribution and the maxima of the $\mathrm{S} / \mathrm{O}$ distribution now need to be examined more closely. The correlation between the maxima of the $\mathrm{W} / \mathrm{E}$ ratio, including operculum, and the $\mathrm{W} / \mathrm{E}$ ratio, excluding operculum, is high (the correlations between Sets 5 and 6 of Tables $5.28 ; \mathrm{P}=34$ and $\mathrm{W}$ is only 26.9). Thus the significance level for this correlation is low in comparison to the number of coincidences, so that the correlation is highly significant. The corresponding correlation between minima is also significant. The minima of the $\mathrm{W} / \mathrm{E}$ ratio with the minima and maxima of the $\mathrm{S} / \mathrm{O}$ distribution have been displayed in Table 5.33. Most of the values of the minima of the $\mathrm{W} / \mathrm{E}$ ratio can be obtained from Diagram 5.30. However, some are not obvious, and there is a need to refer to the original data sheets to obtain some of them. The reason for this is that $\mathrm{W} / \mathrm{E}$ minima must be considered over the entire depth range in which shells appear. In some cases, the W/E plot finishes (is zero) before the limit of occupation is reached. A zero $\mathrm{W} / \mathrm{E}$ ratio in this case must be regarded as a minima. A similar situation can also occur in the first few spits. Thus it is only by reference to

1

See Chapter 6 for a full discussion of fragmentation and shell loss. 
either the shell density diagrams or to the original. data sheets, that one is able to determine whether some of the minima occur near the beginning and/or the end of occupation.

Table 5.33 shows a significant correlation between the S/O maxima and the $\mathrm{W} / \mathrm{E}$ minima. That is, the peaks of the $\mathrm{O} / \mathrm{S}$ distribution correspond to the troughs of the $W / E$ distribution. This means that the smallest number of whole shells tends to coincide with the smallest number of operculum. These minima may be explained by either (a) no fauna in the spit at all or (b) a larger collection of fragments in these areas. The smaller values of the $0 / \mathrm{s}$ ratio (usually less than 1) would support the latter interpretation. The correlation between S/O minima and the $\mathrm{W} / \mathrm{E}$ minima has also been studied, and as is to be expected, the correlation is not significant (Table 5.33).

Summarizing the foregoing it can be said that when an occupational floor is built up in antiquity, large concentrations of shell and other refuse are deposited on the floor, and it is mainly the larger concentrations of shell which enable the original floors to be defined. These areas of heaviest concentration are subjected to damage by human, animal and natural agencies. Some of the shell material is lost, though some may be gained from elsewhere because of movement of material from other areas on the living floor.

After the period of occupation, the shells are exposed for some time during which man, animals and the weather affect the condition of the shells. At the same time, sand filtering over the deposit tends to protect it so that eventually the deposit is buried. Vegetation may further consolidate the deposit. Fragments and perhaps 
whole shells may have been blown or kicked from the original deposit to adjacent areas where sand or soil. has covered up and protected older or even contemporary midden deposits. There are other possibilities, most of which cannot be examined. For example, as the areas of greatest shell concentration are covered up, shells near the surface may be continually re-exposed and broken up in the process. This re-exposing and reworking of the shell material could account for the spread of the peaks. It is difficult to estimate how much of the archaeological material has been reworked. But the thickness of the shell peaks serve as a guide. These are rarely more than six inches in width at the base, so that the amount of reworking is at least limited to this depth.

Method D - Examination of the Whole/Equivalent Ratio per Species

The $\mathrm{W} / \mathrm{E}$ ratio per species per square has been computed from Tables 5.34 and 5.35. (The values in these tables were selected from Tables 5.4 and 5.5). Table 5.36 lists the ratio of $\mathrm{W} / \mathrm{E}$ per species per square. The following comments are significant.

1. Table 5.37 has expressed the information in Table 5.36 in a slightly different form. Here, the ratios per species have been arranged in order of magnitude 0 to 100. For example, for Austrocochlea constricta, two squares have none whatsoever, four have a $\mathrm{W} / \mathrm{E}$ ratio of between 0 and 10, and two have a ratio of between 10 and 20. A most important observation apparent from this arrangement is the high value of the $W / E$ ratio, for both operculum Austrosuccinea. Because operculum are largely indestructable, they have 
a high $\mathrm{W} / \mathrm{E}$ ratio. Although operculum are broken, the fractures are often small so that it is often easy to estimate the original number.

Austrosuccinea is a land snail and was not used by the aborigines for food. It is very small - less than half an inch long. Its occurrence has been tested in relation to the presence of man. That is the correlation between the peaks of the Austrosuccinea shell density plot and those of the shell density peaks has been tested. From Diagrams 5.3-5.4 the depths and spit numbers at which the Austrosuccinea peaks occur were obtained. These are listed in Table 5.38. Comparing these with the shell density peaks (Diagrams 5.3-5.14 or Diagram 5.15, Table 5.28) two correlations were tested (a) correlation of peak values, and (b) correlation with the base of the shell peaks. In the latter case the possibility that the peaks of the Austrosuccinea curves correlate with the base of the peak shell density curves has been considered. By studying these peak correlations, one is able to determine whether the Austirosuccinea peaks are independent of the shell density peaks, correlate with them, or correlate with the upper or lower parts of the lenses.

Results of the analysis shows that there is no significant correlation for either of these cases. One concludes then, that the

Austrosuccinea peaks bear no relation to the peak shell densities or to the presence of man.

The high $\mathrm{W} / \mathrm{E}$ ratio for Austrosuccinea may be explained by one or a combination of the following 
possibilities

It is protected because of (a) its

small size or (b) because it makes its appearance after human beings have left the area, and (c)

because it burrows. Only those snails moving

about on the surface would be susceptible to

damage by human and animal agencies.

2. Table 5.37 suggests that some species are more susceptible to damage than others. (This will of course depend on the method of extraction).

Austrocochlea constricta and Subninella both have very low ratios, i.e. for these species about 50 per cent of the squares have $\mathrm{W} / \mathrm{E}$ ratios of less than 10 per cent. On the other hand Cellana has a reasonably high ratio - between 30 and 60 per cent. The difference between these two groups of ratios is probably significant and might be explained by differences in methods of extraction. For example, it is much easier to extract the animal from Cellana than from either Austrocochlea or Subninella. In contrast to these two species the aborigine would never have had to break Cellana to extract the animal though he may have damaged it during collection. 1 Consequently he may have had

1

Various authors have commented on the state of certain species in midden concentrations. According to Le Soeuf stones were used for knocking limpets from the rock or pieces of stick or bone were used to prise them from their position. Consequently many limpet shells had a small portion of their rim broken. Haliotás was not broken. On the other hand he suggested that Cockle and similar shells were smashed to extract the animal (D. Le soeuf 1902, p.57; 1916, p.7). Other authors claim that they have found particular species of shell broken in a consistent manner. (So far confirmation is not forthcoming from the Promontory material). For example, one field worker recognized the'consistent manner in which the outer lip of the shell was broken in the predominant Turbo' (T.D. Campbell, et. al, 1946, p.468). Spencer suggested that many flakes had been brought to the feasting grounds to '...break open the oyster, mussels and turbos on which they fed' (W.D. Spencer 1928, Vol. 2, p.500). This was how he explained the high percentage of broken shells in the middens. 
to smash or damage certain species. This has not

been proven however, though the distribution of ratios in Table 5.37 suggests that this may have been the case. Thus the ratios for Brachidontes rostratus, a species from which the animal is easily extracted, are also an order higher than those of Subninella and Austrocochlea.

This argument might be carried one stage further. If Cellana was not deliberately smashed, then the number of whole shells remaining in the deposit when compared with the calculated equivalent number of shells will give an estimate of the actual damage caused by men, animals and the elements. Supposing that the

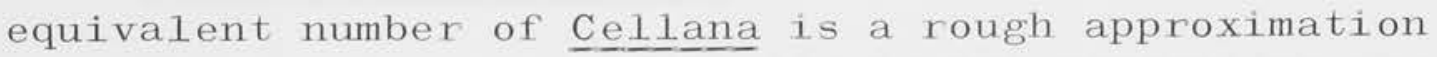
to the original number of shells, it can be seen that between 40-60 per cent of the shells have been broken in some way, However, it has already been shown that a considerable number of shells have been lost in antiquity, so that this figure may be larger if one knew how many shells there had been originally.

In summary, it can be said that if one assumes that the accidental effect of men, animals and the elements is the same for all species, then it is tempting to suggest that the low values of the $\mathrm{W} / \mathrm{E}$ ratios $(0-40$ per cent) for Subninel1a and Austrocochlea are the result of the deliberate smashing of the shells. Arguing from Table 5.37 between 20-60 per cent of Subninella and Austrocochlea were deliberately broken.

Method E-Cooking of Shell Material

Referring now to Tables 5.4 and 5.5 and Diagram 5.31. It is apparent that the aborigines did not roast their shell fauna. The exact method of cooking is not certain. They may have eaten much of their shellfish 
raw or they may have cooked them by placing the shells in hot sand near the fire. The only species to exhibit consistent signs of burning was Subninella. But the number of cases were too few to warrant generalization, and those shells which showed signs of burning were probably burnt accidentally. A considerable number of operculum were also burnt, both on the inside and outside. To be burnt on the inside, one must assume that the animal was first removed. After extraction the animal was probably still attached to the operculum. The Aboriginal then ate the animal and discarded the operculum, possibly into a nearby fire.

\subsection{Summary and Statistics}

The total number of shells in the excavation was 5,660 and these were predominantly Rock Platform (Tables 5.39 and 5.40$)$. In Table 5.40 the various ratios per square per spit, i,e. Pelecypoda/Gastropoda $(\mathrm{P} / \mathrm{G})$; Sandy Bay to Rock Platform $(\mathrm{S} / \mathrm{R})$; Bay or Mud species to Rock Platform (B/R) have been displayed. Table 5.39 summarizes various statistics relating to the shells in this excavation. The overall ratio of Sandy Beach to Rock Platform (No, 6, Table 5.39) is only 0.0014 - or negligible, showing that the collecting area was a Rock Platform environment. Some comment should be made on the state of the shells during and after excavation, Great care was taken during excavating to remove shells in their original state. In a few cases shells were broken, but the number was small and the new fractures were easy to detect. Also the size of fragments collected was limited by the sieve mesh $\left(1 / 8^{\prime \prime}-1 / 4^{\prime \prime}\right)$. A few shells were also damaged in the sieving process. 
Periodic examination of the waste material revealed few she11 fragments.

By using a combination of several techniques it has been shown that there is a fair probability that the postulated occupational floors and their associated faunal material are in situ. Some attempt was made to calculate the number of individuals associated with these floors and limited evidence of their culinary habits has been discussed. In so doing the past has been explored with experimental techniques and far from exhausting all the possibilities of using this type of data, there is yet room for many alternative interpretations and the application of the data in other ways. This analysis will now be used as a model for the study of the excavations at Site 9A. Here some modifications have been made to the techniques outlined above. 


\section{CHAPTER 6}

\section{ANALYSIS OF FAUNAL MATERIAL FROM THE EXCAVATIONS AT WILSON'S PROMONTORY}

\section{PART 2}

FAUNAL ANALYSIS OF EXCAVATIONS AT SITE 9A

\subsection{Selection of Occupational Floors}

1. Excavation No. 1

Excavation No. 1 contained few shells because much of the original soil with its shell fauna had been eroded away. Thus, there has been no attempt to try to locate living floors by the shell density technique. Table 6.1 lists the fauna recovered in the excavation and Diagram 6.1 represents a plot of this data. As can be seen, there is no horizontal consistency in the shell distribution. (Actual numbers of shells have been shown in the diagram). With the exception of Subninella and its operculum, all other species are insignificant so that no attempt has been made to display them in the diagram.

\section{Excavations Nos. 3 and 5}

Table 6.2 lists the weighting factors for these two excavations. (Diagram 6.2 shows the relevant spits and can be used to obtain the various weighting factors). Computation of the weighting factors for Excavation No. 3 is slightly more complicated than for the other cases. This excavation was dug out in two, 2'6" squares instead of the standard $3^{\circ} \mathrm{O}$ " squares. Al1 other measurements of shell densities have referred to 3'0" square units, and in order to make useful comparisons between excavations, the shell densities for $9 \mathrm{~A} / 3$ have to be further weighted by a factor 
$\frac{3 \times 3}{2.5 \times 2.5}=1.44^{\prime}$ Al1 average level depths after division by the standard weighting factor had to be multiplied by $1.4^{\circ}$. The shell densities for this excavation then possess the same units as for the other excavations. Table 6.3 shows the results of these calculations, and Diagram 6.2 displays this data. A plan of the excavation has been drawn in the bottom left hand corner of the diagram. This makes it possible to correlate levels between excavations, even though $9 \mathrm{~A} / 3$ and $9 \mathrm{~A} / 5$ are at right angles. (Reference should be made to the plan in order to see how the level diagrams have been orientated). The data has been plotted by the mean spit method. The thicker lines protruding to the left from the main vertical scale represent the mean spit widths in the excavations. The shell density scale has been chosen so that it is within the 2:6 or 3'0 interval of the square. The peak values of shell density and other relevant data appertaining to these peaks is summarized in Table 6.4. Drawing in the relevant occupational floors for these two excavations is not difficult (Diagram 6.3). A1, A2 and A3 are obvious, but there is some difficulty in choosing through which peak in Square 2, Excavation 9A/5 one should draw A4. The choice lies between Peaks 2 and 3. Tables $6.5-6.8$ show how the various peak shell densities are made up. Peak 2, Excavation 9A/5, Square 2, is almost all Cellana and Subninella (Table 6.5). Peak 2, Square 2 is made up in the same way, while Peak 3, Square 2 consists of Subninella and a few Dicathais; Cellana is absent (Table 5.46). Thus the living floor has been drawn through Peak 2, Square 2, and Peak 2, Square 1, because the faunal distributions are similar. This floor becomes A5, thereby making Peak 3, Square 2, an isolated lens, A4. 
Diagram 6.3 is a scale diagram of both excavations; the sections shown are the same as those shown in Diagram 6.2. The excavations were separated by a 6 " baulk so that the floors shown in Diagram 6.3 are discontinuous. A6 was a secondarily deposited layer in sand, and is recorded simply for the sake of completeness. It is not an original floor.

\section{Lithic Distribution. Table 6.9 shows the} distribution of lithic material in these excavations, and Table 6.10 lists the locations of the various peaks with other relevant data. Correlation between the peak shell densities and the peak lithic densities which is considered in Table 6.58, is significant, as the high Correlation Factor $(0.72)$ suggests that it should be. Thus once again, the peak shell densities - coincident with the living floors - are associated with most of the lithic material.

The fauna making up the various peaks is tabulated in Tables 6.5-6.8, and from these tables the fauna associated with each living floor can be calculated (Table 6.12). It can be seen that there are differences in the faunal distribution between the various levels. A1 is exclusively Mytilus; A2, Austrocochlea, Cellana and Subnine11a; A3 is the same as A2; in A4 Dicathais and Subnine1la predominate; A5 consists of Cellana and Subnine1la. These varied distributions illustrate once again the degree of selection exercised by the aborigines.

The total number of shells associated with each level per square was computed from Table 6.12 (taking care to divide the bivalves by two) and these are displayed in Diagram 6.4 . 
Unfortunately, there are not enough squares to enable contour plots to be drawn. Thus there is little point in trying to calculate the number of Aborigines associated with each floor. The approximate number of aborigines responsible for the deposition of the shells for each floor as a whole has been calculated using Tables 5.24 and 6.12 and these results are shown in Table 6.13. Eventually, this table will be corrected for she11 losses in antiquity.

\section{Excavation No. 6}

Table 6.14 1ists the correction factors for $9 \mathrm{~A} / 6$. Using these values the shell densities were computed and tabulated in Table 6.15. The shell density plots are displayed in Diagrams 6.5-6.7. The living floors were drawn as described above.

With one exception, the levels in each trench were easy to discern. The exception occurred in Trench C, Squares 1 and 2. Here, one could not be sure whether Peak 1, Square 1 belonged to Level A5 or A6. Eventually it was assigned to A6 for reasons which will become apparent shortly

Although the levels were easy to assign per trench, it was not so simple to equate levels between trenches, and considerable caution was exercised in assigning these levels. A1 is an obvious level - because it is widely separated from its nearest neighbour, A3. But other levels are spaced at approximately 6" intervals so that it is possible to assign them incorrectly.

To assist in equating levels, the marine fauna associated with each peak per square was tabulated. The peak shell densities are listed in Diagrams $6.5-6.7$, with the main spits contributing to each peak (Table 6.16). By referring back to the raw data sheet (table 
similar to 5.4 and 5.5) the numbers of each species contributing to the various she11 peaks were extracted and tabulated (Tables 6.17-6.46). A detailed study of the shell distribution and shell types for each postulated living floor enabled one to assign the levels shown in Diagrams 6.8-6.9.

Diagrams 6.11-6.16 showed the number of each species in each square per living floor (A1, A3, A4, A5, $\mathrm{A} 6$ and $\mathrm{A} 7$ ). It will be best to take each floor in turn and discuss the reasons for assigning a level number to it.

A1 (Diagram 6.11)

It is widely separated from the other levels and has a unique species associated with it

(Velacumantis australis). The predominant fauna for this level is Mytilus planulatus, which occurs in all the squares.

A3 (Diagram 6.12)

This level can be assigned without comment in trenches A, B and C. However, in Trench D an extra level appears near the same level as A3 in Trench A. In Trenches E and F, A3 (the lowest level in these trenches, see Diagram 6.10) might be equated with either one of two levels in Trench D. Again A3 in Trench A could also be equated with either of these levels. From Tables $6.32-6.34$ it can be seen that the lower level in Trench D (assigned A2 in Diagram 6.9 and associated with Peak 5 , Square 1, Peak 5, Square 2 and Peak 5, Square 3 in Trench D) is associated with the bivalves Brachidontes and Mytilus. Diagram 6.12 shows that for the assigned level arrangement there are increasing numbers of bivalves in the fauna as one 
progresses from north to south - from Trench C to Trench F. This could be the basis for classing A2 (Trench D) with the lower levels of Trenches E and F. However the problem is further complicated by the fact that these floors are not horizontal, but slope upward from north to south. This can be seen from Diagram 4.13 where sloping shell lenses are shown in the walls of the excavation. Over a distance of $1^{\prime}$, there is as much as a foot rise in level. Thus two possibilities remain (a) either the levels are as they have been presently assigned or (b) the lowest levels in Trenches $\mathrm{E}$ and $\mathrm{F}$ equate with A2, so that one would have A3 extending over Trenches A, B and C, and A2 over D, E and F. The present arrangement was chosen because Austrocochlea occurs in $\mathrm{D} / 3, \mathrm{D} / 4, \mathrm{D} / 5, \mathrm{~A} / 2$ and $\mathrm{A} / 4$ connecting Trenches A and D at this level. Cellana also connects these two trenches. The relationship between the lowest level of Trench E and A3 (the assigned level) of Trench D is not as certain. However, they may be equated via squares $\mathrm{E} / 3$ and D/3 - because of the dominance of Subninella, as they can be also, by the absolute levels at which the floors in each trench occur. Further, A3 in Trench E is at the same level as A3, in Trench D. Nevertheless, some doubt remains as to the reliability of the assigned level arrangement at present.

A4-A8 The problem of assigning these last few levels is not difficult, once A3 has been fixed. A5 can be assigned on the basis of the distribution of $\underline{\text { Polinices sordidus and Austrocochlea constricta. }}$ 
The former appears exclusively at this level (Diagram 6.13). The main fauna for the whole floor is Subninella, which connects all the squares, although Austrocochlea and Polinices provide the links between many of them. Because

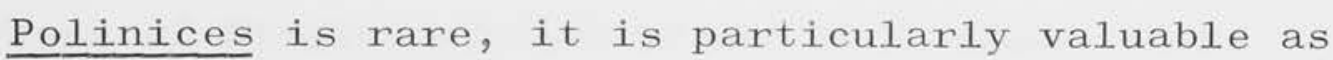
a guide to assisting in equating levels between trenches. The other levels have been assigned automatically, A8 should not be regarded as a floor because its fauna may contain material from the overburden of the various trenches. For example some of the Plebidonax shown in Diagram 6.15 were not in situ but were part of the overburden.

The levels are shown in Diagrams 6.9-6.10. The dotted sections of the floors indicate that no shell appears on these parts of the floors.

Lithic Distribution. The 1ithic density has been plotted in Diagram 6.17 and the peaks are tabulated in Table 6.47. Taking the peak shell densities from Table 6.16 and correlating them with the lithic peaks of Table 6.47 , Table 6.48 shows that the CF is very high $(32 / 38)$. A significance test indicates that the correlation is meaningful (Table 6.66). Thus the peak 1ithic densities coincide with the peak shell densities. Only six peaks cannot be assigned to a peak shell density. However, the distribution of stone is such that it is possible to reconstruct some of the occupational floors on the basis of the peak distributions. For example, A5 has been reconstituted in Trenches B, A, D and E, and this coincides with the level arrangement assigned by using the shell density technique. A6 has been similarly reconstituted in 
Trenches E and F. Isolated stone groups at various levels should not be regarded as unusual and may well be the result of more localized workshop activity. Areas not associated with shell may indicate the intermittent nature of occupation in the area. Comparison of Diagrams $6.8-6.10$ and 6.17 shows that nearly all the peaks are directly associated with shell peaks, or may be associated with an occupational floor by extending the levels through the isolated lithic peaks.

Coincidence of lithic and shell peaks is strong evidence for the in situ nature of the floors.

Diagrams 6.18-6.23 show the total she11 concentrations in each square for each occupational floor. Approximate contours of equal shell numbers have been drawn on the floor plan in an attempt to determine the location of individual shell heaps. In most cases, only part of these shell heaps could be discerned. However, for A3a, A5b and c the entire shell heaps (closed shell concentrations) were recovered. Table 6.49 shows the number of shells of each of the main species which contribute to each of the shell concentrations. They were derived from Diagrams 6.11-6.66. Using Table 5.24, the number of adult males associated with each of the shell concentrations has been estimated and tabulated in Table 6.50. The computation does not take into account shell losses in antiquity. For shell concentrations which are 'open' (i.e. their geographic area is undefined because of limited excavation) no more can be said than that greater than ' $\mathrm{x}$ ' adults were involved in the accumulation of the shell heap. For 'closed' shell concentrations, one is able to say that approximately 
' $\mathrm{x}$ ' adult Europeans (aborigines?) contributed to the accumulation of these heaps. Thus for A3a about five adult males could have formed this concentration; for A $3 b$ at least six, but probably more than six, adult males contributed to its formation.

These occupational floors contain 83 per cent of the total number of shells in the excavation (Table 6.51). That is, most of the shell is contained in the peaks. The other 13 per cent contribute to the troughs and to some of the isolated lenses which were not incorporated into any continuous floor.

\subsection{Correlation of Other Peak Ratios}

\section{Excavations Nos. 3 and 5}

Table 6.52 shows the data plotted on Diagrams 6.24 and 6.25. Diagram 6.24 depicts the $0 / \mathrm{s}$ ratio and Diagram 6.25 the $W / E$ ratio. At the foot of Table 6.52 the overall ratio per square is noted. Tables 6.53 and 6.54 1ist the peak values taken from Diagrams 6.24 and 6.25, respectively. As was done for Excavation No. 1, Site 11, the $\mathrm{W} / \mathrm{E}$ ratio including operculum (Set 5) and the $W / E$ ratio excluding operculum (Set 6) were considered separately. The $0 / \mathrm{S}($ Set 7 ) and $W / E$ peak ratios have been correlated with the peak shell density ratios (set 4 ) by the method described previously and the results are shown in Table 6.55. Some statistics of the various distribution are set out in Table 6.56 .

In Table 6.57 various CFs have been computed for correlation between combinations of peak ratios and the peak shell densities of Table 6.55. These CFs are summarized in Table 6.58. Two CFs are given. The first represents the sum total at the bottom of each column of Table 6.57 , divided by the total number of separate 
rows. The resulting $\mathrm{CF}$ is a stringent figure of merit for the various correlations. The second $C F$ has been calculated by dividing the total by the number of shell peaks (see Table 6.56). This factor measures the degree of correlation of other peaks relative to the she11 density peaks; it takes no account of the fact that there may be ' $\mathrm{X}$ ' peaks which do not correlate at a11. If the first $\mathrm{CF}$ is over 50 per cent, then a significant correlation is very likely, and if the second $\mathrm{CF}$ exceeds 50 per cent a significance is only probable.

Results of significance tests are shown in Table 6.59. The value of $\mathrm{N}$ has been calculated from the average levels shown in Diagram 6.2. The significance for each correlation per square has been computed in order to compare these results with the overall figure. In general, individual calculations show the same trend as the overall calculation. Also comparisons of Tables 6.59 (total) and 6.58 show that in general, the CF reflects the calculated degree of significance.

Results of these correlations are similar to those described for Excavation 11/1. For example a significance resulted for correlation between the $\mathrm{W} / \mathrm{E}$, $0 / \mathrm{S}$ and peak shell density; and the $0 / \mathrm{s}$ ratio is greater than 1 for nearly all the peaks. Further, correlation between sets 4,5 or 6 and 7 and the magnitude of the peak shell density yielded a Correlation Coefficient of 0.44 (Table 6.60). This is less than the significance level for a Type 1 error, so that one may conclude that there is no correlation between the CF and the peak she11 density magnitude.

Thus conditions for Excavations 3 and 5 are the same as those described for $11 / 1$. The lenses are in 
situ, but because the $0 / \mathrm{S}$ ratio is greater than 1 for most of the peaks, much of the material must have been lost in antiquity. (The total $0 / \mathrm{s}$ ratio for Excavation $11 / 1$ is 2.02 - Table 5.39).

\section{Excavation No. 6, Site 9A}

Similar results were obtained for this excavation. The $\mathrm{W} / \mathrm{E}$ ratios are plotted on Diagrams 6.26-6.28 and the $0 / \mathrm{s}$ ratio on Diagrams 6.29-6.31. The peak values for the $\mathrm{W} / \mathrm{E}$ ratio including operculum are set out on Table 6.61 and the $W / E$ ratios excluding operculum on Table 6.62, and the $0 / \mathrm{s}$ ratio on Table 6.63. Statistics dealing with peak ratio are given in Table 6.64 and the correlation between peak ratio is considered in Table 6.65

The CFs have been computed (Table 6.66) following the usual procedure using the data in Table 6.65 . Results of significance tests and calculations of the CFs are summarized in Table 6.67. (It will be recalled that the value of $\mathrm{N}$ was derived after the manner described in Table 5.27).

Table 6.67 shows that the results of the first analysis are again duplicated. Correlations between the $\mathrm{W} / \mathrm{E}, \mathrm{O} / \mathrm{S}$ and peak shell densities are significant; there is a high incidence of $0 / \mathrm{s}$ peak ratios greater than 1 (only 12 out of 115 peaks are less than 1). Calculation of the Correlation Coefficient for a correlation between sets 5 or 6 and 7 and the magnitude of the peak shell densities was only 0.1 , which is less than the significance level for 120 degrees of freedom. Therefore no correlation is apparent (the calculation has not been included in the text because of its length) . 


\subsection{Examination of the $W / E$ ratios per Species}

\section{Excavations Nos. 3 and 5}

Table 6.68 shows (a) the number of whole shells per species, (b) the number of equivalent shells per species, (c) the $\mathrm{W} / \mathrm{E}$ ratio per species, and (d) the equivalent number of shells expressed as a percentage of the total number of shells - including non-edible and rare species. ${ }^{1}$ Table 6.69 takes the data in Table 6.68 and considers the degree of correlation between the $\mathrm{W} / \mathrm{E}$ ratio and the percentage number of shells per species. The idea behind this test is to see whether the magnitude of the $\mathrm{W} / \mathrm{E}$ ratio can be correlated with the number of shells. For example, Subninella is one of the most abundant species in the excavation and it has the lowest $\mathrm{W} / \mathrm{E}$ ratio; therefore one is testing the hypothesis that if there are more of ' $\mathrm{x}$ ' (per species), a high incidence of breakage will result, i,e, a lower W/E ratio. Table 6.69 shows the Correlation

Coefficient for 11 degrees of freedom is less than the significance level so that the hypothesis may be rejected.

Table 6.70 reworks the same problem but excludes those species which are rare, or which weight the result unfairly. (Rare species are defined as those with a total number less than 3). Since operculum are almost indestructable and Austrosuccinea and Notocypraea are not edible, these categories have been omitted.

Recalculation of the Correlation Coefficient results in an even worse correlation. (But the sign of the

Correlation Coefficient is now negative indicating that

1

These figures are obtained by adding up the total equivalent number of shells (column 3 of Table 6,68) and then dividing each number in this column by this total. 
a decreasing $\mathrm{W} / \mathrm{E}$ ratio is in proportion to increasing numbers of these species).

\section{Excavation No. 6, Site 9A}

The raw data is presented in Tables $6.71-6.76$. Adding up the last columns of these tables, the total number of whole and equivalent shells from this excavation have been tabulated (Table 6.77). The W/E ratio has been calculated and the equivalent shells converted into percentages. Tables 6.78 and 6.79 show the calculation of the Correlation Coefficient for (a) all shells inclusive: the Correlation Coefficient is insignificant and positive, (b) all fauna but excluding non-edible species and operculum. Here the Correlation Coefficient is negative, but still insignificant. Thus there is no relation between the magnitude of the $W / E$ ratio and the number of shells per species.

Computation of the $\mathrm{W} / \mathrm{E}$ ratio for $9 \mathrm{~A} / 6$ can be made from Tables 6.41 and 6.80 . The $W / E$ ratio per species are shown in Table 6.81(a). The fauna has been ranked in order of decreasing $\mathrm{W} / \mathrm{E}$ ratios for Excavations Nos. 3 and 5 (together) and No. 6 (Tables 6.82 and 6.83). Consider now the three lists of fauna for the four excavations. Omitting rare species from consideration, it is apparent that the ranking for the three data sets is identical for the main species - operculum, Cellana, Subninella and the bivalves. The ranges of values for the $W / E$ ratios of each species falls within those derived for Excavation $11 / 1$ (see Table 5.37), i.e. Subninella, Site $11,0-40$ per cent $(A v=15$ per cent); Site 9A, Excavation No. 6, 13 per cent; Nos, 3 and 5 , 6 per cent; No. 1, 27 per cent; Cellana, Site 11, 20-60 per cent $(\mathrm{Av}=36$ per cent $) ;$ Site $9 \mathrm{~A}$, Excavation No. 6, 
41 per cent; Nos. 3 and 5,54 per cent; No, 1,60 per cent; operculum, Site 11, 40-100 per cent $(\mathrm{Av}=78$ per cent); Site 9A, Excavation No, 6, 79 per cent; Nos. 3 and 5, 77 per cent; No. 1, 85 per cent; Austrocochlea, Site 11, 0-50 per cent ( $\mathrm{Av}=5$ per cent); Site 9A, Excavation No. 6, 23 per cent; Nos. 3 and 5, 16 per cent; Total shells, Site 11, 49 per cent; Site 9A, Excavation No. 6, 54 per cent; Nos. 3 and 5, 55 per cent; No. 1,64 per cent (see Tables $6.81(\mathrm{a}), 6.84(\mathrm{a})$ and $(\mathrm{b}), 6.85(\mathrm{a})$ and $(\mathrm{b}))$.

These figures are consistent, Generally speaking, in all the excavations about 50 per cent of the shells are broken. Previously it was postulated that some species were deliberately smashed in order to extract the animal and certain ranges of $\mathrm{W} / \mathrm{E}$ ratio were quoted to support this idea. The argument is further supported by the $\mathrm{W} / \mathrm{E}$ ratio of these excavations. Subninella, Austrocochlea and other species where the animal could be difficult to extract (e.g. Dicathais, 29 per cent, 13 per cent; Cabestana, 12 per cent) have low $\mathrm{W} / \mathrm{E}$ ratios. Shells from which the animal can be easily extracted have $\mathrm{W} / \mathrm{E}$ ratios an order of magnitude higher, e.g. Cellana ( 41 per cent, 54 per cent); Ostrea ( 48 per cent, 100 per cent); Katelysia (66 per cent); and Poneroplax (76 per cent, 83 per cent). Species like Brachidontes have $\mathrm{W} / \mathrm{E}$ ratios which vary from 2 per cent to 100 per cent. Although it is easy to extract the animal from Brachidontes the shell itself is not robust and shatters easily, accounting for the wide range of $\mathrm{W} / \mathrm{E}$ ratio. The same comments apply to Mytilus which have consistently low ratios and are rarely found whole. 
The overall $\mathrm{O} / \mathrm{S}$ ratios for each excavation are also consistent, i.e. Site 11, 2.02 (Table 5.39); Site 9A, Excavation No. 6, 1.92 (Table 6.85); Nos. 3 and 5, 1.27 (Tables 6.84(c)); No. 1, 0.76 (Table 6.81(b) - but the sample is too small). In general a factor of 2 is involved for this ratio. Returning to Tables 6.49 and $6.51(\mathrm{~b})$ consider the $0 / \mathrm{S}$ ratio of the closed heaps on some of the occupational floors of Excavation $9 \mathrm{~A} / 6$. Thus for $\mathrm{A} 3 \mathrm{a}$ the $\mathrm{O} / \mathrm{S}$ ratio is 2.26; for $\mathrm{A} 4 \mathrm{a}, 2.56$; for A5b, 1.79; and for A5c it is 2.08. These values are consistent with the overall $0 / \mathrm{S}$ values for the excavation and they suggest the magnitude of the loss of shell on the shell heaps. That is the overall.

figure for the excavation adequately reflects the losses in the individual heaps. No new information can be expected from a study of the $\mathrm{W} / \mathrm{E}$ ratio per species as a function of the number of each species per closed shell heap. The proportionate frequency of occurrence of the main species is roughly constant in each heap and the figures for the entire excavation merely reflect the frequency distribution.

\section{SHELL MOVEMENT STUDIES}

The problem of movement of shell fauna in antiquity will now be considered in much greater detail. In the next section the results of some experiments which were designed to illuminate this problem are discussed. The faunal remains on Site $9 \mathrm{~A}$ will then be examined and eventually correction factors will be derived and applied to the shell concentration on the living floors of the excavations. In this way the shell numbers can be corrected and new population estimates derived. 


\subsection{Experiments carried out to Ascertain the Degree of Shell Movement in the Present Environment}

\section{Introduction}

Attention has been given to the problem of studying movement by the wind, the effect of the elements and of men and animals on exposed shell midden fauna. During high winds no movement of shells could be seen, so that in order to document shell movement, controlled experiments had to be set up where it could be studied on a scientific basis.

A large grid system was laid out on the A series soil at Site 9A (Diagram 4,2). The system consisted of 6' squares with a datum (marked on the plan as a triangle - position C). A plain table survey enabled the contour plan shown in Diagram 4.2 to be drawn.

The numbers of each shell species in each 6: square were counted (see Chapter 8, Appendix 8.3) by adding up the number of shells per square, and placing this in the appropriate grid square on a plan of the site. Contours of equal shell density were then drawn and these are shown in Diagram 6.32. It is obvious from this diagram that there are large areas with very little shell ( see also Diagrams $8,6-8,7$ ). A careful examination of areas of minimum shell concentration revealed that they had been subject to wind erosion because of their exposed position (see Plate 4.6). For example the area near A (Diagrams 4.2 and 6.32) has been eroded down to the nodule layer.

Subsequent shell counts in some of the squares also revealed that the number of shells varied.

\section{Plebidonax Distribution}

An experiment was set up to study the movement of shells in the sandy environment, a little to the north 
of the main grid (Experiment G). Here Plebidonax was being eroded out of a B series lens. As the sand was blown away the Plebidonax moved downwards towards the grid into the direction of the prevalling wind. The distribution of Plebidonax (Diagram 8.6) shows that they are more concentrated towards the north side of the grid - that is, adjacent to where Plebidonax has been eroded from a B series lens. A few Plebidonax occur on the grid itself but many of these may be accounted for by their migration from eroded B series lenses on the south side of the grid across the grid itself.

It will be shown presently, that the shells within the grid system have mostly derived from the A series soil and that there probably have been few intrusions of shells from B series lenses. Plebidonax does not appear to have been present in any abundance in A series times, Less than 20 were recovered in all of the A series excavations, and all these were recovered in $9 \mathrm{~A} / 6$, where they occurred spasmodically in the top three spits only. There is other evidence to suggest that Plebidonax was not an important species in the ecological environment in A series times (see Chapter 10).

\section{$\frac{\text { Location of Experiments }}{\text { (See Diagrams } 4.2,6.32}$ and Plate 4.16)}

Besides the shell movement experiment set up at G, another seven experimental stations were situated in various positions for different reasons. Experiment F was located on the exposed cliff face of Site 9C. Here there was no protection from the wind and consequently there were few shells to be seen. A, B, E and $H$ were set up in slightly less exposed areas. However, in the 
region surrounding these stations shells were sparse. The experiments were set up in these positions to try to ascertain whether or not this absence of shells was due to wind movement. $C$ and $D$ were located in reasonably sheltered areas. Their positions were chosen in order to be able to compare the results of experiments from sheltered and unsheltered stations.

\section{Experimental Procedure}

1. Shells of different species were collected inside the grid. These were not washed, but were left as far as possible in their original state.

2. In order that they could be recovered quickly the shells were painted bright red. Each shell was given a code number.

3. White labelled stakes were driven into the ground at various preselected stations A, B, C etc.

4. Selections of shells were placed around and within four inches of each stake. Bivalves were planted with their interior towards the ground.

5. A first series of experiments failed because visitors to the area picked up the red shells thinking that they were rare species. To overcome this type of problem, the stations were partly surrounded with wire netting to impress upon 
visitors that the red shells were part of an

experiment. Signs were erected requesting them not to interfere with the experiments. (Plate 6.1 shows one of the experiments at initiation).

\section{Measurements}

The stations were set up on the 10 April 1965 and measurements were taken on every subsequent field trip to the Promontory, The distance to each shel1 was measured with a steel tape - from the centre of the stake at each station to the centre of the shell. The bearing was taken with a prismatic compass and the error was estimated at less than 5 degrees.

Ideally measurements should have been taken at regular intervals over a long period of time. However, this was impossible, so that the data analysed below has limited validity. Details of the shell experiments for each station are shown in Tables 6.86-6.99.

Additional information is contained in the column labelled 'Comment?,

\section{Analysis of Results}

Tables 6.100-6.103 summarize the analysed results. Movement of shells was treated as a vector (having magnitude $=$ distance moved, and sense $=$ bearing). Thus for each species a vector diagram could be drawn (Diagram 6.33) so that the total distance moved over the period of study could be computed. This distance is simply the sum of all vectors. Likewise the average bearing could be calculated by measuring the bearing of each sub-vector and averaging. (The bearing was measured relative to the magnetic north):

One cannot compare distances and angles in their present form because of the time differences between measurements. Thus the distance figures have been 
converted to a Distance/Time unit, in order to make comparisons over a fixed period of time. The time unit selected was the week: thus the time between the initiation of the experiments and the various measurements was 2 (first measurement), 4, 6, 8, 21 and 42 (sixth measurement) where the time unit is the week. In the case where a shell is still available for measurement at time $x$, but has disappeared altogether by time y, providing there is little separation between $x$ and $y$ one divides the total distance moved up until time $x$ by the time from initiation to measurement at time $x$. However for shells that have disappeared between, say the fourth and fifth or the fifth and sixth measurements, where the interval is large the mean time of $(x+y) / 2$ was used. Row 6 of Tables 6.100-6.103 shows the Distance/Time figures for the various species.

It should also be noted that the vector magnitudes in each measurement interval are themselves the vector sum of a number of unknown shell movements. The shells can be expected to move about much more as the interval between measurements increases, Thus for long time intervals bigger errors can be expected in any estimation of the distance moved, $i$, e. one measures the magnitude of the resulting movement vector between measurement periods and not the sum of the magnitudes of the individual sub-vectors contributing to the resultant. Thus these results should be used cautiously and only to indicate the trends. Table 6.104 shows the Distance/Time data ranked according to the highest and lowest values of $D / T$ (Distance/Time). Referring now to Experiment A (Table 6.100), the $\mathrm{D} / \mathrm{T}$ may be ranked one to seven as follows: 
$\mathrm{D} / \mathrm{T}$

Ranked

1.1

2.9

5

1.4

1. 3

1.05

1.6

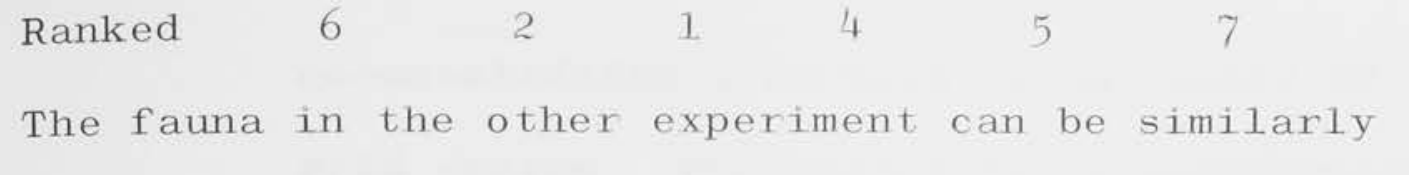

ranked with a ' 1 ' for the shell exhibiting the greatest

$\mathrm{D} / \mathrm{T}$. The ranking numbers for each species are then averaged (the last column of Table 6.104), or alternatively the $\mathrm{D} / \mathrm{T}$ for each species can be averaged, and the averages ranked. Table 6.104 shows that the greatest movement occurs for Brachidontes and the least movement for operculum. These results are to be expected because of the nature of the shells themselves. Brachidontes is very light, and therefore extremely susceptible to wind action; operculum are flat and present little area to the wind so that little movement results.

The average movement vectors for each experiment have been plotted on Diagram 6.33. The following observations are relevant:-

(a) Those areas most exposed have the vectors of greatest magnitude.

(b) The least exposed areas have the vectors of smallest magnitude.

(c) The areas of heaviest concentration of shell correspond to the least exposed areas.

(d) The prevailing winds at Wilson's Promontory are from the south west and the west. It is apparent from the sense of the resulting vectors that the shells on the grid have moved in the direction of the prevailing winds. The exception is Experiment G. Clearly some other factor is operative here. In general the shells have moved towards the east; but they have also moved south. The 
explanation is readily apparent. Experiment

$G$ was situated on the slopes of an

unconsolidated sand dune to the north of the

grid system. Prevalling winds continually

removed sand from around the area of the

shell experiment causing the shells to slip

forward into the wind. At the same time the

wind blows the shells towards the east. The

slightly greater concentrations of Plebidonax

on the north edge of the grid (the north edge

is approximately situated at the start of the

B series dune) is thus explained. Hundreds

of Plebidonax are scattered over the slope

between the eroded $B$ series lens and the

beginning of the A series soil. The shells

are gradually finding their way to lower

horizons and will eventually reach the A

series soil where their movement patterns

will become synonomous with the shells of the

other experiments.

Table 6.105 is an attempt to ascertain which

species are the most susceptible to fragmentation.

However, the experiment was not carried out under ideal

conditions. Nor were the number of the various species sufficient to give reliable results. Thus the

suggested ordering of the species - from those with the highest tendency to those with the least tendency to fragment - must be regarded as a preliminary attempt to define the fragmentation behaviour of the various species.

1

Evidence for the fragmentation of shells was also recovered in Excavations $9 \mathrm{~A} / \mathrm{I}$ and $9 \mathrm{~A} / 5$. In these excavations distinct layers of shell fragments could be discerned in the loose unconsolidated aeolianite (see Chapter 4, pp. 46, 48). 


\section{Method of Computation}

The total number of fragments at the end of the experimental period has been noted in Tables 6.86-6.99. The fractions shown in Table 6.105 have been calculated by dividing the total number of fragments (per species) for all the experiments, by the total number (per species) of these shells involved in all the experiments.

\subsection{Assessment of Sections $6.3-6.4$}

In terms of the discussion of the destruction of fauna in antiquity the results expressed in Tables 6.104 and 6.105 are important. Comparison of Tables 6.82 and 6.83 and the results of the shell experiments summarized in Tables 6.104-6.105 reveal some important facts. The fauna ranked for movement (Table 6.104) have the same ordering as the fauna in Tables 6.82 and 6.83 . That is, those species which move the most have the lowest $\mathrm{W} / \mathrm{E}$ ratio. Further, using Table 6.105 with caution, it can be seen that all the main species have a tendency to fragment. Cellana and Subninella have quite high fragmentation ratios. If one associates movement of shell material with fragmentation (and loss) then it may be stated on the basis of these experiments, that many of the shells in the ancient middens have been lost by these processes. An aspect of this problem which needs to be taken into consideration is the fact that the A series environment was probably different. Other evidence suggests that the area was not as open as it is today (see Chapter 10) so that the wind and the elements probably have more effect on the fauna exposed on the extant surfaces. Thus one cannot claim that these results completely explain the $W / E$ ratios of 
the archaeological shells. (Indeed it was suggested that men and animals were responsible for a considerable part of the damage to the midden fauna). What can be said, however, is that wind and the elements had their effect and that those species with low $\mathrm{W} / \mathrm{E}$ ratios (Table 6.83 ) were the most effected. One can also argue that fragmentation caused by any process would have led to the ultimate disappearance of the shell. The fragmentation study also indicates that different species have different tendencies to fragment, so that making allowances for loss of shell in antiquity becomes very difficult, In view of the importance that has been placed on the $0 / \mathrm{S}$ ratio, the outstanding tendency for operculum to remain in situ in the face of very adverse conditions is significant.

An attempt will now be made to correct the estimates of the numbers of adult males associated with the various shell heaps. Clearly, for estimates based on Subninella alone, one needs to double the number of shells. 1 However, because the estimates were calculated mainly on the basis of operculum and not Subninella itself, one does not need to apply a correction for this species. Assuming that other species with low $\mathrm{W} / \mathrm{E}$ ratio have been affected in a similar manner by both man and the elements (smashing, fragmentation and subsequent visits by other aborigines), one needs to double the number of Dicathais, Austrocochlea and Cabestana. Assuming that those species with higher $W / E$ ratio have been equally effected by man (subsequent to consumption, however, as the shells of these species were probably not damaged initially) and the elements it is possible to carry out 
some calculations to determine the sort of correction one needs to apply to the archaeological fauna. The figures obtained for the $0 / S$ and $W / E$ ratios for Excavation 9A/6 will be used in the computations. One should not be alarmed by the seeming exactness of these calculations as the results are to be used as guides only.

Let the number of Subninella at time $t_{1}$ be $2 x$. Then at $t_{2}$, the time of excavation, the number of Subninella is $x$ (arguing from the operculum/Subnine 1 la ratio).

At time $t$, let $P$ per cent of the shells be deliberately broken. Between time $t_{1}$ and $t_{2}$ other factors take their course and $f$ per cent of the remaining shells are broken. One makes the assumption that $f$ will be the same for all species. Then the number of broken shells at time $t_{2}-$ assuming no loss of shells in antiquity is $\mathrm{N}$ where

$N=\frac{P}{100} \times 2 x+2 x\left(1-\frac{P}{100}\right) \times \frac{f}{100}$

At time $t_{2}$ the number of whole shells will be $2 \mathrm{x}-\mathrm{N}$. Thus the $W / E$ ratio at time $t_{2}$ can be written

$M=W / E=\frac{2 x}{x}=-N$

for Subninella $W / E=0.13$ and $2 x=4200$ ( see Table

6.77, Excavation No. 6).

$$
\begin{aligned}
\therefore \quad & \frac{2 x-N}{x}=0.13 \\
& \quad \frac{4200}{2100} \frac{N}{10}=0.13
\end{aligned}
$$

$\therefore \quad \mathrm{N}=3926$

Now a certain percentage $\mathrm{S}$ of the broken shells will be lost. Again assume that $S$ is constant for all she11s. Thus 


$$
\begin{aligned}
S & =\frac{x}{N} \times 100 \\
& =54 \text { per cent from equation (iii) }
\end{aligned}
$$

Putting in the values of $N$ and $x$ into equation

(i) it reduces to

$$
P+f-0.01 f P=93.3
$$

Now consider the case of a shell such as Cellana where one makes the assumption that at time $t_{1}, P=0$. If the total number of shells at $t_{1}$ is $D_{\text {, then }} N_{1}$ the number of shells broken between time $t_{1}$ and $t_{2}$ will be $\mathrm{N}_{1}=\mathrm{D} \times \frac{\mathrm{f}}{100}$

The whole to equivalent ratio $\mathrm{W} / \mathrm{E}$ at time $\mathrm{t}_{2}$ $M_{2}=W / E=\frac{D-N_{1}}{D_{2}}$

where $\mathrm{D}_{2}=$ number of equivalent shells at time $t_{2}$. Using the values in Table 6.77 $\mathrm{M}_{2}=\mathrm{W} / \mathrm{E}=0.41, \mathrm{D}_{2}=409$ equation (vii) may be reduced to $\mathrm{D}=167+\mathrm{N}_{1}$ from equation (vi)

$\therefore \quad D=167+\frac{D}{100} \frac{x}{f}$

$\therefore \quad D=\frac{167}{1-\frac{f}{100}}$

The number of equivalent shell at time $t_{2}$

$$
\begin{aligned}
& \mathrm{D}_{2}=\mathrm{D}-\mathrm{N}_{1}+\mathrm{N}_{1}-\frac{\mathrm{S}}{100} \times \mathrm{N}_{1} \\
& \therefore \mathrm{D}_{2}=\mathrm{D}-\frac{\mathrm{S} \times \mathrm{N}_{1}}{100}
\end{aligned}
$$

substituting for D from equation (viii)

$$
\begin{aligned}
& \mathrm{D}_{2}=167+\mathrm{N}_{1}-\frac{\mathrm{S} \times \mathrm{N}_{1}}{100} \text { and } \\
& \mathrm{D}_{2}=409, \mathrm{~S}=54 \\
& \therefore \quad 409=167 \times \mathrm{N}_{1}-\frac{54 \times \mathrm{N}}{100} \\
& \therefore \mathrm{N}_{1}=526
\end{aligned}
$$


substituting $N$, in equation $(x)$

$\therefore \quad D=693$

from equation (vi)

$f=76$ per cent

$\ldots \ldots \ldots(x i i i)$

from equation (v)

$\mathrm{P}=72$ per cent

These percentages are interesting in that they indicate the effect of man and the elements subsequent to the deposition of the shell is about the same as the effect of man on the shells at deposition. Naturally these figures must be used with caution, as they are values computed on assumptions which may not be entirely valid. The fragmentation study points to some variability of the effects of the elements and man on different species (Table 6.105). Thus the assumption that $S$ and $f$ are constant for all species may not be correct. Nevertheless the results of the above analysis may be accepted as an indication of the effect of man and environment on the archaeological fauna. Table 6.106 lists the correction factors which must be applied to correct shell numbers for losses in antiquity. The average value of the $W / E$ ratio have been calculated over the four main excavations. For those species marked $U$ on the table a $p$ correction has not been applied. Thus for Cellana, the correction would be a factor $693 / 409=1.7$. That is, all equivalent values of Cellana have to be multiplied by this factor. There is no correction for Subninella as pointed out above. Assuming that $p$ is about the same for Austrocochlea, Dicathais and Subninella the correction factors can easily be calculated from the equations above. Thus for Austrocochlea using equation (v), and the figures in Table 6.77, equation (i) may be 
$\mathrm{D}=1.07 \mathrm{~N}$

where $\mathrm{P}=72$ and $\mathrm{f}=76$.

Equation (ii) can be rewritten with $\mathrm{D}=2 \mathrm{x}$

$\mathrm{N}=\mathrm{D}-\mathrm{M} \times \mathrm{D}_{2}$

$\ldots \ldots \ldots,(\mathrm{xvi})$

$\therefore \quad \mathrm{D}=15.3 \times \mathrm{M} \times \mathrm{D}_{2}$

, . . . . (xvii)

which is a general result.

Thus one may calculate D by using Table 6.77, The correction factor will be $\mathrm{D} / \mathrm{D}_{2}$

i.e. C. Factor $=15.3 \times \mathrm{M}$

$\ldots \ldots \ldots(x v i i i)$

In Table 6.106 the correction factors have been

rounded off. For cases where $P=0$ the correction

factor reduces to

C. Factor $=4.2 \times \mathrm{M}$

$\ldots \ldots \ldots+(x i x)$

Unfortunately these calculations cannot take into account species with unusual W/E ratio, e.g. such as Mytilus and to a lesser extent Brachidontes. $P$ is almost certainly zero for these species, yet the M value is extremely low. As was suggested previously, these two species, being light, are highly susceptible to damage from movement and this may account for the very low $N$ value ( $f$ and $S$ values listed above will not apply for these species; $f=0$ for Mytilus). The correction factors will be of the order

$$
\frac{1}{1-\left(\frac{S}{100}\right)}
$$

where $\mathrm{S}$ is likely to be much greater than 50 per cent. Possibly a factor of between 2 and 5 is involved. For purposes of computation, correction factors of the order 3 has been used.

Using Table 6.106, Tables 5.25, 6.49 and 6.50 have been recalculated by correcting for loss of shell (Table 6.107). Rare species like Velacumantis and Polinices, have been given an arbitrary correction 
factor of 2 - based on the $\mathrm{W} / \mathrm{E}$ ratio from Table 6.83 .

(The occurrence of these species in the midden material makes little difference to the overall calculation). Using Table 5.24, the number of adult males associated with each shell heap have been calculated (Table 6.108). Comparisons of Table 6.108 with Tables 5.25 and 6.50 shows that the corrections to Table 6.106 are important. The estimates for Excavation $9 \mathrm{~A} / 6$ in most cases has not increased very much. However for Excavation $11 / 1$ the number of adult males has increased by 100 per cent (from 91 to 180 ; compared with $9 \mathrm{~A} / 6$ where the increase is 26 per cent - from 150 to 190). The reason for the different rates of increase lies in the predominance of different fauna in the two excavations. In $9 \mathrm{~A} / 6$, the main fauna is Subninella which one does not have to correct. In $11 / 1$ other species are predominant which require correction.

A glance at Table 6.108 shows that the numbers associated with the shell heaps are fairly consistent. Although it is tempting to discuss these results in terms of groups, it must be remembered that many of the heaps have not been excavated in their entirety. These cases cannot be considered when making comparisons between group numbers. However, the closed heaps provide some information; 9, 15, 19, 25, 36 and 37 are the group numbers suggested in these cases. Unfortunately, insufficient entire heaps have been excavated to make any generalizations. But one can suggest that the smaller heaps probably resulted from the accumulation of shells eaten by a small group of aborigines at a single meal or over a very short period of time. 


\subsection{B Series Excavated Fauna}

Little can be said about Excavations $9 \mathrm{~A} / 2$ and $9 \mathrm{~A} / 4$ because of their small size. Relevant data has been summarized in Table 6.113. Comparison of the $W / E$ ratios in Tables $6.83(9 \mathrm{~A} / 6)$ and $6.113(9 \mathrm{~A} / 2$ and $9 \mathrm{~A} / 4)$ reveals that with the exception the ratios per species are of the same order. For Brachidontes and Plebidonax the ratios are considerably smaller in the A series excavations which suggests that these two species may have undergone some reworking during A series times (i.e, the B series lenses were still in situ when excavated, accounting for the higher W/E ratios for these species).

If the $W / E$ ratios of Table 6.113 are arranged in order of highest to lowest values and these are compared with the ordering of the species in Tables 6.104 and 6.105 it can be seen that those species with the highest $\mathrm{W} / \mathrm{E}$ ratios tend to fragment least. However, the movement study (Table 6.104) does not compare favourably, indicating that most of the shells in $9 \mathrm{~A} / 2$ and $9 \mathrm{~A} / 4$ have not yet undergone reworking.

\subsection{Cooking of Shell Food}

Results of investigations of excavations numbers 3, 5 and 6 confirm the preliminary remarks made in Chapter 5. Very few shells have been roasted. In most cases Subninella and its operculum is the only species to reveal signs of burning. Tables 6.109 to 6.112 depict the ratios of burnt to unburnt shells for these excavations. It can be seen that the overall ratios are of the order 1 to 10 per cent. Any cooking methods remain obscure, though it is evident that the shells were not cooked directly. Table 6.1.13 indicates that a 
higher percentage of shells were burnt in the B series excavated fauna.

Some ethnologists have made similar observations. Spencer noted that very few shells were actually burnt and that only Subninella and its operculum showed any sign of burning (B. Spencer 1918, p.115). Le Soueff has suggested that most of the animals were eaten raw or that they were put in or near the fire for very short intervals, just long enough to kill them (W.H.D. Le Soueff 1902, p.57; 1916, p.3), Haliotiøs and large mussels, he claimed, were usually cooked. (This observation has not been confirmed at the Promontory). On the other hand, Horne noted that Subnine11a and Voluta were frequently cooked and he postulated that other species were eaten raw after their shells had been smashed or that they were cooked first and then extracted from their shells ${ }^{1}$ (G. Horne 1921, pp.51, 53). It is interesting that in New South Wales, aborigines have been observed and photographed eating Plebidonax. 'The Áborigines took the pippies to the fireplaces, extracted the animal and roasted it in the ashes' (F.D. McCarthy 1941, p.23). This description would best explain the appearance of the pippi shells so abundant in the $B$ series middens. Very few are burnt or broken and most are very fresh and white in appearance.

Horne also noted that the operculum of Subninella was frequently burnt. 


\section{CHAPTER 7}

\section{HYPOTHETICAL EROSION OF A SERIES SOILS}

\subsection{Introduction}

In this chapter an attempt will be made to show that most of marine faunal material on the grid of 9A, has been eroded from the A series soil, and that much of the material which once belonged to the higher levels of this soil has since disappeared. Thus this investigation is related to the shell movement studies described in Chapter 6, while attention is also given to the problem of the movement of lithic material in antiquity.

Four A series excavations have been described for Site 9A, and three of these extend from an uneroded surface to the nodule layers (Excavations 9A/3, 5 and 6). Excavation $9 \mathrm{~A} / 1$ was conducted inside the grid in order to demonstrate the degree of erosion on this part of the A series soil.

A situation has been considered, where instead of material being excavated from $9 \mathrm{~A} / 3,5$ and 6 , it has been eroded out. The effects of this hypothetical erosion have been studied in spits of six inches. Erosion would leave the occupational material lying on the surface. Provided that there was no loss of material due to wind movement or human and animal activity, as erosion proceeds, an increasing amount of occupational material should accumulate on the surface. Graphs have been drawn of the accumulation of individual species, total shells, and total stone per $6^{\prime}$ square, as a function of height above the nodule layer. The 6' square unit was chosen because the grid system on Site 
$9 \mathrm{~A}$ had been laid out in $6^{\prime}$ squares; the ultimate object is to make direct comparisons between the shell and lithic material on the grid squares and similar material which has been hypothetically eroded from the excavation areas. The number of each species per 6: square is known for each grid square; and by augering each 6' square down to the nodule layer, one can ascertain how much more occupation can be expected per square. Since one has a graph of, 'height above the nodule layer' versus 'accumulated occupational material', one can predict how much material should be lying on the surface of the grid. A direct comparison of predicted and actual results can then be made.

The assumptions of this method are:-

1. The rate of accumulation of the soil above the nodule layers is relatively uniform. This has been discussed in Chapter 4 where it was shown that accumulation is fairly uniform.

2. That the variation of shell density with depth is uniform over the whole area and volume of the soil. However, occupation may vary from place to place on the original occupational floors, so that this assumption must be treated with caution. Its vagueness is partly offset by several factors:-

(a) Average values were taken for each hypothetical spit in each excavation. Unfortunately the largest excavation was only $1^{\prime} \times 15^{\prime}$ and in this area discontinuities and different concentrations were apparent. By averaging the number of shells per

1

This may be approximately true for a localized area and for the shell material. However, it will not hold for stone material which is much rarer and highly localized. 
6' square/6" spit, an attempt was made to take into account varying shell densities in time and space.

(b) The grid system is adjacent to the main excavations. Results are likely to be more valid when one considers eroded grid squares near the geographic location of the excavations.

(c) Shell concentrations on the various floors may often be of similar size, though it has been shown that the variations in shell heap size may also be quite large.

(d) The results will be more reliable for a large number of predictions (and therefore a large number of comparisons).

3. That occupation extends to, and not beyond, the nodule layer. This is a fair assumption based on the results of several excavations and on observations of eroded A series occupational soils. Occupation may not necessarily extend down to the nodule layer; but it certainly never goes below it. Therefore the nodule layer is a reasonable point from which to measure heights to the various spits.

\subsection{Determining the Degree of Erosion on the Grid System Soil}

An augering grid was laid out on Site 9A, superimposed but not concurrent with the faunal grid. The plan of the new grid is shown in Diagram 7.1 , where $10^{\prime}$ squares are superimposed on the $6^{\prime}$ square grid system. Lines of the new grid running from east to west were labelled Run A, Run B, etc. The grid was laid out with a prismatic compass and steel tape and checks were made on fixed points on the old grid to 
allow for errors in layout. Consequently it was found that the new grid system was not quite perfect (see diagram). Each junction of the grid was levelled in with a Dumpy Level, and each measurement was referred to the site datum C. Diagrams 7.2 and 7.3 show Runs A to L. (The vertical scales have been exaggerated). The height of each node on the grid is given as relative to the datum (= zero height).

Each node on the new grid was augered. This was carried out with a $3.4^{\circ}$ auger in two to three inch spits. A careful record was kept at each stage of augering, i.e. colour of soil, presence of charcoal, shell, nodules. Surface observations were also recorded, i.e. whether sand and/or shell was lying on the surface of the grid, and whether the nodule layer was exposed at the surface nearby. The various information obtained from the augering of each node was codified (Table 7.1) and is displayed in Diagrams 7.2 and 7.3 . These show the extent of erosion over the grid system. It will be noted that as one progresses from south to north and from east to west, less erosion is apparent and the soil becomes deeper. Using these diagrams the lowest extent of occupation for each grid square has been computed. By reference to the appearance of impenetrable rock, or to the first appearance of buff coloured sand - which is generally synonomous with the limit of occupation and the beginning of the nodule layer, and by constant reference to the she 11 and charcoal fragments in the auger spits, it is possible to establish the maximum depth of occupation at each node to within a few inches. The distance was measured from the lowest point to the eroded grid surface. 


\subsection{Hypothetical Erosion of Uneroded Areas}

(a) Excavation No: $9 \mathrm{~A} / 6$

This excavation consisted of 12 squares ( $\left.3^{\prime} \mathrm{x} 3^{\prime}\right)$ excavated down to the nodule layer, and 18 squares $\left(3^{\prime} \times 3^{\prime}\right)$ excavated to within one to two feet of the nodule layer. The nodule layer occurred at approximately $10^{\prime}$ below the site datum, and all measurements have been referred to this level. 1

Imaginary six inch spits were extended from the -10'0 level to the surface and the fauna in each of these spits was studied. The hypothetical. level control for this excavation is shown in Table 7.2. For each square in every trench the actual spits comprising the hypothetical ones are given. By using this table one can compute the fauna contained in each hypothetical spit. Tables $7 \cdot 3-7.8$ show the results of these calculations for each trench. Cellana, Subninella, Gastropoda and the sum total of shells in each spit were each examined separately. Thus for Trench B, Square 1 (Table 7.4), Level 1 (i.e., 0-0.5' above the nodule layer or $-10.0^{\prime}$ to $-9.5^{\prime}$ below the site datum) has no Cellana, one Subninella, seven Gastropoda and a total of 77 shells altogether. To compute these figures one needs to work from the average level. diagrams via Table 7.2 and from tables of equivalent number of shells (Tables 5.4 and 5.5). It can be seen from Tables $7.3-7.8$ that the first few spits do not extend to Square 5 which was not dug to the nodule layer. The last series of columns in these tables give the new totals for each shell group per trench. The data in the totals columns of Tables 7.3-7.8 has been 
taken and reassembled in Tables 7.9-7.10. Total 1 and total 2 of Table 7.9 represents the total number of Subninella per level, and the total number of Cellana per level for the entire excavation, i,e. for Level 4 (1.5' to $2.0^{\prime}$ above the $-10.0^{\prime}$ level) there are 67 Subninella and 9 Cellana. These totals still have to be converted to averages per $6^{\prime}$ square in order to make them compatible with the shell counts on the grid. The conversion factors differ for each spit because the depth of excavation was not uniform over the entire excavation. One needs to refer to the average level diagrams to extract the conversion factors. These are given in Table 7,11 . By multiplying the totals 1 and 2 of Tables 7.9 and 7.10 of each spit by the appropriate conversion factor the average total 1 and total 2 results (last columns of Tables 7.9 and 7.10 ). These totals represent the average number of shells per hypothetical spit per 6' square.

Now consider what would happen if the soil was to erode. As the soil disappeared the shellswould be left lying on the surface, and as erosion proceeded a greater number of shells would accumulate on the surface e.g., Table $7.12(\mathrm{a})$ shows that if Spit 11 was eroded off, one shell would be left on the surface; after Spit 10 had disappeared 15 shells would be seen and so on. These cumulative densities are computed by starting at spit 11 (Tables 7.9 and 7.10 ) and adding on the average total for each spit one at a time, i.e. erosion of Spit 10 would leave $1+14$ shells; erosion of Spit 9 would leave $1+14+43$ shells etc. Complete erosion of the site would leave an average of 978 shells per 6\% square. The results in Table $7.12(\mathrm{a})$ are displayed on Diagram 7.4 . 
Similar calculations can be performed for the lithic material. Tables 7.1 .3 and 7.14 show the number of stones in each hypothetical spit per square per trench. The last columns of Table 7.14 show the average number of stones per spit per 6' square (using the conversion factors of Table 7.11). The cumulative totals are listed in Table $7.12(b)$ and plotted in Diagram 7.5.

Thus using Diagrams 7.4 and 7.5 one can predict the number of shells and stones which should be lying on the surface after a specified amount of erosion. To form some idea of the accuracy of these predictions, the other three excavations can be analysed in a similar manner. Because these excavations are small (in comparison with number 6) the volume of occupational material is also small. Results of these calculations may be regarded as stringent measures of the accuracy of predictions made on the basis of the analysis of Excavation number 6 .

(b) Excavations Nos. $9 \mathrm{~A} / 1,9 \mathrm{~A} / 3$ and $9 \mathrm{~A} / 5$

The level control for these excavations is set out in Tables $7.15(\mathrm{a})$ and $(\mathrm{b})$. For Excavations 3 and 5 the control point was $-9.5^{\circ}$. Tables 7.16 and 7.17 1ist the she11 data per spit, 7.18 and 7.19 show the faunal totals per spit and the cumulative shell densities for Excavations $9 \mathrm{~A} / 3$ and 5 , and $9 \mathrm{~A} / 1$ respectively. Excavation $9 \mathrm{~A} / 3$ was taken out in two $2^{\prime} 6^{\prime \prime} \times 2^{\prime} 6^{\prime \prime}$ squares, while Excavation $9 \mathrm{~A} / 5$ was taken out in $3^{\prime} \mathrm{O}^{\prime \prime}$ squares. The combined sum of fauna per hypothetical spit represents only $2 \times 3 \times 3+2 \times 2.5 \times 2.5=30.5$ square feet. The standard unit, however, was the 6 ' square $(=36$ square feet). Thus all the cumulative shell densities in Table 7.18 have been multiplied by 
a factor $36 / 30.5=1.18$ so as to have the unit as number of shells per $6{ }^{\prime}$ square. These results have been plotted in Diagram 7.4 .

Table 7.19 shows two cumulative totals. Excavation number $9 \mathrm{~A} / 1$ was situated in an eroded portion of the grid area. After removing the sand dune on top of the A series soil, the soil erosion line was reached. Here shells were found lying on top, and partly exposed in the soil. One presumes that these shells have been eroded from the soil before it was covered over by the sand dune. Theoretically these shells should represent the combined cumulative shell density of all preceding erosion. One of the totals in Table 7.19 adds these shells in; the other excludes them. For Excavation 9A/1 Subnine11a, Cellana, Gastropoda and total shells including surface shells have been plotted on Diagram 7.4. There is little difference between the number of Gastropoda and total shells so that they have been plotted as one graph. The differences between Subninella and Cellana - including surface shells - and

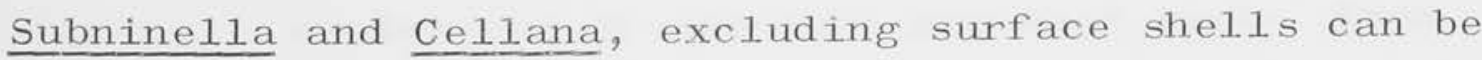
readily seen in Table 7.19 so that Cellana has not been plotted in Diagram 7.4.

The analysis was repeated for lithic material. Tables 7.20 and 7.21 and Diagram 7.5 show results of these calculations.

\subsection{Comments on Data}

In contrast to $9 A / 1$, Excavations $9 A / 3$ and $9 A / 5$ are geographically located fairly close to Excavation 9A/6. Diagram 7.4 shows that:

(a) Most of the faunal material occurs within the same depth range $(2.0$ to 4.5 feet above the limit of occupation); 
(b) That Pelecypoda becomes more important, and can only be easily distinguished in the lowest levels of the excavations.

(c) The error range varies considerably depending on depth. The errors in general increase with increasing depth;

(d) For Gastropoda and Pelecypoda, errors are of the order 200 (or 40 per cent) between $0-3.0^{\prime}$. From $3.0^{\prime}$ to $5.5^{\prime}$ they are of the order 100 $($ or 20 per cent);

(e) Gastropoda - errors as in (d);

(f) Subninella - little error apparent;

(g) Cellana - of the order 200;

(h) $9 \mathrm{~A} / 1$ is situated at some distance from $9 \mathrm{~A} / 3$, 5 and 6. It can be seen that there is little difference between the plots with and without surface material. Thus, either this excavated volume contained much less faunal material than other parts of the site, or else much of the faunal material previously eroded out of the soil has been lost. Even allowing for the maximum error suggested by the comparison of Excavations $9 \mathrm{~A} / 3,9 \mathrm{~A} / 5$ and 9A/6, the figures are in no way compatible. One assumes, then, that material has been lost from the surface. (Compare with Chapter 6).

In order to make a comparison between $9 \mathrm{~A} / 1$ and the other excavations it would be necessary to erode off al1 spits above 8 of Excavations $9 A / 3,9 A / 5$ and $9 A / 6$ and allow all the eroded material to disappear. One then considers only the erosion of spits 7 to 1 in these excavations. Tables 7.22 and 7.23 consider this 
comparison (using Tables $7.10,7.14$ and $7.18-7.21$ to derive the figures).

It can be seen that in general the figures are more compatible (excepting total shells for Excavation number 6). The differences between predicted and actual values may be as much as three times the actual value (the predicted value may be three hundred per cent out). For the comparison of Excavations $9 \mathrm{~A} / 6$ and $9 \mathrm{~A} / 1$ - Pelecypoda and Gastropoda - the error may be as much as 1200 per cent.

Comparison of these excavations shows that some sort of allowance must be made for errors in predictions. That is, error ranges must be specified if Diagram 7.4 (derived from Excavation 9A/6) is to be used to predict accumulated she1l densities. For example, from Diagram 7.4 one would predict that at the 3. $0^{\prime}$ level of Excavations $9 \mathrm{~A} / 3$ and 5 there should be an accumulation of 310 Gastropoda. In fact the correct value is 435 - an error of 125 or 35 per cent. For the eroded Excavation $9 \mathrm{~A} / 1$ one would predict that the accumulation of Gastropoda at Level 3 should be 133 (from Table 7.22). In fact it is 53 - an error of +80 or 150 per cent. Thus predicting the values of shell densities may involve considerable error and great care needs to be exercised in enterpeting results of these investigations.

Diagram 7.5 shows that the lithic plots for Excavations numbers 3 and 6 are reasonably compatible. Errors of the order 50 occur at higher levels, i.e. the prediction at 4.0 feet (using Excavation 9A/6) is 115 . For Excavations $9 \mathrm{~A} / 3$ and $9 \mathrm{~A} / 5$ the actual value is 40 (error is +75 or 300 per cent); below three feet the error is negligible. Examination of the cumulative 
1ithic distribution for Excavation $9 \mathrm{~A} / 1$ shows that it is in no way comparable with the other two excavations (there were no surface stones). A compatibility test, similar to that described above has been carried out and summarized in Table 7.23. Here the accumulation of 1ithic material in Spits $1-6$ in Excavations $9 \mathrm{~A} / 3$ and 9A/5 is shown. Predictions are fair for this case with errors ranging from zero to 300 per cent. By its very nature one would not expect stone to move. Unfortunately this topic has not been properly investigated experimentally. Table 7.23 and Diagram 7.5 suggest that one would need to accept errors in predicted values of up to 1600 per cent before an hypothesis of no stone movement could be accepted.

Thus movement of stone material remains a possibility (see later).

In summary, it must be recognised that considerable errors may be involved in predictions from the excavated data. Thus, when assessing the importance of predictions, orders of errors will be examined rather than the absolute figures.

\subsection{Predicted and Actual Value of Fauna on Grid}

Four traverses across the grid were considered. The results of these traverses are set out in Tables $7 \cdot 24-7 \cdot 27$

\section{Explanation of Tables}

Column No. 1 lists the faunal grid number which corresponds most closely to the augering grid number (column 2). Traverse number one was orientated south to north and traverses three and four from east to west. The equivalent faunal square was assigned by referring to Diagram 7.1. Having selected the traverses one 
needs to refer to the profiles discussed previously (Diagrams 7.2-7.3). For each node along the traverse on the augering grid, these diagrams give the depth of occupation (column 3, Tables 7.24-7.27). By dividing the depth by 0.5 , the number of hypothetical increments or spits are obtained (column 4). Using the depths in column 3, and Diagrams 7.4 and 7.5 (with Excavation number 6 as the standard) the values in columns 5, 6, 12 and 16 can be filled in, i.e. the predicted values of Gastropoda and Pelecypoda, Gastropoda, Subninella and Cellana respectively. Then using the spit number in column 4 (= eroded level) and referring back to Tables 7.9 and 7.10 the numbers of Pelecypoda and Gastropoda (column 7), Gastropoda (column 8), Subninella (column 13) and Cellana (column 17) associated with these levels can be predicted. By using the spit numbers in column 4, but adding on one level, predictions of numbers of Pelecypoda and Gastropoda (column 9), Gastropoda (column 10), Subnine11a (column 14) and Cellana (column 18) for the level above the eroding level can also be obtained. These last two categories have been included for the following reason: in the case where it is not possible to demonstrate a relationship between predicted and actual grid fauna, one could assume that this discrepancy is due to more recent loss of the surface fauna. In this case the shells left on the surface of the grid will be (a) shells blown there from elsewhere on the grid and/or (b) shells being eroded out of the soil at the time and/or (c) shells eroded out of the level that preceded the one being presently eroded. For these cases, predictions in columns 7-10, 13-14, 16-17 should be more compatible with the actual numbers of shell fauna (shown in columns 11, 15 and 19). 
Table 7.28 is a similar table for the stone

material. 'Level' means number of stones in the eroding level, and 'Level Plus' means the number of stones in the level that preceded the presently eroding level.

\subsection{Evaluation of Data}

Examination of Tables $7.24-7.28$ reveals no correlation between predicted cumulative totals and actual values. The statistical correlation between predicted Gastropoda and actual values on grid has been examined in Tables 7.30 and 7.31. The Correlation Coefficient $(0.072)$ is very much less than 0.30 - the significance figure for a Type 1 error, and 43 degrees of freedom. Thus there is no correlation between predicted and actual values.

Table 7.31 examines the correlation hypothesis in another way. Using Tables 7.24-7.27 the average values of predicted and actual values for each hypothetical spit have been computed. The Correlation Coefficient is now 0.273 which is still very much less than 0.811 (the significance level for a Type 1 error). 1

In Table 7.32 a further possibility has been considered - namely that it might be a better proposition to average the number of shells in the four faunal squares surrounding the augering node. The numbers in the first row, i.e. 11(d) etc. correspond to the column numbers in Tables 7.24-7.27. Thus $11(\mathrm{~d})$

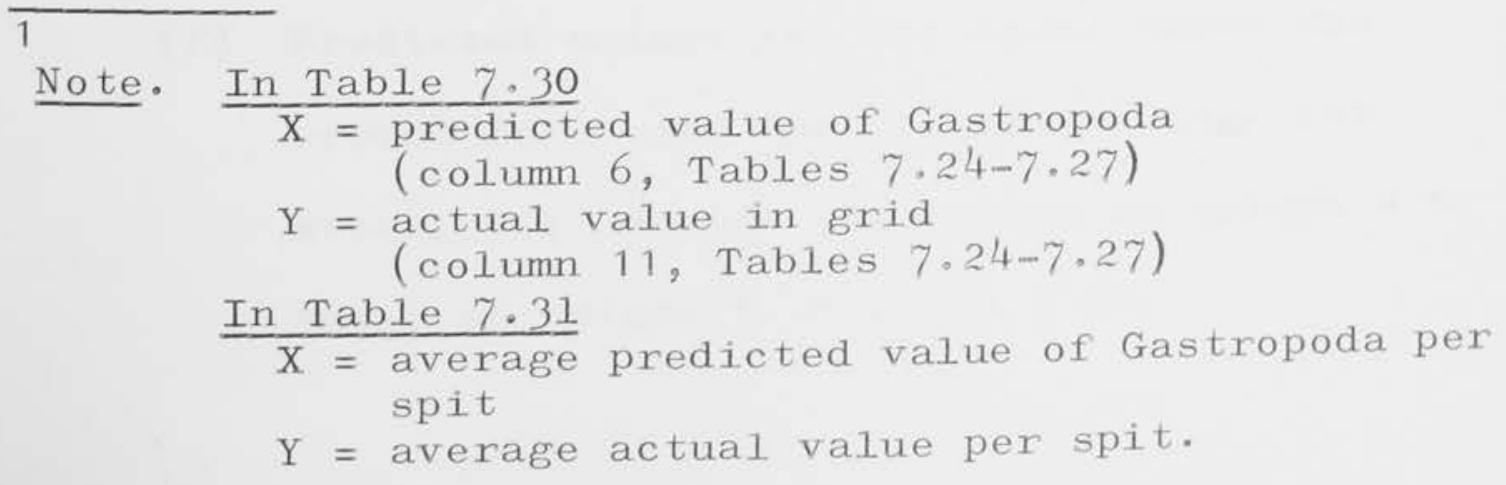


compares the averaged values to the value in the square surrounding the augering node. It can be seen that there is little difference between the two sets of values.

The problem is now considered in terms of orders of error. If the predicted value is $\mathrm{P}$ and the actual value is $A$, then $P / A=E$ the order of error. Table 7.34 considers the variation of E for several cases:-

(a) Predicted values and actual values Gastropoda and Pelecypoda, i.e. divide the numbers in column 5 by those in column 11 of Tables $7.24-7.27$.

(b) Predicted values for the eroded level itself and the actual values - Gastropoda and Pelecypoda, i.e. divide the numbers in column 7 by those in column 11 of Tables 7.24-7.27.

(c) Predicted values for the level above the eroded level and the actual values Gastropoda and Pelecypoda, i.e. divide the numbers in column 9 by those in column 11 of Tables $7.24-7.27$.

(d) Predicted values and actual values - for stone, i.e. divide numbers in column 2 by those in column 5, Table 7.28 .

(e) Predicted values for the eroded level itself and the actual values - for stone, i.e. divide numbers in column 3 by those in column 5 of Table 7.28 .

(f) Predicted values for the level above the eroded level and the actual values - for stone, i.e. divide the number in column 4 by those in column 5 of Table 7.28 . 
For each case the average value of $\bar{E}$ and the

Standard Deviation $\sigma$, has been calculated.

It has been suggested that predicted values (P) for shell, can be as much as three to four times

greater or less than the actual value (a), and that for those spits above number 4 the errors might be less of the order A (i.e., 100 per cent error in prediction).

Table 7.35 shows that on the average, the shell predictions are six times the actual values and are still outside the suggested error margin. On the other hand when one considers the order of error for predictions for eroded level and level above eroded level, these averages $E$ have dropped considerably. For the sample considered, the predicted and actual values approximately agree. The order of magnitude of error has dropped well within the postulated error limits. Further tests on these average values reveal that there is a real difference in the means $(\bar{E})$. If

$\mathrm{D}=$ difference between the mean values

$=\overline{\mathrm{E}}_{1}-\overline{\mathrm{E}}_{2}$ and

$s=2 \sqrt{\frac{\sigma_{1}^{2}+\sigma_{2}^{2}}{43}}$

then providing $D$ is greater than $S$, the difference is significant. 1

Table 7.33 considers the variation of E for particular species. It can be seen that the results are similar to those just described. The average for the straightforward case of Predicted (P) and Actual (A) yields average values of very high magnitude.

NOTE: In reality this formula should be applied to samples of fifty and over. The sample in this case is 43; since $S<<D$ in the tests - it may be used as an approximation. 
On the other hand, for the cases of 'eroded level' and

'Level above eroded level' the value of $\bar{E}$ has dropped

inside the error range, so that the results again

suggest that more reliable predictions have been made.

However correlation analysis still fails to yield a

significance. Table 7.35 tests for correlation between

Gastropoda 'Level above eroded level' and actual values.

There is no significant correlation. Re-examination of

these figures, in terms of error ranges, could produce

a better correlation, because the present data sets do

not take the allowable error range into account. In

this respect it might be better to restate the

predicted values in terms of ranges rather than as

continuous variables. 1

The foregoing suggests that the shells gradually

disappear after being eroded out of the soil.

Table 7.34 shows that the stone material behaves similarly to shell. Predictions for accumulated stone density are less reliable than for shell. However, there is a striking improvement in the value of $\overline{\mathrm{E}}$ for 'eroded' and 'level above eroded level'. The difference between the means remains significant. It is tempting, therefore, to suggest that stone also moves. Unfortunately, no experiments have been carried out to verify this hypothesis. Referring back to Diagram 7.5 it will be recalled that errors may be of the order $A$ and as much as $3 A$ (i.e., predictions may be out by three hundred per cent). However if the stone

1

Predicted and actual values were put into diserete ranges 0-50, 50-100, 100-150, etc., and the Correlation Coefficients recalculated. A significance was still not obtained. Recalculation in terms of ranges more compatible with the maximum likely error could still produce a better correlation, i.e. 0-100, 100-200, etc. 
distribution for Excavation $9 \mathrm{~A} / 1$ is the accumulated density for the entire soil, errors in $P$ of the order 16A are allowable. Acceptance of such a figure would put an $\bar{E}$ value of 12.5 within the limits of agreement so that it could be argued that the surface lithic material has not moved. In fact, errors of this order can be expected because assumption two (see page 2 ) does not hold for lithic material; the latter is not uniformly distributed over the site, and the lithic density is much less than for sheli material, so that it is more difficult to obtain reliable predictions for stone. Thus one is forced to rely solely on control. excavations for an estimate of the likely range of error. Further, although fragmentation and shell loss has been documented (see Chapter 6), there is no evidence to suggest that stone is effected similarly. Assuming that the stone material does move (but that it is not destroyed), concentrations of stone should be found along the general direction of the prevailing winds in the more sheltered pockets of the site.

However no such concentrations have been observed. Six months of observation of some small stones situated near Shell. Experiment A, failed to produce any evidence for stone migration, 1

\subsection{Summary}

Evidence has been brought forward to suggest that much of the shell material eroded from the A series soil on Site $9 \mathrm{~A}$ has been lost, so that shells situated on the present surface should be fully representative of the fauna exploited in A series times. The evidence

However, very small flakes possibly could migrate in high winds. 
for lithic material is not as clear, although it has been tentatively suggested that it does not migrate. Consequently lithic material found on the present surface of Site $9 \mathrm{~A}$ is the accumulated result of erosion. 


\subsection{Introduction}

In Chapter 4 differences in faunal species and lithic materials were noted between the A and B series middens. In this chapter an attempt will be made to quantify the characteristic faunal and stone material of the $B$ series middens. Once this has been achieved a statistical comparison can be made between the $A$ and $B$ series material.

In order to ascertain the contents of Aboriginal middens, many of which are of immense size, some method of sampling is necessary, If one was to collect every stone, and examine every shell and piece of bone, excessive time would be spent on a single midden. ${ }^{1}$ At Wilson's Promontory a sampling method has been developed which is fairly rapid and gives analysable results. Unfortunately time did not permit investigations to be as broad and as detailed as they might have been. Nevertheless four sites have been sampled by the method described below.

Most of the larger sites at Wilson's Promontory are middens situated in an unconsolidated sandy environment ( $B$ series). In order to understand the sampling technique some general comments on the morphology of this type of environment are relevant,

\subsection{The Nature of the Midden - The Blow Out}

The geomorphological feature - the blow out is a common sight in all areas where there are unconsolidated 
dune sands. There are several varieties of the blow out :

(a) A type of blow out is produced when a foredune is blown back by the wind so that sand collects in a tongue for some distance behind the foredune (Diagrams $8.1,1(\mathrm{a})$ and 1(b)). The sand tends to collect parallel to the wind direction,

(b) When sand smothers the vegetation on a previously stabilized dune face this part of the dune becomes mobile (Diagram 8.1, 2(a) and $2(\mathrm{~b}))$. The wind removes sand from the unconsolidated face, blowing it out to the sides and over the top of the dune face to be re-deposited. The rate at which the face of the dune is destroyed and the areas of re-deposition are built up is dependent on the steepness of the dune face. In general, the steeper the dune face the faster the rate of erosion. For steep-faced dunes re-deposition tends to occur at the sides of the dune rather than behind, After some time the entire centre of the dune may be removed down to the water table, leaving behind two steep-faced ridges parallel to the prevailing wind direction (Diagram 8, 1, 2(c) and 2(d)).

Sand supply varies. Sand may be obtained from the foredune which in turn receives its supply by the cut and fill process, ${ }^{1}$ While the primary source of sand is the vast deposit underlying Waratah Bay, material is 
also provided from the erosion of the Pleistocene dunes along the coast.

(c) A blow out type, similar to the one just described, but of a slightly different origin, is also present at Wilson's Promontory.

There is a series of older B series dune ridges which are large and high, and which have been stabilized in the past. They are orientated in the direction of the prevailing wind. However, in recent times the faces of these dunes ( $i, e$, that part of the dune facing the oncoming winds) have been destabilized. Sand has been blown out to the sides and over the tops of the dune face. The accumulation of sand on the sides and behind the dune face smothers the vegetation, causing further destabilization and erosion. Sand is also blown well back along the dune ridge, but its deposition is not enough to damage the vegetation cover on the tails of the ridges, and in these regions the ridges remain stable, Over a period of time, the whole dune face moves back along the ridge in the direction of the prevailing wind (Diagram $8.1,3(\mathrm{a}), 3(\mathrm{~b})$ and $3(\mathrm{c}))$.

The differences between blow out types 2 and 3 are a function of the initial physiography, The initial dune for type 2 is essentially broad faced with a short

1

Carbonate tests on (a) the present beach sands, (b) the present B series dunes, (c) beach sands near Walkerville, (d) A series soils, and (e) Pleistocene dune sands, show that the percentage carbonate is approximately the same for (a), (b) and (c), but different from (d) and (e). 
tail. The final phase (Diagram 8, 1, 2(d)) produces the nucleus for the formation of parallel dune ridges.

Type 3 has an initial dune of this parallel variety similar to the final stage of type 2. Here 1 ong, parallel dune ridges have been formed and stabilized in antiquity; subsequently, erosion of the dune face has been initiated.

Where vegetation has been growing on a dune for a considerable period of time a humus is formed, i.e. the top layer of sand is converted into a sandy soil, light brown to grey in colour. The maturity of the soil will depend on the period of stabilization. These soil profiles can be seen in the blow out areas of dune systems. Several profiles may occur in a blow out face, indicating different periods of stabilization. The method of formation of these soils is suggested in Diagram 8,2, A dune may have several distinct periods of stabilization and later erosion causes portions of these profiles to be exposed. It is important to realize that there is often difficulty in relating one profile to the next because the dune soil dips tend to be confused, $i, e$, soils are formed on the sand surfaces existing at the time, Thus there is no reason for newer soils to lie parallel to their predecessors, There may be a tendency to relate exposed soils in different parts of the midden to the same period of soil formation on the basis of scant evidence; for example, when two soils have the same angle of dip. But soils may also be related even when their angles of dip are not the same, for this will depend on the original topography. Thus great care has to be exercised when correlating profiles. 
8.3 The Nature of the Midden - Formation

The foregoing discussion of dune morphology is related to Aboriginal middens by the fact that most blow outs are strewn with Aboriginal remains including lithic material, shell fauna, bone, camp fires, etc. The answers to questions, such as whether any cultural and chronological evidence may be extracted from such sites, and at what stage in the formation of the blow out were the Aborigines camping there, tend to be very complex.

The simplest type of blow out situation is shown in Diagram 8.1, 3(c). Here the fossil soils exposed in the blow out face are clearly associated with the first stages of ridge formation. The Aboriginal material found on the face of the blow out may have derived from three main sources:-

(a) It may have been deposited after the blow out was formed,

(b) It may have been associated with the soils in the blow out face, but subsequent erosion of these soils has caused the material to erode out and be scattered down the face of the dune.

(c) It may have come from lenses situated between the soil profiles, Subsequent erosion of these lenses has caused the material to erode out and scatter down the face of the dune.

Combinations of all three possibilities are likely and indeed occur. This situation is illustrated in Diagram 8.3. Occupational lenses in both soil and sand are shown here, As erosion proceeds, cultural material in lens $b_{2}$ mixes with material of lens $b_{1}$. Eventually material from $b_{2}$ and $b_{1}$ arrive at the soil surface. 
Erosion proceeds more slowly, but after a time, material from $a_{3}, a_{2}$ and $a_{1}$ in the soil becomes mixed with $b_{2}$ and $b_{1}$. Thus in the final stages, one has a mixture of material from five lenses. To further complicate the issue Aborigines may have camped on any one, or all of the erosional stages, This fact is acknowledged by the addition of a cultural factor $\mathrm{x}$, where $x$ represents the most recent cultural deposit. Diagram 8.4 shows a practical situation on a blow out face. Cultural material contained in the three soil profiles shown is represented by $a, b$, and $c$. It is clear that as one moves from top to bottom of the blow out the degree of mixing increases. However, if one could excavate behind the face of the dune, the cultural material from the three lenses would be recovered in a stratified, unmixed context. Unfortunately this is often impossible because sand is a dangerous excavating medium, and trenches more than five to six feet deep tend to collapse when the sand dries out. Thus in most cases one returns to the material on the face of the dune and attempts to sort it out in the most efficient manner possible. If, for example, all the lithic material was collected between $c$ and $b$, then one could feel fairly sure that this material would not contain lithic material from $b$ and a (assuming stone material cannot be blown uphill).

Likewise, material collected between b and a should contain no a. Thus one has a crude means of distinguishing the cultural material in different parts of the midden. If the formation of $a, b$ and $c$ belonged to different periods, then radio-carbon dating can establish (rightly or wrongly as the case may be) the chronology of the cultural sequence. 
A faunal analysis carried out in a similar manner may prove significant. ${ }^{1}$

Exposed soil profiles are more consolidated than the sandy medium. As a consequence, sand is blown from above and below the soil prior to the erosion of the soil itself. When there is enough overhang, the weight of the exposed soil in the overhang causes the soil to break away in large lumps.

\subsection{The Nature of the Midden - Observation}

It can be seen from the foregoing that it is important to examine all features of a blow out carefully, i.e. the midden morphology, and all exposed profiles must be examined for signs of occupational material. For example, a detailed analysis of a blow out might reveal that none of its soil profiles contains occupational remains. In these circumstances it might be possible to say whether the midden debris was deposited after, during, or before the blow out started, and whether material was contained in sand lenses. (Alternatively, erosion may have proceeded to the stage where the occupational horizons in the soils had been completely stripped, removing all the evidence).

The occurrence of camp fires on open sites can be of considerable importance. If they are found in between soil profiles then they may be interpreted as belonging to buried sand lenses; or they could be used as evidence to show that the blow out had been occupied recently. The extent and concentration of shell fauna

1

It has been shown elsewhere, that faunal material does not move uphill. However, it will move downward, and the wind does have some effect. Fragments of shell are more susceptible to movement than whole shells (see Chapter 6). Appendix 8,1 sets out the mechanism by which shells move in various environments. 
may reveal important morphological features, $i, e$, if faunal material only occurs up to a certain height on the midden - then it may be concluded that the last stage of the dune was formed subsequent to the latest occupation. Large concentrations of shell embedded in charcoal matrices situated in the sand environment often will prove to be in situ lenses. When several lenses of this type are found over the blow out surface, this may be sufficient evidence to demonstrate that some occupation has been fairly recent: $i$, e. when the lenses and fireplaces appear to be associated with the blow out face, It follows that any method of sampling a midden site must take into account the morphology of the blow out,

Before proceeding to outline methods of random sampling it is as well to note that there are many cases where erosion has proceeded so far that little useful information can be extracted by a morphological study, Such is often the case for type 2 blow outs, where the centre of the dune has been almost or completely blown away. Sometimes the size and the shape of these dunes suggest that they are of fairly recent origin. In these cases the material distributed on the dune faces or on the corridor floor between the lately formed dune ridges can be assigned a unicultural role. In the case of very recently formed dunes, the material deposits may be directly associated with the blown dune face. Examination of the sides of the blow out may help to support such a hypothesis. If the fossil soils contain no Aboriginal remains (ox if there are no soils at all) - if there is no evidence of buried lenses in the sand itself, and if there appears to be a sparseness of Aboriginal material on the sides 
of the blow out, then it may be valid to conclude that the material remains are directly associated with the extant dune face. This situation does ocour, but there are no set rules for dealing with blow outs. Each blow out-midden site must be examined separately and treated as the situation demands.

\subsection{Random Sampling of B Series Middens}

Appendix 8.2 describes in detail a method of random sampling midden sites. Hexe an attempt has been made to quantify middens in terms of comparable parameters.

Appendix 8.3 sets out to describe the method of counting and to derive an estimate of the error correction to be applied at various sampling levels. A correction curve has been deduced and is displayed in Diagram 8, 10, Similar treatment has been given to the sampling of 1ithic material (Appendix 8,3). Diagram 8,8 shows the percentage correction curves for each material type.

Random Sampling of Sites 2, 5. and 9D

Diagrams 2.3-2, 4 show the locations of the three sites, whilst Diagrams $8,12,8,14$ show the detailed plans of each area. Data relevant to the topographical. description of the sampling sites is set ort in Table 8.12. It can be seen that they are situated at various distances from the HWM (high water mark) and having various degrees of slope (from 0,1 to 0,6). They are all orientated in roughly the same direction. The detailed topographical descriptions for each site are set out in Appendix 8.4.

Sites 5 and 9D were treated as unicultural sites but with several parts. Site 2 was divided into three sections. Tables $8,13-8,14$ show how each site was sampled. 
The frequency list of species per 6' square for Site 2 is shown in Table 8.15. (Numbers prefixed by C mean the total shells corrected by using Diagram 8,10). The last two columns represent the total average for the midden - i,e, treating it as a homogeneous unit, The total figure has been used for comparing middens because the faunal material over the three sections appears to be uniform, suggesting that a similar ecological situation prevailed during the three periods of dune formation. The central part of the middens contain the most shell. The total number of shells was obtained by:

(a) Neglecting all non-edible species, and

(b) Neglecting operculum (in order to make comparisons with Sites $9 \mathrm{~A}$ and 10A, (Note that the number of bivalves had to be divided by two).

The results for sites 5 and $9 \mathrm{D}$ are shown in Tables 8.16 and 8.17 . For purposes of comparison the percentage frequencies of occurrence of each species for the three sites have been displayed in Table 10.4. In terms of orders of magnitude it can be seen that there is fair agreement between the relative frequencies of occurrence of these species at each site. Very little stone was found on these sites. The average amount of lithic material pex 6 s suare for each site is set out below:

Site Flint $\times 10^{-3}$ Quartz $\times 10^{-3}$ Quartzite $\times 10^{-3}$

$\begin{array}{lrrr}2 & 25.2 & 2.7 & 0.2 \\ 5 & 87.0 & 31.0 & 2.6 \\ 9 D & 194.0 & 282.0 & 58.0\end{array}$

Thus the variation of stone density between sites is considerable. 


\section{CHAPTER 9}

\section{ENVIRONMENTAL EVIDENCE}

\section{AND ARCHAEOLOGICAL SHELLS}

This short chapter is introduced to draw attention to the fact that limited environmental evidence can be extracted from archaeological shells, and that unless close attention is given to the biology and the crystal structure of the individual species, most measurements on the shells are of little value.

The archaeological shells were originally collected by the aborigines from the fossil shore platform (presumably not far distant from where they were later deposited). These shells retain evidence of the local oceanic environment because their growth characteristics and crystal structure are determined by the nature of the environment from which they were collected. Temperature is a key factor affecting the crystal structure of shells. By studying the structure of archaeological shells it is possible to estimate the temperature of the ocean at the time of their growth and consequent1y to make certain deductions about the local climate at that time,

Only the results of this research need to be mentioned here, since these are relevant to the study of the ecology of the area outlined in chapter 10.

Methods and problems are fully elaborated in Appendices 9.1-9.3, while results relevant to the next chapter are summarized below.

\footnotetext{
'Environment' as it is used here means the 1 ocal area or region.
} 
In these Appendices three methods have been suggested for extracting environmental evidence from archaeological shells. Each method is limited by the lack of refinement in the technique itself, and by too few measurements. On the other hand, lack of knowledge of the biology and the effect of a number of other environmental factors on the various species (including Cellana) tends to further limit the use of these results. Some of these factors have been discussed for Cellana, and others have been discussed through related species. However, until these have been thoroughly investigated, results obtained by the three techniques must be treated with caution.

For the west coast areas, all three methods suggest that the ocean temperature in A series times was about $3^{\circ}$ higher than at present. If such was the case the environment and the ecology of the area must have been very different, for a warmer sea temperature would affect such factors as marine life, rates of sedimentation, carbonate exchange rates, evaporation, salinity and so on. These factors would in turn affect the rainfall and the rate of erosion, and indirectly determine which species of flora and fauna predominate on the landscape nearby. 


\section{CHANGES IN COASTAL ECOLOGY}

In this chapter, the evidence presented in Chapters 5 to 9 will be reviewed in an attempt to show that changes in climate and ecology have occurred since A series times.

Table 10.1 is a compounded list of fauna, including species found in the extant and ancient environments. Three groups are specified - Rock Platform, Sandy Beach and Bay (estuarine and muddy) conditions, corresponding to three different environments. It will be noted that some species may live in more than one environment.

In the following pages a study will be made of:-

(a) the distribution and frequency of extant fauna,

(b) the distribution and frequency of $B$ series midden fauna (surface),

(c) the distribution and frequency of A series midden fauna (surface),

(d) the distribution and frequency of $B$ Soricies fauna (excavated),

(e) the distribution and frequency of A series fauna (excavated).

\section{1 Distribution of Extant Fauna}

The extant environment on the west coast of Yanakie may be classed as Sandy Beach, for with the exception of a few Rock Platforms between Darby Beach and Cottars Lake, the entire distance between Darby Beach and Shallow Inlet is a long sandy stretch of 
beach. Table 10.2 indicates that Sandy Beach species are rare between Darby Beach and Cottars Lake, but predominate further north. Estuarine shells are found more frequently as Shallow Inlet is approached. The Rock Platforms consist of (a) granite cliffs (Site 1) and (b) remnants of dune limestone ridges which have been eroded away by the sea. Some of these platforms stretch hundreds of yards out to sea and at low tide it is possible to walk out along them for some distance. The distribution and orientation of the platforms suggest that in the not so distant past, the coastline between Darby Beach and Cottars Lake may have been a series of small, open bays, with (then uneroded) Rock Platforms forming the arms of the bays (see Chapter 3).

10.2 Distribution and Frequency on B Series Middens It can be seen from Table 8.2 that, in general, the fauna in the $B$ series middens reflects the type of fauna found nearby. ${ }^{1}$ Thus at the southern end of the beach, few estuarine (or muddy condition) shells are found on the middens. However, this is not the case at the northern end of the beach where Rock Platform fauna are common in midden fauna, $i . e$ estuarine conditions exist at Shallow Inlet, and do not exist at Darby Beach (except for a small stream which is usually cut off from the sea).

The occurrence of Rock Platform species in the B series middens all along the beach means that the Aborigines must have frequently walked some distance to

1

Mitchell has noted similar correlations elsewhere. 'Shells on all middens behind those portions of the strand line that are sandy, are mostly sand loving species, and behind the rocky coastline rock loving species'. (S.R. Mitche11, 1949, p.124). 
collect fauna. For example Aborigines camped at

Shallow Inlet would have had to walk about seven miles to the nearest rock platform to collect Rock Platform fauna, while Aborigines camped at Darby Beach would have had to walk up to ten miles to collect certain types of estuarine or Muddy Bay species (oyster). Thus, when considering the distribution and frequency of fauna on midden sites, one should be aware that certain species might have been collected and transported to the midden over considerable distances.

An attempt was made to further define the distribution of extant and $B$ series midden faunas, by random sampling the beach between Darby Beach and Black Rock. At the time it was thought that washed fauna would reflect the distribution and frequency of the extant fauna. However, a fast off shore drift brought shells from further north, so that the results were hard to interpret.

A string 200 yards 1 ong was divided into 200 one yard intervals. Twenty of these lengths were selected from a book of random numbers (sampling at the ten per cent level) and painted red to aid identification. Commencing at the granite at Darby Beach, the coast was then sampled in two hundred yard stretches. The technique was only used between low and three quarter tides.

At each sampling point, operators walked at right angles to the line of the string in a lane one yard wide - down to the water edge - and to the foot of the foredune. All species and their frequencies were recorded. The type of data sheet used is shown in Table 10.3. Space is provided in this table for a description of the coastal features immediately behind the section being sampled. 
Diagram 10,1 summarizes the sampled data. The fauna has been divided into Pelecypoda (upper) and Gastropoda (lower) Starting from the bottom right hand corner, one moves north in 200 yard intervals. The numbers of each species per sampled section are plotted in each interval. In the upper part of each series of diagrams, the coastal feature immediately behind each section has been noted, Several observations can be made from this diagram.

1. The appearance of Anapella, Katelysia and Homalina at this end of the beach, means that they must have been washed down from further north, for they are not found in this area.

2. The Rock Platform species are well represented, particularly near the rock platform areas themselves (i,e. Sites 1-3, 9A and 11).

3. Fauna is sparse along sandy stretches and dense near the rock platform areas. The rock platform areas may act as traps for washed shells.

4. In general, this method failed to provide significant information relating to the $B$ series middens.

Sampling beyond cottars Lake revealed that all Gastropoda (with the exception of polinices) disappeared. Only Sandy Beach and Sand-Mud species appear. Most of the species on the $B$ series middens are represented in the sampled fauna, (Species such as

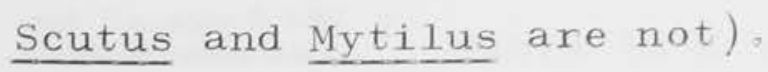


10. 3 Distribution and Frequency of Fauna on A series wid yowake $B$ Series Surface Sites, and in A and B Series owd yamakic B Excavations

Table 10.4 summarizes the data ${ }^{1}$ for the following series of sites:-

1. surface sites, A series,

2. excavated sites, A series,

3. excavated sites yanakie B siks

3. excavated sites, B series.

4. surface sites. Yanakie B sites

The frequencies have been expressed as percentages of the total number of shells - excluding non edible species, The total number of shells for each case was calculated by adding in the number of Subninella only. Operculum were not used because they were not counted on surface sites $9 \mathrm{~A}$ and 10A. The following observations can be made:...

(a) there is an increase in the percentage of Sandy Beach species in the B-series middens. Plebidonax becomes the dominant species:

(b) there seems to be an increased preference for bivalves in the $\mathrm{B}$ Bankeries middens;

(c) the percentage Subninella had dropped quite markedly in the $B$ angkie $B$ series midden material:

(d) Austrocochlea is rare in the $B$ series middens.

Table 10,5 sets out numbers of each species at each site considered. Analysis of variance was carried out to test (a) for homogeneity within the A and $B$ Y Yanakie $B$ sites series respectively (b) for differences between the A seres and YAraku Bsiles 2 Table 10.6 sets out the results of

$\overline{1}$

The percentages for the $B$ series middens were obtained from the results of random sampling (chapter 8, Tables $8,15,8.16$ and 8.17 )

2

The author devised and wrote a suitable computer programme for this analysis. 
these calculations. Although several combinations of sites have been considered, it is important to realize that Excavations $9 \mathrm{~A} / 1$ and $9 \mathrm{~A} / 2,9 \mathrm{~A} / 3,9 \mathrm{~A} / 4$ and $9 \mathrm{~A} / 5$ were trial trenches only and since the fauna recovered in these excavations can hardly be regarded as representative, they may be omitted from the analysis. 1 Tests for homogeneity within each series show no significance at the one per cent level, and approximately no significance at the five per cent level. For the $B$ asikeries siles is insignificant at both the one per cent and five per cent levels, while for the A series the variation is at par at the one per cent level and significant at the five per cent level. Testing between the $A$ and $B$ and Yawakic $B$

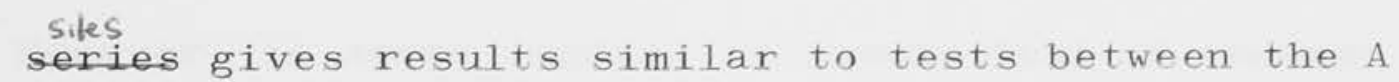
series sites by themselves, though a significance is obtained at the five per cent level. The results of these calculations indicate that if any difference does exist between the $A$ seres and Yaurkie $B$ sites $B$ series it is subtle, and must be measured in terms of the variations in the species themselves, For example, the significance ratios for tests on the $\stackrel{\text { Yanalui }}{B}$ series sites (between species) are quite insignificant, while those on the $A$ series and on the YANAKLC 3
B series sites are 20-50 per cent higher, and significant, Detailed examination of Table 10,4 reveals that the range of species in the $A$ series is greater than for the $\mathrm{B}$ series and that the difference in variances (between species) can be explained in terms of different frequencies of Plebidonax in the two sequences

In Table 10,6 those calculations marked with an asterisk are the important results. 
These conclusions suggest that (a) there may have been a change in the coastline which had produced conditions favourable for supporting Plebidonax colonies and/or (b) there has been a change in preference of shell fauna, $i$, e. from wholly Rock Platform to Sandy Beach species.

Changes of preference have been documented for other areas, particularly New Zealand (R。Green 1963, p.69). Other authors have attempted to relate changes in ecology to changes in preference (N.C. Nelson 1909, p.338; 1910, pp.376-7: C.W. Meighan, et, a1. 1.958, pp. 12-3). Alternatively Gifford has used man's interference with the seashore environment to explain changes in midden character (E.W. Gifford 1916, p.10). However, it seems logical to assume that if changes of physiography caused the proliferation of other edible species, particularly if they are easy to collect, the aborigines would take advantage of this new food source.

Table 5.40 (for Excavation No, 11/1) and Tables 10.7-10,15 (for Excavation 9A/6) show the various ratios for each spit in these excavations, e.g. $\mathrm{P} / \mathrm{G}=\mathrm{Pelecypoda/Gastropoda}$ (measures the ratio of bivalves to Gastropoda).

$\mathrm{S} / \mathrm{R}=$ Sandy Beach/Rock Platform (indicates the type of coastline)

$\mathrm{B} / \mathrm{R}=$ Bay or Muddy Bay/Rock Platform (indicates the type of coastline).

Examination of these ratios reveals that:-

(a) The $\mathrm{P} / \mathrm{G}$ ratios are fairly low;

(b) The $\mathrm{S} / \mathrm{R}$ and $\mathrm{B} / \mathrm{R}$ ratios are very low.

The overall ratios for these excavations are shown in Table 10,16 and these compare favourably with the ratios for the A series surface sites ( $9 \mathrm{~A}$ and $10 \mathrm{~A}$ ). 
Yanthie $B$

The ratios for the $B$ series sites are shown on the same table, Here:-

(a) the $P / G$ and $S / R$ ratios are at least an order of magnitude higher than those for the A series sites,

(b) the $B / R$ are mostly zero.

Although the A series $B / R$ ratio is very low it is still measurable,

These ratios support the contention that a change of coastline has taken place and that Bay species were to be found in the area in the early part of the sequence, However, these species were never really important and they may have been brought to the area from elsewhere.

Table 10, 17 examines the frequency of occurrence and the stratigraphic position of the Bay, Sandy Beach and rarer species for Excavation No, 9A/6. Generally, oyster (Ostrea) is found below spit $7,{ }^{1}$ This type of oyster requires fairly sheltered conditions.

Velacumantis is only found in Bay conditions and is frequently associated with and found inshore from oyster beds, Velacumantis is found only in the lower levels of the excavation. Pieces of the coral Plesiastrea urvillei were also found in the lower levels of the excavations. This coral is usually found 20-30 feet below the surface of the ocean and it flourishes in warm Bay conditions. Katelysia rhytiphora - a Bay species - was found in the lower levels of Excavation No. 1 (9A/1 - levels $10 G / 1$ and 2, $10 \mathrm{H} / 2,10 \mathrm{H} / 4$ - Table 6.1), and a single example was

It also occurred in spits $0 / 5 / 2$ and $F / 1 / 4$ in the upper levels. 
found in level C/1/15 of Excavation 9A/6. Two

Velacumantis shells were found in level $2 / 20$ of

Excavation 9A/5, On the other hand, all the Sandy

Beach species (Plebidonax and Polinices) were found in the upper levels of $9 \mathrm{~A} / 6$ (Spits 1 to 8), and Plebidonax occurs mainly in spit 1 with a single example in Spit $3(\mathrm{~B} / 1 / 3)$.

Although the evidence is limited, there is the suggestion that a change of coastal environment has occurred, and that this change is indicated by the occurrence of these rarex species. The change appears to have begun towards the end of A series occupation when Sandy Beach species begin to appeax in the midden fauna.

There are many eroded A series sections with exposed shell lenses along the coast from Darby Beach to Cottars Lake, Examination of these lenses has shown that the types of species which have been identified in the A series middens (through excavations) are general for all the A series sites, No Plebidonax

(characteristic of $B$ middens) have been found in any of these lenses, which testifies to their rare occurrence in A series midden fauna.

Thus when all the evidence is taken into account, a change of coastline is favoured. The change progressed from a Bay type to a Sandy Beach environment, though it is uncertain how far the change had progressed by the end of A series times. At any rate by $700 \mathrm{~A} . \mathrm{D}$., the change was complete and Plebidonax dominated the midden fauna. This change of preference accounts for the slightly lower percentages of Subninella and Austrocochlea in the $B$ Sarie $B$ 
fauna; for these species were no longex collected to the same extent as they had been in A series times.

10,4 Vegetation and Climate

The extant vegetation in the general area around Sites $9 A$ and 11 is described in Appendix 10,1. The botanist was asked to investigate whether the $\mathrm{A}$ and $\mathrm{B}$ series dunes could be distinguished by their vegetations, $i$,e, the older dunes may have different and older populations than their more recent counterparts, However, he concluded that the populations were identical. This result was not unexpected as most of the vegetation on Yanakie is secondary growth.

Six peat samples were selected from the peat beds between sites $9 \mathrm{~A}$ and $10 \mathrm{~A}$. These were submitted to the Botany Department, Melbourne Univexsity, for pollen analysis. The results are set out in Appendix 10.2 . Although it is difficult to argue from so few results, these suggest that the vegetation cover in A series times was different (or at least that some other species were present) from those seen in the area today. Casuarina woodland (and perhaps Eucalyptus forest) may have been the important communities. Under these circumstances, the climate would have been a little wetter than it is at present. There are few Eucalyptus trees on Yanakie today, However, at the turn of the century they were quite common further south. For example, the axea between the jetty in south-west Corner Inlet and Darby was described by one naturalist as

Cattlemen used to burn off the area regularly. 
a thickly timbered flat, extending to the ti tree covered sand dunes which margin the ocean beach. Most of the timber which consists principally of fair size

Eucalyptus, with a few scattered Blackwoods, has been singed, only their whitened skeletons remaining to show what once had been. (V.N. vol, XXIX, No, 9, 1913, p.171).

This pocket of forest may have been a remnant from A series times.

In Chapter 9, some evidence was presented to suggest that the mean annual sea temperature was higher than it is today, If this was so, then the ecology of the entire area would be effected, and the erosion of the coastline may have been accelerated during this period.

\section{Summary}

The southern portion of the west coast of Yanakie consisted of a series of small bays with headlands projecting a little way out to sea. Behind the foredune in each cove, interdune lakes provided visitors with a constant supply of fresh water. At low tide the Aborigines could collect fauna from many exposed reefs which were generally quite accessible. Camps were set up beside the lakes and in the sanctuary of the Casuarina (and Eucalyptus?) woodland nearby. The summers were very hot and during winter it frequent1y rained, The presence of Cabestana on A series camp sites indicates that the Aborigines came to the area in spring and summer although there is no evidence to suggest they did not also camp here in winter. ${ }^{1}$

There is no evidence to suggest that the Aborigines placed any reliance on hunting ox fishing. 
Table 10,18 lists the distribution of orhre, bone and wood in the main excavations, Three unidentifiable fragments of bone were found indicating that bone can be preserved in the A series soil. However, in all the eroded A series sections (and midden areas) examined, not a single piece of bone has been found.

The nature of the midden deposits themselves (their irregular unconcentrated deposits) suggests that the area was never visited for any length of time. In Chapters 5 and 6 , the original shel 1 heaps on the various occupational floors were reconstructed and it was suggested that each pile was the refuse dump of a single meal of a small group of Aborigines. ' Thus, the South Yanakie area was probably visited spasmodically by small bands of Aborigines, probably in the warmer part of the year, and for the sole purpose of gathering, The sea receded slightly towards the end of A series times, but later it began to rise again ushering in a new era of increased erosion.

As time passed, the headlands of the bays were eroded back, and the reefs further out to sea disappeared. Continuous beaches appeared which supported colonies of Plebidonax. The Aborigines took advantage of the new food source and it soon became an important food shell.

At the northern end of the beach, exosion had long since done its work, and sandy beaches were well established, Here Plebidonax must have been important long before it could be collected at the southern end of the beach. The fact that only a few are found in

\footnotetext{
C.W. Meighan, et, al, has put forward the same type of argument as being applicable to all foraging peoples. (C.W. Meighan, et, al, 1958, pp. 2-3).
} 
the A series soils at the southern end of the beach shows that no preference had developed for this species by the end of A series times, $i, e$, Plebidonax woutd were probobly

almost certainly have been available at the northern end of the beach at the time. In other words, the Aborigines simply ate the shellfish available locally. 


\section{LITHIC ANALYSIS}

In the remaining chapters attention will be given to the description and interpretation of the stone material excavated and collected on the surface. The prime objectives of the analysis are:-

1. To describe the stone material.

2. To ascertain whether there have been any changes in stone technology from A series times to the present.

3. To select the most important and discriminating features of the various industries and use these as a basis for comparing them.

4. To compare the standard typological methods used in Australia at the present time with a more elaborate scheme described below.

\section{1 Description}

For purposes of description all flakes and cores have been treated as rectangular blocks ${ }^{1}$ (Diagram 11.1). Each stone was described in five stages (a) material, (b) measurements, (c) shape, (d) cross section, and (e) working. The information was coded onto IBM 80-column punch cards. 2

1 For definitions of the various terms such as flake, core, bulb of percussion and so on, the reader is referred to S.R. Mitchel1 1949, pp.16-18 and F.D. McCarthy et. a1., 1946. 2

There are many advantages in storing data on punch cards, particularly when huge quantities of data has to be processed. (See J.C. Gardin 1958, p.355). 
Table 11. 1 shows how the raw data is recorded.

Details of the descriptive scheme are given below.

(a) Material

A1l flake and core material from Wilson's

Promontory falls into one of ten classes. The

Quartzite class is broad, and includes materials which have been called Jasper (S.R. Mitchel1 1949, p.92) and Chalcedony (ibid). The Quartzites themselves are generally fine grained and range from brown to brownred in colour. 1

(b) Measurements

For flakes, these include length (maximum), breadth (maximum and mean), thickness (maximum and mean), weight, striking platform (absent or present), striking angle (degrees), and bulb (present or absent). Measurements were taken with the flake orientated with its bulb away from, and the striking platform nearest to the observer. In cases where both striking platform and bulb were absent, the flakes were orientated with their longest axis at right angles to the observer and with the bulbar side face down. For backed blades with il1-defined orientation, the backed edges were orientated to become the left lateral margin.

Cores were orientated so that their most

pronounced platforms were face down. These platforms

1

Dr J. Talent of the Mines Department, Victoria, carefully examined artifacts made of this material. He concluded that it was impossible to assign them to any but a very general classification because their composition varied so much. Slides of samples showed that they varied from indurated very fine sandy Siltstones (indurated Siltstone with appreciable angular Quartz grains in the size range of very fine sand according to the Wentworth scale) to very fine Quartzites (interlocking grains approximately $0.1 \mathrm{~mm}$ in diameter). 
were called the bases of the cores. The length and width of the base, the height and the weight of each core were measured and recorded. The number of platforms and the flaking angles on each core were also noted. Only the angle of retouch was noted in the case of retouched cores.

Lengths were measured to nearest millimetre, angles to within 5 degrees and presence or absences were indicated by a 1 or 0 respectively.

\section{(c) Shapes}

Twenty five shapes have been considered. One of these shapes was assigned to each flake and they were labelled 'irregular' if none of these shapes approximated the flake outline.

Four basic shapes were provided for cores.

(d) Cross Section

A choice of 21 cross sections is provided. The most characteristic cross section was assigned to each flake. 1 Where the flake has a non symmetrical cross section it must also be noted as a left (L), right (R) orientation.

Five typical cross sections are provided for cores. (e) Working

This has been divided into several classes:-

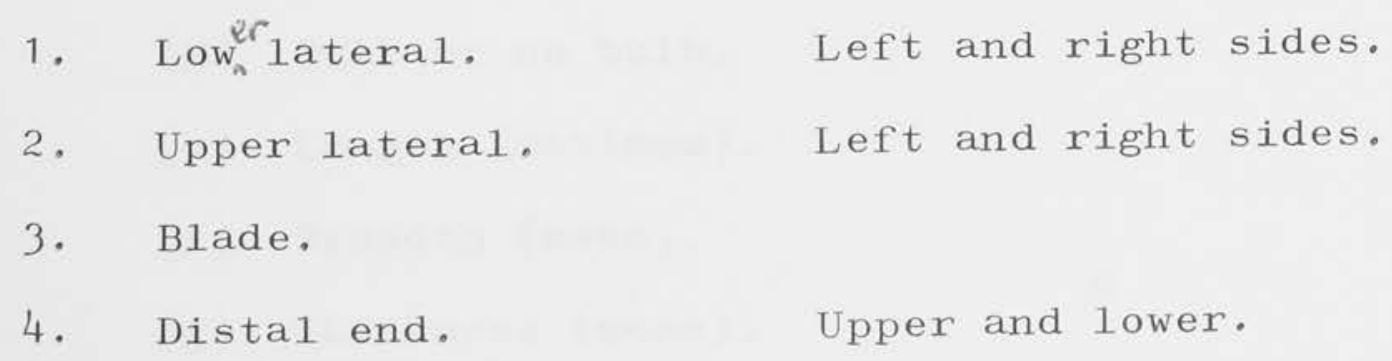
sketch a three dimensional diagram of the flake it would give the closest approximation to the outline of the flake. 
Butt - Upper face

Bulbar face

Vertical face

6. Utilization.

Left lateral.

Right lateral.

Distal.

The sub-classes in each group are self explanatory (see Table 11.1). Wherever possible the scraping angles were measured (usually to within $5^{\circ}$ ). Cores were treated in a similar, but simpler manner.

Waste Flakes

With the exception of Group (e) above, the descriptive system is applicable to wasteflakes. The analysis of waste flake material was carried out in the hope that it could be classified into groups and that these groups could be used to assist in defining the cultural assemblages. In fact, the waste flakes analysis was the first attempt to describe stone material in terms of parameters. To this end a less sophisticated descriptive system was evolved which consists of 9 major groupings:-

(a) Stone type (5 types).

(b) Shape (8 shapes).

(c) High backed or not high backed,

(d) Bulb or no bulb.

(e) Length (maximum).

(f) Breadth (mean).

(g) Thickness (mean).

(h) Weight.

(i) Striking angle.

The high backed group denotes whether the flake is asymmetrical and of similar cross-section to that of an orange segment. The height must be of the order $1 \frac{1}{2}$ 
times the width of the flake before it can be classified as high backed. Raw data was recorded on sheets similar to Table 11.2 .

Thus in the wasteflake analysis two methods of description have been used as this second scheme was used to analyse the waste flakes of Site 9A (surface). Subsequently it was found to possess no particular advantage over the more general descriptive system, so that waste flakes from all the other sites were analysed using the general system.

\subsection{Punch Card Coding - Waste Flakes (Special Analysis)}

Table 11.3 shows the break down of the various parameters and the columns which are taken up on the punch card. Continuous variables have been divided into ranges and given discrete values. The right hand side of the table lists the equivalent values of each parameter in the other descriptive systems so that if desired, the two systems can be used side by side.

Thus any flake is described by a series of 9 parameters e.g. 1, 4, 0, 0, 7, 5, 7, 5, 0 according to the individual values of each parameter.

\subsection{Punch Card Coding - Waste and Worked Flakes and Cores (refer to Table 11,1)}

Two cards are required per flake to store all the information about its characteristics.

\section{Standard Class}

For purposes of comparing the computerized classification with the standard classification each implement was assigned a 'standard class'. Sixty such categories were selected after a careful examination of McCarthy's classification (1946) and the tools from Wilson's Promontory (Table 11,4). These standard 
classes are fairly general and include only the most important tool types in the assemblage. For example, most of the tools which have retouch on the butt fall into the 'facial' class. So few have retouch on the vertical face that a separate 'vertical' class has not been included. The 'utilized' classification applies to flakes with no retouch but which have indications that they have been used. Tools were divided into two groups - less than or greater than two centimetres in length, This is an arbitrary distinction and was designed to test the notion that size of the tool affects the tool type. Columns 1-2 of card 1 are used to record the 'standard class'.

A11 physical measurements have been coded exactly i.e. length, say $6.23 \mathrm{~cm}$, would appear as follows.

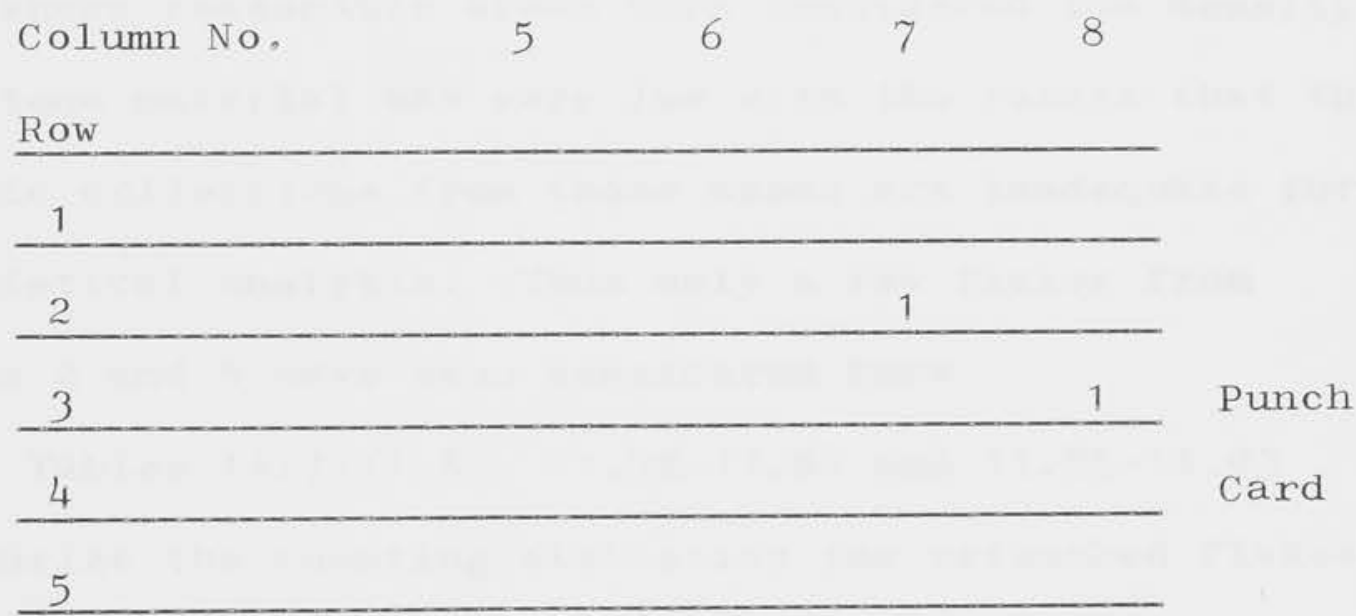

$6 \quad 1$

The decimal point was not recorded. Column 2 of Table 11.1 shows which card and which columns the information is to be recorded on. Physical parameters have been recorded to two decimal places (except angles).

Table 11.5 shows how the information on Table 11.1 can be transferred onto 80-column punch card layout before putting the data onto punch cards. Card 1 corresponds to a single line, card 2 to a second line. 
The data can be transferred directly from Table 11.5

onto IBM punch cards.

Core and flake data have been recorded similarly but only one card is required per flake or core. Table 11.6 shows how the various parameters are distributed over the two cards.

\subsection{Gross Features of the Worked and Waste Flakes}

A11 programmes were written in Fortran for the IBM 360 computer housed at the A.N.U. Computer Centre. 1 Most of the following work was conducted with the aid of the computer,

The first stage in the analysis consisted of counting the numbers of each parameter for the assemblages at each site. At Sites 2, 5, 9D and Oberon Bay where reasonable areas were considered the density of stone material was very low with the result that the lithic collections from these areas are inadequate for statistical analysis, Thus only a few flakes from Sites 2 and 5 have been considered here.

Tables $11.7-11.57,11.58-11.84$ and $11.85-11.93$ summarize the counting statistics for retouched flakes, waste flakes and cores respectively for all the sites considered, including both surface and excavated, The counting has been divided into four major divisions corresponding to total assemblage, and the three main material types - Flint, Quartz and Quartzite. Each number has been expressed as a percentage of the total number of flakes (or cores) in the division.

1

With the exception of four programmes (including two counting and two statistical) all programmes were written and devised by the author. 
In Chapter 7 the relationship of the surface material to the excavated material of Site $9 \mathrm{~A}$ was discussed in detail. An attempt was made to show that most of the surface material on $9 \mathrm{~A}$ derived from the A series soil so that the much larger sample of the surface site could be used to define the Yanakie A assemblage. The surface and excavated materials are related not only by the faunal remains, but also by similarities of implement types and the material from which they have been made.

In order to use the surface material from $9 \mathrm{~A}$ to define the Yanakie A assemblage, one must first show that there have been no obvious changes in technology throughout A series times. To this end one must use the limited information from the A series excavations.

In Chapters 5 and 6 the original living floors in each of the excavations were reconstructed. A computer programme was written which assigned each stone recovered from the excavation to one of these floors and which calculated the means and standard deviation for each of the continuous parameters per level.

Tables 11.94-11.97 show the results of the analysis for Excavations $9 \mathrm{~A} / 6$ and $11 / 1$. Retouched and waste flakes have been considered separately. Although some of the flakes could not be assigned to any level, many of them could be correlated with shell peaks, e.g. two Quartzite tools (retouched) and 17 waste flakes (including 15 Quartzite and 2 Quartz) of $9 \mathrm{~A} / 6$ are directly associated with she11 peaks but not with floors.

Tables 11.98 and 11.99 show the actual parameters and distribution of retouched tools in the cultural levels for Excavations $9 \mathrm{~A} / 6$ and $11 / 1$ respectively. 
The waste flakes in each excavation were subjected to a type of Multivariate analysis in order to test whether there were any significant differences in the flake material through time. ${ }^{1}$ The analysis considers up to 10 parameters, including variables with discrete values. Thus for waste flakes these were material, length, width, thickness, weight, bulb, striking angle, striking platform, shape and cross section. In order to make valid comparisons between levels or sites, the sample number in each level or from each site was the same.

Table 11.100 summarizes the results of several statistical tests. These show:-

1. For waste flakes there is no significant difference between $9 \mathrm{~A} / 6$ and $11 / 1$ hence one can test between excavations (sites).

2. The waste flake material in $11 / 1$ and $9 \mathrm{~A} / 6$ is also compatible. Thus one can combine the waste flake material from these excavations for further tests. 3. There is no significant difference between the retouched flakes in $9 \mathrm{~A} / 6$ and $11 / 1$. Taken in conjunction with the fact that the few specialized tools (Tables 11.98-11.99) which are found in these excavations ranged through all the A series levels, these results enable one to make the assumption that the material within the A series soil is unicultural. Thus the lithic material from $9 \mathrm{~A} / 6$ and $11 / 1$ can be combined and treated as a single unit,

1

Mr N, Tuckwell (Statistics Department, A.N.U.) supplied the author with the programme for this analysis. See Appendix 11,1. 
4. Significance tests on waste flake material from 9B and 9D shows that this material can also be lumped together.

5. When the waste flake material of the $A$ and $B$ series is tested real differences between the two series are apparent.

6. Because the waste flake material of $9 \mathrm{~A}$ has been described differently, one cannot make a direct comparison between it and the excavated material in terms of 10 parameters. However tests can be carried out using 4 parameters, including length, breadth, width and weight. For this test a random sample of 702 flakes was drawn from the total number of waste flakes for Site 9A. Further, since flakes less than one centimetre in length were not considered in the waste flake analysis of surface material from $9 \mathrm{~A}$, in order to compare surface and excavated waste flakes, only those flakes equal to or greater than one centimetre in length were used in the analysis. Tests between material from $9 \mathrm{~A}$ and $9 \mathrm{~A} / 6$, and $9 \mathrm{~A}$ and $9 \mathrm{~A} / 6-11 / 1$ (combined) show that the waste flake material from the three sources are reasonably compatible.

7. Tests on the retouched flakes from $11 / 1,9 \mathrm{~A} / 6$ and 9A show that they are compatible. A random sample of 137 tools was selected from the retouched implements of $9 \mathrm{~A}$ for this test.

8. Testing between material types of retouched tools from the $9 \mathrm{~A}$ material results in a significance. Summarizing the foregoing, the following points have emerged:-

(a) That lithic material in the A series soil is homogeneous thxoughout time. 
(b) Material from 11/1 and $9 \mathrm{~A} / 6$ can be treated as one unit.

(c) Tools and waste flake material in the two excavations and from $9 \mathrm{~A}$ are related, and that one can justify the use of surface material to define the Yanakie A industry.

(d) Differences in waste flake material between the A and B series suggests that different industries may be involved.

(e) That the material from which the tools are made is an important factor in deciding the physical characteristics of the tool and by inference the tool type.

Some of these points will now be examined in more detail below.

11.6 Gross Features of Retouched Material - Site $9 \mathrm{~A}$

(a) Length, Breadth, Width and Weight and Other Continuous Variables

The means and variances for each continuous variable for each site per material are shown in Tables 11.29 and 11,32, Unfortunately the implement sample from the B series is too limited to define the assemblage so that one can only directly compare each B series tool with the much larger collection from the A series, For the present then, attention will be concentrated on the tools from $9 \mathrm{~A}$.

Comparing the means for the various parameters (Tables $11,30-11,32$ ) there are obvious differences between the materials which were confirmed in the Multivariate analysis. When the length, breadth, thickness and weight data for each material type are restated in terms of frequency ranges, different 
The mean striking angles for all three materials are over $100^{\circ}$. $t$ tests between materials show that the difference between Flint $\left(106.1^{\circ}\right)$ and Quartz $\left(103.5^{\circ}\right)$ is significant, Flint and Quartzite $\left(105.6^{\circ}\right)$ is borderline and Flint and Quartzite is not significant. Thus there is a tendency for the finer grained material (Flint and Quartzite) to have higher striking angles.

(b) Bulb and Striking Platform

As is to be expected, Quartz has the lowest number of observations both for striking platforms and bulbs. Bulbs are very rare on reef (opaque) Quartz flakes and common on clear Quartz. However the majority of flakes are reef Quartz. Flint flakes are the easiest to orientate, and both striking platforms and bulbs are frequently present. For Quartzite the bulb is not as frequently observable as it is on Flint.

These facts are demonstrated in Table 11.35 (c) where the proportion of Flint flakes with both bulb and striking platform exceeds Quartzite by 20 per cent, and the latter exceeds Quartz by 15 per cent. Table $11.35(\mathrm{~b})$ gives a rough measure of the overlap of these two observations relative to the number of flakes with striking platforms. It is important to have some idea of the overlap in order to assess the reliability of the method of orientating the flakes. Thus there is a high degree of overlap for Flint, considerably less for Quartzite and Less again for Quartz. In terms of the efficiency of orientation these figures mean that 91 (or 27.3 per cent) Flint, 158 (or 40.7 per cent) Quartz, 338 (or 50.6 per cent) Quartzite flakes have to be orientated without reference to either striking platform or bulb. of the total assemblage this 
represents 604 (or 40.5 per cent) of all the flakes. At first, this appears to represent a low efficiency of orientation. However other factors must be taken into account before accepting this figure at its face value. Firstly the observation 'striking platform' is given a score of one only if the platform is still largely intact. In cases where it has been trimmed away (but is still identifiable) or where there is any doubt about its identification a zero score has been assigned to the parameter. Thus many points which can be orientated satisfactorily and nearly all the geometrics (which constitute 15.5 per cent of the assemblage) fall into this group. In consequence, the actual number of cases where the orientation is axbitrary or undefined is small, Striking angles cannot always be measured even when a striking platform is present. Of flakes with striking platforms only 53.3 per cent (FIint), 33. O per cent (Quartz), 33.5 per cent (Quartzite) and 44.7 per cent (total) had their striking angles measured.

(c) Shapes (Tables 11,37-11,44)

The most important shapes (greater than 5 per cent of the total assemblage) are 25 (irregular), 6, 4 (trapezoid), 2 (rectangular, fat), 1 (rectangular, long), 17 and 7 (segment). These comprise respectively 20.0 per cent, 7.4 per cent, 6.4 per cent, 5.8 per cent, 5.2 per cent and 5.2 per cent or 40.1 per cent of the total assemblage (refer to Table 11.1 for the key to the shape code).

When the proportions of each shape are compared in terms of materials fair agreement results. Those that 
show differences do not comprise important classes. 1

In fact some of the percentages are so low that they may not be indicating real trends (see table below).

\begin{tabular}{|c|c|c|c|c|}
\hline Odd & Shape & Flint & $\begin{array}{c}\% \\
\text { Quartz }\end{array}$ & $\frac{\%}{\text { Quartzite }}$ \\
\hline $\begin{array}{l}\text { Quartzite } \\
\text { Quartzite } \\
\text { Flint } \\
\text { Flint } \\
\text { Flint } \\
\text { Flint }\end{array}$ & $\begin{array}{r}5 \\
9 \\
10 \\
16 \\
22 \\
24\end{array}$ & $\begin{array}{l}2.1 \\
3,6 \\
1.5 \\
1.2 \\
0.9 \\
1.5\end{array}$ & $\begin{array}{l}1.9 \\
2.2 \\
3.8 \\
2.9 \\
2.6 \\
3.8\end{array}$ & $\begin{array}{l}3.6 \\
1.4 \\
2.9 \\
2.4 \\
4.1 \\
2.1\end{array}$ \\
\hline
\end{tabular}

(d) Cross Sections (Tables 11,41-11,44)

The significant cross sections are 21 (irregular, 21.6 per cent), 9 ( 14 per cent), $13(9.8$ per cent) 18 $(7.5$ per cent $), 10(8.4$ per cent $), 20(6.5$ per cent $), 5$ ( 5.0 per cent, $7(3.8$ per cent $)$ and $3(3.4$ per cent) comprising 58.3 per cent of all the flakes in the assemblage, Again there is little variation in the proportion of cross sections between materials. As was found for shape, those that show some variation form a small part of the total assemblage e.g.

\begin{tabular}{|l||c|c|c|c|}
\hline \multicolumn{1}{|c||}{ Odd } & $\begin{array}{c}\text { Cross } \\
\text { Section }\end{array}$ & $\begin{array}{c}\% \\
\text { Flint }\end{array}$ & $\begin{array}{c}\% \\
\text { Quartz }\end{array}$ & $\begin{array}{c}\% \\
\text { Quartzite }\end{array}$ \\
\hline Quartz & 2 & 0.9 & 1.9 & 0.5 \\
Quartzite & 3 & 5.1 & 4.8 & 2.3 \\
Quartz & 13 & 11.7 & 5.4 & 10.4 \\
Quartzite & 14 & 1.8 & 1.9 & 4.5 \\
Quartz & 19 & 2.4 & 1.0 & 3.1 \\
\hline
\end{tabular}

1

The criterion used to distinguish differences in shape distributions between materials was that one proportion should be approximately twice another. E.g. for shape 5 the distributions were Flint (2.1 per cent), Quartz ( 1.9 per cent), Quartzite ( 3.6 per cent); hence Quartzite can be distinguished from Flint and Quartz. 
(e) Correlation between Cross Section and Shape

A computer programme was written to examine whether there were any important combinations of shapes and cross sections, The conclusion reached was that there were no really significant combinations, of the total assemblage 365 (or 25 per cent) of the flakes had either irregular shape or irregular cross section. Groups of flakes greater than or equal to 10, with combinations of shapes and cross sections (including irregular) made up 40.3 per cent of the assemblage. Of these only 337 (or 22.6 per cent) of the total assemblage had actual combinations of shape and cross section (excluding irregular),

The dominant shapes were:-

(a) Trapezoid with various cross sections including $4(15), 9(21), 10(13), 13$ (17), or 4.5 per cent of the total.

(b) Segment with various cross sections including $7(12), 15$ (10), or 1.5 per cent of the total.

(c) Shape 2 with various cross sections including $9(11), 13(12), 20(11)$, or 2.4 per cent of the total.

(d) Shape 6 with various combinations of cross sections including 9 (22), 10 (13), 13 (6), 20 (13), or 3.6 per cent of the total.

Dominant cross sections were:-

(a) Cross section 9 with various combinations of shapes including 1 (15), 2 (11), 4 (21), $6(22), 15(15), 25(25)$, or 7.4 per cent of the total.

1

The number in the brackets is the number of flakes with this combination of shape and cross section. 
(b) Cross section 10 with various combinations of shapes including 4 (13), 6 (13), 25 (18), or 3. 0 per cent of the total.

(c) Cross section 13 with various combinations of shapes including 2 (12), $4(17), 6$ (6), or 2.3 per cent of the total.

(d) Cross section 18 with various combinations of shapes including 1 (11), 6 (11), 22 (10), or 2.2 per cent of the total.

(f) Scraping Angles (Tables 11.53-57 and 11.104) Consider Table 11.104(a). For the Blade group the numbers of observations are too small to be reliable so that these angles have been ignored, Likewise, the distal end (lower) Flint group have been omitted and even the results for Quartz (lower) and Quartzite (lower) must be treated with caution, while upper lateral (Quartz) is too low and has been dropped.

Tables 11.29-11.32 1ist the means and variances for each scraping angle per material, Using Table 11,104(a) in conjunction with these tables each scraping angle class per material was subjected to a $t$ test to determine whether there was any real distinction between the scraping angles $L$ and $R$ and $U$ and $L$ respectively, Results of the tests indicate that no distinction can be made between them so that each pair of scraping angles was averaged and a new table of average scraping angles compiled (Table 11.104(b)), 1 Each class of scraping angle was then considered separately, $t$ tests were applied to the various average values for each material in order to find out

1

For distal end a significance was obtained but the result can be ignored for reasons outlined above. 
whether the various scraping angles are dependent on material. The results may be summarized as:-

1. Lower Latera1. Flint-Quartzite not significant; Quartz-Flint and Quartz-Quartzite significant.

Although a significance is obtained, statistically, all three scraping angles lie within the $5^{\circ}$ measuring exror so that only the trend should be noted here.

2. Upper Lateral. Flint-Quartzite not significant; Quartz-Flint significant; Quartz-Quartzite significant. However the number of observations for Quartz is too small to argue that a significance is meaningful, and the trend should be noted here also.

3. Blade. Too few observations.

4. Distal, Again there were too few observations. Quartz is higher and there is no significance for Quartzite-Flint.

5. Butt. There is no significance for Flint, Quartz and Quartzite combinations.

Overall then, there is a strong tendency for Quartz to have slightly higher scraping angles than for either Quartzite or Flint, However, concerning the butt, the scraping angle on all three material types are about the same. Flint and Quartzite have similar scraping angles for all classes.

These results are summarized in the table below.

\begin{tabular}{|l||c|c|}
\hline $\begin{array}{c}\text { Scraping } \\
\text { Angle }\end{array}$ & $\begin{array}{l}\text { Flint and } \\
\text { Quartzite }\end{array}$ & Quartz \\
\hline Lower lateral & $86.6^{\circ}$ & $90.4^{\circ}$ \\
Upper lateral & $95.1^{\circ}$ & $99.6^{\circ} ?$ \\
Distal & $83.8^{\circ}$ & $88.3^{\circ} ?$ \\
Butt & $90.8^{\circ}$ & $90.8^{\circ}$ \\
\hline
\end{tabular}


Consider now the variation of scraping angle as a function of its position on the flake.

The variation of from $83.8^{\circ}$ to $95.1^{\circ}\left(11.3^{\circ}\right)$ is well outside the estimated exror of measurement. Thus these variations are significant and it would appear that the scraping angle is dependent on its position on the flake. The variation may be explained by the fact that both the lower lateral and distal ends tend to be acute angle edges while the upper lateral tends to be obtuse. On the other hand the butt angle (between the vertical and upper face) tends to be right angled.

These results would also indicate that Quartz is a harder medium to control.

(g) Working - Butt (Tables 11.45-11.48)

Table 11.48 shows that a high percentage of flakes ( 25.7 per cent) have been utilized on the upper face. 7.5 per cent of the total number of flakes have retouch on the upper face, and 6.4 per cent on the vertical face. A total of 34.1 per cent of the entire assemblage has some sort of working on the butt and 15. O per cent are actually retouched. Thus the butt of the flake is an important working area in this industry. The type of material from which the tools are made affects the proportion with working on the butt (in each material class). For example, the proportion of tools with retouch on the bulbar face is 11.2 per cent for Flint, 7.7 per cent for Quartzite and 1.9 pex cent for Quartz, Differences in proportions are also apparent for the vertical face $i, e .4 .5$ per cent for Quartz, 3.3 per cent for Flint and 8.5 per cent for Quartzite.

Only Quartzite and Flint are considered here. It is unsafe to argue from the figures for Quartz. 
(h) Working - Other (Tables 11.48 and 11.49)

In contrast with the butt, Table 11.49 shows that 22.5 pex cent of all the tools have retouch along the lower lateral left hand margin, and 35,2 per cent have trimming either on the left or the right hand lower lateral margins. Thus side scraping tools also form an important part of this assemblage. ${ }^{1}$ other important classes of working are distal end, lower and upper lateral, and near-lower lateral.

In general, retouch is confined to the butt upper face and the lower lateral left hand margin (complete or in part). Few flakes have retouch on the blade or on the upper lateral margins. Distribution in Materials (Tables 11.45-11.52)

1. Lower lateral complete. Quartzite (LHS) has the highest proportion (26.4 per cent) followed by Quartz ( 21.1 per cent) and Flint ( 14.1 per cent). Thus there would seem to be a stronger tendency to retouch flakes on the LHS than on the RHS. This tendency is most marked for Quartzite (26.4 per cent, LHS, compared with 14.5 per cent, RHS). However the different proportions can be largely explained in terms of flake orientation efficiency. For example, all geometric microliths (with no striking platforms and/or bulb) have been

1

In this and in subsequent chapters, terms such as ' end', 'side' and 'scraper' are frequently used and in the McCarthy classification the terms are meant to be used in a functional sense. However in this analysis the terms are descriptive only (terms which are familiar to the archaeologist) and are not meant to assign some function to the tool. It has been shown that deducing the function(s) of apparently simple tools, such as the 'end scraper' can be quite complex. (S.A. Semenov 1964, p. 85 ; S.I. Dakaris et. a1. 1964, p.231). 
arbitrarily orientated with their backed margins to the left. Geometric microliths contribute 9.0 per cent of all Flint, 17.3 per cent of all Quartz and 17.4 per cent of all Quartzite tools. In other words the arbitrary orientation of the geometric could compensate for an apparent tendency to retouch flakes more on the left hand than on the right hand margins.

2. Lower lateral, upper lateral and lower end are the most important retouched groups. Once again there are different proportions of retouch depending on the flake material i.e, end (lower) Quartzite (12.7 per cent), Quartz ( 9.9 per cent) and Flint (6.9 per cent).

(i) Working $\frac{\text { Utilization Distribution }}{\text { (Tables 11.45-11.48) }}$

Utilization is mainly distributed on the complete lateral margins, with more on the left than on the right. However, the distal end is frequently utilized ( 4.1 per cent compared with 3.2 per cent for left lateral margins). Most utilization percentages are well down on the retouch percentages.

\section{Distribution in Materials}

Several factors are apparent from Tables 11.45$11.47:-$

1. For the right lateral, Flint is low (0.6 per cent) compared with Quartz ( 4.2 per cent) and Quartzite (2.1 per cent). Also Quartz is high compared with both Quartzite and Flint.

2. For the distal end, Quartz ( 7.4 per cent) is much higher than for either Quartzite ( 3.3 per cent) or Flint ( 3.0 per cent). 
3. For the right lateral distal end, Flint $(0,6$ per cent) is low compared with Quartz (1.9 per cent) and Quartzite (1.3 per cent).

4. Comparison of the other utilization classes per material reveals that the proportions per class are approximately the same.

These results suggest that the amount of utilization per flake is dependent on the flake material and that, in general, Quartz flakes tend to have slightly more utilization than either Flint or Quartzite.

Of all the flakes, 25.7 per cent have utilization on the upper face of the butt, and 6.9 per cent have it on the vertical face. With the exception of the upper face, the other proportions of utilization on the butt - per material - are consistent, For the upper face, the proportions differ for Flint (37.9 per cent the highest), followed by Quartzite (24.9 per cent) and Quartz (16.6 per cent).

(j) Retouch and Utilization Indexes $($ Appendix 11.2)

These indices were devised in order to have a measure per assemblage of:-

(a) the amount of retouch (retouch index = RI);

(b) the amount of utilization (utilization index = UI) :

(c) the amount of utilization and retouch (the utilization-retouch index = UR).

These indexes with their variances have been calculated for each site as a whole and for each material class.

$t$ tests were used to investigate the differences between indexes per material, These showed:1. That the UI for Flint is significantly lower than those of Quartz and Quartzite. 
2. That the UI for Quartz and Quartzite are not significantly different,

3. That the URs for each material class are significant $1 \mathrm{y}$ different from each other in all combinations. Unexpectedly, Flint has the lowest index ( 7.9 per cent) followed by Quartz ( 8.77 per cent) and Quartzite (10,15 per cent).

4. That the RI for Flint is significantly lower than those for Quartz and Quartzite.

5. That the RI for Quartz and Quartzite are not significantly different.

These results demonstrate that the working on the flake is dependent upon the type of material and that tools made in Flint appear to have less working than either Quartz or Quartzite tools. 1

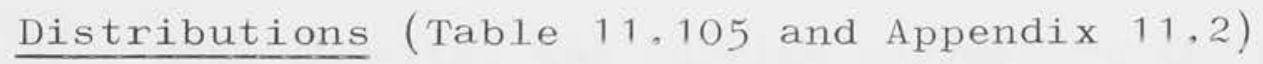

The flake indexes fall into one of several discrete ranges. $^{2}$ A comparative study shows that:-

1. Quartzite has the greatest variety of working.

2. Flint has the greater proportion of flakes in the first group, indicating that it was simply worked.

3. In the Quartz and Quartzite group retouch is important at the 6 per cent, 18 per cent and 35 per cent levels, The first group comprises mainly flakes with retouch on the butt or on one third of the lateral margin; or on the end of the flake. The 18 per cent group is made up mainly of flakes retouched completely along one lateral margin and the 35 per cent group of flakes have been

1

This may be because Flint tends to have a naturally sharp edge.

2

These several specific ranges are hereafter called groups. 
retouched along two lateral or a single lateral margin plus some other part of the tool.

\begin{tabular}{|c|c|c|c|c|}
\hline \multirow{2}{*}{ Index } & \multirow{2}{*}{ Group } & \multicolumn{2}{|c|}{$\%$ No, of Tools in Group } \\
\cline { 3 - 5 } & & F & Q & QT \\
\hline UR & $0-4$ & 93.09 & 91.96 & 85.70 \\
RI & $0-3$ & 81.30 & 76.77 & 71.12 \\
UI & $0-1$ & 90.50 & 81.33 & 82.24 \\
\hline
\end{tabular}

The table above indicates that most of the flakes have UI in the first group, RI in the first three groups and UR within the first four groups.

Summary

From the foregoing analysis the following points have emerged and these may be taken as characteristic of the Yanakie A assemblage at Site 9A.

1. Both physical and working parameters are dependent on material.

2. Flint tools tend to be longer and broader than either Quartz or Quartzite tools.

3. The average striking angles for all three materials is over 100 degrees, with Flint and Quartzite higher than Quartz.

4. Few Quartz tools have bulbs of percussion, while many Flint tools have both bulbs and striking platforms.

5. Trapezoid, rectangular, segment and irregular are amongst the important tool shapes.

6. The more important cross sections include irregular, triangular (isosceles, right angled and scalene) and trapezoid.

7. Several combinations of trapezoid or segment shapes and various cross sections are also important. 
8. Several combinations of scalene or triangular cross sections and various shapes are important.

9. Scraping Angles: scraping angles are of the order $90^{\circ}$ but the actual angle is dependent on the position of the retouch on the tool. There is no distinction between Quartzite and Flint scraping angles but there may be small differences between these and Quartz scraping angles.

10. Most of the retouch and utilization is concentrated on the butt and the lower lateral margins of the tools. More Flint tools have utilization on the butt than either Quartzite or Quartz, but Flint has the least number with retouch on the butt. Likewise, more Quartzite tools have working on the lower lateral margins than either Quartz or Flint, while Flint has the smallest number of examples.

11. The various indexes for each material class confirms that Flint tools are the simplest, and that Quartzite tools tend to be the most complex.

11.7 Gross Features of Waste Flake Material - Site 9A

Two analyses are available for this material. The first treats the waste flakes of $9 A / 6$ and $11 / 1$ in a manner similar to that described above, and the second treats the waste flake material from $9 \mathrm{~A}$ by a slightly different method. Consider firstly the waste flake material from $9 \mathrm{~A} / 6$ and $11 / 1$.

(a) Continuous Variables (Table 11.78)

The striking angles were $t$ tested for differences between materials. It was found that:-

1. There was no significant difference between Flint and Quartzite striking angles, 
2. A significance was obtained between Quartz and Quartzite.

3. A significance was obtained between Quartz and Flint,

These results agree with the trend indicated in the retouch analysis. However, the mean striking angles are al1 less than their retouched counterparts, i,e,

\begin{tabular}{|l|c|c|c|}
\hline & \multicolumn{3}{c|}{ Striking Angles } \\
\cline { 2 - 4 } & Flint & Quartz & Quartzite \\
\hline \hline $\begin{array}{l}\text { Waste } \\
\text { Retouch }\end{array}$ & 101.4 & $\begin{array}{r}98.6 \\
103.5\end{array}$ & 102.9 \\
106.1 & 105.6 \\
\hline
\end{tabular}

Although the waste flake striking angles all lie within the five degree error margin, there is a tendency for lower Quartz striking angles.

Similar comparisons of the mean lengths and breadths of retouch and waste flakes shows that the mean values of the retouch flakes are consistently higher, i.e.

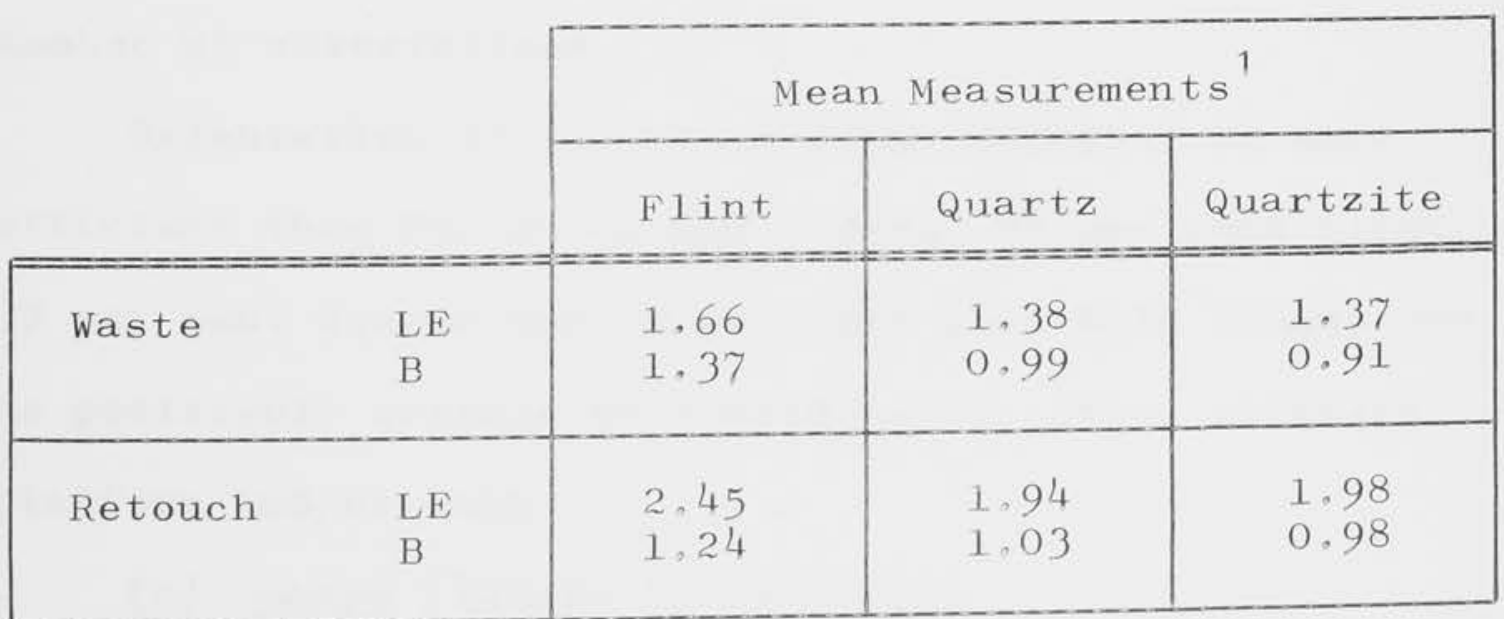

Also, the dimensions of Quartz and Quartzite flakes (retouched and waste) are similar, but different from those of Flint flakes which are considerably larger. Smaller waste flake mean values are to be expected, but the reason for the lower striking angles is not clear.

${ }^{1} \mathrm{LE}=$ Length, $\mathrm{B}=$ Breadth. 
(b) $\frac{\text { Striking Platforms and Bulbs }}{\text { (Tables 11.79-11.81) }}$

The number of flakes of all material classes with a striking platform is much higher than for retouched flakes and the proportion of flakes in each material class with striking platforms is about equal

(approximately 80 per cent). These figures demonstrate that many of the retouched flakes must have been reworked on the butt, The biggest discrepancy is between 78 per cent for Quartz (waste) and 49.6 per cent (retouch), For Quartzite, proportions are 80 per cent waste and 58 per cent retouch,

Fewer bulbs are observed on the waste flakes than on the retouched material. The proportion has dropped dramatically from 51.0 per cent (retouch) to 28 per cent (waste) for Flint, for Quartz, 14.7 per cent (retouched) to 7.0 per cent (waste) and for Quartzite, 31.6 per cent (retouch) to 25,0 per cent (waste). Although the proportion with bulbs is less for the waste flake material, Flint still has the highest, Quartzite the second highest and Quartz the lowest number of observations.

Orientation of the waste flake material is more efficient than for retouched flakes; 84 per cent Flint, 77 per cent Quartz and 80 per cent Quartzite flakes can be positively orientated according to either striking platform and/or bulb.

(c) Shape (Tables 11.66-11.69)

The important shapes in each material class are set out in the table below: 


\begin{tabular}{|c|c|c|c|}
\hline \multicolumn{2}{|c|}{ Proportion of Flakes with Various Shapes } \\
\hline Shapes & Flint & Quartz & Quartzite \\
\hline \hline 1 & 10.8 & 11.3 & 12.9 \\
2 & 5.9 & 5.1 & 3.2 \\
3 & 5.3 & 0.9 & 1.1 \\
4 & 4.2 & 5.4 & 6.5 \\
5 & 7.2 & 5.4 & 4.3 \\
6 & 10.4 & 7.0 & 7.5 \\
7 & 3.6 & 6.5 \\
\hline
\end{tabular}

Marked differences in distribution occur for shapes 3,4 and 7 .

These seven shapes make up 43.8 per cent of the total number of Flint flakes, and these together with a further 27.7 per cent of irregular Flint flakes comprise the majority of the Flint waste flakes. For Quartz, the proportions are 38.7 per cent (seven shapes) and 30.9 per cent irregular, and for Quartzite 42.0 per cent (seven shapes) and 25.8 per cent irregular.

The table below compares the proportions of irregular flakes per material-waste versus retouched flakes:

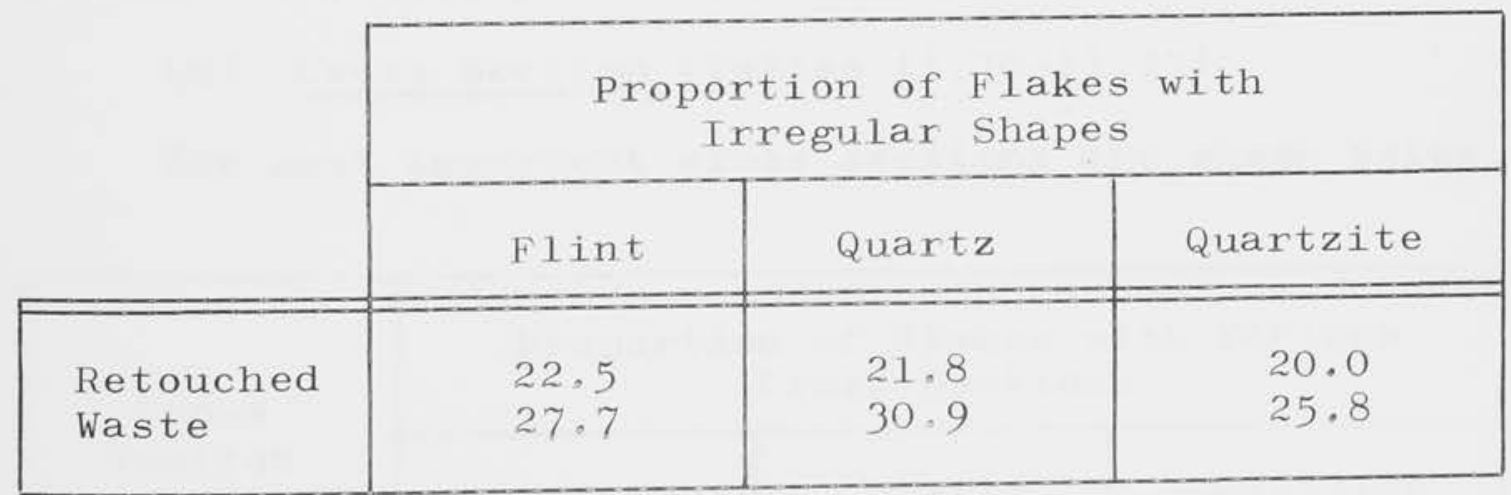

These results are not unexpected, The proportions of irregular shapes amongst the retouched flakes per material is approximately the same, while they are higher and less uniform for the waste flakes, One would expect the retouch ${ }_{\lambda}^{2 d}$ tools to have more specific shapes than the waste flakes and that the proportion of 
irregular shapes would be lower for the retouched

flakes. Since Quartz is a difficult medium from which to manufacture specific shapes, a slightly higher proportion of irregular waste flakes results.

Table 11.106(b) compares the proportions per material of the most important shapes for waste and retouched flakes. In general, the same shapes are important for both waste and retouched flakes and many of the proportions pex shape per material are approximately the same, Exceptions include shape 1 (all materials), 4 (Flint), and 7 (Flint and Quartzite). 1 For shapes 1 and 7 the proportion of waste flakes is much higher than for retouched flakes so that one can assume that these shapes tend to occur more frequently by chance when the flakes are being struck from a core. One could interpret the large discrepancy between the proportion of waste (o per cent) and retouched flakes ( 5.4 per cent) for Flint with shape 4 as resulting from a deliberate attempt to produce and utilize this shape, Shapes 17 and 21 can be similarly interpreted.

(d) Cross Section (Tables 11,70-11.73)

The most important cross sections are shown below:

\begin{tabular}{|c|c|c|c|}
\hline \multirow{2}{*}{$\begin{array}{c}\text { Cross } \\
\text { Section }\end{array}$} & \multicolumn{3}{|c|}{$\begin{array}{c}\text { Proportion of Flakes with Various } \\
\text { Cross Sections }\end{array}$} \\
\cline { 2 - 4 } & Flint & Quartz & Quartzite \\
\hline \hline 5 & 3.4 & 4.9 & 4.3 \\
9 & 15.6 & 15.4 & 17.2 \\
10 & 15.8 & 14.2 & 20.5 \\
14 & 3.0 & 3.4 & 8.6 \\
18 & 5.1 & 2.4 & 1.1 \\
20 & 5.9 & 7.6 & 7.6 \\
\hline
\end{tabular}

Where proportions are both below 5 per cent, distinctions have not been considered. 
Differences in distributions are apparent for cross sections 10,13 and 14.

The table below compares the proportion of irregular waste flakes per material to the proportion of irregular retouched flakes per material:

\begin{tabular}{|l|c|c|c|}
\cline { 2 - 4 } & \multicolumn{3}{|c|}{$\begin{array}{c}\text { Proportion of Flakes with Irregular } \\
\text { Cross Sections }\end{array}$} \\
\hline & Flint & Quartz & Quartzite \\
\hline $\begin{array}{l}\text { Retouched } \\
\text { Waste }\end{array}$ & 25.4 & 23.3 & 18.9 \\
& 30.9 & 21.9 & 17.2 \\
\hline
\end{tabular}

These proportions per material for Quartz and Quartzite can be regarded as identical and the results indicate that little attention was paid to the shape of the cross section when manufacturing the tool. 1 From the high proportions of irregular shapes and cross sections for Flint tools and from the fact that they have the simplest retouch and utilization treatment, one concludes that Flint (round at the Promontory) was not as well suited to the manufacture of the more complex implements as was Quartz and Quartzite. However, the drop of 5 per cent in the proportion of retouched Flint flakes with irregular cross sections compared to waste flakes could indicate a tendency to make particular cross sections.

In Table 11.106(a) the proportions per material of the most important cross sections for waste and retouched flakes are compared. In general, the same cross sections are important for both waste and retouched flakes and the proportions of flakes in each

1 That is, for the way in which it has been defined in this analysis. 
material are approximately the same, There are one or two notable exceptions, The proportion of cross section 10 in the waste flakes tends to be much higher for Flint and Quartzite, and the proportion of 13 is much higher for Flint retouched flakes. This may indicate that cross section 10 occurs more frequently by chance as flakes are struck from cores. On the other hand, the higher proportion of cross section 13 for Flint (retouched) may mean that it was deliberately manufactured.

\section{(e) Combinations of Shape and Cross Section}

In the total assemblage, 13.8 per cent have both irregular shape and cross section; 39.4 per cent have either irregular shape or irregular cross section. There are only four groups of flakes which have identical shapes and cross sections and which have more than eight flakes in each group. 'These groups comprise 5.8 per cent of the total.

For Flint flakes, 16.3 per cent have both irregular shapes and cross sections and for Quartzite the number is approximately 10 per cent. All other groupings are insignificant.

Turning now to the analysis of waste flake material from site $9 \mathrm{~A}$, the results of the analysis are summarized in Tables $11.78,11.83-11.84$ and 11.107 . (Refer back to $\frac{p .38}{3}$ for the key to these tables).

No attempt will be made here to discuss these results in detail as they are largely self-explanatory. Table 11.78 shows that Flint flakes tend to be longer and broader than Quartz or Quartzite flakes; Table $(2,9)$ number $=8 ;(2,10)$ number $=12$. 
11.83 shows that the overall percentage of flakes with bulbs is approximately the same as waste flakes from 11/1-9A/6 (compare with Table 11.79(b)); Table 11.107 shows the relationship between shape and material. It is difficult to make a direct comparison with the other scheme, because its 25 shapes have been compressed to only 8 in this scheme. The more restricted choice of shapes accounts for the greater proportion of irregular flakes. Four out of the seven (actual) shapes have approximately the same proportion of flakes per material class. ${ }^{1}$ The proportion of flakes per material for the other three shapes varies significantly.

\section{Summary}

The following points have emerged as important in assisting to define the Yanakie A assemblage:-

1. The mean striking angle per material for waste flakes are all less than their retouched count erparts.

2. The mean striking angle for Quartz tends to be lower than the mean values for Quartzite or Quartz. A11 mean striking angles are greater than $98^{\circ}$.

3. Flint flakes tend to be longer and broader than Quartzite and Quartz flakes.

4. The mean flake lengths and breadths of the waste flakes are much lower than for retouched flakes.

5. A much larger proportion of waste flakes have bulbs and striking platforms compared with the retouched flakes. The lower proportion of striking platforms for retouched flakes indicates a tendency for the butt to be reworked. 
6. The orientation efficiency for waste flakes of all materials is of the order 80 per cent.

7. With few exceptions the shape and cross section distribution for the waste flakes is approximately the same as for retouched flakes. The range of important shapes and cross sections (retouched) is slightly greater than for waste flakes. If a higher proportion of waste flakes have a particular shape (or cross section) compared with the retouched proportion, then one may conclude that this shape tends to occur more frequently during flaking from a core. Higher proportions per shape (or cross section) for the retouched flakes may be interpreted as indicating that this shape (or cross section) was deliberately manufactured.

8. The proportion of waste flakes with irregular shapes exceeds the retouched flakes by about 5 per cent, The evidence suggests that little attention was paid to obtaining particular cross sections, except perhaps for some Flint tools.

\subsection{Gross Features of Worked Core Material - Site 9A}

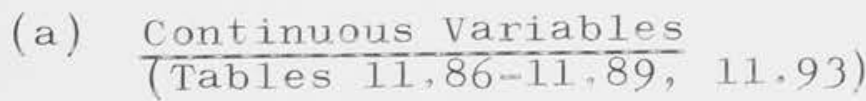

Quartz cores tend to be a little larger than either Flint and Quartzite cores. The latter usually have similar dimensions. Scraping angles accord well with those recorded for the flake materials. The average angle tends to be about $90^{\circ}$.

(b) Shapes and Cross Sections (Table 11.90)

This table shows that regular shapes or cross sections rarely occur, and when they do they are probably fortuitous. 
(c) Working (Table 11.92)

It is apparent from this table that:-

1. Utilization is more common than retouch,

2. Most of the retouch and/or utilization occurs around the level edge of the working platform (base).

3. Quartz cores tend to have more utilization than either Quartzite or Flint,

4. Most cores have only one platform. However a high proportion of Quartz and Quartzite cores have two platforms, and a significant number of Quartz cores have two platforms.

\section{Summary}

The type of core tool produced is dependent upon the material. 


\section{Yawake A wad Yawakic B Assembiego
ARTIFACTS FROM THE A AND B SERIES}

In the last chapter the gross features of the A series assemblage were considered and important traits were defined. In this chapter an attempt will be made to isolate and define the most discriminating tool types for the assemblage of Site 9A. Having isolated these 'types', the excavated assemblages will then be considered. Finally the Yanakie A and B assemblages will be compared and other artifactural material discussed.

$$
\text { (F.D.McCorthy tal } 1946 \text { ) }
$$

12. $1 \frac{\text { McCarthy Classification/- Yanakie A Flake Material }}{\text { (Tables 11.7-11.10, 11.108-11.109) }}$

(a) Normal Flake Tools - Total

Considering Table 11.7 (total) it can be seen that not all tool classes are important. In fact 13 classes comprise 73.4 per cent of the total assemblage (Table 11.108) and a further 21 tool classes account for only 7.6 per cent of the total.

Table 11.109 considers the distinction between large and small flake tools. In most cases size does not appear to be a major factor in determining tool type. Appreciable differences are noted for tool classes, two sides and end, two sides and two sides and butt, and for these three tool types size may be important.

of the tool classes shown in Table 11.109 only five are important. These are shown in the table below. 
(b) Backed blades - Geometric Microlith Total As sem ba ge.

The se comprise 15.5 per cent of the assemblage and are made up as follows:

\begin{tabular}{c|l|c}
\hline No. & Tool Description & Percentage \\
\hline 1 & Trapezoid & 5.2 \\
2 & Segment & 3.4 \\
4 & Thumbnail & 2.4 \\
5 & Scalene & 2.2 \\
\hline
\end{tabular}




\begin{tabular}{|c|c|c|}
\hline No. & Tool Description & Percentage \\
\hline \hline 1 & Side (sma11 and large) & 15.8 \\
2 & 2 sides and end (nearly all & 9.2 \\
3 & greater than 2 cm.) & 5.5 \\
4 & End (small and large) & 21.0 \\
5 & Butt-facial (smalland large) & 7.2 \\
\hline
\end{tabular}

These five classes comprise 53.2 per cent of the total assemblage.

(c) Backed Blades - Pointed - Total Assembiage

These comprise 15.0 per cent of the total and are made up as follows:

\begin{tabular}{|c|c|c|}
\hline No. & Tool Description & Percentage \\
\hline 1 & $\begin{array}{l}\text { Single edge only - lower edge - } \\
\text { distal - plain butt }\end{array}$ & 3.0 \\
\hline 2 & $\begin{array}{l}\text { Single edge only - lower edge - } \\
\text { distal - trimmed butt }\end{array}$ & 3.0 \\
\hline 3 & $\begin{array}{l}\text { Single edge only - lower edge - } \\
\text { complete - plain butt }\end{array}$ & 3.1 \\
\hline 4 & $\begin{array}{l}\text { Single edge only - lower edge - } \\
\text { complete - trimmed butt }\end{array}$ & \\
\hline 5 & $\begin{array}{l}\text { Single edge only - lower edge - } \\
\text { complete upper edge - distal } \\
\text { and plain butt }\end{array}$ & 1.0 \\
\hline 6 & $\begin{array}{l}\text { Single edge only - lower edge - } \\
\text { complete upper edge - distal - } \\
\text { and trimmed butt }\end{array}$ & \\
\hline 7 & Other & 1.9 \\
\hline
\end{tabular}

(d) Backed Blades - Total Assembiage

Backed blades comprise 30.5 per cent of the assemblage and there are 10 types of importance. $\underline{\text { Summary }}$

In the entire assemblage there are 15 important tool types, 6 of secondary importance and 21 of little diagnostic value.

Consider now the breakdown of the types in terms of materials. 


\section{(a) Normal Flake Tools - Material}

Table 11.110 has been derived from Tables 11.711.10 and lists the proportion of flakes in each tool class per material. By examining this table one can arrive at several important conclusions, relating to the dependence of tool types on size and material.

1. There is a greater tendency for tools more than $2 \mathrm{~cm}$. in length to be made from Flint than in either Quartzite or Quartz. The proportions are Flint ( 57.3 per cent), Quartz (29.5 per cent) and Quartzite (32.1 per cent).

2. Higher proportions of tool types 3, 7, 9 and 14 are made in Quartzite $(1.8,0.9,3.6)$.

3. Higher proportions of tool types 1, 6 and 8 are made in Flint, followed by Quartz (16.8, 13.2, 9.1).

4. Higher proportions of tool types 11,12 and 13 are made in Flint, followed by Quartzite (33.2, 8.0, $12.5)$.

5. The proportion of Quartz flakes with utilization $(15,31)$ is higher than for either Quartzite or Flint. This is to be expected since it is often difficult to tell when Quartz flakes are retouched and/or utilized.

6. For the tool group with lengths below $2.0 \mathrm{~cm}$. the proportion of Quartz tools is greater (38.8 per cent) while the proportion of Flint tools has dropped to 20.1 per cent. The Quartzite proportion has remained the same ( 32.9 per cent). These proportions support the assertion that longer tools are made from Flint, and conversely,

The numbers in the brackets are the combined proportions per material (Flint, Quartz, Quartzite) for the four tool types mentioned. 
that Flint is generally unsuitable for making small tools. On the other hand Quartz and particularly Quartzite are suitable for manufacture of both small and large tools.

7. For the smaller tools the Quartzite proportion predominates or is equal to the Quartz proportion, i.e. 16,17 and $31(5.6,17.9,9.7)$, and 18,19 , $20,21,32,33(8.9,9.3,8.0)$.

8. For tool type 25 the drop in proportion for Flint from 24.3 per cent (greater than $2 \mathrm{~cm}$ ) to 9.3 per cent (less than $2 \mathrm{~cm}$ ) is highly significant.

9. Nosed tools tend to be made exclusively in Quartzite.

(b) Backed Blades - Geometric Microliths Material

The proportions Flint (9.0 per cent), Quartz (17.3 per cent) and Quartzite ( 17.4 per cent) verify the tendency to make the smaller tools in Quartz and Quartzite. The breakdown per tool class is:

1. Isosceles - Flint (0.3 per cent), Quartz ( 1.6 per cent), Quartzite (1.0 per cent).

2. Thumbnail - Quartz (3.5 per cent), Quartzite (1.0 per cent).

3. Scalene - Flint ( 1.2 per cent), Quartz ( 1.9 per cent), Quartzite ( 2.7 per cent).

(c) Backed Blades - Pointed Types - Material

The proportions Flint ( 13.5 per cent), Quartz ( 14.8 per cent), and Quartzite (16.9 per cent) indicate an approximately equal tendency to make pointed implements in any of the three materials.

12.2 McCarthy's Classification - Flake Material Physical Properties of Tools

Each standard class was studied in detail and the variation of each morphological characteristic (see 
Table 11.1) was studied within each class. ${ }^{1}$ Since it has been shown that material is important in deciding the tool type each class was separated into stone type and considered separately. Table 12.1 sets out the mean values of some of the continuous variables for some of the main tool types. Where numbers of tools were too small to give reliable results, these tool classes were omitted. In order to contrast the large and small tools of a particular class the class pairs are depicted together in Table 12.1. Four points are obvious from this table, namely:

1. In all cases the small tools have mean lengths less than $2 \mathrm{~cm}$. (as expected).

2. The Flint tools are larger than either the Quartz or Quartzite tools in each class.

3. All the geometric microliths are 'small' (1ess than $2 \mathrm{~cm}$. long).

4. The point classes tend to be longer than the geometrics, and are often over $2 \mathrm{~cm}$, in length, The range and distribution of parameters for each class has been discussed in detail in Appendix 12.1. Here further evidence is presented for the dependence of tool type on material. It has also been confirmed that few geometric microliths can be correctly orientated, and that many point forms have had their butt (including striking platform) worked away. ${ }^{2}$ Finally one of the most important facts to emerge from this study is that very few geometrics have any utilization. (They have retouch only). A higher

\footnotetext{
1

By using the counting programs on each class. 2

Class 40 (geometric) can often be orientated because the butt end is a part of the tool.
} 
percentage of point forms have utilization but again the numbers are small compared with the amount of utilization found on flakes in the normal flake classes. The latter frequently have both retouch and utilization and sometimes only utilization. These differences in the distribution of utilization over the tool classes can be interpreted as being due to the different tool functions. No utilization suggests that the geometrics, and to a lesser degree the point forms, were not used to manufacture other tools or to carry out other tasks. In northern New South Wales and in South Australia, backed blades have been found with gum adhering to their backed edges. (D.J. Mulvaney 1960b, p.79; I. McBryde 1967). This suggests that they had been hafted into some sort of weapon (i.e. a barb of a spear, perhaps). If this was their purpose, one would not expect to find utilization on these flakes. Thus the lack of utilization on the backed blades from Wilson's Promontory, especially when contrasted with the working distribution on the other flake tool classes, would support this view.

\subsection{A Computer Classification of the Yanakie A Lithic Material}

Worked flakes, waste flakes and cores have been classified on a non-functional basis with the aid of an IBM computer. The detailed description of the technique used is described in Appendix 12,2. Results are shown in Tables 12.6, 12.8, 12.9, and Diagram 12.5.

Examination of Table 12.6 reveals some striking facts:

1. The range of Quartzite tools exceeds both Quartz and Flint. 
2. That with the exception of one class, all Quartz tool types are also made in Quartzite.

3. That of 10 Flint tool classes only five are made in Quartzite, and only three of these are made in Quartz, Five new Flint classes have been introduced.

4. Class 2 appears to be common to all three material classes,

A comparison of the McCarthy classification with the computer classification shows that although certain we11 known 'types' have been identified by the computer, many more have not been recognized, Table 12.11 ists those tools directly comparable, Flakes with their upper butt face retouched or utilized, trapezoids, geometrics and one or two types of Bondi point forms have been recognized. Overall, these results are to be expected, for some of the backed blade forms are typologically (non-functionally speaking) quite distinctive and can be expected to appear as 'types'. An advantage of using this new system is that greater constraint has been introduced into the grouping of similar flake material (i,e. the greater number of paramaters makes grouping more difficult). Thus only the most distinctive groupings have been isolated. In general this method of classification retains only those tools likely to be of diagnostic value, and while it does reproduce some of the standard types it refines and subdivides them.

A variety of A series tools are shown in Diagrams 12.6-12.14. (See Table 12.20 for the key to each drawing). 


\subsection{Excavated Material}

Using the same technique as described in Appendix 12.2, the excavated material from $9 \mathrm{~A} / 6$ and $11 / 1$ has been classified and depicted in Table 12.7. ${ }^{1}$ The diagnostic tools are arrayed per cultural level below (p.218). In 9A/6 there were no diagnostic implements in the lower levels. Class 2 appears in all the levels shown below while the more complex tools were rare. In terms of dates, Level 5 of Excavation 9A/6 (containing both geometrics and a Bondi point - see Table 11.98) has been carbon dated to $3480 \pm 90 \mathrm{BP}(\mathrm{GAK}-970)$, Leve1 3 (containing geometrics - see Table 11.99) of Excavation $11 / 1$ has been dated to $3920 \pm 90 \mathrm{BP}(\mathrm{GAK}-968)$. Unfortunately, the number of tools from these excavations is too small to permit definite conclusions about changes through time. An examination of the waste flake material (see Chapter 11) revealed no obvious differences from top to bottom of the assemblage. The limited information in the table above may lend slight support to a no change hypothesis. At this stage then, one can say that on the basis of this evidence, the archaeological material may be homogeneous but that this could only be confirmed by recovering and examining a much larger number of implements in more extensive excavations. ${ }^{2}$

Several cores were recovered in the A series excavations. Computer analysis failed to reveal any

See Tables 11.98-11.99 for the full listing of implements from these two excavations. 2

Undiagnostic implements do occur in most levels of both excavations. For example geometrics (McCarthy's classification) occur in level 4 of $9 \mathrm{~A} / 6$ (see Table 11.98) and level 2 of $11 / 1$ (Table 11.99). Further, a possible Quartz fabricator has been identified by McCarthy in $11 / 1$ (A/1/13/2). 


\begin{tabular}{|c|c|c|c|c|c|c|c|c|c|c|c|}
\hline Level & & & Dis & ibutic & f Diag & tic $\mathrm{T}$ & s per & & & & Excav. \\
\hline $\begin{array}{l}7 \\
6 \\
5\end{array}$ & $\begin{array}{l}3 \times 2(a) \\
2 \times 2(d)\end{array}$ & $2(b)$ & $\begin{array}{l}2(c) \\
2 \times 2(c) \\
2(c)\end{array}$ & $3(\mathrm{a})$ & $3(b)$ & $7(\mathrm{a})$ & $10(b)$ & 12 & 18 & $\begin{array}{l}20 \\
20\end{array}$ & $9 A / 6$ \\
\hline $\begin{array}{l}4 \\
3 \\
2\end{array}$ & $\begin{array}{l}2(a) \\
3 \times 2(a) \\
2(a)\end{array}$ & $2(b)$ & $2(\mathrm{c})$ & 10 & $15(\mathrm{~b})$ & & & & & & $11 / 1$ \\
\hline
\end{tabular}


diagnostic core tools. The distribution of the cores through the various levels is shown in Table 12.16 .

Diagrams 12.15-12.16 show some of the tools from these excavations (see also Table 12.20).

\subsection{Other A Series Excavations}

A few flakes were recovered from the other excavations on Site 9A. None of these were diagnostic however. Tables 12.17-12,19 1ist the evidence for each excavation. 1

\subsection{The Yanakie A and Yanakie B Assemblages}

Little has been said about the B assemblages. However too few implements were recovered to enable it to be adequately defined. Those which have been examined are included in the tables of Chapter 11. Although the sample is small several tendencies can be noted:

1. Tables $11.29-11.32$ indicate that the average $B$ Yanpakie $B$ series worked flakes tend to be bigger than those of the A series.

2. Table 11.78 indicates that the average B series waste flake tends to be bigger than those of the A series.

3. Tables 11.7-11.10 indicate that the variety of $B$ YAwakie B serios implements may be less than for the A series.

4. Tables $11.34,11.80$ and 11.82 indicate that there may have been a change in emphasis in material used for tool making, Quartzite appears to have been replaced by Flint. Indeed, this observation has

The $M$ in these tables stands for microlithic or flakes less than or equal to $2 \mathrm{~cm}$. in length. 
been confirmed by a careful examination of a large volume of material from a number of $B$ series gites 6. Yanakie B assembleges

both along the Yanakie and Oberon Bay coastlines.

The reader is referred to Appendix 2.1 (Yanakie

West sites), Appendix 2.3 (Wilson's Promontory

West sites) and Tables 12,12-12.13. These tables

clearly demonstrate Flint and Quartz are the

dominant materials found on BA series midden sites.

5. Table 12.14 compares various statistics for

several sites. ${ }^{1}$ Thus, there may be a tendency for B ${ }_{\text {Anaker }}$ series 1ithic material to have a greater

total-core/total-flake ratio and a higher core-tool/

flake-tool ratio.

6. Table 12.7 1ists the computer classification of the assemblage from Site 9B. Nearly all these implements are in Flint, and Class 2 is again important.

7. Table 12.15 compares the shell and stone densities of $A$ and $B$ series sites. Although the excavations were limited so that the information from these must be used with caution, it is apparent that both shell and stone Yarakie B sites are much lower than on A series sites.

A few $\mathrm{B}$ series tools are included in Diagrams $12.6-12.14$.

\subsection{Other Artifactural Material}

(a) Edge Ground Axes

These were associated exclusively with B series middens. Three of these aves were faud in nowthern $B$ sercs middens awd-phese were in Appendices 12.3 and 12.4 (P1ate 12.1).

1

The numbers for Site 9D are the actual stone numbers considered - not the values corrected for sampling error. 


\section{(b) Large Core Tools}

Large Flint nodules with a few crude flakes removed and with a little utilization are frequently found in Yavakic $B$

the B series middens, Unifacially flaked pebble tools

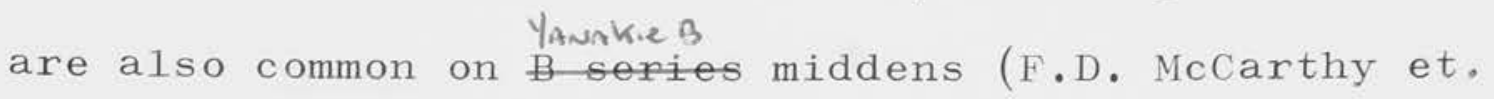
a1. 1946 ).

(c) The Barke B $B$ series Aborigines used shell artifacts. Two specimens of Plebidonax from Excavations $9 \mathrm{~A} / 2$ and $9 \mathrm{~A} / 4$ showed clear signs of use polish, while other specimens exhibited fractures possibly caused by utilization. 1

\section{(d) Sandstones and Nodules}

Many hammerstones were found both on the A and $B$ series sites. Typical hammerstones were sandstone pebbles with flattened ends. Pieces of limestone and sandstone nodules were also common, particularly on A series sites. These also featured in the excavated material. It is certain that they were brought from eroding A series outcrops nearby, but their purpose remains obscure. Many pieces are burnt which perhaps suggests that they were used as part of the camp fire, ${ }^{2}$ However, other nodules may have been used for breaking shells. Sandstone nodules have been used as mullers and pounders. A cigar shaped sandstone nodule was found broken in two in $9 \mathrm{~A} / 6$. Careful examination of its surface showed that it had probably been broken as the result of over use as a percussion tool and its

1

Shell tools are known in other parts of Australia, including Plebidonax tools. (R. Lampert, 1966, p.114 see other references in his text; B. Spencer, 1928, Vol. II, p.705). 2

In $9 \mathrm{~A} / 6$, burnt limestone was found in Spits $\mathrm{B} / 4 / 10$, $\mathrm{B} / 3 / 11, \mathrm{C} / 2 / 7, \mathrm{C} / 4 / 7, \mathrm{~F} / 4 / 8$. In $11 / 1$, in spits $\mathrm{A} / 1 / 10$, $\mathrm{A} / 3 / 7$. 
centre was pitted from use. ${ }^{1}$ Another lump of sandstone from $9 \mathrm{~A} / 6$ was used both as a chopping tool as we 11 as a muller. ${ }^{2}$ Similar tools were recovered from the surfaces of $9 \mathrm{~A}$ and $10 \mathrm{~A}$.

(e) Ochre

Ochre was frequently used by the A series

Aborigines. Large lumps were found on the A series surface sites, and pieces of ochre were found all

through the A series excavations (see Table 10,18). Ochre was rarely found on B series sites.

\section{(f) Bone Material}

Table 10.18 shows that a few bone fragments were found in the upper levels of the excavation. However, there is no evidence to suggest that the A series

Aborigines were hunters, and all evidence suggests that they visited the Promontory to gather. However, a fair quantity of bone material (including birds and marsupials) has been found on the B series middens. An examination of the historical evidence suggests that no aborigines came to the Promontory area after about $1860,{ }^{3}$ so that if one attributes the bone material on the B series middens to the Aborigines, it must be at least 100 years old. Bone material can survive on these open sites for long periods, for a common type of bone artifact was found on one of the HANakiz $B$ which can only date to this period or beyond. 4

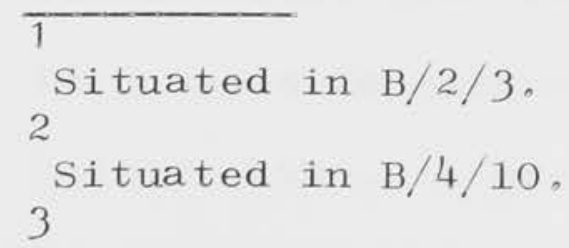

The historical evidence is not included here, but will be published subsequent1y. 4

The artifact was a nose bone (Plate 12,2) similar to one described by B. Smythe, 1878, Vol. I, p.277; see also E.M. Curr, 1887, Vol. III, p.544, where a nose bone of a Gippsland native is mentioned. 
Appendix 12.5 sets out the identified fauna from the various sites. Leaving aside the sheep, rabbit and other introduced species, bird bones are most common. There is no definite evidence that any of the species identified were killed by Aborigines, but the fact that bones can survive for long periods suggests that many of them could have been deposited by Aborigines.

Should this have been the case, birds and small marsupials (including wallaby) would have been the important game foods.

\section{(g) Pitch}

A large lump of pitch was recovered from Excavation 11/1. Subsequent tests (described in Appendix 12.6) showed the pitch to be natural. Thus the pitch must have been brought up from the beach onto the A series dunes by the Aborigines. What they used it for remains obscure. However, had they melted the pitch it would have been ideal for use as a hafting gum.

12.8 Sources of Material

\section{Flint}

This was obtained from nodules washed up onto the nearby beach for huge nodules weighing many pounds have been found on the midden sites with flakes struck from them。

\section{Quartz}

Quartz could be obtained from the nearby granite, but it could also be obtained from beach pebbles, Plate 12. 3 shows an extensive pebble bed to the north of Cottars Lake. A great variety of stone material are found here including Quartz, Quartzite, Granite, Flint, Aplite, Sandstone and Mudstone. Mitchell suggests that the Wilson's Promontory Granites were a major source of Quartz for the surrounding areas, but no extensive 
quarries have been found to date (S.R. Mitche11 1949 , $\mathrm{pp}, 90,110)$

Jasper, Fine Quartzite/Silicious Materials

The nearest source is the Cape Liptrap area about twenty miles away. 1

\section{Sandst one}

Obtained from the rubble heap on the beach. Beautiful pebbles with silicious bands are found both on the beach and only on the B series middens. The sandstones of the A series middens appear to come from eroded A series sites.

\section{Limestones}

Obtained from the rubble heap on the beach and from eroded A series sites.

Axe Materials (including Diabase)

The polished axe materials were probably obtained from the Cape Liptrap area or Mt William. Real Quartzites are available in the foothills of the mountains 40 miles to the north of Wilson's Promontory. Chert

The nearest source is the Cape Liptrap area (see footnote 1).

Dr J. Talent (Mines Department, Melboume) is of the opinion that the black Chert and Jasper ultimately derived from the Walkerville-Grinder Point Cambrian Be1t. The Sandstones, Argillacious/Silty Sandstones come from the Cape Liptrap region, from the Lower Devonian-Upper Silurian Belt. A lot of this material is found in the storm beach and contemporary gravels on the west side of Waratah Bay. 
There is some cuiderie which suggests that the edge ground ave was known to the Yanakie A Aborigines (see page 220) 


\section{THE ABORIGINES OF WILSON'S PROMONTORY}

The Yanakie A aborigines were familiar with an advanced level of stone technology. The finely worked backed blade tools are ample evidence of their skill. Many of these smaller tools were made in Quartzite which appears to have been an extremely popular and suitable material for making stone tools. 1 Similar tools were executed in Quartz, while the larger, less complicated tools were made in Flint, Both Flint and Quartz were available locally while the Quartzite had to be brought into the area from up to forty miles away. The two facts that so many of the tools are made from Quartzite, and that it could not be obtained locally suggest that the Aboriginal craftsmen placed considerable importance on Quartzite as a raw material. Little can be said about the function of the various stone tools. Backed blades seem to lack or have very little utilization in comparison to normal flake tools. This suggests that they were not used as working tools, and that they could have been used for spear barbs. It has also been suggested that natural pitch washed upon the beach may have been used as a hafting material.

Their diet consisted mainly of shell fauna. This was collected from the nearby rock platforms and brought up into the woodland behind the beach. Here

1

Since other assemblages to date have not been defined in computer language, in this chapter the terms ibacked blades', geometric microliths' and 'Bondi point forms' (McCarthy-Wright terminology) will be used. 
the animals were eaten and the shells discarded. There is no evidence to suggest that hunting or fishing contributed to their diet, But it is unlikely that the numerous tools made and used by the Yanakie A Aborigines were all associated with exploiting the marine environment. One must assume therefore that many of their tools were used to prepare vegetable foods, or to exploit other organic materials.

These Aborigines used ochre, perhaps to decorate their bodies (?) and their weapons,

As time passed and the coastline changed, and Plebidonax became a predominant species in the area. Its meaty flesh was eaten with relish and its robust shell was probably used to prepare othex foodstuffs. Quartzite tools were no longer important, and their stone tool kit became simpler. Most of the tools were made in. Flint or Quartz and were longer and had much less working than their Yanakie A counterparts. Examination of the diagnostic implements (Table 12.7) for both the Yanakie A and the Yanakie B assemblages suggests an underlying continuum, where the simpler diagnostic tools axe common to both assemblages, and where the backed blade (Quaxtzite tradition) elements have been dropped from the Yanakie tool kit.

The tendency to make simpler tools and in more available materials may be partly explained by supposing that the Yanakie B Aborigines utilized more organic materials than did the Yanakie A Aborigines, 1 For example, they were certainly using shell and probably

Cf, D.J. Mulvaney 1960a, p.13. 
used bone tools. ${ }^{1}$ Such an hypothesis seems reasonable for organic materials are generally more readily available and more easily worked than stone. The most sophisticated B series stone tools are the edge ground axe and the unifacially worked pebble.

It is clear that the Bunare B series Aborigines supplemented a shellfish diet (collecting) with marsupial and bird life (hunting).

Different densities of shell and stone material on Yanakie A and B sites suggest several things. For example, the much lower shell density in B series sites might be interpreted as meaning that the area was visited less frequently in $\mathrm{B}$ Sories times than in $A$ series times or that a shellfish diet was supplemented with other foods, The much lower lithic density in the Yañaki.e B $\mathrm{B}$ series sites might mean that there was less dependence on stone tools in B.series times.

13.1 The Yanakie B Fauna, Pxe-Contact

It is difficult to determine the faunal populations living on and near the Promontory before the arrival of Europeans. But it is clear that there was a general dearth of animal life in the area by the middle to later nineteenth century. Stokes (1846, p.431) was at Refuge Cove before 1850, and he noted the absence of Kangaroos, Wallabies and birdlife, Gregory and Lucas saw few animals on their expedition to the promontory, though occasionally they saw wallaby and a few bears, Birds were more frequently seen along the Yanakie coast. ${ }^{2}$

1

The recent Gippsland Aborigines used mussel shells as tools (B, Smyth 1878, vol.I, LIII), A literature search has not produced evidence that other shells were used similarly.

2

J.B. Gregory and A.H.S. Lucas 1885a, p.89, 1886, pp.152-3; J.B. Gregory 1885 . 
Murray commented on the fact that he saw no Wallabies or native bears on the Promontory during his geological

survey of the area (Gippsland Guardian 20 August 1887). However, reports at the turn of the century

contrast with these accounts. One author claimed that thousands of Koala and Wallaby skins had been regularly taken out of the Promontory before 1906 (Vic. Nat., 1906, vol.XXII, no. 12, p.197). Al1 sources agree that there were no Kangaroos, Emus or Rabbits before 1900. ${ }^{1}$ But Hares, Foxes and Dingoes were plentiful and the latter killed off the weaker animals, one observer noted their activities along the beach fronts where bones of animals, including Wallabies, bears and Blue Tongue lizards were frequently seen. 2 In the early twentieth century the main animals inhabiting the Promontory were the Black Tailed Wallaby, Koala Bears, Dingo, Porcupine, Grey and Ring Tailed Opossums, Hares and Foxes,

Birds which were commonly seen on the isthmus and in the south-west of Corner Inlet include Albatross, Gannets, Terns, Coxmorants, Sea Eagle, Osprays, Red Oystercatcher (whose nest was frequently found in the dunes), Pelicans, Black Swan and Black Duck.

(A.D. Selby 1960, p. 3; Vic. Nat, 1906, vol.XXII no. 12,

\section{1}

Vic. Nat. 1906, vol,XXII, no. 12, p.195: 1910, vol. XX̄VI, no. 9, pp.129-37, No Rabbits p.198, A.D. Selby, p.2; A.J. Ewart, 1909, p.149. No Rabbits, a few Hares, plenty bears, Wallabies, Dingoes, Bandicoots.

J.A. Kershaw in his review (1928) stated that at its inception, the National Park had only about six species of native animals - Black Tailed Wallaby, Native Bear, Echidna, Bandicoot, Ring Tailed Opossum - Dingoes, Hares and Foxes. No Kangaroos, Wombats, Common Opossum, Emus, Lyre-bird. Introduced - three species of Kangaroos, three species of Wallaby; two species of Wombat, three species of Opossum, plus Emus, Mallee Hares etc. (J.A. Kershaw 1928, p, 300).

2

Vic. Nat, 1906, vol,XXII, no, 12, p.198. Hardy had noted wild dogs at Sealer's Cove in 1908. Vic. Nat. 1908, vol.XXIV, p, 151 . 
p.195). Other bixds frequenting the west coast of

Yanakie were Sea Curlews, Pacifio Gulls, Doltiels and

Sooty Oyster Catchers (T.W. Audus 1911, p.208), Between

the landing jetty in south-west Cornex Inlet and Darby,

the country used to be covered in forest

... a thickly timbered flat, extending across to the sea tree covered sand dunes which margin the ocean beach. Most of the timber which consists principally of fair size eucalyptus, with a few scattered Blackwoods, has been ringed, their whitened skeletons remaining to show what once had been.

There had been plenty of Wallaby and Koalas, Dingoes and Hog Deex, but by 1913 few were to be seen. ' (Today there are no eucalypts or blackwoods in the entire area). In 1915, on the Tongue Point side of Darby, Emus, Kangaroos, Wallabies and Wombats were quite common. (Vic, Nat, 1915, vol. XXXI, no. 10, p, 146),

Soon aftex the National Park came into existence (in 1908), the Management gave notice that it was anxious to obtain all varieties of native fauna, particularly Kangaroo, Rock Wallaby and Wombats (Vic. Nat. 1910, vol. XXVII, no, 2, p.35). By 1911, several Emus, Lyre-bixds, Kangaroos, Wallabies, Wombats and Opossums had been set Loose in the Park (Vic. Nat, 1911, vol, XXVIII, no, 8, p.168), Introductions continued over the next few years and Sir Baldwin Spencer reviewing the situation in 1918, proudly announced that approximately 200 native animals had been introduced since 1908.2

Vic. Nat 1913, vol, XXIX, no, 9, p.171, A few Koala and Wallabies were to be seen. in this area (between the Vereker Range and Darby River in 1915). Vic. Nat, 1915, vol, XXXI, no, $10, \mathrm{p} .145$. 2

Argus, 10 Sept, 1918: Vic。 Nat, 1917 XXXIV, no, 1, p. 36, put the figure at 192; Vic. Nat, 1917 XXXIII, no. 3, $\mathrm{p}, 40$, Kangaroos had been introduced into the Park from north and north-west Australia. 


\subsection{Ethnological Data Collected by Other Workers}

Kenyon visited the area in 1906 along with

Pritchard (geologist) and Kershaw (naturalist), 1 They

traced the middens from Shallow Inlet to Oberon Bay,

noting that there was plenty of food(including shellfish, smoll marsupials, birds)and organic materials. Fresh water was

also abundant. In the middens themselves they found

huge accumulations of shell, Quartz and Flint chips,

broken stone implements, axes, hammer and grinding stone,

bones of animals and birds, and a single bone implement.

Kenyon claimed that all this material was very recent,

and suggested that the Aborigines 'did not get onto the

Promontory until very little before ourselves: (A.S.

Kenyon 1906, p,223).

Kenyon comments on the ease with which one could progress from bay to bay on the Promontory itself. He described these areas as 'comparatively open timbered country', through which one could easily pass. Today this is not the case, and such journeys (except via the made road) are impossible, for the scrub along the coast is almost impenetrable, Consequently, unless the

ancient Aborigines negotiated their way to these bays by canoe, it is likely that the older scrub communities were not as dense as they are today,

1 (continued from p.229)

A series of letters contained in the files of the Fisheries and Games Dept, describes how the Woodside community had been having trouble with Kangaroos. The authorities decided to catch as many as possible and release them on the Promontory, Ietters - 26 July 1912, 30 July 1912, 5 Aug. 1912, 24 Aug, 1912, deal with this problem, 1

Excursion to Wilson's Promontory Vic. Nat. 1906, vol. XXII, no, 12, pp, 191-223, Sections relevant to the aboriginals axe as follows:-

General Zoology, J.A. Kershaw, pp.199-201; Geological Notes, G.B. Pritchard, p.222; Ethnology, A.S. Kenyon, p.223. See also P.J.F. Coutts 1966, pp. 37-43. 
On the othex hand, the aborigines may have periodically burnt the scrub off, not only to provide the fauna with new feed, but to keep the Promontory accessible, A. Local informant has suggested that the aborigines frequenting the Promontory did delibexately burn off the scrub in Autumn to ensure a Summer food supply for the fauna, 1 However, his sources $x$ emain obscure; upon closex questioning he could only suggest that this must have been the case, for when the Promontory was no longex burnt off, the sorub increased to such thickness that when it was fired accidentally most of the fauna was destroyed. However, it should be pointed out that thexe is some evidence to suggest that the Gippsland Aborigines were in the habit of burning off, For example, early pioneers in Gippsiand frequently blamed the Aborigines for staxting fires (T.J. Coverdale 1920, pp.45-7).

Sir Baldwin Spencer visited the Promontory in 1918, and some of his observations are summarized below.

(a) There was plenty of stratified material, some of it up to six feet thick.

(b) Shell heaps were often composed of one species only.

(c) The most common species of shell was the Subnine1.1a undulata; but its operculum was more common than the shell itself. To account for the different frequencies of occurrence he suggested that shell material moved more easily than the operculum.

(d) Few shells were actually burned. Of these, he noted that Subninella and its opexculum were the most frequentiy burnt. Upon this evidence 
he concluded that most of the shellfish were eaten raw.

(e) Included in a list of fauna found in the middens are broken bird bones and claws of rock lobster, He doubted whether the bird fauna was associated with the other midden material.

(f) Shell fauna could be collected from two reefs stretching out to sea north of Darby River.

(g) Stone tools consisted of crude flakes. There were few well made implements and he found only one stone axe.

(h) Source of stone - implements for smashing shells were made from Quartzite which he claimed comes from the interior of the Promontoxy. The Sandstone was obtained locally. Chert must have been brought from up to 40 miles away.

(i) He claimed that all this material was recent,

(j) These middens were 'temporary eating places' because no well made implements were found there. I,e., Spencer claimed that only well made implements were found on permanent camp sites and suggested that the better made implements would be found further inland where their permanent camp sites were supposed to be situated. 1

Except for the last two points, these observations are a tribute to Spencer's powers of observations, for

1

Sir B. Spencer 1918, pp.113-6 (also Plate 1, fig. 1 and 2); 1928, vol.II, p.500, fig. 343; W.B. Spencer and F.J. Gillen 1927, vol, II, p.537, fig. 182. 
it has been shown in the foregoing that they are all

valid. Spencer somehow missed the backed blade industry, and clearly underestimated the age of the material he was examining. As to his assertion that inland camp sites would produce better made tools, one must agree with Mulvaney that he was mistaken (D.J. Mulvaney 1960a, p. 11).

There can be little doubt that other collectors have been busy in the area but in most cases their activities remain undocumented, A party visiting the Promontory in 1920 record that they found various artifacts in the area, However they were never described and they have since been lost (G, Nethercote 1920, p.126). Many local residents have collections of artifacts. For example, Keane Pilkington of Sandy Point has grinding stones, axes and so on, but he is unable to relate where he found them. ${ }^{1}$ He claims that a large, well grassed paddock nearby is a vast midden and that excavation would reveal thick midden deposits; again that another area, now the site of a housing estate, was once a large Aboriginal camp, However it remains impossible to guage how much material has been destroyed since Europeans first settled in the area or how much has since been removed by collectors.

Human Remains

Several human skeletons have been found at the Promontory; some of these may have been Aboriginal. None of this skeletal evidence is available for examination, so that all one can do is list the material found, 
(a) 1906, Portions of a skull and skeleton were

found in the dunes, associated with bones of

fish, Wallabies and a species of bush rat, No

othex information is given. The author

implies the bones are Aboriginal (J.A. Kershaw 1906, $\mathrm{pp} \cdot 198-9)$

(b) 1918, Spencer chanced upon a burial during

his visit, He describes the find as follows:-

The bones, consisting of parts of the cranium, the lower jaw, ribs, arms, and leg bones, were lying exposed on the surface of a small midden, mixed up with the remnants of shells, They were all more or less friable, and had evidently been uncovered and recovered, time after time by the drifting sand, Whether the body had been deliberately buried or whether the native had chanced to die on the spot and his body been left on the surface it is impossible to say; but there was at least no evidence of a definite burial, and the bones lay on the surface amongst the remnants of the shellfish... (Sir B. Spencer 1918, pp. $1.15-6$ ).

(c) Murray Black Black discovered a skeleton at Darby Beach many years ago, It was buried in sand, beneath two shell layers approximately two feet below the surface, However, it is not clear whether the skeleton was older or younger than the two shell layers (Murray Black, Interviewed).

(d) David Debenham, He has found bones at Cottars Lake, These wexe sent to Melbourne University and have since disappeared. Debenham suggested that the skeleton was not that of an Áboriginal. (D, Debenham. Interviewed).

(e) During the current Archaeological work, a human fibula was found on a $B$ series midden 
(Site 13). The bone might have belonged to an Aboriginal.

\subsection{The Ethnology of the Gippsland Aborigines}

No direct information is available about the aborigines who visited Wilson's Promontory in recent times. However, the short account given below of the Gippsland tribes may well typify the kind of life led by the B series Aborigines,

The Gippsland tribes are said to have been five in number - including the Brabralung, Braiakaulung, Bratauolung, Krauatungalung and Tatungalung, the five tribes as a group being called the 'Kurnai' of Gippsland, 2 of direct interest is the Brataualung tribe, whose territory began at Cape Liptrap - ran east to the mouth of Merriman Creek, then inland to about Mirboo and included Port Albert and Wilson's Promontory. The tribe had alternative names and has been called variously Bradowoolong, Brataualung, Bratanolung, Tarrawarracka and Tarrawarrachal (N.B.Tindale, 1940, p.197).

The coastal natives lived mainly on fish and shellfish, This diet was supplemented with an occasional Wallaby and bear, and in season, with Mutton birds, 3 To carry on their fishing activities, they had canoes which Smyth reckons were of a particular type. ${ }^{4}$

1

The bone was identified by Professor N.W.G. Macintosh (Anatomy Dept, University of Sydney). He has expressed the opinion that the bone might be Aboriginal. 2

N.B. Tindale 1940, pp, 196-7; A.W. Howitt 1904, p, 73;

R.B. Smyth 1878, Vol. I, p.36; E.M. Curr 1887, Vol. III, pp, 539-40. 3

E.M. Curr 1887, Vol, III, p.545; G.H。 Haydon 1846, p.51; A.W. Howitt (unpublished notes); R.B. Smyth, 1878, vol。I, $\mathrm{pp}_{4}, 204-5,208,210$.

R.B. Smyth 1878, Vol. I, p, 408; also Vol. I, p,LVIII E.M. Curr 1887, Vol. III, p.548; G.H. Haydon 1846, p. 43. 
The bark was folded 'and tied up at the ends to form stem and stern". They were flimsy arrangements, and the Áborigines took care never to venture too far from the coast in them (R.B. Smyth 1878, vol.I, p.lix). Most of the fishing was done at night. A small fire was placed in the canoe and its light attracted the fish to the surface where they were speared. Fishing in this manner was very common, particularly on the lakes further east from Port Albert. Here Haydon had observed their canoes 'creeping along the shore in great numbers' (G.H. Haydon, 1846, p.43). The Aborigines also fished with hooks and lines and it was the women who did most of the fishing in this manner. (R.B. Smyth, vol. I, p.202; Fig. 226, p.391; E.M. Curr 1887, vol. III, p.548). Smyth 1ists the most common species of fish caught by the Gippsland

Aborigines and includes Schnapper, Gurnet, Flounder and Flathead (R.B. Smyth 1878, vol. I, p.204),

The Aborigines also used their canoes to go on short expeditions in good weather. One area frequented was Rabbit Island off Wilson's Promontory which is a Mutton Bird rookery, Mussels are also abundant there.

The Brataualung Aborigines would leave the Welshpool area and cross to snake Island, From here they went to Mount Singapore on the north-east of the Promontory, a journey of about one-and-a-half miles of open water, Hugging the east coast of the Singapore Peninsula they worked their way down the coastline until they were opposite Rabbit Island. From here it was an easy journey to the island (A.W. Howitt, unpublished notes). Rabbit Island may have been a regular food collecting area for the Aborigines of this area, for they appeared to resent Europeans coming to the island. In 1846, the remains of a sealer's hut and garden could still be seen on the 
island, A story was current that the Aborigines had destroyed them after demanding that the occupants leave the island (G.H. Haydon 1846, p.81).

The Gippsland Aborigines themselves were said to be 'finer looking men than the generality of New Hollanders: (G.H. Haydon 1846, p.43). They wore opossum-skin rugs to give them some measure of protection. Many had nose bones. Their weapons consisted of the usual tomahawk (edge-ground), spears tipped with stone and having wooden barbs, shields, boomerangs and wommeras, ${ }^{1}$ It is interesting to note that Quartz was used for spear tips ${ }^{2}$ (hafted into position with the gum of the grass tree). The settlers thought it was glass, as it is often difficult to tell the two apart. Apparently Fint was a more common material, however.

An interesting Aboriginal legend centred about the rugged mountains of Wilson's Promontory. The Promontory was the home of a spirit called Loo-errn, and no-one outside the Brataualung tribe could enter this area without going through a strict ritual to obtain the authorization to do so, Once a visitor had been accepted by the spirit he was prohibited from killing any member of the Brataualung tribe, ${ }^{3}$ Loo-errn was also a very practical spirit, for in times of trouble the

$\overline{1}$

E.M. Curr 1887, Vol.III, p.544, Nosebones are mentioned by G.H. Haydon, plate opp. p.107. 2 3 P.P.H. 8 June 1841; R.B. Smyth 1878, Vol.I, p.246. R.B. Smyth 1878, Vol.I, pp.453-5; A.W. Howitt 1904, p.485. The south-west Gippsland Aborigines were not regular visitors to the more westerly areas, except on excursions of war. The Brataualung tribe did venture as far west as the Tarwin River during the egging season to obtain bark for their canoes. (C.W. Sherard 1898, p.37; G. MacKaness 1841, p.8). 
Brataualung people would cross to Mount Singapore in their canoes where they were secure from the attacks of their enemies. 1

The Gippsland Aborigines were very numerous at the time of first contact with the settlers. Various estimates put their original number at between 1,000 and 2,000. 2 They often moved or met in numbers upwards of 100. 3 But in the twenty years, 1840-60, their numbers diminished rapidly, mainly through disease and bloody warfare. The census of 1853-4 shows the number of Gippsland aborigines had dropped to $126^{4}$ (W.M. Thomas, ibid). By 1862 , Curr reckons there were on 1 y 150 Gippsland Aborigines left (E.M. Curr, ibid). This figure is consistent with the census returns of 1863 where a total of 221 is given for south-eastern Australia (R.B. Smyth 1878, vol.I, p.43). This means that the Gippsland Aboriginal population was reduced by nine-tenths in twenty years, a very striking measure of the effect of white contact on the Aborigines. Although the original figure for the number of Aborigines comprising the Brataualung tribe are not known, by 1863 there were only 17 left (ibid).

\footnotetext{
A.W. Howitt, unpublished papers, Wilson's Promontory. 2

C.J. Tyers 1898, p.200; T, McCombie 1858, p.86; G.H. Haydon 1846, p.89; W.M. Thomas 1898, p.79; E.M. Curr 1887, vol.III, p.544; R.B. Smyth 1878, vol.I, p.36. 3

McMillan saw 100 in January 1840, A. McMillan 1898, p.258. The Gippsland Company saw a party of 30. W.A. Brodribb 1883, p. 32, The Robinson-Hardon expedition came across a deserted camp which could accommodate 100 aborigines. G. MacKaness 1841, vol. I, pp.49-50, other references and numbers are given below: Argus, 9 March 1847, pp.2, 200; 16 March 1857, pp.6, 100; W.T. Dawson, ibid., 7 September 1855, pp.1-200. 4

This figure is only approximate, but even if it is out by one hundred per cent it still testifies to the tragedy of the situation.
} 
Intertribal warfare was probably a major reason for the decrease in numbers, for it appears that conflict between the tribes increased in the fifties, 1 Constant annexation of tribal territory by Europeans progressively restrioted the Aborigines movements and diminished the area of their natural habitat, Consequently the displaced tribes were brought into conflict with their neighbours. Where close contact existed between Europeans and Aborigines 'the worst habits and vices of civilization" were adopted by the Aborigines. While under the influence of alcohol, they committed atrocities against each other and against the settlers (T. McCombie 1858, p,86). Reprisals naturally followed.

\subsection{Cultural Affiliations of the A Series ond Yaunkie B $B$ Material}

So little archaeological work has been carried out in Victoria that it is difficult to find comparative material. The Yanakie B assemblage is typical of most coastal dune areas, A similar industry has been excavated at Glen Aire. Mulvaney writes that inot a single primary flake or core possessed flake scars which indicated any particular skill in stone working? (D.J. Mulvaney 1960a, p.11), a description that could well be applied to the Yanakie B flake tools. His date of

$\overline{1}$

As has been continually pointed out, the Gippsland tribes were always very war-like, In 1838, for example, they were supposed to have killed 150 Aborigines from the counties of Bonoke, Evelyn and Mornington (R.B. Smyth 1878, vol. I, p.32), Other cases: Fight between the Gippsland and Port Phillip tribes while the former were drunk. Argus, 11 July 1849; Intertribal wars mentioned in Dawson's letter book 1855 - see references above; also Argus, 5 April 1855, p.6; 20 Sept, 1855; 30 June 1855, p.5; 20 Jan, 1857; 16 March 1857; G. Mackaness 1841 , p.64. This section illustrates the hatred felt for the Gippslanders; also ibid., p.8; R. Jamieson 1898, p.160. 
$370 \pm 45 \mathrm{BP}(\mathrm{R}-728)$ places the Glen Aire assemblage in a recent context, and younger than the Yanakie $B$ date of $1260 \pm 90 \mathrm{BP}(\mathrm{GAK}-682)$

One or two earlier dates are available for other Victorian surface sites. Gill obtained dates of $538 \pm 200 \mathrm{BP}(\mathrm{C}-601)$ for a midden at Koroit Beach and $1177 \pm 175 \mathrm{BP}(\mathrm{C}-600)$ for a midden at Goose Lagoon. (E.D. Gi11 1953b, p.82; 1955b; G.H. Dury 1964, p.105; 1966, p.160). These assemblages consisted of a bone and crude flake industry and did not contain backed blades (S.R. Mitchel1 1958, p.198)。

In Victoria there is no excavated material available to compare with the Yanakie A assemblage. A11 comparative material is situated in New South Wales, South Australia and Queensland. Gill has recently demonstrated that geometric microliths were in use after 1900 B.C. at Port Campell, Victoria. However, the relationship of the date to the backed blades is inadequately defined (E.D. Gil1 1965, p.301; 1964, p.11)。 His occupational material extends to about $13^{\prime \prime}$ below the surface, his date came from the $10^{\prime \prime}-11^{\prime \prime} 1$ evel, and the backed blades came from higher levels $\left(5^{\prime \prime}-8^{\prime \prime}\right)$. His date then, must be a lower limit and may be too old (.E.D. Gi11 1964, p.10)。

Sites outside Victoria, and relevant to this discussion are shown in Diagram 13.1. 1 This diagram shows that there are few well defined assemblages at present in Australia. When excavations are situated so far apart geographically it is not valid to make 
comparisons between the assemblages. ${ }^{1}$ All one can do is set out the present evidence and make one or two

comments.

Diagram 13.2 is a time distance chart which attempts to (a) define the rates of diffusion for two main types of backed blades, (b) to take into account the geographic barriers to diffusion, (c) to show how other 'types' fit into the sequence with their chronological relationships to the backed blade forms. 'Distance' for the diagram is measured along the coast from McBryde's site in New England to Mulvaney's site in South Australia. The distance to Kenniff Cave has been measured overland from Fromm's Landing.

Diagram 13.2 postulates a coastal diffusion of the backed blade industry into New South Wales. This and a further possible diffusion route are shown in Diagram 13. 3.

Diagrams 13,2 and 13.3 were constructed by taking into account the surface distribution of backed blades (Diagrams 1.1 and 1.2 ), 2 the coastal geography of eastern Australia (Diagram 13.1), and the present known $\mathrm{C}^{14}$ dates for backed blades.

The Wilson's Promontory data has been superimposed on Diagram 13.2. It is clear that either much older

1

Indeed, it is often tenuous to compare assemblages from regional excavations. One recalls the stratigraphic case at Devon Downs, where Tindale and Hale (H.M. Hale and N.B. Tindale 1930, p.204) defined four cultural sequences. The principal implements of his Mudukian culture were the geometric microliths and the so-called bone 'muduk'. His Pirrian culture (defined by the Pirri point) contained no geometric microliths, yet Mulvaney excavating in an adjacent axea in 1960 found Pirri points to be associated with microliths, thus causing complications to Tindale's cultural sequence (D.J. Mulvaney 1960b, p.78; 1961, p.83). 2

The surface distributions of backed blades is still undefined. 
backed blades will be found in South Australia or else, the time-distance diagram does not represent a possible diffusion picture. An alternative diffusion process (Diagram 13.3, B) would fit the present data more satisfactorily if older dates could be obtained for backed blades in assemblages in north-east New South Wales and south-west Queensland, At this stage it is pointless to theorize further, and until more assemblages have been excavated, particularly along the coastline of Victoria and New South wales, the mode of diffusion of the backed blade industry will continue to remain obscure.

Geometric microliths and Bondi points are clearly associated at Wilson's Promontory, though the latter were rare in the A series excavations, This observation accords well with excavation evidence from other sites ${ }^{1}$ (see Diagram 13,2). A notable exception occurs for Fromm's Landing where Bondi points appear to supersede geometric microliths, 2 Since Bondi points are older than 3000 BP at the Promontory it is unlikely that they are any younger in South Australia, so that further excavations in South Australia should produce Bondi point forms in association with, and perhaps as old as, the geometric microlith。

$\overline{1}$

In 1948, Mccarthy asserted that geometric microliths belonged with Bondi points to his eastern. 'Bondian' phase. He envisaged the addition of geometric microliths to the Bondian toolkit at some subsequent stage in the industry. In view of the carbon dates available for geometric microliths in Queensland, South Australia and New South Wales, his conclusions are now doubtful (F.D. McCarthy 1948, p.31). The classification suggested above is arbitrary and should not be referred to in a cultural sense. 2

Mulvaney, in his excavation of rock shelter No. 2 at Fromm's Landing, found a classic Bondi point at level 2. His geometric microliths occurred in levels 8-10 which represents a wide stratigraphic separation (J.D. Mulvaney $1960 \mathrm{~b}, \mathrm{pp} .72,79$;.D. McCarthy 1964, p.201). 


\subsection{Conclusion}

There is little need to stress further the urgency of conducting excavations in areas similar to Wilson's Promontory. At present hundreds of sites are available for excavations, but this may not be the case in years to come. Erosion, housing estates and pillaging take a heavy toll of coastal sites every year, so that there is an urgent need to devote time and attention to these valuable and hitherto untapped sources of information. Eighty-nine years ago, one of the greatest ethnologists of the time hinted that shell middens would prove to be a worthwhile object of study. Unfortunately, these comments (of 1878) are equally applicable in 1967 and it is perhaps appropriate that one concludes 'the archaeology of Wilson's Promontory' by quoting his advice to future field workers:

The shell-mounds in Victoria are, as a rule, never opened by anyone. Few people know that they have been found by the natives; and there is therefore no wanton injury done to them. In one or two places I have seen a shell-mound cut through where a track to the coast has been formed; but the old middens are not interferred with; and future archaeologists will find abundant fields for research, in all parts of Australia, when more attention is given to the habits of the natives and a deeper interest is felt in their earlier history. What may be disclosed by a thorough examination of some of the ancient murrin-yong heaps and shellmounds one cannot guess, but it is not improbable that valuable discoveries may yet be made. (B. Smyth 1878, vol.I, p.242). 
CULTURE CHANGE AND SURFACE COLLECTING IN AUSTRALIA

Mulvaney has also noted these problems (J.D. Mulvaney $1964 \mathrm{c}, \mathrm{p} .429)$, and the author has discussed some of the implications of surface collecting elsewhere (P.J.F. Coutts 196\%). The ideas expressed by Sir Baldwin Spencer in the early twentieth century gave free license to collectors to pillage sites. He led a group of field workers who believed that the Australian aborigine was a recent arrival in Australia.

This meant that there could be little if any typological development in the Aborigine's 1ithic tool kit. The implications of such a philosophy were profound and led to the destruction of both surface and stratified sites. (D.J. Mulvaney 1957, p.34; 1964c, p.429). Lack of any advance in his tool making ability meant that a stratified site could be dug up without fear of destroying a chronologically defined tool sequence. All tools belonged to the one culture, so that there was no point in careful excavation.

He expressed the view, in several publications, that 'the nature and form of implements is not a question of the stage of culture, but depends primarily upon the material available (W.B. Spencer and F.J. Gillen 1889, p.635; also in 1927, vol.II, pp.536-7; W.B. Spencer 1914, p.77). 'Palaeolithic and neolithic implement ranges, the exact type produced being a product of the material at hand, are found mixed together so that had such a tribe as the Arunta become extinct, leaving behind it in the form of stone implements and some rock drawings the only traces of its existence which would have persisted, 
the modern ethnologist would have been not a little puzzled by finding, side by side, the most crudely and most beautifully flaked and chipped stone implements and at the same time ground axes' (W.B. Spencer and F.J. Gillen 1927, vol,(ii), pp.536-7). Spencer warns the archaeologist not to interpret the diverse mixtures of lithic traits as evidence of cultural stratification, i.e. such as the terms palaeolithic and neolithic are used in Europe. Instead, the reason for the diversity of 1 ithic tools is a function of the material available. The only cultural stratification he could envisage was a difference in the Tasmanian and Australian tool kits. He believed the Tasmanians had arrived in their home via a land bridge in great antiquity (W.B. Spencer 1914, p.34) bringing with them a very crude lithic technology (W.B. Spencer and F.J, Gillen 1899, p.635). The 'Australoid', a modern aborigine, arrived in Australia after Tasmania had ceased to be part of the mainland. These new immigrants brought with them a superior technology which changed little from that time to present day, 
Site Y.W. 1

Situated at the south end of Darby Beach. Midden material is found on the steep slopes of the granite which rises sharply from the sea. Most of it is badly fragmented and dispersed amongst the undergrowth. Midden material is found all through this area extending as far back as the swamp (see Diagram 2.2, Site 1a).

Site Y.W.2

See Random Sampling Section for a description of this site. All flakes were collected from this site.

Site $Y \cdot W \cdot 3$

Scattered midden matexial was found a 11 along the top of the A series dunes ${ }^{1}$ north of Darby Beach. Most of the material was being or had been eroded from the A series occupational soil, though some of it may have come from soil horizons in the B series dunes which overlay the A sequence and which have been eroded away subsequently. Collections at this site are likely to be reliable.

Site Y.W.

A small midden situated at the foot of the Pleistocene dunes at the northern end of Site Y.W. 3. Stone collection was complete.

Site Y.W.

This site is situated about a hundred yards inland behind the foredune. It is slightly protected from the 
wind, though the midden material lies on a blow out surface. Stone collection was complete.

Site $Y \cdot W \cdot 9 A-9 D$

See Chapter 8 for a full description of each of these sites.

\section{Site Y.W.10A}

This is a very large site consisting in the main of a large destabilized dune whose face has been blown back exposing numerous soil horizons containing aboriginal material. At the northem end of the site the overlying dune has been completely blown off leaving the underlying A series exposed. Subsequent erosion has stripped most of the A series occupational soil leaving extensive aboriginal material lying about on the dark soil surface. In other areas the soil has been stripped completely exposing the nodule layer. Extensive collections were taken from a flat section of the exposed A series soil. Thus the collections from this site will mainly represent A series cultural material.

\section{Site $\underline{Y} . W \cdot 10 B$}

The overlying B series dunes and the A series occupational soil have been entirely stripped from most of this area. Collections are not representative of the entire area.

\section{Site Y.W. 11}

This is another fairly extensive midden (see plan of site Diagram 4.15). The overlying B series dune has been blown back from the seaward portion of the site leaving the A series soil exposed. The soil in turn is very much exoded in areas adjacent to the beach. Some hundred yards or so in from the western boundary of the 
site, a B series blow out face climbs steadily towards the back of the site. The northward boundary is a high stabilized B series dune - overlying an older A sequence. The A series dunes have been eroded back by sea and great dune limestone rocks extend out into the sea forming rock platforms upon which numerous mollusca thrive. Cliffs rising to a height of $40^{\prime}$ extend for some hundreds of yards to the north of the site.

Material which has exoded out of the occupational soil is found along the cliff tops,

Collections were confined to the region where the A sexies soil has been exposed by erosion. Therefore the collection represents mainly A series cultural material.

Site $Y . W .12 A$ and $12 B$

Site 12A is a badly exposed B series blow out. It is not very large and most of the flake material was collected. Shell was common on this site and Plebidonax predominates. Site $12 \mathrm{~B}$ is situated on the northern side of 12A. Midden material lies exposed on a narrow ledge of A series soil and is flanked to the east by an unstabilized B series dune, A few artifacts have been eroded from the soil and although most of them were collected, they form a poor sample.

\section{Site Y.W.13}

This site is situated in a sheltered valley between two stabilized dune ridges. The midden is not very extensive and collections were complete.

Site Y.W.14, 14A and 14B

This is a small area situated on the A series soil which forms a ledge overlooking the beach. It is very exposed, and the material is badly weathered.

Collections were not representative of this site. 
Sites $14 \mathrm{~A}$ and $14 \mathrm{~B}$ (not shown on map) are located about a hundred yards inland, behind the foredune. They are situated in small clearings on the top of high vegetated B series dunes. All stone material was collected from these sites. Two points are worth noting. Firstly these sites are almost inaccessible today; and secondly they must be very recent by virtue of their geomorphological situation.

Site Y.W.15A and $15 \mathrm{~B}$

These two sites are separated by a low dune ridge. $15 \mathrm{~A}$ is situated on a blow out and most of the material is found on the western part of the site, The first hundred yards of the site is relatively flat, because most of the B series dune has been blown away. Over the ridge the sand has been completely blown down to the A series soil which is exposed for some distance on the westerly perimeter of the site. However, most of the site is on a B series surface,

Both sites are fairly large and the collections (in both areas taken from the B series surface) are not extensive.

Sites $Y . W .16 A$ and $16 B$

Site $16 \mathrm{~A}$ is situated in a well protected dune valley, The material is situated on a sandy surface in a hollow between two paxallel dune ridges. On the seaward side a well vegetated high dune ridge protects the western end of the site from the strong sea breezes. Consequently midden material is well preserved, Stone is not plentiful. Collections were made on the westerly side of the midden and although the sample was small it reflects both the sparseness of lithic material and the material used. 
16B is situated furthex west and is located on top of an eroded and exposed A series occupational soil overlooking the beach. Collections from this site were fairly extensive (because of its smal1 area) though for this reason they are probably not representative.

$\underline{\text { Site }} \underline{Y} \cdot \mathrm{W} \cdot \underline{17}$

This is a very large blow out, stretching for hundreds of yards to the east. On the lower part of the site a small A series outcrop is exposed, However, large though the site was, there were few flakes, and the collection taken from the area was fairly representative.

$\underline{\text { Site }} \underline{Y} \cdot W_{0} 18$

This is a small exposed area on a dune blow out situated between Site Y.W.I7 and Cottars Lake, The shells look very fresh and are predominantly plebidonax. Flakes were rare so that most of them were collected,

Site Y.W.19

This site is situated on the north side of cottars Lake. For some hundreds of yards north of Cottars Lake the foredune is protected by a pile of pebbles. These include sandstones with silicious veins, big grained Quartzite pebbles, Flint nodules, Basalt and granite pebbles, Many similar stones are found on the middens suggesting that the rubble heap was an important source of stone material. The shells on this site are very fresh looking, Flakes were few and collections are fairly representative.

Site Y.W.22

This site is a long low inland (approx. 300 yards in) blow out with material scattered widely over its 
surface. It is the first big midden after cottars Lake. Flakes were again fairly scarce. Because of the size of the midden collections were not extensive.

Site Y.W.23

This site is situated a little further along the beach and extends from the foredune approximately 500 yards inland, It is bounded on the north and south by low unconsolidated dune ridges, Extensive collections were made, but the midden area is so large that comments made for Site Y.W.22 apply here.

Sites Y.W.24A and $24 \mathrm{~B}$

Sites 24 and 25 are situated in a vast valley, half a mile wide at its western end, and extending for at least three quarters of a mile inland, Light scrub now covers the centre of the site and this protects what must at one time have been a huge open area of midden deposit. The site has been divided into four sections (excluding the vegetated area), Sites $Y . W .24 A$ and B are situated in the south-west corner of the valley. Y.W.24A is difficult to reach from the beach, for it is located approximately 150 yards inland through dense scrub. It is approximately 75 yards 1 ong and 25 yards wide, All midden material lies on sand and is fairly well protected. Site Y.W.24B lies to the south-east of this site in an oblong valley. It is protected to the north, south and west by relatively high stabilized dune ridges. Midden material (on sand) is well preserved. This site is approximately the same size as Y.W.24A. Collections from both sites are fairly representative. Flake material was fairly common. 
Sites Y.W.25A and 25B

Y.W.25A lies on loose sand in a long gully running parallel to the northern boundary (i,e, a very high unstabilized dune ridge) of the valley described above. There is little material in the north-west corner of the site, but as one proceeds eastward along the dune ridge, midden material increases. Most of the collecting was carried out in the north-east corner of the valley. Site Y.W.25B is situated in the mid-eastern end of the valley and is separated from Y.W.25A by a series of low dune ridges and by extensive scrub.

Most of the material here is lying on a black soil which could be the A series occupational soil for calcarenite is exposed in several places in the vicinity (see Chapter 3). The area is distinctive because of its flatness. 


\section{A.PPENDIX 2.2}

\section{YANAKIE EAST (YE) SITES, DIAGRAM 2.5.}

Sites Y.E. 1 and 2

Both sites are situated on rocky outcrops overlooking Rock Platforms from which all species in the midden material can be obtained today. In both areas material is badly weathered and of limited extent and concentration. No stone was found at either site.

Fauna. Mainly Rock Platform including predominantly Subninella and Cellana, with Dicathais, Notohaliotis, Mytilus and Brachidontes.

These sites do not appear to have been used frequent $1 y$.

Site $Y \cdot E \cdot 3$

This midden is situated at the southern end of the beach. Material is found scattered down the steep cliff face. It is very badly broken up and very sparse. Much of the site is overgrown by the vegetation. No stone was found.

The material is so limited that very few visits could have been made to the area.

Fauna. As for Y.E.4.

Site Y.E.4

Midden material is found for some hundreds of yards along the beach extending north from the tractor shed at the outlet of a small. creek. The material is being eroded from a light grey sandy immature soil at the top of the present foredune, The area is lightly vegetated with ti tree and banksia. The vegetation cover is contemporary with the soil indicating that the deposit 
is very recent, There is no midden material on the surface.

Fauna. Predominant specie is Ostrea, Less abundant shells include Mytilus, Brachidontes,

Subninella and Cabestana.

Artifacts. No retouched implements were found, and only a few crude chips of Quartz were present, 


\section{APPENDIX 2.3}

WILSON'S PROMONTORY (WPW) AND (WPE) SITES

\section{Site WPW, 1}

WPW. 1 is the most southern aboriginal site in the Oberon Bay area. The granite climbs steeply from the water's edge and Aboriginal material is found on the sides of the mountain up to about $50^{\text {: }}$ inland. Just north of the granite where the new dune (ND) sequence begins, midden material is found eroding from an immature light grey soil, Light scrub now covers most of this area, so that examination of the extent and range of material was necessarily limited. The material is badly weathered.

Fauna. Rock Platform species including Subninella, Cellana, Dicathais, Mytilus and Brachidontes.

Artifacts. Materials consisted of Quartz and Flint only, with occasional Sandstone or Granite hammerstone, The chips were large and crude and few were retouched. Because much of this material is being eroded from the most recent soils (soils stabilizing recent dunes) most of the material remains must be of recent origin.

\section{Site WPW, 2}

This site is situated approximately 30 yards behind the foredune and is difficult to reach, Here there is a lightly vegetated new dune with approximately $2-3$ feet of stratified aboriginal material exposed in a badly eroded face of the dune.

Fauna. All Rock Platform species, including Chiton and a large number of Notohaliotis. 
Artifacts. An extensive collection was made of exclusively Quartz and Flint artifacts. These were large and crude, with few retouched or utilized flakes.

\section{Site WPW. 3}

WPW, 3 is situated just south of the beginning of a Pleistocene outcrop, An ND sequence overlies the Pleistocene sequence and the material at the site is associated with the older sequence. Destabilization has probably occurred fairly recently, for ti tree trunks with their roots still embedded in the sand litter the landscape. Material is sparse and the site is of limited extent,

Fauna, A lot of bone material was collected including numerous bird bones. Shel1 fauna was predominantly Rock Platform, including the usual species!' Phacosoma occurred less frequently.

Artifacts, A fair number of stone implements were examined, Quartz, Flint and Quartzite tools all occurred (predominantly Flint and Quartz)。 Flakes were generally smaller than on the previous site indicating that there may be some difference in age (culture?) between these sites. However, although no well defined backed blades were found all the tools did not fall into the 'recent' category, For example, one tool appeared to be a broken trapezoid, another belonged to the 'Woakwine' tradition and others appeared similar to tools in the A series assemblage of Site 9A. Sandstone and Granite hammerstone were plentiful.

Site WPW. 4

This site was situated on very recent low dune hummocks which were only $10-15$, above HWM, ${ }^{1}$ The midden 
material is quite concentrated and situated on the seaward side of the small stream.

Fauna, A large quantity of bone material was found (unidentified). She11 fauna consisted of the usual Rock Platform varieties with some Plebidonax.

Artifacts. Mainly made from Flint, with some Quartz and a few flakes of Quartzite.

\section{Site WPW. 5}

This is a huge site situated in a great valley running back from the beach into the interior of the Promontory. The sides of the valley consist of Pleistocene dunes capped by a newer dune sequence which is partly stabilized by a dense layer of vegetation. In other areas destabilization and subsequent erosion have caused the new dune sequence to erode down to the underlying Pleistocene dunes.

Although midden material is widely scattered about the area, most of it is situated in the valley itself. So little material is found on the calcarenite that it is doubtful whether it arrived there by erosion from an old soil. Examination of the sides of the valley for occupational lenses proved fruitless and erosion has possibly been so great that all major lenses have already been demolished.

Fauna. Mainly Rock Platform with some Plebidonax. Artifacts. Made of either Flint or Quartz with few well made implements. Some flakes of Quartzite and a single flake of chert were also recovered.

Site WPW. 6

Most of the material on this site is widely scattered and situated on loose sand. However, it does not extend very far up the side of the ND sequence, 
indicating that most of the occupational lenses have already been eroded away.

Fauna. Mainly Rock Platform with a few Plebidonax and other Sandy Beach species, i.e. Tucetilla and Phacosoma.

Artifacts. Made of either Flint or Quartz with a few flakes of Quartzite。

\section{Site WPW.7}

This site is situated in and around the area of the mouth of Growlex's Creek at the north end of the bay. Material lies scattered down the granite slopes to the north of the stream, and in many places it may be seen eroding from recent soils overlying the granite. Thick scrub covers most of the granite area so that much of the midden material is protected. The soils are shallow and very sandy,

A hundred yards or so to the south-east of the creek exit, scattexed midden material is found on low recent sand hummocks.

Fauna, Almost exclusively Rock Platform including Subninella, Cellana, Dicathais, Austrocochlea, Cabestana, Mytilus and Brachidontes.

Artifacts. Vexy few stone flakes were found. These were exclusively Quartz.

Site WPW.8

WPW. 8 is situated in the south-west corner of Norman Bay. Midden matexial is exposed in cleared areas along the walking track between the end of the beach and the Tidal River Hikexs' Camp. Mainly because of trampage the material is very fragmentary. Extensive man-made alterations have been made to the area including the planting of scrub ti tree. Midden material 
is likely to have been extensive at one time as the area is favourably situated, However, today there is little visible evidence of old camp sites.

Fauna, Rock Platform.

Artifacts. No stone was found,

Scattered midden matexial is found all along the hikers' track between. Norman Bay and Little Oberon Bay suggesting that the Aborigines at one time travelled between these areas by overland.

\section{Site WPW.9 (Picnic Bay)}

Midden material is found at the north end of the beach and in the foredunes and is often located in areas down to the HWM. Shell fauna is typically Rock Platform, very badly weathered and broken up. No stone material was found.

\section{Site WPW.10 (Whisky Bay)}

The beach front is semi-circular. The back of the beach rises sharply onto Granite hillocks. The foredune is fairly well stabilized with immature soils sealing the sequence. At the middle to northern part of the beach, approximately $30^{\prime}-40^{\prime}$ above the HWM and behind the foredune the vegetation has been destroyed and an immature sandy soil has been exposed, The soil is being eroded away exposing Aboriginal material including charcoal, shell and stone, This material is scattered and badly bxoken. The occupational soil appears to run down under the present foredune.

Fauna. Dicathais, Mytilus, Notohaliotis,

Subninella, Cellana and Austrocochlea.

Artifacts. A few flakes of Quaxtzite. Higher up the hill on the noxth side of the beach, shells were scattered about in the undergrowth and could be seen in 
eroded sections. Here Brachidontes and Cabestana were abundant. (Neither of these species was found in the area previously described). A few flakes of Quartz were found here.

At the southern end of the beach, more mature soils overlie the granite which in places rises to over $1^{\prime}$, Midden material is found in these soils lying both on top of and situated within eroded sections of the soil. However, most of the material evidence is found on the northern slope of the south end of the site. In places the shells are heavily concentrated. At the southern side of the south end of the beach midden material is found down to a few feet above HWM. It is apparent that the sea has cut back the occupational soil leaving stratified midden material exposed,

Fauna. Rock Platform - particularly Mytilus and

\section{Cellana.}

Artifacts, No flakes were found.

\section{Sites WPE. 1 and WPE, 2}

These sites were situated at the southern and northern comers of Waterloo Bay on the east coast of the Promontory. At both sites material was being eroded from shallow soils capping steep Granite slopes. Both sites are covered with heavy scrub. However, extensive examination revealed that the midden material is sparse in both areas, particularly on the southern site. Material remains were scattered and not prolific, indicating that these areas were not visited frequent1y. The fauna in both areas was Rock Platform. No stone was found. 


\section{METHODS OF EXCAVATION}

The methods employed in the various excavations at Wilson's Promontory depended upon the excavating medium. For example, excavations were carried out in both soils and sand. The method of excavation used in each of seven excavations are described below.

\section{Equipment}

Two sets of two sieves were used. The sieves were a 2'6" square boxlike arxangement. Each pair of sieves was swung from a Handy Andy (Dexion) frame, The sieves in each unit comprised one $\frac{1}{4} "$ and one $1 / 8$ " mesh. The finer mesh was used to collect charcoal. One sieve pair was painted blue, the other white.

Eight plastic buckets were employed: two blue, two green, two yellow and two red. The red and blue buckets were associated with the blue sieves, the green and yellow buckets with the white sieves. Each pair of buckets also belonged to a particular sieve. Unless strictly supervised, buckets were never emptied into any but their assigned sieves.

The soil was frequently damp so that it was often difficult to force it through the sieves, Gentle agitation with the hands was often required and gloves were provided to protect the sievers' hands. Each sieve had its own find tins. These were checked periodically to make sure they were not overfull. Labelled bags were used to store the excavated matexial. Excavating equipment consisted of four sets of cement trowels, four sets of fixe shovels, four sponge 
rubber kneeling mats, brushes, plastic bags for collecting charcoal, texta-colors for labelling bags, axes and rulers. Levels were taken with a dumpy level and staff. The dumpy was periodically checked against the site datum peg. For all excavations in a single area all levels were referred to this datum, During excavations, equipment was stored in a large tent erected near the site.

Finds were put into white double-lined paper sugar bags which were labelled as follows:

TRENCH NO.; SQUARE NO.; SPIT NO.; DATE: SPECIAL NOTES.

The archaeologist had the sole responsibility for labelling and for the comments on each bag. Field notes were recorded in a standard note book. At the end of each day the find bags were transported to the base camp in a steel trunk. Here they were removed and carefully stored in wooden crates. Bags were checked off against entries in the field note book.

\section{Excavation in Soils (see Diagram 4.1)

Site 9A

Four excavations were conducted on Site 9A. Three were pilot trenches and the fourth was a major excavation. Each excavation was undertaken for a specific reason (see Chapter 4 ).

(a) Excavation 1

This was a single trench 15 feet by 3 feet. The excavation necessitated the removal of a small sand dune overlying the soil. The dune sand was taken off in horizontal 4 inch spits down to the soil surface. Excavation then proceeded in 2 inch to 3 inch spits from the south end of the trench. The soil surface was very uneven so that the first few spits only penetrated 
Squares 1 and 2. As the excavation proceeded further into the soil, the trench was extended northward over the full five squares. Finds from each square per spit were bagged. The order, the size of the spits taken out, and the occurrence of charcoal are shown in Diagram $4 \cdot 3$.

One excavator, one bucket runner, and two sievers were employed on this excavation.

The excavation was laid out in a north-south direction with a compass and string. Wire pegs were driven into the ground (or sand) at the appropriate three post intervals. A11 pegs were offset by six inches from the actual excavated area in order to keep them as markers during the excavation. The sieves were situated approximately ten yards to the north of the excavation.

(b) Excavations Nos. 3 and 5

Before work could commence on Excavation 3, overlying dune material had to be removed down to the soil. However, it was found that the loose sand surrounding the area of the excavation dried out and the walls tended to collapse onto the excavation area. Driftwood was used to build a retaining wall. Hessian bags, tacked onto these walls, also helped to check the fall of sand. In this way an area $3^{\prime} 6^{\prime \prime} x 7^{\prime} 0^{\prime \prime}$ was cleared and a $5^{\prime} 0^{\prime \prime} \times 2^{\prime} 6^{\prime \prime}$ trench was pegged out in the usual way with an east-west orientation.

Work in such a small trench was difficult. One excavator, one bucket runner and two sievers were employed. The excavation proceeded in 2 inch to 3 inch spits, a square at a time. Material from each 2'6" square per spit was bagged. Charcoal was periodically 
collected on the fine mesh sieve. The occurrence of charcoal and the spit sizes are shown in Diagram 4.4 . Excavation $9 \mathrm{~A} / 5$, a $6^{\prime} \times 3^{\prime}$ excavation, was laid out adjacent to Excavation $9 \mathrm{~A} / 3$ with a north-south orientation. This time the sand overlying the soil was dug out in spits. The walls were continually sprayed with water in order to prevent them from falling in. Once the soil had been reached, photographs were taken and sections were drawn. A much larger area of sand was then removed, and a retaining wall was erected to stop sand from falling in from the sides of the trench. The excavation area was laid out and work proceeded as for Excavation $9 \mathrm{~A} / 3$. Diagram 4.5 shows the spit sizes and the location of charcoal samples collected.

(c) Excavation 6

An extremely large volume of sand overlying the soil was first removed. A $9^{\prime} \times 1^{\prime}$ excavation was laid out in three $3^{\prime} \mathrm{x} 12^{\prime}$ trenches, A, B and C (see Diagram 4.18). White pegs offset six inches from the working area were driven into the ground.

Two trenches were excavated simultaneously. Trench A was assigned to the blue sieves, trench B to the white sieves. A spit from Squares 1 and 4 in trenches $A$ and C was first removed. The excavators (four of them) then turned inward and removed similar spits in Squares 3 and 4. In this way trenches $A$ and $C$ were removed. The baulk in between the two trenches (trench B) was protected by wide wooden planks. Carriers used the baulk to remove buckets. Each carrier was assigned a sieve, a set of buckets (i.e. a single colour) and an excavator. In all, then, there were 4 excavators, 4 carriers, 4 sievers, a supervisor and an archaeologist involved on this excavation. 
Spits were taken out in 2 inch to 3 inch bites. A careful watch was kept for any stratigraphic features such as changes in colour, shell concentrations or charcoal horizons. Charcoal and shel1 were collected both in the sieve and in the excavation and excavators were encouraged to remove material in the trench before it reached the sieve. Where wall stratigraphy or changes in colour on the floor of the excavation were apparent, care was taken to try and follow the stratigraphy, The site supervisor was responsible for providing the excavators and sievers with labelled bags, for periodically checking to see that the right buckets were being taken to the right sievers and so on.

After a spit had been removed from the trench, levels were taken at the corner of each square before proceeding with the next spit.

When the removal of trenches $A$ and $C$ was complete, trench $B$ was taken out by working in from the excavated trenches. The excavation was later extended east and south (see Diagram 4.18).

Excavation 6 was situated in a very exposed area. Slight winds caused sand from the nearby dunes to blow continually across the excavation area. Thus, working conditions were not very comfortable. To protect the excavating team, a large $6^{\prime}$ high screen of plastic and hessian was erected on three sides of the excavation (Plate 4.16).

$\underline{\text { Site } 11}$

(a) Excavation 1 (Diagram 4.18)

This excavation was situated on the top of a cliff about 45 feet above sea leve1. A large area of sand was removed before the excavation could be commenced. It was laid out in a north-south direction and an initial 
area of $12^{\prime}$ by $6^{\prime}$ (two $12^{\prime} \times 3^{\prime}$ trenches) was pegged out. The two trenches were excavated in $3^{\prime}$ squares in approximately 2 inch to 3 inch spits. Later the excavation was extended to the north by a further 6 feet (Diagram 4.18).

Since the site was directly open to the prevailing winds, a screen was erected on the west side of the excavation to protect the excavation team (Plate 4.15).

\section{Excavations in Sand}

\section{Site 9A}

Two excavations were conducted on lenses situated in a sandy environment.

(a) Excavation 2 (Diagram 4.7)

This lens was located in a very difficult position. Consequent1y, the excavation was carried out in two stages. An area of scrub on top of the dune was cleared and an east-west trench $6^{\prime} \times 3^{\prime}$ was laid out and excavated to a depth of approximately 6 feet. The walls of the trench were kept in place by the roots of the overlying and nearby scrub. Spits varied between 9 inches to 12 inches in depth.

When this stage was complete, a north-south trench was dug from the east end of the first trench so that the southern end of the new trench lay about a foot above the charcoal lens. Using the new trench as a platform, a working area was cleared on the slopes of the dune. The lens was covered with sand and built outwards down the dune to protect it. Having taken these precautions, a small trench of $5^{\prime} \times 5^{\prime}$ was laid out on the artificial floor with an east-west orientation. It was so situated that all material excavated was well behind the previously exposed face of 
the 1ens. Two inch to three inch spits were taken out down to and through the lens. Two squares, one $5^{\prime} x 2^{\prime}$ the other $5^{\prime} \times 3^{\prime}$, were surveyed in. The excavation was carried out in haste as the sand tended to dry out quickly and collapse into the trench. Thus the walls were kept wet by constant spraying in order to check this. An artificial ramp was built up to the excavation level to give easy access to the area. Charcoal and shell material were collected both in the trench and off the sieve. The spits removed are displayed in Diagram 4. 8

(b) Excavation 4

This lens was situated on a particularly steep part of the dune face (Plate 4.2). It was fairly consolidated but badly eroded on the exposed face. In order to obtain an uncontaminated charcoal sample, the lens was excavated some feet behind the exposed face. A baulk, constructed from driftwood, was placed just south of the exposed part of the lens. Sand was then dug out from above and behind the lens and thrown against the baulk. Gradually a sand platform was built up which eventually covered the lens and protected it from damage. A $4^{\prime} x 2^{\prime}$ trench (two $2^{\prime} x 2^{\prime}$ squares) was laid out with an east-west orientation. The southern line of the excavation was positioned about a foot north of the exposed part of the 1ens. This guaranteed that the charcoal obtained in the excavation had not been exposed (at least in recent times).

The method and problems involved in this excavation were similar to those described for Excavation 2. Consequently, the trench was dug quickly. Roots were encountered in both excavations and these helped to hold the walls of the trenches together. The presence of 
roots was noted as possible sources of contamination of carbon samples. 


\section{METHOD OF SOIL ANALYSIS ${ }^{1}$}

A11 results have been expressed in terms of the oven-dry soil passing a $2 \mathrm{~mm}$. sieve, except that of gravel, which is shown as a percentage of the air-dry field sample.

Electrical conductivity $\left(\mathrm{E}, \mathrm{C} \cdot 20^{\circ} \mathrm{C}\right)-\mathrm{A} 1$ : 5 soilwater suspension was shaken for 1 hour at $20^{\circ} \mathrm{C}$, and the conductivity determined with a 'Philips' conductivity bridge and dip cell.

Soil reaction $(\mathrm{pH})$ - This was determined on the above suspension, with a 'Jones' glass electrode pH meter.

Chloride ion (C1-) - The electrometric silver nitrate titration method of R.J. Best was used, as described by Piper (1942).

Particle size analysis - Where necessary samples were pre-treated to remove carbonates and organic matter by the methods described by Piper (1942). A hydrometer was used to determine silt and clay percentages, and hand decantation and sieving for the separation of coarse and fine sands.

Calcium carbonate $\left(\mathrm{CaCO}_{3}\right)$ - This was calculated from the carbonate content, as determined by the rapid titration method described by Piper (1942).

Organic carbon (Org C) - The wet combustion method of Walkley and Black, as described by Piper (1942) was used. No 'recovery factor' has been applied to these results.

$\overline{1}$

Details provided by F. Gibbons, Soil Conservation Laboratories, Melboume. 
Total nitrogen (N) - A semi-micro Kjeldahl

technique described by Metson (1956) was used. In this method $0.2-0.5 \mathrm{~g}$. of finely ground soil is digested with sulphuric acid, and the ammonia is titrated with standard acid after recovery by distillation in a Markham still.

Hydrochloric acid extract - The extract was prepared by boiling $4 \mathrm{~g}$. soil with $20 \mathrm{ml}$. concentrated hydrochloric acid with refluxing for 4 hours, with subsequent filtration and dilution of $200 \mathrm{ml}$. Phosphorus was determined in an aliquot of this extract using a modification of the Berenblum and Chain colorimetric procedure (Hutton, unpublished data), and potassium was determined in another portion of extract by means of a 'Lange' flame photometer. 


\section{TESTS OF SIGNIFICANCE ${ }^{1}$}

Suppose one has $n$ columns of $+^{\prime}$ s and zeros, i.e.

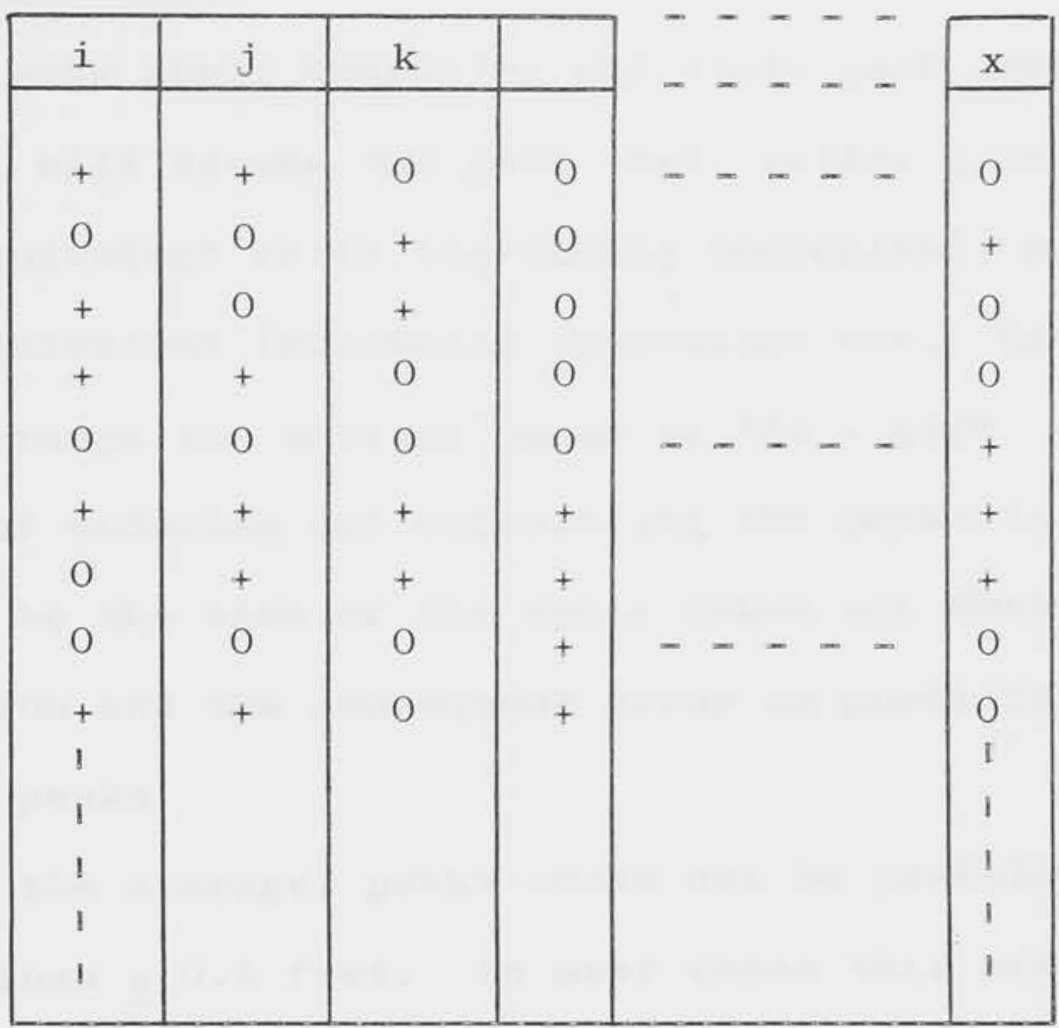

One wishes to determine whether or not there is a significantly large number of cases where there are $n$ +'s in a row.

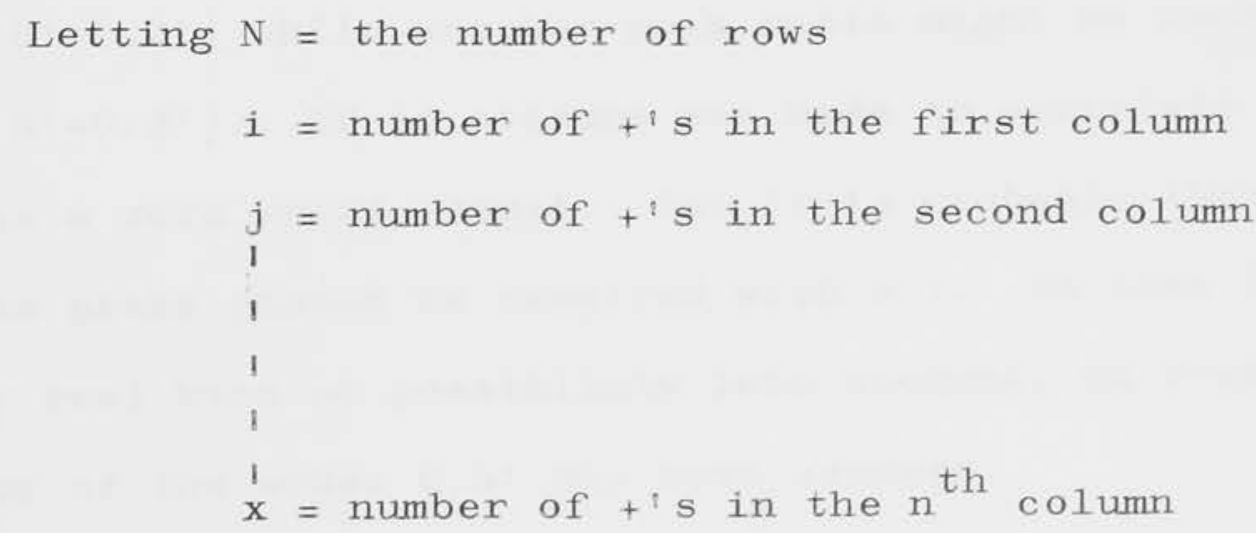

then $W=$ significance factor

$$
\begin{aligned}
& =\frac{k j k \cdots x_{n}}{N^{n-1}} \\
& +1.7 \sqrt{\frac{i(i-1) j(j-1)-x(x-1)}{N^{n-1}(N-1)^{n-1}}+\frac{i j k}{N^{n-1}}+\left(\frac{i j k}{N^{n-1}}\right)^{2}}
\end{aligned}
$$


Then if $W$ exceeds the number of cases for which there are $n+{ }^{\prime} s$ in a row, i.e. $P$, one does not have a significantly large number of + correlations.

The above equation must now be transformed into a form, convenient for use in these calculations. In the following section one will be testing the correlation between peak shell densities and other peak shell ratios. Column i will become the peak shell ratio, $j$ the whole/equivalent ratio (including operculum), $\mathrm{k}$ the whole/equivalent (excluding operculum) etc. One must still arrange the various peaks in the + zero form. The method of ordexing and correlating the peaks is closely related to the size of the spits taken out during excavation and the consequent error in positioning the various peaks.

On the average, peaks could not be positioned to better than \pm 0.1 feet. In most cases this error has been stated as 0.2 feet (meaning that this is the range over which one can locate the peak). A borderline example of peak correlation would be where a peak was actually positioned near one extreme of its error say at $-\left(9.0^{\prime}+0.2^{\prime}\right)$ while another peak ratio might be near $-\left(9.4^{\prime}-0.2^{\prime}\right)$. If an attempt was made to correlate these peaks a zero would result. Yet it is probable that these peaks should be credited with a 1. To take this very real kind of possibility into account, an overall error of the order $0.4^{\prime}$ has been assumed.

Accepting then, that one may position or correlate peaks to within $0.4^{\prime}$ a mechanical system has been designed for correlating and ordering the peaks. Table 5.26 shows how this was done. The left hand column has a set a depth ranges increasing in steps of $0.4^{\prime}$. Taking the depths at which peak shell densities occur 
for each square (from Tables 5.15 and 5.16 ), one may now plot their positions in column two of Table 5.26. In the same way one can take the peak values for other ratios and plot them in, in the other columns. The actual depth of the peak can be inserted or alternatively, $a+$ will suffice。

Correlations between the various peaks and the peak shell density (i,e, P) can then be noted. i, j, k etc. are obtained by adding up columns $2-6$ vertically. Determining the value of $\mathrm{N}$ is more difficult. The value of $N$ must be carefully chosen as it can radically effect the computation of significance factors, For each square one is concerned with the distribution of +'s for each peak value or ratio over a number of arbitrarily defined spits of depth 0.4'. Out of these spits (in each one square) one is asking the formula to decide whethex the coincidence of a number of peaks of different variables is gxeater than could occur by chance, Obviously coincidences can only occur where shell is found in the excavation. Thus in computing the value of $N$ for each square one counts only these spits (arbitrary of magnitude 0.4: - Table 5.26) which contain she11.

Table 5.27 demonstrates the method of calculating $N$. $\mathrm{N}$ is computed per square by noting the depth range in which she11 occurs from Diagrams 2-5.12. Dividing this range by 0.4 gives the value of $N$ for that particular square. Table 5.27 shows the calculation of $\mathrm{N}$ for Excavation No. 1, Site 11 (which is to be used shortly), and also for Excavation No. 6, Site 9A, which will be used in Chapter 6 .

Having determined the values of $N, i, j, k$ and $P$ etc for each square, the total values of these parameters, 
for the excavation as a whole, are obtained by adding up the individual values for each square, i.e.

$$
\begin{aligned}
& N \text { total }=\sum_{a} N \\
& i \text { total }=\sum_{a} i \text { etc. }
\end{aligned}
$$

where $\mathrm{a}=$ number of squares.

One may then compute $W$ for the entire excavation and if $W>P$ one concludes that the particular correlation being considered is not significant. 


\section{MOVEMENT OF SHELLS IN ANTIQUITY}

It is clear from Chapter 6 that shells become separated from their original matrix and move under the action of the wind. The sites that are described below are all B series sites so that the shell fauna lies mainly on sand. Diagram 8.11 suggests the mode of movement in both sandy and soil environments.

In sand, the rate of movement of shell material will depend very largely on the angle of the erosion face. Steepex angles will produce more movement. However, most movement depends on the wind force for without wind there can be little movement, The wind undermines the shells (by removing sand) causing the shells to slip forward into the wind. At the same time they move sideways according to the slope and the wind force. Shells situated on a slope parallel to the wind direction are the worst affected and these may move parallel to the wind.

Shell movement is more severe on sand than in soils and it takes longer for the elements to release a shell in a soil. Even when freedfrom, the soil, matrix adheres to the shell and remains there until water washes it away. On the other hand the wind cleans shells in a sandy matrix. Consequent1y, shells being eroded out of the soil tend to be heavier and dirtier (the soil remains inside and outside the shell) so that more effort is required to move them. On the other hand, shells in a sandy environment are usually clean and newLooking. Diagram 6.32 illustrates that of the eight expeximents set up, the shells in the experiment 
situated in the sandy environment moved and disappeared second only to the experiment in the most open area on Site 9C. Eroded soils are generally fairly horizontal, making it harder for the shells to move. In contrast, the sandy environments are generally inclined, and assist movement. Summarising the foregoing, three points have emerged for destabilized environments:1. Shells move when they are situated in a sandy environment.

2. She11s in a sandy environment move faster and further than those associated with soils.

3. Erosion of a sandy environment proceeds more quickly than does a soil environment. 


\section{APPENDIX 8.2}

\section{RANDOM SAMPLING}

The steps for random sampling a midden site are set out as follows:

1. Morphological examination of the blow out, and division of the midden into sections according to the position of soil horizons. Sections are areas between two soil profiles and each includes the lower of the two profiles.

2. Beach Axis, The area is examined to determine the extent of aboriginal material. The beach axis is a line parallel to the beach and which defines the furtherest extent of material deposits towards the beach. A base line is laid out along the beach axis and pegs are driven into the ground to mark north-south limits of the deposits. The pegs are called Base Pegs (see Diagram 8.15). The base length is measured in six foot units.

3. Next a plan is made of the midden and its area is approximated to a series of rectangles. A specially prepared sheet is available for this purpose (Diagram 8.15). It consists of a labelled grid system where each quarter inch square represents a 36 square foot area in the actual grid system. The total number of squares on the sheet is 10,000. If the midden has some peculiar shape, care must be taken to see that the base coordinates are chosen to allow the odd shaped midden to be outlined on the table. The base line is plotted out along the horizontal axis of the table and the compass bearing of the beach axis is marked in. 
The initial coordinates of the Base Pegs are arbitrary but they must be chosen so that the remainder of the midden can be easily mapped onto the table.

4. Starting at one extreme of the beach axis, the first section of the midden is approximated to a series of rectangles and these are plotted on the chart. Exposed soil profiles are carefully marked in. Pegs mark the corners of the rectangles.

5. This process is repeated for the rest of the midden. Each section is given a number; the lowest part of the midden being designated Section 1. A section may comprise several rectangles or parts, each being labelled A, B, C, etc.

6. For each section of the midden the total number of six feet squares is computed, i.e. by multiplying the length by the width of each rectangle (part) and adding up the number of six feet squares in each section. The following table illustrates this process:

\section{MIDDEN ANALYSIS - SITE 1}

\begin{tabular}{ccc} 
Section No. & $\frac{\text { No. of }}{\text { Rectangles }}$ & $\frac{\text { No. of }}{\text { Squares }}$ \\
\cline { 2 - 3 } 1 & 3 & 340 \\
2 & 2 & 790 \\
3 (top) & 5 & 530 \\
4 (top & 200
\end{tabular}

It was decided that 5 per cent of the middens should be sampled (see later). Thus the number of squares sampled in each section would be as follows:

Section No. $\quad \frac{\text { No. of Squares }}{\text { to be Sampled }}$


7. Each section is then considered separately on

charts of the type shown in Table 8.1. For section 1, 17 is marked off (corresponding to the sampled squares). A book of random numbers is then consulted. Starting at some convenient point in the tables, 17 numbers are selected which correspond to the number of each square in section 1 (these squares are shown in Diagram 8.1). ${ }^{1}$ The 17 square numbers are placed in column 2 of Table 8.1.

8. Having determined which squares are to be sampled they are then marked on the midden plan and given a number 1-17 (taken from Table 8.1). Using the midden plan and a scale ruler, the coordinates of each square (in units of six feet) are determined. The distance to each square is measured from the two Base Pegs on the beach axis of the midden. Alternatively, if the distances are too great (more than 200 feet), the coordinates may be measured from other fixed points. But the new Base Pegs must be accurately located with respect to the original Base Pegs on the beach axis. This process is repeated for the other sections.

9. Wooden pegs with small red flags are provided. Each peg has a number 1-50. A 1ine, approximately 200 feet long and divided into six feet lengths, is attached to each Base Peg. Several personnel are involved in the following operation:

1

It will be recalled that each square has a number 1 to 10,000 and that the sampling tables have the same range. Thus the tables of random numbers can be used in conjunction with the special chart upon which the plan of the midden has been plotted. 
The controller (a) has the completed control chart (Diagram 8,15). He will call out a peg number (e.g. number 6) which he obtains from Table 8.1. A second person (B), will then collect the appropriately numbered peg. The controller then gives the left hand coordinate. A third person (C), in charge of the left hand line, will then unroll his line to the appropriate distance. The controller will then call the coordinate to the man on the right hand line (D), who moves his line into position, Where the two lines meet, and the strings are taunt, the flag man plants his peg and the square is located. Often other personnel are required to help clear the line of debris or to prevent it from being blown about by the wind.

All the squares to be sampled are located in this manner.

10. The counters and collectors are the next to move into the area. Each person is issued with a special board and tables (see Table 8,2). The left hand column of these tables is a list of the faunal species. The horizontal axis has a series of numbers (1-30) corresponding to the numbered pegs. The operator walks up to a peg, notes its number and draws a six feet square around it, He will then count the number of each species in the square and enter the total in the appropriate columns of the table. He then removes the peg and leaves it lying face down. Thus there should be no chance of another operator repeating his work. All the lithic material in the square is collected and 
placed in a bag which is labelled with the site number, peg number and the date.

When the first section is finished, the team moves on to the next one. The method has proved to be fast and efficient, e.g, two and a half acres can be sampled in two days with a team of six men.

11. Other measurements have still to be made. Detailed studies of midden sites, it is hoped, will enable comparisons of midden material and midden descriptions. However, suitable parameters need to be selected. The blow out axis is a parameter which may be defined as the direction in which most of the sand comprising the dune site has been blown. Generally speaking, the axis is determined most easily from stereo pairs. It is usually the longest axis of the blow out, and runs parallel to the prevailing wind. However, in new blows, the extent of the blow out can be limited, with the result that this axis may be hard to define.

A plan of the extent of the blow out is plotted from stereo pairs and superimposed on the midden plan. Middens rarely cover a blow out entirely, For purposes of comparison, the ratio of midden area to blow out area can be calculated for each site sampled.

Comparisons are made between the shape of the midden and the shape of the blow out. If the midden plan is similar to the blow out plan, then the question of whether the aborigines deposited material in the topographic situation provided by the blow out, or whether the material has been redeposited by the wind, should be considered. Further information on this aspect may be obtained 
by examining the nature of the faunal

concentrations. An initial survey of the midden should reveal whether the shell material is uniformly concentrated, in isolated dense concentrations, in heavy concentrations spread over the whole midden, or lightly concentrated, and so on. Observations on the distribution of fragments over the midden, the state of the fauna (newlooking, old, weathered, fragmented, etc.) on signs of European occupation (cattle tracks, vehicle tracks, etc.), may affect the final interpretation of the midden material, and consequently must be carefully examined,

Often a midden may be classed as unicultural. In this case there is no need to random sample the whole area. But in the final analysis account must be taken of this fact, and due allowance made in the calculations. The total area of the midden must always be known, even when the whole midden area is not sampled.

Other factors used for comparing the middens are set out below:

(a) Maximum height of the midden above HWM,

(b) Maximum distance of the midden extent along the beach axis.

(c) Maximum distance of the midden from the HWM measured from the mid-point of the beach axis.

(d) The height of the mid-point of the beach axis above or below HWM,

(e) The distance of blow out along the blow out axis (a rough, relative measure of age of the blow out), 
(f) The extent of the midden along the blow out axis,

(g) Ratio of Pelecypoda to Gastropoda and Rock Platform to Sandy Beach species as measures of selection and physiographical changes along the beach.

Table 8.3 lists the entire range of parameters measured for each midden sampled. 


\section{COUNTING TECHNIQUES AND SAMPLING ERRORS}

Before describing the results of sampling various middens, some attempt must be made to ascertain the errors involved in using the method. This has been done in a detailed examination of two surface sites, Sites 9A and 10A. On these sites all the shells were counted, so that it is possible to random sample them at various sampling levels, and because the true average value per species are known one can calculate the errors at each sampling level.

The location of these two sites is shown in Diagram 2.3. Each site was laid out in a grid system orientated in a north-south direction. A prismatic compass was used to determine bearings and a tape measure sufficed for measuring distances. Large pegs were driven into the corners of each grid system. At Site $9 \mathrm{~A}$, the main part of the grid system was laid out in 6 feet squares by marking the ground with a stick. This saved a considerable amount of time and energy for the grid was of such a size that thousands of pegs would have been required to mark the boundaries of each grid square. Diagram 4.2 shows the surveyed grid layout at Site 9A. Small masonite discs each marked with a grid number were provided and placed in the appropriate squares so that operators could tell the position of each square in the grid system. These discs were held in position by a long nail driven into the ground, Diagram 8.5 shows the plan of Site 1OA which was also laid out in 6 feet squares. The area of $10 \mathrm{~A}$ was much smaller (compared with Site 9A) and pegs were driven into the corner of each grid square (Plate 8,1), 
Operators were provided with a 6: square frame which was divided into one foot squares by thin wires. The frame was placed over each of the grid squares to facilitate counting, Operators counted from left to right along the first row of one foot squares and proceeding down the frame along each consecutive row. The subdivisions in the frame were found to be highly desirable.

Operators were trained initially to recognize the various species of fauna on the midden. They learned to recognize species from their fragments and to make assessments of shell numbers from heaps of fragments. When they had satisfied certain test requirements, they proceeded to classify and count shells on the grid. However, constant supervision and checking of squares was maintained to ensure a high standard of identification and counting,

Most of the counting was carried out by systematic visual examination of each shell heap. Shells were only collected when squares were particularly dense, and where the 'eye method' proved difficult to apply. Although many shells were fragmented they were still compact enough to be treated as a single shell by the 'eye method". However, had these shells been removed, they would have fallen to pieces, thereby increasing the difficulties of estimating total shell numbers. Thus wherever possible the ieye method: was used. Before commencing to count, operators filled in the site number and the date at the top of data sheets (similar to those shown in Table 8.2 ), they then moved the frame into position, noted the grid number and started to count, One species was counted at a time and

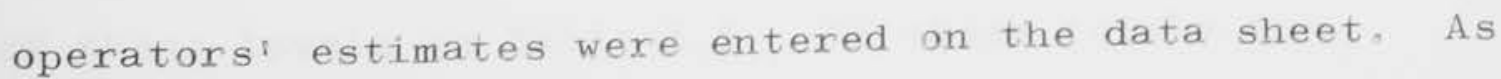


each square was finished the grid disc was removed,

Later, all this information was transferred onto a master sheet,

Shell counts were first taken at Site 9A, Large numbers of operculum were involved, so that they were difficult to count (by virtue of their size), and consequently they were neglected. Amphineura were not counted because they had been overlooked. At Site 10A the latter were counted (but not operculum). The same technique of counting and classification was used on all sites random sampled, (Here operculum were counted),

The raw data for Site 9A cannot be presented here as it is too numerous, However, Diagrams 8.6 and 8.7 show the data in histogram form. The raw data for Site 10A has been set out in Table 8,4 .

Sampling at various levels will now be considered. For Site 10A there are 48 squares, (Refer to Tables 8.5 and 8.6$)$. In the left hand column the number $n$ refers to the number of squares $(n=1$ to 48). Using tables of random numbers a number 1 to 48 has been inserted in column 2 against each value of $n_{0}$

The squares in the grid which have grid numbers $A / 3$, $A / 4$ etc. have been given equivalent numbers $n, e \cdot g, A / 3$ $=3, \mathrm{~A} / 4=4 \mathrm{etc}$. Thus for a value of $\mathrm{n}=6$, the random number is 4 which is equivalent to grid number A/4, Using the data on Table 8,4 the number of each species for grid square A/4 can be written opposite the entry $\mathrm{n}=6$ (Table 8.5), For Site 10A the sampling levels were 20 per cent, 40 per cent, 60 per cent, 80 per cent and 100 per cent. The 20 per cent level corresponds to a value of $n=10$, the 40 per cent level to $n=20$ and so on. The running totals pex species are shown in each of these levels in Table 8.5. If these totals are 
divided by the value of $n$, the average number of shells per 6 feet square per speciles per sampling level is obtained.

These averages are displayed in Table 8.7. The correction at each sampling level is obtained by subtracting the average value at each sampling level from the average value at the 100 per cent level. (The corrections are also shown in Table 8,7). The same procedure was followed for the grid at site $9 \mathrm{~A}$. Results are displayed in Table 8.8. In both cases the errors in the mean at each level ( $\&$ ) have been calculated by dexiving the standard deviation $(\sigma)$ and dividing it by the square root of the sample number, i. e. $\sigma / \sqrt{n}$. The variances have also been calculated for Site $9 \mathrm{~A}$.

The averages for both sites, with their error bars, have been displayed in Diagram 8.9 as functions of the sampling level. As can be seen there is a wide variation in shell numbers per species between the two sites. For Subninella Site $9 \mathrm{~A}$, the average values for sampling levels less than or equal to lo per cent are markedly out of alignment with those at 20 per cent, 50 per cent and so on. The errox at the 20 per cent 1 eve 1 is negligible; at the 5 per cent level it is of the order 27 per cent. Thus it is not possible to draw a linear graph through the coordinates. The non linear behaviour at the lower sampling level must be due to an unfortunate selection of squares in the sampling procedure. However, when the error bars are taken intc. consideration it is possible to draw a straight line through the six sampling points. 1

The graphs for Sites $9 \mathrm{~A}$ and $10 \mathrm{~A}$ are very similar up to the 20 per cent level. 
In general the error at levels less than 20 per cent is fairly high. Table 8.9 considers the average percentage error at the 5 per cent level for each species for the two sites, This average error will be used to correct sampling proceedures at the 5 per cent level. The corrections to be applied at other sampling levels can be obtained from Diagram 8,10, which is a graph of the percentage corrections per species as a function of the sampling level.

An important consideration in using these errors is the effect of species density (per 6 feet square) on the error at each sampling leve1. That is, one wishes to know whether the density of species (or total shell density) affects the value of the sampling error. Some consideration needs to be given to this problem, because the densities on Site $9 \mathrm{~A}$ and $10 \mathrm{~A}$ are quite different to those of the B series sites. However it is on the basis of calculations on the A series surface sites that error corrections have been deduced, so that one needs to justify the use of these corrections on B series sites.

Table 8.9 shows that there is a considerable difference in the magnitude of the averages for the various species between sites $9 \mathrm{~A}$ and $10 \mathrm{~A}$ ( 5 per cent leve1). Thus if it can be demonstrated that the error is independent of magnitude for these cases, it should be equally true for differences in magnitude between A and $B$ series sites (i,e, the error corrections could be applied to B series sites).

Not all species appear in Table 8.9 and only those species that are common to both sites are compared. In this table, the average number of shells per species and the average error per species have been ranked. 
Similarly the divergence between the errors per species (at the 5 per cent level) for the two sites have been listed in the last column of the table. Comparison of the ranked shell numbers and errors, suggest that there is little correlation, i,e, that the exror is not dependent on the number of shells. A standard correlation test (Table 8.10) confirms this, The divergence magnitudes, when compared with she 11 numbers per species, are fairly constant suggesting that the errors per species are independent of magnitude for the two sites. Correlation between error per species of Sites $9 A$ and $10 A$ is not significant (Table 8.11). Thus the errors are fairly random and the average values of the percentage errors per species (Table 8.9, and Diagram 8.10) must be regarded as estimates only. It will be noted from Table 8.11 that there is a tendency for the errors to go down as the shell density per six feet square goes up. Diagram 8.10 will be used to correct the estimates of the number of shells per species derived in the random sampling procedures.

Lithic Material (worked and unworked)

This was split up into Flint, Quartz, Quartzite and other. Table 8.18 sets out in detail the number of worked and unworked flakes of each material for each grid square at Site 10A. No attempt has been made to present similar data for Site $9 \mathrm{~A}$ because it is too copious.

The method of calculating the sampling error is the same as that described previously for the shell material. Tables 8.19 to 8.20 sets out the detailed calculations for Site 1OA at five sampling levels and Table 8,21 shows similar results for two sampling levels for Site 9A. The percentage correction has been plotted in 
Diagram 8,8, This is negligible for the 40-100 per cent levels for all materials, but below this it can be quite high - of the order 50 per cent. Thus it would be safest to sample at the 40 per cent level, but because of the great saving in time the 5 per cent level was again used. Average corrections applied to lithic material are as follows: Flint, +25 per cent; Quartz, +10 per cent; and Quartzite, + 50 per cent.

For Sites 2 and 5 complete collections followed sampling. Results were as follows:-

\section{Materia 1}

Flint Quartz Quartzite

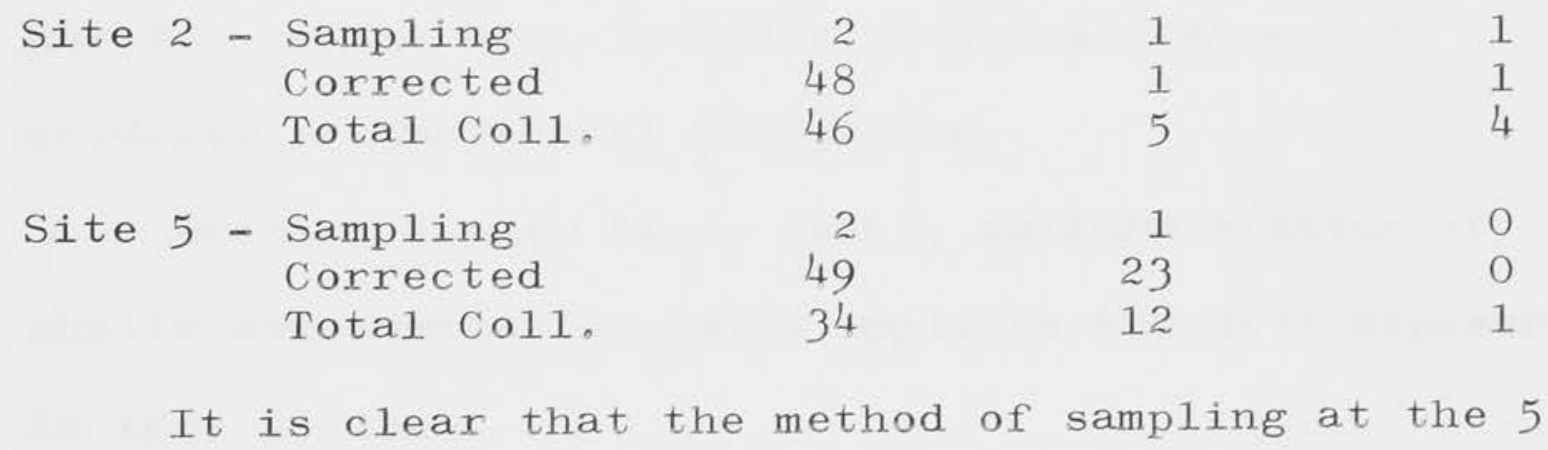

per cent level gives reasonable results. However, the technique is limited to a consideration of total flakes (worked and unworked) and cannot be expected to give reliable results for calculating the total number of worked flakes. 


\section{TOPOGRAPHICAL NOTES}

Site 2 (Plate 8.2)

This site was very exposed. It is situated adjacent to Darby River. In contrast to Section 3 which has only recently been destabilized, Sections 1 and 2 have very little dead Ti tree scattered over their surfaces.

Section 1 has a fairly uniform scatter of shells and the blow out sides are vegetated. The exposed soil horizon to the east is badly eroded and shows no evidence of aboriginal occupation.

Section 2 also has a fairly uniform scatter of shells and similar comments apply to the soil exposures in this section.

In section 3 there are no exposed soils except at the very top of the blow out. Here, an immature and recent soil may be seen. The sides of section 3 are vegetated. Concentrations of Brachidontes and Plebidonax are found on the south side of the midden.

The site yielded little lithic material. Much of the latter may have been removed by collectors because the site is adjacent to a well frequented beach.

Site 5

This site is fairly well protected. The tangled scatter of dead Ti tree trunks suggest that destabilization commenced only recently. The shell material was not uniformly scattered over the sampling area but occurred in isolated patches. More material tended to be concentrated at the north end of the midden, There were concentrations near areas where soil 
and sand lenses were being eroded out of the steep face of the blow out, Thus a light grey immature soil approximately one foot thick was situated at (a) (Diagram 8.13), Shells were embedded in the soil, and were being eroded out and scattered down the face of the dune. A similar situation was apparent at (b). Here the soil was about $1^{\prime} 6^{\prime \prime}$ thick with a charcoal-shell band embedded in it. Some of the material in the grid system must have derived from (b). Possibly (a) and (b) are contemporary. Site 5 was treated as unicultural and it is likely that all the material on the surface has derived from the exosion of these soils,

Site 9D (Plate 8.3)

This site will be treated in more detail to illustrate the complexity of some midden sites.

General Description. Site 9D consists of loose sand being supplied from the modern foredune and from older dune series nearby, The front of the dune has been blown down to the water table and the exact relationship of this part of the dune to its more easterly counterpart is not clear. Diagram 8.14 is a plan of Site $9 D$ and Diagram 8.15 shows the sampling method used on the site. Site 9D is situated between two ridges of A series dunes. The foredune in front of 9D overlies a peat layer, There appears to be an. immature soil horizon containing aboriginal material approximately 3 feet above the peat, This soil can be traced for some distance along the beach, from site 9C southwards beyond the most southerly extent of 9D. The same soil exposure can be traced inland underneath the foredune and other smaller dunes which are stabilized by light scrub, to the most westexly extent of 9D. The 
base line of the midden is situated at approximately the same height above sea level as the immature soil. The area below 1400 (Diagram 8.15) is essentially flat and extremely damp, Thus the water has great difficulty in seeping away so that an area of bad drainage has developed. 1

Throughout this flat area soil exposures can be seen. These are badly exoded and their state of preservation is generally poor. Very little of the original soil horizons remain. It appears that it was originally approximately $3^{\prime}$ thick. Stratigraphically it can be divided into three layers:-

(a) $0-1$ : light grey immature humus with shel1 and charcoal.

(b) $1-2$ ' grades from grey-buff hard sand. (c) 2-3: buff, loose sand.

In the area $0-1400$ nearly a 11 this soil has been removed, though outcrops of the soil do occur in the lower areas. The soil is best preserved between the base of the midden and the foredune, The latter area is

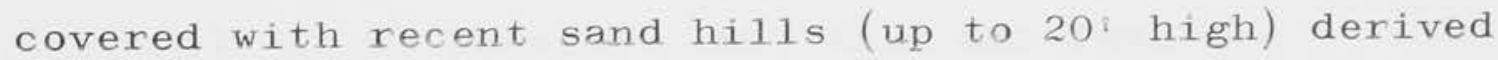
from the foredune. The light scrub which covers these hillocks is probably watered by fresh water which seeps out over the peat and beneath the soil layers. In places the hillock sand has been stripped down to the soil which lies exposed. The latter contains aboriginal remains which may also be seen in the soil exposures along the beach. Aboriginal material is also found scattered through the scrub between the beach axis of 9D and the foredune, but the greatest concentrations occur near soil exposures. Remembering that the foredune and 
the hillocks are among the most recent additions to the coastal area, some alternative explanations for the presence of material so far to seawards are set out below:-

(a) This material was deposited very recently by Aborigines.

(b) It has derived from the soil but has been deposited on the foredune and hillocks by the wind, From the presence of large amounts of driftwood amongst the hillocks, it is certain that high tides can disturb and wash material up into the area.

(c) The main dune comprising Site 9D behind the vegetation line may have at one time covered this area. It could have been blown back causing material in the body of the dune to be redeposited in lower horizons. Ti tree trunks which are scattered all over 9D, indicate that the area was once completely covered by vegetation.

(d) It is possible that this material was deposited by a combination of all or some of these factors.

The flatness of the region between the beach axis and the foredune suggests an origin for the soil. The present edge of the blown dune may represent the original extent of the peat inland. During and after the formation of the peat, the area would have been flat and swampy. Later the swamp was filled with sand. However before the sand drifts were able to build up too much, a period of stabilization. (vegetation growth) caused a soil to form only a few feet above the original peat line. possibly the entire area of 9D was under 
vegetation at this time, so that one contemporaneous soil may have covered the entire area.

Today, beyond 1400 , the midden climbs slowly and soil exposures are absent, Thus, either the soil continues under the dune, or it was never widely distributed, Alternatively, the soil which once covered 9D has been completely destroyed. This latter possibility is the most likely.

Midden Remains. There is evidence to suggest that the aborigines camped in a sandy environment on this site, for there are several concentrations of shells of different species in the area, Brachidontes is a very small and light shell. The shell experiments previously described indicated that once they were freed from their soil or sand matrix they disappeared. In situ deposits are indicated by a number of concentrations of these shells still embedded in a sand and charcoal matrix.

In general, midden material on 9D is widely scattered and with several concentrations of material. Towards the back of the midden the faunal material becomes very sparse and much of it is fragmentary (probably carried there by wind).

Analysis. Since the morphology of the midden was not clear, the site was treated as unicultural, though it is possible that mixed material is present on the site.

The plan of the blow out was drawn from field measurements and sterio pairs. Detailed sectioning of the midden is shown in Diagram 8.15. Descriptions of the soil exposures follow below. 
$\frac{\text { Notes on Exposed Soil Profiles of Site 9D* }}{\text { (Refer to Diagram }}$

(a) Surface undulating, 1" to 5" depth of soil exposed. No artifacts or visible stratification. Exposures poor.

(b) Flat exposures. Shell and artifacts lying loose on surface, Probably deposited there from sand above. None are embedded.

(c) Flat soil exposure. Three Subninella undulata are embedded to a depth of half an inch. Numerous numbers of other species lying loose on surface of soil. Embedded specimens could have been buried by the soil wash from just above, $i, e$, they are not necessarily in situ.

(d) Sloping exposure with two embedded shells in the upper portion of the soil. Subninella undulata and Cellana tramoserica). Some shells embedded in a light brown sand - a mixture of dune sand and a weathered soil layer beneath the loose sand.

(e) Plane exposure following the dip of the blow. No stratified material.

(f) Prominent horizontal exposure, Maximum exposed depth 14". Average 8". Austrosuccinea australis scattered sparsely through the top 6 " of the soil. They are also embedded in the surface of the soil. Presence of other minute gastropoda noticed.

(g) Slightly undulating surface exposed. No stratified material.

\footnotetext{
* The author wishes to thank Miss M. Opthorpe (geologist with BHP) for these notes.
} 
(h) Seventeen inch vertical section of soil

exposed. Austrosuccinea australis and

Subninella are embedded in top surface of soil.

(i) Numerous Subnine1la undulata, Plebidonax

deltoides and operculum are embedded in this soil (top only). Two feet vertical height of soil exposed, Charcoal is embedded in soil.

(j) Chaxcoal is embedded in soil. 
ENVIRONMENTAL STUDIES AND SHELL FAUNA

Many factors affect the growth characteristics of marine shells. To determine these factors there is a need to study the ecology of extant species. In so doing the variables can be isolated and the problems more closely defined. Thus before proceeding to the archaeological situation some of the principle factors efffecting the ecology of shell fauna need to be discussed.

\section{Marine Ecology}

Nearly all the shell fauna recovered in the A series excavations belongs to the intertidal or Littoral Zone. ${ }^{1}$ Most of the following comments apply to the Littoral Zone and to a lesser extent to the Sublittoral and Supralittoral Zones.

Numerous authors have commented on the complexity of the Littoral Zone (K.M. Wilbur and C.M. Yonge 1964, p.59). ${ }^{2}$ The following factors effect the species distribution: the area in which the marine fauna is found, the amplitude of tidal oscillations, climate, degree of exposure to wave action, exposure and emersion times, intensity of light, salinity, temperature, humidity, available oxygen, time available for feeding and the substratum (ibid). These factors effect the various species differently.

1

A full definition of this zone will be found in J.W. Hedgpeth 1957, fig. 1, p.18 and M.S. Doty 1957, pp.550-1. 2

Their book entitled 'Physiology of Mollusca' and H.B. Moore's 'Marine Ecology' (1958) were used as basic texts for this chapter. Detailed bibliographies will be found in both books. 
In general, temperature is the most important single factor affecting a shell's growth characteristics (H.B. Moore 1958, p.17), and in the Littoral Zone it makes itself felt in several ways. At low tide mollusca are exposed for varying periods of time depending on their height above the lower limits of the Littoral Zone and on the tidal period itself. During low tide the exposed shells are subjected to solar radiation and if they are to survive they must be able to withstand temperatures far in excess of any encountered while they are submerged (C.M. Yonge et a1., 1964, p.60). In these cases air temperature is very important.

As the tide recedes, numerous rock pools are left behind, and depending on their size and distance from the splash line these pools may become environments in which molluscs can exhibit extreme growth characteristics. ${ }^{1}$ These pools may record temperatures well outside the normal annual range, while evaporation or rain can cause changes in salinity which the animals must be able to withstand to survive (M.S. Doty 1957 , p.575). Thus it is possible to obtain physiological variations in particular species within a single habitat, though these variations are likely to be much less than those which can occur between habitats well separated geographically (K.M. Wilbur et al., 1964, p.73).

It has been shown that temperature effects not only the geographical distribution of a species, but also the growth rate and the size of the species (G. Gunter 1957, pp.171-2). In general the size of many species increases as the equator is approached (ibid., p.178).

1

Rock pools are discussed in H.B. Moore 1958, p.181 and M.S. Doty 1957, p.570. 
Moore (1958) has discussed the effect of temperature and other factors on the growth characteristics of mollusca in considerable detail. He points out that temperature effects the reaction rate, the solubility of oxygen in water, and salinity. These factors influence the growth rate of the mollusca, e.g. the respiratory rate and the precipitation of Calcium carbonate (ibid,, p.17). Salinity effects organisms through specific gravity control and variations in osmotic pressure (ibid, p.39). Wave action will often determine the type of species found in a particular area, for in very open situations, waves can do great damage and only those species with the ability to remain in position, can survive (ibid, p.55). Currents effect the food supply to the area (ibid, p.63) and tides determine both the duration of, and the time of exposure (ibid, , p.76).

\section{Cellana tramoserica and Subnine11a undulata}

The two dominant species recovered in the A series excavations were Cellana and Subninella (Table 10.5). Other species were recovered, but in general they are too fragmentary or rare to warrant further investigation. Quite a number of Subninella and a large number of Cellana have been recovered in a perfect state so that these species, particularly the latter, may be subjected to a more intensive study. Unfortunately, relatively little is knownabout the biology of either species. Subninella is found between the mean low water neap (L.W.N.) to mean low water spring (L.W.S.) (R. Endean et a1., 1956, p.103), Their usual habitat is amongst boulders, or in crevices covered with seaweed. They are found all along the coast of Victoria and the east coast 
of Australia as far north as Currumbin, just north of the New South Wales-Queensland border (ibid). Cellana live between mean high water neap to mean low water neap and their geographical distribution in eastern Australia is similar to Subninella, except that Cellana are found as far north as Double Island Point (ibid,, p.104). Cellana are often exposed for long periods of time, while Subninella are generally continually immersed (or in rock pools) or are situated within the splash zone.

Although little is known of Cellana itself a fair amount of information has accumulated on related species. In order to illustrate the complex nature of the ecological factors effecting the growth characteristics of this species it will be valuable to discuss some of this data.

\section{(a) Distribution}

The abundance and distribution of limpets depends on several factors. According to Lewis (1954, pp.85, 96) the amount of sunlight and splash or spray are the governing factors, Other authors suggest that availability of food is more important (ibid., p.95). However the distribution pattern is also dependent on the local physiography, and in very exposed positions, wave action can significantly effect distribution (N. Abe 1933, pp.173-4).

Young animals tend to colonize in the low tide region, where the spats are alternatively exposed and drowned (N.S. Jones 1948, p.62), In the case of Patella vulgata when growth has proceeded beyond about $3 \mathrm{~mm}$, in length there is a tendency for the animal to leave the spat and migrate (ibid). With Acmaea dorsuosa, the younger animals (less than three years old) tend to remain lower down, those older than four and five years 
live higher up and those between four and five years are random scattered about the original colony (N. Abe 1933, pp.175-6). Dispersion and reformation of colonies appears to be a function of atmospheric temperature (ibid., p.173).

Patella tends to stop migrating when it reaches a length of between 10-15 mm. (E.S. Russe11 1907, p.859). From its 'home' position it makes excursions to browse on surrounding algae of up to several yards while covered by the incoming tide. In general the animal returns to its original position before being exposed by the outgoing tide ( $\mathrm{J} . \mathrm{R}$. Lewis 1954, pp.97-8; N.S. Jones 1948, pp.66, 68; E.S. Russe11 1907, p.857). There is some evidence that the younger animals may wander while exposed at low tide (E.S. Russell, ibid).

(b) Growth Rate

The growth rate is a function of environment. For example, Jones has demonstrated that limpets in the Port Erin district tend to grow much faster in their first year than similar species in the La Cite and Dinard districts (N.S. Jones 1948, p.63). He claims the growth rate is dependent on the presence of Fucoids and Balanus zones and suggests that limpets living on bare rock grow faster than those in other habitats (ibid, p.73).

Fucoids favour a high growth rate in the spats while the presence of algae and barnacles inhibits the size and distribution of the colony.

Orton lists comparative figures for patella from different habitats for the different year groups, and it is clear that there are wide variations in the rates of shell growth (T.H. Orton 1928, p.867). Animals of similar age in the same colony can exhibit variations in growth rate (ibid), 
In general, the rate of growth falls off after $x$ years and there tends to be less growth during the warmer months of the year (E.S. Russe11 1909, pp.244-5). The smaller animals (less than $25 \mathrm{~mm}$.) of Patella grow almost continuously throughout the year with a tendency to slower growth in midsummer and midwinter. Animals with shell lengths greater than about $25 \mathrm{~mm}$, do not grow continuously, growth usually ceasing altogether between the end of August and February (European winter) (J.H. Orton 1928a, p.858; 1928b, pp.865, 873).

\section{(c) Growth Characteristics}

In general, the shell of the limpet does not grow uniformly (E.S. Russe11 1909, p.250) and the architecture of its shell is dependent on the local environment. Comparison of various ratios, such as the length/breadth, and the length/height of shells from both high and low water areas shows that marked differences can occur between shells in the two zones (ibid., 1907, pp.860-1). She11s from the high water areas tend to be narrower and higher. Comparison of similar ratios for sheltered and non-sheltered areas shows that shells from exposed areas are thicker, heavier and in general more irregular in outline (ibid., pp.862-3, 865). Russel1 has also distinguished rough shells, which tend to be heavier and thicker, and smooth shells. The degree of roughness is a function of the rock surface to which the limpets are attached (ibid., p.868). On the other hand the height of the shell is a function of the degree to which the animal is subjected to desiccation (J.H. Orton $1928 \mathrm{~b}, \mathrm{p} .873)$ and the position of the apex shifts as growth proceeds (E.S. Russe11 1909, p.249).

\section{Ce11ana tramoserica}

The foregoing illustrates the complex nature of the colonization of the Littoral Zone by the limpet in 
European contexts. Little is known about the Australian species. However several factors have been established:-

(a) the size of Cellana is independent of wave action (G.R. Meyer, et a1., 1963, p.190);

(b) the density of Cellana is dependent on the locality and wave action (ibid, p.189). Areas with least wave action and exposed platforms tend to have greater concentrations of shells (ibid,, p, 189). Wave action appears to be effective only in Spring (A.K. O'Gower, et a1., 1965, p.215), Density is also dependent on the wind (whether it is dry or warm) and the density of the larger individuals tends to be associated with 'cool' seasons (ibid, p.216);

(c) Cellana seems to be associated with other species, particularly Austrocochlea constricta (G.R. Meyer, et al., 1963, p.191) :

(d) Temperature and wave action are the most important factors effecting the seasonal abundance of Cellana (A.K. OiGower, et al., $1965, p .217$ )

Unfortunately the effect of temperature on the growth characteristics of the Limpet have not been studied in detail, though there is evidence to suggest that it is one of the most important single factors affecting its growth.

Consider the following hypothesis: Suppose that a measurable parameter of the shell (y) is determined mainly by the temperature of the habitat $t$. Then if different habitats have different ranges of temperatures they should have different ranges of $\mathrm{y}$. 
It has been demonstrated that there may be a

considerable variation in growth rate (and presumably temperatures) between habitats. There are many shell parameters to choose from. In the papers cited above, length has been used as a measure of size because it tends to reflect the behaviour of all the other parameters. Other parameters include width, thickness, height, weight, circumference, and combinations of these converted to ratios.

In order to compare measurements between and within habitats some information must be available about the age of the shells. Thus comparisons are made in terms of shells of specific ages, or in terms of the yearly or periodic growth ranges. Unfortunately it is not easy to determine the age of Cellana. The growth rings are often not clear and thin sectioning reveals a myriad of lines which cannot be interpreted.

\section{Sampling}

If one collects a colony or colonies of limpets and plots a length-frequency histogram it is possible that several modes will result, The spaces between these modes correspond to age classes. Normal curves can be fitted to the modes and the range of $y$, or the value of y at which each peak occurs per age class (period) may be determined (K.M. Wilbux and C.M. Yonge 1964, p.225, fig.8). If measurements were made at various time intervals on the one colony, the means of each age class would shift slightly, i.e. because the shells are growing continuously. Thus the range of y for each periodic interval would vary depending on the time of the year the sample was collected. This problem can be overcome in one or both of two ways, (a) collections can be made at several intervals during the year, and from 
different colonies, (b) the sample can be random, extending over a wide area and many colonies. ${ }^{1}$ In this way the sample will contain a complete range of life histories so that the widest range of $y$ for each age class can be determined from the histograms.

Studies of Cellana and Subninella have been made from similar habitats along the coast of New South Wales and Victoria. The method of sampling at each station is described in Appendix 9.2.

Diagrams 9.1 and 9.2 show the relationship between the weight of animal plus shell, and the operculum length (Diagram 9.1), and the shell Iength of Cellana (Diagram 9.2), Since weight is approximately proportional to age these diagrams indicate that for both species the growth rate drops off as the animal gets older. They also demonstrate the wide range of weight for each shell length (and vice versa). This scatter of values is a feature of all parameters. Diagram 9.3 illustrates the scatter for length versus width (Cellana), and Diagram 9.4 the scattex for length versus circumference (operculum), Similar results are obtained for other parameters. Thexe is no parameter which gives unique values, so that when $y$ is chosen, one must be prepared to accept insensitive functions which produce a scatter of results. To this end, length was selected as y mainly because it is a convenient parameter to measure。

Diagrams $9 \cdot 5-9.8$ are the histograms of the length frequencies for Cellana from different localities. Several modes are apparent in each diagram (Diagram shells), provided growth stops before death. 
9.5 - five; Diagram \$.6 - five; Diagram 9.7 - four; etc).

Table 9.1 lists the possible range of $y /$ age class intervals for Cellana from several habitats, and an attempt has been made to correlate age classes per habitat. The average temperature of the ocean in the vicinity of each habitat is given at the foot of the table, Although the arrangement in the table is somewhat arbitrary, the result suggests that the range of $y$ per growth period is inversely related to the temperature of the habitat.

Diagrams 9.9-9.12 show histograms of the frequency of the length distribution for operculum for various habitats. It is apparent from these diagrams that no information can be obtained on the age of the species by this method. Diagram 9.12 is a circumference-frequency histogram for operculum, and it may be possible to determine age groupings from this form of data. However, for the remaining part of this Appendix, attention will be directed to the study of Cellana, for, from the point of view of age grouping, it appears to be the more promising of the two species.

\section{Calcite Aragonite Ratios}

The method of age determination described above is not very sensitive, A further way of approaching the problem is through a study of the structure of the shell itself. The shell may be composed of one or more combinations of three carbonates, calcite, axagonite and vaterite (K.M. Wilbur and C.M. Yonge 1964, p.263). Where shells are made up of combinations of these carbonates the ratio of one type of carbonate to the other is principally temperature dependent (ibid, p.266). If the temperature of the habitat is reflected in these 
ratios one has a complete temperature record of the environment contained in each shel1. Preliminary analysis showed Cellana to be composed of a combination of calcite and aragonite, so that this species proved suitable for further investigation. On the other hand Subninella and Plebidonax are unsuitable because they are composed of 100 per cent aragonite.

The two most important factors effecting the calcite-aragonite ratio ${ }^{1}$ are salinity and temperature (H.A. Lowenstam 1954a, pp.42-3; 1954b, pp.289-93, 308). However small changes in salinity are ineffectual and this factor needs to be considered only in areas such as the Baltic Sea or in estuarine conditions where the salinity is significantly different from the Atlantic and Pacific Oceans (ibid, 1954b, p.308)。

Shells tend to lay down more aragonite during the warmer months of the year (ibid, 1954a, p.43). Consider a shell which begins to grow in August (Australian winter). Throughout winter the she11 will tend to lay down mostly calcite and during spring and summer there is an increased tendency to lay down aragonite. Thus if the shell was collected in January of the following year it would contain a complete temperature record of the previous few months in terms of its C/A ratio, The ratio would be large for August and smaller for January. Older shells collected at the same time will contain temperature records extending back to the previous summer and beyond (ibid., $1954 \mathrm{a}$, p. 45; 1954b, p.309), If a large number of she11s are considered, and a growth characteristic measured for each shell is plotted as a function of the average C/A 
per she1l, the resulting curve should have periodic peaks and troughs corresponding to the annual (or periodic) growth cycle of the species, Lowenstam has demonstrated that this type of behaviour does indeed occur (ibid., 1954b, p.310, fig.7).

However, there are several complicating factors associated with this technique.

1. Some species do not grow throughout the year and the secreting temperature range may not coincide with the environmental range. The temperatures above or below which the species will not grow are called threshold temperatures (ibid, 1954b, p. 309; 1954a, p.46; H.A. Lowenstam and S, Epstein 1954, p.208; S, Epstein and H.A. Lowenstam 1953, pp.424-5).

2. Temperature effects different species in different ways (i.e. a species effect) (H.A. Lowenstam 1954b, $\mathrm{p}, 45)$.

3. The volume of shell laid down is dependent on the age and the history of the shell as weIl as the temperature.

4. Assuming that the shell only grows at certain times of the year, the time of collection becomes important unless adequate precautions are taken to ensure a representative sample is taken. For this case the range of $C / A$ ratios will be smaller than for species which grow over the full temperature range of the habitat. This means that the temperatures derived by the C/A method for shells which do not grow all the year round will be displaced from the actual average annual temperature of the habitat,

From a consideration of related species it would 
probably takes place when the shell is covered by water, so that the temperatures reflected in the C/A ratios should be representative of the local oceanic environment. However it is difficult to assess the behaviour of limpets living in tidal pools and these may give temperatures in excess of the open oceanic environment.

\section{Temperature of Habitat and Shell Growth}

Diagram 9.13 shows the C/A ratios for Cellana from three different areas as functions of shell length. 1 A number of peaks and troughs are apparent, though the lack of points on these graphs making their final shape a little arbitrary.

For each age group the length range for each habitat can be plotted as a function of the mean temperature of the environment. In so doing one does not need to know the absolute calcite or aragonite values, the peak C/A ratios, or the exact growth period. Ideally then, one could plot several length ranges/age class interval (first year range, second year range etc.) versus temperature. However in order to take into account the fact that there can be shifts in the limits of these ranges it is more valid to plot the range multiplied by the maximum length reached for the particular age group considered (factor $x$ - see Table 9,2). $x$ has been plotted as a function of temperature for each of the second to the fifth growth periods (Diagram 9, 13). The first period has not been considered because it is inadequately defined, 2 Juvenile specimens were usually

1

The method of determining the $\mathrm{C} / \mathrm{A}$ ratio is discussed in detail in Appendix 9.3.

2

The second growth period is also inadequately defined for the Broulee sample. 
too small to analyse since they did not provide enough powder for an $\mathrm{X}-\mathrm{ray}$ analysis.

These graphs are not linear and the lines shown are lines of best fit. This situation is not unexpected because $x$ may be influenced by factors other than temperature. However each habitat was chosen so that these factors were minimal or in common (see Appendix 9.2).

Comparisons of Table 9.1 and Diagram 9.13 for Wilson's Promontory (extant species) show that modes (Table 9.1) and minimas (Diagram 9.13) are in approximate agreement. However the resolution of both methods of age grouping is not good and refinements need to be made. Equal1y, other factors which may effect the biology of Cellana also need to be investigated.

Nevertheless, these preliminary results may be used to illustrate a method of determining the temperature of the ancient environment.

6. Temperature of the Fossil Oceanic Environment Diagram 9.13 shows plots of the $\mathrm{C} / \mathrm{A}$ ratio for Cellana from the upper and lower levels of $11 / 1$. The factor $\mathrm{x}$ has been computed for each growth period and is tabulated in Table 9.2(b), Table 9,2(c) shows the stratigraphic position of the shell samples used in the C/A determinations. Using the level diagrams 5.1 and 5.2 in conjunction with Diagram 4,14, the age of the upper and lower levels have been computed as approximately 3,600 B.P. and 6,100 B.P. respectively. It was not possible to cover the entire growth cycle of the fossil samples. Those portions shown in Diagram 9.13 correspond to the fourth and fifth (or possibly the third growth periods). The predicted temperatures are shown for each of these growth periods 
in Table 9.2(b) (taken from Diagram 9.13). Leaving aside the possibility that the $x$ values might belong to the third growth cycle, slightly higher average annual temperatures are indicated for the lower levels $(6,100$ B.P. level). On the other hand temperatures for the upper levels $(3,600$ B.P.) are compatible with present mean sea temperatures.

The slightly increased mean temperature could have been caused by a difference in local topography. In Chapter 4 it was suggested that this section of the coastline in A series times consisted of a series of small bays. It is possible then that Cellana colonies within these bays lived in an envixonment with a slightly higher mean annual temperature than the open ocean nearby. However, several experiments have been carried out on the variation of temperature along coastlines with small bays. The results of many measurements indicate that the variation of oceanic temperature within and outside the bays is of the order half to one degree (at high tide), that is of the same order of exror as the temperature measurements themselves. It is possible then that the temperature predictions could represent the temperature of the older open oceanic environment. However until the method is refined one can say little more.

The C/A ratios for the archaeological shells are in general higher than for the extant species. The arangonite has probably been leached from the shells over a long period of time. This leaching effect should be approximately the same for all the Cellana within the soil, so that although the absolute values of the C/A ratios cannot be used as a basis for comparing archaeological and extant species, their C/A ratios (as 
a function of length) should still define the positions of the peaks and troughs.

This technique shows great promise, Aboriginal middens consisting mainly of shell fauna are found along much of Australia's coastline. If this technique could be refined it would give the archaeologist a powerful tool, both for extracting important environmental evidence and for dating sequences. Once the temperature-x graphs have been established for a local area, radio-carbon dating can establish the chronology of the sequence. A graph of temperature (or $\mathrm{x}$ ) versus time could then be employed to interpret local surface material. Shell fauna from open sites would then be indispensable in assisting to determine the chronology and ecology of past cultures.

Comparison of modes (Diagram 9,14) and troughs for the archaeological shells shows the same general agreement as was obtained for the extant species. 1 Unfortunately, the numbers of shells were too small to properly define the age groups, and for the upper levels the resolution was too poor to make any comparison. For the lower levels, peaks were located in the approximate ranges $2,7-2,8,2,9-3,0(?), 3,3-3,4,3,6-3,7$ and $4,1-4,2$. Troughs occurred at $3.46,3.82$ and $4.14 \mathrm{~cm}$. (Diagram 9.13) and these are in approximate agreement with the modes given above. Thus 3.3-3.4 would correspond to periods (3), 4 or 5, 2,9-3.0 (?) to periods (2), 3 or 4 etc. Temperatures approximately the same as, or three degrees higher than present are obtained by the mode method, depending on whether the highest mode is equated to growth periods 4 or 5 (Table 9.1).

1

Comparison was made between lower levels (approximately $11.5^{*}+0.2^{\circ}$ ) and upper levels (Cellana contained in the top three spits of the excavation). 


\section{Paleotemperature Measurements}

A further method of determining the temperature of the ancient environment has been utilised. The technique depends on the fact that the oxygen isotopic ratio $0^{16} / 0^{18}$ for shells is inversely proportional to the temperature of the habitat, No attempt is made here to describe the method or the experimental technique used. The reader is referred to C. Emiliani (1956, 1957) and F. Dorman and E. Gill (1959) for a full account of the principles involved, Dorman (C.S.I.R.O.) carried out the measurements on Cellana and intends to publish details of the experimental technique presently. He claims he can measure temperatures to within $1^{\circ} \mathrm{C}$. Twenty-three temperature determinations were made including six extant species. In Table 9.3 the shells have been arranged into archaeological levels (see Chapter 6) and the means and standard deviations for each level have been computed, Significant tests between levels show that the temperature variations are negligible. However a positive significance results when any of the archaeological levels are tested against the extant temperature. These results indicate that the average temperature of the ancient habitat exceeded its modern counterpart by approximately $5^{\circ} \mathrm{C}$. Paucity of measurement prevents further differentiation between levels.

The application of $0^{16} / 0^{18}$ measurements to extant species has been used to indicate decreasing C/A ratios with increasing temperatures (H.A。 Lowenstam 1954(b), p.317) and to investigate the threshold temperatures of various species (ibid, 1954(a), p, 46; S, Epstein and H.A. Lowenstam 1953, pp, 424-5). If one knows the temperature range of the environment, then the measured 
$0^{16} / 0^{18}$ temperatures indicate whether growth is

continuous throughout the range, e,g, a paleotemperature less than the annual mean would indicate that the shell secretes only in the colder part of the year.

The mean temperature for the extant environment at Wilson's Promontory determined by the $0^{16} / 0^{18}$ method is $9.8^{\circ} \mathrm{C}$ (Table 9.3) which is outside the lower limits of the mean annual temperature range. From a consideration of related species it appears that growth is not continuous, and takes place in the colder part of the year. This would account in part for a low $0^{16} / 0^{18}$ temperature, Thus although these results indicate a significant difference between past and present oceanic temperatures, the temperature is not the annual mean values and some correction would have to be applied to obtain the actual mean value, Consequently, the mean annual temperature of the ancient environment will be greater than $15^{\circ} \mathrm{C}$, probably about $18^{\circ} \mathrm{C}$, 
COLLECTING SHELL SAMPLES

AND MEASURING TEMPERATURES

1. Sampling

Samples of Subninella and Cellana were collected at the following stations.- Curracurrang, Shell Harbour, U11adul1a, Broulee, Merimbula, Eden, Mallacouta, Ricketts? Point and Wilson's Promontory, 1 Each station was selected so that it was situated on open coastline, subject to the open oceanic swell, away from estuaries and in a rock platform environment.

Cellana was collected, colony by colony, in areas ranging from the low water to the high water areas. Subninella was collected in colonies ranging from beyond the low water mark (in water up to two feet deep) to the limits of the splash zone, Samples of each species were selected from a mixture of these colonies. Generally, 500-600 of each species were collected at each station, but only 200-300 were actually measured. The operculum (which had been removed from the animal) and the shell of Cellana were carefully oven dried before any measurements were taken. For the stations at Wilson's Promontory, Broulee and Shell Harbour, two separate samples were taken at different times of the year. Measurements were carried out on a special measuring board graduated in $\mathrm{m} . \mathrm{m}$.

Dates of collections are as follows:Curracurrang 15 Dec, 1965: Shell Harbour 15 Dec, 1965 , 3 Mar. 1966: Ulladulla 16 Dec. 1965: Broulee 16 Dec. 1965,7 Nov, 1966 ; Merimbula 17 Deo. 1965 Eden 17 Dec. 1966; Mallacouta 18 Dec, 1966 ; Wilson's Promontory 2 Jan. 1966, 12 Aug 1966 Ricketts Point 30 Dec. 1965. 


\section{Temperatures}

Temperature measuring stations were set up in the following areas:- Shell. Harbour, U1ladulla, Broulee, Eden, Ricketts: Point and Wilson's Promontory. The object of setting up these stations was to determine the annual temperature range and the mean annual temperature of the local oceanic environment. To this end local volunteers were supplied with a thermometer (graduated in ${ }^{\circ} \mathrm{C}$. and accurate to within $1^{\circ} \mathrm{C}$ ) and instructions on how, where and when to take temperatures. The thermometers were calibrated against a standard kept in the Archaeology Department in the A.N.U. Correction factors were derived for each thermometer and these were used to correct temperatures received from the stations throughout the year.

The regularity with which data was collected at each station varied from station to station. For example, at Broulee, almost daily measurements were taken from two areas, whereas at Shel1 Harbour and U1ladulla measurements were taken at weekly, fortnightly, and sometimes monthly intervals.

Those people asked to make the temperature measurements were instructed to:

(a) try to take the measurements on the same part of the tidal cycle,

(b) to take an average of three separate temperature measurements,

(c) to make sure that the thermometer had been well immersed below the surface before taking a temperature reading,

(d) to take the temperature in open water only never in rock pools or in inlets or in still 
(e) to take measurements as often as possible, and to include weather conditions and the air temperature at the time.

The resulting approximate temperature ranges and mean averages are set out below:

\section{$\frac{\text { Temperature Range }}{{ }^{{ }_{\mathrm{C}}}} \frac{\text { Mean Average }}{{ }^{{ }_{\mathrm{C}}}}$}

She11 Harbour

$\begin{array}{ll}14-21 & 18 \cdot 0 \\ 13-21 & 16 \cdot 5 \\ 14-22 & 18.4 \\ 13-20 & 16.0 \\ 12-24 & 18.7 \\ 11-20 & 15.2\end{array}$

U1ladulla

Broulee

Eden

Ricketts' Point

$11-20$

$15 \cdot 2$

The means were calculated graphically by plotting the monthly average temperatures. Unfortunately, the data are limited, but it must suffice for the time being, as there is a lack of similar data for the New South Wales and Victorian coastlines. ${ }^{1}$ Published data are limited to the Sydney area (W.J. Dakin et al., 1948 , p.186, fig, 2; A.K. O:Gower and G.R. Meyer 1965, p.207) and the Queens1and coast (R. Endean et al., 1956, pp.92-3). 


\section{APPENDIX 9.3}

\section{CALCITE-ARAGONITE DETERMINATION \\ BY X-RAY ANALYSIS}

The method of analysis used to determine the $\mathrm{C} / \mathrm{A}$ ratio was similar to that described by Lowenstam (1954(b), pp. 286-7). However, a different technique was used to prepare samples, and a more sophisticated method of determining the ratio has improved reproducibility and accuracy from Lowenstam? $\mathrm{s} \pm 10$ per cent (ibid., p.287) to \pm 5 per cent。

\section{Preparation of Samples}

Samples were cleaned, dried and weighed. The length, width and height of each shell was also measured. During grinding, mechanical conversion of Aragonite to Calcite can occur, so that it is important to establish a crushing technique that is fast, yet has a minimal conversion effect. The optimal suitable grain size also needs to be determined.

To investigate the effects of crushing techniques several shells were cut in half and the individual halves were crushed in different ways and the results compared. Samples were crushed by hand to several sieve sizes and the $\mathrm{C} / \mathrm{A}$ ratio determined. Various methods of hand crushing were employed. It was found that to obtain reasonable reproducibility samples needed to be reduced in size to well below 300 mesh. When samples were crushed to meshes of this order it was found that all methods of hand crushing ( $i, e$ grinding, gentle and violent crushing with a pestle and cylinder) gave similar results. The following table illustrates these points: 


\begin{tabular}{|c|c|c|c|c|c|}
\hline $\begin{array}{l}\text { Run } \\
\text { No. }\end{array}$ & Mesh & Grinding & \multicolumn{2}{c|}{ Pestle and Cylinder } & $\begin{array}{c}\text { Ba } 11 \\
\text { Mi11 }\end{array}$ \\
\hline 1 & 200 & 18.04 & 15.34 & 13.31 & 18.41 \\
2 & & 26.91 & 18.51 & 15.72 & 15.28 \\
3 & & 15.53 & 16.64 & 18.21 & 14.21 \\
\hline 1 & & 11.91 & 12.10 & 12.20 & 11.84 \\
3 & & 11.93 & 11.90 & 13.00 & 13.36 \\
\hline 300 & & 12.10 & 12.30 & 11.98 & 12.90 \\
\hline
\end{tabular}

One half of each shell was crushed in a small ball mill and it was found that results were compatible with hand crushed specimens, This technique is advantageous, because besides subjecting every shell to precisely the same type of crushing and for the same period of time, it is fast and efficient. Tests were carried out to determine optimum times required for crushing and the effects of mechanical crushing on the $\mathrm{C} / \mathrm{A}$ ratio. Two minutes appeared to be enough time to crush the largest shells, though crushing time did not appear to affect the $\mathrm{C} / \mathrm{A}$ ratio. The fact that this method yields results similar to those obtained by the hand crushing techniques shows that mechanical crushing does not produce any more conversion than other methods.

Thus all shells were crushed in the ball mill to grain sizes less than 300 mesh.

\section{Machine Conditions}

The C/A ratios were determined with a Philips X-ray diffraction machine with a nickel filtered copper target and equipped with a goniometer, Geiger counter and graph recorder. Optimum machine conditions were determined experimentally as volts $-40(\mathrm{KU})$, amps-24(MA), countex 4 , rate meter 8 , time constant 2 , multipliex 1 , and time 
cycle 64 seconds, Although the peak ratios were recorded on a graph recorder, a counting technique was used to determine the $\mathrm{C} / \mathrm{A}$ ratios, A preliminary examination of the spectrum led to the following counting procedure being devised:-

(a) Background count at $25,7^{\circ}(64$ secs $)$ B1

(b) Count for 64 seconds starting at $25.7^{\circ}-$ C1

(c) Background count at $27^{\circ}(64$ secs $) \quad$ B2

(d) Count for 64 seconds starting at $28.9^{\circ}-$ C2

(e) Background count at $30,0^{\circ}$ (64 secs) - B3 recalling that the main Aragonite peak occurs at $26.2^{\circ}$ and the Calcite peak at $29.4^{\circ}$.

$$
\begin{aligned}
& \mathrm{C} 2=\left(\frac{\mathrm{B} 2}{2}+\mathrm{B} 3\right) \\
& \text { The } \mathrm{C} / \mathrm{A} \text { ratio }=\overline{\mathrm{C} 1-(\overline{\mathrm{B} 1}+\mathrm{B} 2)}
\end{aligned}
$$

where C1, C2, B1, B2, B3 are the number of counts for each counting stage,

The goniometer speed was set at $1^{0} ; 2 \theta$ per minute and the slits sizes were $\frac{1}{2}^{\circ}, 0,2^{\circ}$, and $\frac{1}{2}^{\circ}$ respectively, Samples were mounted in a polythene holder with a circular aperture.

To help avoid preferred orientation of the Calcite crystals, the polythene holder was placed on top of a glass plate specially roughened on one side, and the sample was poured into the aperture, The open side of the aperture was packed down, smoothed off, and covered with a small circular peice of glass plate slightly bigger than the aperture. The glass plate was held in position by Durex tape. The holder was then inverted and the glass plate with the rough face removed. The effectiveness of this method was tested by running several samples from the same shell and examining the reproductibility. Satisfactory results were obtained. 
The first 40 samples were each run three times and the results averaged. Agreement was so good that only two determinations were run on succeeding samples. For large shells, where the volume of powder far exceeded that which could be accommodated in the aperture of the target holder, two to three separate samples from the same shell were run, and the results were averaged.

Other mounting techniques were tried but were found to give unsatisfactory results. 


\section{$\frac{\text { BOTANICAL REPORT ON AREA IN THE }}{\text { VICINITY OF SITES } 9 \text { to } 11}$}

by R.F. Parsons,

Research Scholar,

Botany Department, University of Melbourne

\section{The Present Vegetation of the Area}

The vegetation of the area is very similar to that of other coastal areas throughout south-east Australia.

\section{Vegetation of the B Series Dunes}

The B series dunes include areas of the unstabilized calcareous sands. The pioneer vegetation on this substratum consists of the dune grasses Spinifex hirsutus (native) and Ammophila arenaria (introduced from Europe). More sheltered and stable areas of the B series dunes carry either heaths or thickets (depending on age and degree of protection from the salt-spray bearing winds), in which the following shrubs are important constituents: Leptospermum laevigatum, Acacia longifolia var. sophorae, Leucopogon parviflorus, Helichysum gunnii and Olearia axillaris. The ground stratum includes Lepidosperma gladiatum, Scirpus nodosus and Carpobrotus aequilaterus. Some areas of dead shrubs were noted and it is considered that the most likely reasons for these deaths are inundation by sand and subsequent re-exposure, or unusually severe storms accompanied by lethal amounts of wind-born salt spray.

\section{Vegetation of the A Series Dunes}

Seaward dunes of this series are usually more or less buried under the more recent B series dunes. Landward dunes inland from the excavation site have 
woodland of Banksia integrifolia about $25^{\prime}$ high with a

dense shrubby understory dominated by Leptospermum

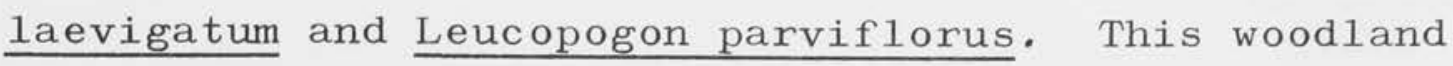
can also develop on B series dunes where physiographic protection is adequate. There was no evidence that the different soil characteristics of the A series dunes compared to the B series dunes had any effect on species distribution - this is not surprising as these two alkaline soils are derived from the same parent material and are presumably similar nutritionally. Degree of exposure to wind and salt-spray, and degree of sand stability seem to be the major determinants of species distribution on both types of dunes.

The following is a list of the common plant species found around the excavation site.

\section{Shrub Community on B Series Dunes}

Acacia longifolia var. sophorae

Acaena sp.

Ammophila arenaria

Banksia integrifolia

Calocephalus brownii

Carpobrotus

Cirsium vulgare

Clematis microphylla

Correa alba

Cichondra repens

Exocarpos cupressiformis

Geranium potentilloides

Helichrysum gunnii

Hibbertia sericea

Hypochoeris sp.

$\frac{\frac{\text { Banksia }}{\text { integrifolia }}}{\frac{\text { Woodland on }}{\frac{\text { Deries }}{\text { Dunes }}}}$

$\mathrm{x}$

$\mathrm{x}$

$\mathrm{x}$

pioneer

grass

X

X

$\mathrm{x}$

X

$\mathrm{x}$

X

X

X

X

X

X

X 


\section{Shrub Community

on B Series \\ Dunes}

\section{Banksia in tegrifolia Woodland on A Series Dunes}

Lagenophora stipitata

Lagurus ovatus

Lepidosperma gladiatum

Leptospermum laevigatum

Leucopogon parviflorus

Lomandra longifolia

Myoporum insulare

Olearia axillaris

Pomaderris oraria

Pteridium esculentum

Scirpus nodosus

Senecio elegans

S. lautus

Spinifex hirsutus

Tetragonia amplexicoma

$\mathrm{x}$

$\mathrm{X}$ $\mathrm{x}$

X

$\mathrm{x}$

X

$\mathrm{X}$

$\mathrm{X}$

X

$\mathrm{X}$

$\mathrm{X}$

$\mathrm{X}$

$\mathrm{x}$

$\mathrm{x}$

$\mathrm{x}$

$\mathrm{X}$

pioneer

grass

$\mathrm{x}$ 
ANALYSIS OF POLLEN SAMPLES FROM THE PEAT AT WILSON'S PROMONTORY, VICTORIA

by $\mathrm{Dr}$ S. Duigan, Botany Department, Melbourne University

It has not been possible to provide a detailed pollen analysis of the samples. Each set of figures in the enclosed table represents a count of only 100 pollen grains, the number of samples treated is small and precise identification of the pollen was not attempted. Hence it must be stressed that the conclusions suggested below are only of the most tentative kind [refer to Table 10.19].

In view of the fact the Compositae as a whole is insect-pollinated, a somewhat surprising feature of the diagram is the abundance of pollen of this family, particularly in the top and bottom samples. The pollen of the subfamily Tubuliflorae* could represent Olearia axillaris and/or Helichrysum paralium (ㅂ.gunnii), both of which are common along the front of the dunes at the present time. According to Parsons (personal communication), these two species are especially important on exposed foredunes, but he points out that they are normally mixed with dwarfed Leptospermum laevigatum and Leucopogon parviflorus, neither of which is represented in the parts of the pollen diagram which show high Compositae values. Unfortunately, vegetation in which $\underline{\text { o.axillaris }}$ and $\underline{H}$.paralium play an important part is not included in the communities studied by Hope (unpub.), who is investigating the relation of modern pollengrain to plant communities; the only community in his survey which shows similar high values for 
Compositae pollen is the fern gully, but the high

values for fern spores there are not matched in the relevant horizons of the peat. However, the values for fern spores in the peat may indicate that a fern gully was closer to the site in the past than it is now.

The occurrence and distribution of pollen tentatively identified as Typha is interesting. This genus does not occur in the vicinity of the peat at present, but is seen at the Darby River bridge. Some environmental change (? drying out) is presumably responsible for its absence from the top sample. The high values for Cyperaceae at H2 $\frac{1}{2}$ suggest a sedge swamp. This may be comparable with the Cyperus lucidus$\underline{\text { Phragmites communis grassland described by Parsons }}$ (1966) for Tidal River, but the figures for Gramineae pollen are rather lower than would be expected under such circumstances. Although the pollen is difficult to identify even at the family level, it is possible that an appreciable part of it belongs to Gahnia, which may indicate something like the Gahnia clarkei swamps of the present day.

Casuarina is one of the few genera in the area which is represented by wind-pollinated trees or shrubs, and hence there is always the possibility that the pollen will be over-represented. However, in Hope's surface samples, the values for Casuarina approach those at $\mathrm{E} 2 \frac{1}{2} "$ and $\mathrm{K} 2 \frac{1}{2} "$ only when Casuarina is an important constituent of the surrounding vegetation. Hence it is possible that, at these two levels, Casuarina woodland or heath with Casuarina occurred in the vicinity of the deposit.

Although it is dangerous to make deductions from the absence of pollen, the fact that Melaleuca pollen is either absent or reduced to a negligible quantity of 
unrecognizable grains suggests that the peat was not

formed under a Melaleuca ericifolia thicket of the kind which is so conspicuous along the lower reaches of both Derby River and Tidal River at the present day. There appears to be little doubt that Melaleuca pollen would be abundant under such circumstances, as Hope obtained a value of 57 per cent for Melaleuca from a moss polster in a Melaleuca ericifolia thicket at Tidal River.

The picture which emerges seems to be of a peat forming in a swamp in which Cyperaceae, Gramineae and, in the earlier part, Typha were important constituents of the vegetation but which did not include Melaleuca in any quantity. Adjacent higher areas may have had a vegetation in which shrub Compositae were prominent, and communities in which Casuarina was conspicuous may also have been present.

* On reading this over, Dr Ashton has pointed out the fact that olearia glutinosa, which grows at present on drained river banks, may be another possible source of Compositae pollen of this type. 


\section{STATISTICAL TESTS}

by N. Tuckwe11,

Economics Department, Australian National University

\section{Multivariate Analysis}

Use: to test for similarity between assemblages.

From $q$ sites one takes $\mathrm{N}$ observations and on each of these $\mathrm{N}$ artifacts one makes $\mathrm{P}$ measurements. Let there be $\mathrm{Nq}$ artifacts from site $q$, so that

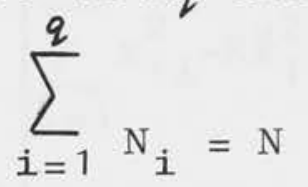

If $\mathrm{x}_{\mathrm{pN}_{1}}=\mathrm{N}_{1}$ th measurement of the $\mathrm{pth}$ property then for site 1 , one can form the matrix of observations

$$
\left[\begin{array}{llll}
\mathrm{x}_{11} & \mathrm{x}_{12} & \ldots & \mathrm{x}_{1 \mathrm{~N}_{1}} \\
\mathrm{x}_{21} & \mathrm{x}_{22} & \cdots & \mathrm{x}_{2 \mathrm{~N}_{1}} \\
\dot{\mathrm{x}_{\mathrm{p} 1}} & \mathrm{x}_{\mathrm{p} 2} & \cdots & \mathrm{x}_{\mathrm{pN}_{1}}
\end{array}\right]
$$

Over $\mathrm{N}_{1}$ observations for property $\mathrm{p}$, one determines a mean, so that one can then form a vector of mean values

$$
\left[\begin{array}{l}
\bar{x}_{11} \\
\bar{x}_{21} \\
\bar{x}_{p 1}
\end{array}\right]
$$

for, say, site 1 . Then for sites $2-q$ one can get similar vectors of means. Taking the mean values from these vectors of means a grand mean vector is derived

$$
\left[\begin{array}{l}
= \\
x_{1} \\
\vdots \\
= \\
x_{p}
\end{array}\right]
$$


Next one derives the $p^{*} p$ symmetric matrix $\Sigma_{w}$, equivalent to the sums of squares and cross-products of deviations from the site means, and $\Sigma n$, the $p^{*} p$ symmetric matrix representing the sums of squares and cross-products of deviations from the grand mean.

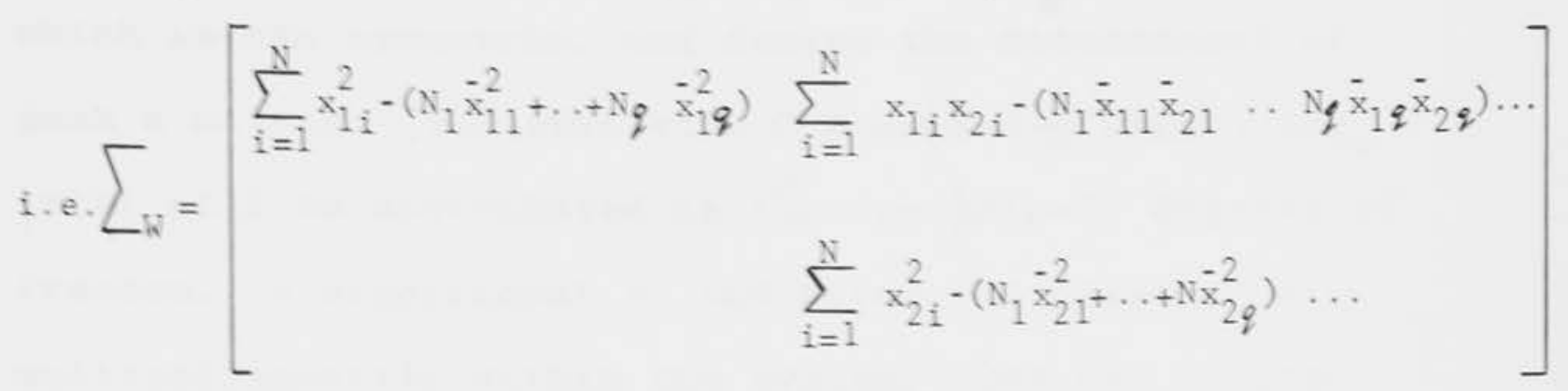

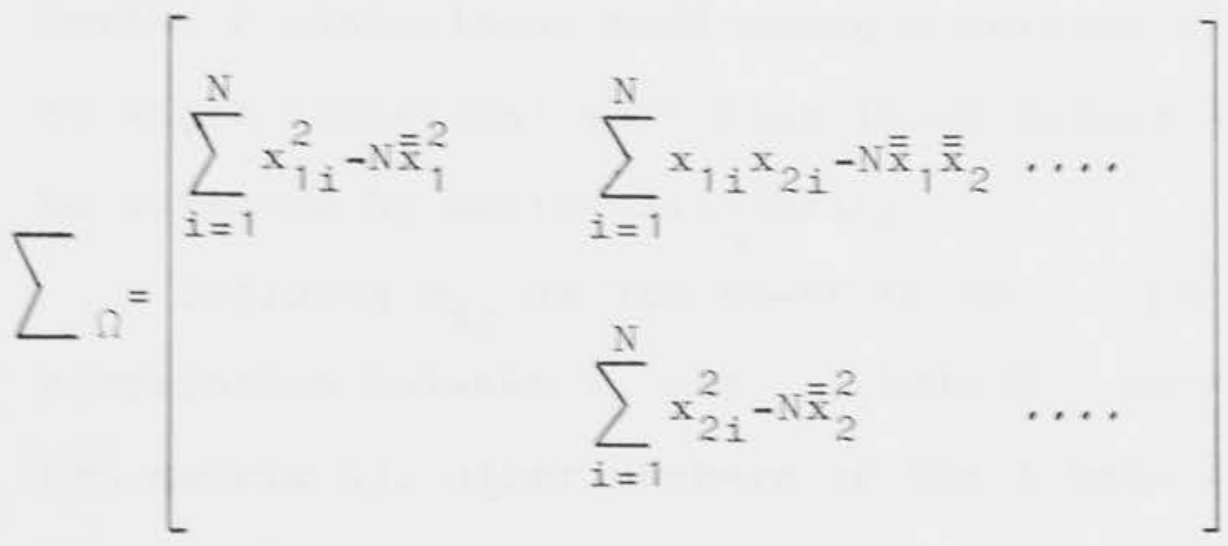

The determinants of each of these two matrices are used to define the statistic $U=\left|\Sigma_{w}\right| /\left|\Sigma_{n}\right|$. This ratio will always be less than or equal to 1 . The closer the statistic is to 1 , then the more significant will be the association between sites. As a test statistic, calculate CHi $=-\left[N-1-\frac{1}{2}(p+q)\right] \log _{e} U$, then such a statistic CHi will tend to be distributed as $x^{2}$ with $p^{+}(q-1)$ degrees of freedom.

One can then conclude that if $X^{2}$ is significant at the desired level, the association is not strong.

\section{Multicollinearity}

Use: for finding the degree of association between variables.

One views the multicollinearity as an interdependency condition; it is defined in terms of lack of 
independence, or the presence of interdependence signified by high intercorrelation within a set of variables.

Say have $\mathrm{n}$ parameters each with $\mathrm{N}$ observations and let the Nxn matrix of observations be $X$. Determine $X^{\prime} X$, which is $n * n$ symmetric, and derive the determinant of such a matrix. The statistic CHi $=-\left[N-1-\frac{1}{6}(2 n+5)\right] \log _{e}$ $\left|X^{\prime} X\right|$ will be distributed as $x_{\nu}^{2}, \quad \nu=\frac{1}{2} n(n-1)$ degrees of freedom. A significant $\chi^{2}$ indicates the presence of multicollinearity within the system. One can further derive F statistics, indicating a measure of the extent to which individual variables in an independent set may be affected by multicollinearity.

Defining $r_{i j}$ as the co-efficient of partial correlation between $X_{i}$ and $X_{j}$ (both $N * 1$ vectors of the $N * n$ matrix $X)$, other members of the $X$ held constant, the statistic

$$
t_{i j}(\nu)=\frac{r_{i j^{*}(N-n)}}{1-r_{i j}^{2}}
$$

with $\nu=N-n$ degrees of freedom, will be distributed as student's t. Such off-diagonal elements of the matrix $X$ 'X provide useful measures of collinearity, even in the absence of rigid assumption concerning multivariable normal distribution properties.

$$
\text { By scanning such } t_{i j} \text { one can determine which }
$$
relationships are significant and so delete from the system those variables which can be satisfactorily explained by the presence of other variables within the system. 


\section{RETOUCH AND UTILISATION INDEXES}

These indexes were computed on a scoring basis. Seventeen varieties of retouch and ten varieties of utilization are listed in Table 11.1. The method of scoring for retouch is set out below.

\begin{tabular}{|c||l|c|c|}
\hline $\begin{array}{c}\text { Position of } \\
\text { Retouch }\end{array}$ & & L.H.S. & R.H.S. \\
\hline \hline \multirow{2}{*}{ Lower Lateral } & Complete & 3 & 3 \\
& Near & 1 & 1 \\
Upper Lateral & Distal & 1 & 1 \\
& Complete & 3 & 3 \\
End & Dear & 1 & 1 \\
Butt & Upper & 1 & 1 \\
& Lower & 1 & 1 \\
& Bulbar & 1 & 1 \\
& Vertical & 1 & 1 \\
& Upper & 1 & 1 \\
\hline
\end{tabular}

The maximum possible score for any flake would be 17.

If the total score for any single flake is $p$ then the RETOUCH INDEX ( $r i$ ) per flake is defined as

$$
\mathrm{ri}=\mathrm{p} / 17 \times 100
$$

For $n$ flakes comprising an assemblage $A$ the RETOUCH INDEX is defined as

$$
\text { RI } I_{A}=\frac{\sum^{n} 0^{n} p_{n} / 17 \times 100}{n} \cdots \ldots .
$$

The method of scoring for utilization is set out below.

\begin{tabular}{|l||l|c|c|}
\hline $\begin{array}{l}\text { Position of } \\
\text { Utilization }\end{array}$ & & L.H.S. & R.H.S. \\
\hline \hline Laterial & Complete & 3 & 3 \\
& Near & 1 & 1 \\
End & Distal & 1 & 1 \\
Butt & Bulbar & 1 & 1 \\
& Vertical & 1 & 1 \\
& Upper & 1 & 1 \\
\hline
\end{tabular}


The maximum possible score for any flake is ten.

If the total score for any single flake is $p$, then the Utilization Index (ui) per flake is defined as

$$
\mathrm{ui}=\mathrm{p} / 10 \times 100
$$

For $n$ flakes comprising an assemblage $A$ the Utilization Index is defined as

$$
\mathrm{UR}_{\mathrm{A}}=\frac{\sum_{\mathrm{n}=0}^{\mathrm{n}} \mathrm{p} / 10 \times 100}{\mathrm{n}} \cdots \ldots(\mathrm{ii})
$$

Similarly for a Utilization-Retouch consideration, the maximum possible score for any flake is 27.

Thus if the total score for any single flake is $p$, the Utilisation-Retouch index (ur) is defined as

$$
\text { ur }=\mathrm{p} / 27 \times 100
$$

For $n$ flakes comprising an assemblage A the

Utilization-Retouch index is defined as

$$
\mathrm{UR}_{\mathrm{A}}=\frac{\sum_{n=0}^{\mathrm{n}} \mathrm{p}_{\mathrm{n}} / 27 \times 100}{\mathrm{n}} \cdots .(\mathrm{iii})
$$

A computer programme was written to calculate the three indexes.

The same programme also counted the number of flakes with indexes falling within set ranges. 0-1, 1-2 ....... 99-100. Thus one can study the frequency with which individual flake indexes recur in the assemblage (Table 11.105). 
DESCRIPTIONS AND CHARACTERISTICS OF SOME STANDARD CLASSES OF A SERIES TOOLS

1. Classes 1 and 16

Class 1 -Flint. Retouch concentrated on the distal end of the lower left hand lateral edge ( 17 per cent). Twenty-two per cent have either the left or right hand lower margins completely retouched. There is more utilization on the left hand than on the right hand margins.

Quartz. Retouch is concentrated on the lower left hand margin (13.0 per cent of flakes are completely retouched). 8.7 per cent of Quartz flakes have their upper left hand margin retouched, and a similar number have their lower right hand margin completely retouched. There is more utilization on the right than on the left hand margins, i.e. 21.7 per cent have some kind of utilization on the right as compared with 12.9 per cent on the left hand margin.

Quartzite. Retouch is concentrated on the lower left hand lateral edge (complete 10.6 per cent, distal 16.7 per cent) and lower right hand lateral edge (complete 15.2 per cent). Most of the utilization is on the left hand margin (complete 7.6 per cent, distal 7.6 per cent, near 3.0 per cent). Upper lateral retouch is not important.

The distribution of working on the lateral margins differs for the three material types. In general, the lower left hand distal margin is the most important working area for Quartzite and Flint, while the complete left hand and right hand margins are important for Quartz. 
Range of lengths are: Flint, 2.0-5.5 cm; Quartz, $2.0-3.5 \mathrm{~cm}$; Quartzite, $2.0-4.5 \mathrm{~cm}$.

Class 16. The distribution of retouch on the lower lateral margins is shown below. Upper lateral working is not important in this class.

\section{Distribution of Working on the Lower Lateral Margins}

\begin{tabular}{|l|r|r|r|r|r|r|}
\hline \multirow{2}{*}{} & \multicolumn{2}{|c|}{ Flint } & \multicolumn{2}{c|}{ Quartz } & \multicolumn{2}{c|}{ Quartzite } \\
\cline { 2 - 7 } & $\mathrm{L}$ & $\mathrm{R}$ & $\mathrm{L}$ & $\mathrm{R}$ & $\mathrm{L}$ & $\mathrm{R}$ \\
\hline \hline Complete & $\begin{array}{r}6.2 \\
12.5\end{array}$ & $\begin{array}{r}6.2 \\
\text { Distal }\end{array}$ & $\begin{array}{r}13.9 \\
5.6\end{array}$ & $\begin{array}{r}19.4 \\
5.6\end{array}$ & $\begin{array}{r}19.4 \\
9.7 \\
6.5\end{array}$ & $\begin{array}{r}19.4 \\
3.2 \\
\text { Near }\end{array}$ \\
\hline
\end{tabular}

Differences in distribution of retouch are apparent; not only between material, but between Class 1 and 16 . The differences include:

1. For Quartzite, more flakes have complete retouched margins in Class 16 than in Class 1 (up to 10 per cent more).

2. For Quartz, more flakes have retouch on the lower right hand margin for Class 16 than Class 1 (8.7 per cent Class 1 cf. 19.4 per cent Class 16).

3. For Flint, less flakes have retouched margins in Class 16. The distribution of retouch on the lower margins of Class 16 has completely altered, The proportion of flakes with retouch on the 'near' position has increased by 10 per cent $(2.4$ per cent Class 1 to 12.5 per cent Class 16$)$.

The distribution of utilization for classes 1 and 


\begin{tabular}{|c|c|c|c|c|c|c|c|}
\hline \multirow{3}{*}{ Class } & \multicolumn{7}{|c|}{$\begin{array}{c}\text { Per cent No Flakes with Utilization on } \\
\text { the Lateral Margins }\end{array}$} \\
\hline & \multirow{2}{*}{ Working } & \multicolumn{2}{|c|}{ Flint } & \multicolumn{2}{|c|}{ Quartz } & \multicolumn{2}{|c|}{ Quartzite } \\
\hline & & L & & L & $\mathrm{R}$ & $\mathrm{L}$ & $\mathrm{R}$ \\
\hline 1 & $\begin{array}{l}\text { Complete } \\
\text { Distal } \\
\text { Near }\end{array}$ & $\begin{array}{l}6.2 \\
6.2\end{array}$ & & $\begin{array}{r}11.1 \\
5.6 \\
2.8\end{array}$ & $\begin{array}{r}11.1 \\
5.6 \\
5.6\end{array}$ & $\begin{array}{l}1.6 \\
1.6 \\
1.6\end{array}$ & $\begin{array}{r}11.3 \\
3.2\end{array}$ \\
\hline 16 & $\begin{array}{l}\text { Complete } \\
\text { Distal } \\
\text { Near }\end{array}$ & $\begin{array}{l}4.9 \\
4.9 \\
2.4\end{array}$ & $\begin{array}{l}2.4 \\
2.4 \\
2.4\end{array}$ & $\begin{array}{l}4 \cdot 3 \\
4 \cdot 3 \\
4 \cdot 3\end{array}$ & $\begin{array}{l}8.7 \\
4.3 \\
8.7\end{array}$ & $\begin{array}{l}7.6 \\
7.6 \\
3.0\end{array}$ & $\begin{array}{l}3.0 \\
3.0 \\
3.0\end{array}$ \\
\hline
\end{tabular}

Differences are apparent within and between classes. Important observations include:

1. For Flint the distributions for both classes are approximately the same.

2. For Quartz, the percentage flakes with utilization in Class 16 has dropped (and conversely the amount of retouch has increased).

3. For Quartzite, utilization in Class 16 is concentrated on the left hand margin.

Shapes and cross-sections for Classes 1 and 16 appear to be random. Range of lengths for all three materials in Class 16 range from $0.5-2.0 \mathrm{cms}$.

2. Classes 6 and 21

\begin{tabular}{|c|c|c|c|c|}
\hline \multirow{2}{*}{ Class } & \multicolumn{4}{|c|}{$\begin{array}{l}\text { Per cent No of Flakes with } \\
\text { Working on Distal End }\end{array}$} \\
\hline & Working & Flint & Quartz & Quartzite \\
\hline 6 & $\begin{array}{l}\text { Retouch } \\
\text { Utilization }\end{array}$ & $\begin{array}{c}33.1 \mid 33.1 \\
33.1\end{array}$ & & $\begin{array}{c}61.7 \mid 18.3 \\
18.3\end{array}$ \\
\hline 21 & $\begin{array}{l}\text { Retouch } \\
\text { Utilization }\end{array}$ & & $67.131 .4^{5.0}$ & $\begin{array}{c}75.9 \\
5.0\end{array}$ \\
\hline
\end{tabular}

The table above summarizes the distribution of working per material for these two classes. Retouch 
tends to be concentrated on the lower lateral distal margin. For Quartzite the per cent retouch on this margin increases for the smaller tools.

Shapes and cross-sections are random.

3. Classes 11 and 25

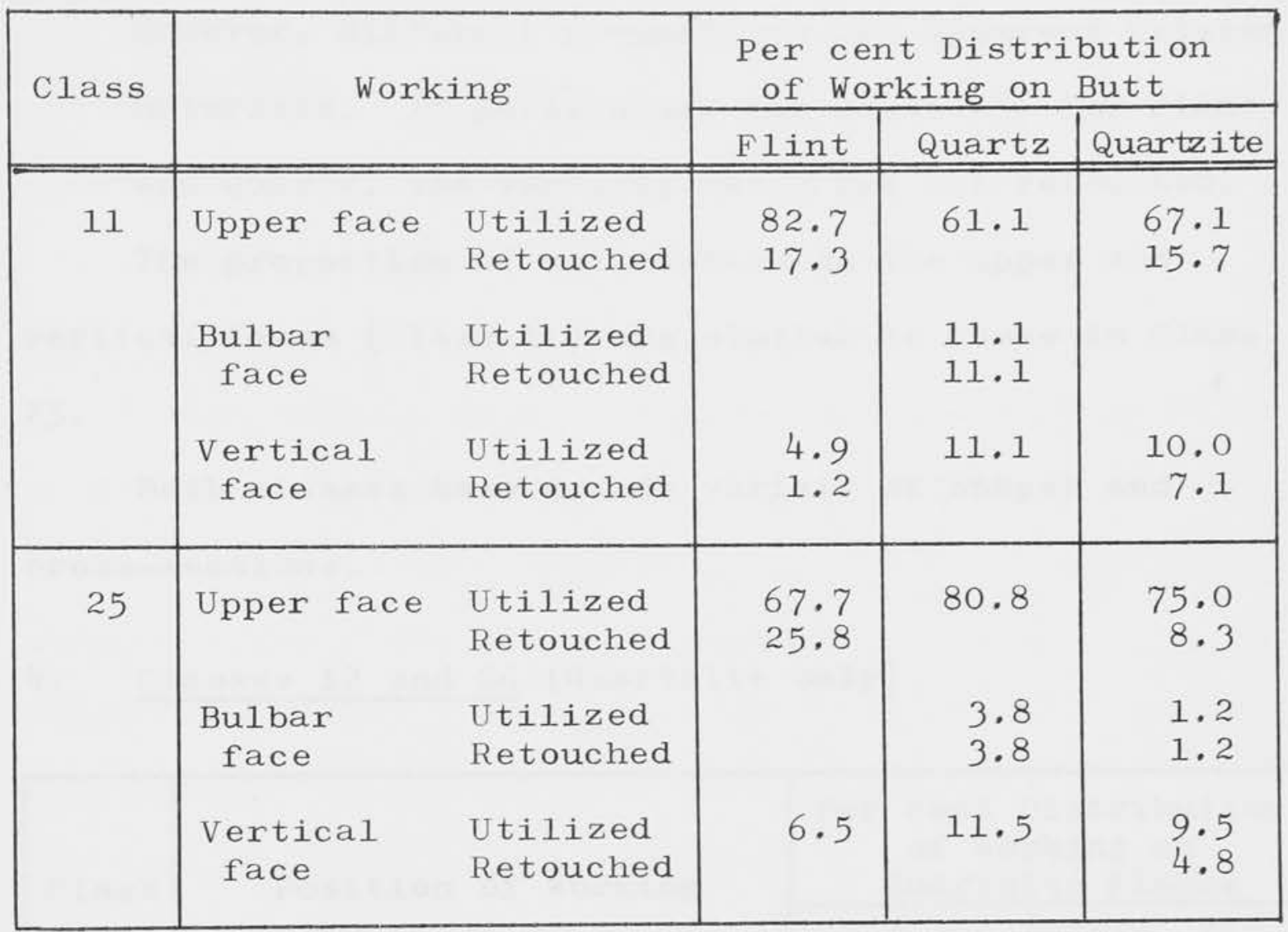

The distribution of working per material per class is shown in the table above. Important differences are apparent both within and between classes.

1. Flint tools - most of the retouch is situated on the upper face with a slightly higher proportion on the smaller implements. Utilization is also more common on the upper face, particularly on the larger implements.

2. Quartz - no implements of either class have retouch on the upper and vertical faces. However a number are retouched on the bulbar face. All faces have utilization, particularly on the upper face. The smaller implements have more utilization than their larger counterparts. 
3. Quartzite - retouch on the bulbar face is rare for Class 25 and non-existent in Class 11. For Class 11 the proportion of flakes having retouch on the upper face is approximately the same as for Flint. Likewise, the proportion of retouch on the vertical face (C1ass 11) is similar to that for Class 25. However, different proportions are apparent between materials. In particular, for Class 25 , for Flint and Quartz, the vertical faces are not retouched. The proportion of utilization on the upper and vertical faces (Class 11) are similar to those in Class 25.

Both classes have a wide variety of shapes and cross-sections.

\section{Classes 12 and 26 (Quartzite only)}

\begin{tabular}{|c|c|c|c|c|c|}
\hline \multirow[t]{2}{*}{ Class } & \multirow[t]{2}{*}{ Position of Working } & \multicolumn{4}{|c|}{$\begin{array}{c}\text { Per cent Distribution } \\
\text { of Working on } \\
\text { Quartzite Flakes } \\
\end{array}$} \\
\hline & & $\begin{array}{l}\text { Reto } \\
\mathrm{L} \\
\end{array}$ & $\begin{array}{r}\mathrm{uch} \\
\mathrm{R} \\
\end{array}$ & $\begin{array}{c}\text { Utiliz } \\
\mathrm{L}\end{array}$ & $\begin{array}{c}\text { ion } \\
\mathrm{R} \\
\end{array}$ \\
\hline \multirow[t]{2}{*}{12} & $\begin{aligned} \text { Lower lateral - } & \text { Complete } \\
& \text { Distal } \\
& \text { Near }\end{aligned}$ & $\begin{array}{r}25.8 \\
3.2 \\
3.2\end{array}$ & $\begin{array}{r}12.9 \\
3.2\end{array}$ & 3.2 & \multirow[t]{2}{*}{3.2} \\
\hline & $\begin{aligned} \text { Upper lateral - } & \text { Complete } \\
& \text { Distal } \\
& \text { Near }\end{aligned}$ & $\begin{array}{l}3.2 \\
6.5\end{array}$ & 3.2 & & \\
\hline 26 & $\begin{aligned} \text { Upper lateral - } & \text { Complete } \\
& \text { Distal } \\
& \text { Near } \\
\text { Upper lateral - } & \text { Complete } \\
& \text { Distal } \\
& \text { Near }\end{aligned}$ & $\begin{array}{r}23.1 \\
2.6 \\
5.1 \\
\\
2.6 \\
2.6\end{array}$ & $\begin{array}{r}10.3 \\
5.1 \\
5.1 \\
2.6 \\
7.7\end{array}$ & & 2.6 \\
\hline
\end{tabular}




\begin{tabular}{|c|c|c|c|}
\hline \multirow{2}{*}{$\begin{array}{r}\text { Position } \\
\text { on }\end{array}$} & \multirow{2}{*}{$\begin{array}{l}\text { of Working } \\
\text { Butt }\end{array}$} & \multicolumn{2}{|c|}{$\begin{array}{l}\text { Per cent Distribution } \\
\text { of Working on the Butt } \\
\text { of Quartzite Flakes }\end{array}$} \\
\hline & & Class 11 & Class 26 \\
\hline Upper face & $\begin{array}{l}\text { - Utilized } \\
\text { Retouched }\end{array}$ & $\begin{array}{l}32.3 \\
16.1\end{array}$ & $\begin{array}{l}38 \cdot 5 \\
15.4\end{array}$ \\
\hline Bulbar face & $\begin{array}{l}\text { - Utilized } \\
\text { Retouched }\end{array}$ & $\begin{array}{l}3 \cdot 2 \\
6.5\end{array}$ & 2.6 \\
\hline Vertical face & $\begin{array}{r}\text { - Utilized } \\
\text { Retouched }\end{array}$ & $\begin{array}{l}22.6 \\
12.9\end{array}$ & $\begin{array}{l}12.8 \\
20.5\end{array}$ \\
\hline
\end{tabular}

The percentage distribution of retouch and utilization on the lateral edges and butt are shown in the tables above. With the exception of the proportion of utilization and retouch on the vertical face of the butt, there is little difference in the distribution of working between the two tool classes. A higher proportion of small tools have more retouch (but less utilization) on the vertical face of the butt.

Both classes have a wide variety of shapes and cross-sections.

\section{C1ass 35}

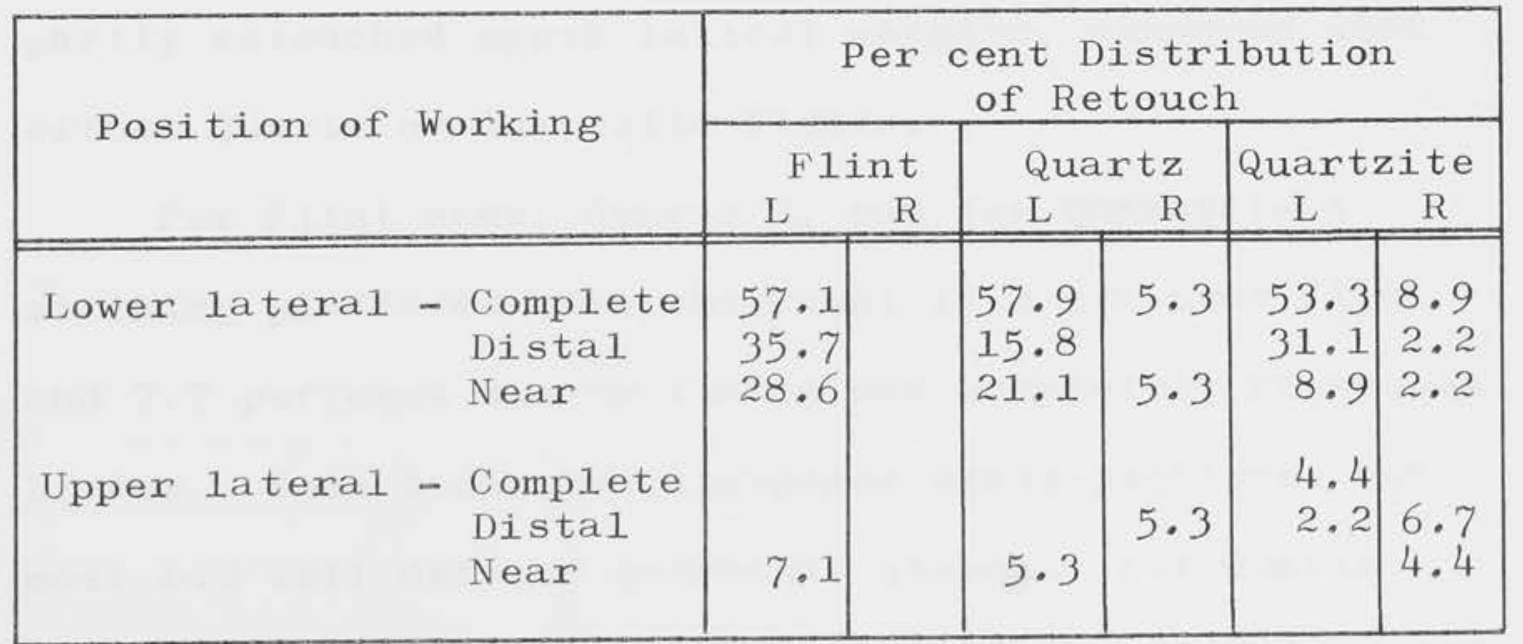

The distribution of working on the flakes per material class is very similar. The smaller proportion of Quartz flakes with retouch on the lower lateral distal end is notably different from the proportions for 
Striking platforms were rarely observed; for Flintone, Quartz - two and Quartzite - two. There were no irregular cross-sections for this class, and crosssections numbers 4 and 5 were the most common.

Length ranges: Flint - (1.0-2.5); Quartz $(0.5-2.5)$; Quartzite - (0.5-3.0).

\section{6. $\quad$ Class 36}

\begin{tabular}{|c|c|c|c|c|c|c|}
\hline \multirow{3}{*}{ Position of } & \multirow{3}{*}{ Working } & \multicolumn{5}{|c|}{$\begin{array}{c}\text { Per cent Distribution } \\
\text { of Retouch }\end{array}$} \\
\hline & & $\mathrm{F} 1 \mathrm{in} t$ & \multicolumn{2}{|c|}{ Quartz } & \multicolumn{2}{|c|}{ Quartzite } \\
\hline & & & $\mathrm{L}$ & $\mathrm{R}$ & $\mathrm{L}$ & $\mathrm{R}$ \\
\hline Lower lateral & $\begin{array}{l}\text { - Complete } \\
\text { Distal } \\
\text { Near }\end{array}$ & $\begin{array}{l}87 \cdot 5 \\
12.5 \\
12.5\end{array}$ & $\begin{array}{l}69.2 \\
15.4 \\
15.4\end{array}$ & & 93.1 & 3.4 \\
\hline Upper lateral & $\begin{array}{l}\text { - Complete } \\
\text { Distal } \\
\text { Near }\end{array}$ & $\begin{array}{l}12 \cdot 5 \\
25 \cdot 0 \\
25 \cdot 0\end{array}$ & $\begin{array}{r}7.7 \\
15.4 \\
7.7\end{array}$ & & $\begin{array}{l}3.4 \\
6.9 \\
3.4\end{array}$ & \\
\hline
\end{tabular}

The distribution of working depends on material for this class. A much higher proportion of Quartzite and Flint flakes have completely retouched lower lateral left hand margins in comparison with Quartz flakes. On the other hand a higher proportion of Flint flakes have partly retouched upper lateral margins, compared with either Quartz or Quartzite flakes.

For Flint none, Quartz 2, and for Quartzite 5 striking platforms were observed; 12.5 per cent Flint and 7.7 per cent Quartz flakes had completely retouched blades. Some tools had irregular cross-sections, but most had well defined geometric shapes. For Quartz flakes, cross-section No. 4 accounted for 30.8 per cent of the tools, and for Quartzite No. 5 ( 13.8 per cent), No. 7 (27.6 per cent) and No. 15 ( 24.14 per cent) comprising 65.5 per cent of the total number of tools. 
Length ranges: Flint - (1.0-3.5); Quartz -

$(1.0-3.0)$; Quartzite - $(0.5-3.0)$.

7. Classes 39-41 (Quartzite on 1y)

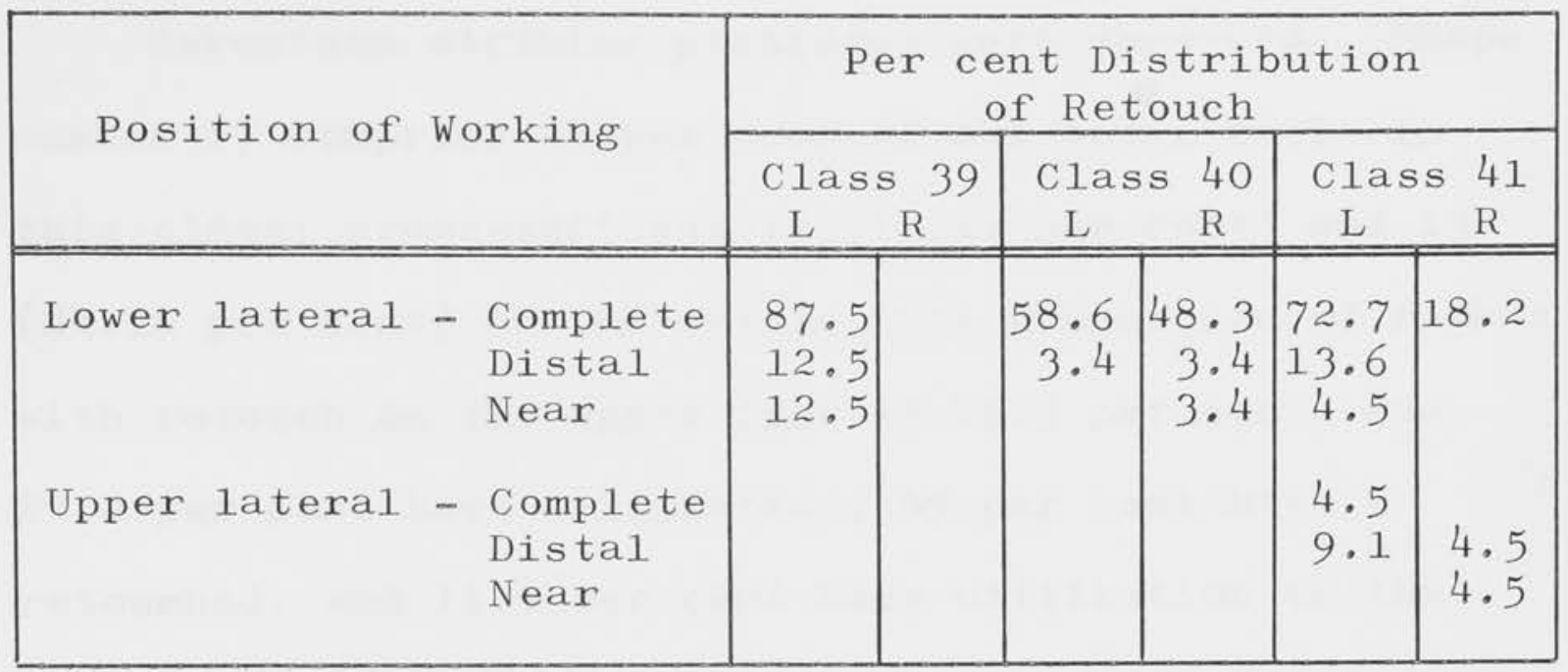

The proportions of working per class are shown in the table above. Striking platform observations were as follows: Class $39-1$, Class 40 - 12, Class $41-2$. Classes 40 and 41 were also worked on the butt end, on both the upper face $(6.9$ per cent Class $40,9.1$ per cent Class 41) and the vertical face (13.8 per cent Class 40 , 9.1 per cent Class 41). Very little utilization was observed on any of these tools.

No particular cross-sections appeared to dominate in any of the three classes.

8. Classes $46-48$

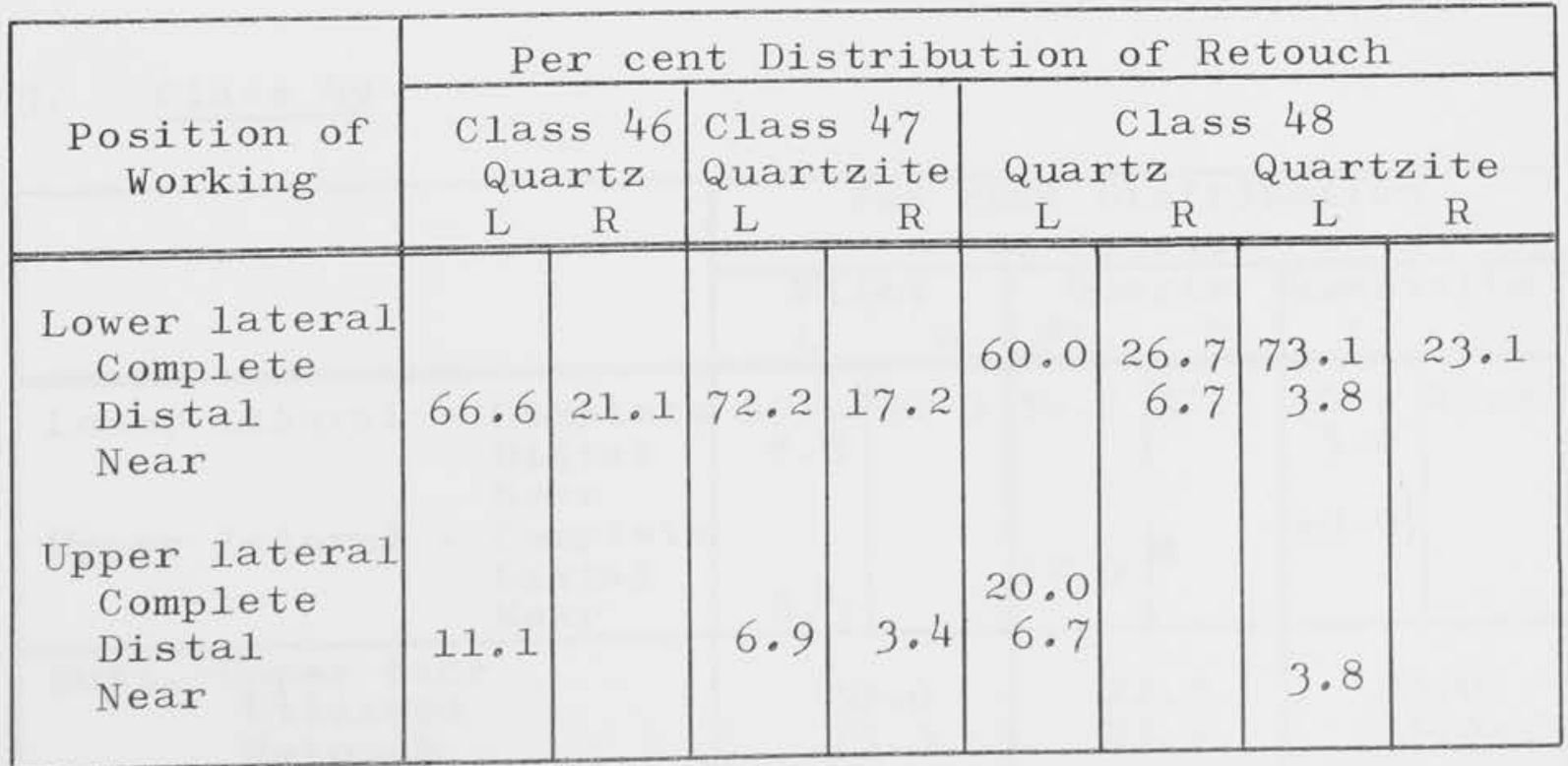




\section{Class 46}

Four striking platforms were observed.

Length range $-(1.0-3.0)$.

Class 47

Seventeen striking platforms were observed. Shape number 17 comprise 44 per cent of the total tools in this class; cross-sections 18 (17.24 per cent) and 13 (24.14 per cent) of the total. The proportion of flakes with retouch on the upper face is 15.3 per cent, and 22.2 per cent have utilization; 49 per cent have a retouched, and 11.9 per cent have utilization on the vertical face.

Length range: $(1.0-3.5)$.

Class 48

Nine striking platforms were observed for the Quartz and 20 for Quartzite flakes. Shape numbers 17 and 11 comprise 36.9 per cent of the total for Quartz, and shape 17, 23 per cent of the total for Quartzite. For Quartz cross-section 9 (23.0 per cent) and 7 (19.2 per cent) are important.

Length range: Quartz - (1.0-3.5), Quartzite $(0.5-3.5)$

Very few of these tools had utilization on the lateral margins.

9. Class 49

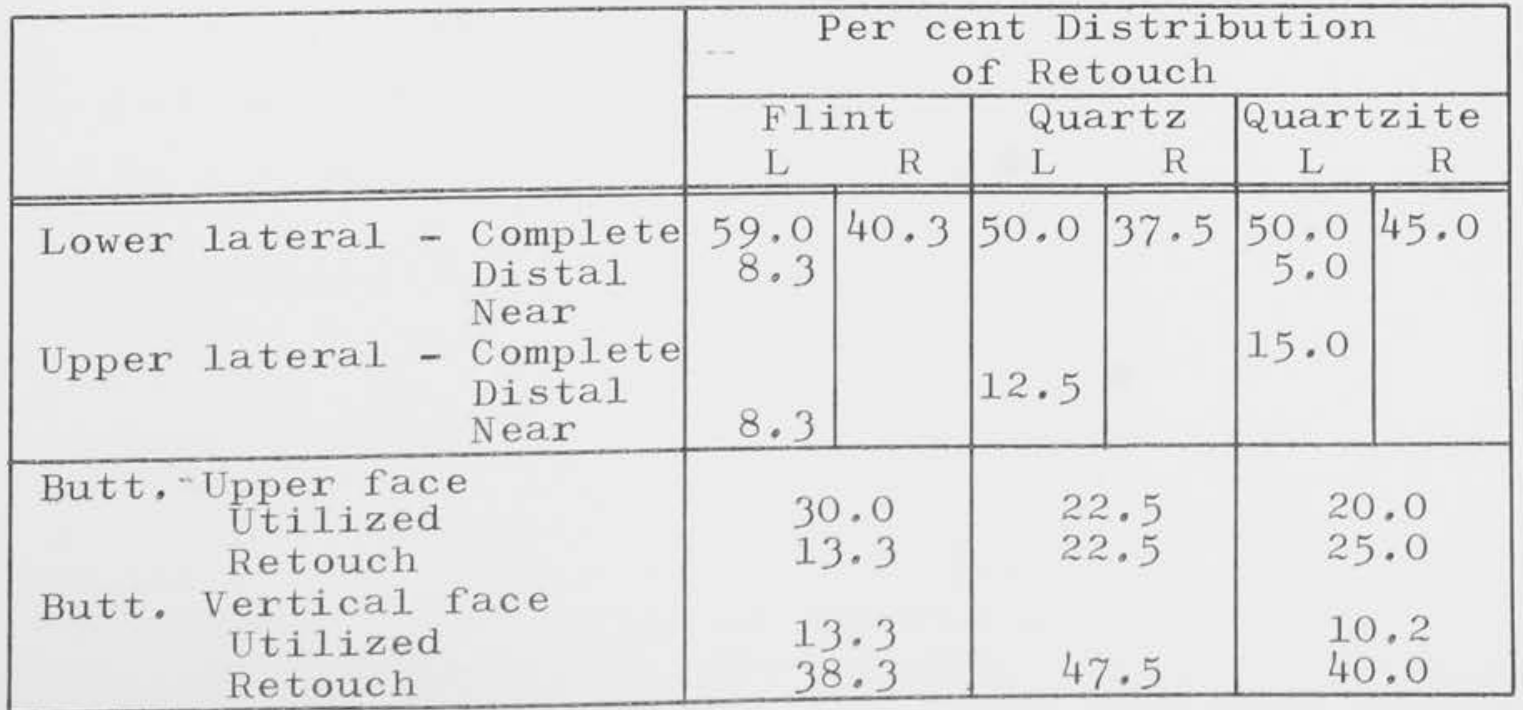


Striking platforms observed were: Flint (7), Quartz (3), Quartzite (10). The proportions of working on each part of the flake per in each material is approximately the same. The only serious difference occurs for Flint where the proportion of flakes with retouch on the butt-upper face tends to be lower than for either Quartz or Quartzite. 12.5 per cent of the Quartz and 5.0 per cent of the Quartzite tools have utilization along their complete right lateral margins. Length ranges: Flint - (0.5-4.0), Quartz $(1.0-4.0)$, Quartzite - (1.0-4.0). 


\section{CLASSIFICATION USING A COMPUTER}

In Chapter 11 a descriptive code was explained in detail. Each flake (or core) was broken down into a number of basic elements, which were described in code form. Finally, this information was transferred on to punch cards. However, when one wishes to compare flake tools within and between assemblages, not all this data is relevant, for much of the information is duplicated ox partly contained within other parameters. Thus one would like to reduce the number of parameters used to describe a single flake to the absolute minimum. When this has been achieved a critical comparison can be made between flake (or core) tools within the assemblage to test whether there are groups of stone tools with similar or identical parameter values. If these groups are large enough one may reduce most of the assemblage to a number of distinct tool classes. 1 These classes will charactexize and define the assemblage and although many tools will not fall within these classes, these classes remain the diagnostic elements of the assemblage (cf. A.C. Spaulding 1960, p,61 ff).

\section{Parameter Reduction}

A statistical test was devised to examine the relationship between the various parameters. For retouched flakes, all variables up to and including cross-section were tested ( see Table 11.1 for the list

'Class' as it is used here is a very flexible concept, and has been generally discussed by Kriegex (1944, $\mathrm{pp}, 272-3$ ). In accordance with his requirements this method of classification is 'flexible enough to allow for additions, subdivisions, recombinations, rewordings, and the like, in the groups where needed, without disturbing othersi (ibid, p.278). 
of variables). The test examines the multi-collinearity or degree of dependence of one variable on each of the other variables. ${ }^{1}$ Thus for retouched flakes of a particular material, all the information about the size and outline of the flake is almost completely contained in two parameters - Iength and shape. The raw material is an outstandingly important parameter. Consequently twelve parameters have been reduced to only three (material, length and shape). Similarly, for cores the parameters are length and width of the base, and number of platforms, For waste flakes, parameters reduce to length and shape.

The number of possible combinations of retouch (and/or utilization) are innumerable, However examination of these combinations (Table 12,2 ) reveals that the number is actually limited to about 170 . The figures in the left hand column represent the coding position (on card 2) for a particular class of retouch ( all Flint and 0,1 per cent of a 11 Quartzite flakes are completely retouched on both the lower left and right hand lateral edges. Of these groups 28 are important (each over 1 per cent of the total), comprising 51.4 per cent of the total ( 49.2 per cent Flint, 54.6 per cent Quartz and 55.5 per cent Quartzite flakes)。The groups may be reduced by remembering that combinations like, $1,2,53$ are the same as $2,1,53$, or that 1,2 is equivalent to 2,1. The 28 important groups are shown in Table 12. 3. In the far right hand column of this table each retouch group has been given a number 1-28. Thus one can now go

The program was supplied by Mr N, Tuckwell of the Statistics Department. Tuckwell was also responsible for interpreting the results. See Appendix 11.1. 
through al1 the groupings in Table 12.2 and assign a retouch number (or class) to each group. If a group does not exactly fit one of the 28 groups it is assigned to one of them according to which retouch class (or group) is the most important within the group itself,

$$
\begin{aligned}
\text { e.g. } 1,19,34 & =2,20,33\} \\
1,19 & =2,20 \\
1,53 & =2,53 \\
1,18,64 & =9 \text { Non standard group } \\
1,19,21,34=4 \quad " ~ & =4
\end{aligned}
$$

The number assigned to each class is shown in the far right hand column of Table 12.2.

Utilization grouping has been considered in the same way. In this case there are 33 groups altogether and these may be reduced to seven important groups comprising 80.4 pex cent of all the flakes with utilization (Table 12.4). There are no important combinations of utilization groups and the seven main groupings are the seven major utilization categories. Unimportant retouch groupings have been assigned to Class 29, and unimportant utilization groups to Class 8. For coxes the six majox retouch/utilization classes have been retained as combinations are not important. Not all shapes are important and for retouched flakes the most significant shapes are shown in Table 12.5. A11 othex shapes have been assigned a 7. For waste flakes, shapes vary with material and the various shape classes are shown in Table $12.8(\mathrm{~b})$.

By examining Tables 11.13-11.20 (worked), 11.5811.61 (waste) and $11.86-11.87$ (cores) where the frequency distributions of lengths, breadths etc, are shown (in $0.5 \mathrm{~cm}$ units) the important frequency intervals may be deduced. These are shown in Tables 
12.5 (worked), 12.8(b) (waste) and $12.9(\mathrm{~b})$ (cores)。

Thus one of five numbers would suffice to describe the length of a worked Quartzite flake.

Summarising the foregoing, it can be seen that the number of parameters needed to describe a flake (or core) has been greatly reduced, For waste flakes two parameters are required (1ength - a number 1-4; shape a number 1-10); for cores four parametexs are requixed (1ength and breadth of the base each having a number 1-4; working - a number 1-6, and number of platforms, 1-4); and for worked flakes five parameters are required (1ength - a number 1-5; mean breadth - a number 1-4: shape - a number $1-7$; retouch, a number $1-29$; and utilization - a number 1 - 8 ).

Flake and Core Description

The object of reducing and describing the parameters in this way is to produce a unique number for each stone tool. Consider now a flake with the following parametex values:

$\begin{array}{lll}\text { 1. } & \text { Material } & \text { Flint } \\ \text { 2. } & \text { Length } & 1,56 \mathrm{~cm} . \\ \text { 3. } & \text { Mean Breadth } & 0.51 \mathrm{~cm} . \\ \text { 4. } & \text { Shape } & 4 \text { (trapezoid) } \\ 5 . & \text { Retouch } & 2,20,33 \\ 6 . & \text { Utilization } & 45\end{array}$

Converting these values into reduced parametex form they become:

\begin{tabular}{|c|c|c|c|}
\hline & & & \\
\hline 1, & Material & Flint & \\
\hline 2. & Length & 2 & Table 12.5 \\
\hline 3. & Mean Breadth & 1 & Table 12.5 \\
\hline 4. & Shape & 3 & Table 12.5 \\
\hline 5. & Retouch & 4 & $\begin{array}{c}\text { Tables } 12,2 \\
\text { and } 12,3\end{array}$ \\
\hline 6. & Utilization & 2 & Table 12,4 \\
\hline
\end{tabular}
by 100, No. 4 by 10,000 , No. 5 by 100,000 and No, 6 by 10,000,000, the following table results: 


$\begin{array}{llr}\text { 1. } & \text { Material } & \text { Flint } \\ \text { 2. } & \text { Length } & 2 \\ 3 . & \text { Mean Breadth } & 100 \\ \text { 4. } & \text { Shape } & 30000 \\ 5 . & \text { Retouch } & 400000 \\ 6 . & \text { Utilization } & 20000000\end{array}$

Adding these up one gets a number 20430102 which uniquely describes the flake tool. Waste and core tools can be described similarly.

In practice, the conversion of each flake (and core) was carried out by the computer.

\section{Classification}

Once the flakes (or cores) are described by a number the process of classification is made easy.

Subtract Count

$\begin{array}{llll}\text { 1. } & 20430102-20430102 & 0 & 1 \\ \text { 2. } & 30520203-20430102 & & \\ 3 . & 82770203-20430102 & & \\ \text { 4. } & 82270103-20430102 & 0 & \\ 5 . & 20430102-20430102 & & 3 \\ 6 . & 82770103-20430102 & 0 & \\ 7 . & 20430102-20430102 & \end{array}$

The principle of the method used for classifying flake tools may be illustrated from the list of converted flake tools above. The computer stores in its memory the unique number of each flake. It then takes the first flake and compares it with every other flake in its memory. The comparison is made by subtraction. Thus if two flakes are identical a zero (o) will result. After all the flakes have been tested the computer adds up the total number of zeros. This total will then represent the number of identical flakes. The answer is printed out and at the same time this flake type is erased from the computex's memory. The computer then goes on to repeat the process with the next flake and so on. In the above table the answer 204301023 would be printed out. 
Table 12.6 shows the resulting classification for each material class. Only groups of four or larger are considered here as numbers less than four are not sufficient to constitute a reasonable grouping. In the right hand column of the table, the McCarthy classification of each flake is given (see Table 11.4) $4 \times 25=$ four flakes of Class 25. The letters VYAQT stand for Victoria, Yanakie, A series, Quartzite. The number following the letters is the class group. The grouping has been arranged according to the distribution of flake working and shape. Thus flakes with the same working and shape fall within the same class. Consequently, although different material classes have different length and breadth parameters they are frequently related by the working-shape parameters and so have been designated similar class numbers.

For Quartzite there are 17 major classes of tools; for Quartz there is only one completely new class (Class 18) and for Flint there are five new classes. Thus altogether 23 classes of tool comprise the Yanakie A ass emblage.

Table $12.8(\mathrm{a})$ shows the waste flake classification. The first figure (Column 2) is the shape, the second the length value. This time the flakes have been classed by length groups and sub-classed in term of the shape distribution.

Table 12.9(a) shows the core classification. The computer class number is made up as follows:

The first digit $=$ number of platforms
The second digit $=$ working classification
The third digit $=$ width of base
The fourth digit $=$ length of base


Again, the classification has been confined to include only those groupings with numbers greater than, or equal to four. Class numbers have been assigned on the basis of the working distribution. Thus there are only two major core classes, ?

Finally the waste flakes from Site $9 \mathrm{~A}$ have been classified by another method. Using the alternative coding system described in Table 11.3, and using only length and breadth to classify the flake material, 26 major classes have been established. ${ }^{2}$ These classes are described in Table 12.10 and in more detail in Diagrams 12.1-12.4. (The ranges in the histograms correspond to the ranges in Table 1..3). The $M$ in the sub-group column of Table 12,10 stands for 'Main'. Diagxam 12.5 shows the relationship between classification, flake number/class and length range. It will be noted that the distribution is multi-modal and that most of the flakes fall within one of several main groups.

VYACF = Victoria, Yanakie, A Series, Cores, FIint. 2 No distinction has been made between materials. 
Five axes are shown in Plate 12.1. Each axe is described below in terms of Mitchell's typology (1949, pp. 78-82). See also F.D. McCaxthy et al 1946, Figs. 261-2, p. 48, text pp. 47-49.

Axe 1

1. Location, Site 9B/3.

2. Length, $12.3 \mathrm{~cm}$.

3. Width, $9.4 \mathrm{~cm}$.

4. Thickness, $3.3 \mathrm{~cm}$.

5. Weight, $525 \mathrm{gm}$,

6. Bifacial axe, flaked and then ground at one end only. Heavily trimmed along the lateral edges.

7. Shape, oblong ovate.

8. Cross-section - Iens.

Axe 2

J. Location, B series site on west coast of North Yanakie。

2. Length, $9.9 \mathrm{~cm}$.

3. Width, $6.4 \mathrm{~cm}$.

4. Thickness, $2,8 \mathrm{~cm}$,

5. Weight, $268 \mathrm{gm}$.

6. Bifacial axe, very badly weathered - flaked and ground. It has been exposed to the weather on one side for some time as it is sand blasted on this side, Extensive trimming along the lateral edges.

7. Shape, oblong ovate.

8. Cross-section, irregular tens. 


\section{Axe 3}

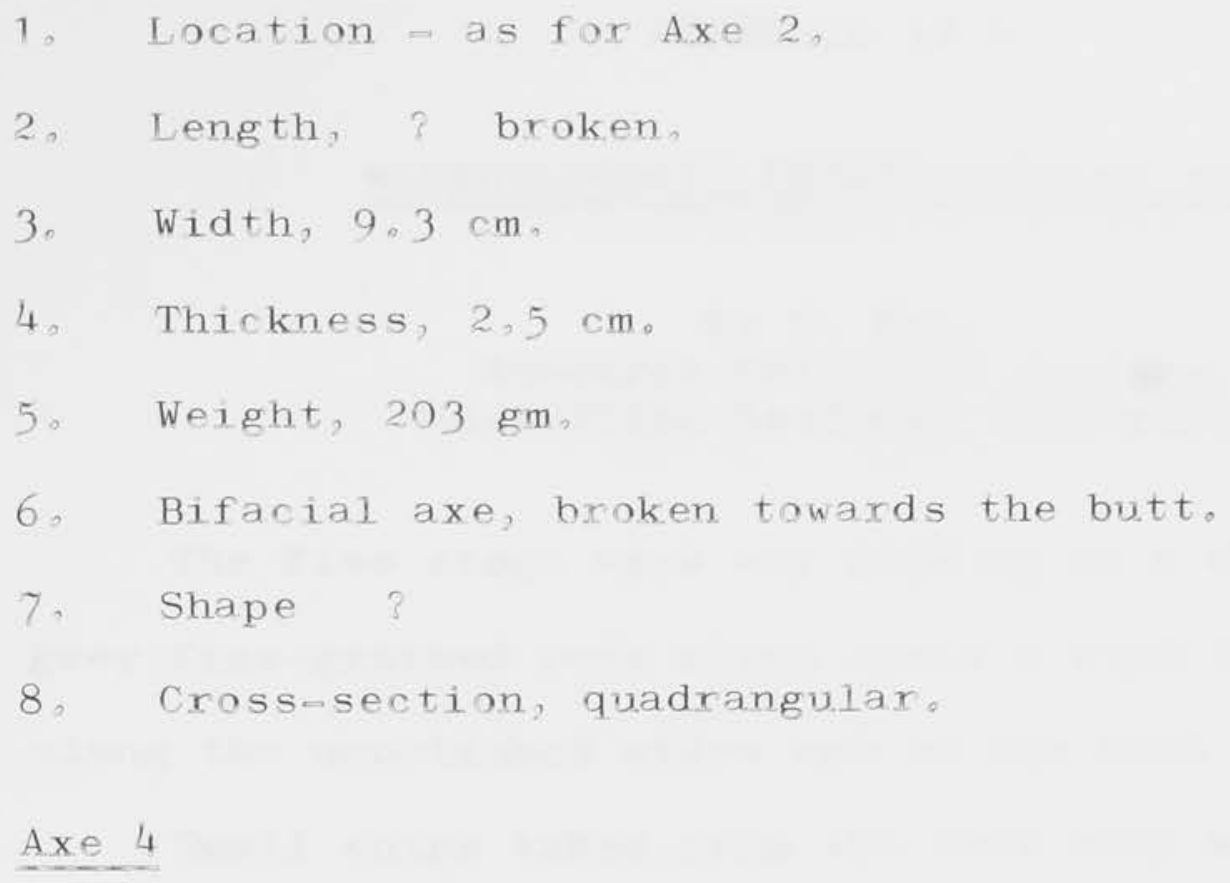

\section{Axe 5}

1. Location - as for Axe?.

2. Length, 10, $0 \mathrm{~cm}$.

3. Width, $8,4 \mathrm{~cm}$.

4. Thickness, $2.7 \mathrm{~cm}$.

5. Weight, $270 \mathrm{gm}$.

6. As for Axe 1. This specimen shows a slight sign of a shoulder towards the butt end. However this effect may also have been caused by a weakness in the stone during flaking,

The matexial. from which these axes have been made is described in Appendix 12.4 . 


\author{
by $C_{2}$ Key, \\ Research Fellow in Geology, \\ Australian National University
}

The five stone axes are made up of a dense dark grey fine-grained rock which shows a weak fissility along the unpolished sides and on the butt ends.

Small chips taken from the butt ends were crushed and examined under the polarizing microscope.

The main mineral constituent of the rock was found to be a matted aggregate of very small greenish fibres. All single fragments were birefringent with straight extinction and low interference colours, and length slow. The refractive index of the mineral was a little above 1.55 and it can therefore be identified as antigorite, one of the serpentine minerals.

The axes can therefore be said to be made from an altexed basic rock of the serpentine type. 
APPENDIX 12,5

ZOOLOGICAL REPORT FROM

WILSON'S PROMONTORY, VICTORIA

\author{
by $J$. Warren, \\ Zoology Department, Monash University, \\ Clayton, Victoria
}

SITE 1

Rabbit skull.

SITE 3

(Misc, she11 and bone)

Undetermined bird: humerus and ulna of medium size species.

SITE 4

Fragment of rabbit skull,

\title{
SITE 9A
}

Section 1

Sheep: 1, immature, right dentary

Rabbit: 1. occipital plus left petrosal

2. two thoracic vextebrae

3. part of left pelvis

Penguin: 1, right femur

2. right tarsos - metatarsus

3. right and left humeri

4. fused carpal

Goose: 1. Ieft humerus

Wallabia bicolor:

$$
\text { 1. right }
$$

Rattus sp.: 1. damaged skul1; lacks occipital and nasal region

Mastacomys: $\quad$ 1. left dentary

Muridae (either Rattus or Mastacomys ox ?)

1. matched paix of tibia 
Isoodon (obesulus?)

1. left dentary

Undetermined: 1. bird quadrate (penguin?)

2. several slivers of fragile bone which may be bird

3. 8 definite bird bones belonging to at least 2 species

Section 2

Isoodon sp.: 1. right dentary

2. ulna

3. tibia

4. femur

Muridae: 1 . tibia

2. right pelvis

Sheep: 1. right dentary

2. pair of scapulae

3. right pelvis

4. portion of maxillary with 2 teeth

5. canon bone

6. right femur

7. rib

8. one thoracic vertebra.

Wallabia sp.: 1. 1eft femur

2. left humerae

3. tibia

4. pair of radii

5. two phalanges

6. two ribs

(all have same degree of weathering and are complementary in size probably one individual).

Rabbit:

1. skull lacking occipital

2. two thoracic vertebrae (do not match) 


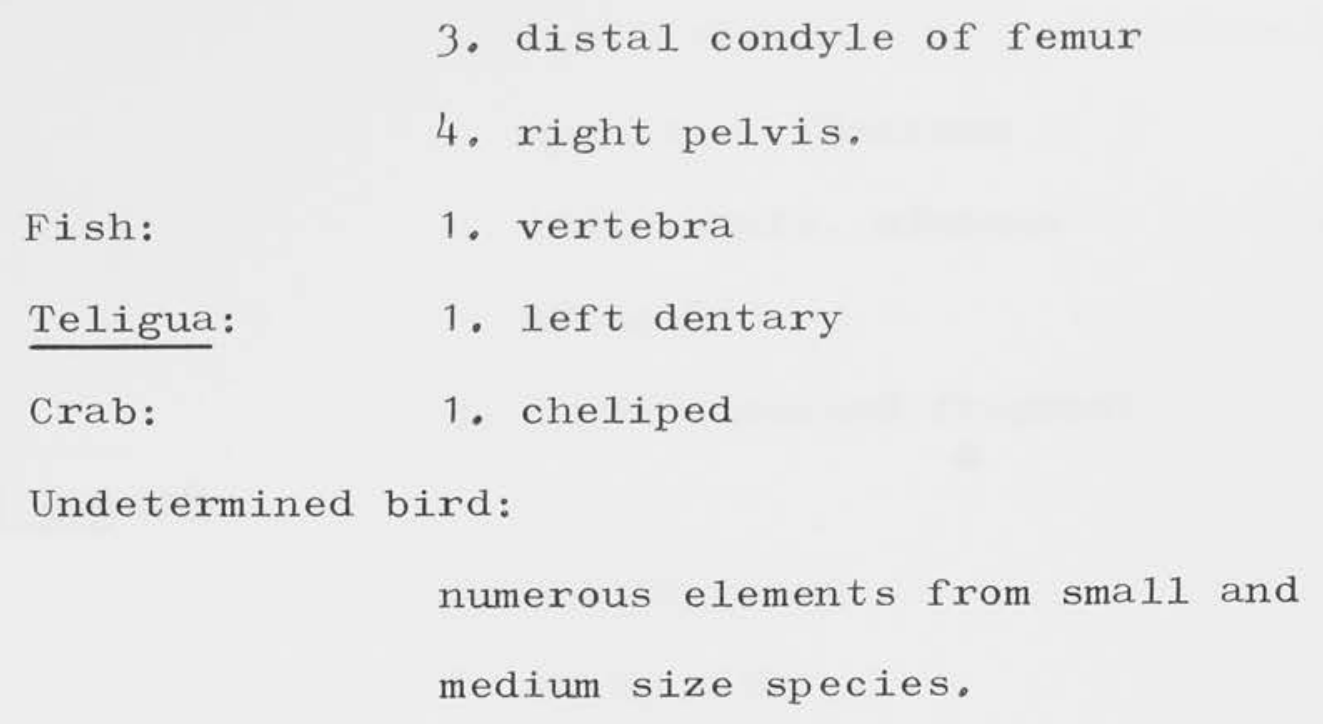

$\underline{\text { Section } 3}$

Sheep:

1. right and left dentaries, very young animal

2. deeply weathered sacrum

3. canon bone from very young animal.

Tiligua sp.: 1. right maxillary.

Undetermined mammal:

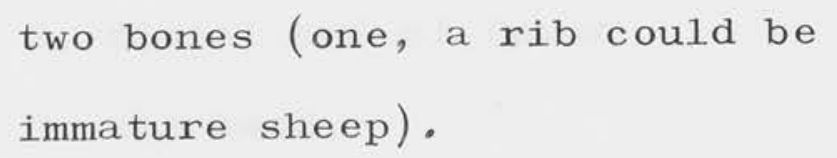

Undetermined bird:

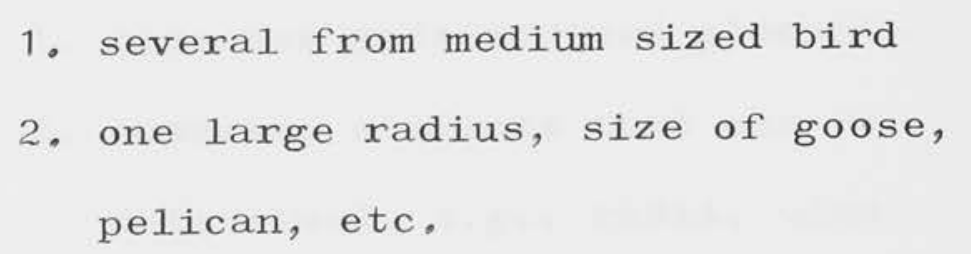

\section{SITE भP $9 \mathrm{C}$}

Rabbit skul1.

SITE 1090

Dog skull.

SITE 11

Undetermined bird:

1. matching humeri, radiu, phalanges plus assorted bones of medium size species. Could be one individual.

SITE IIA $10 \mathrm{~A}$

Bird :

1. Goose, radius and humerus

2. Undetermined: 3 humeri, pair of ulnae, single radius, single 
tibia tarsus. A11 of medium size species. (Maximum of 3

individuals, minimum of 2 : 2 most probable).

3. 7 undetermined fragments.

\section{SITE $1 \pm B$ IOB}
1. rabbit femur
2. sheep ulna
3. rabbit tibia.

SITE 12

Undetermined bird:

1. several elements from medium size species (could be one individual).

\section{SITE 13}

Sheep:

1. condyle of canon bone

2. distal end of femur

3. rib head.

Rabbit:

1. right femur of young individual.

Bird:

1. numerous undetermined elements

2. numerous elements that can be determined, e.g., radii, ulna, humeri, phalanges, etc. From this assortment it is possible to say there is a minimum of 4 individuals represented here and a maximum of 7 . The most reasonable guess would be 5 medium sized birds, based on matching the humeri.

3. 2 radii of large bird (goose?).

SITE $13 / 1$

Bone and she11

Bird :

1. medium sized species, undetermined element plus matching radius and 


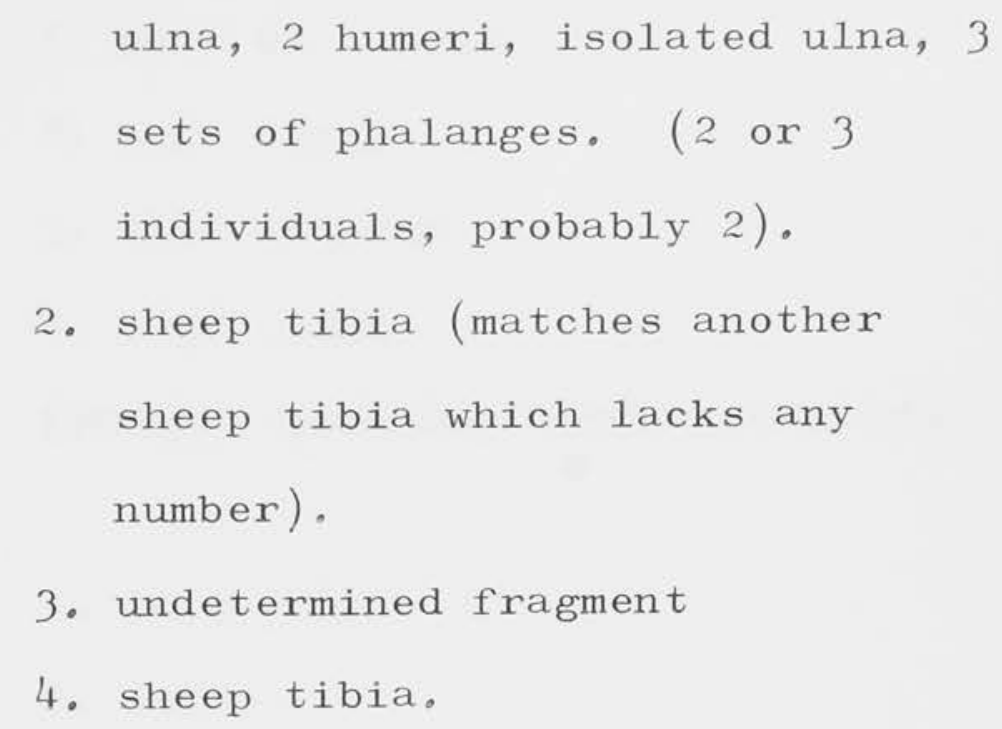

SITE $13 / 2$

1. human fibula (right side).

SITE $13 / 3$

1. fragments - probably sheep tibia.

SITE 14

1. right maxillary
2. left femur
1. left femur
Rabbit:
Undetermined bird:
1. several, including pair of ulnae:
all of medium size species.

\section{SITE 15}

Goose: 1. ulna, tarso - metatarsus, humerus

Undetermined bird:
1. medium sized species, 3 humeri, sorted phalanges, tibiae. Probably 2 individuals.

SITE 16

Fox:
$\begin{aligned} & \text { 2. right ulna (could be small dog) } \\ & \text { 3. left radius - larger than } \\ & \text { abovementioned ulna } \\ & \text { 1. distal end of left humerus } \\ & \text { (broken in half), radius } \\ & \text { 1. left dentary of large species }\end{aligned}$


Sheep:

$$
\begin{aligned}
& \text { 1. pair of humeri } \\
& \text { 2. left femur } \\
& \text { 3. left ischium } \\
& \text { 4. right ulna } \\
& \text { (young - probably single individual). }
\end{aligned}
$$

SITE 19

$$
\begin{aligned}
& \text { 1. left femur } \\
& \text { 2. tibia } \\
& \text { 3. shank of large femur? } \\
& \text { 4. canon bone } \\
& \text { 5. ulna of small individual } \\
& \text { 6. fibula } \\
& \text { 7. rib } \\
& \text { (appears to be } 3 \text { individuals) }
\end{aligned}
$$

Undetermined bird:

1. 2 pairs of humeri probably represents 2 individuals of medium sized species.

SITE 20

Sheep:

1. matching right and left dentaries

2. fragments of another right dentary

3. fragment of left maxillary

4. two isolated cheek teeth

5. postero - lateral fragment of skul1

6. 9 tibiae $(4$ sets $+1=$ minimum of 5 individuals)

7. 3 radii (2 individuals?)

8. 2 different sized femura

9. 13 canon bones (no attempt to match pairs)

10. 1 large humerus

11. 1 small ulna 
12. 1 rib? (could be say large mammal, e.g. Kangaroo)

Goose: 1. ulna

Undetermined bird:

1. several identifiable elements representing probably 2 individuals of medium sized species

Undetermined elements:

$$
\text { 1. } 5 \text { ribs }
$$

Rabbit: 1. skul1 lacking occiput

2. left dentary

3. ulna

Wallabia bicolor:

1. matched right and left dentaries. Wa1labia rufogrisea:

1. 2 dentaries, one left, one right and of the same size. Show the same degree of tooth development so could be one individual. The left dentary is burned and fractured; the occlusal surfaces of the teeth are broken away (not worn natura11y).

SITE 22

Sheep :

1. canon bone

2. ulna

Undetermined bird:

$$
\begin{aligned}
& \text { 1. tibia of medium size species. } \\
& \text { 2. coracoid of medium size species } \\
& \text { 3. fragment of long bone of large } \\
& \text { species }
\end{aligned}
$$


4. 4 bones, 3 from medium size species; 1 from large bird (goose?).

Rabbit: $\quad$ 1. pelvis

Undetermined mammal:

1. tibia

SITE 27

Bird: 1. undetermined fragments of medium size bird, could be one individual. 


\section{APPENDIX 12.6}

\section{REPORT RECEIVED FROM DEPARTMENT OF MINES, MELBOURNE, ON A PITCH SAMPLE SUBMITTED FOR ANALYSIS}

by J.C. Kennedy, Senior Chemist

Description of Sample

A sample of material believed to be pitch was received for analysis.

The sample consisted of angular pellets, black in colour and thinly covered with a brown siliceous coating.

\section{Location of Sample}

Details of the location were given by the sender as follows:

$\begin{array}{ll}\text { West coast of Yanakie } \\ \text { Site } & 11 \\ \text { Excavation } & \text { No. } 1 \\ \text { Trench } & \text { B } \\ \text { Square } & 5 \\ \text { Spit } & 12 \\ \text { Date of sampling } & 1 \text { st June } 1965 .\end{array}$

\section{Results}

Before grinding any sample for analysis, the pellets were lightly brushed to remove as much as possible of the brown siliceous coating.

\section{Physical}

Colour

Lustre

Tenacity

Fracture
Black

Dul1 to shining

Britt1e

Hackly to sub-conchoidal 
Moisture as received 0.91 per cent

$$
\frac{\text { Dry Basis }}{\%}
$$

Carbon

Hydrogen

Nitrogen

Sulphur

Ash

*Volatile matter

*Fixed Carbon

\section{Other Tests}

Specific gravity

Fluorescence under U1traviolet light

Solubility in Carbon

$$
\text { Disulphide }
$$

Fusion point
67.90

$$
6.91
$$

0.55

16.99 $\frac{\text { Dry, Ash-free }}{\%}$ 81.80

$8 \cdot 32$

0.66 3.89

67.6 32.4

1.123

Nil

complete soluble

Between $250^{\circ}$ and $500^{\circ} \mathrm{F}$

*Using British Standard Method for black coal.

\section{Comment}

From the foregoing results, the material would be classed as a natural pitch.

Being more specific and using the Synoptical Table of Herbert Abraham, it is suggested that the material might be classified as follows:

Genus Bitumen

Species

Asphaltite

Member

Glance Pitch or Grahamite. 
Abe, N.

Audas, T.W.

Basedow, H.

Berndt, R.M. \& C.H. 1964

Birdse11, J.B.

Browne, W.R.

Chapman, F.

Campbe11, T.D. \& Noone, H.V.V.

Coutts, P.J.F。

1933 'The Colony of the Limpet', (Acmaea Dorsuosa Gould) Sci. Rep, Tohoku Imp.

University, Biology。 Vol,8 No, 2, pp, 169-87.

'Promontory', Vic,Nat, XXVII, no, $10, \overline{\mathrm{pp}}, 20 \overline{8}=14$.

The Australian Aborigines delaide)

The World of the First
Australian (Sydney).

1949 The Racial Origins of the Extinct Tasmanian'。Rec。 Queen Vic, Mus, (ii) 3., pp. $105-22$.

1963 Pleistocene and Recent Climate of Australia' Aust. Nat, Hist, vol.XIV no, 8, $\overline{p p} \cdot 26 \overline{7}=\overline{70}$.

1923 'Excursion to Torquay', Vic. Nat, vol, XXXIX, pp.153-7.

1943 a South Australian Microlithic Stone Implementsi。 Rec。 of Sth Aust, Mus, vol. VII, pp. 281-307.

1943b Some Aboriginal Camp Sites in the Woakwine Range Region of the South East of South Australia? Rec, of Sth Aust. Mus., vol,VII, pp.371= 95.

1946 :Aborigines of the Lower S.E. of South Australia?. Rec. of Sth Aust. Mus., vol.VIII, no. 3, pp, 445-501.

1966 The Ethnological Evidence of Wilson's Promontory, Victoria', Limbec, pp. $37-43$.

$1967 a$ Coastal. Dunes and Field Archaeology in S.E.

Australia?.Archaeology \& Physical. Anthropology in Oceania (in press).

$1967 \mathrm{~b}$ 'Features of Prehistoric Camp Sites ${ }^{1}$. Mankind (in press).

Coverdale, T.J. 
Curx, E.M.

Daley, C.

Daly, R.A.

David, T.W.E.

Davidson, D.S.

Davies, J.L.

Dawson, W.T.

Dakin, W.J., Bennett, I. \& Pope, E。

Dakaris, S.I., Higgs, E, S。 \& Hey, R.W.

Doty, M.S,

Dorman, F, \& Gi11, E.D。

Dunn, H.D.

Dury, G。H.

1887
The Australian Race, vol, III
(Lond, ).

'Excursion to the National Park', Vic,Nat, vol, XLI, no. 11, pp, $204-10$,

1934 The Changing World of the Ice Age, 8 Vvo, New Haven.

$1950 \frac{\text { Geology of the Commonwealth, }}{3 \text { vols (London). }}$

1937 The Relationship of

Tasmanian Culture', 25th Anniv。 Studies; Philadelphia Anthropological Soc, pp.47= 62 .

1957 The Importance of Cut and Fill in the Development of Sand Beach Ridges'. Aust。 Jour. Science, vol.120, pp. $105-11$.

Letter Book January 1855 to December 1856, Latrobe Library (Melbourne).

1948 A Study of Certain Aspects of the Ecology of the Intertidal Zone of the N.Z. W, Coasti, Aust, Journ, of Scientific Research, Ser, $B$, vol, $1, \mathrm{pp}, 176-230$.

1964 Climate, Environment and Industries of Stone Age Greece?, Proc, Prehist, Soc, (Lond, ), vol, XXX, pp.199-244.

1957 'Rocky Intertidal Surfaces', Mem, Geol. Soc, America, no, 67, vol. 1, pp. $535-85$.

1959 P Oxygen Isotope

Palaeotemperature

Measurements', Proc, Roy. Soc, Vic. NS, vol.71, pt, 1, pp. $73-98$.

1907 TTin Ore on Wilson's

Promontory'. Rec. Geol. Surv. Vic。, vol, II, pt。2, p.103.

1964 Australian Geochronology:

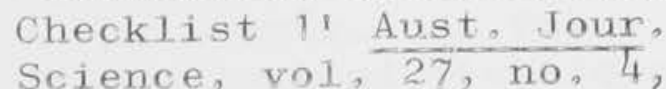
$\frac{\text { Science, }}{\mathrm{pp}, 103=9}$.

1966 Australian Geochronology: Checklist 2' Aust. Journ. Science, vol, 29 , no, 6, pp. 158-62. 
Edwards, A.B

Elkin, A。P.

Emiliani, C.

Epstein, S. \&

Lowenstam, H,A.

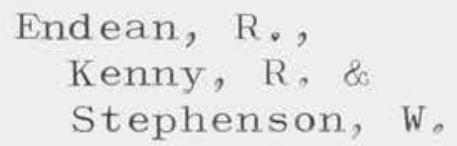

Etheridge, R, \& Whitelegge, T。

Ewart, A.J 。

Ferguson, W. H。

Gardin, J.C.

Gifford, E, W。
1941 The North West Coast of Tasmania', Proc. of the Roy,

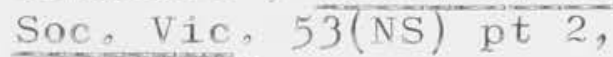
pp. 238-67.

1938 The Australian Aborigines (Sydney).

1956 ' Note on Absolute Chronology of Human Evolution', Science, vol, 123, pp.924-6。

1957 Temperature and Age Analysis of Deep-Sea Cores', Science, vol. 125, pp. $383-7$.

1953 Temperature Shell Growth Relations of Recent and Interglacial Pleistocene Shoal Water Biotdfrom Bermuda', Jour, of Geology, vol. $61, p \bar{p}, 424-38$.

1956 The Ecology and Distribution of Intertidal Organisms on the Rocky Shores of the Queensland Mainland", Aust. Jour of Marine and Freshwater Bes, vol, 7, $\mathrm{pp}, 88-146$.

1907 Aboxiginal Workshops on the Coast of N.S.W.', Rec. Aust, Mus, vol. VI, no, 4, pp, $238-40$ 。

1.909

'Biological Suxvey of Wilson's Promontory?, Vic. Nat, yol. XXV, no, 9, $\overline{\mathrm{pp}}, 142-51$.

1910 'Biological Survey of Wilson's Promontory', Vic, Nat。, vol, XXVI, no, 9, $\mathrm{pp}=129-37$.

1911 'Biological Survey of Wilson's Promontory', Vic. Nat。, vol. XXVII, no. $\overline{9}$ $\overline{\mathrm{pp}}, 178-80$.

1909 Report on Quartex Sheets $67 \mathrm{NE}, 67 \mathrm{SE}, 76 \mathrm{~W}^{\circ}$ Mem。Geol. Surv. Vico, no. $8, \overline{p t} 4$

1958 Four Codes for the Description of Artifacts, An Essay in Archaeological Technique and Theory。 Am, Anthrop., vol. $60, \quad p p=33 \overline{5}-57$.

1916 Composition of California Shellmounds ${ }^{\wedge}$, Univ, of California. Publication in American Archaeology and Ethnology, vol, $12, \mathrm{pp}, 1-29$. 
Gi11, E.D.

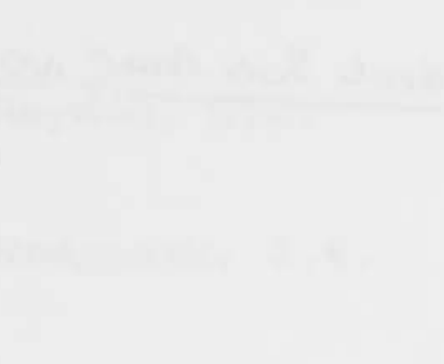

Green, R。C.

Gregory, J.B.

Gregory, J.B. \& Lucus, A.H.S. 1953a 'Fluoxine Tests in Australia on the Keilor Skull and $a$ Tertiary Marsupial'。 Nature, vol. 172, pp, 409-40。

$1953 \mathrm{~b}$ 'Geological Evidence in Western Victoria Relative to the Antiquity of the Australian Aborigines' . Mem. of Nat. Mus.Vic, vol. 18, pp.25-92.

$1954 \mathrm{a}$ 'Aboriginal Kitchen Middens and Marine Shel1 Beds'。 Mankind, vol. 4, no, 6, pp.249-53.

$1954 \mathrm{~b}$ 'Keilor Man', Antiquity, vol, $28, \mathrm{pp}, 11 \overline{\mathrm{O}-3}$.

$1955 a$ 'The Age of Keilor Man', Australia. Anthropoa, vol. $50, \mathrm{p} .4 .17$.

1955b 'Aboriginal Midden Sites in Western Victoria Dated by Radio Caxbon Analysis', Mankind, vol. 5, pp.51-5.

1955c 'The Australian Arid Period', Aust. Joux. of Science, vol. 17, pp.204-6.

1964 Quaternary Geology, RadioCaxbon. Datings and the Age of Australites. Unpublished.

1965 'Radio-Caxbon Dating of Australitos. Occurrences Microliths, Fossil Grasstree and Humus podsol. Structures', Aust. Joux of Science, vol. 27, no.10, pp. 300-1.

1963 'A Review of the Prehistoric Sequence in the Auckland Provincel. Public, of the Auckland Archaeological Soc. no. 1 w. . Axchaeological Association Newsletter no. 2.

1885 'To Wilson's Promontory Ovexland, part 1 . Vic. Nat., vol. II, pt 4, pp.43-8.

$1885 \mathrm{a}$ 'To Wilson's Promontory Ovexland Part II', Vic. Nat., no. 5, $\mathrm{pp} .54--9$.

$1885 \mathrm{~b}$ 'To Wilson's Promontory Overland Part III', Vic. Nat. vol. II, no. 7, pp.87.-90.

1886 'To Wilson's Promontory Ovexland Paxt IV', Vic. Nat. vol. II, no. I2, pp.150-4. 
Guntior, G 1957 'Temperature'. Mem Geok Soc Amer, no 67 vel2, $p p 159-84$ 
Gresser, P.E,

Haydon, G.H.

Hedgpeth, J,W.

Horne, G。

Howitt, A, W ,

Huntex, G.

Hale, H.M. \& Tindale, N.B。

Jamieson, R.

Jennings, J,N 。

Jones, N.S.

Jones, R.

Jones, F. Wood

Keble, R。A。
1962 INew Distributional Records of Stone Implements in N.S.W. and Queensland". Part 1. Mankind, vol, 5, no, 12, pp. $512-33$.

1846 Five Years Experience in Australia, Felix (London).

1957 'Classification of Marine Environments', Mem. Geol. Soc, America, no. 67, vol. 1, $\mathrm{pp}, 17-27$.

1921 'Aboriginal Coast Camps of Eastern Victoria!, Vic, Nat., vol, XXXVIII, $\mathrm{pp}, 48-53$.

(undated) Diary of: (unpublished).

1904 The Native Tribes of S,E. Australia (London).

Temperature ${ }^{8}$ Mem.Geol. Soc. America, no. 67, vol. 2, pp. $159-84$.

Notes on Some Human Remains in the Lower Murray Valley, South Australia?, Rec, Sth Aust. Mus, IV, pp. $\overline{145-218}$.

1898

Letters from the Victorian Pioneers (Melbourne), pp.159-60 (August 1853).

1959

The Submaxine Topography of Bass Strait?. Proco. Roy.
Soc, Vic。, vol, pp. 49-72,

1948 Iobservations and Experiments on the Biology of Patella vulgata at Port St. Mary Isle of Man', Trans, of Liverpool Biological Soc, vol. LVI, pp.60-77.

1965 Archaeological Reconnaissance in Tasmania - Summer, 1963/64, Oceania, vol, XXXV, no. 3, pp. $\overline{191-201}$,

1935 Sexies of Three Talks entitled 'Tasmania's Vanished Race', A.B.C.

1928 'Kitchen Middens on the Mornington Peninsula', Vic. Nat。, XLV, pp.151-9.

1946 The Sunklands of Poxt Phillip Bay and Bass Strait', Mem. Nat, Mus, Vic, no, 14, pt 11, pp.69-122. 


\begin{tabular}{|c|c|c|}
\hline & 1947 & $\begin{array}{l}\text { 'Notes on Australian } \\
\text { Quaternary Climates and } \\
\text { Navigation. } \\
\text { Vic, no, } 15, \frac{\text { pem. Nat, Mus. }}{\text { pp. } 28-81 \text {, }}\end{array}$ \\
\hline Kemp, T.E, & 1963 & $\begin{array}{l}\text { The Prehistory of the } \\
\text { Tasmanian Aborigine', Aust, } \\
\frac{\text { Nat, Hist }}{\mathrm{pp}, 242-7} \text {, vol, XIV, no, } 8 \text {, }\end{array}$ \\
\hline Kenny, J,P.L. & 1921. & $\begin{array}{l}\text { 'Tin Deposits of Wilson's } \\
\text { Promontory', Rec, of Geol. } \\
\frac{\text { Surv, Vic, vol. V, pt }}{\mathrm{p}, 252 \text {, }}\end{array}$ \\
\hline \multirow[t]{3}{*}{ Kenyon, A.S. } & 1906 & $\begin{array}{l}\text { 'Excursion to Wilson's } \\
\text { Promontory?, Vic. Nat, , vol. } \\
\text { XXII, no, 12, pp.191-223. } \\
\text { Sub-article entitled } \\
\text { 'Ethnology', p.223. }\end{array}$ \\
\hline & 1912 & $\begin{array}{l}\text { 'Camping Places of the } \\
\text { Aborigines of S,E, Australia', } \\
\frac{\text { Vic Hist, Mag, vol, ii, }}{\mathrm{pp} .97-110}\end{array}$ \\
\hline & 1927 & $\begin{array}{l}\text { Stone Tmplements on } \\
\text { Aboriginal Camping Grounds', } \\
\text { Vic Nat, vol, XLIII, } \\
\text { pp.280-5, }\end{array}$ \\
\hline $\begin{array}{l}\text { Kenyon, A.S., } \\
\text { Mahony, D.J. \& } \\
\text { Mann, S.F. }\end{array}$ & $1923 a$ & $\begin{array}{l}\text { : Evidence of Outside Culture } \\
\text { Inoculations , A.A.A.S. } \\
\text { XVII, pp. } 464-6 \text {, }\end{array}$ \\
\hline & $1923 \mathrm{~b}$ & $\begin{array}{l}\text { Austral-Tasmic Connexion', } \\
\frac{\text { A.A.A. S。 vol. XVII, }}{\mathrm{pp}, 467-9} \text { ? }\end{array}$ \\
\hline \multirow[t]{2}{*}{ Kershaw, J,A. } & 1906 & $\begin{array}{l}\text { 'Excursion to Wilson's } \\
\text { Promontory', Vic. Nat, vol, } \\
\text { XXII, no. 12, pp.191-223, } \\
\text { Sub-article entitled 'General } \\
\text { Zoology', pp, } 197-207 \text {. }\end{array}$ \\
\hline & 1928 & $\begin{array}{l}\text { 'Notes on the National Park, } \\
\text { Wilson's Promontory', Vic. } \\
\text { Nat, vol, XLIV, no, } 1 \text {, } \\
\text { pp. } 300-2 \text {. }\end{array}$ \\
\hline Krieger, A,D。 & 1944 & $\begin{array}{l}\text { The Typological Concept', } \\
\frac{\text { Am, Antiq }}{\mathrm{pp}, 271-88} \text {. vol, } 9 \text {, no, } 3 \text {, }\end{array}$ \\
\hline Lampert, R.J. & 1966 & $\begin{array}{l}\text { 'An Excavation at Durxas } \\
\text { North, N.S.W.', Archaeology } \\
\text { and Physical Anthropology in } \\
\frac{\text { oceania, vol. } 1, \text { no. }}{\text { pp, } 84-118}\end{array}$ \\
\hline Legge, R.W. & 1929 & $\begin{array}{l}\text { Tasmanian Stone Culture', } \\
\text { Pap, \& Proc, Roy. Soc. Tas., } \\
\mathrm{Pp}, 39-43 .\end{array}$ \\
\hline
\end{tabular}


Lewis, A, N ,

Lewis, J。R,

Lowenstam, H。A.

Lowenstam, H,A \& \& Epstein, S.

Macintosh, $N, W, G$ 。

Mackaness, G,

Macintosh, N.W.G. \& 1965 Barkex, B,C.W.

MacPherson, J。H, \& Gabriel, C,J.

Massola, A,
Correlation of the

Tasmanian Pleistocene Beaches and River Terraces in Unglaciated Areas', Pap. and Proc, Roy. Soc. Tas., $\mathrm{pp} .75-86$

1954 iobservations on a High Level Population of Limpets', Jour. Animal Ecology, vol. 23, pp.85-100.

1954 a Environmental Relations of Modification Compositions of Certain Carbonate Secreting Marine Invertebrates. Proc, Nat Acad, of Science, vol,

$1954 \mathrm{~b}$ : Factors Affecting the Aragonite: Calcite Ratios in Carbon-Secreting Marine Organisms ${ }^{2}$ Jour of Geology, vol. $62, \mathrm{pp}, 284-322$ 。

1954 Paleotemperatures of the Post Aptian Cretaceous as Determined by the oxygen Isotope Method:, Jour, of $\mathrm{pp}, 207-48$.

1949 A Survey of Possible Sea Routes Available to the Tasmanian Aborigine?, Rec, Queen Vic, Mus, tiii 3 Vol 2, No3 pp, $12.3-43$ \&

1963 Prigin and Physical

Diffexentiation of the Australian Aborigine, Aust, $\mathrm{Nat}$ Hist, vol, XIV, no, $\overrightarrow{8}$, $\mathrm{pp}, 24 \overline{8}-\overline{52}$.

1941. The Journal of Robinson Through Gipps.Land in 1844. George Augustus Robinson's Journey into South Eastern Australia 1844 with George Henry Haydon's Narrative of part of the same journey. Australian Historical. Monographs, vol. I, pp. 5-69.

The Osteology of Aboriginal Man in Australia?, Oceania Monographs, no, 12, pp.1-72.

1962 Marine Molluscs of Victoria (MUP),

'Aboxigine Relics in Victorial, Aust, Nat, Hist, vol. XIV, no, 8, pp-254-8. 
Mahony, J,D,

McBryde, I。

McCarthy, F.D.
1943

The Problem of the Antiquity of Man in Australia", Mem. Nat, Mus. Vic, $13, \mathrm{pp} . \overline{7}=56$.

1962 Archaeological Field Survey Work in Northern New South Wales', Oceania, vol. 33, pp, 12-7.

1963 istudies of Environment in Northern New South Wales', pp, 63-70 in New England Essays, Ed, R.F。 Warner. Pub, Univ, of New England, N.S.W

1965 'Radio Carbon Dates for Archaeological Sites in the Clarence Valley, Northern New South Wales? Oceania, vol, XXXV, no, 4, pp. $260-6$ 。

1966 In Recent Australian Radio Carbon Dates? Newsletter of Aust. Inst, of Aboriginal studies, vol, 2, no, 3 pp. $20-6$.

1967 ANZAAS Conference (Melb。).

1941 Two Pebble Industry Sites of Hoabinhien I Type on the North Coast of N.S.W., Rec, of Aust, Mus, vol. XXI, no, 1, $\mathrm{pp}, 21-6$.

1943a 'An Analysis of the Knapped Implements from Eight Elouexa Industry Stations on the South Coast of New South Walesi, Rec. Aust, Mus, vol. XXI, no, $3, \mathrm{pp}, 127-53$.

1943b The Coroid and Knapped Stone Implements of the Bathurst District', Rec, of $\frac{\text { Aust }}{\mathrm{pp}, 99-209}$

1947 :The Analysis of the Large Stone Implements* from five workshops on the North Coast of N.S.W.r, Rec, Aust, Mus, vol, XXI, pp, $411=30$ 。

1948 The Lapstone Creek Excavations: Two Culture Periods Revealed in Eastern New South Wales?, Rec, of Aust, Mus, vol, XXII, no, 1, pp. $1-34$. 
1964 The Axchaeology of the Capertee Valley, New South Wales'. Rec of Aust, Mus. ,

$1965 \mathrm{a}$ The Aboriginal Past: Archaeological and Material Equipment' in Aboriginal Man in Australia (Sydney), ed, by R.M. \& C.H. Berndt, $\mathrm{pp}, 71-100$ 。

1965 b Private Communications.

1966 In 'Recent Australian Radio Carbon Dates', Newsletter of $\frac{\text { the Aust. Inst of Aborig. }}{\text { studies, vol. }}$ $\mathrm{pp}, 20-6$.

McCarthy, F.D., Brame 11, E。 \& Noone, H.V.V.

McCarthy, F.D. \& Davidson, F。A.

McCarthy, F.D. \& MacIntosh, N.W.G.

McCombie, T。

McMillan, A。

Megaw, J.V.S.
1946

: The Stone Implements of Australia!. Mem. Aust. Mus, vol. IX, ppo $1=94$.

1943

- The Elouera Industry of Singleton, Hunter River, N.S.W.', Rec, Aust, Mus, , vol. XXI, no, 4, pp, $210-30$.

1962

'The Archaeology of

Mootwingee Western N.S.W.'。 Rec。 of Aust. Mus, vol. 25, no. 13, pp. $249-9 \overline{8}$.

1966 Recent Australian Radio Carbon Dates? Newsletter of Aust. Inst. of Aboriginal Studies, vol. 2, no. 3, p, $2520-26$

1858 The History of the Colony of Victoria (Melbourne).

1898 :Memorandum of Trips by A. McMillan from Maneroo District, in the year 1839 , to the South West of that District, towards the sea coast, in search of New Country?. Letters from Victorianpioneers, pp.254-9 (August 1853)。

1965 Excavations in the Royal National Park N.S.W.: A First Series of Radio-Carbon Dates from the Sydney

District'。 Oceania, vol. $X X X V$, no, 3, $\overline{p p}, 202-7$ 。

1966 The Excavation of an Aboriginal. Rock Shelter on Gymea Bay, Port Hacking, N.S.W.', Archaeology and Physical Anthropology in Oceania, vol. 1, no, 1, $\mathrm{pp} .23=50$. 
Metson, A,J,

Meighan, C, W。,

Pendergast, D。M 。

Swartz jro, B.K, \& Wissler, M.D。

Meyer, G.R。 \&

O'Gower, A.K.

Mitchel1, S.R。

Moore, H.B.

1958

Mulvaney, D。J.
'Observations on Visits of the Tasmanian Aborigines to the Hunter Islands? Pap. \& $\frac{\text { Proc of Roy Soc Tas., }}{\text { pp. } 155-62 \text {. }}$

1936 The Problem of the Tasmanian Aborigines', Pap. $\frac{\& \text { Proc, of Roy. Soc. Tas., }}{\mathrm{pp} .85-92 \text {. }}$

1949 'The Tasmanians - A Summary', $\frac{\mathrm{Rec}, \text { of Queen Vic . Mus }}{\mathrm{no}, 3, \mathrm{pp}, 145-50 \text {. }}$

1956 'Misoellaneous Notes on the Culture of the Tasmanian Aborigines? Mem, Nat, Mus. Vic, vit20, pp, $1 \overline{91}=200$ 。

Methods of Chemical Analysis for Soil. Survey Samples? N.Z. Dept, of Scientific \& Industrial Research. Bull. no, $12, p p .1-208$ 。

Ecological Interpretation in Archaeology. Part 1, Am. Antiquity, vol, 24, pp. $1-23$.

1963 The Ecology of Six Species of Litteral Gastropods Association between Species and Associations with Wave Action?, Aust, Jour. of Marine \& Freshwater Research,

1949 Stone Age Craftsmen (Melbourne).

1958 in Aboxiginal Bone Industry', Mankind, vol, 5, no, 5, ppo.194.9.

1962 Analysis of Some Australian Aboriginal Surface Sites'. Mankind, vol. 5, no, 11, pp. $466-70$,

Marine Ecology (Ny)

1957 Research in the Prehistory of Victoria: a Criticism and Report on a Field Survey', $\frac{\text { Historical Studies Aust. and }}{N_{0} Z_{0}, \text { vol. 8, pp. 32-.43. }}$

1960 a Archaeological Excavations on the Aire Biver, Otway Peninsula, Victoria! Proc. Roy. Sockic vol. 75 , part 1 , $\mathrm{pp}=1-15$. 
1960 'Archaeological Excavations at Fromm's Landing, Sth Aust.', Proc. Roy. Soc., Vic vol. 72, $\overline{\mathrm{pp}} \cdot 53-85$.

1961 'The Stone Age in Australia' Proc. Prehistoric Soc. (Lond) vol. XXVII, pp.56-107.

1962 'Advancing Frontiers in Australian Archaeology'. Oceania, vol. 33, pp.135-

1964 a 'Australian Archaeology, 1929-1964; Problems \& Policies', Aust. Joux. Science, vol. 27, no. 2, pp.39-44.

$1964 \mathrm{~b}$ The Pleistocene Colonization of Australia'. Antiquity, vol. XXXVIII, pp. $263-7$.

$1964 \mathrm{c}$ The Prehistory of the Basalt Plains', Proc. Roy. Soc. Vic., vol. $7 \overline{7}, \mathrm{pt} 2$, pp. $427-32$.

Mulvaney, D.J. \& Joyce, E.B.

Mulvaney, D.J.,
Lawton, G.H.,
Twidale, C.R.

Murray, R.A.F.

Nelson, N.C.

Nelson, N.C.

1964
- Axchaeological \&

Geomoxphological

Investigations on Mt Moffatt Station, Queensland, Australia'。 Proc. of Prehistoric Soc. (Lond.), vol. XXXI, pp.147-212.

Archaeological Excavation of Rock Sheltex, No. 6, Fromm's Landing, South Australia'. Proc. of Roy. Soc.Vic. (NST vol. 77, pt 2, pp. $479 \cdots 516$.

1876 'Report of the Geology and Mineral Resources of S.E. Gippsland'. Rep. of Prog. Surv, of Vic., vol. III, p. 134.

1909 IShe11-Mounds of the San Francisco Bay Region'. Univ. of California, Publication in Amexican Archaeology and Ethnology, vol. 7, pp.309-48.

'The Ellis Landing

Settlement'. Univ。of

California Publications in American Archaeology \& Ethnology, vol, 7, pp.357426 .

Nethercote, G.
- A Gixls Camp at the National Paxk', Vic. Nat,, vol. XXVI 9. pp. $1 \overline{26-31}$. 


\begin{tabular}{|c|c|c|}
\hline Noone, H.V.V. & 1943 & $\begin{array}{l}\text { 'Some Aboriginal Stone } \\
\text { Implements of Western. } \\
\text { Australia? } \frac{\text { Rec, of Sth }}{\text { Aust. Mus., vol. VII, }} \\
\text { pp.271-80. }\end{array}$ \\
\hline \multirow[t]{3}{*}{ Orton, J.H. } & $\begin{array}{r}1913- \\
15\end{array}$ & $\begin{array}{l}\text { On the Breeding Habits of } \\
\text { Echinus Miliaris with a note } \\
\text { on the Feeding Habits of } \\
\text { Patella Vulgata'. Jour. of } \\
\text { Marine Biol, Ass. U.K. } \\
\text { vol. } 10, \mathrm{pp}, 254-7 \text {. }\end{array}$ \\
\hline & $1928 \mathrm{a}$ & $\begin{array}{l}\text { 'Observations on Patella } \\
\text { Vulgata Part } 1 \text {, Sex } \\
\text { Phenomena, Breeding and She } 11 \\
\text { Growth'. Jour, of Marine } \\
\text { Biol. Ass, U,K, vol. 15, } \\
\text { pp, } 851-62 .\end{array}$ \\
\hline & $1928 b$ & $\begin{array}{l}\text { Observations on Patella } \\
\text { Vulgata, Part II, Rate of } \\
\text { Growth of Shel1? } \frac{\text { Jour, of }}{\text { Marine Biol, Ass. U,K. }} \\
\text { vol. 15, pp,863-74. }\end{array}$ \\
\hline $\begin{array}{l}\text { O'Gower, A.K. \& } \\
\text { Meyer, G.R. }\end{array}$ & 1965 & $\begin{array}{l}\text { The Ecology of Six Species } \\
\text { of Litteral Gastropod, } \\
\text { Molluscs, } 1 \text { : Seasonal } \\
\text { Variations in the Six } \\
\text { Population'. Aust, Jour. of } \\
\text { Marine \& Freshwater Research, } \\
\text { vol. } 16, \text { no. 2, pp.205-18. }\end{array}$ \\
\hline Parsons, R.F。 & 1966 & $\begin{array}{l}\text { The Soils and Vegetation at } \\
\text { Tidal River, Wilson's } \\
\text { Promontory', Proc, Roy. Soc, } \\
\text { Vic, NS, vol, } 79, \text { pt }, \\
\text { pp.319-54, }\end{array}$ \\
\hline Piper, C.S. & 1942 & $\frac{\text { Soil and Plant Analysis }}{\text { (Univ, of Adel.). }}$ \\
\hline Pritchard, G.B. & 1906 & $\begin{array}{l}\text { 'Excursion to Wilson's } \\
\text { Promontory'. Vic, Nat。, } \\
\text { vol. XXII, no. } 12 \text {, pp.191- } \\
223 \text {. Subarticle entitled } \\
\text { 'Geological Notes', pp.219- } \\
23 \text {. }\end{array}$ \\
\hline Pulleine, R.H. & 1929 & $\begin{array}{l}\text { The Tasmanians and Their } \\
\text { Stone Culture'. A.A.A.S., } \\
\text { pp. } 294-314 \text {. }\end{array}$ \\
\hline Reed, K.J. & 1959 & $\frac{\text { Report of Nat, Parks Trust, }}{\text { pp.50-1 (unpublished). }}$ \\
\hline Robertson, A.J. & 1913 & $\begin{array}{l}\text { 'Physiographical Notes', } \\
\frac{\text { Vic. Nat, , vol. XXIX, no. 9, }}{\text { pp.139-80, }}\end{array}$ \\
\hline Rootenberg, S. & 1964 & $\begin{array}{l}\text { Archaeological Field } \\
\text { Sampling', Amer. Antiq., } \\
\text { vol. } 30 \text {, no, } 2, \mathrm{pp}, 181-8 \text {. }\end{array}$ \\
\hline
\end{tabular}


Russe11, E.S.

Semenov, S.A.

Sherard, C.W.

Smyth, R•B.

Souef, W。H.D。 Le

Spaulding, A.C.

Spencer, W.B.

Spencer, W.B. \& Gillen, F.J.

Spiege1, M.R,

Stokes, J.L.
1907 'Envixonmental Studies on

the Limpet'. Proc, of the Zool. Soc., London, pp.85670 .

1909 'The Growth of the Shell of Patella Vulgata L。', Proc. of the Zool. Soc., London, pp. 235-52,

1964 Prehistoric Technology (London).

1898 Letters from Victorian pioneers, pp. 36-7 (August 1853 ). (Melbounce)

1878 The Aborigines of Victoria (Melbourne), 2 vols,

1902 IOn the Shell-fish Food Remains of Aboriginals'。 Vic, Nat, vol, XIX, no, 4, pp.56-8 with comments in vol, XIX, no. 1, p. 3, 1902 .

1916 'Aboriginals' Culinary Methods \& Kitchen Middens'. Vic, Nat, vol, XXXII, pt 1, pp, $1-11$.

1960 istatistical Description and Comparison of Axtifact

Assemblagesi in The

Application of Quantitative Methods on Archaeology (New York ed. by R.F. Heizer and S.F. Cook, Viking Fund. Publications in Anthropology, no, 28, $p p .60-92$.

1914 The Aborigines of Australia. In Federal Handbook, ed, by G.H. Knibbs, pp. 33-85.

1918 'Kitchen Middens and Native Ovens, Vic. Nat,, vol, XXXV, no, 7, p. p.113-8.

1928 Wanderings in Wild Australia,

1889 The Northern Tribes of Central Australia (1904 edition, London).

1927 The Axunta, 2 vols (London).

1961 Theory and Problems of Statistios (NY). $1846 \frac{\text { Discoveries in Australia, }}{\text { vol. II (London). }}$ 
Tindale, N.B.

Thomas, W.A.

Thorpe, W.W.

Tuddenham, W.

Tyres, C.J.

Walkley, A. \&

Black, I.A.

Wilbur, K.M. \&

Yonge, C.M.

Wright, W.R.

\section{Documents}

Selby, A.D.

1960

1964

1964
Results of the HarvardAdelaide Universities Anthropological Expedition, 1838-9. 'Distribution of Australian Aboriginal Tribe'. A field survey. Trans. Roy.
Soc. Sth Aust., vol. 64, pp. $140-231$.

1955 'Archaeological Site at Lake Menindee, N.S.W.' Rec. of Sth Aust. Mus., vol. XI, pp.269-95.

1898 'Brief Account of the Aborigines of Australia, Feliz' in Letters from Victorian Pioneers (Melbourne)

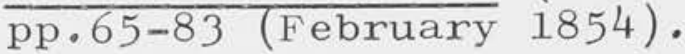

1932 'Lake Burrell Rock Shelter Faunal Remains'. Mankind, vol. 1, no. 5, pp. $\overline{109-10 .}$

\section{Personal Communication.}

1898 Letters from Victorian Pioneers (Melboume), pp.193-204 (July 1844).

1853 Letter contained in the La Trobe Library (Melbourne) dated 18th March 1853, to the Colonial Secretary.

1934 'An Examination of the Detjareff Method for Determining Soil Organic Mattex and a Proposed Modification of the Chromic Acid Titration Method'. Soil Science, no. 63 , pp.251-64.

$\frac{\text { Physiology of Mollusca, }}{\text { vol. I (NY). }}$

ANZAAS Conference Lecture.
Fisheries and Games Dept. (Me1b.)
Account of the Author's experience at Wilson's Promontory in the early part of the century. Contained in National Parks Authority Files.

Files contain numerous letters referred to in the text. Also valuable newspaper clippings . 


\section{Newspapers}

Argus (Melbourne).

Gippsland Guardian.

Port Phillip Herald.

\section{Interviews}

M. Black of Lower Tarwin, Victoria, aged 91.

D. Debenham, Foster, Victoria.

J. Jones, Foster, Victoria, aged 86.

K. Pilkington, Sandy Point, Yanakie, Victoria, 


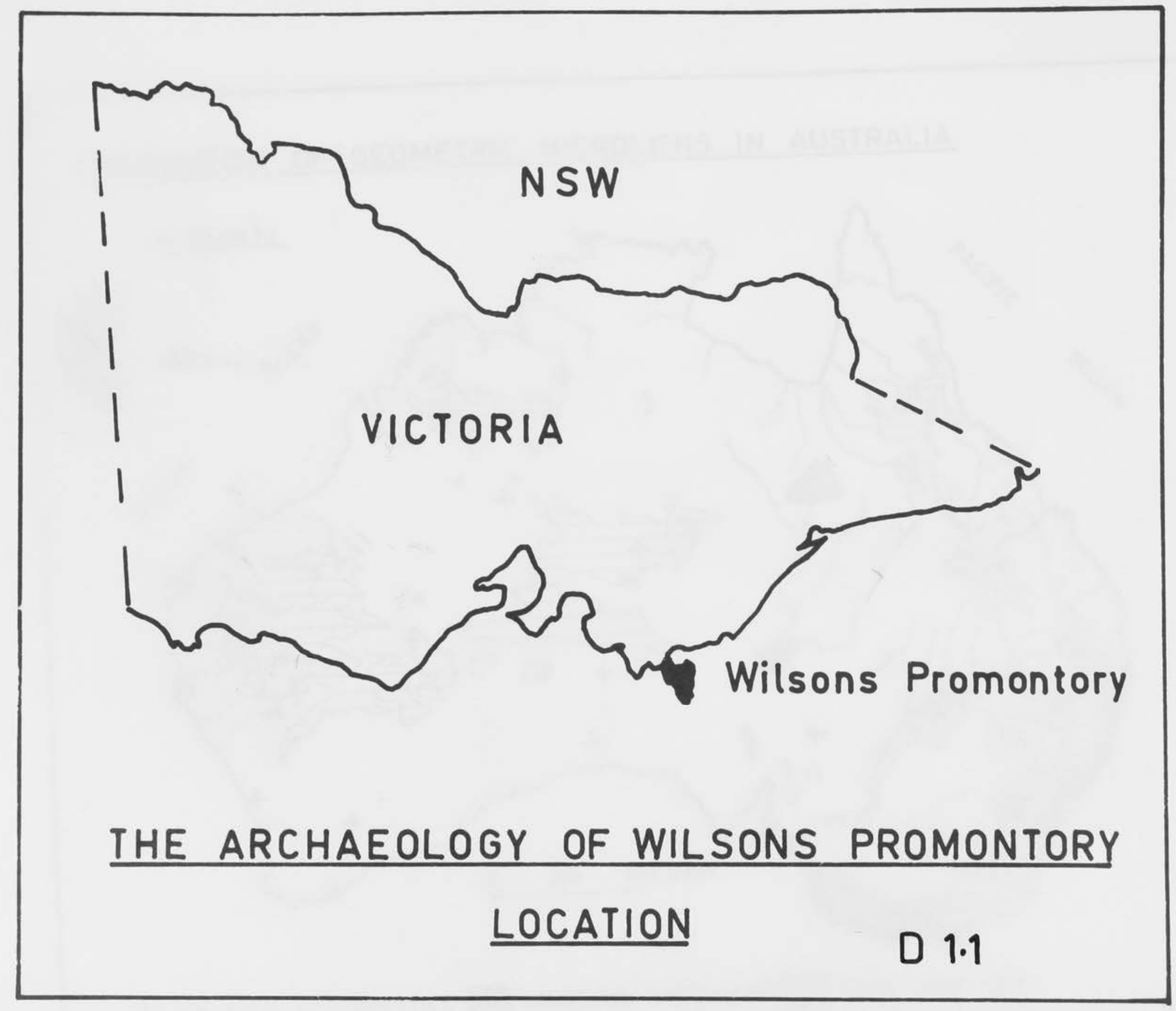




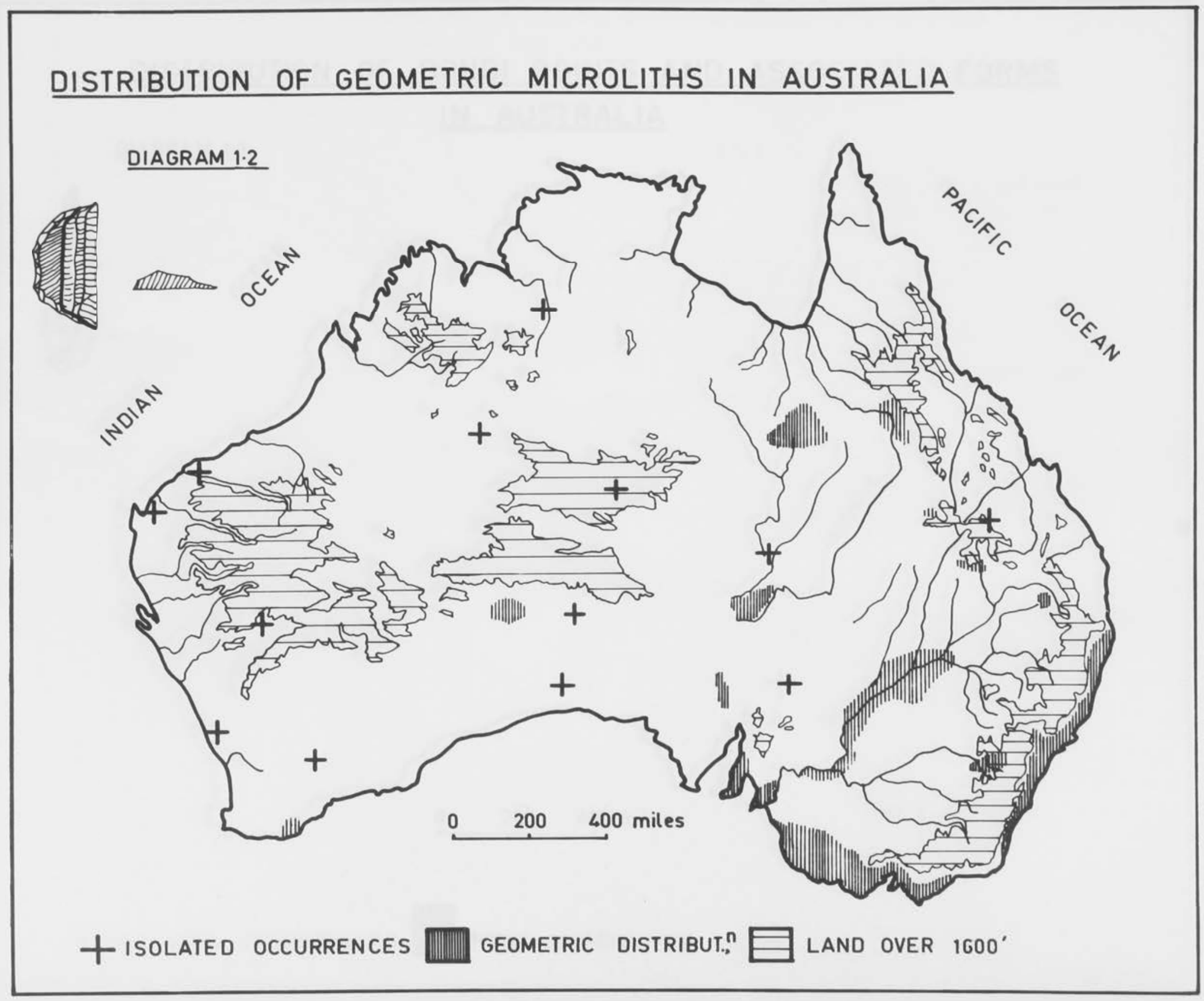




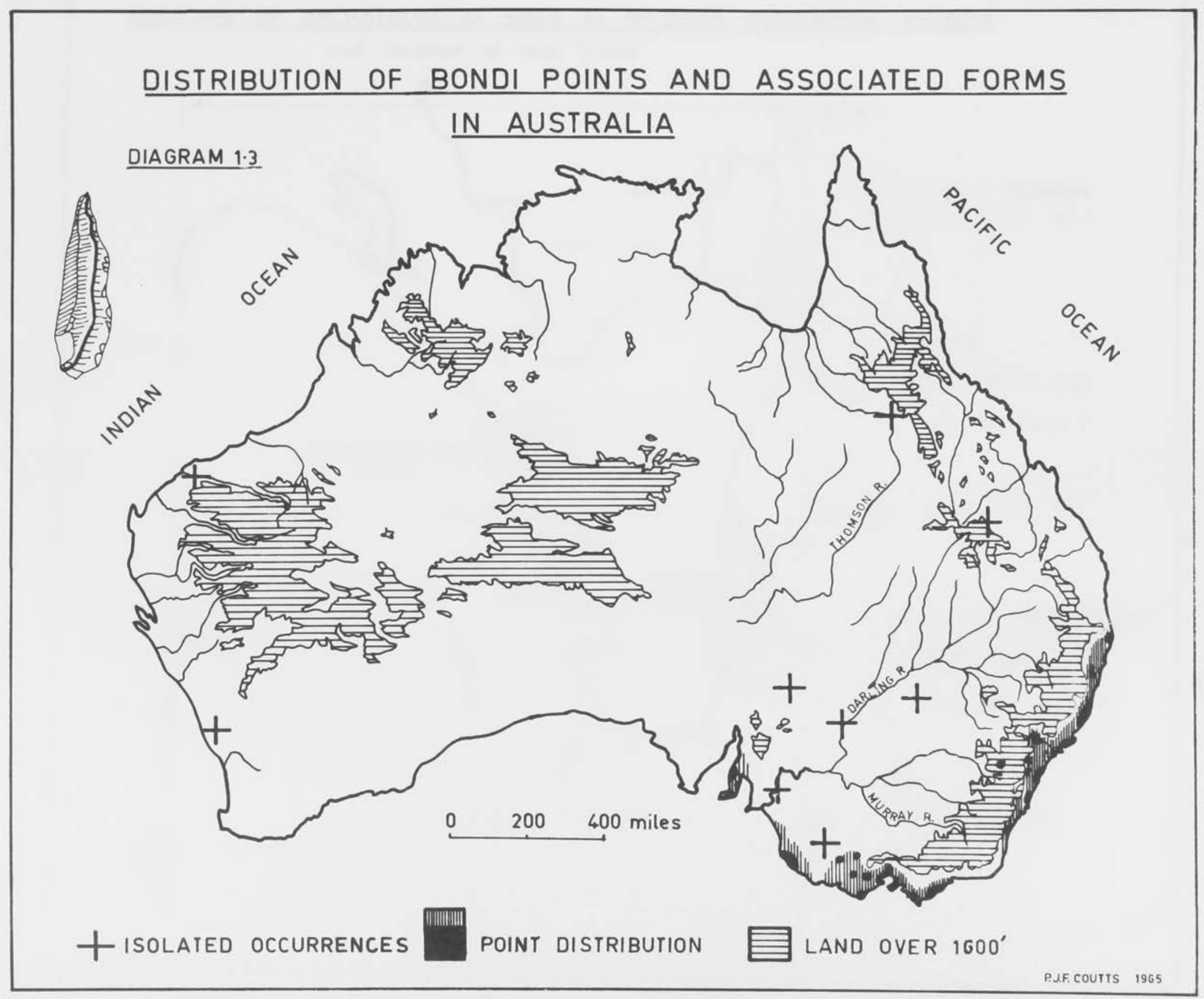




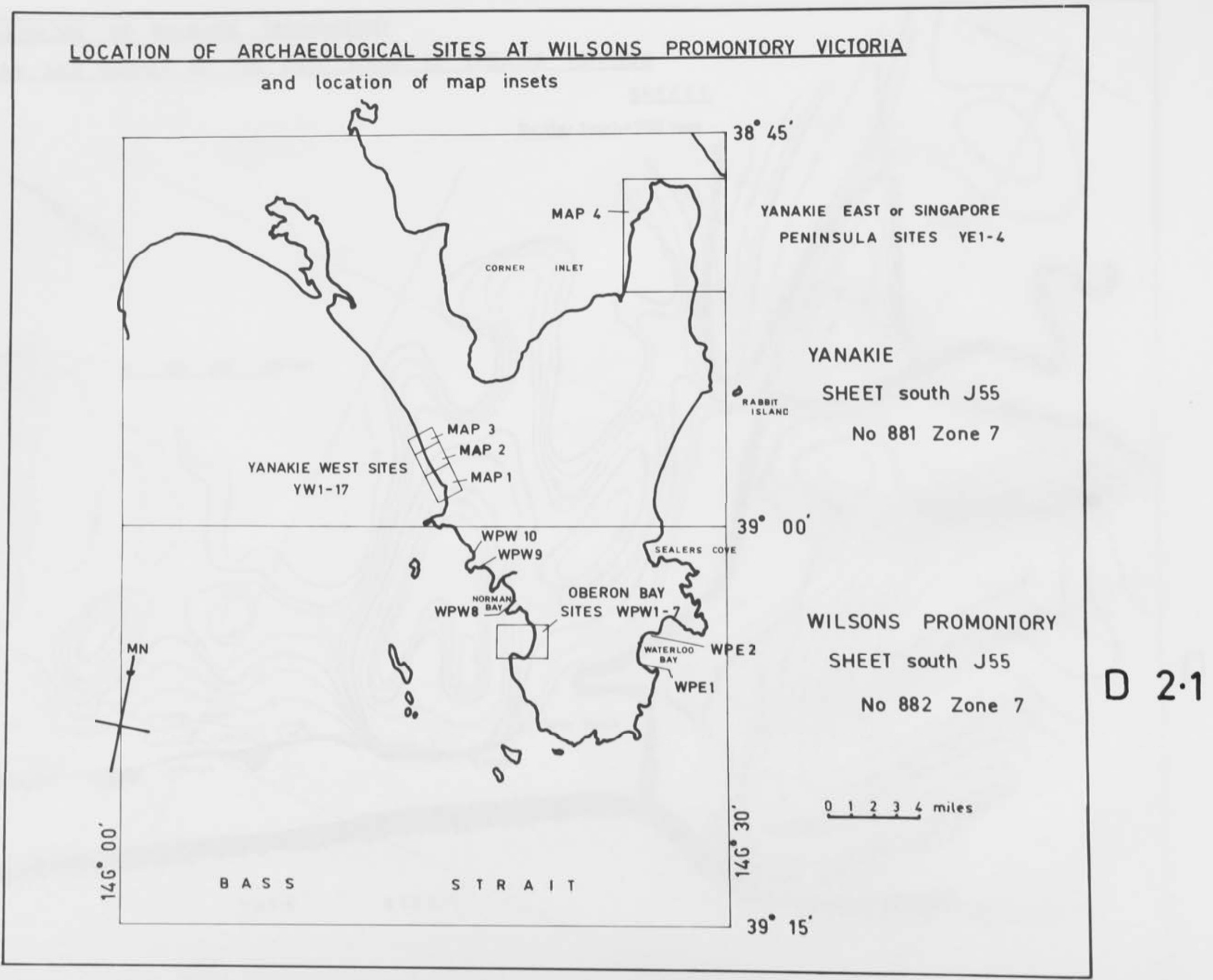




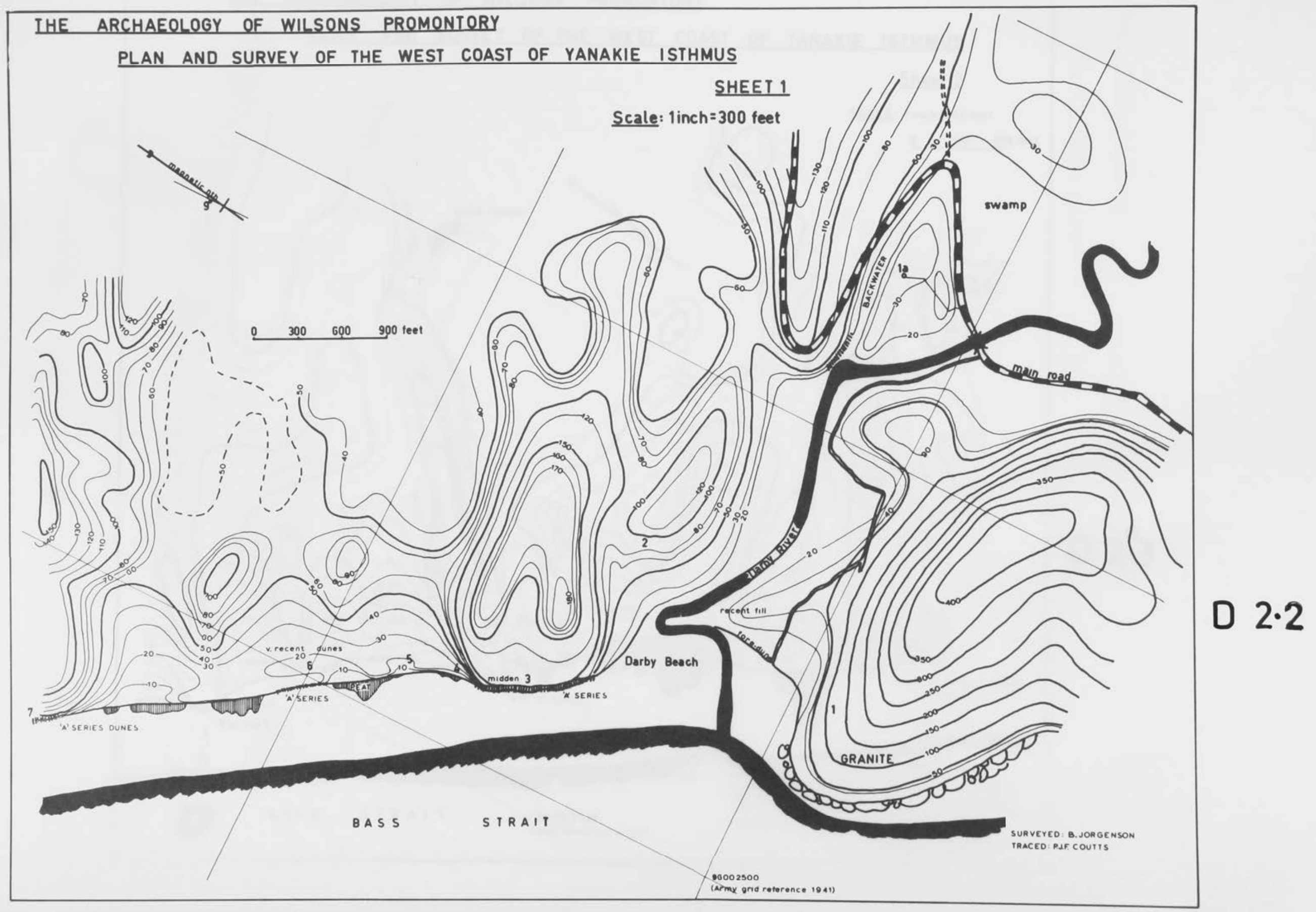




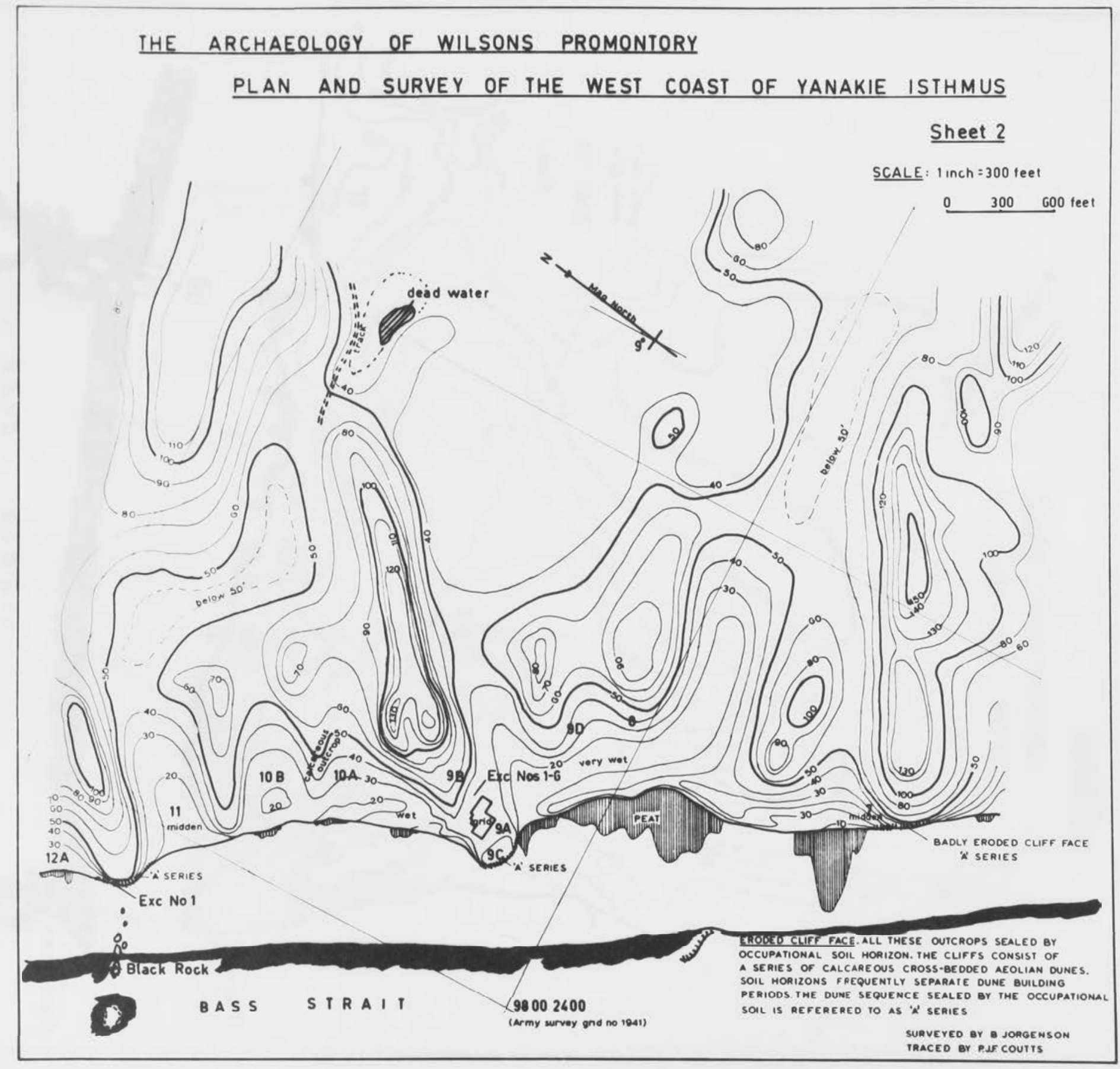

D $2 \cdot 3$ 


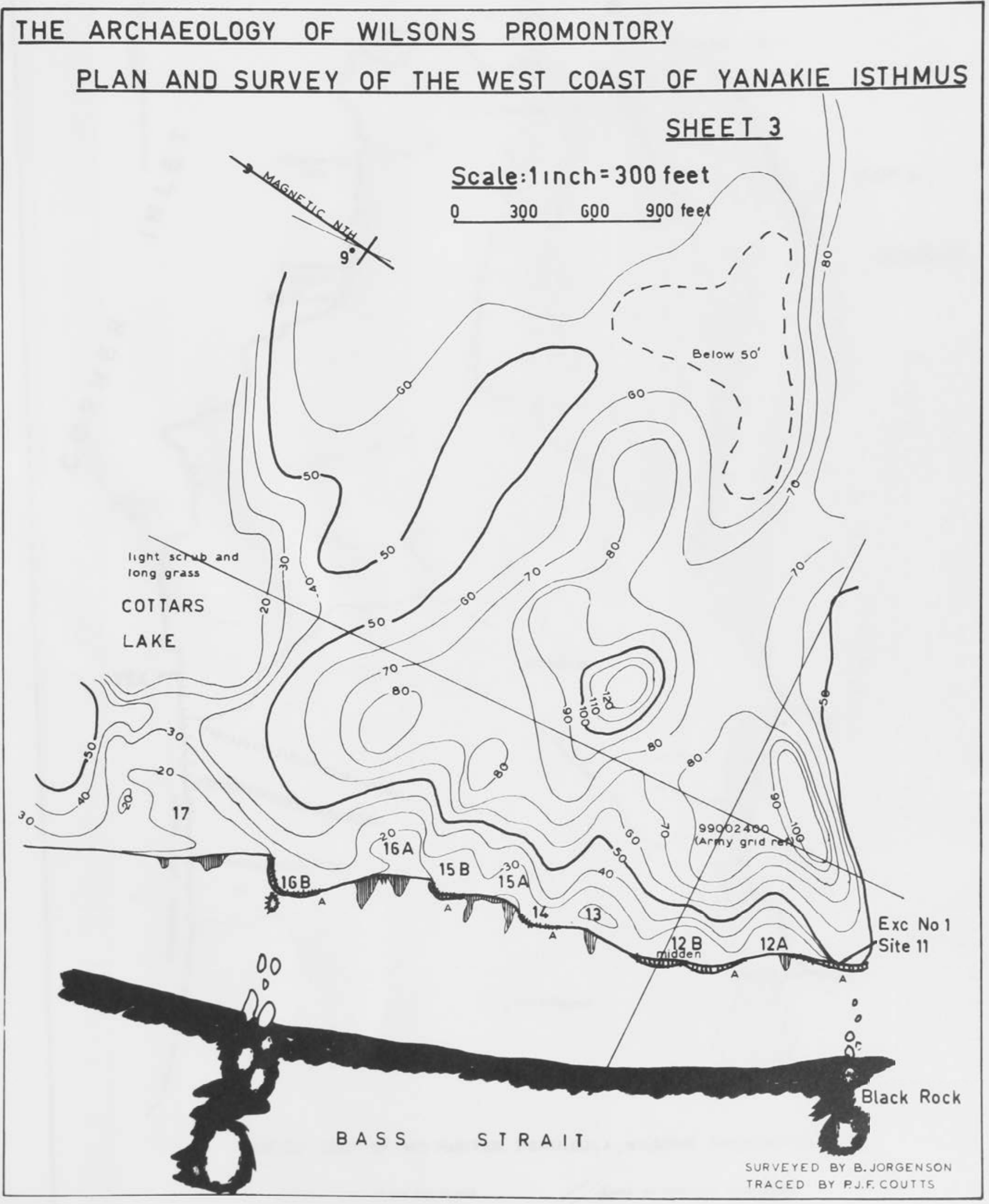

D $2 \cdot 4$ 


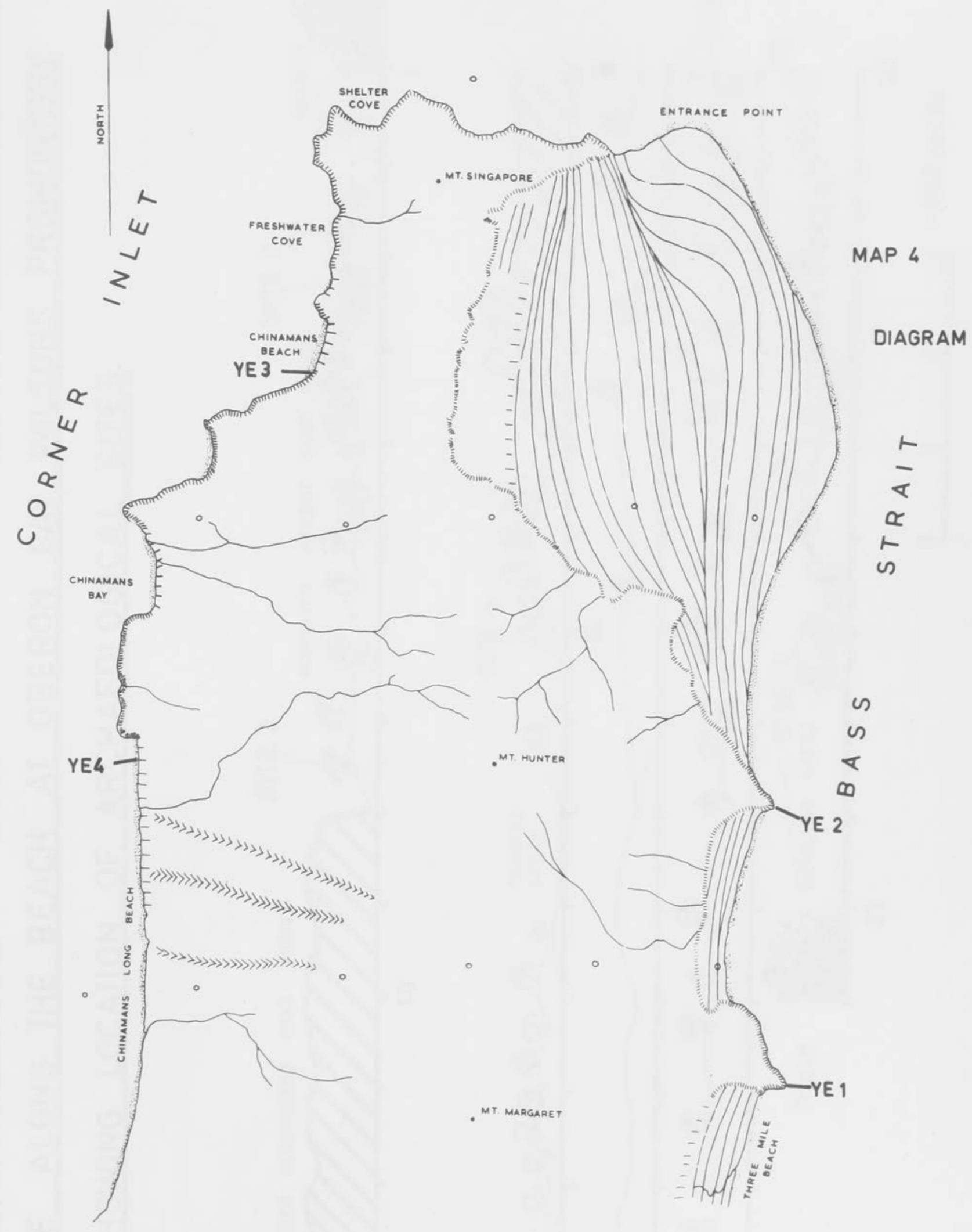

SKETCH MAP OF MT. HUNTER PENINSULA, WILSONS PROMONTORY.

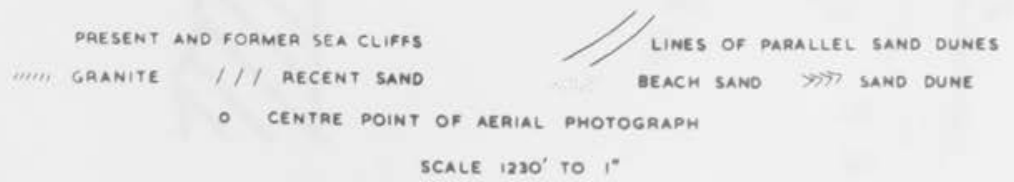




\section{PROFILE ALONG THE BEACH AT OBERON BAY WILSONS PROMONTORY}

SHOWING LOCATION OF ARCHAEOLOGICAL SITES
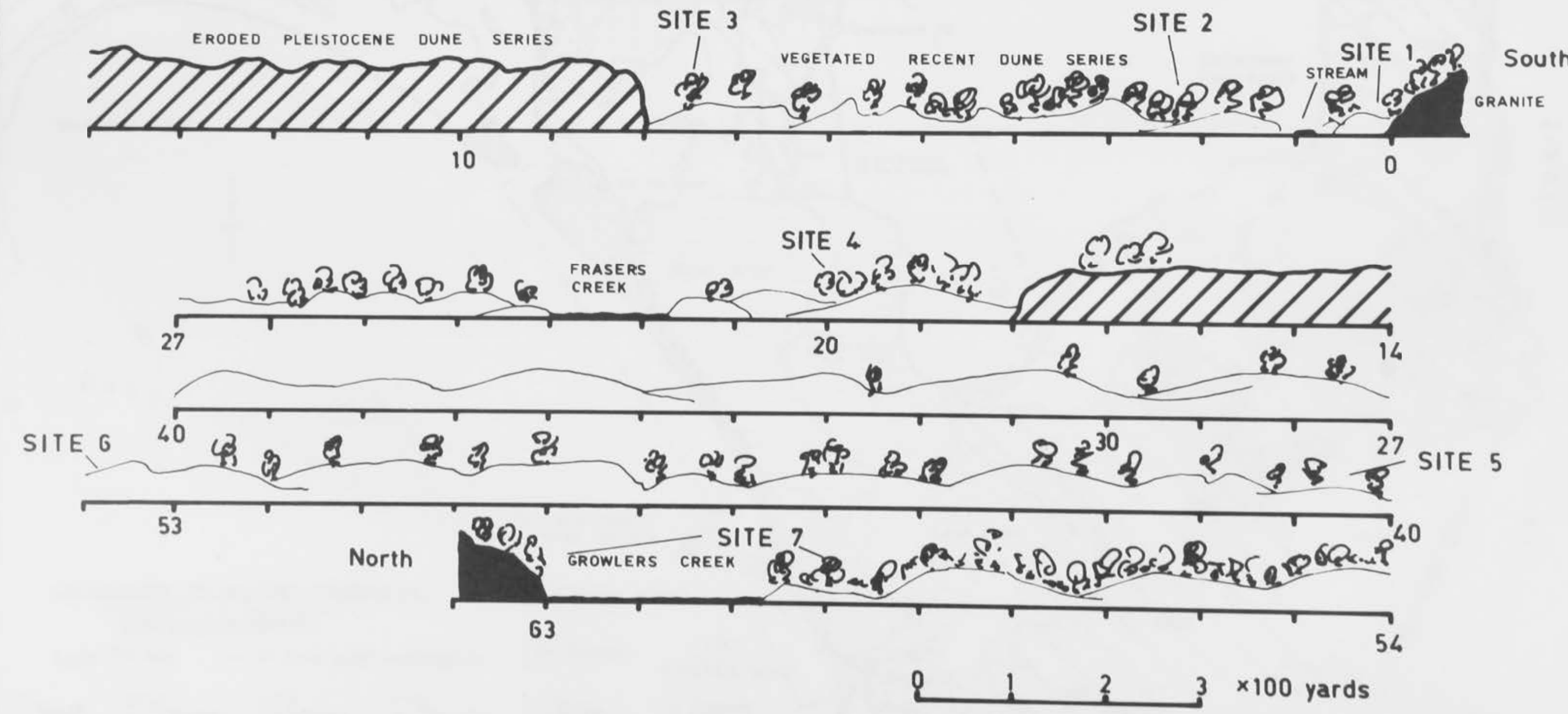

$02 \cdot 6$ 


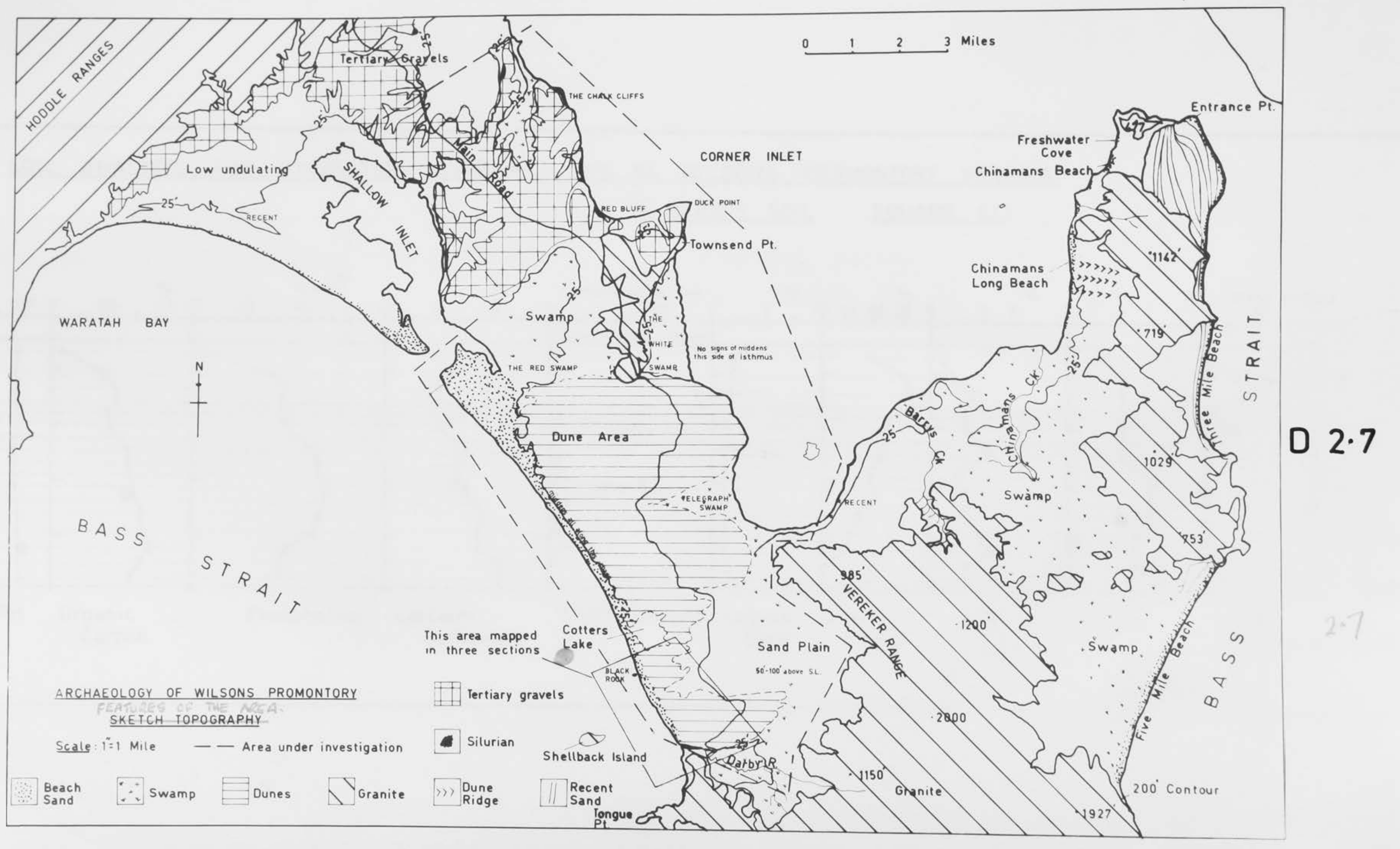




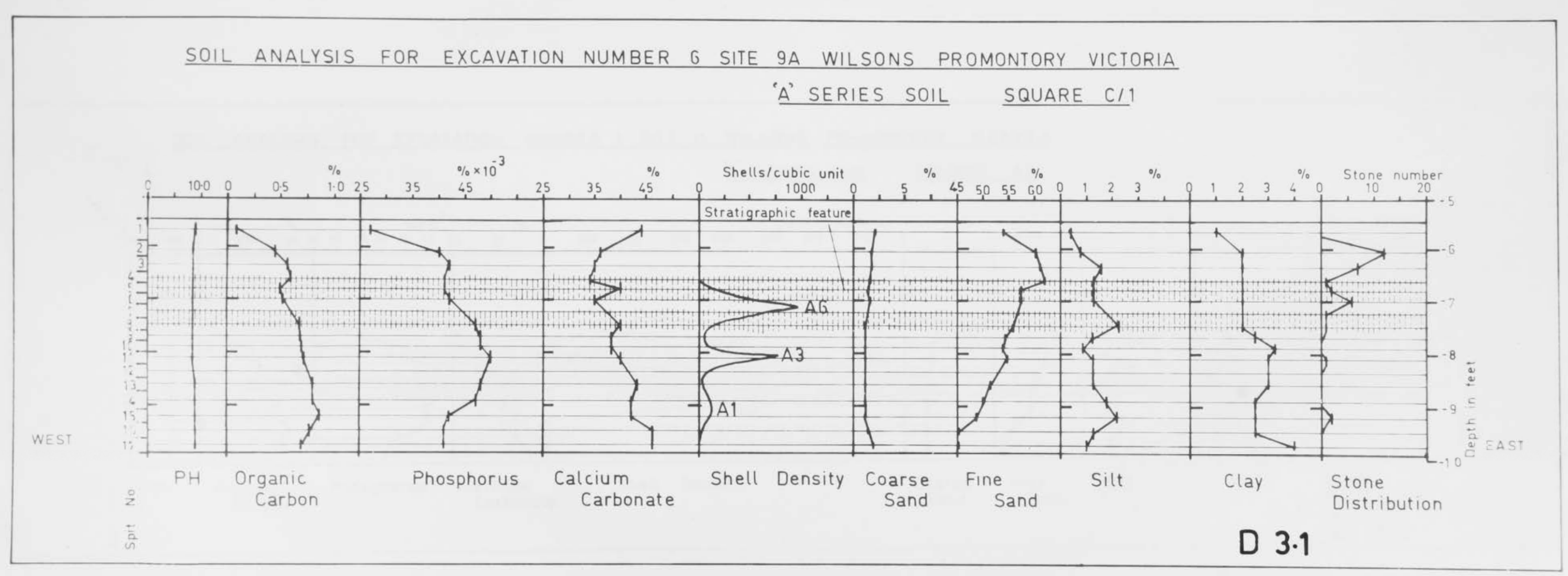




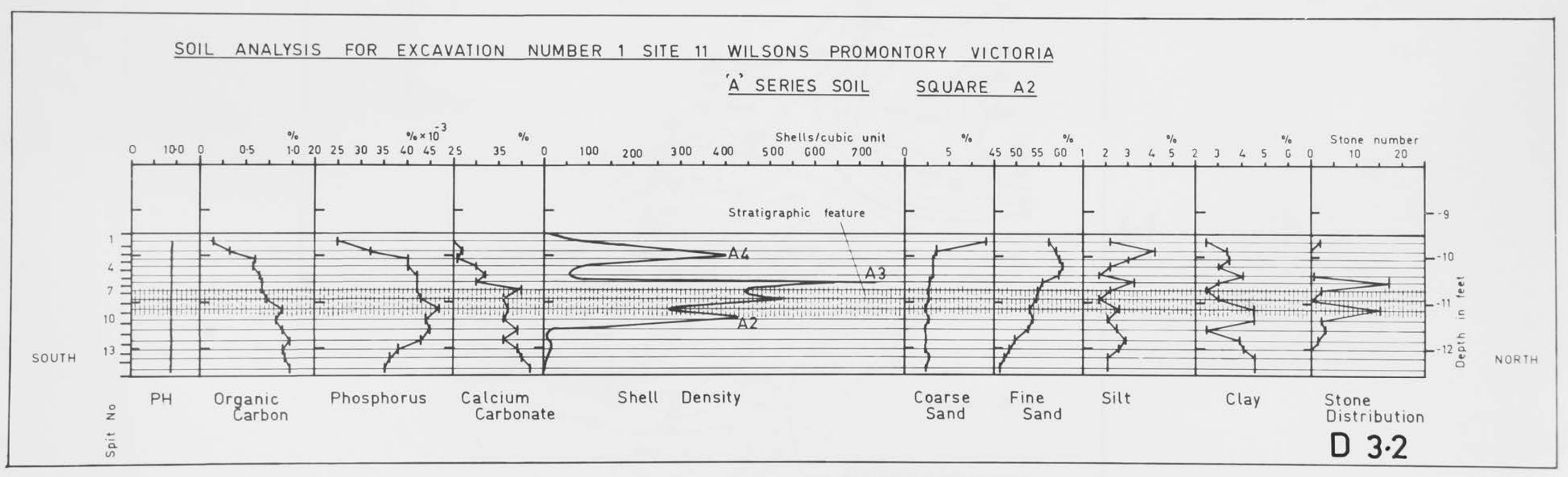


PLAN OF SURVEY OF WILSONS PROMONTORY SITE $9 A$ AND $2 B$

Scale: 1 inch -60 feet

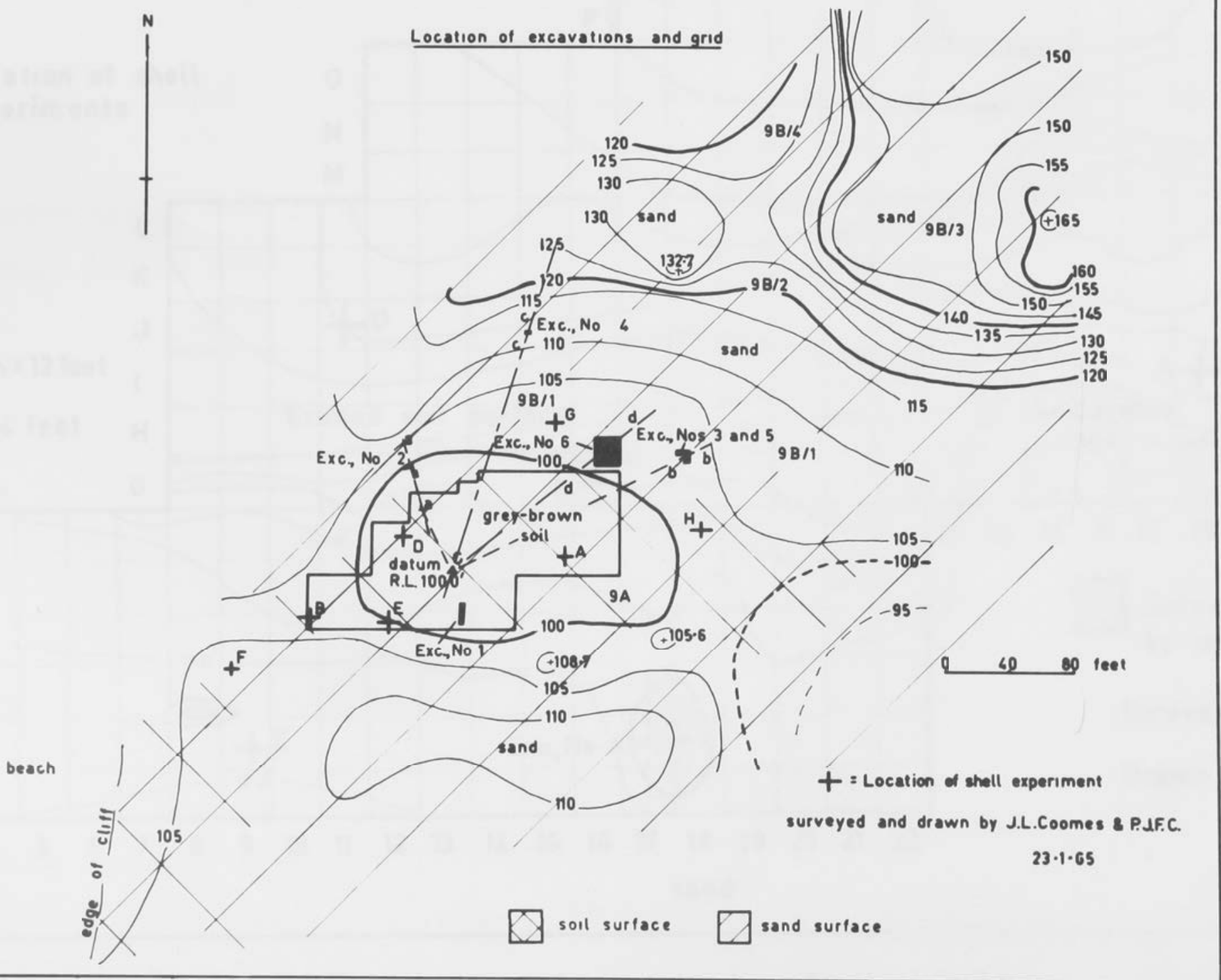

$4 \cdot 1$ 


\section{THE ARCHAEOLOGY OF WILSONS PROMONTORY}

\section{SURVEY AND PLAN OF GRID ON SITE 9A}

$$
+
$$$$
\text { tocation of shell }
$$
experiments
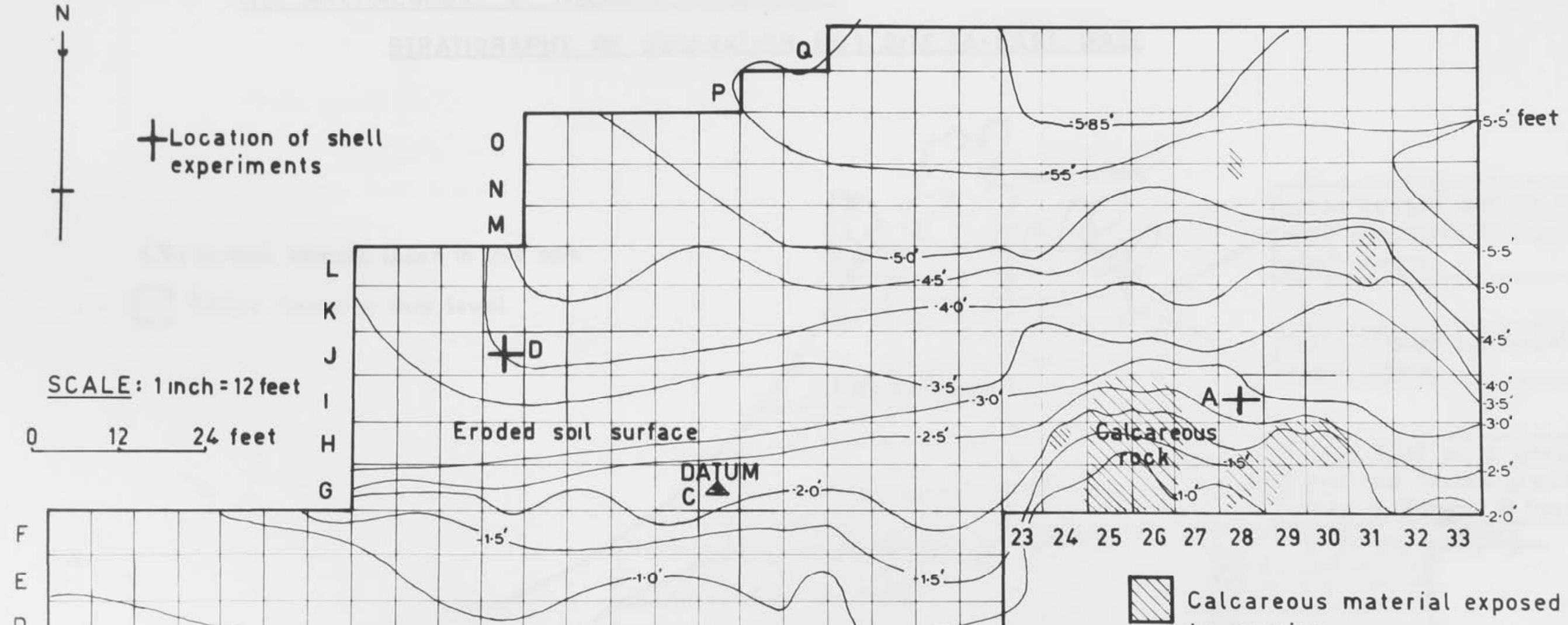

$\begin{array}{lllllllllll}23 & 24 & 25 & 26 & 27 & 28 & 29 & 30 & 31 & 32 & 33\end{array}$

D

C

B

A

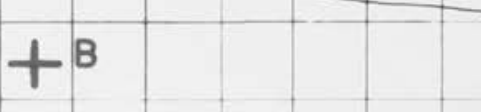

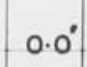

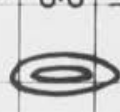

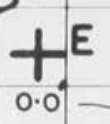
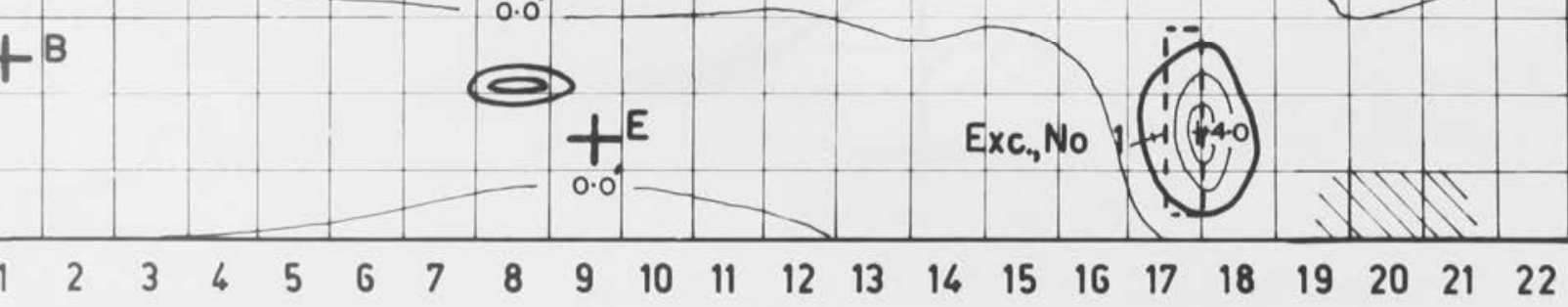

Dalcareous material exposed by erosion

Surveyed by J. Pollitt

Drawn by P.J.F. Coutts

August 1964 


\section{THE ARCHAEOLOGY OF WILSONS PROMONTORY}

\section{STRAIIGRAPHY OF EXCAVAIION NO 1. SITE 9A-EAST WALL}

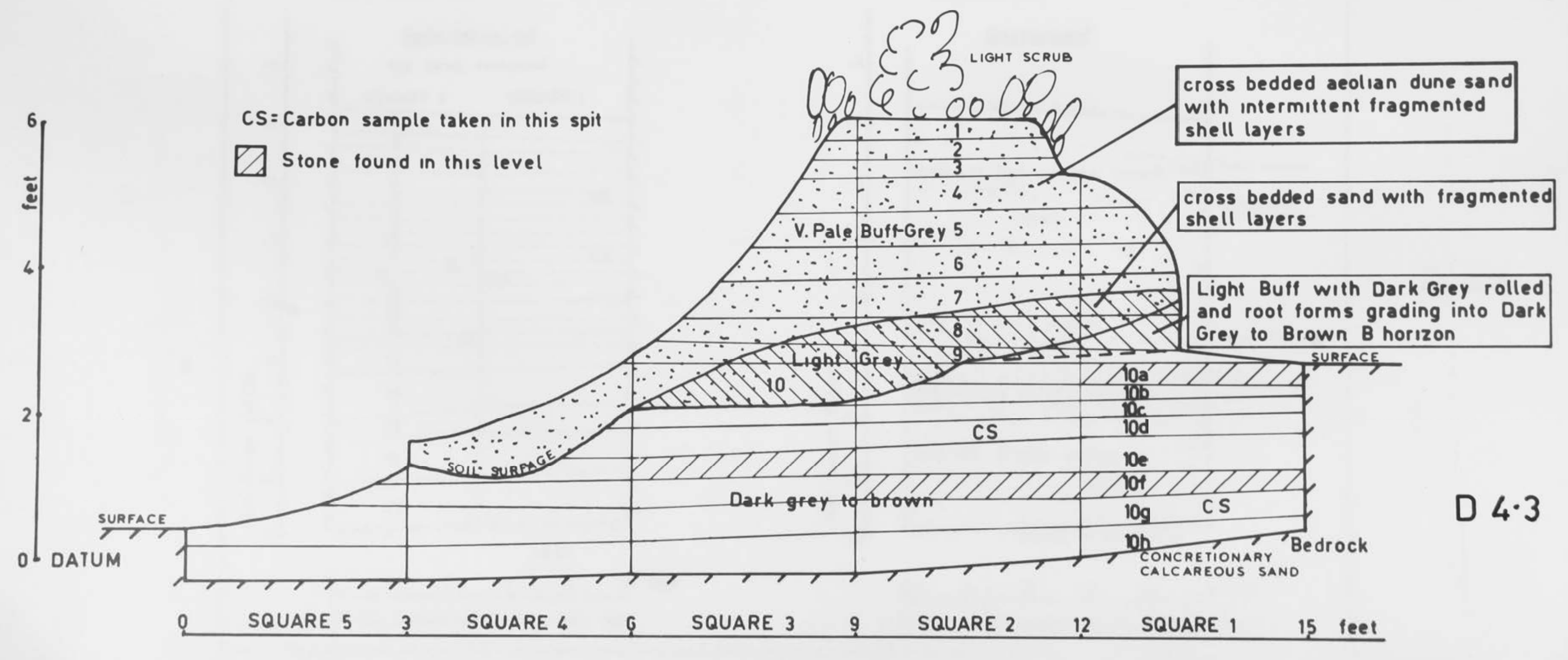




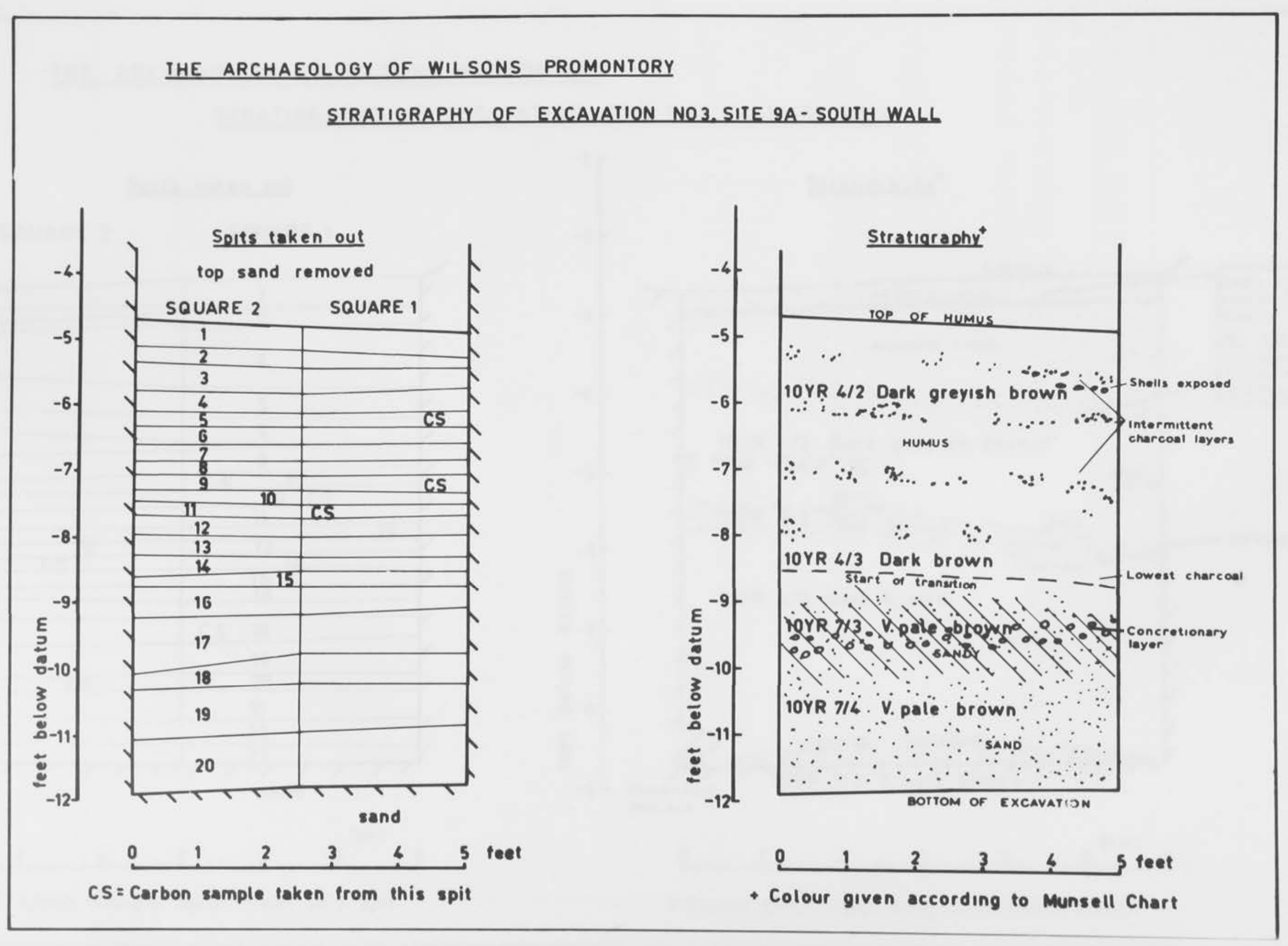

D $4 \cdot 4$ 


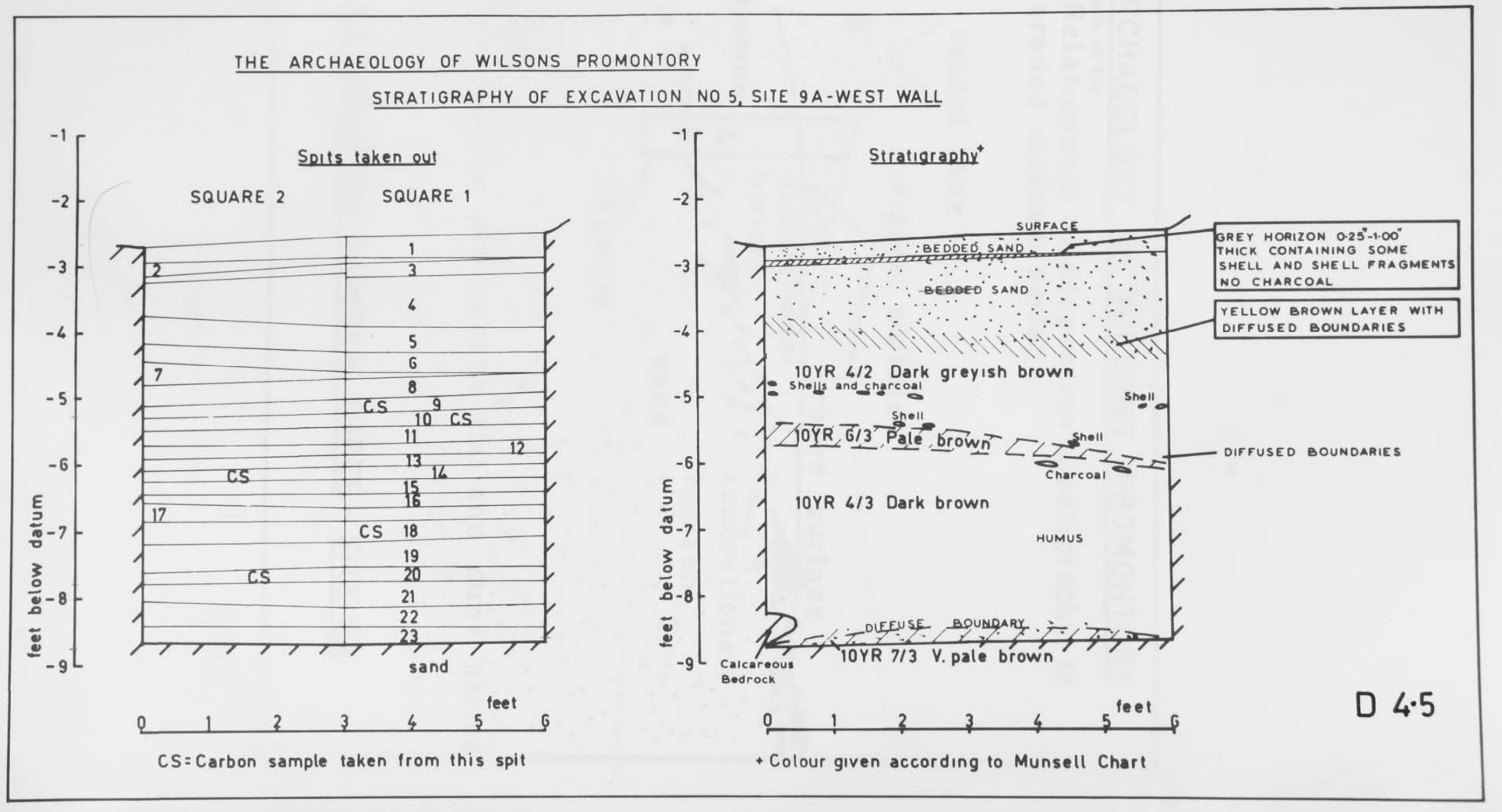




\section{ARCHAEOLOGY OF WILSONS PROMONTORY}

- Relationship of excavation stratigraphy to eroded midden surface

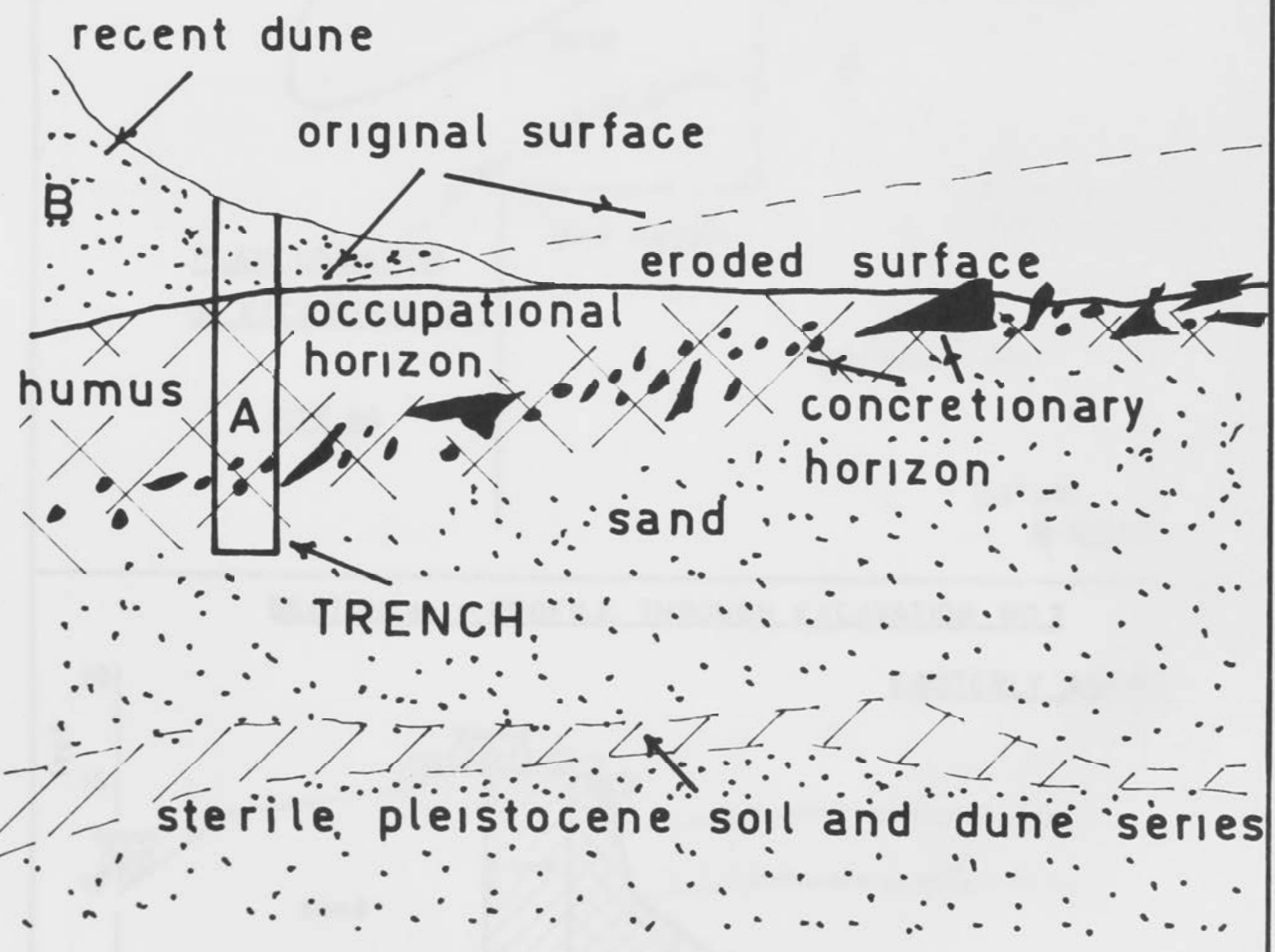

EXCAVATION NUMBER THREE - SITE 9A 


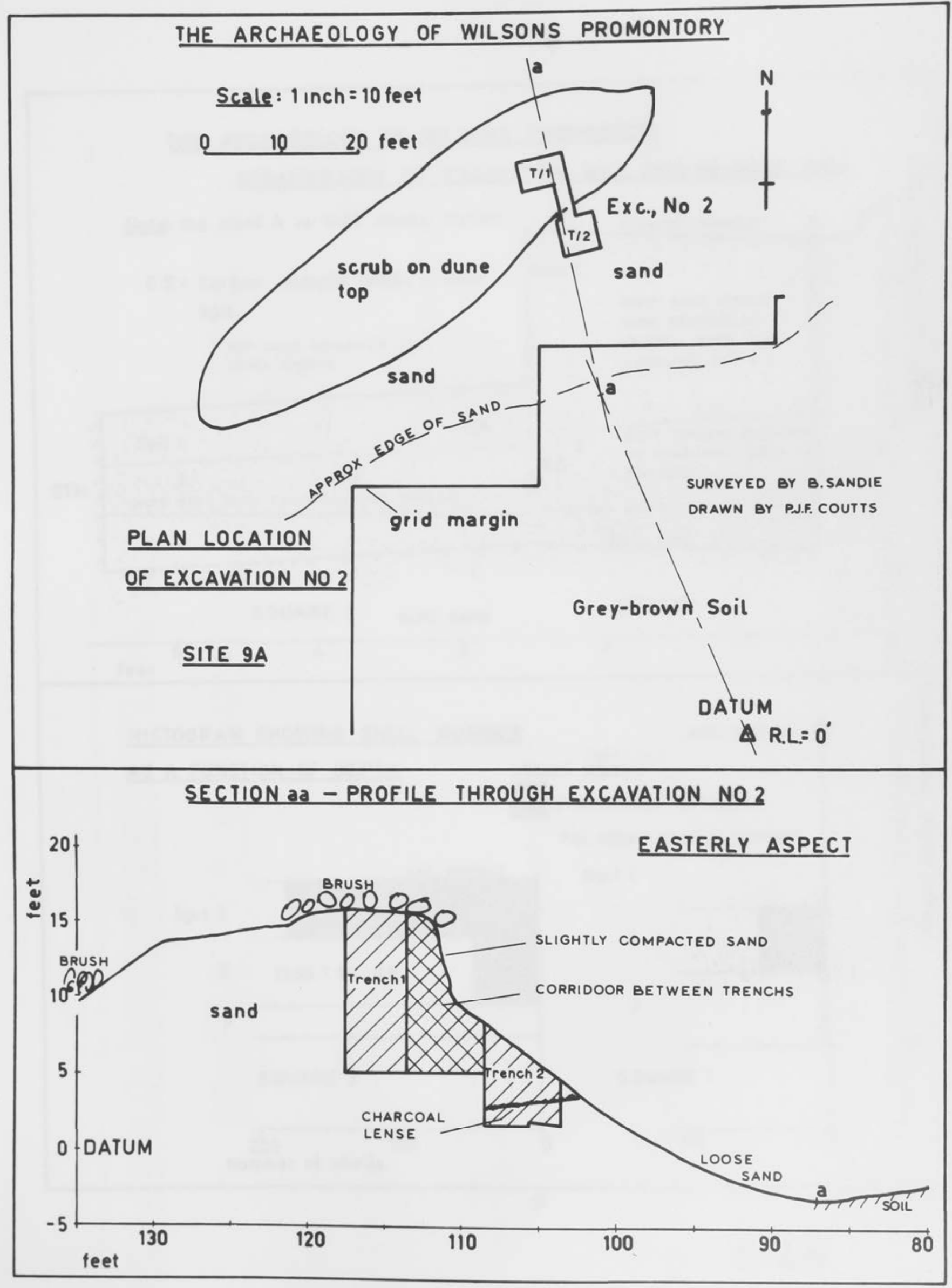

D 4.7 


\section{IHE ARCHAEOLOGY OF WILSONS PROMONTORY}

\section{SIRAIIGRAGHY OF EXCAVATION NO2, SIIE 9A-WESI WALL}

Note: the point A is $6.29^{\prime}$ above datum

CS = Carbon sample taken in this spit.
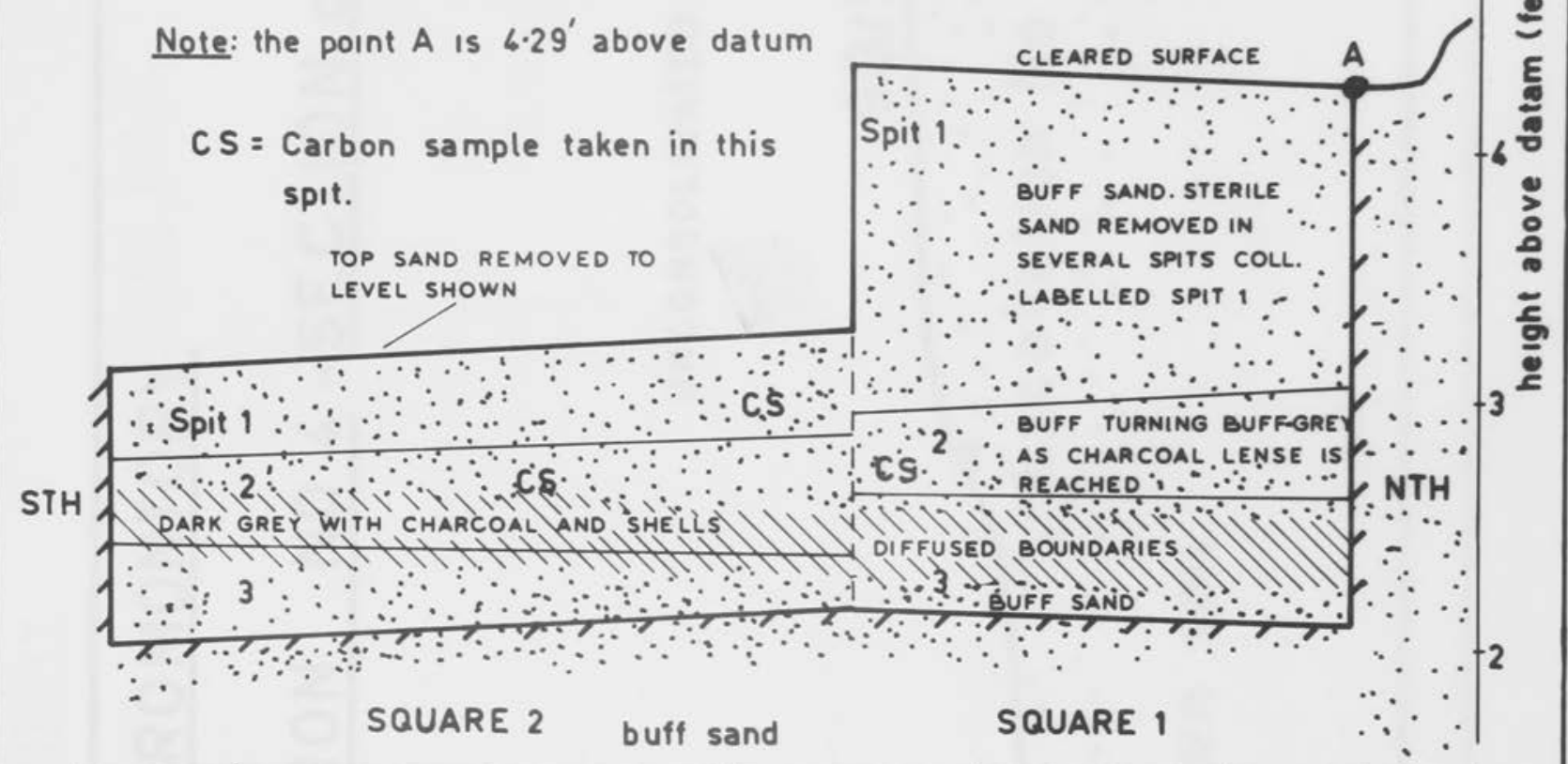

feet

53

2

HISTOGRAM SHOWING SHELL NUMBER

AS A FUNCTION OF DEPTH

Shell types:

Plebidonax deltoides

All other shells insignif,

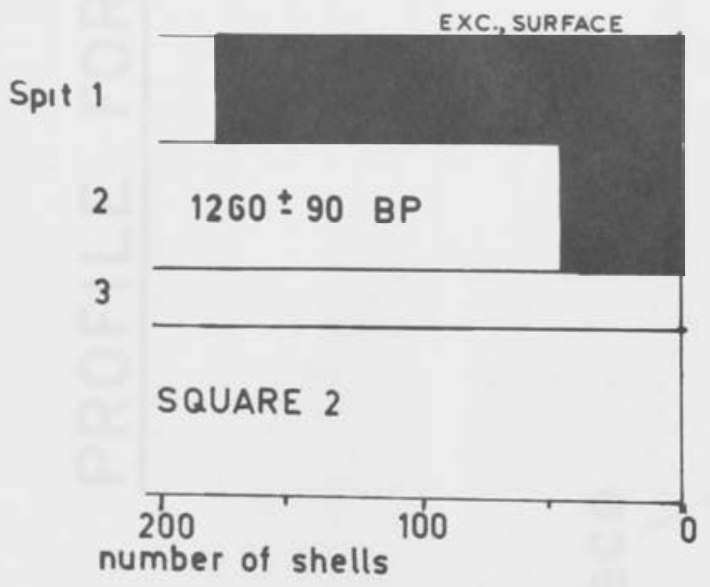

Spit 1

EXC., SURFACE

number of shells 


\section{THE ARCHAEOLOLOGY OF WILSONS PROMONTORY}

\section{PROFILE FOR EXCAVATION NO 4 -SECTION CC}

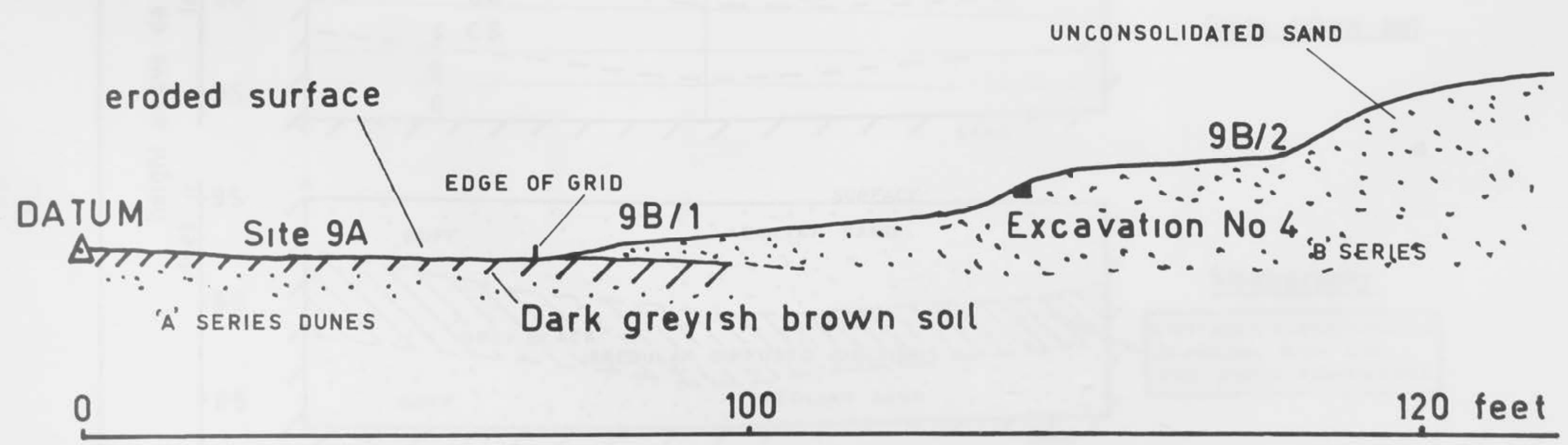




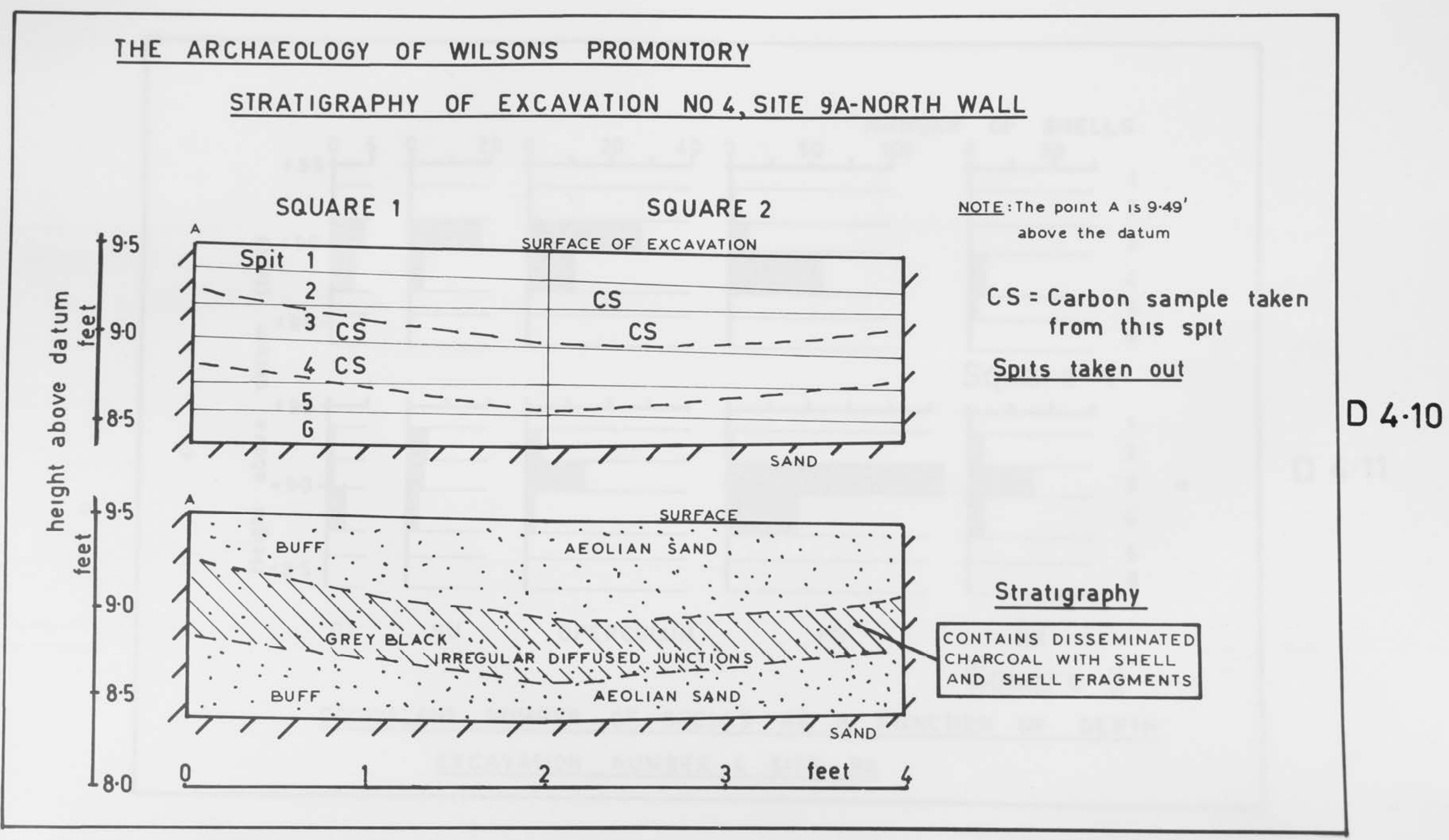




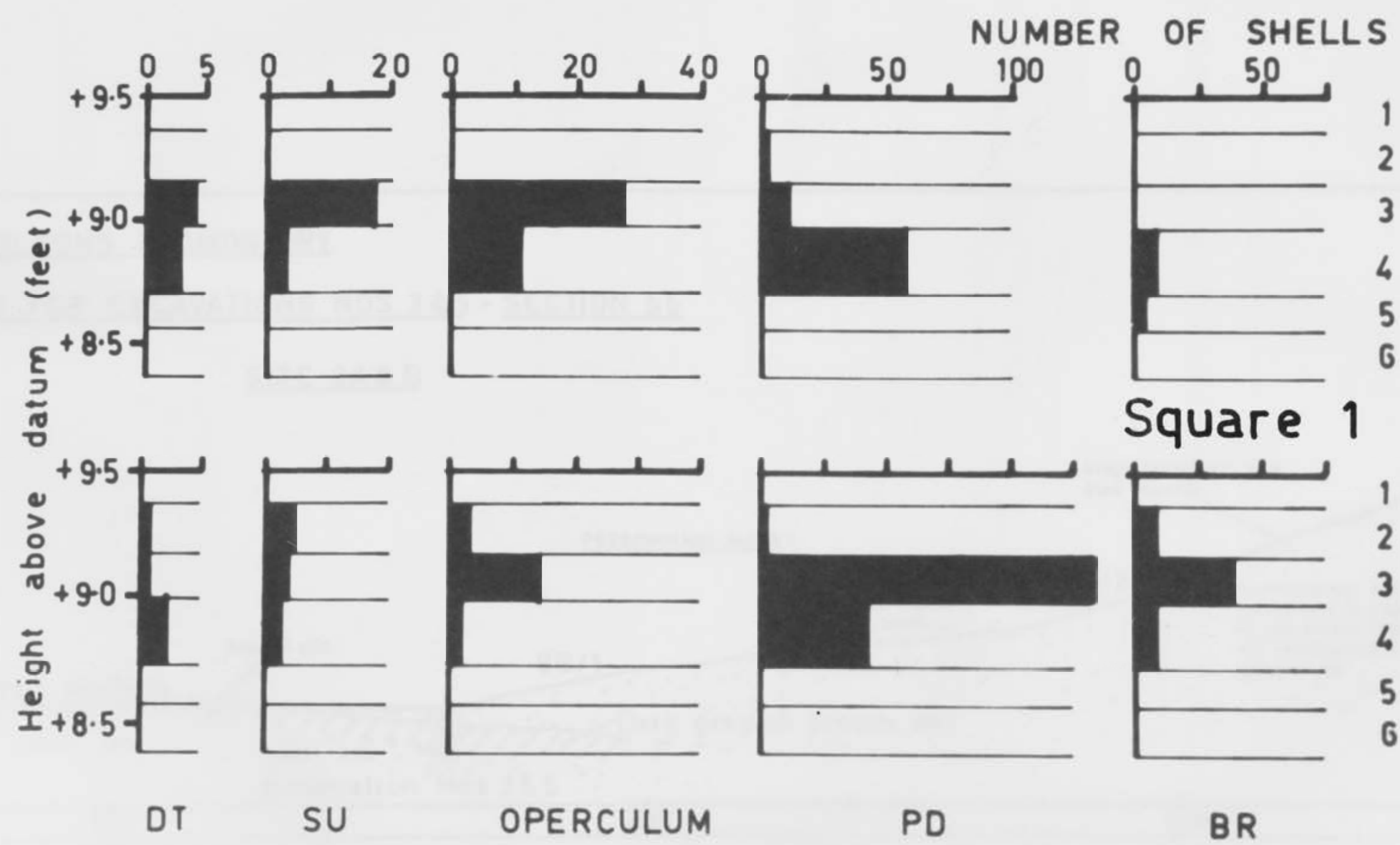

D $4 \cdot 11$

Square 2

EQUIVALENT NUMBER OF SHELLS AS A FUNCTION OF DEPTH EXCAVATION NUMBER 4 SITE $9 A$ 


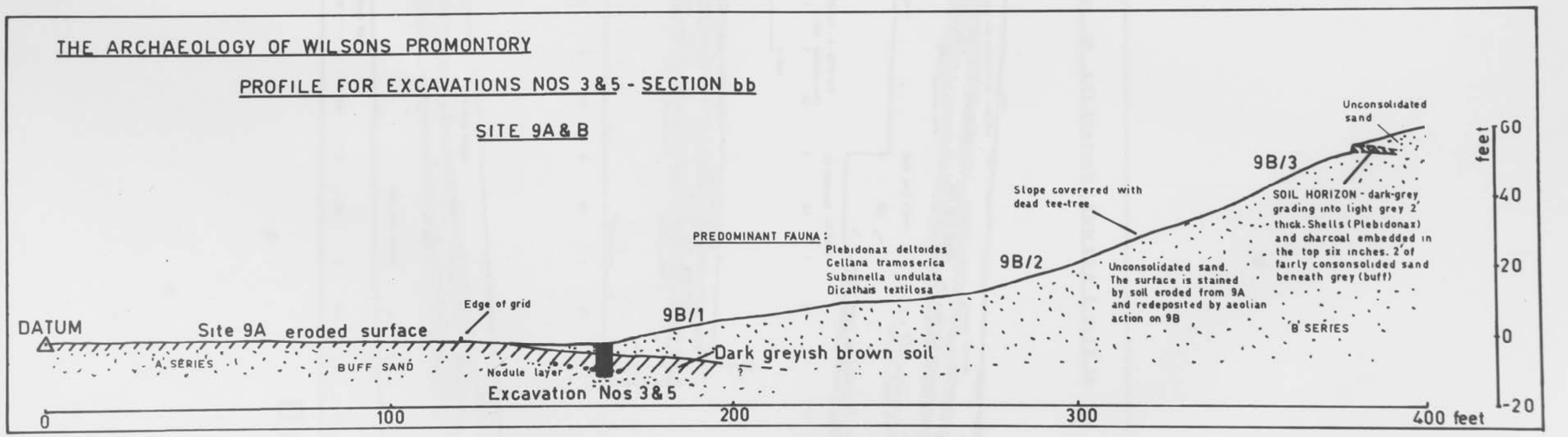

100

Nodule layor

200

300

D $4 \cdot 12$ 


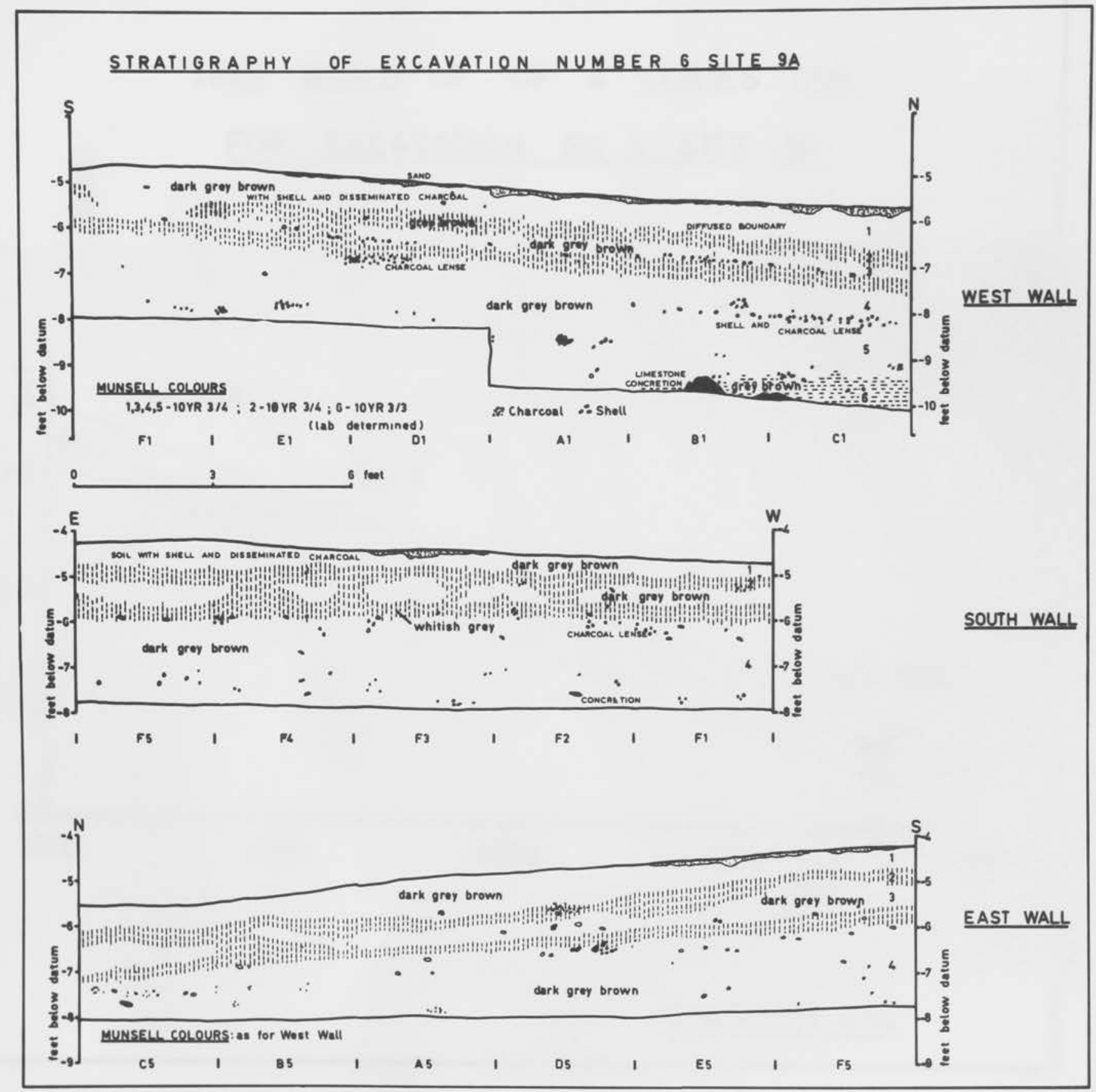

D 4.13 

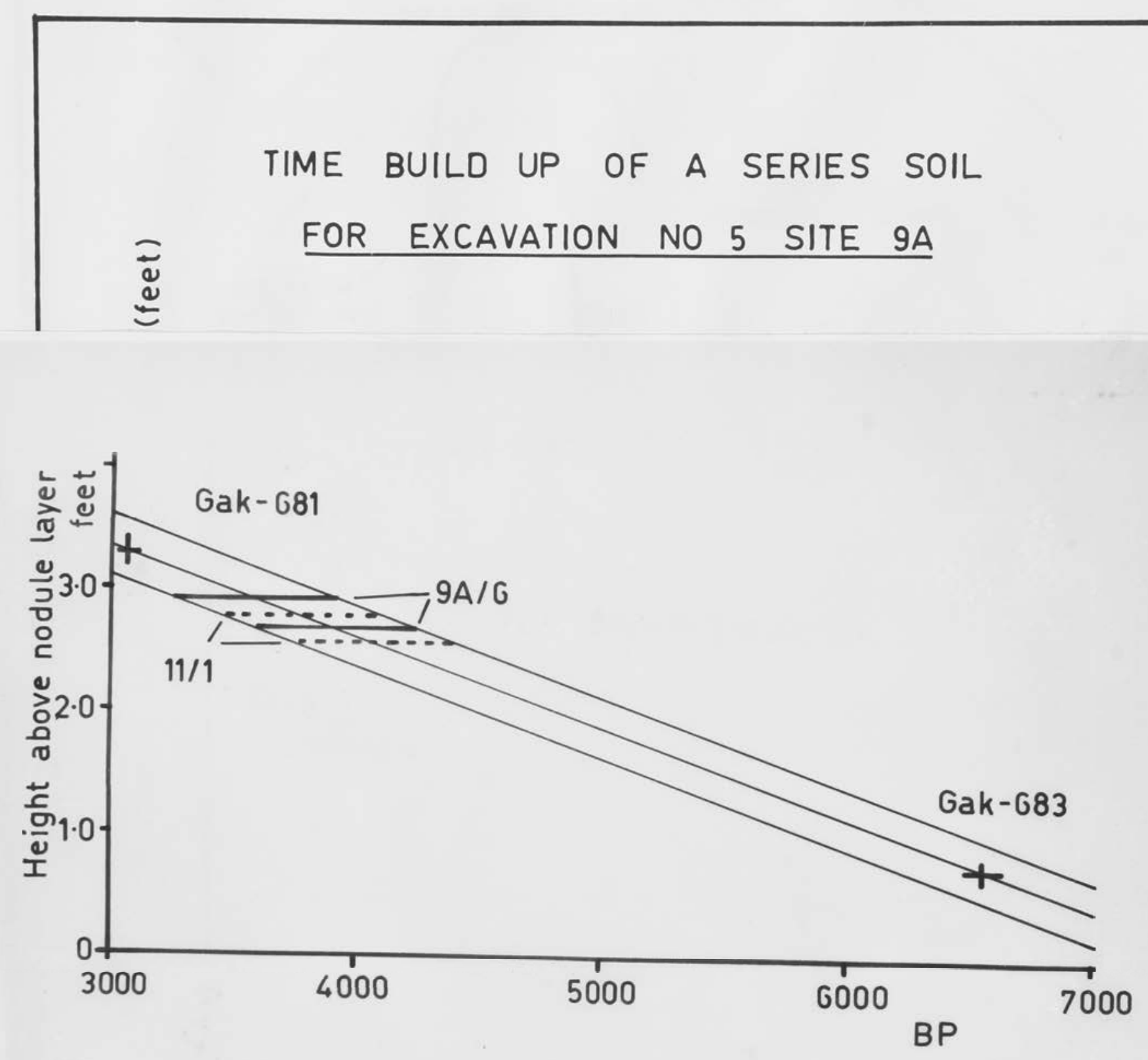

DIAGRAM 4.14 


\section{THE ARCHAEOLOGY OF WILSONS PROMONTORY}

\section{PLAN AND SURVEY OF SITE 11}

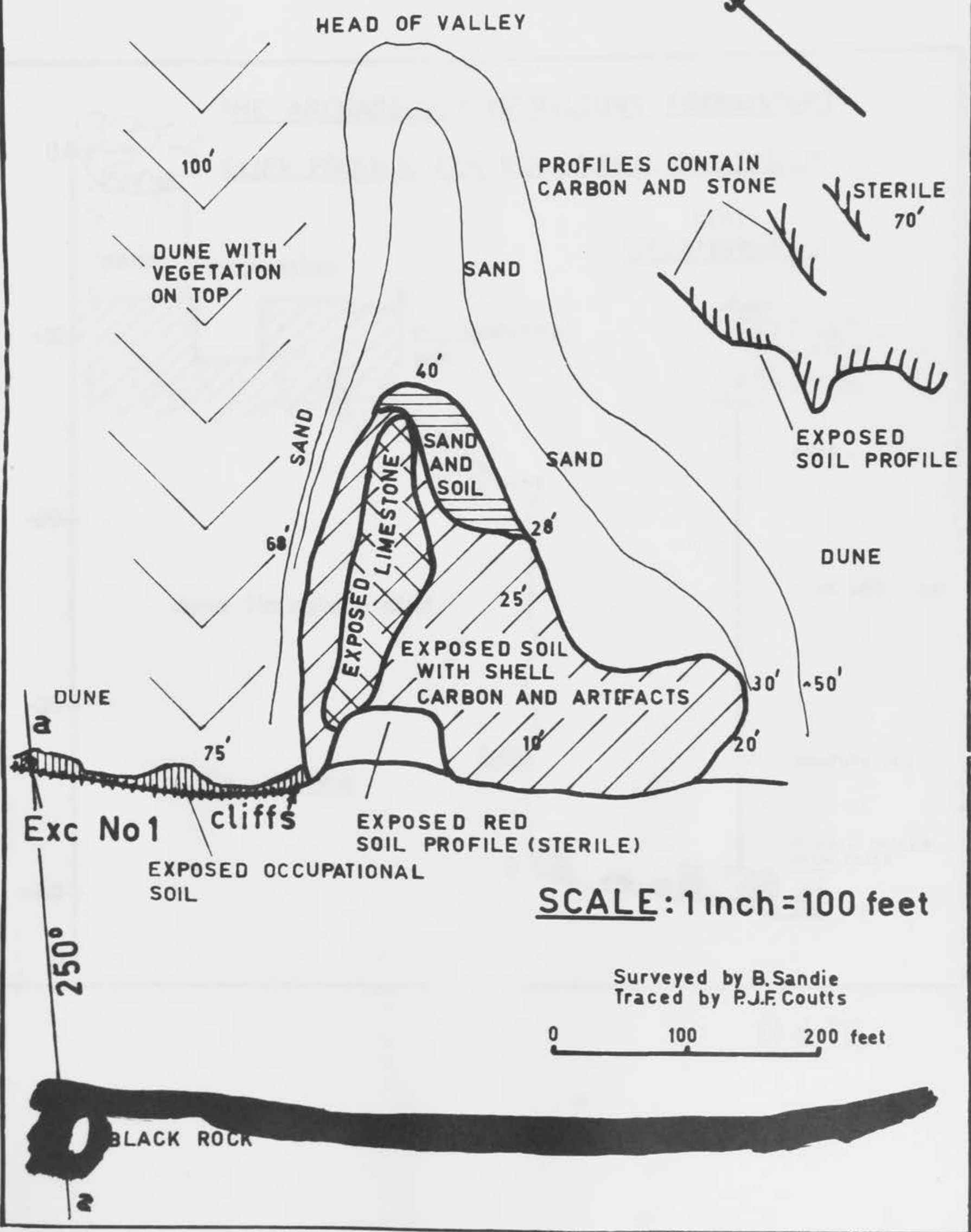

D $4 \cdot 15$ 


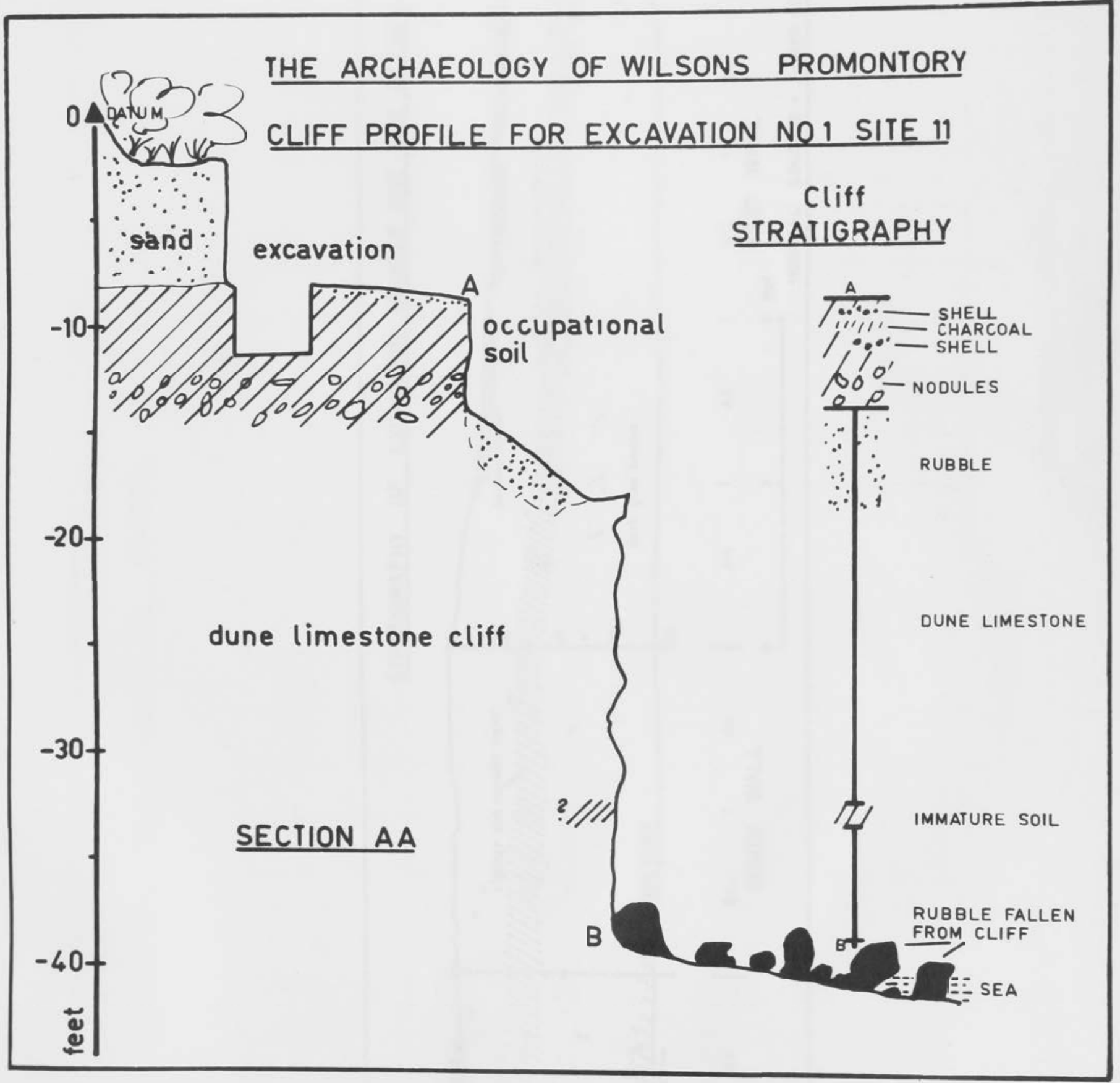

D $4 \cdot 16$ 


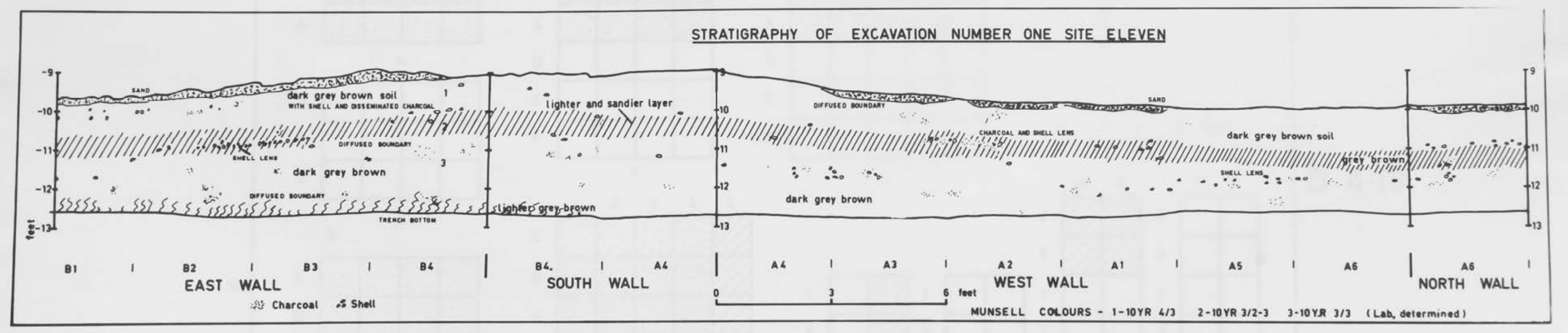




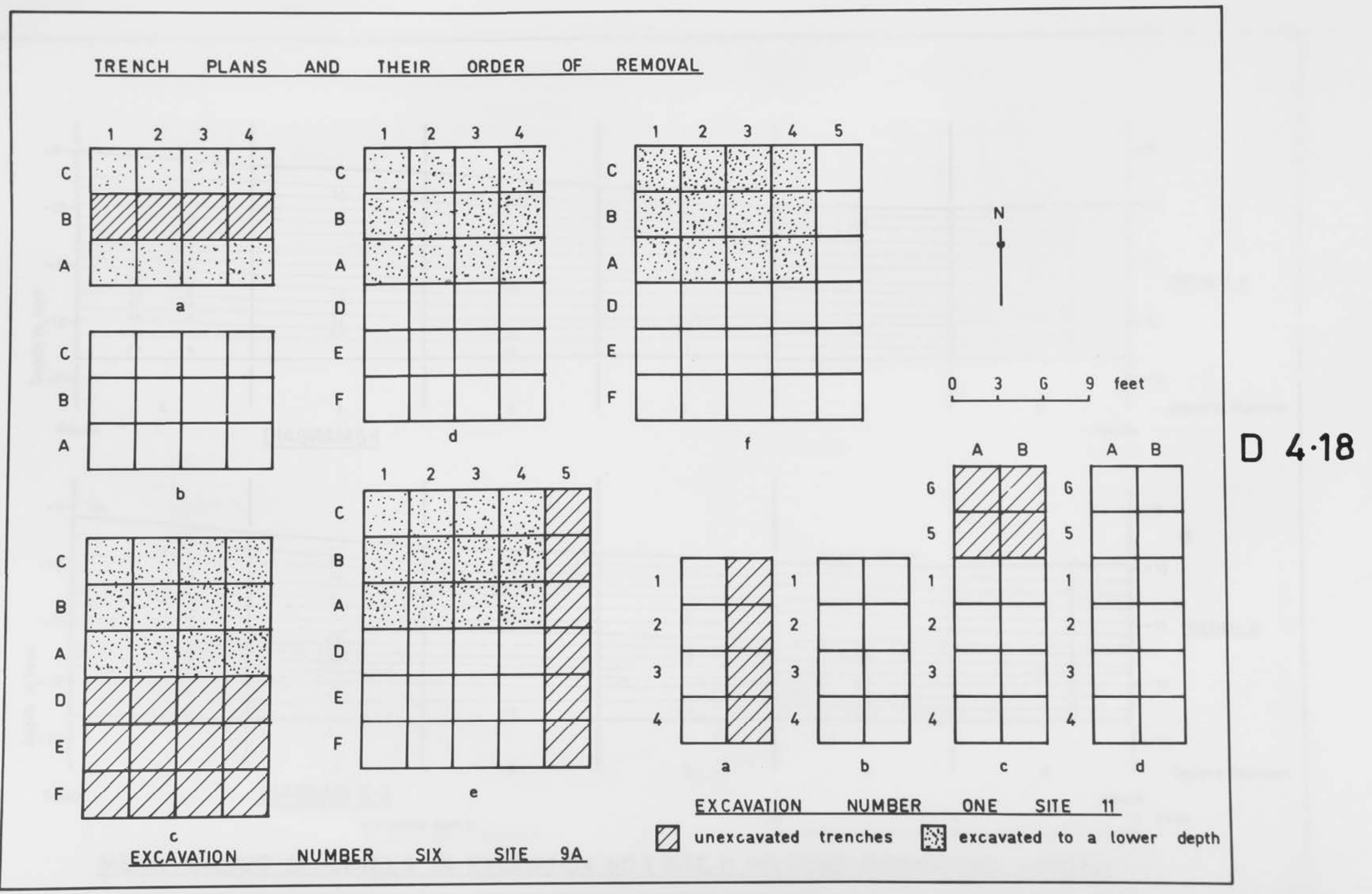



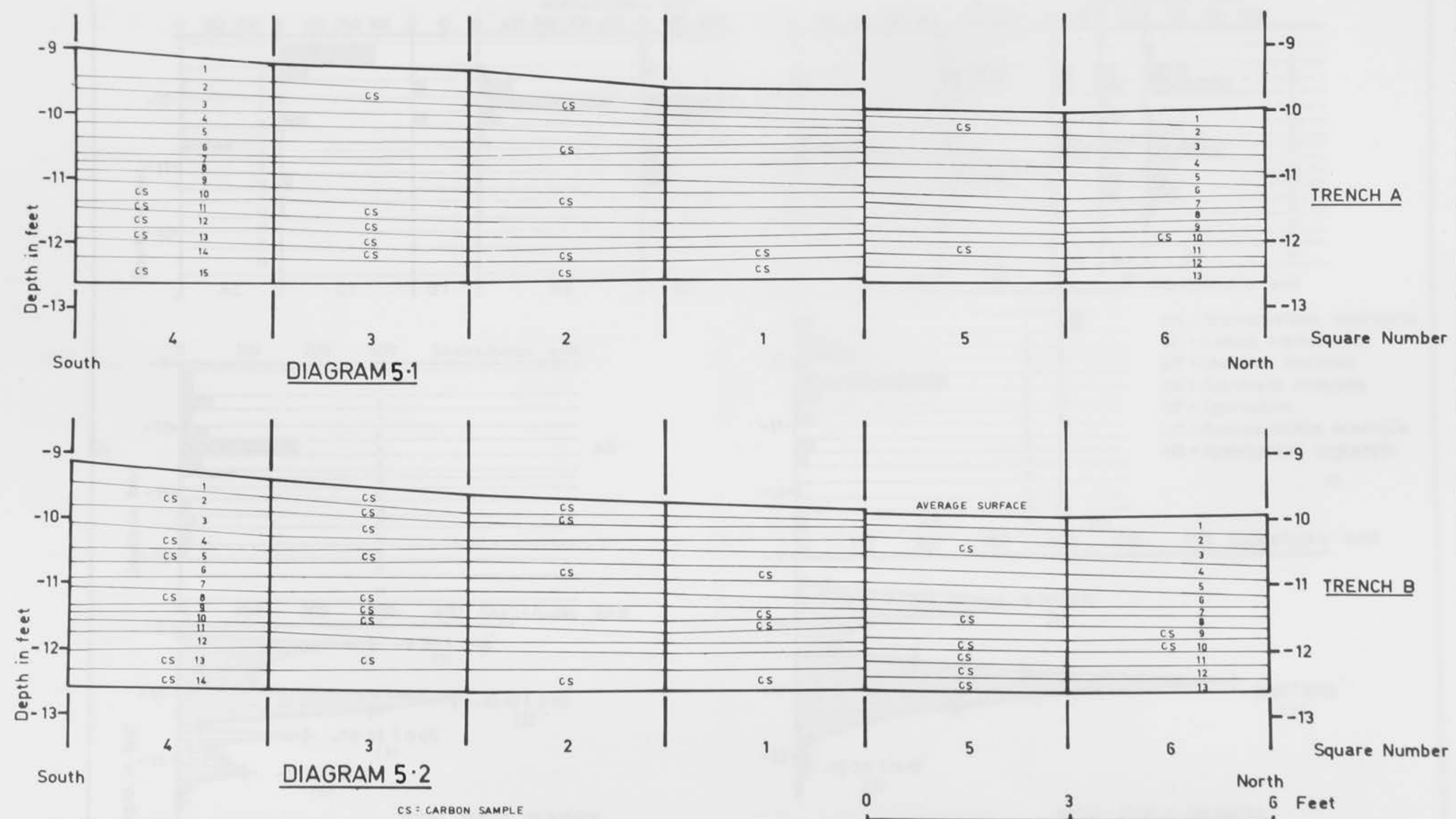

MEAN VALUES OF LEVELS IN EXCAVATION NO 1 SITE 11 WILSONS PROMONTORY VICTORIA 


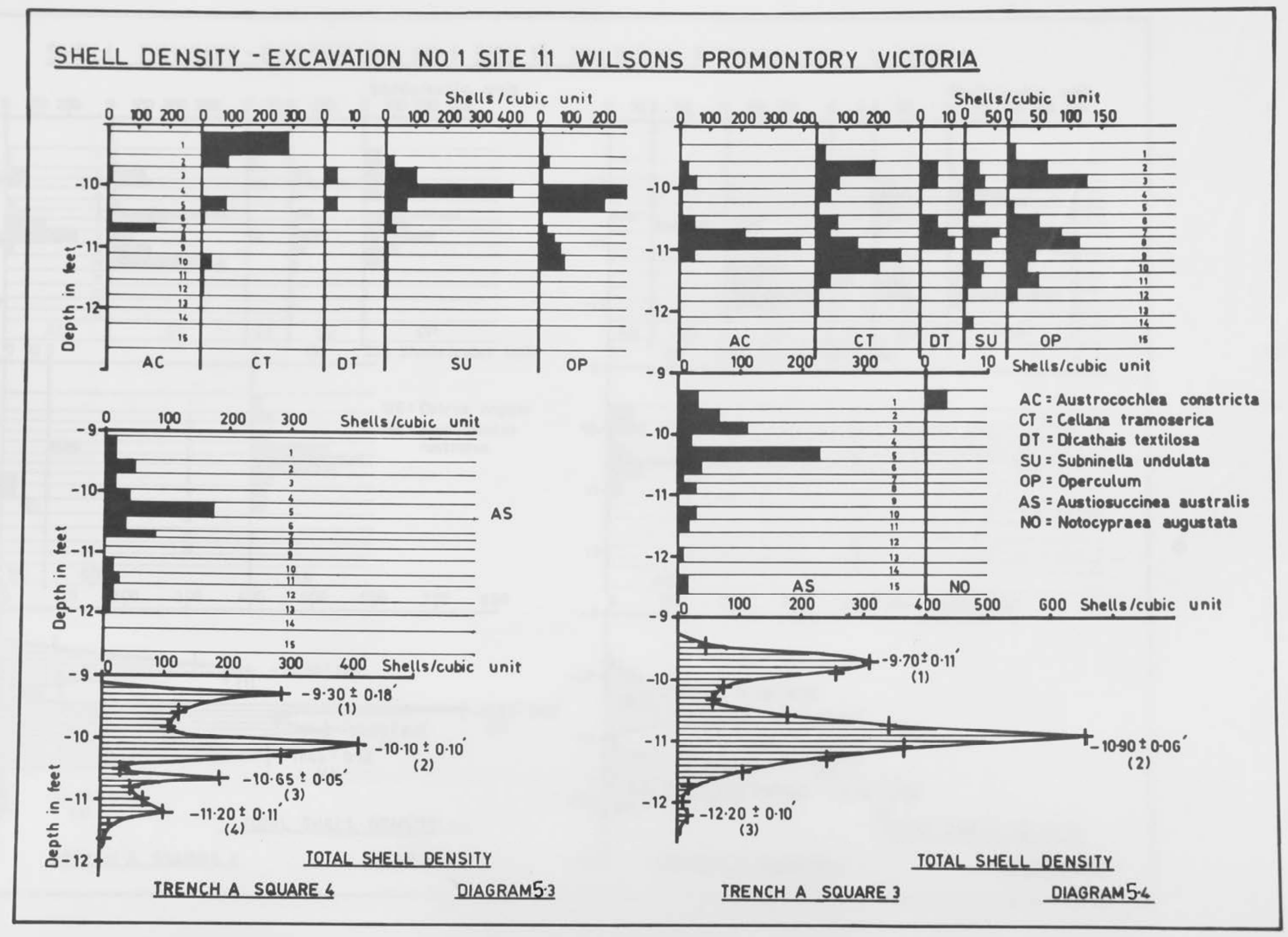




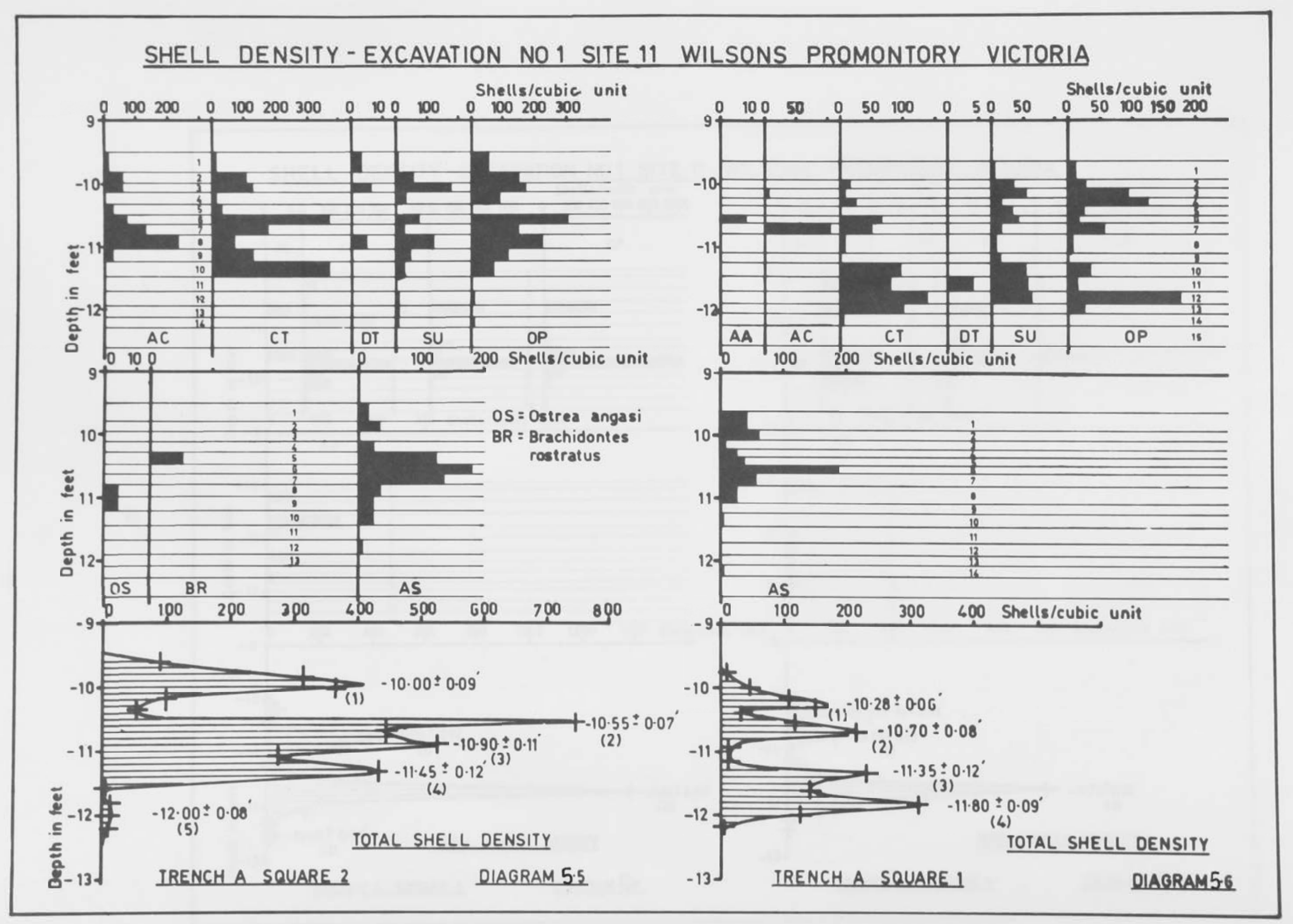




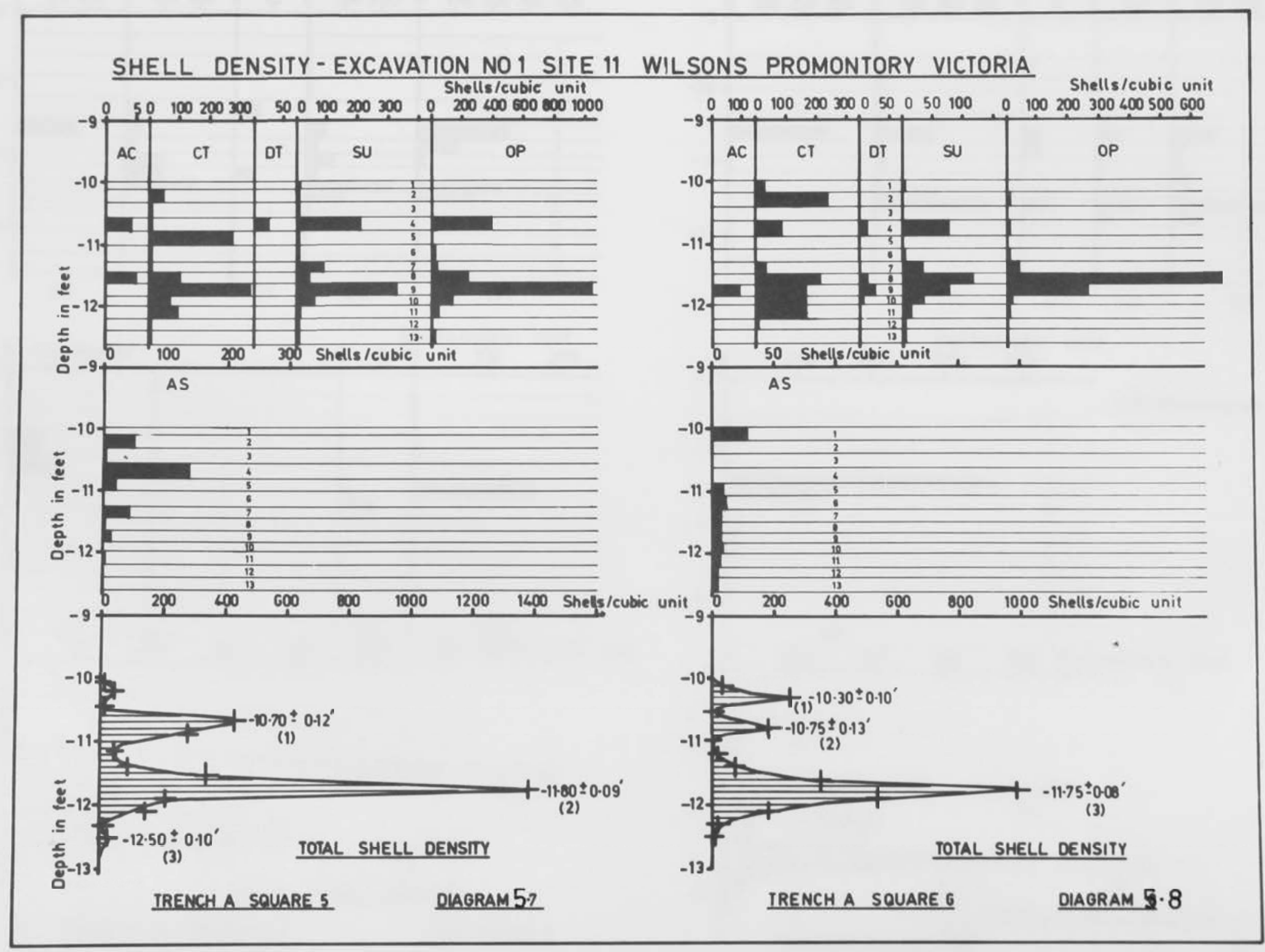




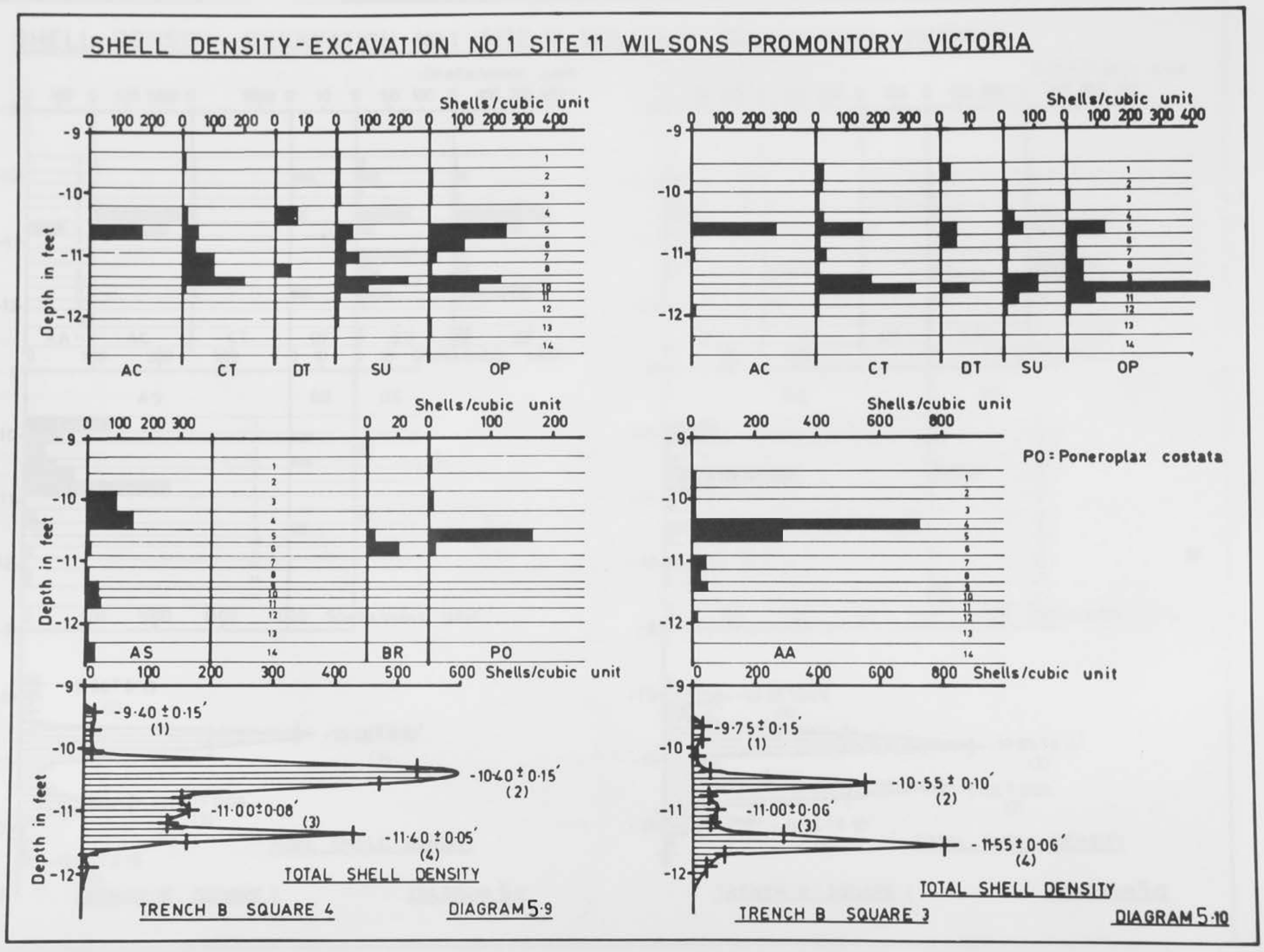




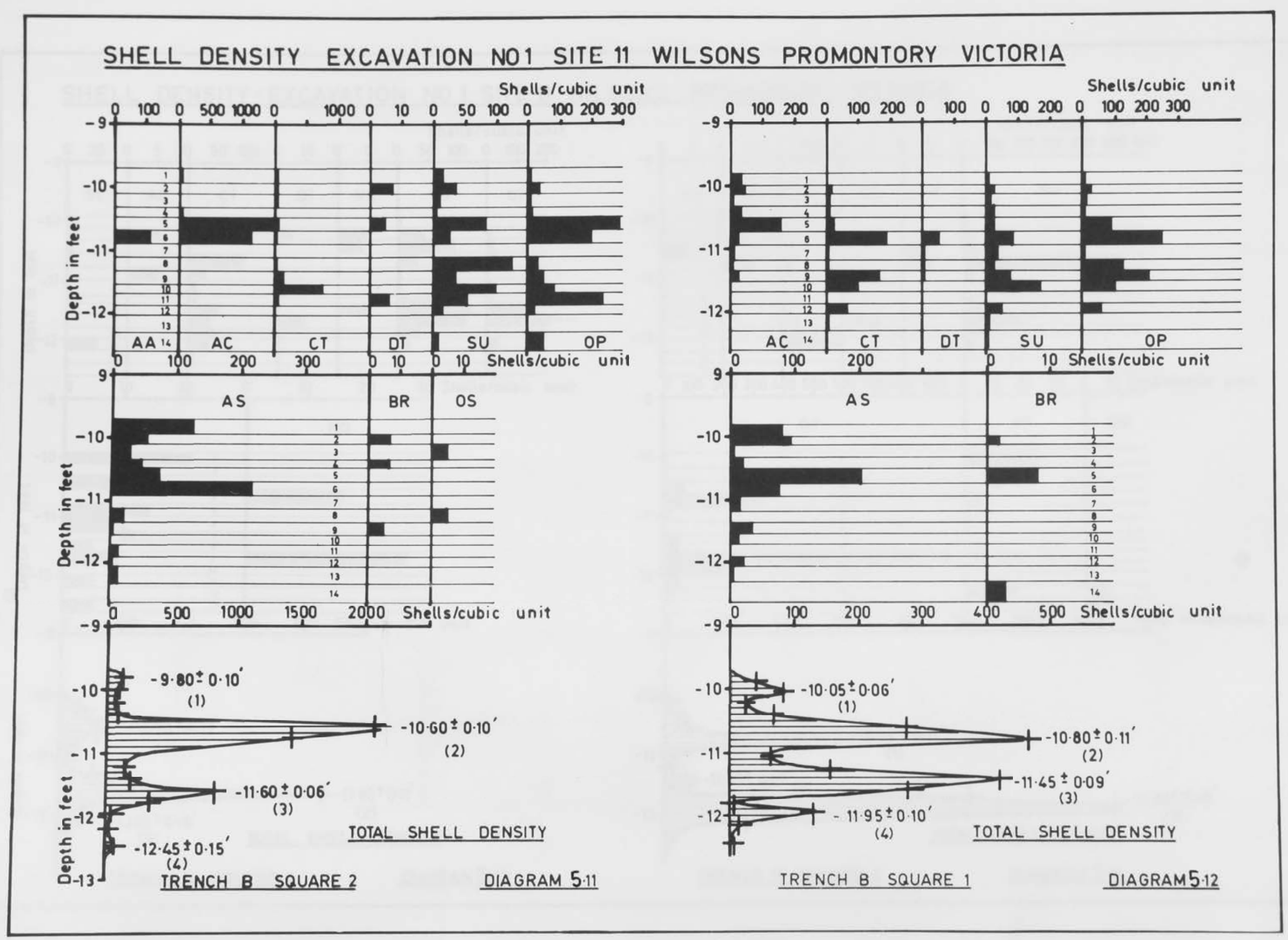




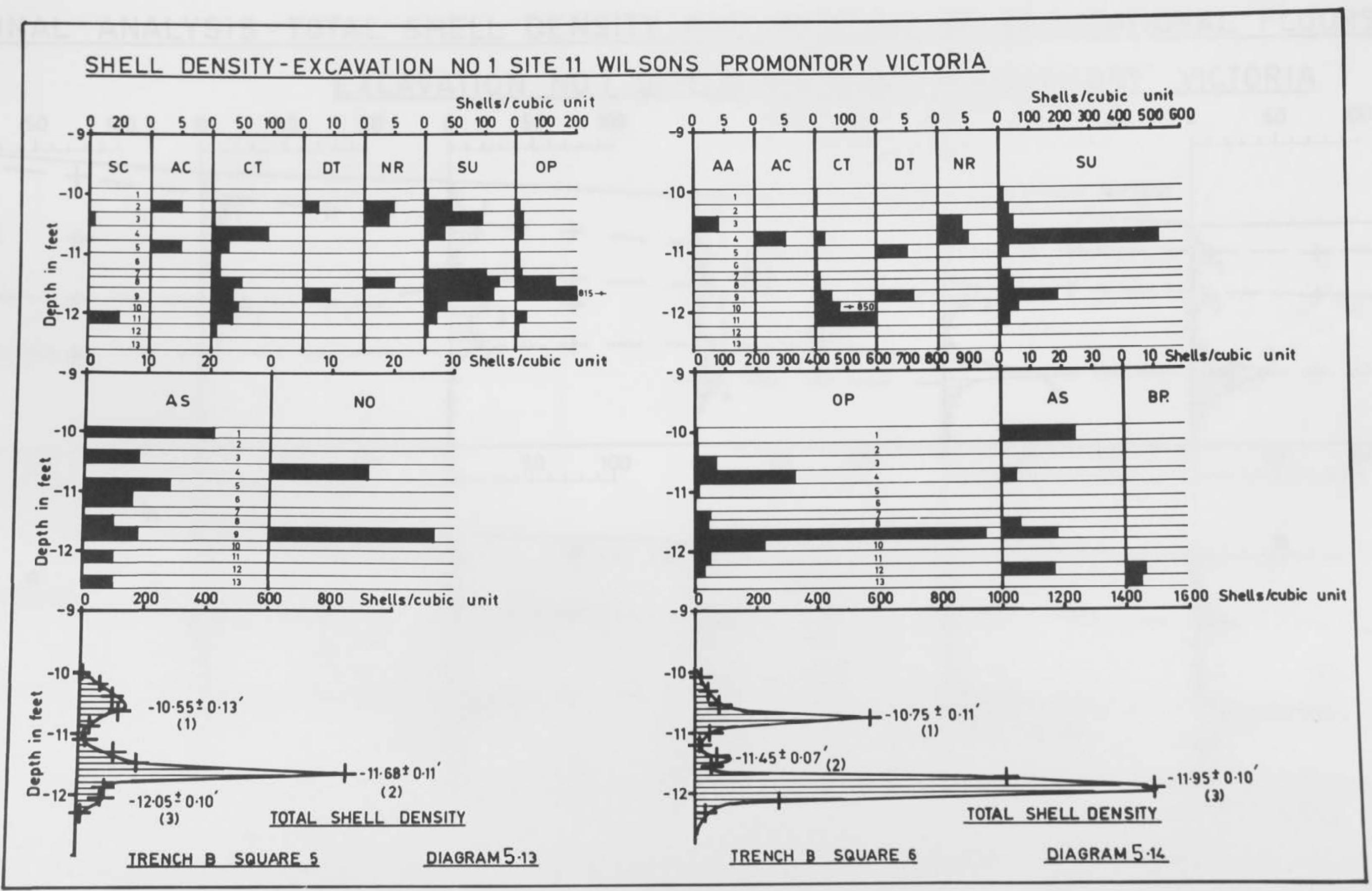


FAUNAL ANALYSIS: TOTAL SHELL DENSITY AND POSITION OF OCCUPATIONAL FLOORS EXCAVATION NO 1 SITE 11 WILSONS PROMONTORY VICTORIA

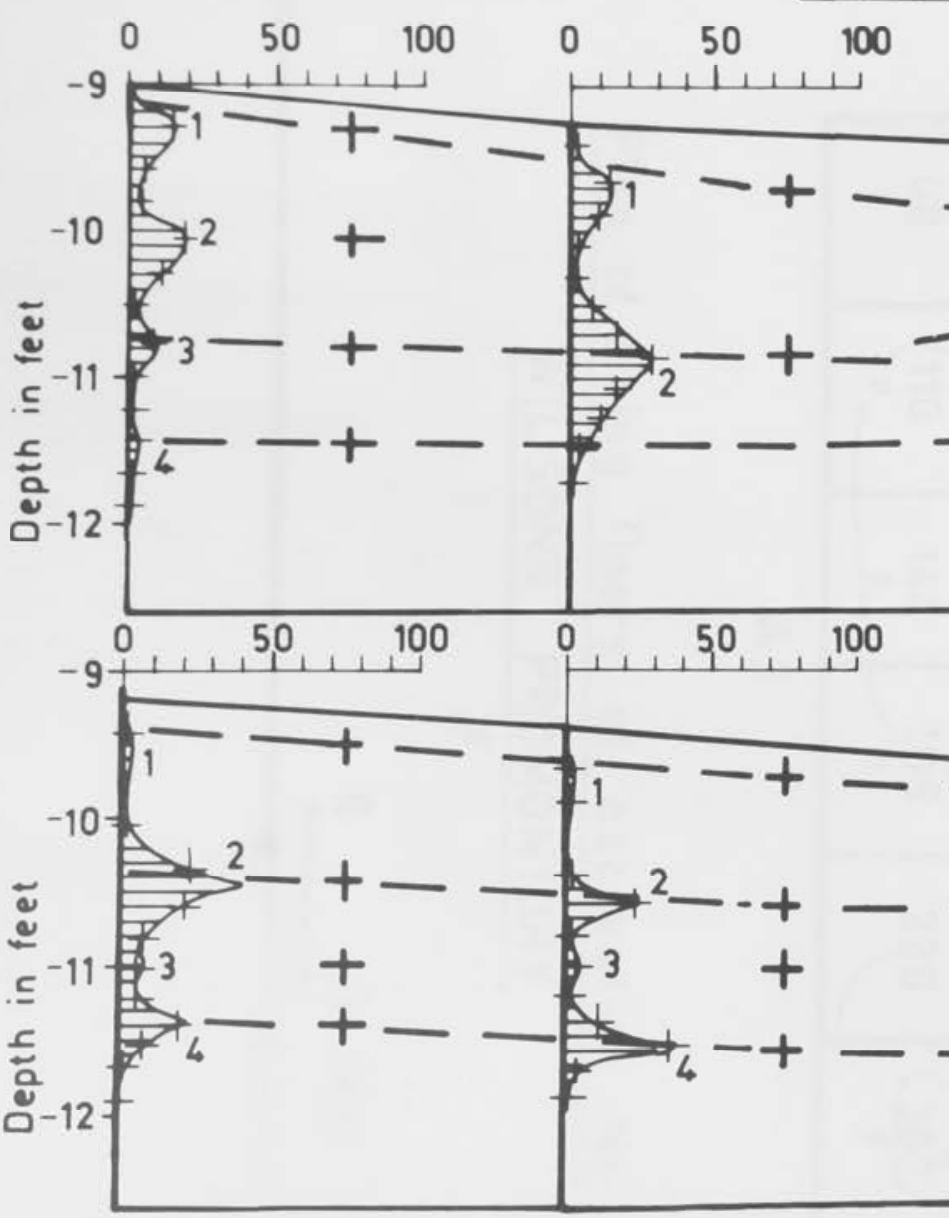

SQUARE NO

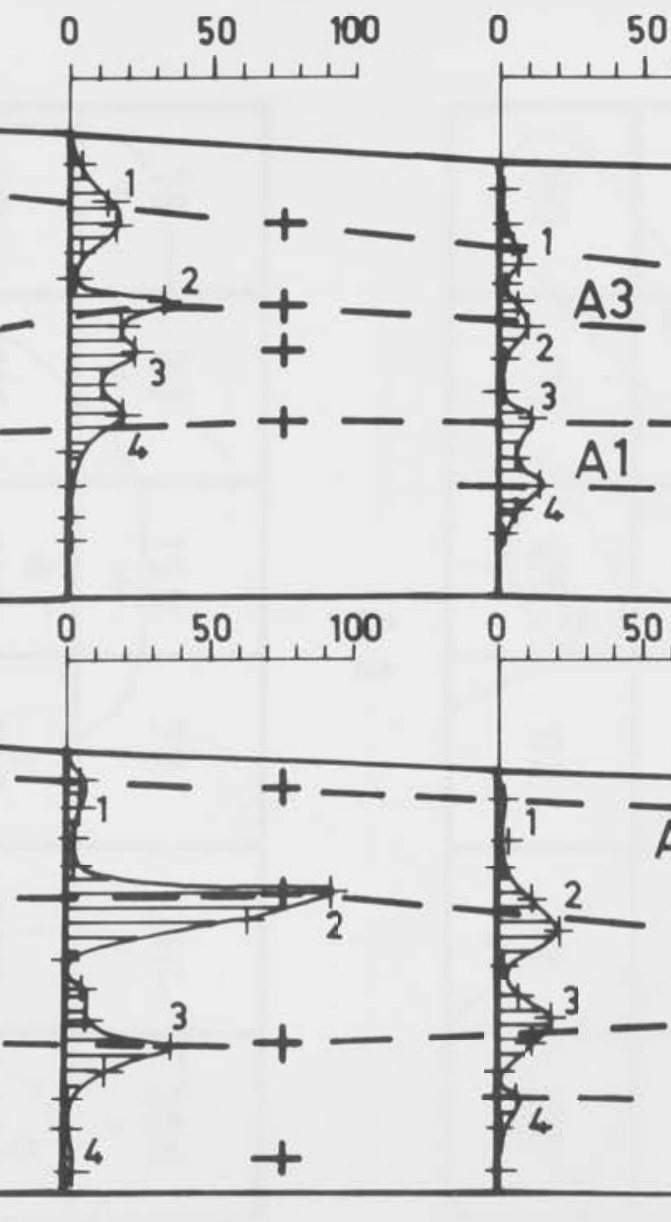

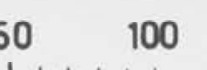

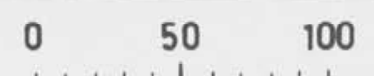

(1)

0
0

50
100

$00 \%$ Shell density

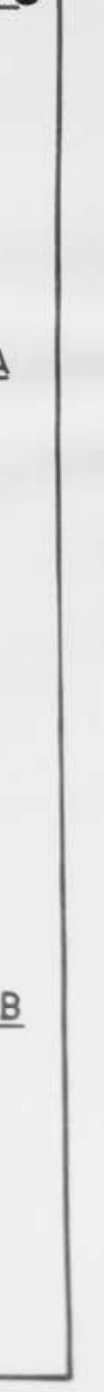




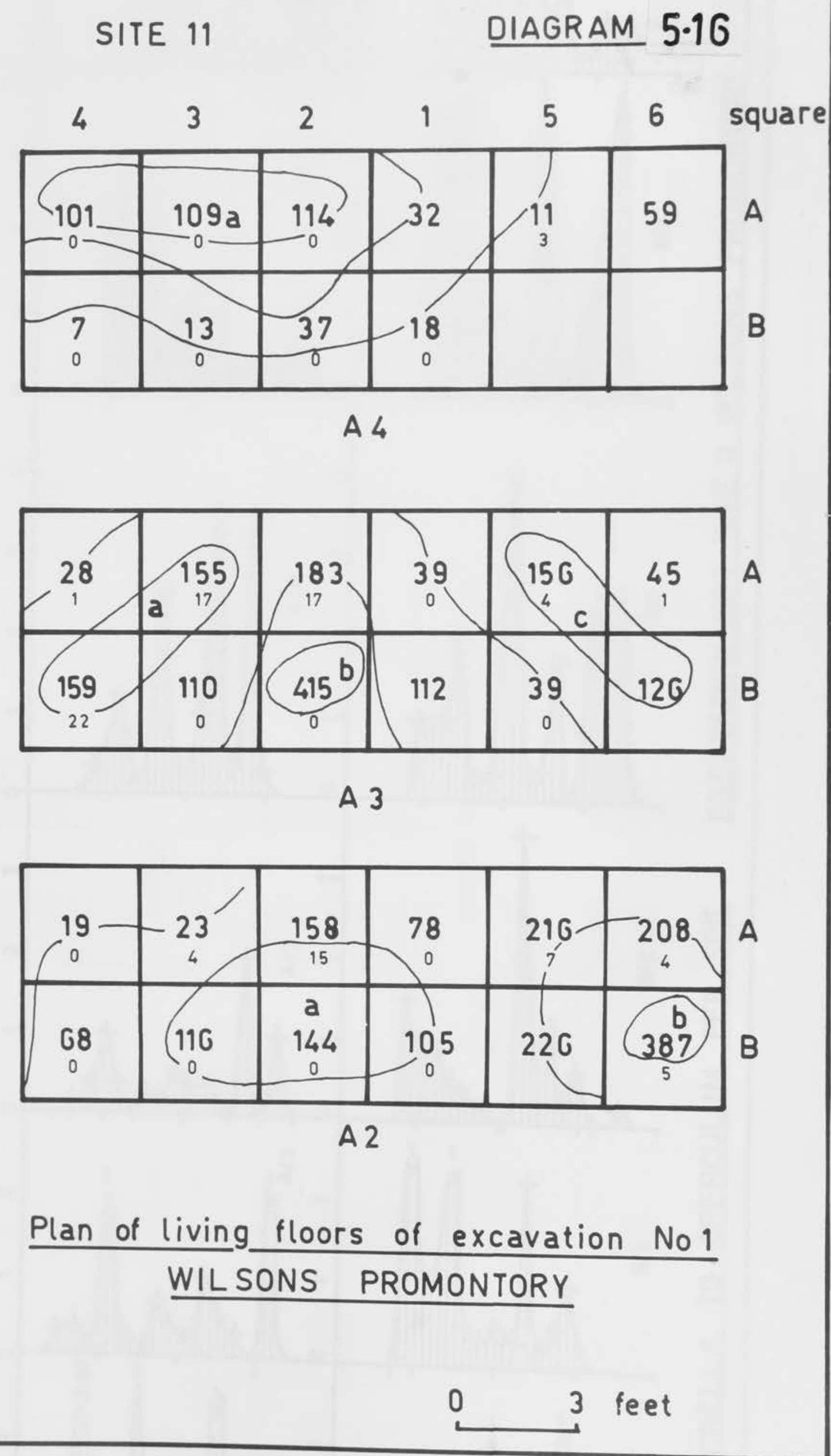




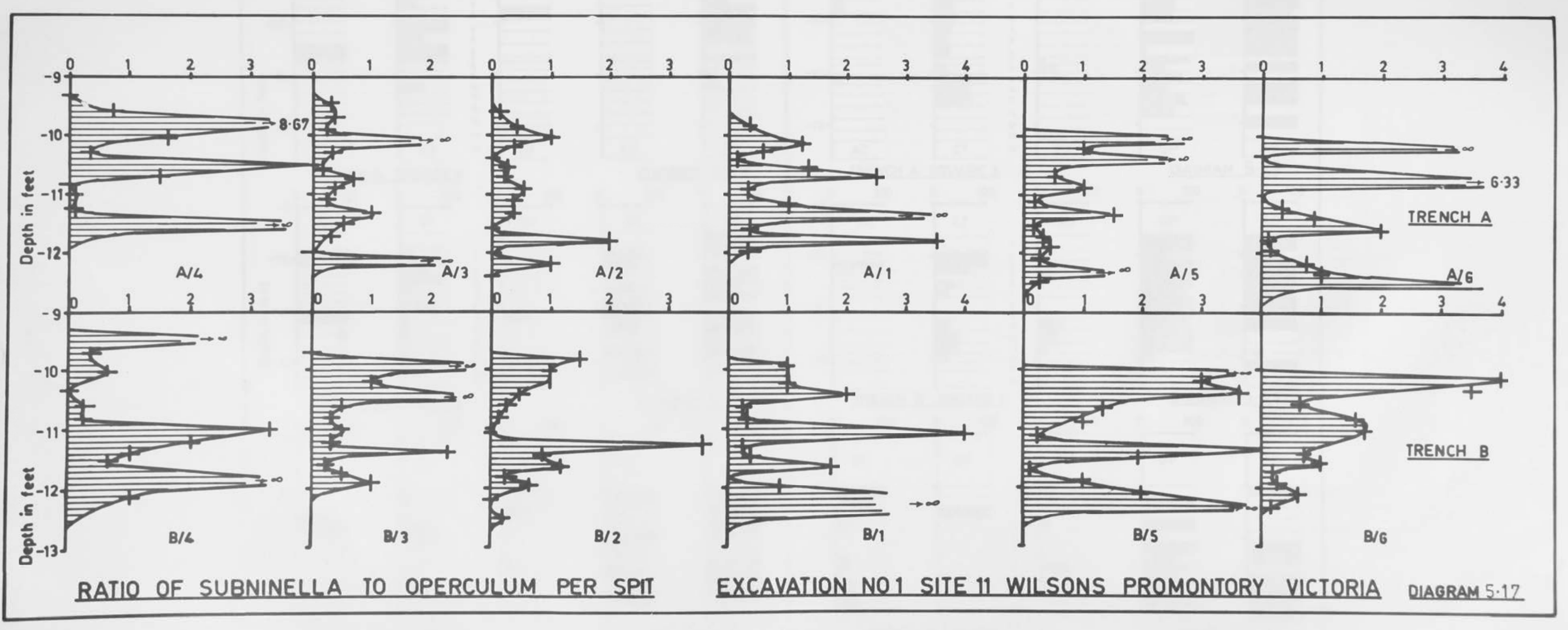




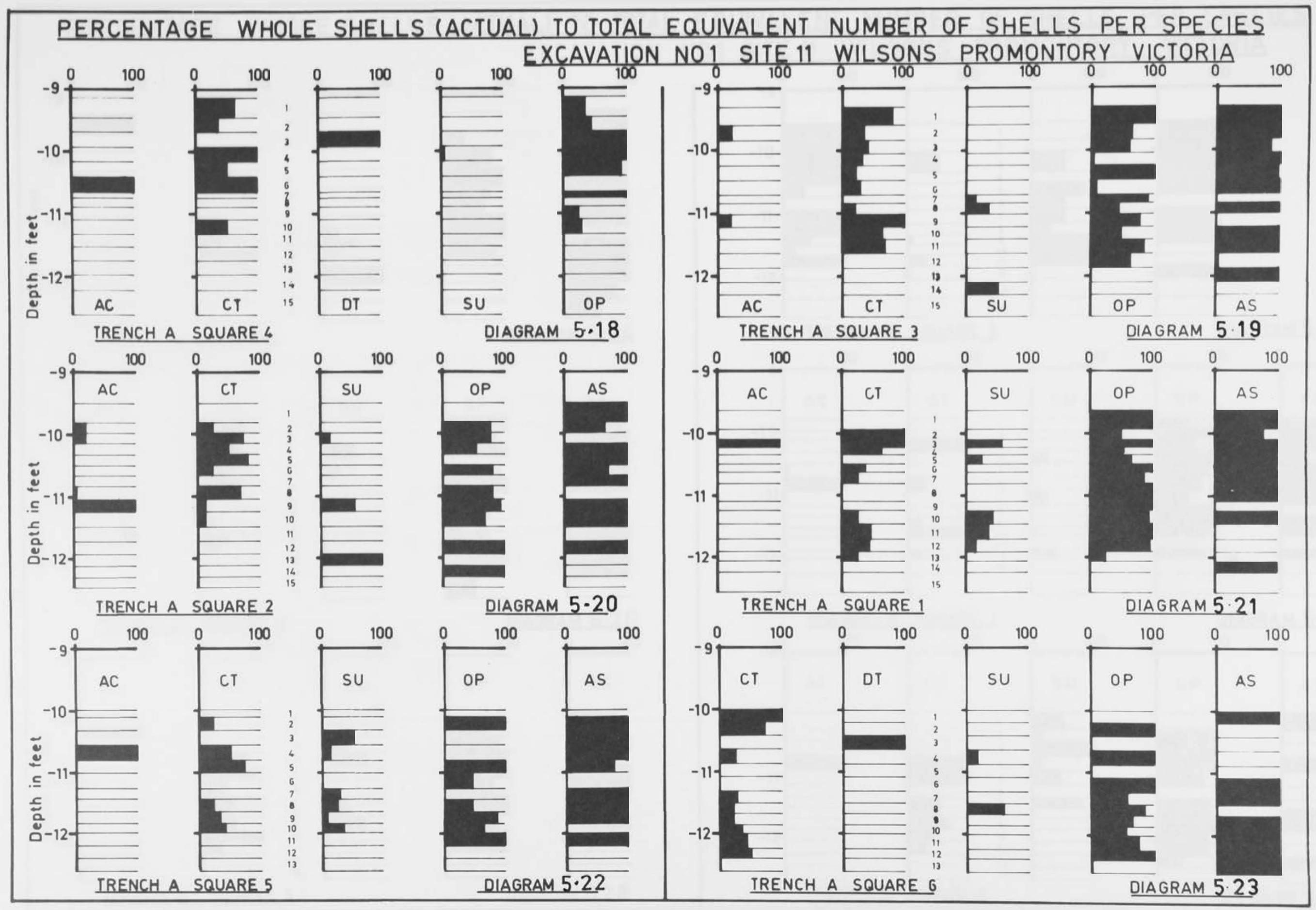




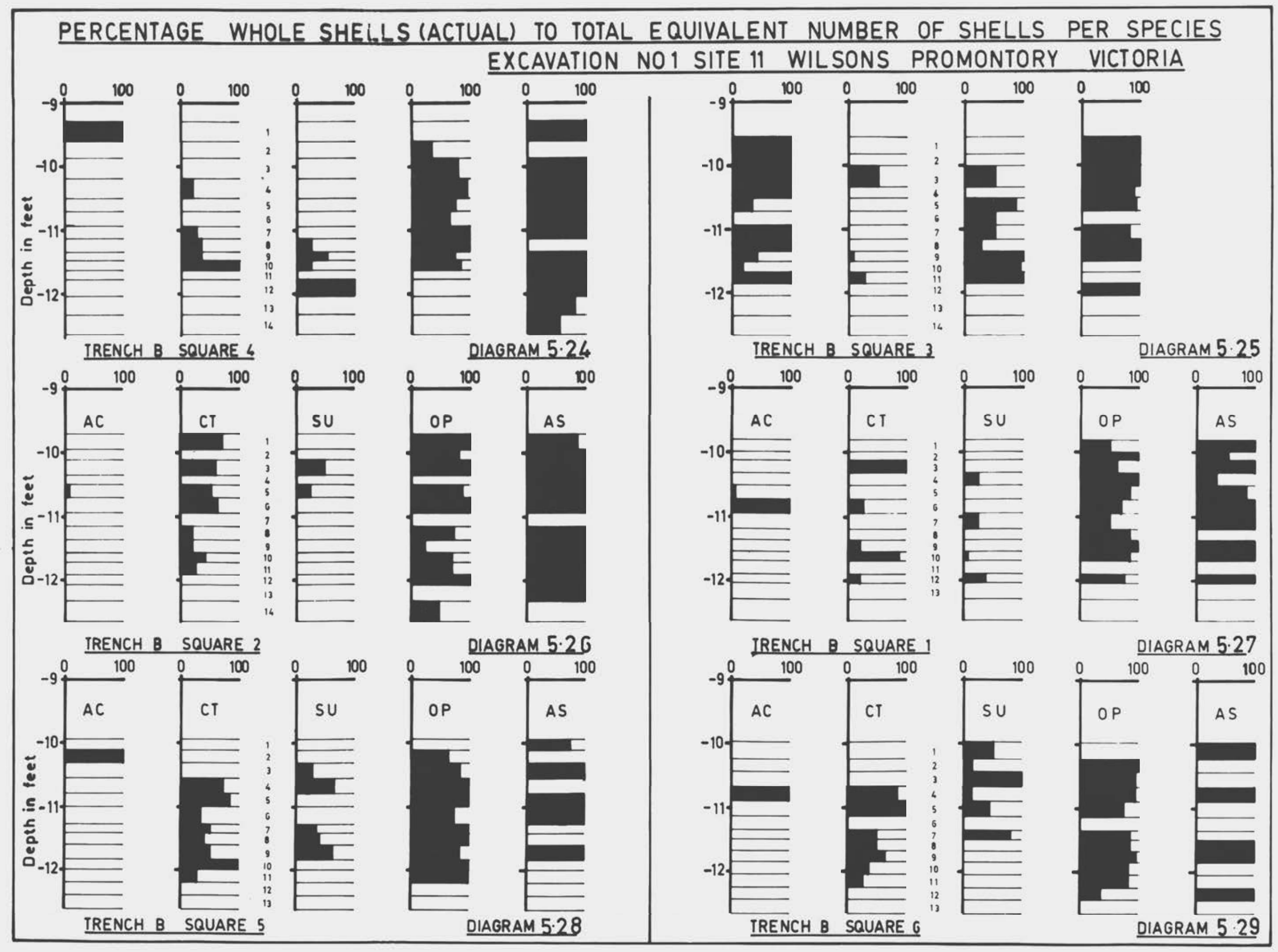




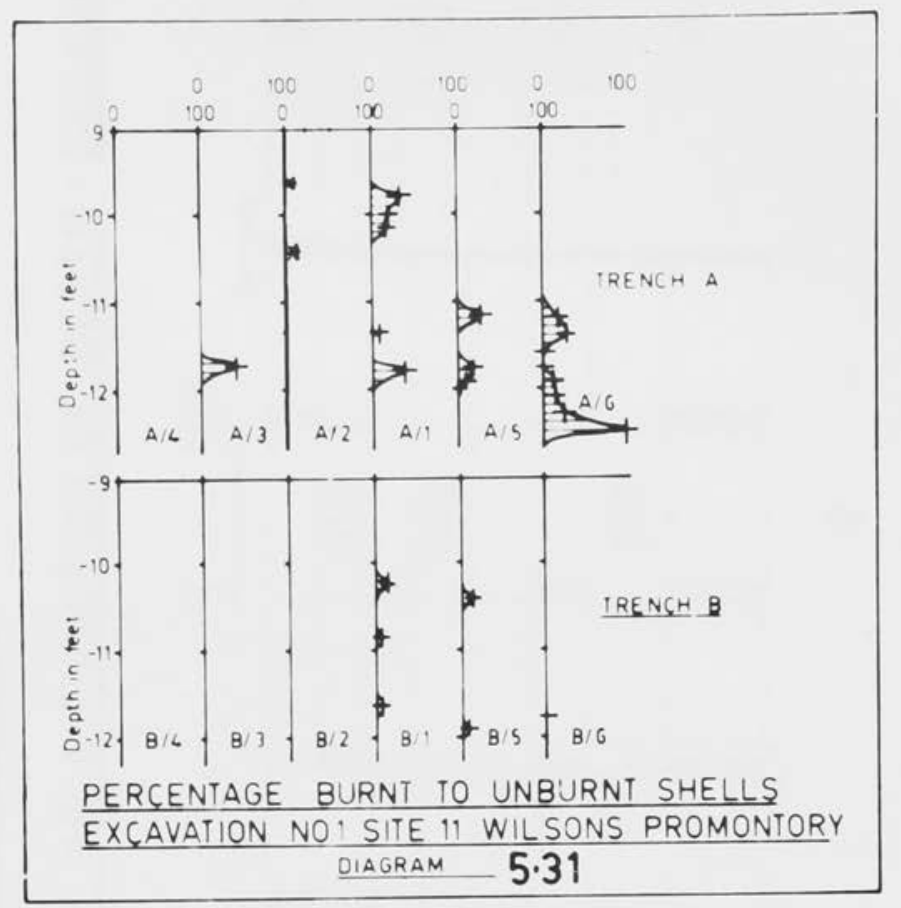

PERCENTAGE WHOLE (ACTUAL) TO TOTAL EQUIVALENT NUMBER OF SHELLS PER SPII EXCAVATION NO 1 SITE 11 WILSONS PROMONTORY VICTORIA DIAGRAM 5.30
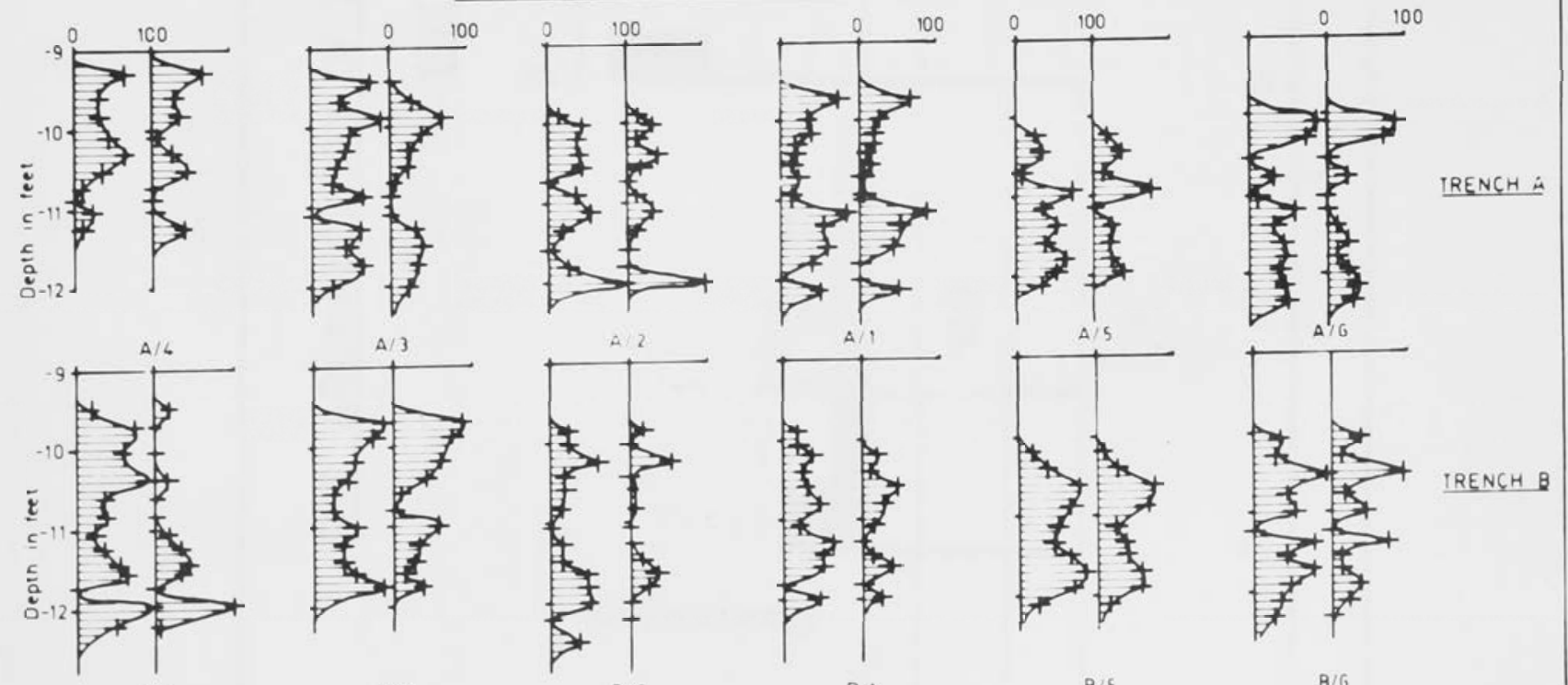

B/6

B/3

B/I

B/5

$B / 6$ 


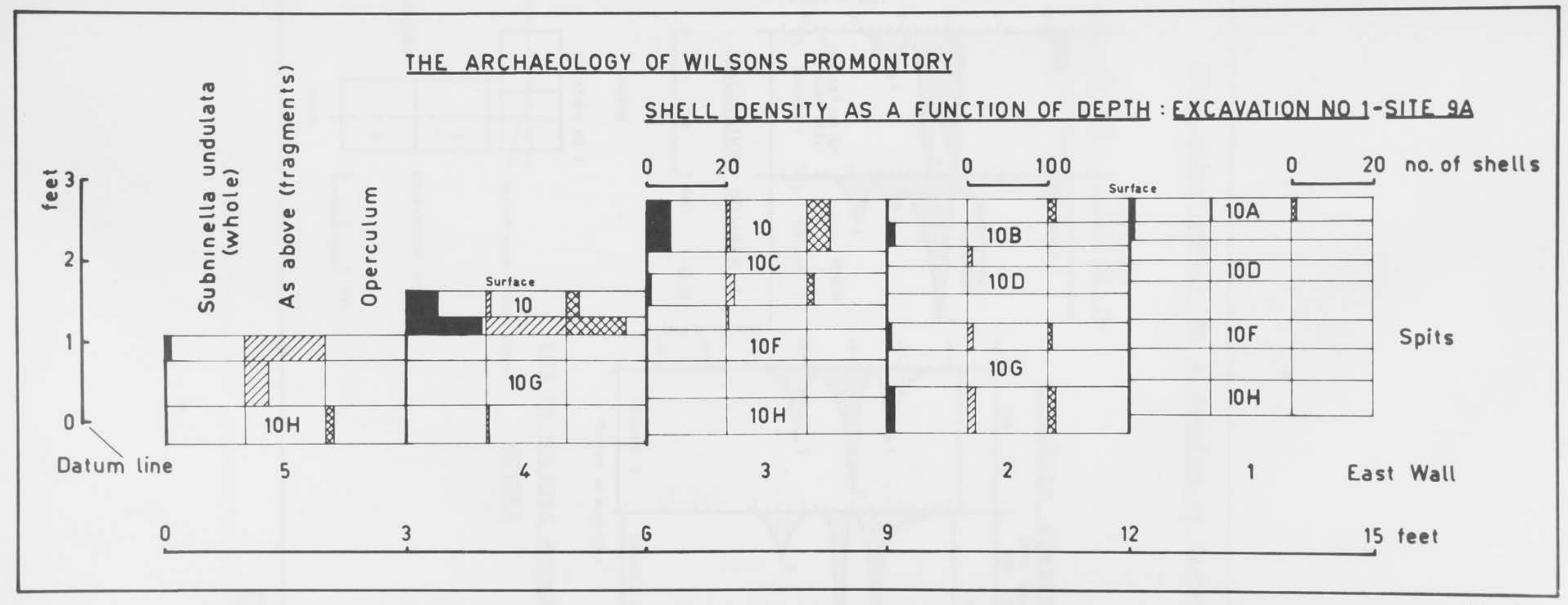




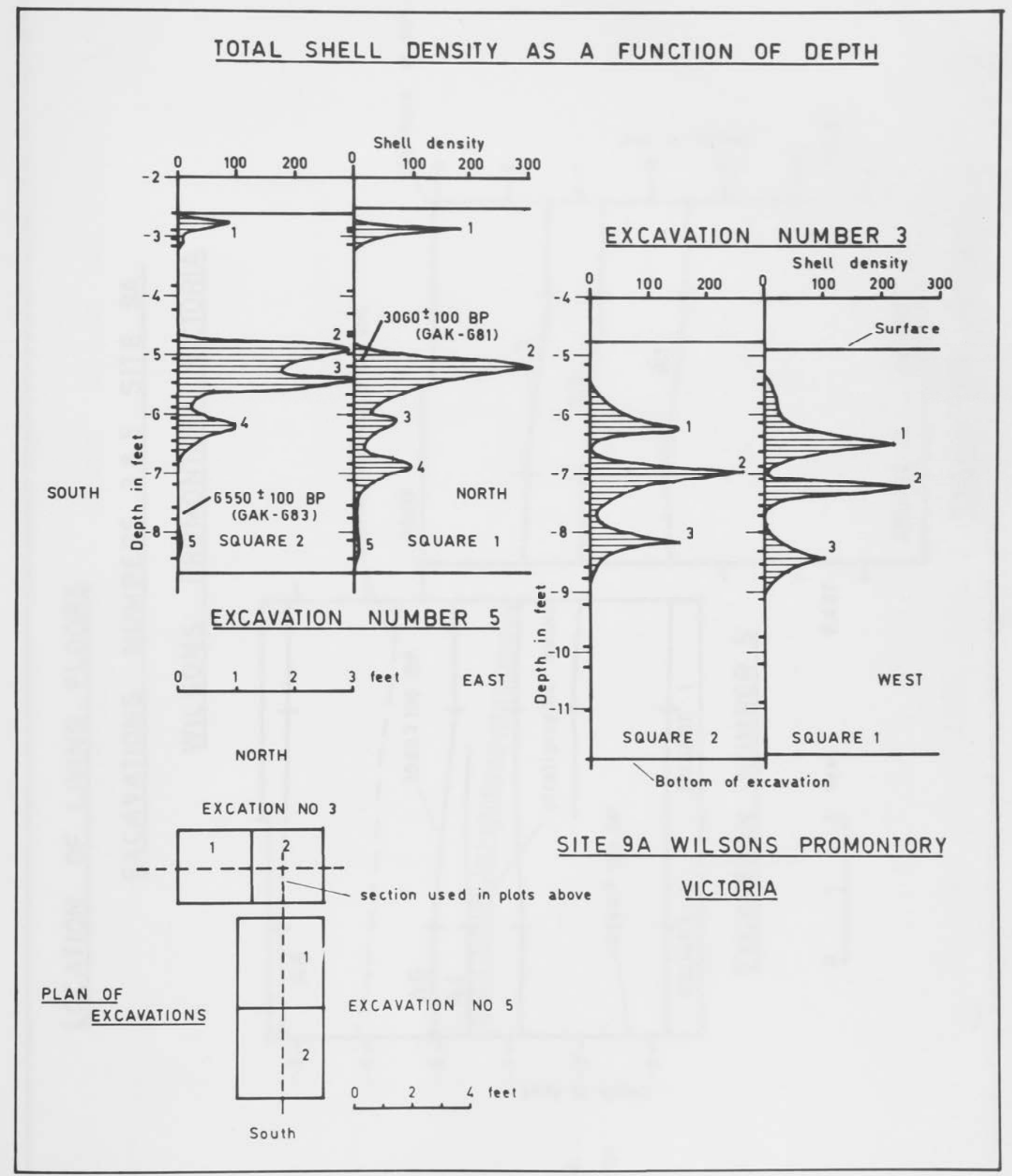

D $0 \cdot 2$ 


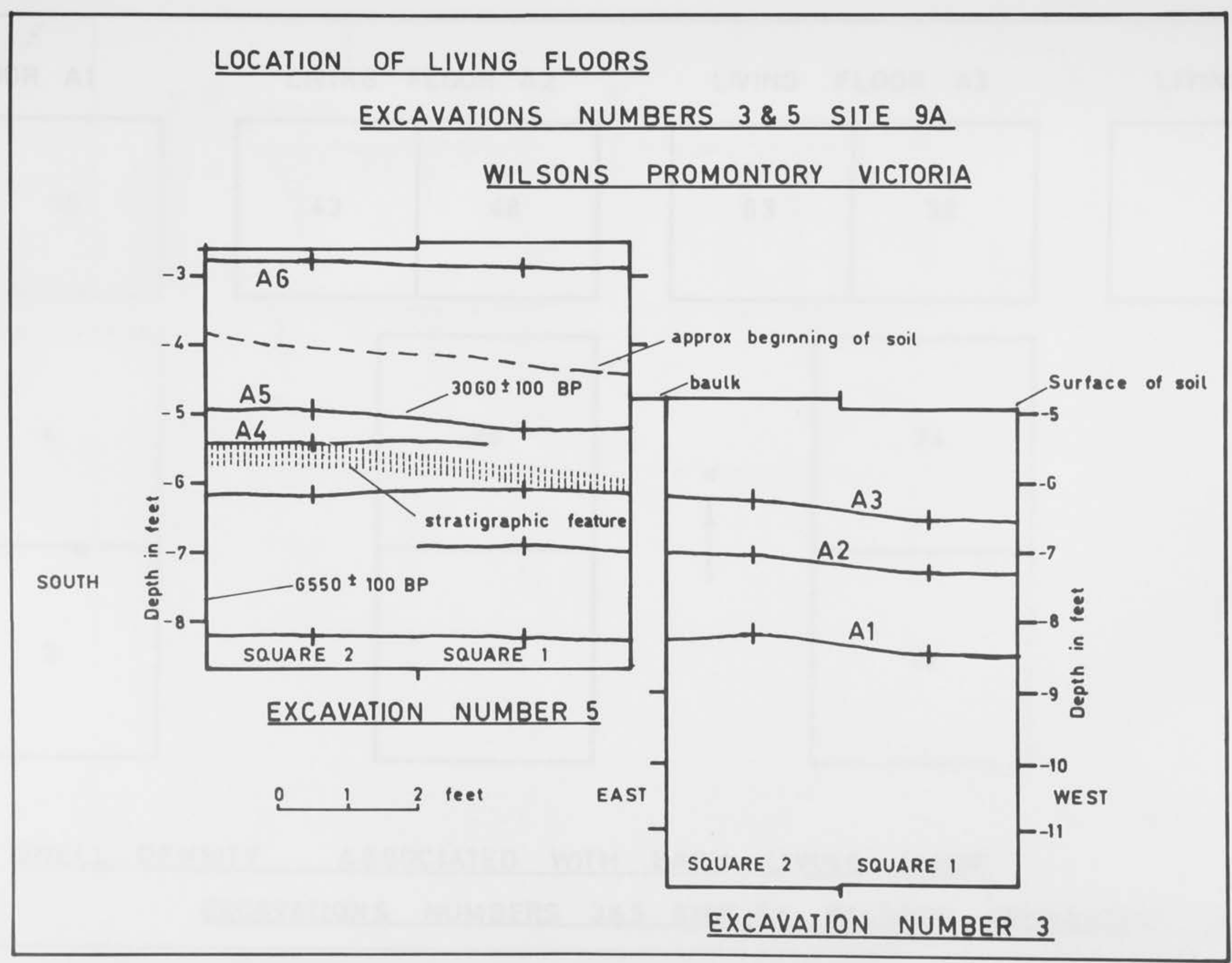

D 0.3 


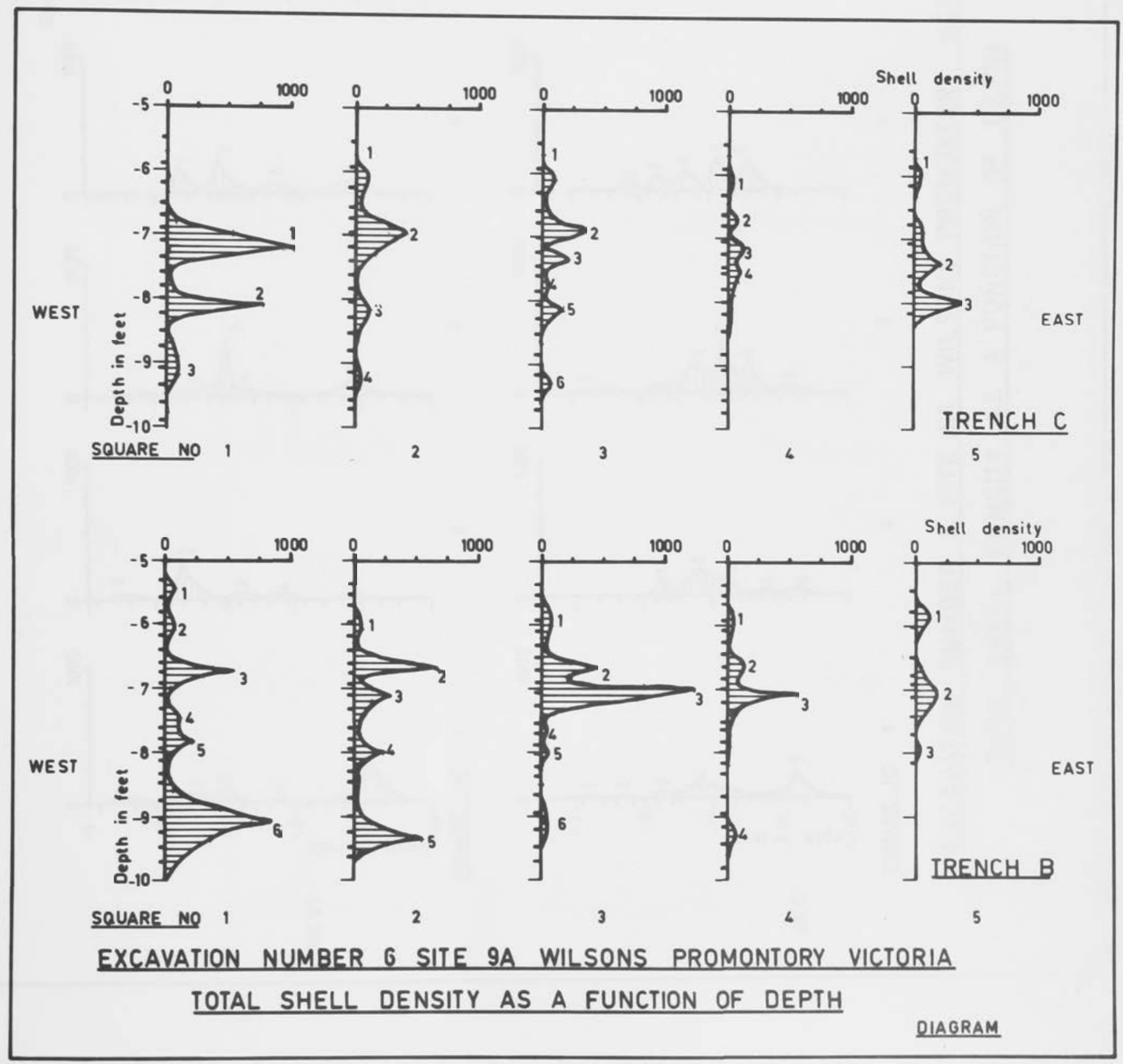

D 0.5 


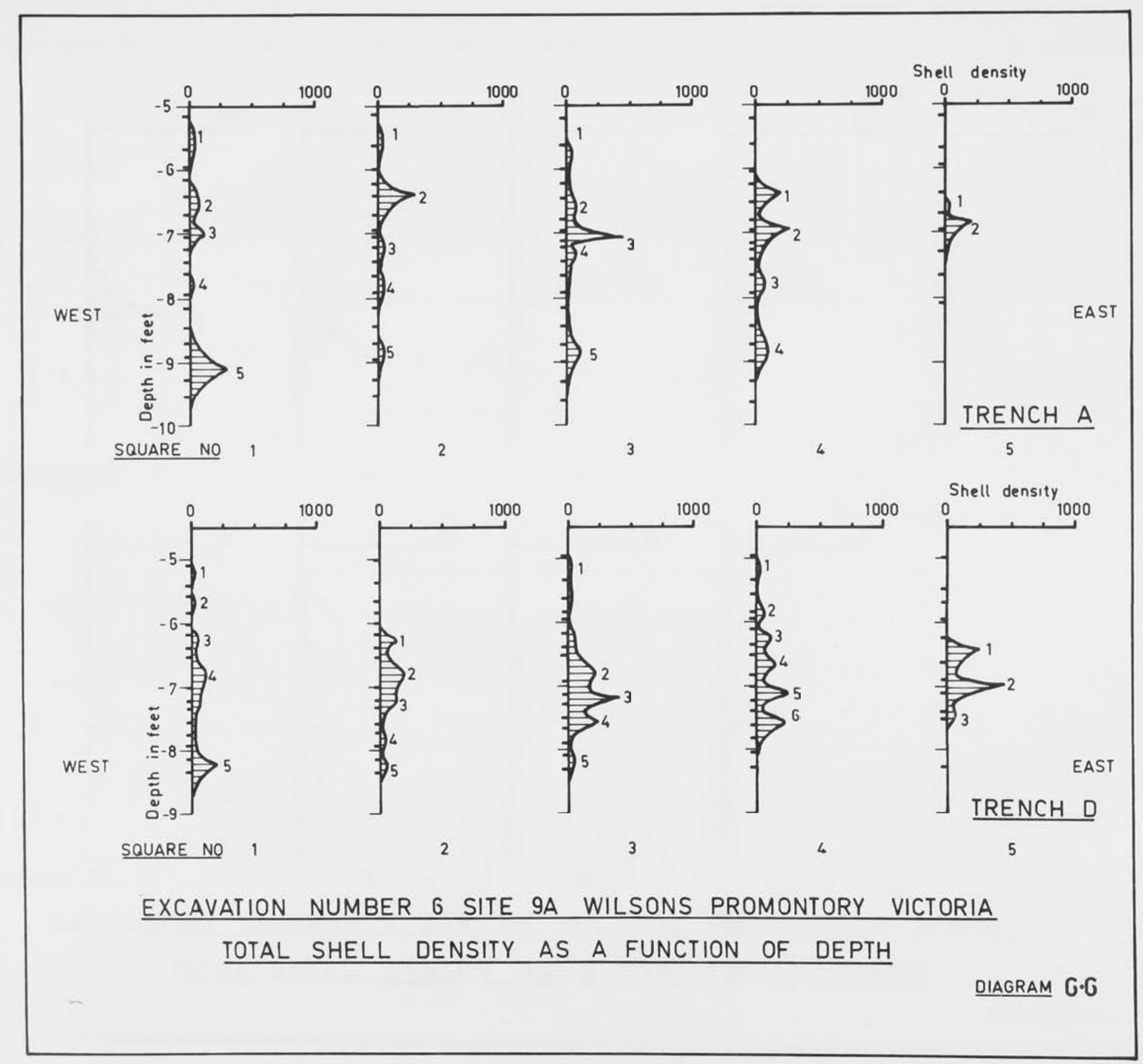




$$
\begin{aligned}
& \text { EFEFE } \\
& \text { AEFEE }
\end{aligned}
$$



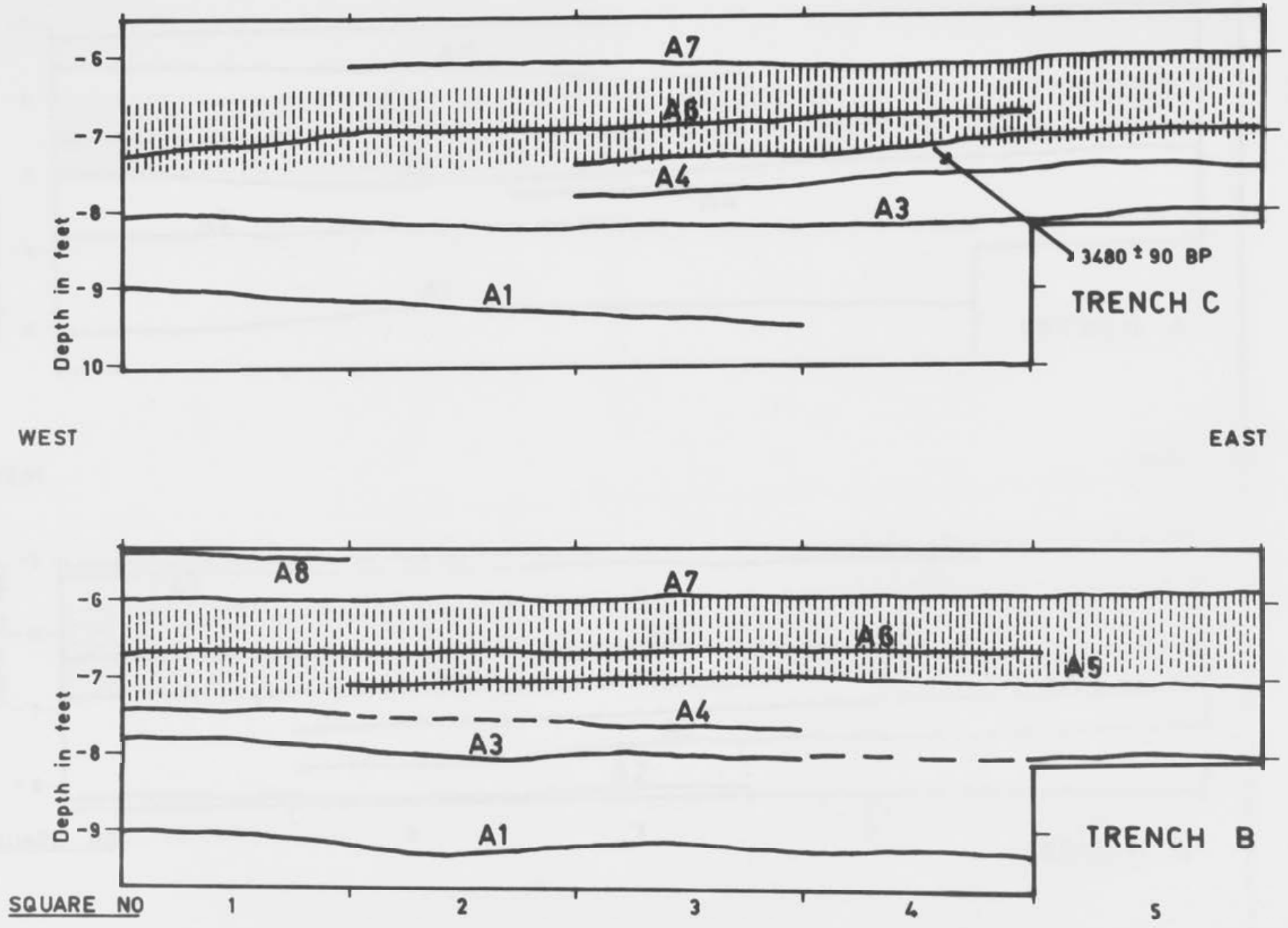

EXCAVATION NUMBER G SITE 9A WILSONS PROMONTORY VICTORIA LOCATION OF LIVING FLOORS 


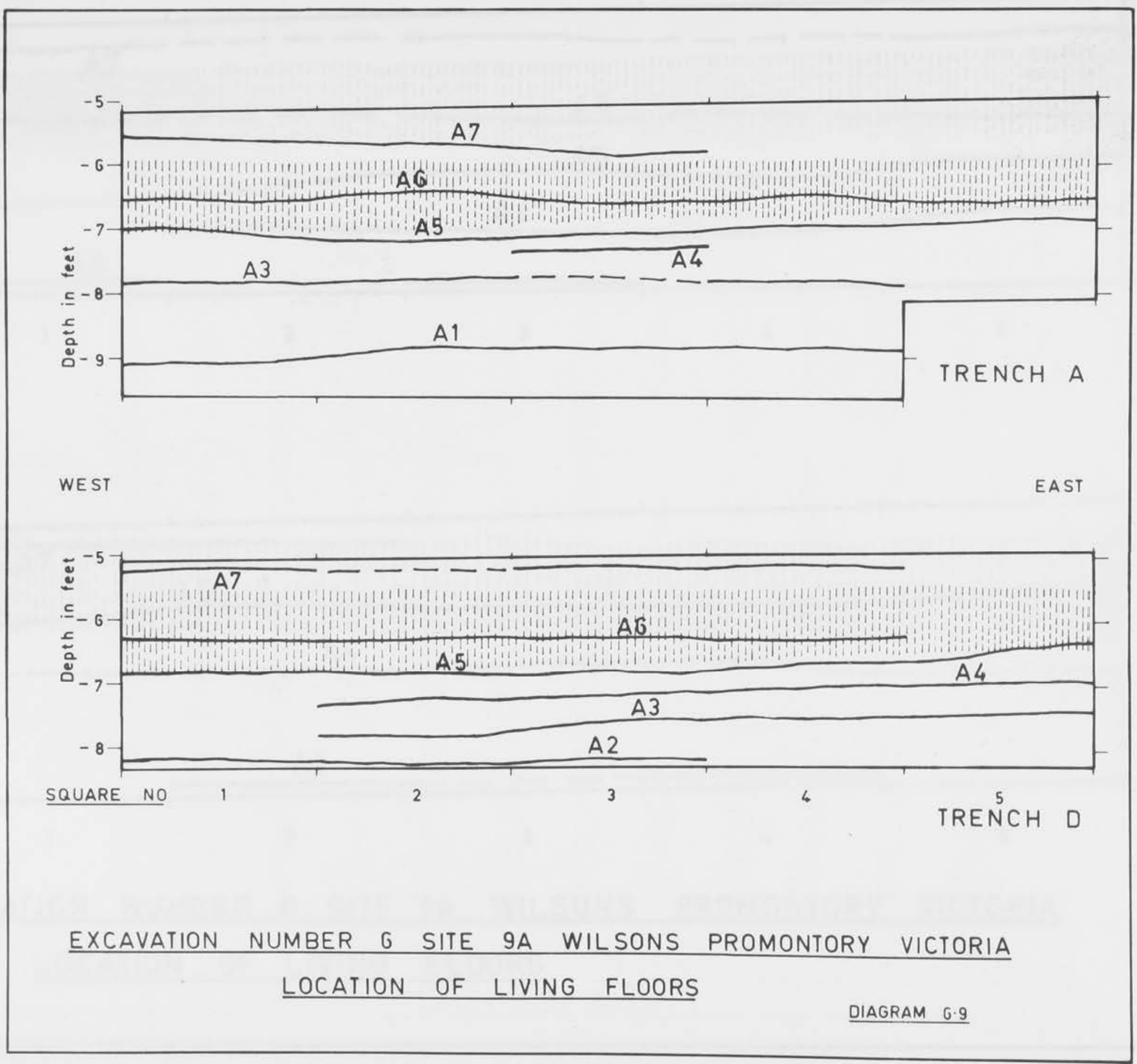




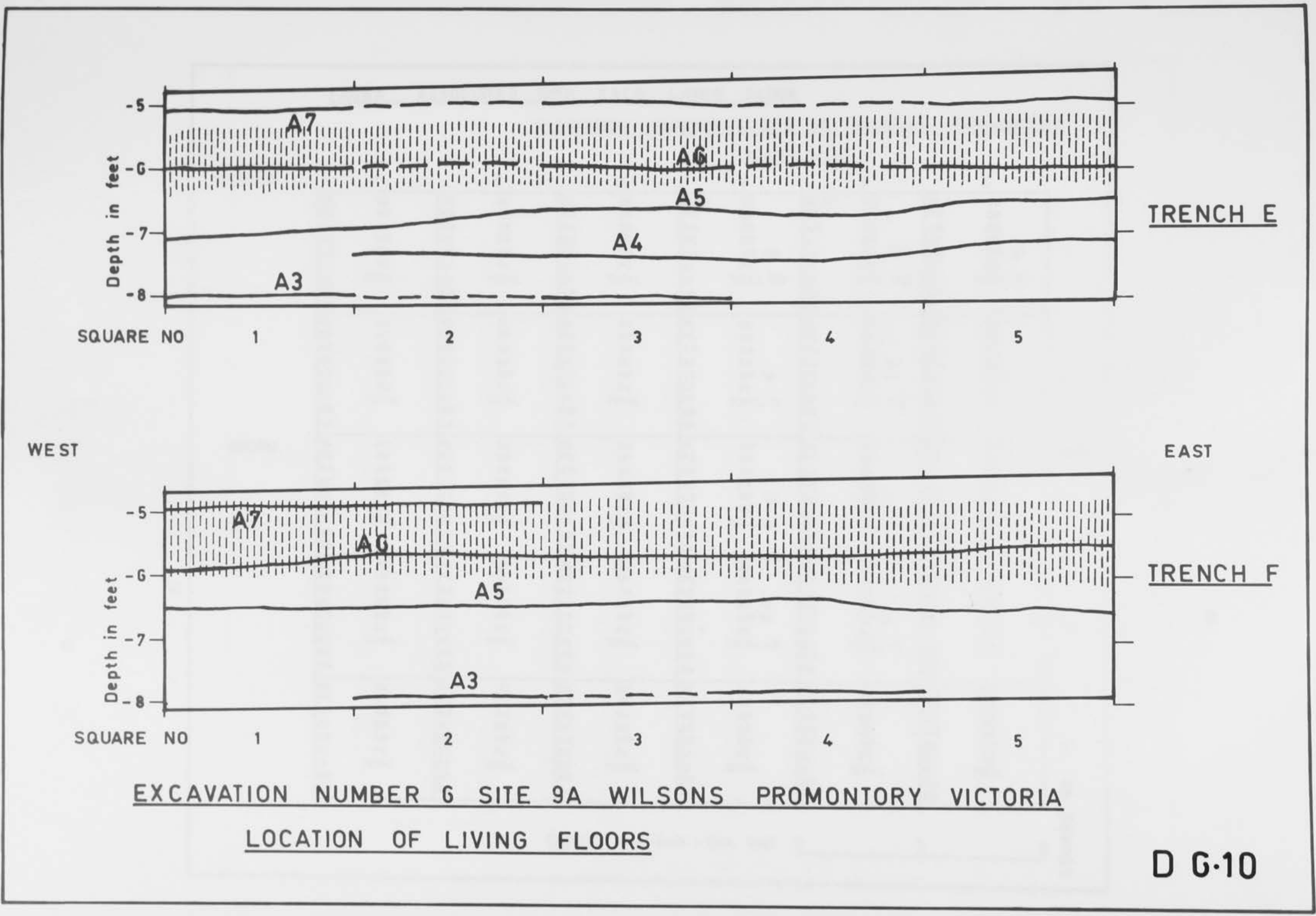




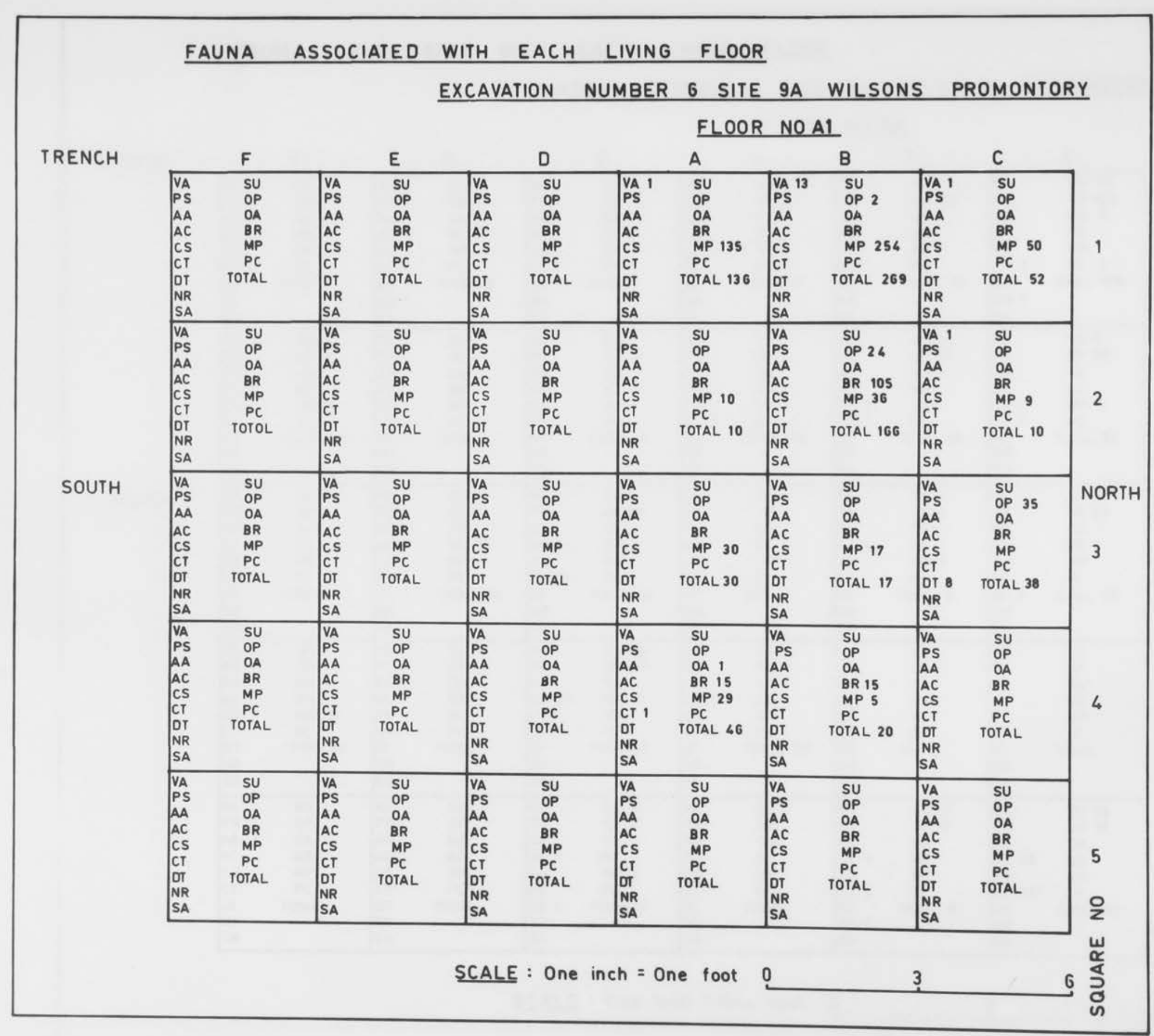

D 0.11 


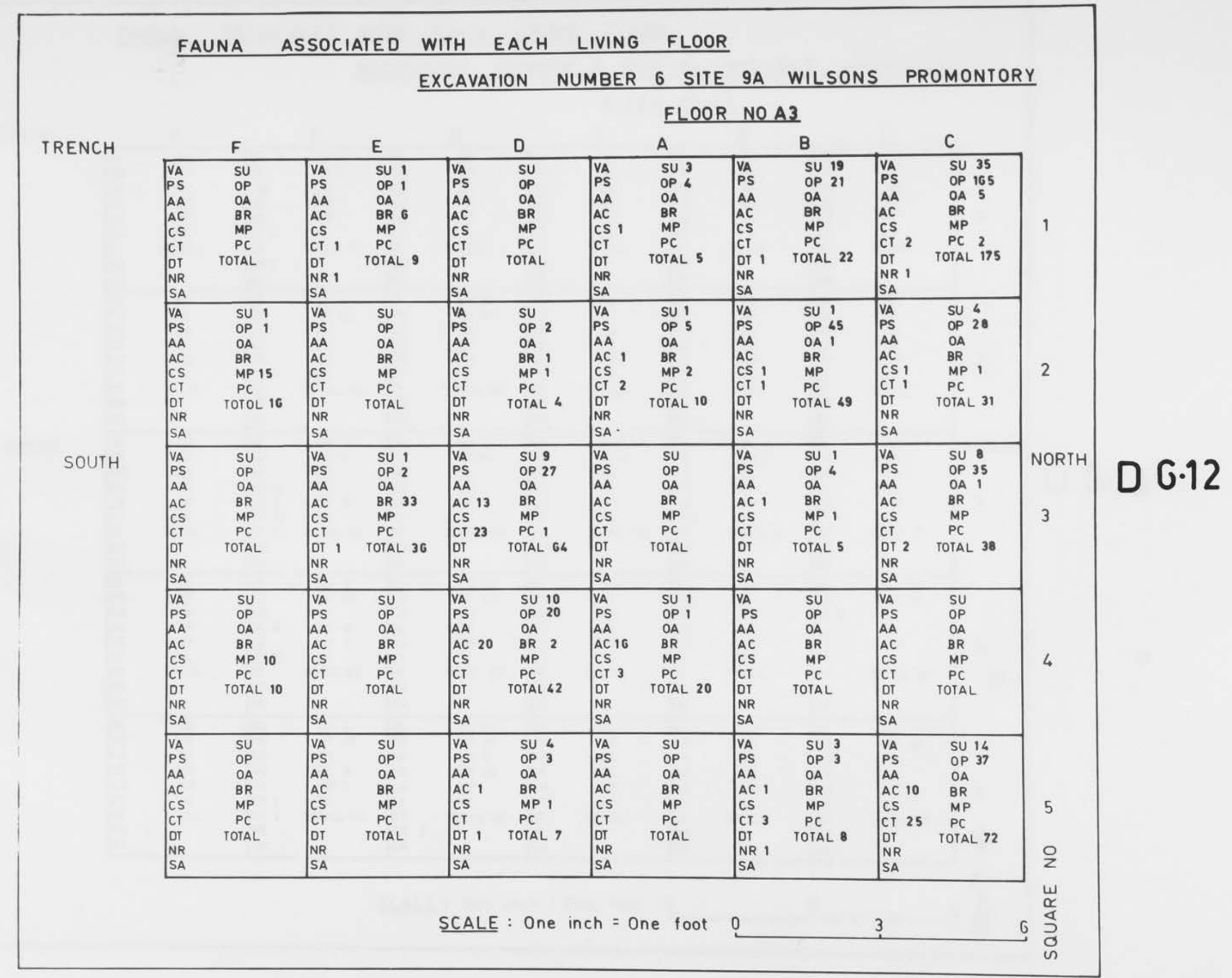




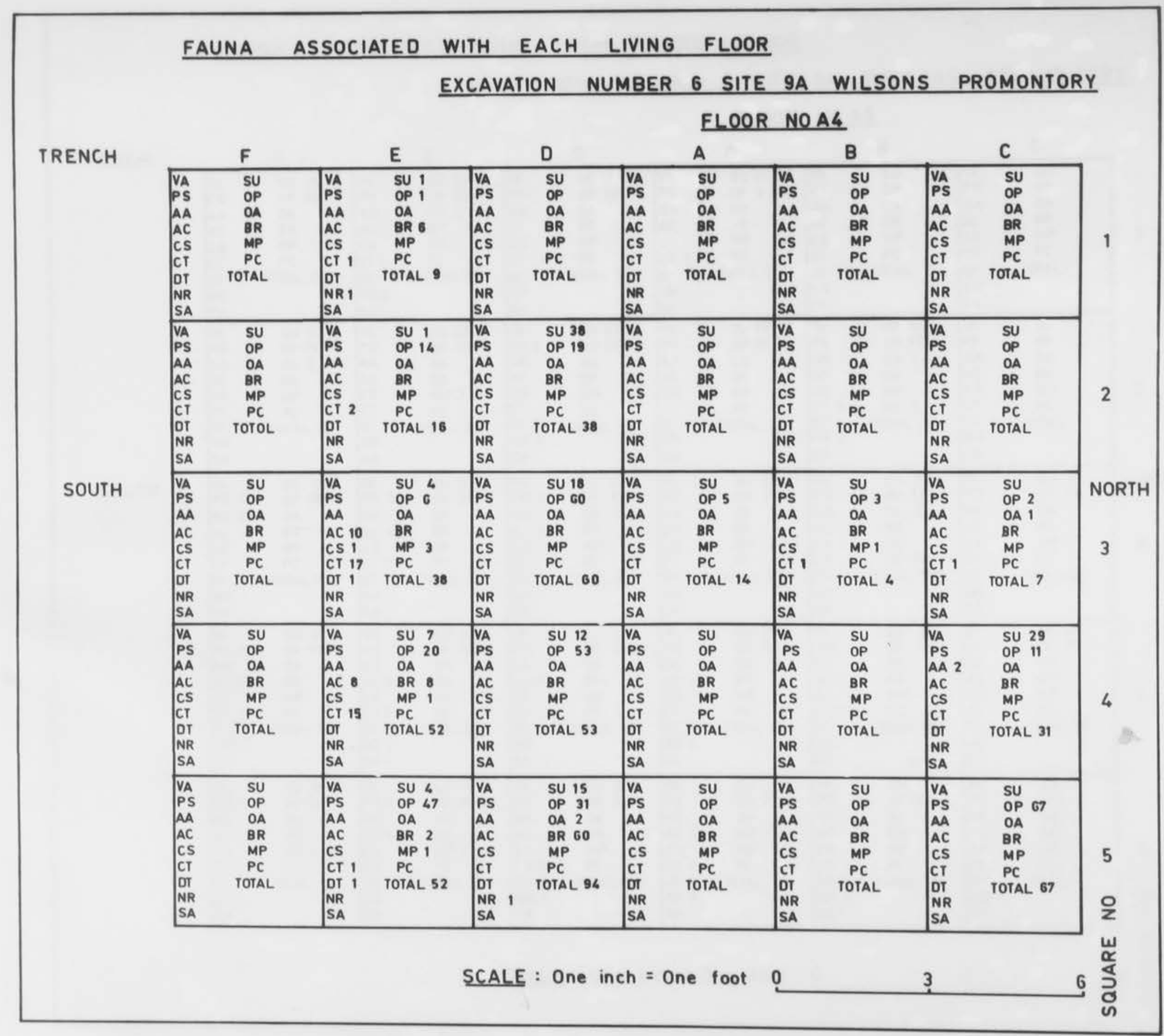

D 0.13 


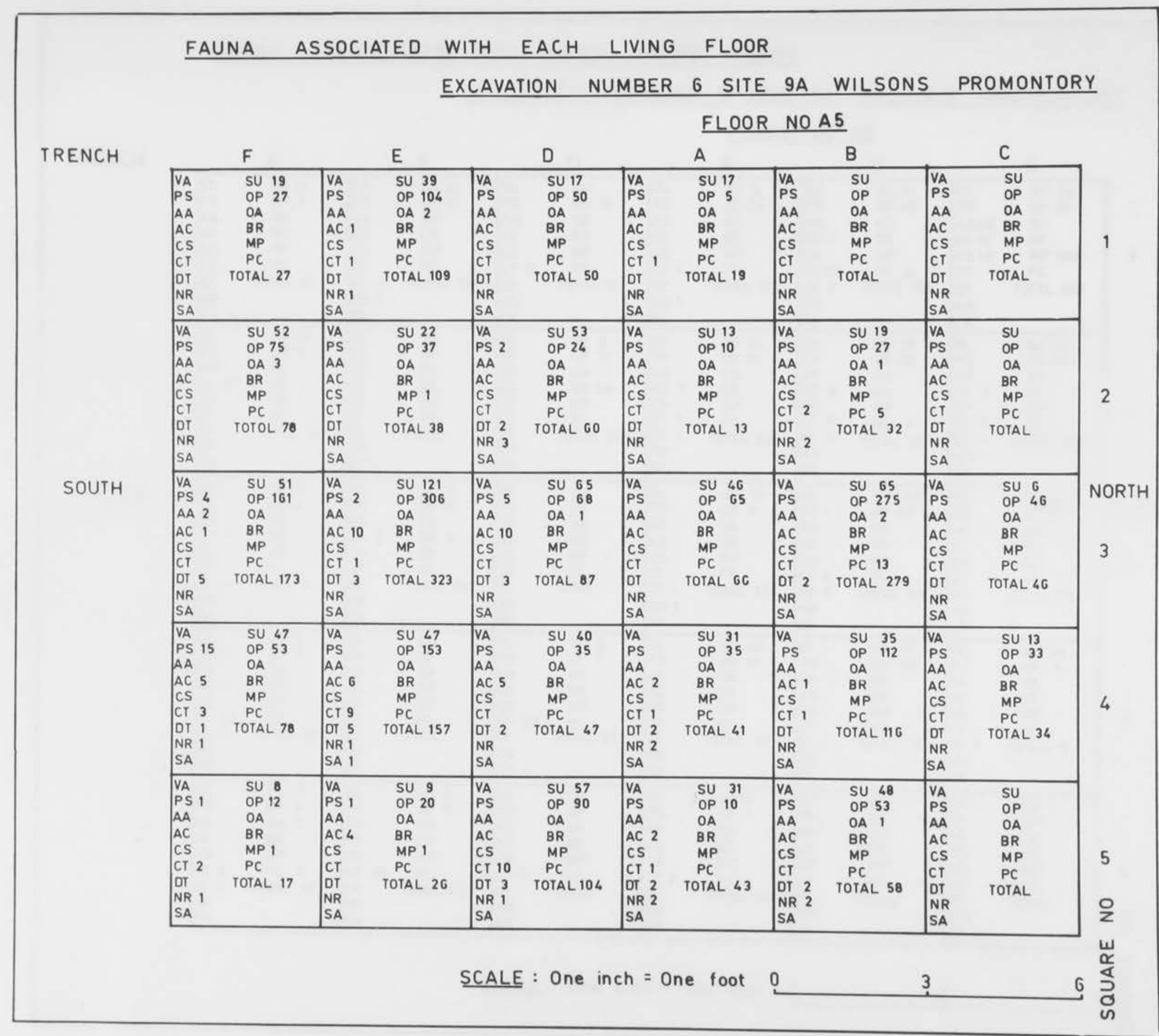

\section{0.14}




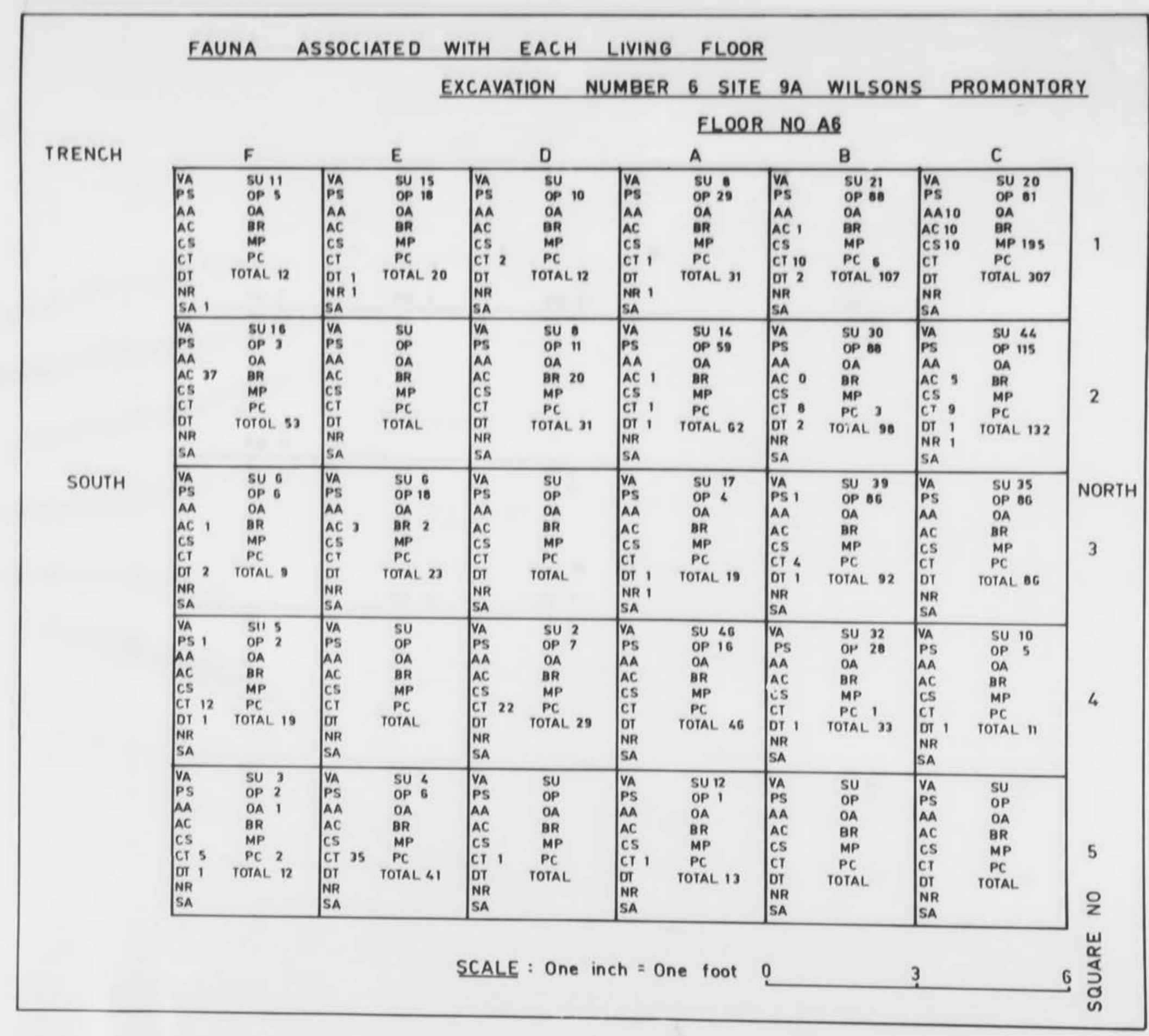

D 6.15 


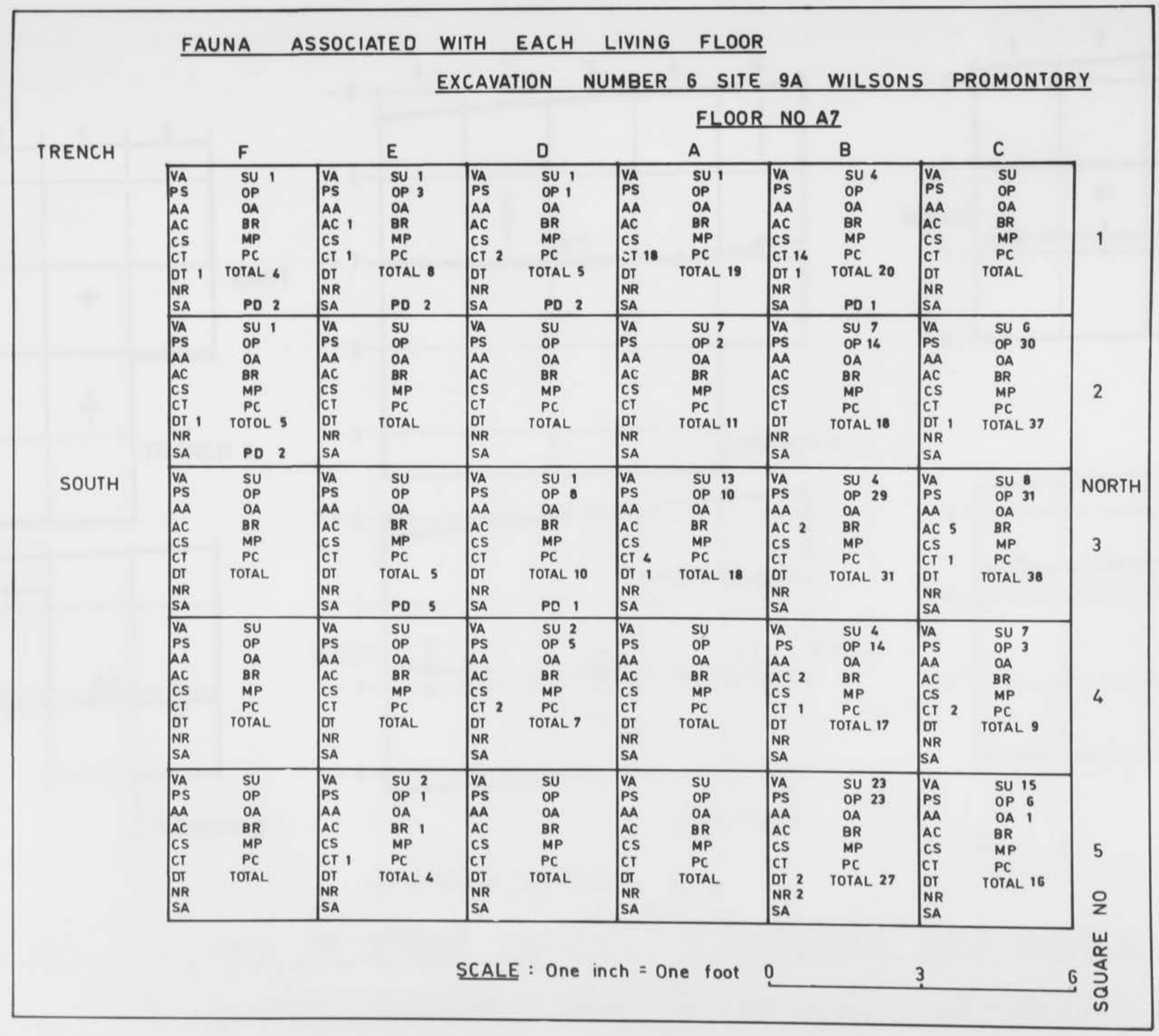

D 0.10 

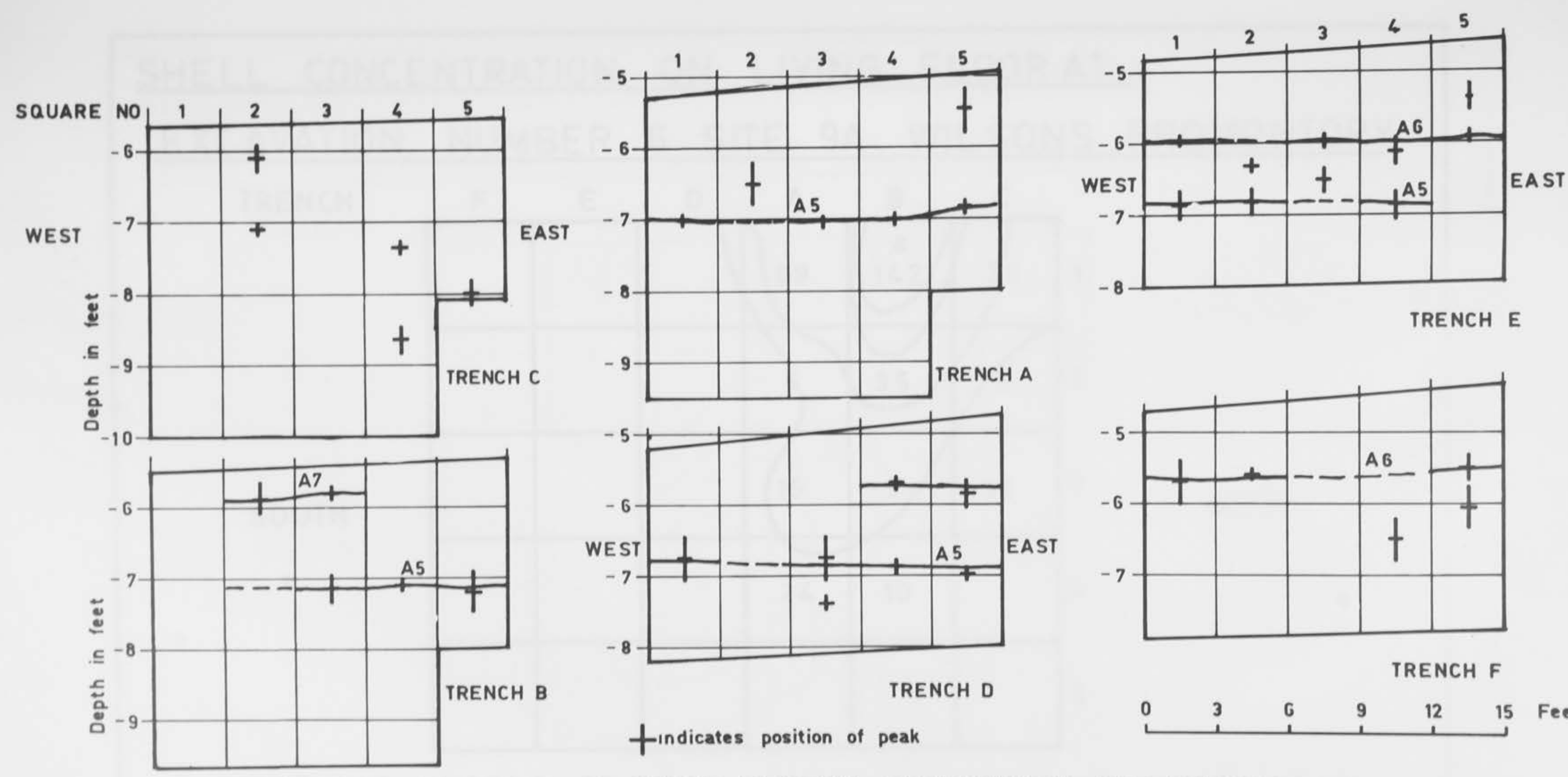

TRENCH D

TRENCH F

tindicates position of peak

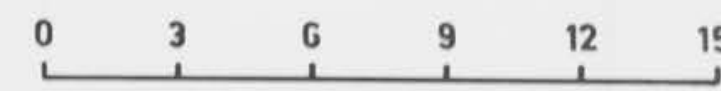

5 Feet

LOCATION OF PEAKS OF STONE DENSITY DISTRIBUTION PER TRENCH

EXCAVATION NUMBER 6 SITE 9A WILSONS PROMONTORY VICTORIA 


\section{SHELL CONCENTRATION ON LIVING FLOORA1}

EXCAVATION NUMBER G SITE 9A WILSONS PROMONTORY

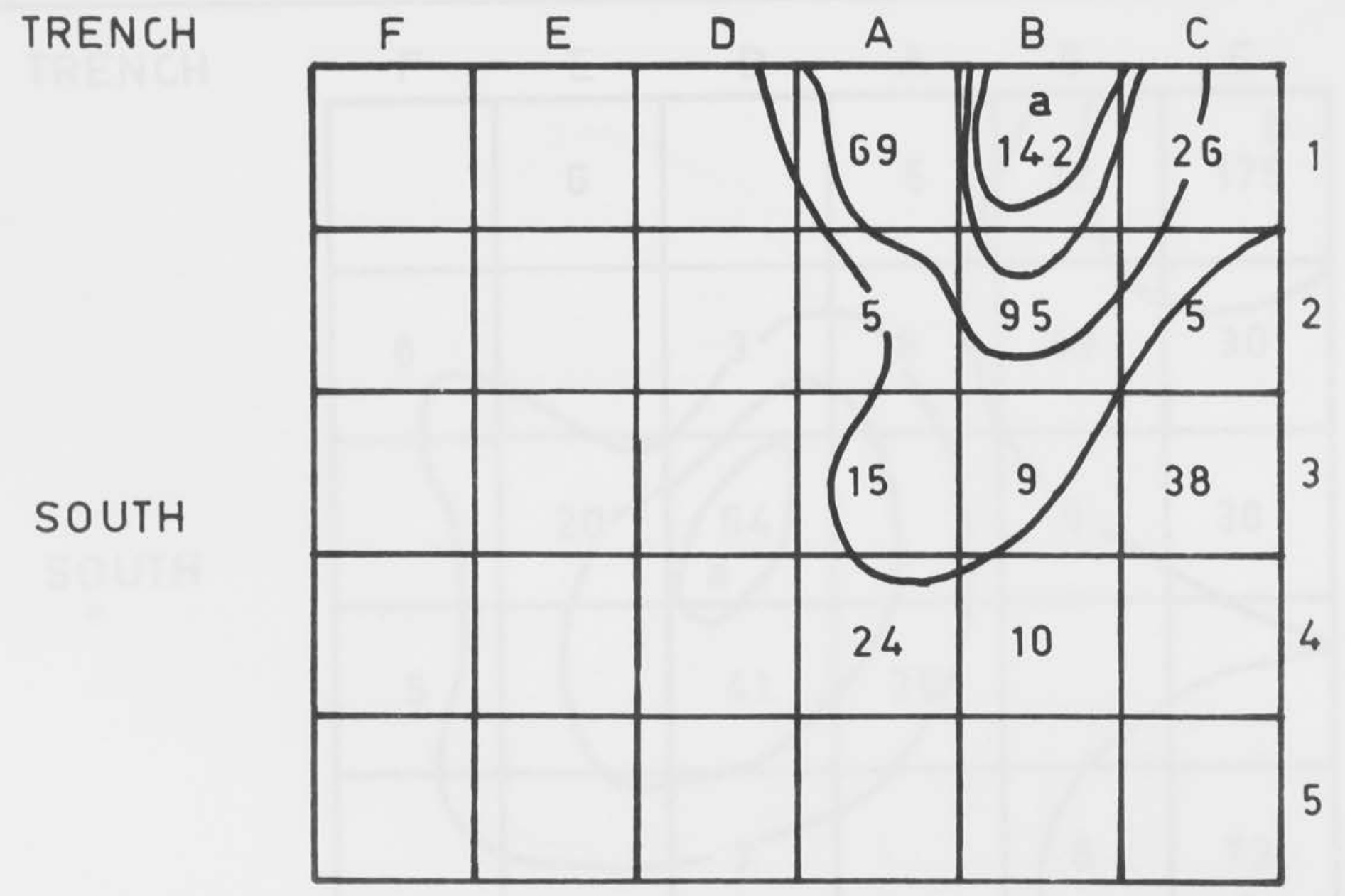

NORTH

DIA GRAM 0.18 


\section{SHELL CONCENTRATION ON LIVING FLOORA3}

EXCAVATION NUMBER G SITE 9A WILSONS PROMONTORY

TRENCH

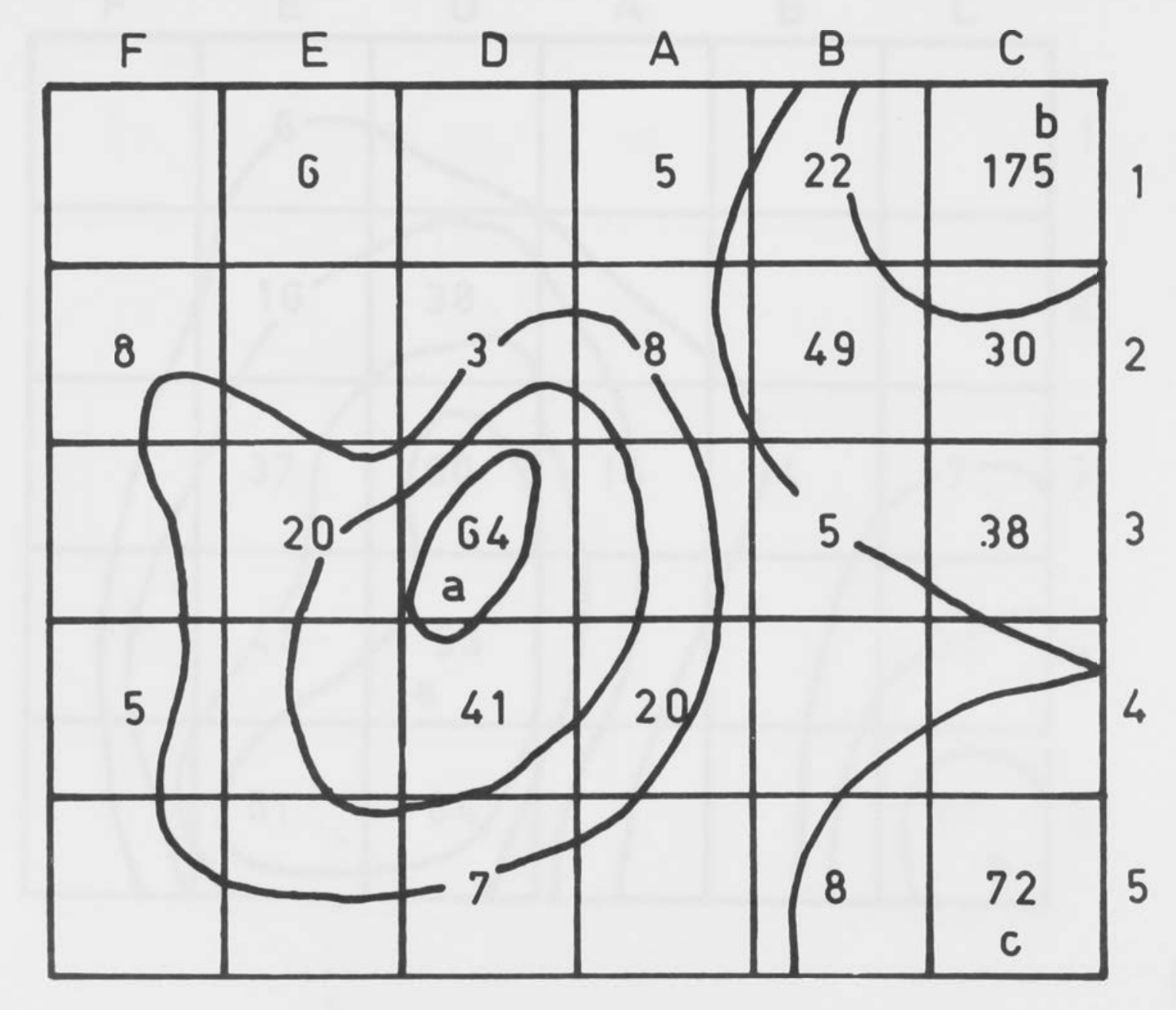

NORTH

SOUTH

DIAGRAM G.19 


\section{SHELL CONCENTRATION ON LIVING FLOOR A4}

EXCAVATION NUMBER G SITE 9A WILSONS PROMONTORY
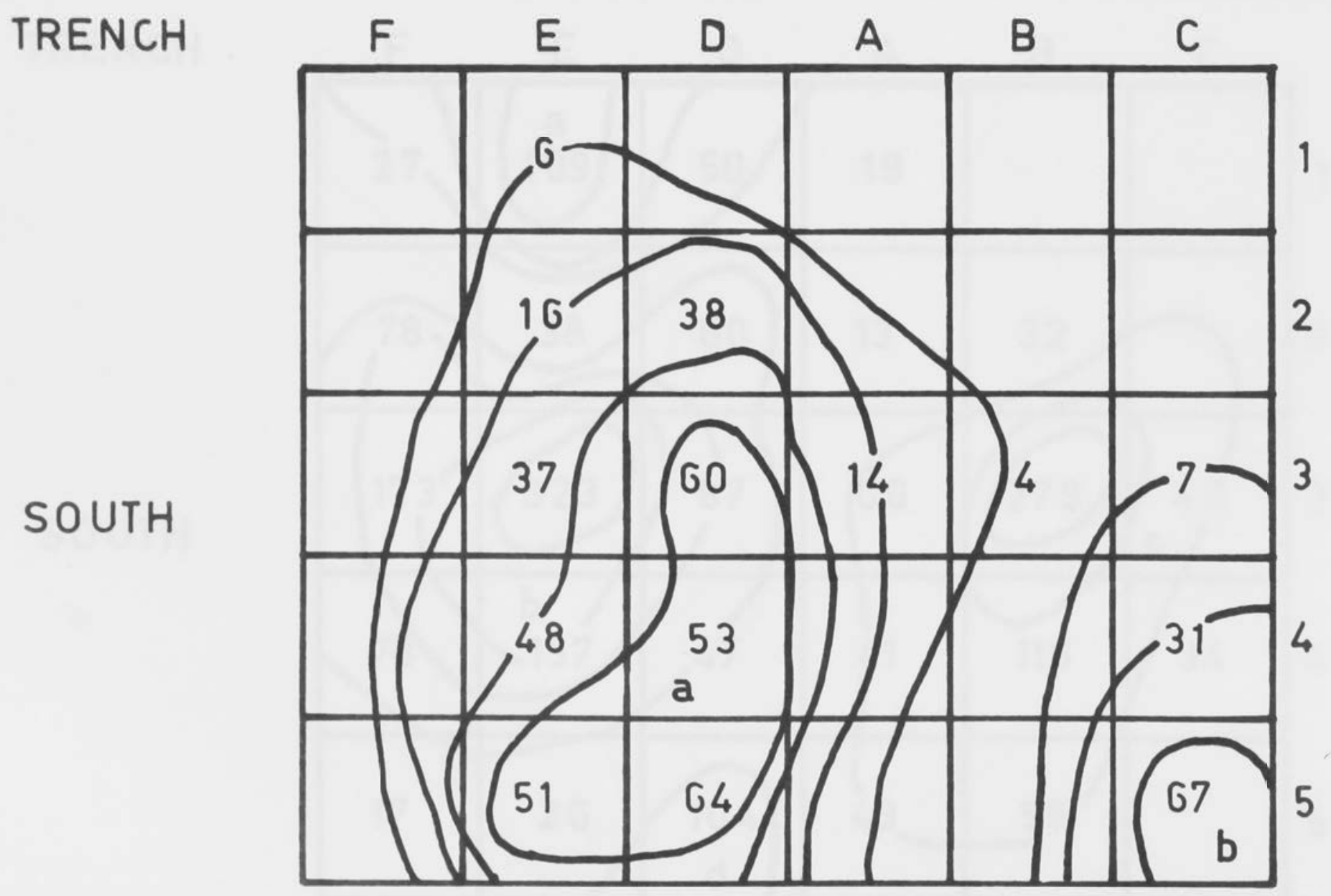

NORTH 
SHELL CONCENTRATION ON LIVING FLOOR A5

EXCAVATION NUMBER G SITE 9A WILSONS PROMONTORY

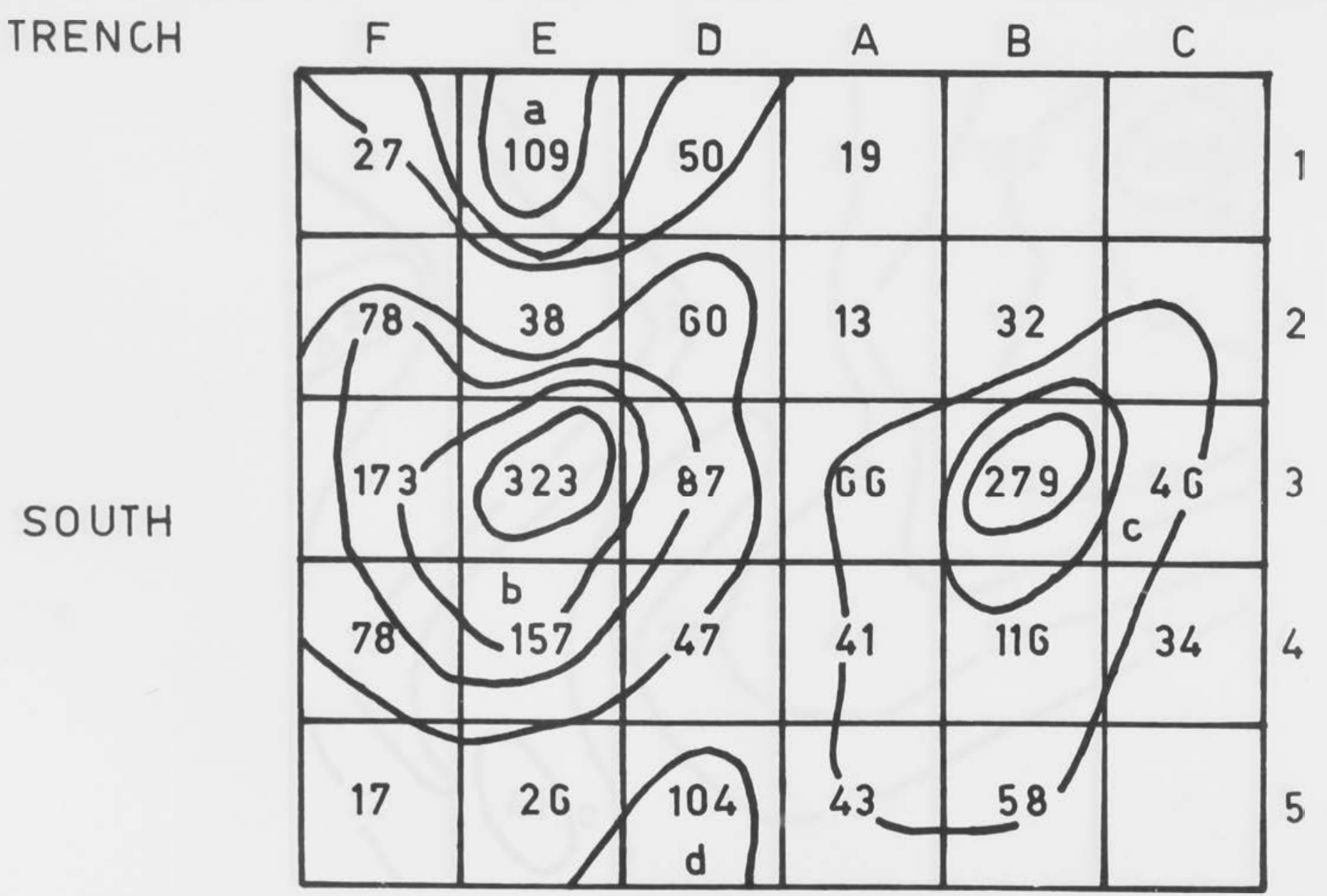

NORTH

DIA GRAM G.21 
SHELL CONCENTRATION ON LIVING FLOOR AG

EXCAVATION NUMBER G SITE 9A WILSONS PROMONTORY
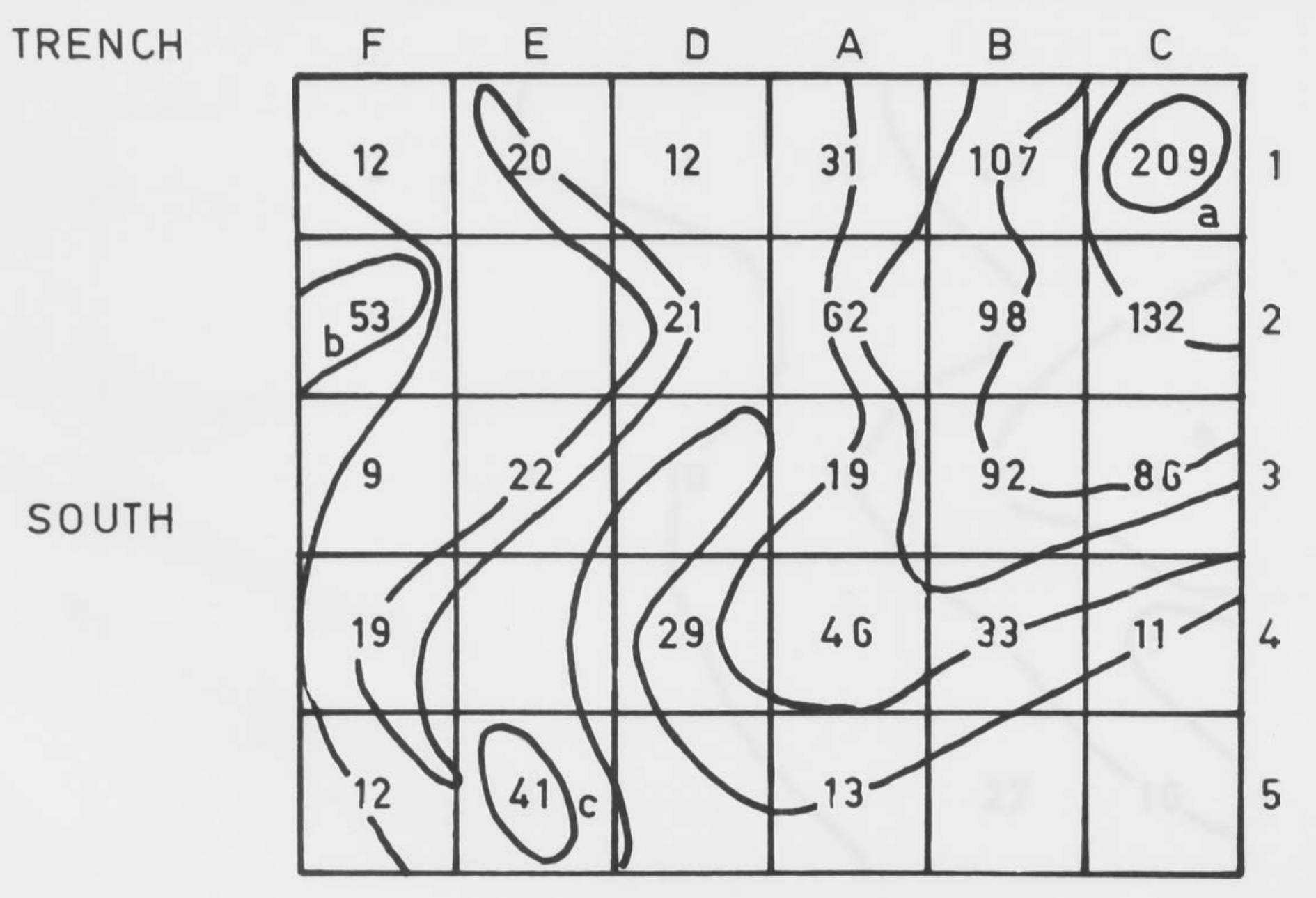

NORTH

SOUTH

DIA GRAM G.22 


\section{SHELL CONCENTRATION ON LIVING FLOOR A7}

EXCAVATION NUMBER G SITE 9A WILSONS PROMONTORY
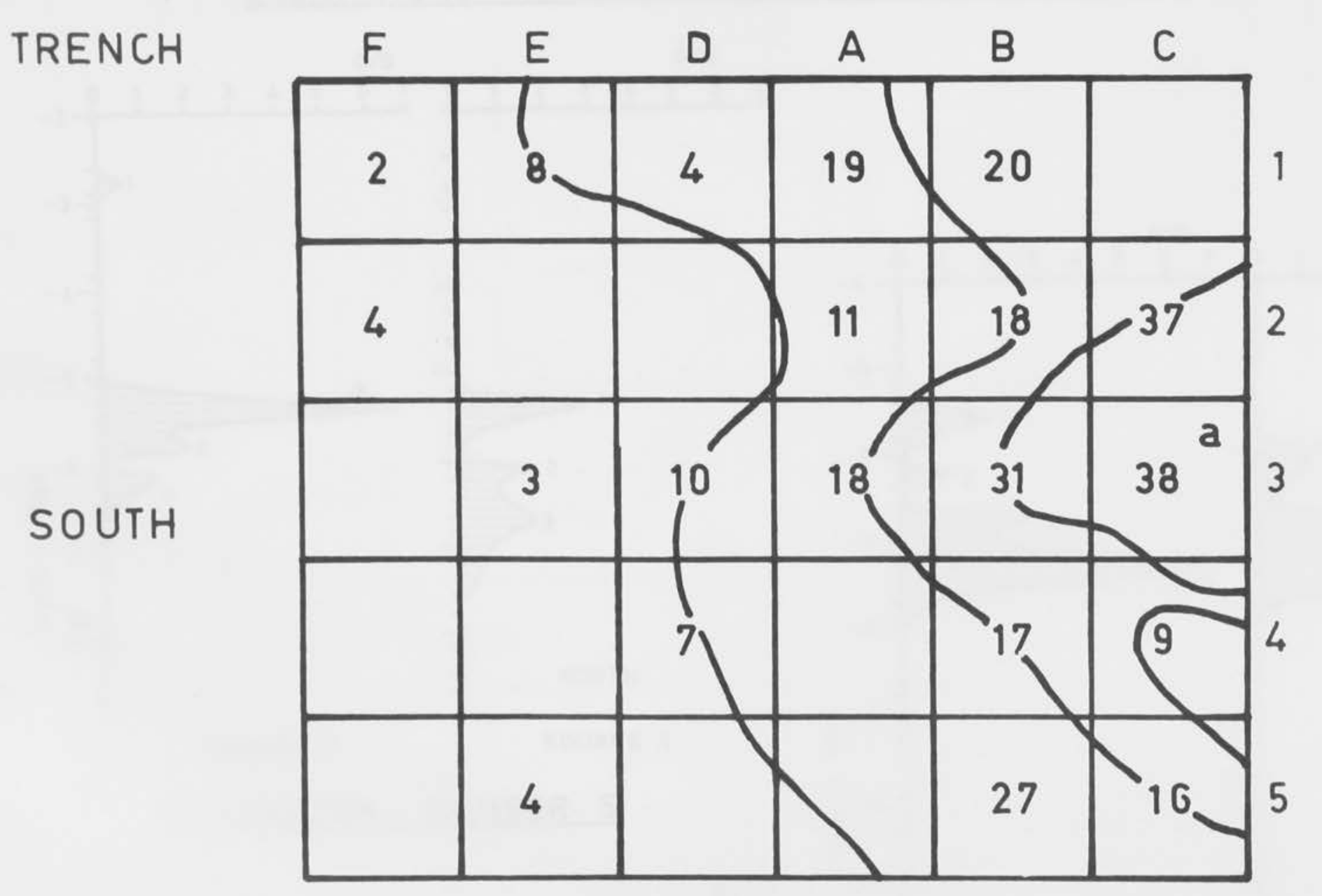

NORTH

SOUTH

DIA GRAM 0.23 


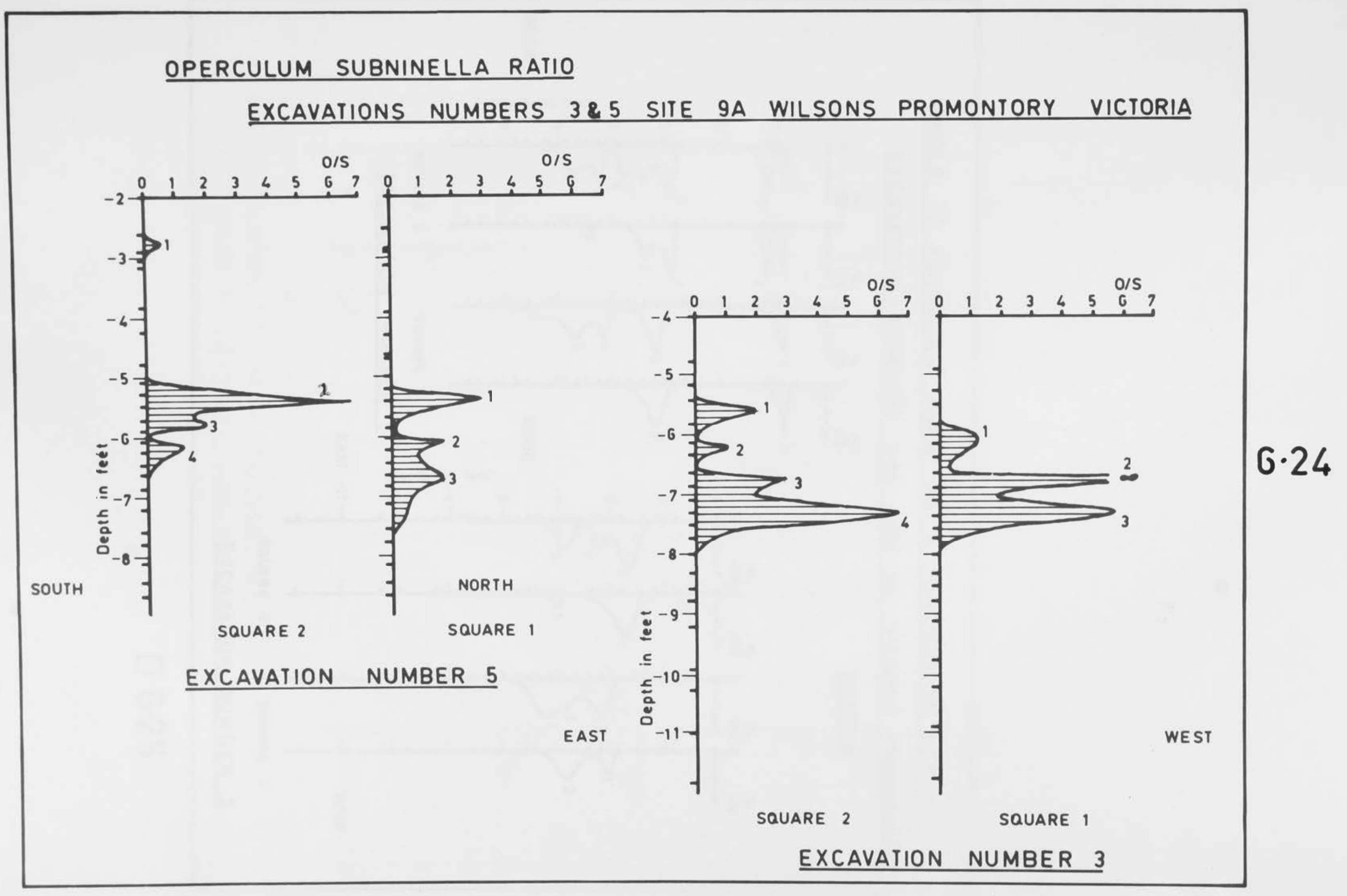




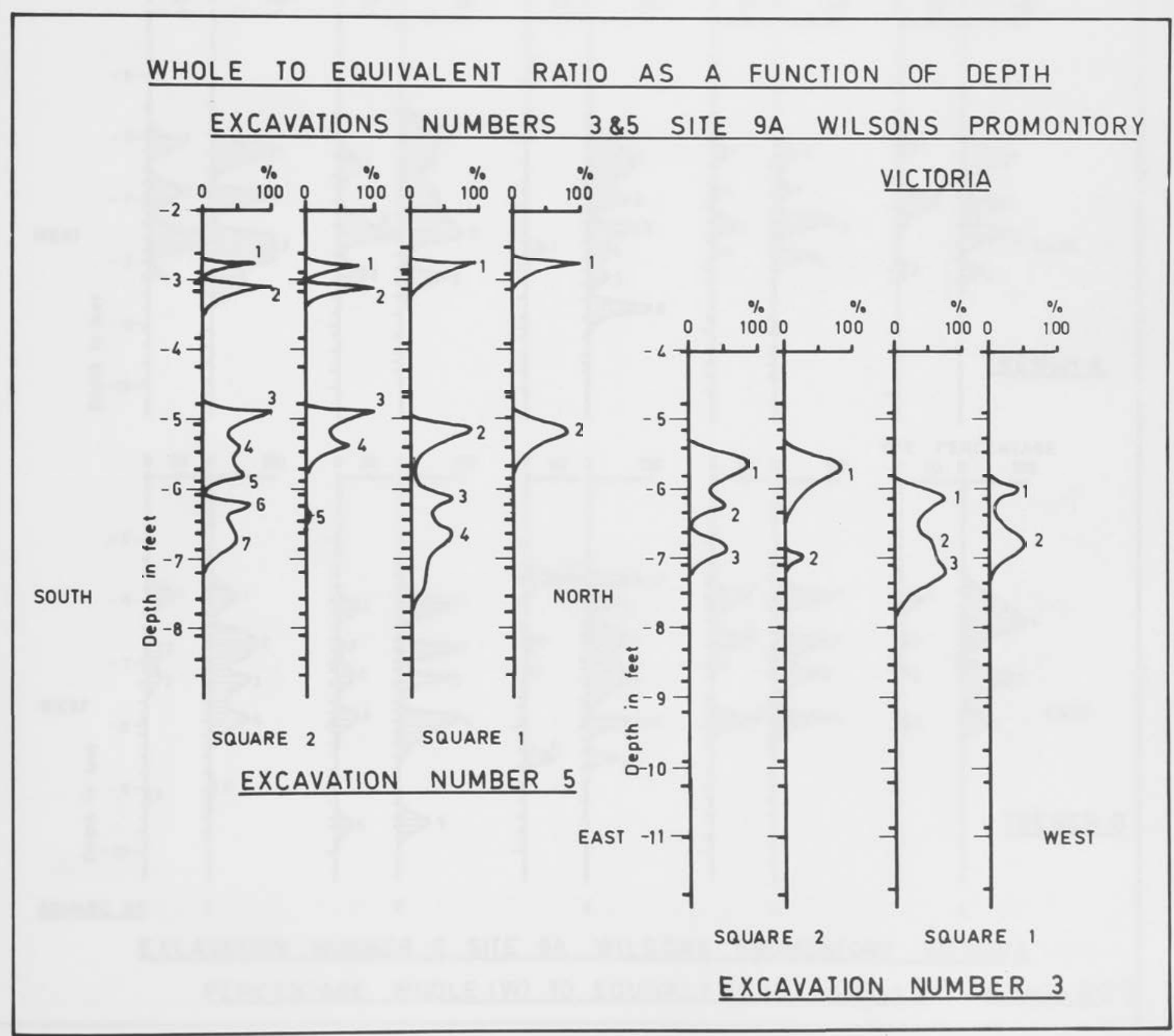

\section{6.25}




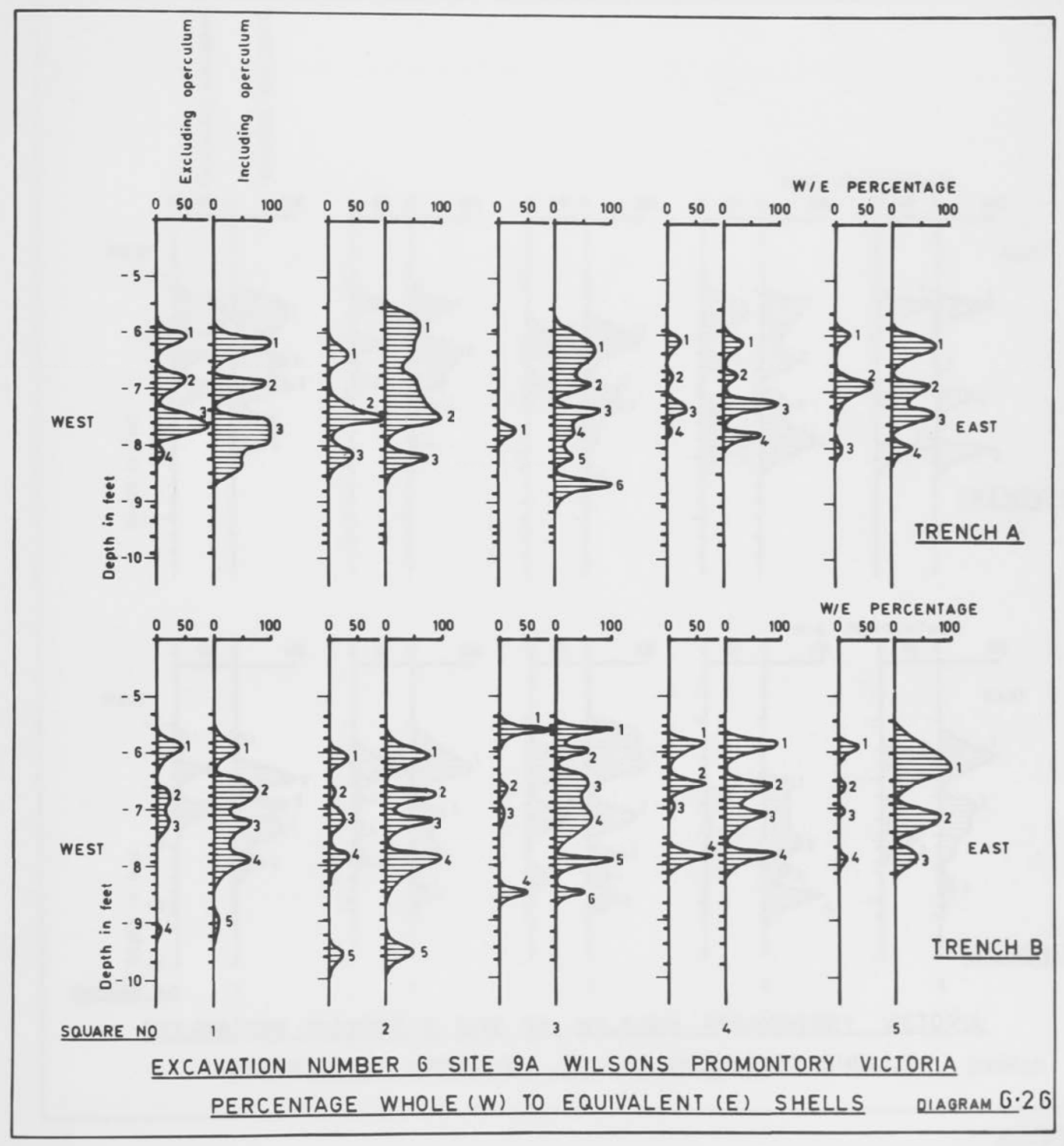




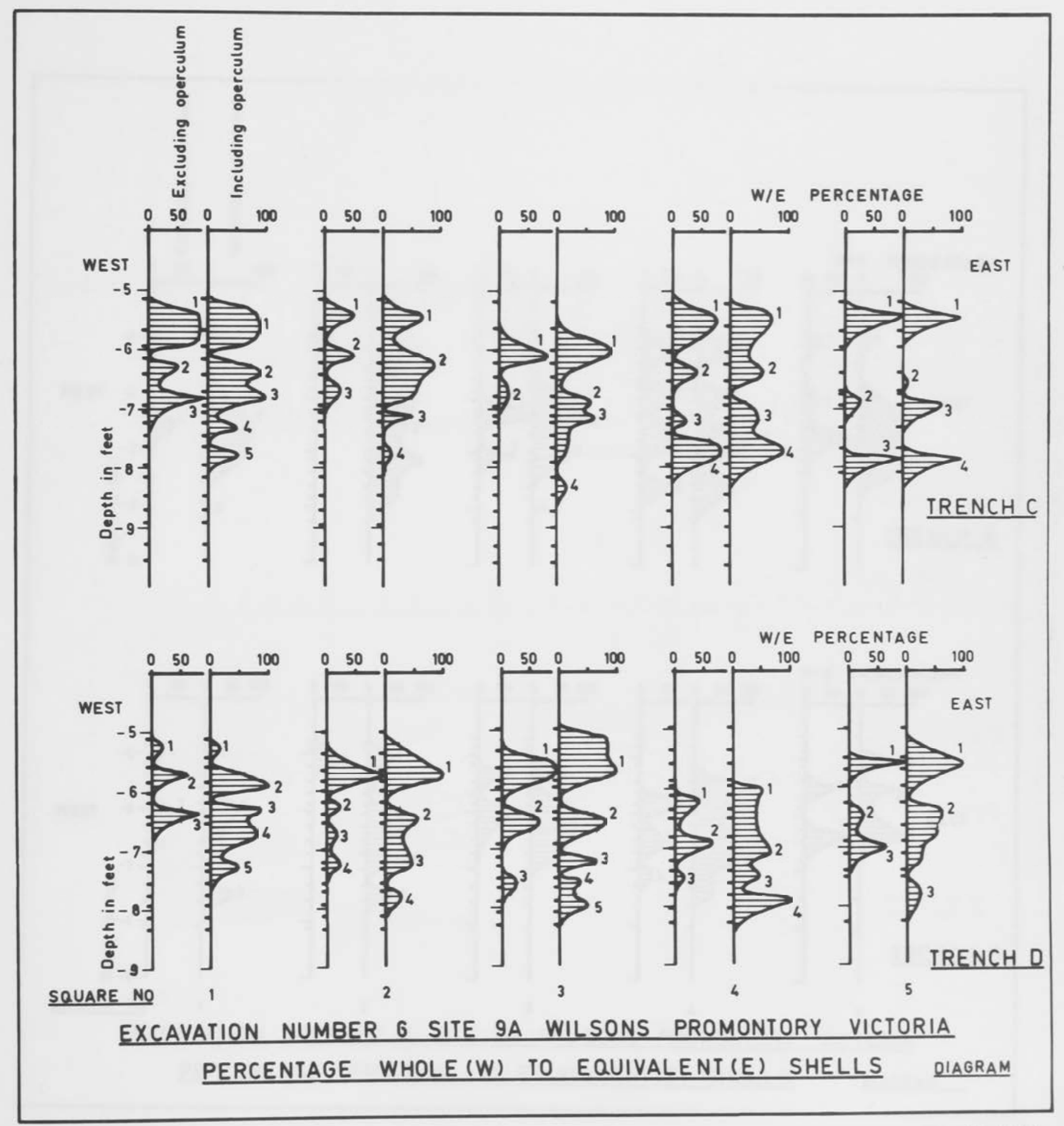




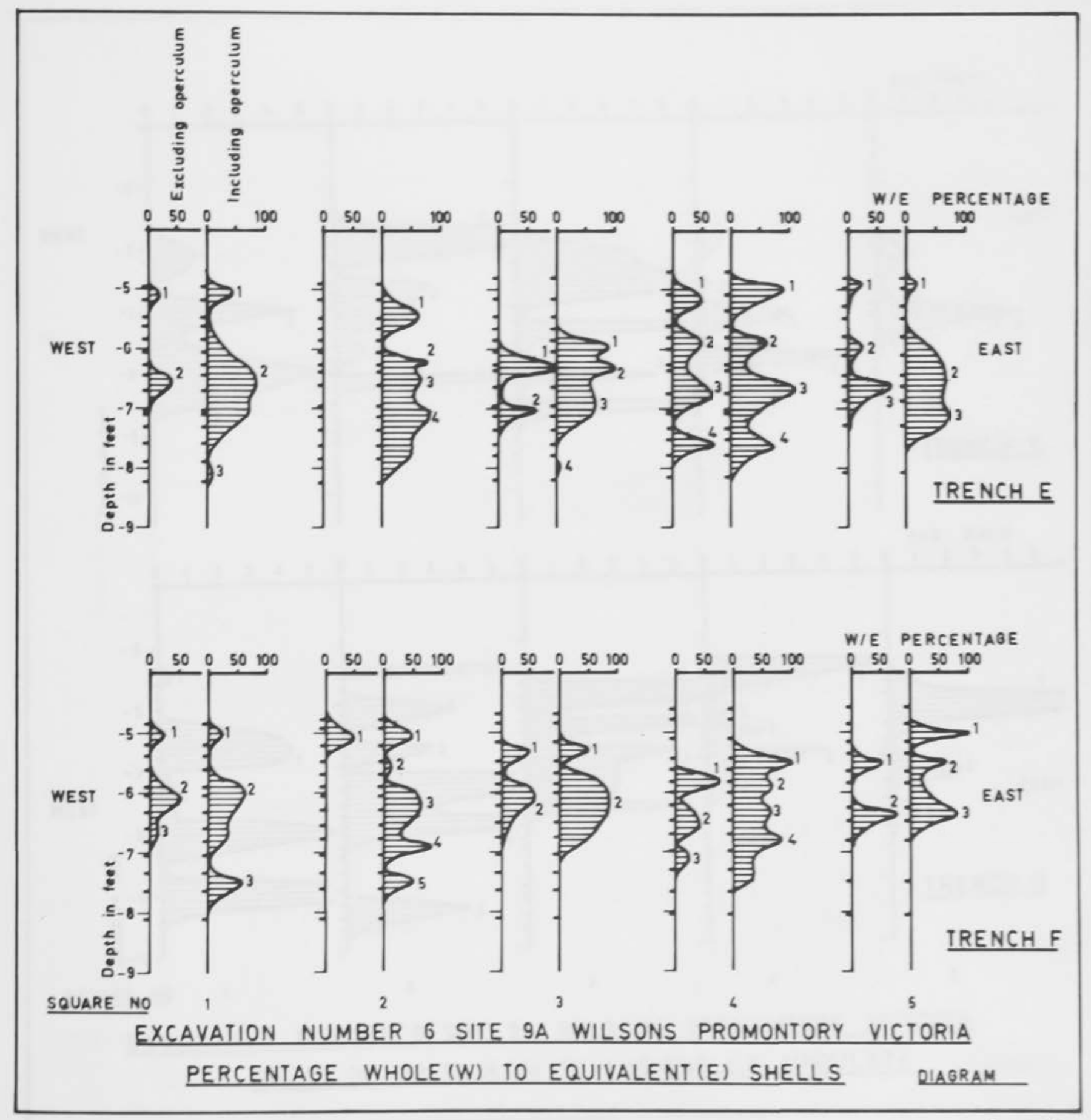




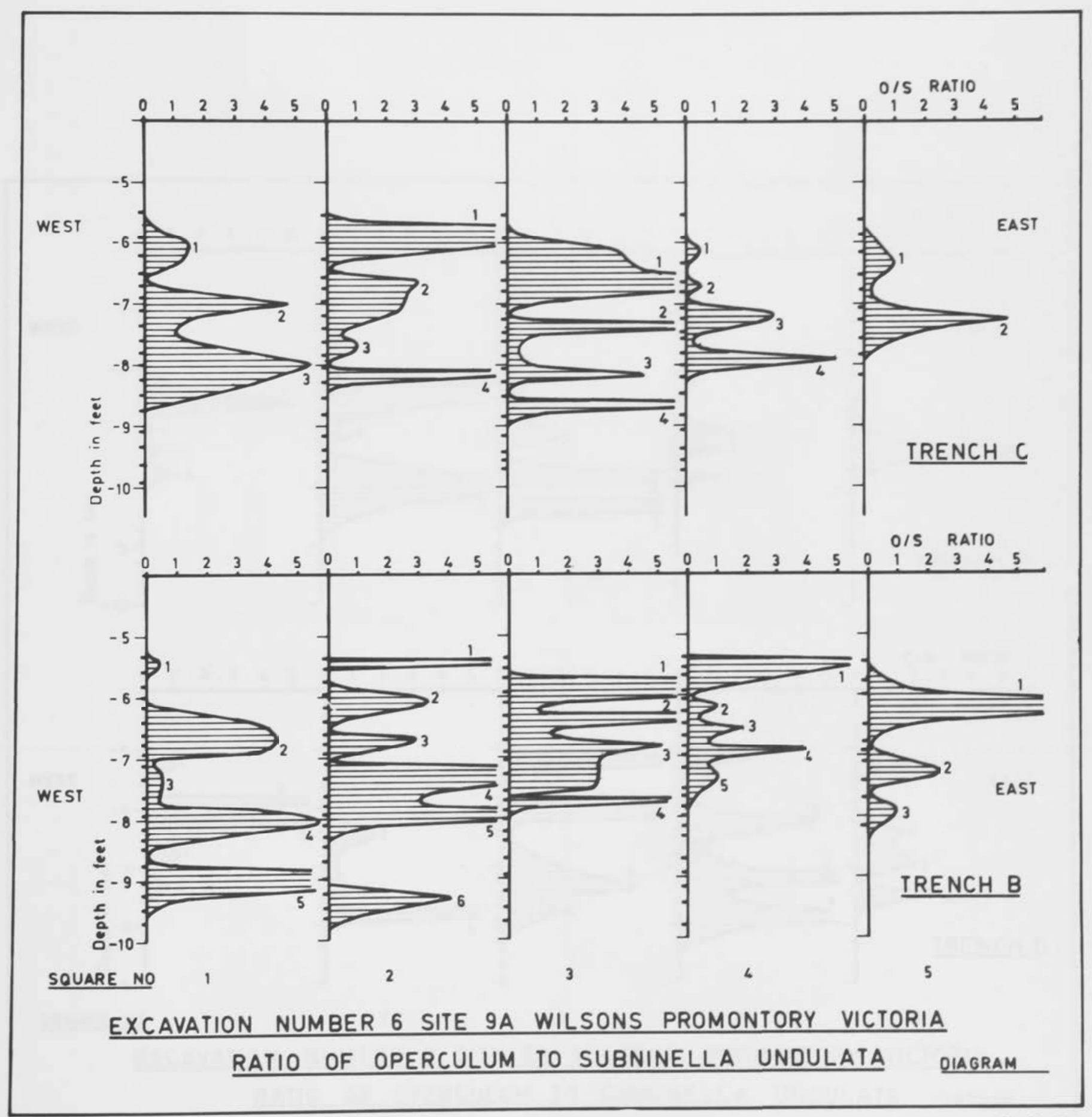

6.29 


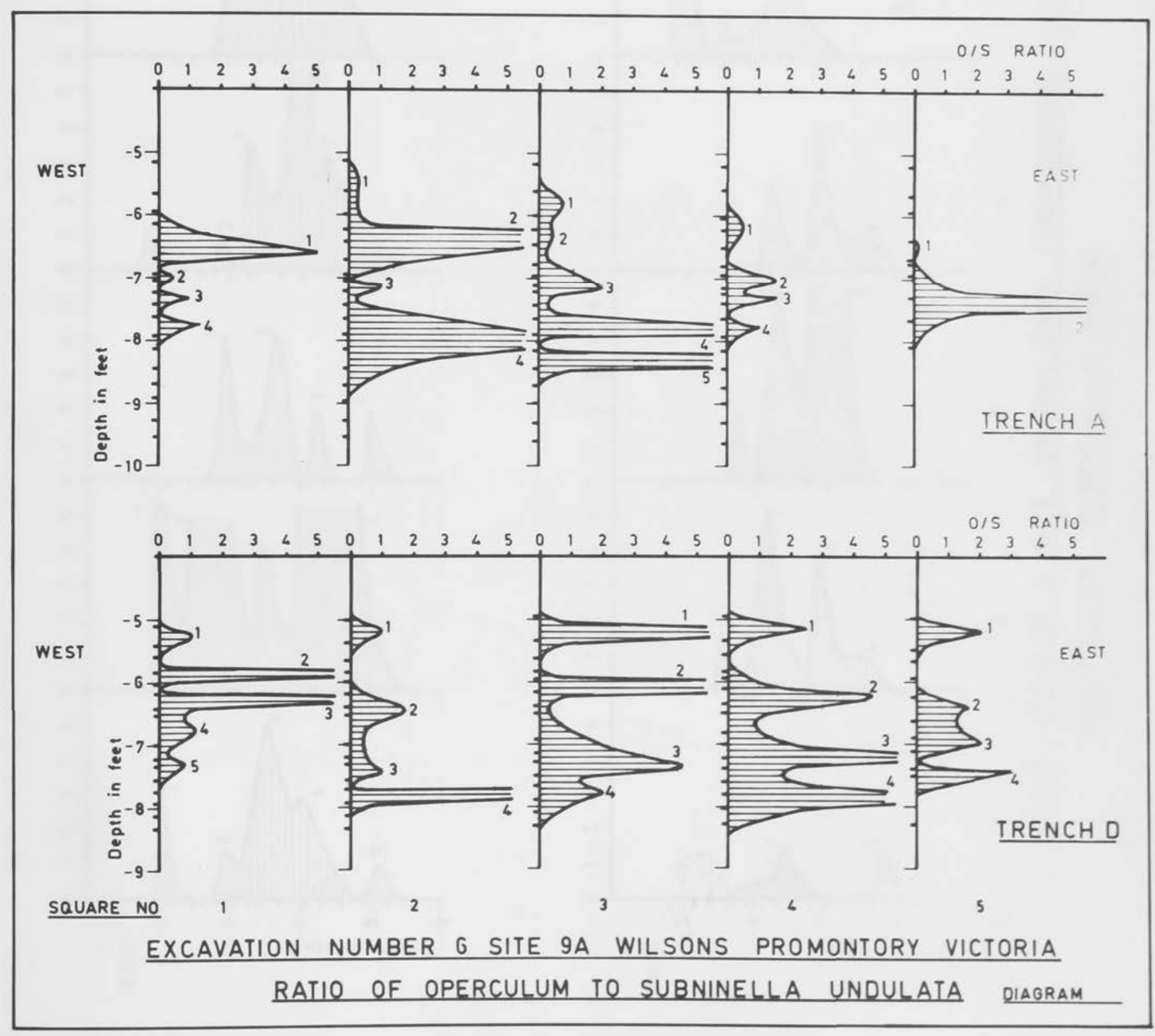




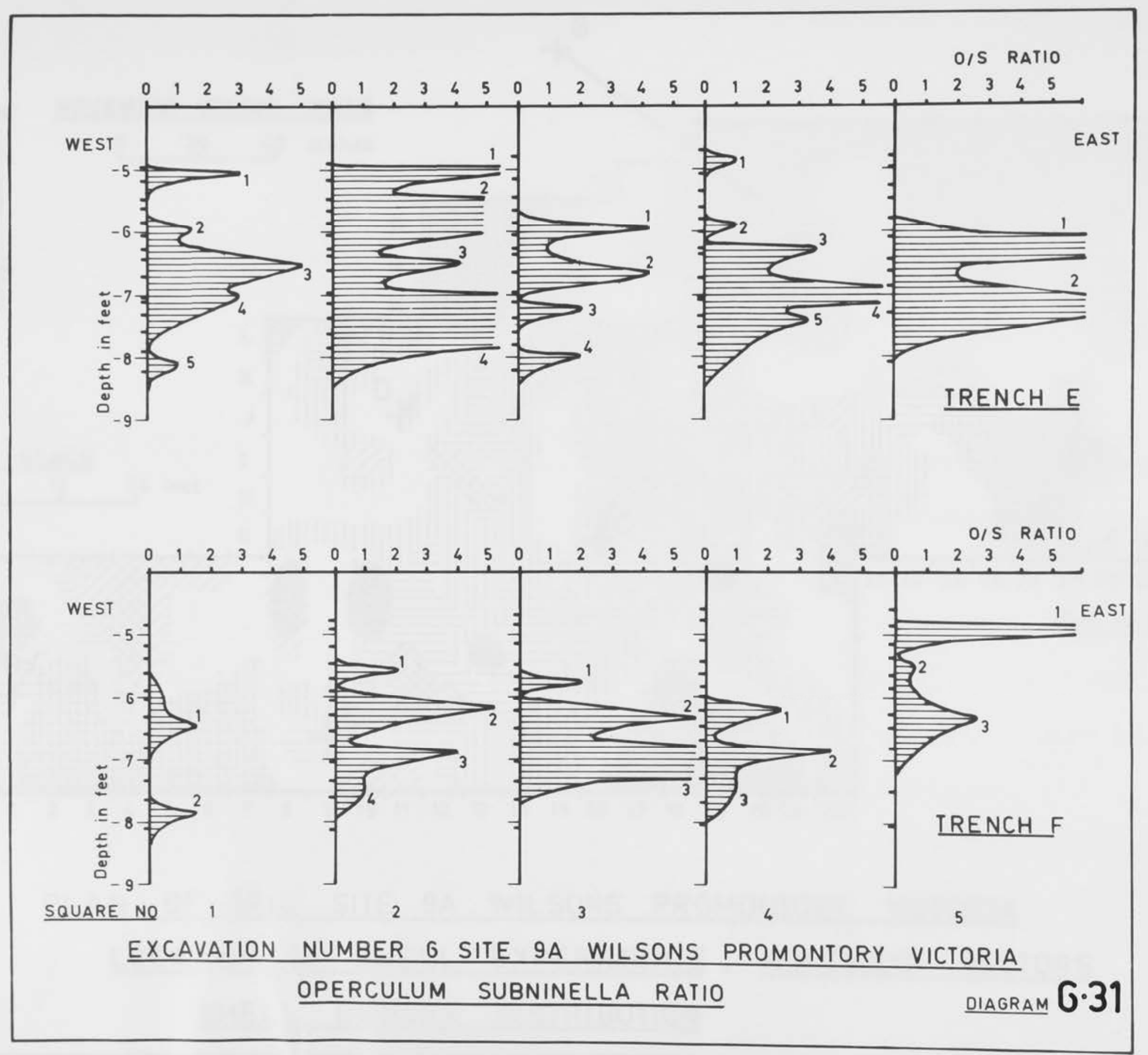




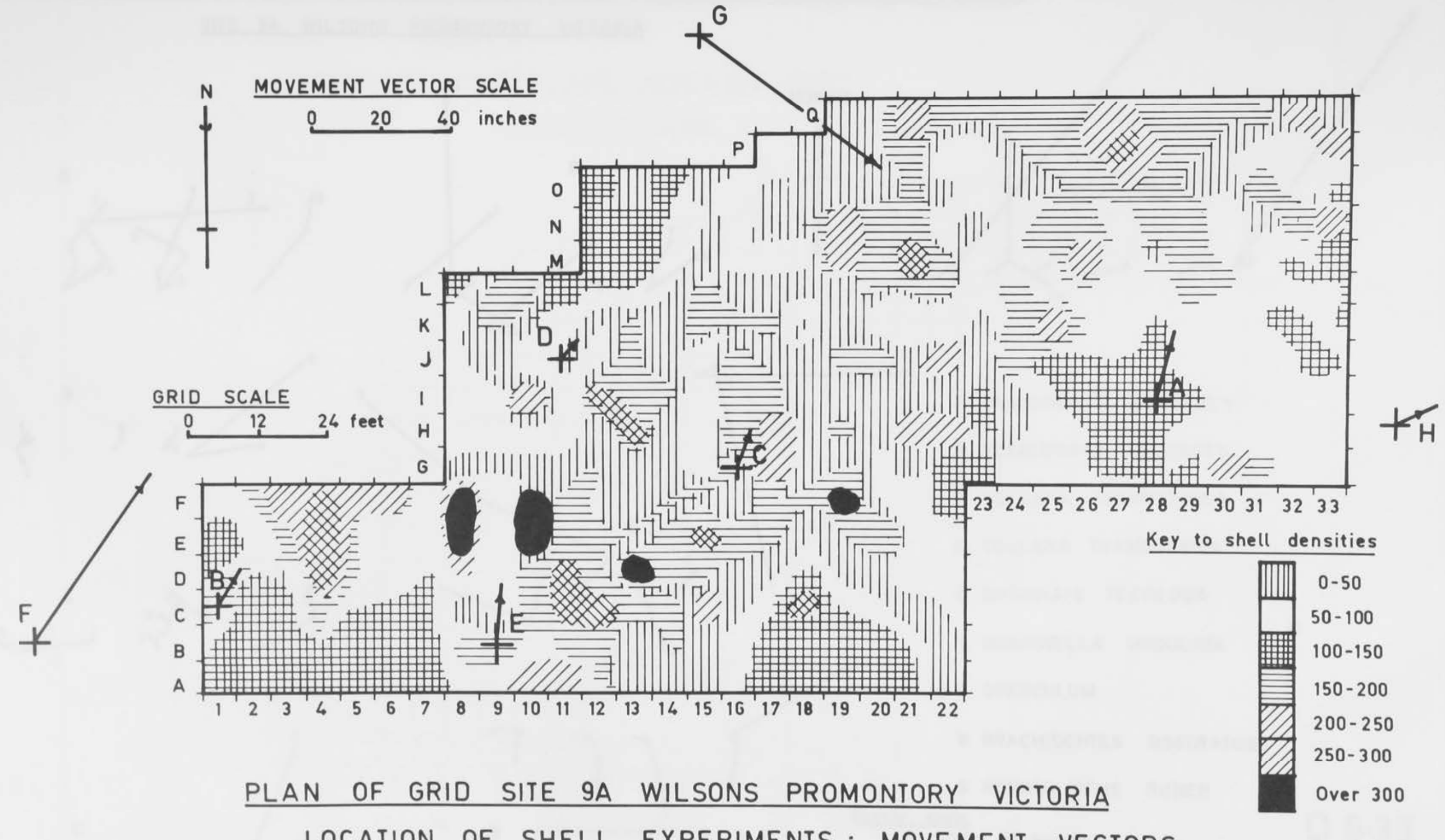

LOCATION OF SHELL EXPERIMENTS ; MOVEMENT VECTORS 


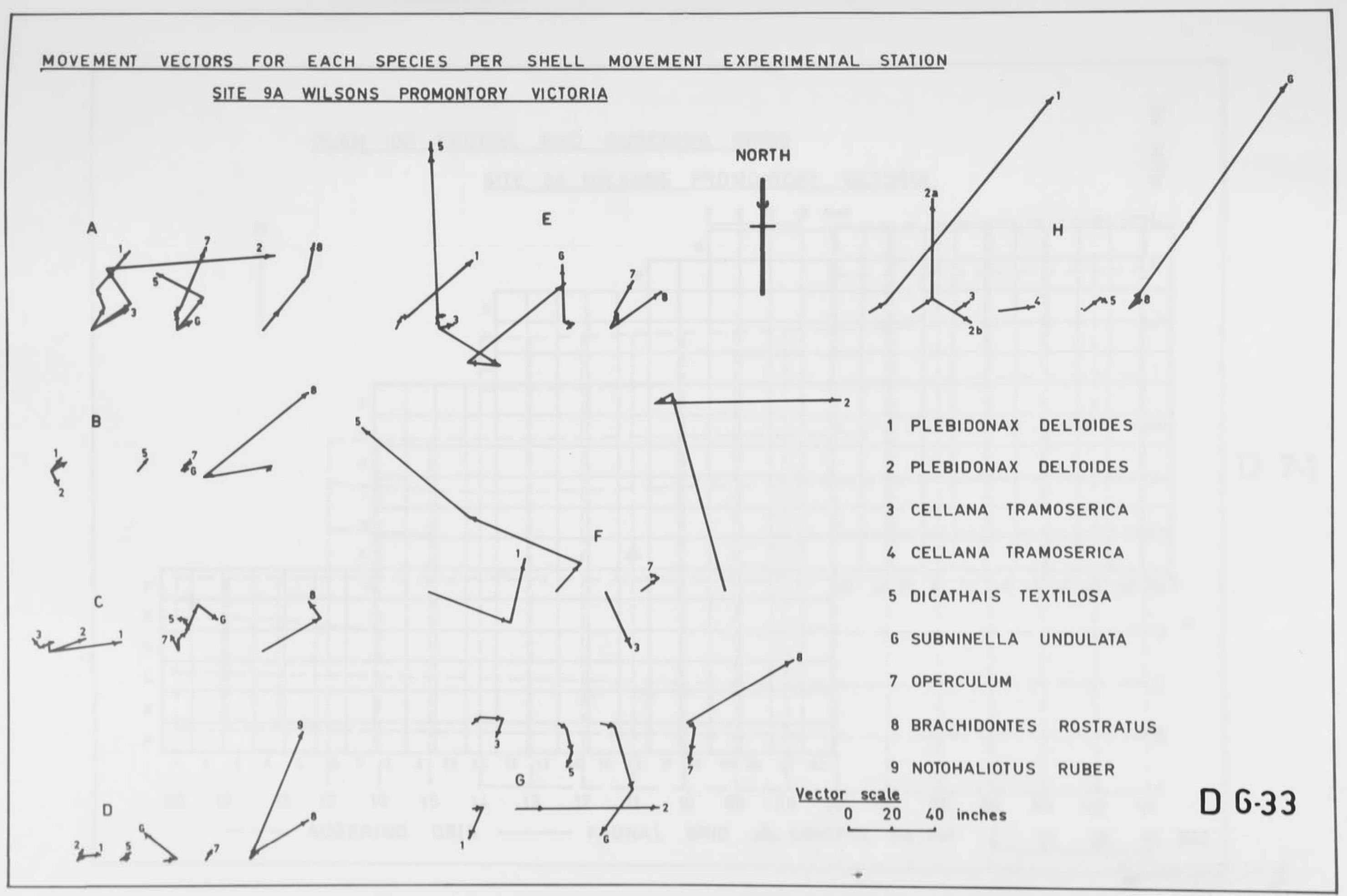


PLAN OF FAUNAL AND AUGERING GRIDS

SITE 9A WILSONS PROMONTORY VICTORIA

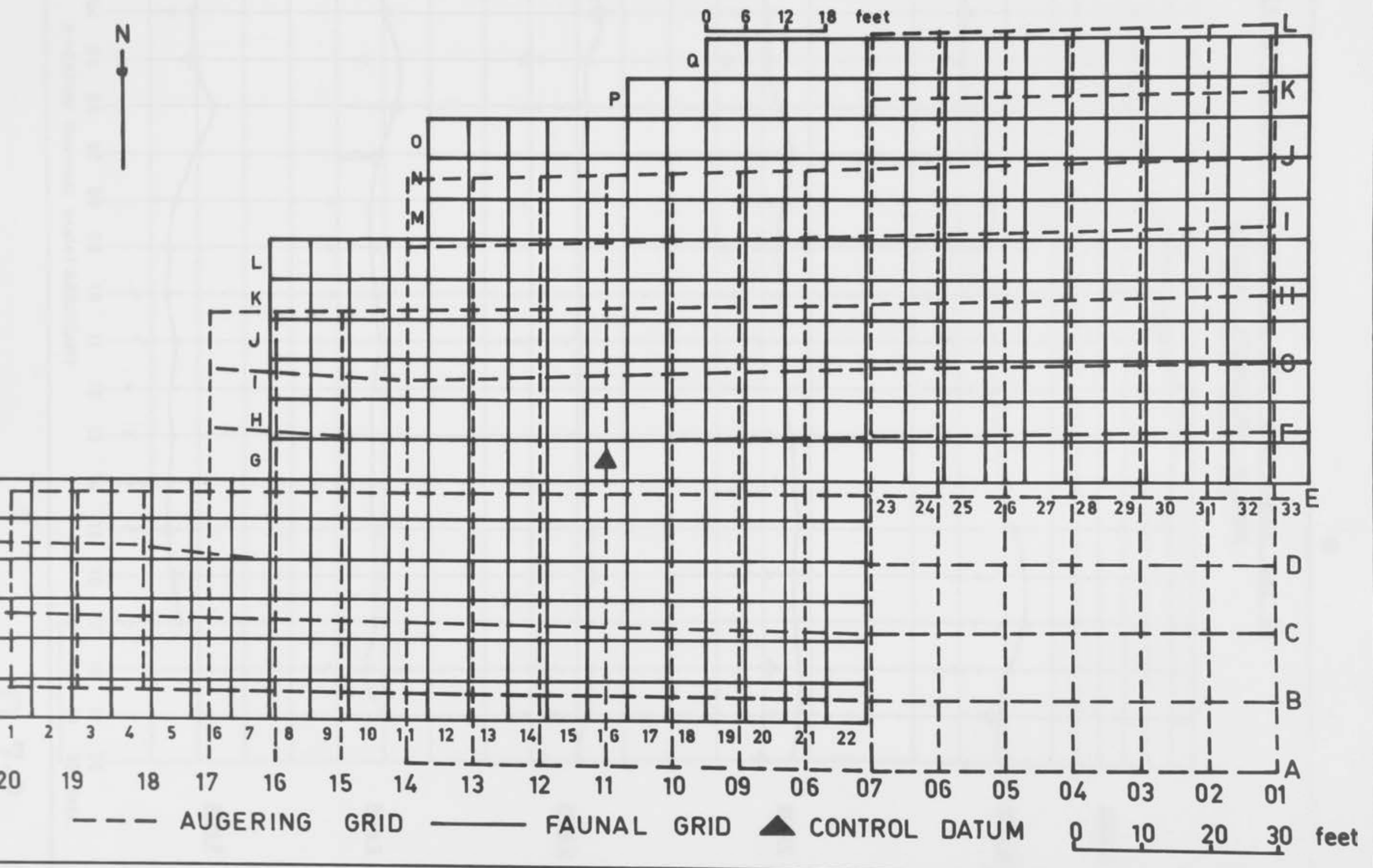

$F$

E

D

c

B

A 


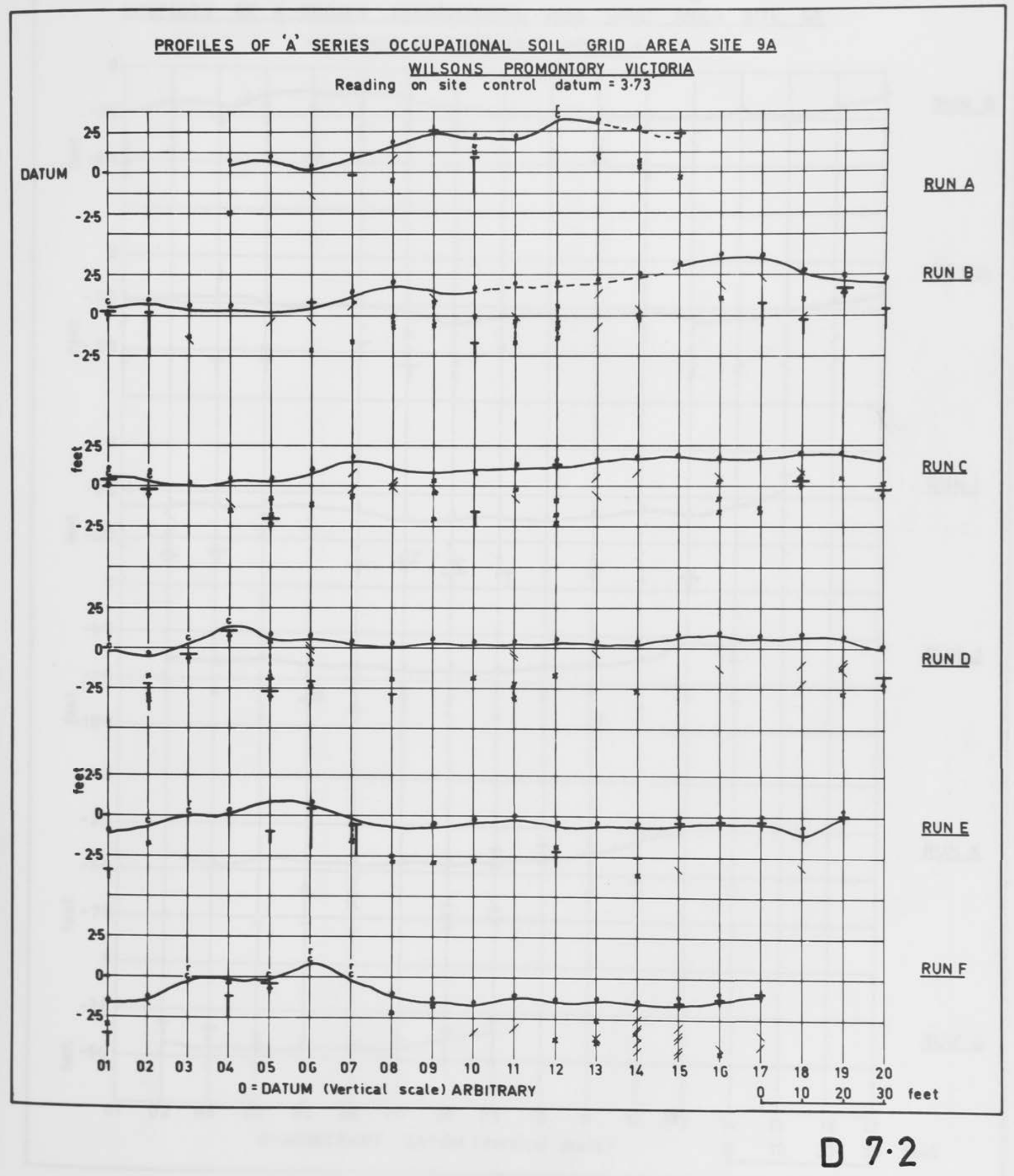




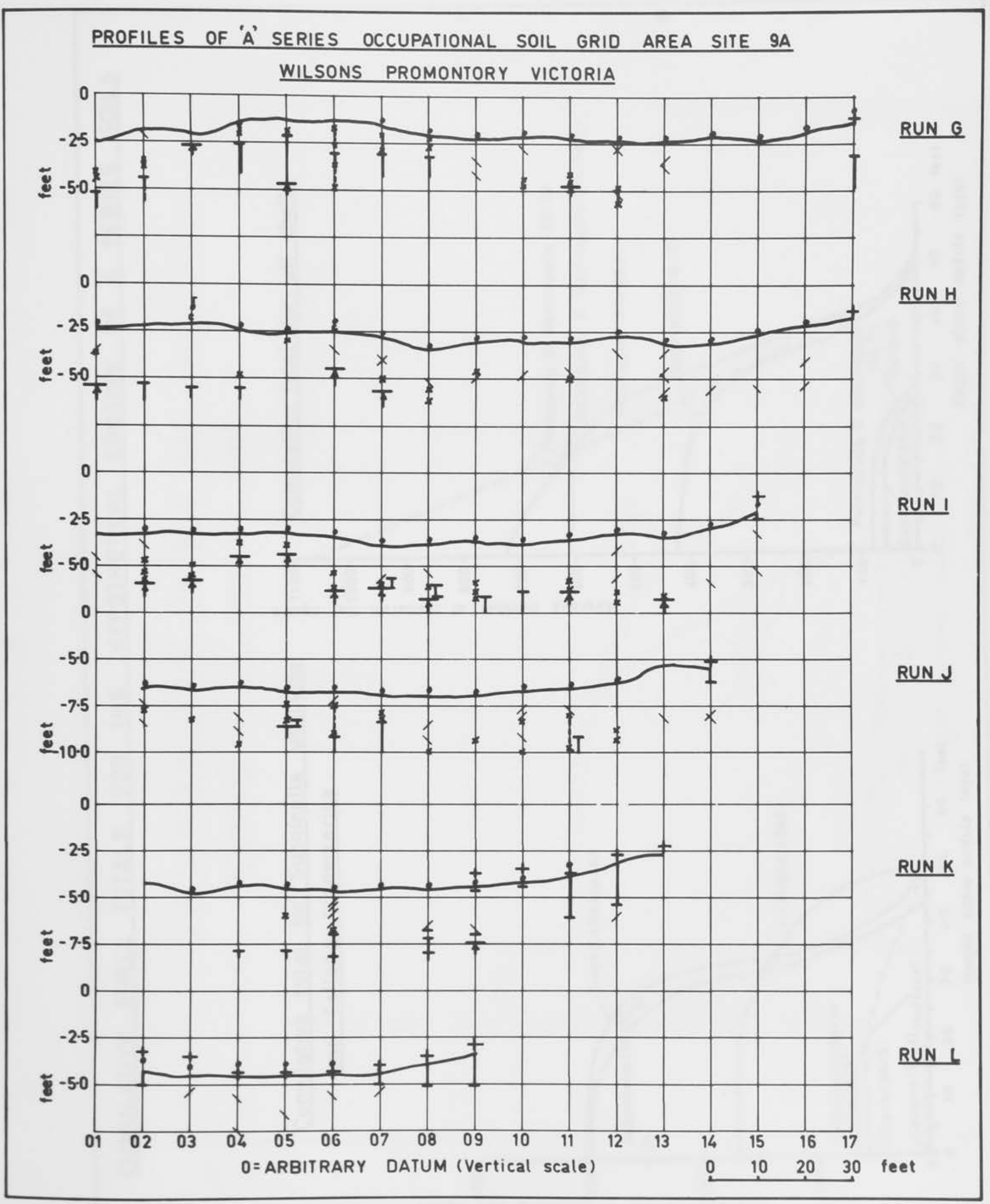

D 7.3 


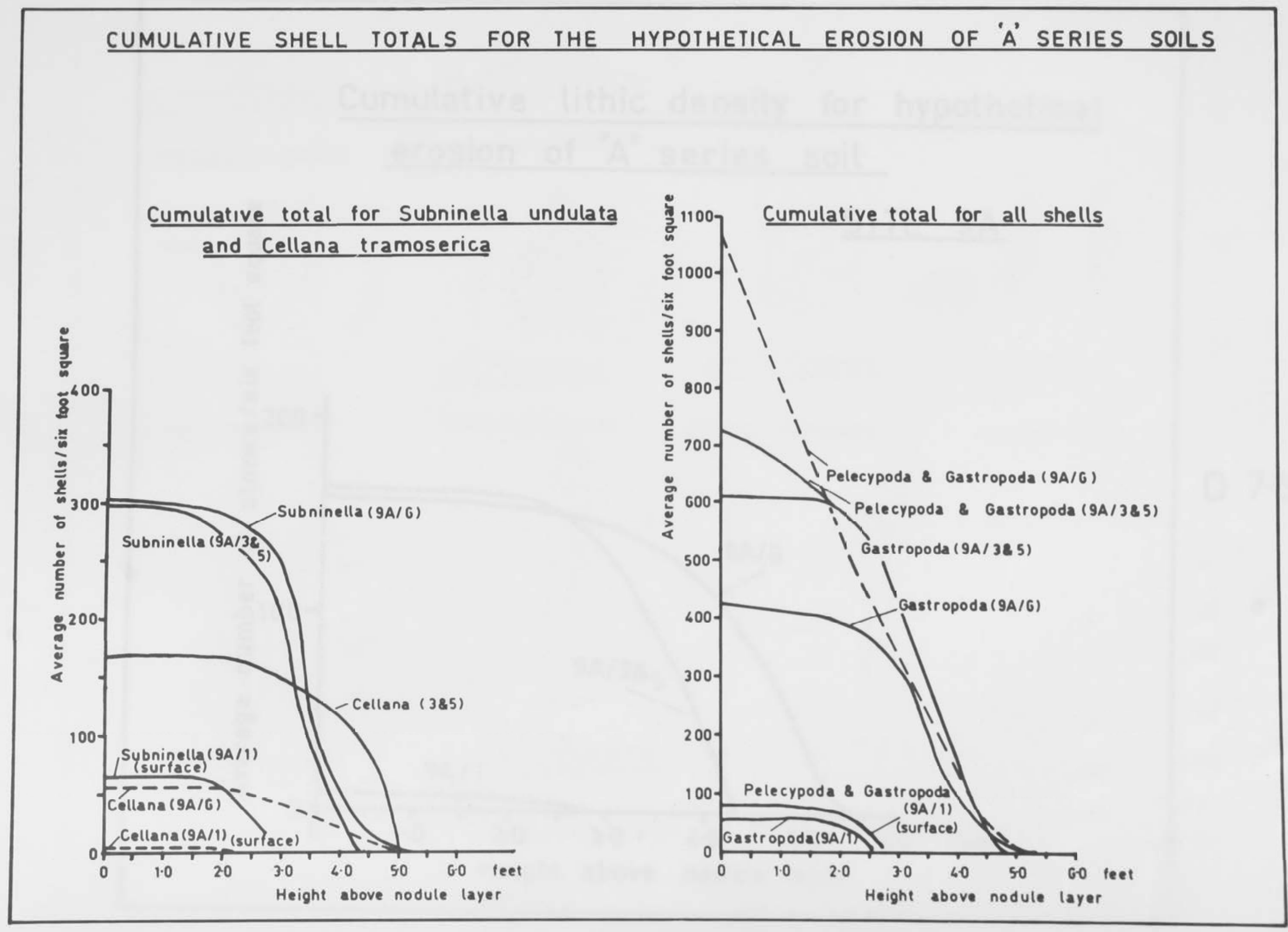

D $7 \cdot 4$ 
Cumulative lithic density for hypothetical erosion of 'A' series soil

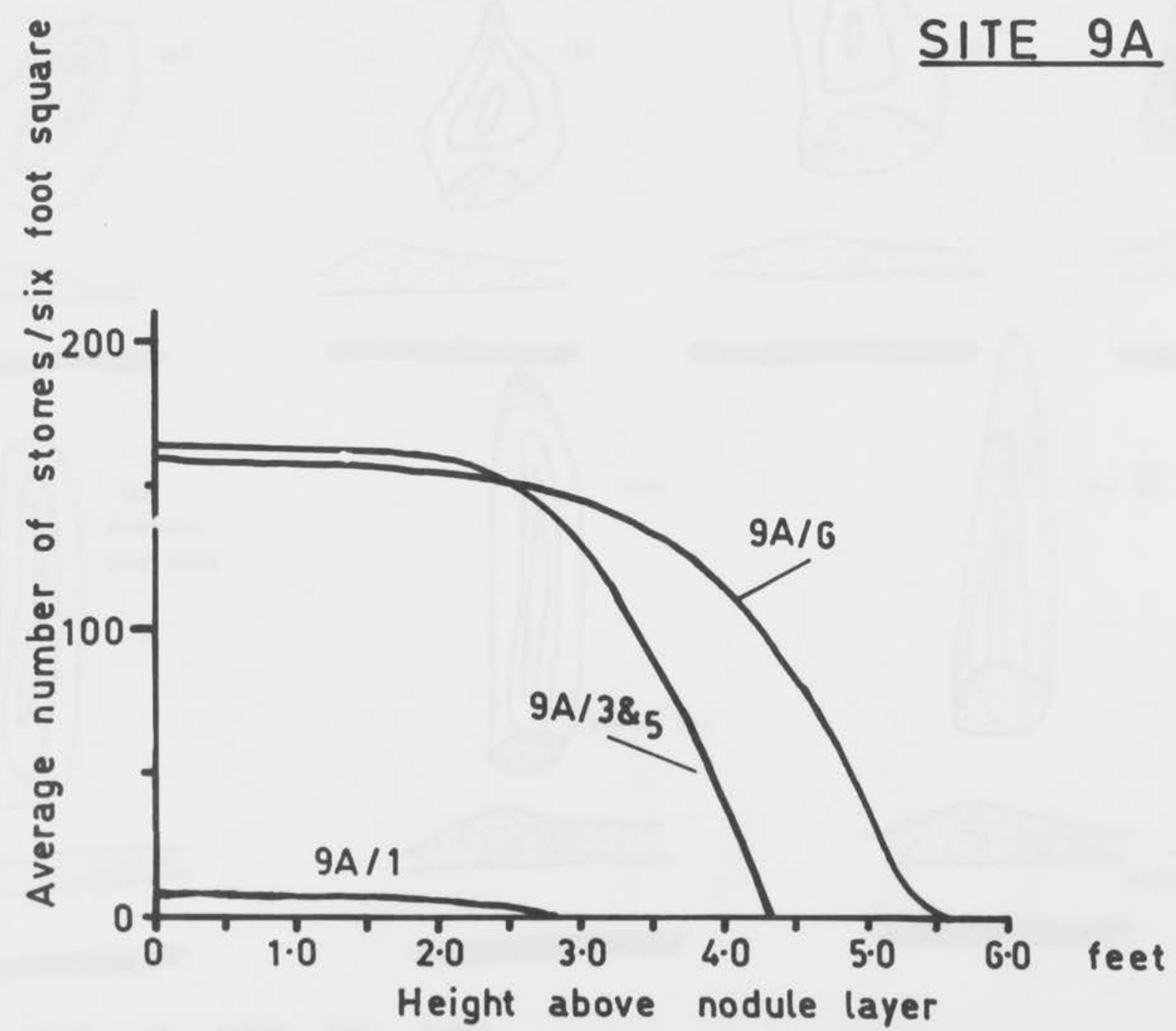

D $7 \cdot 5$ 


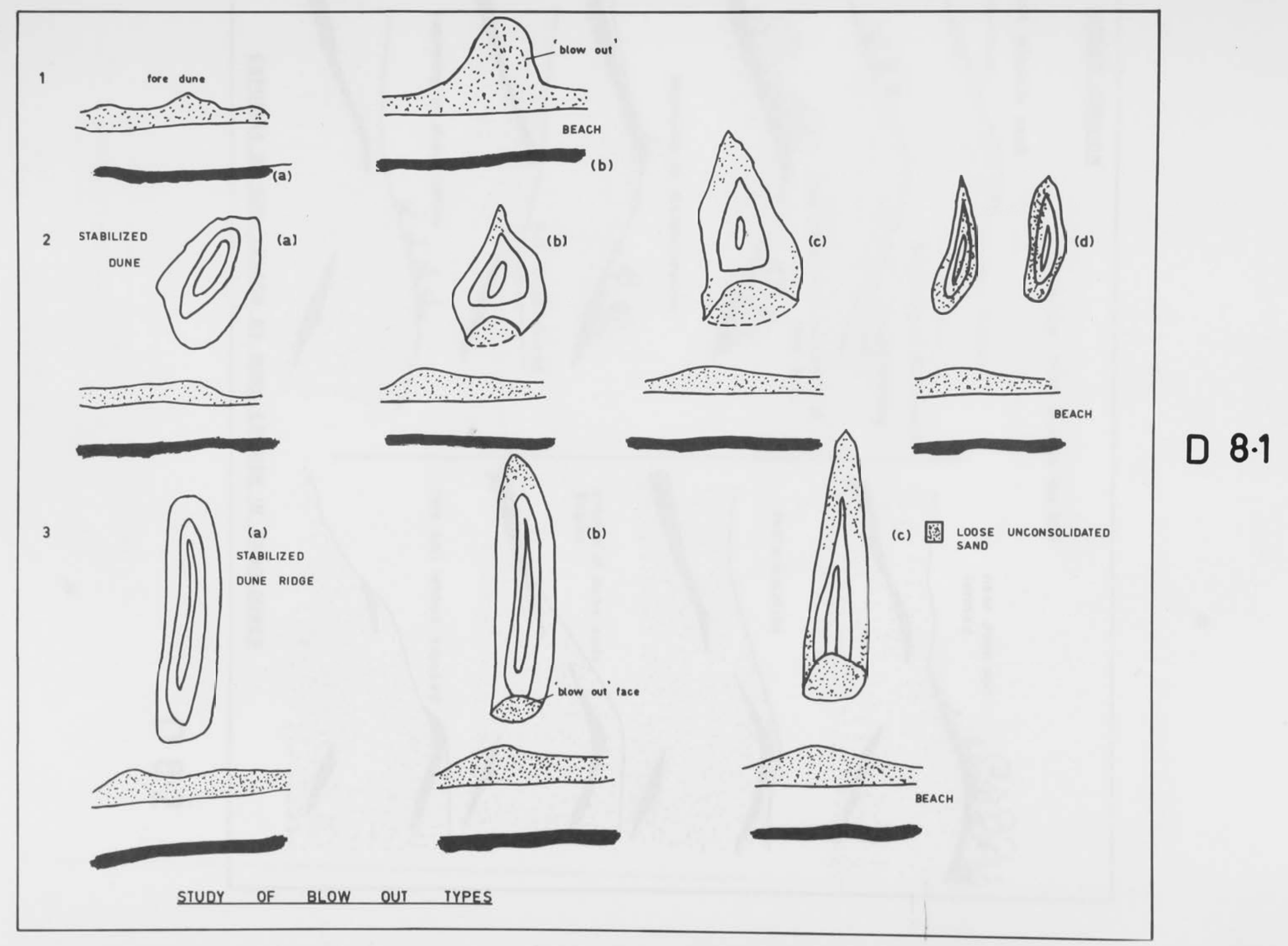




\section{MIDDEN EROSION}

Prevailing wind is from the NW

wind deposits sand

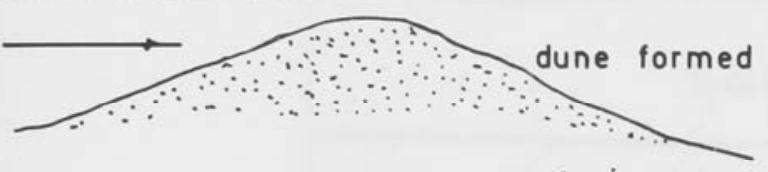

beginning of stabilization
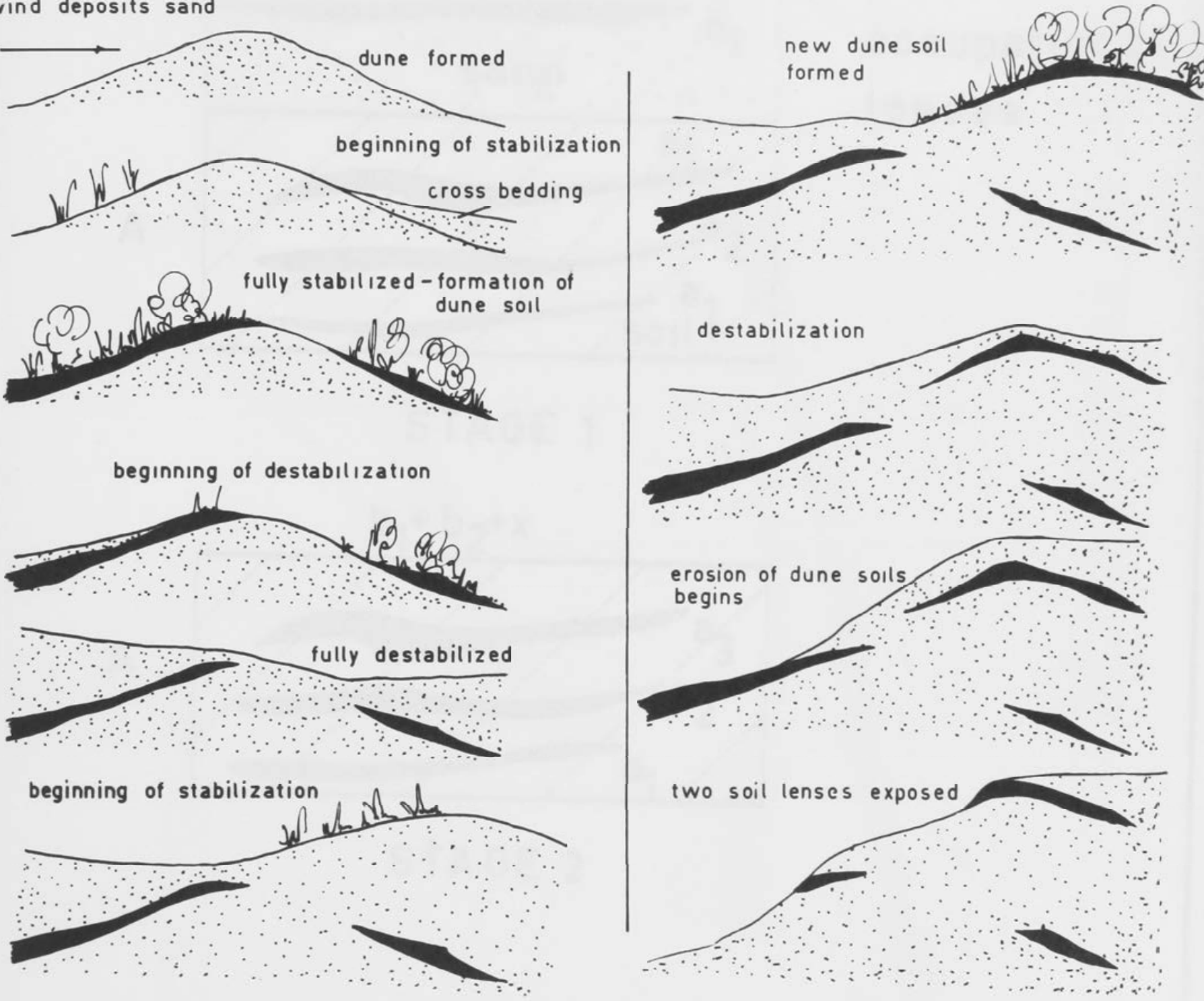

EXPOSING OF SOIL LENSES BY WIND EROSION IN SAND DUNES

D $8 \cdot 2$ 


\section{MIDDEN EROSION}

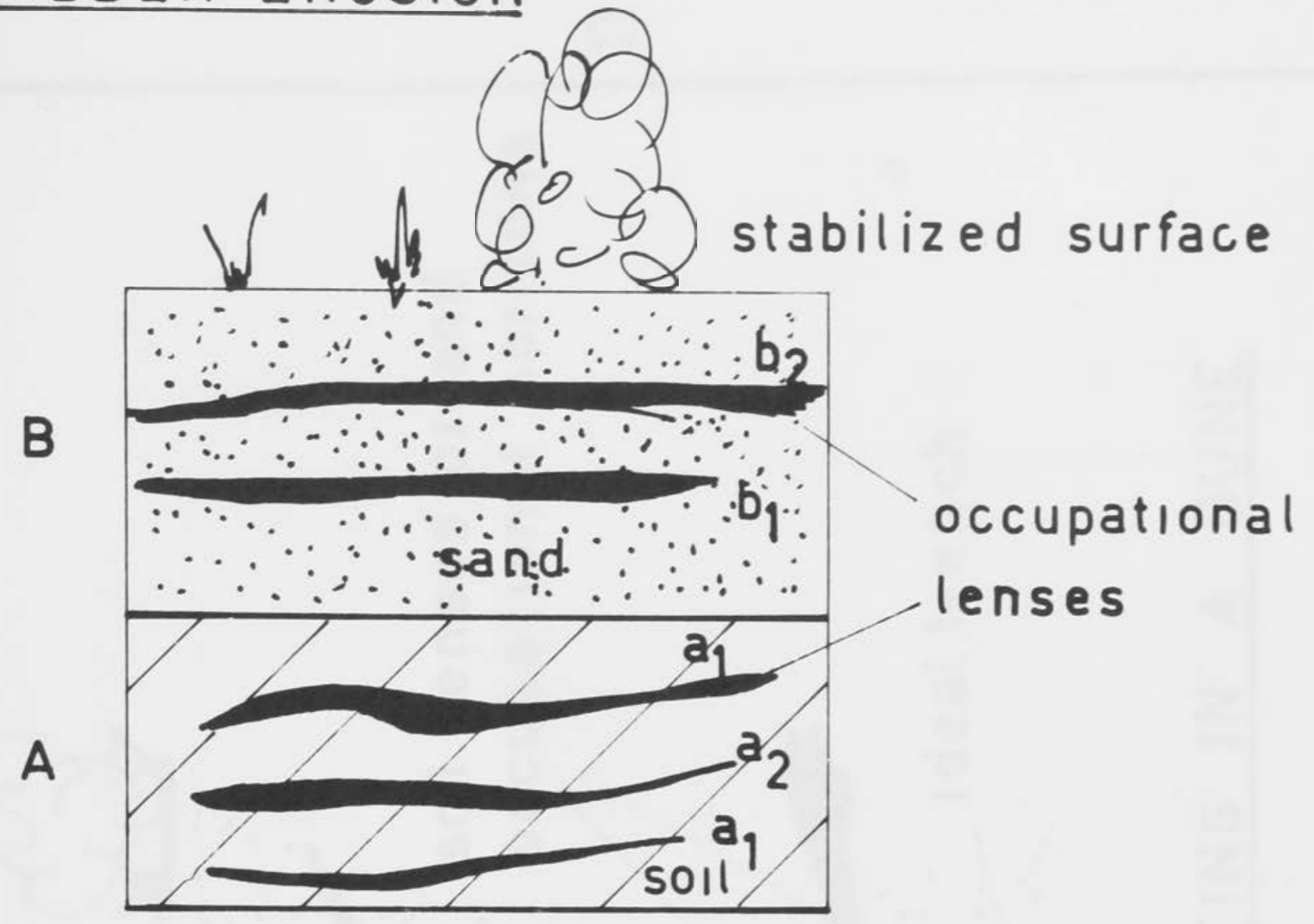

\section{STAGE 1}

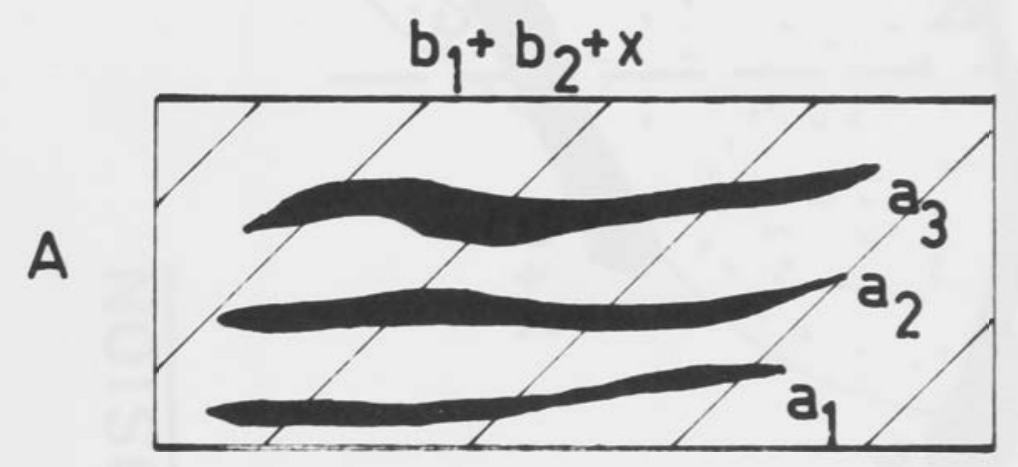

STAGE 2

A

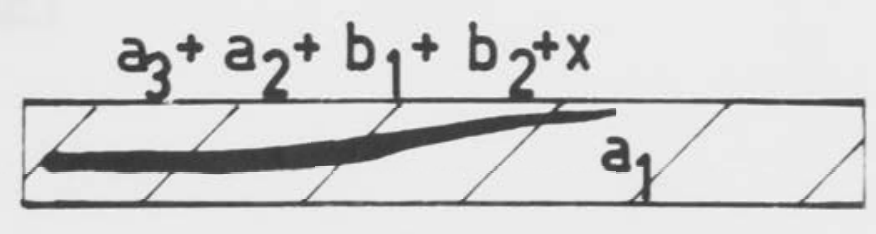

$$
\text { STAGE } 3
$$

STAGES OF LENSE COLLAPSE 


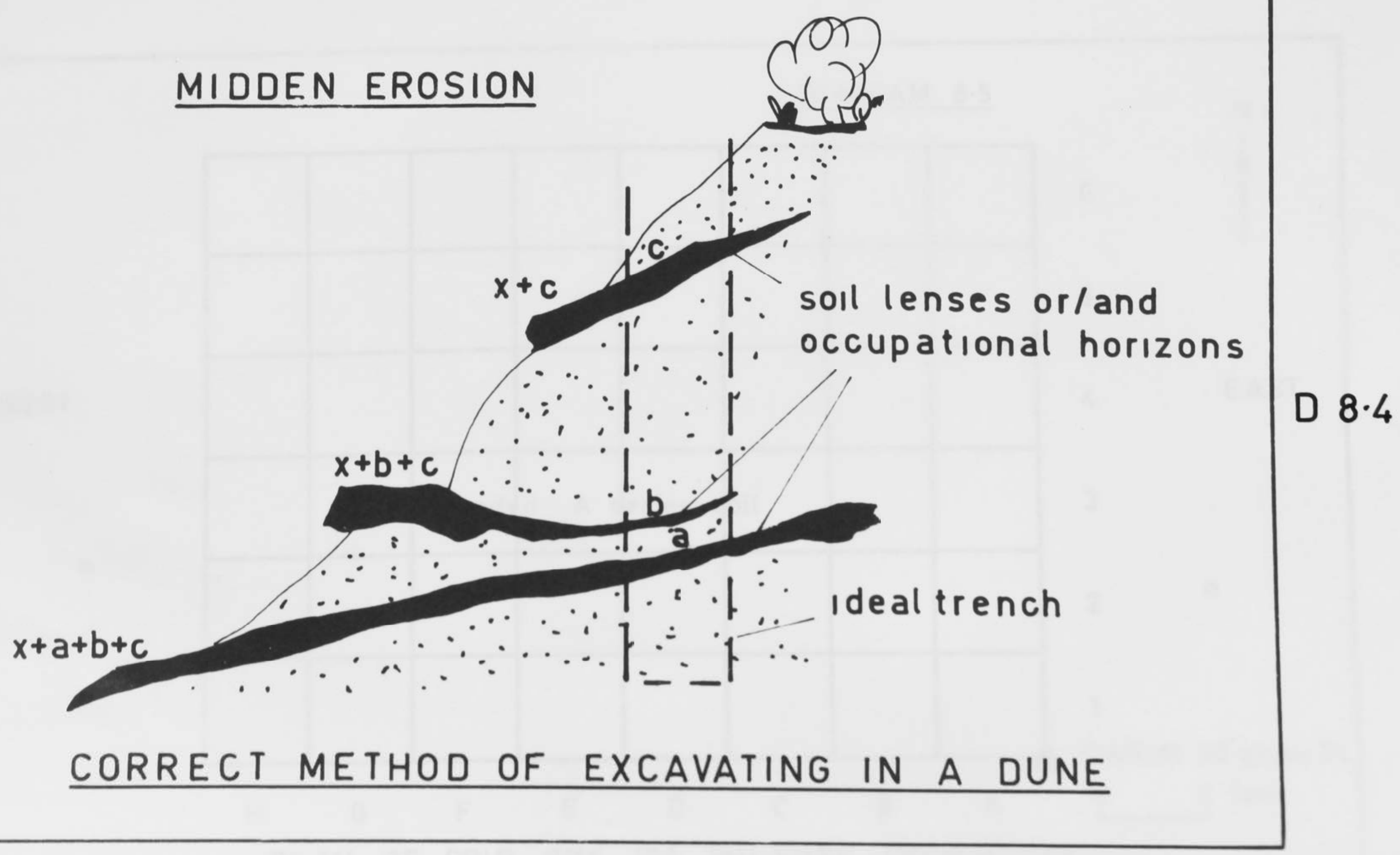




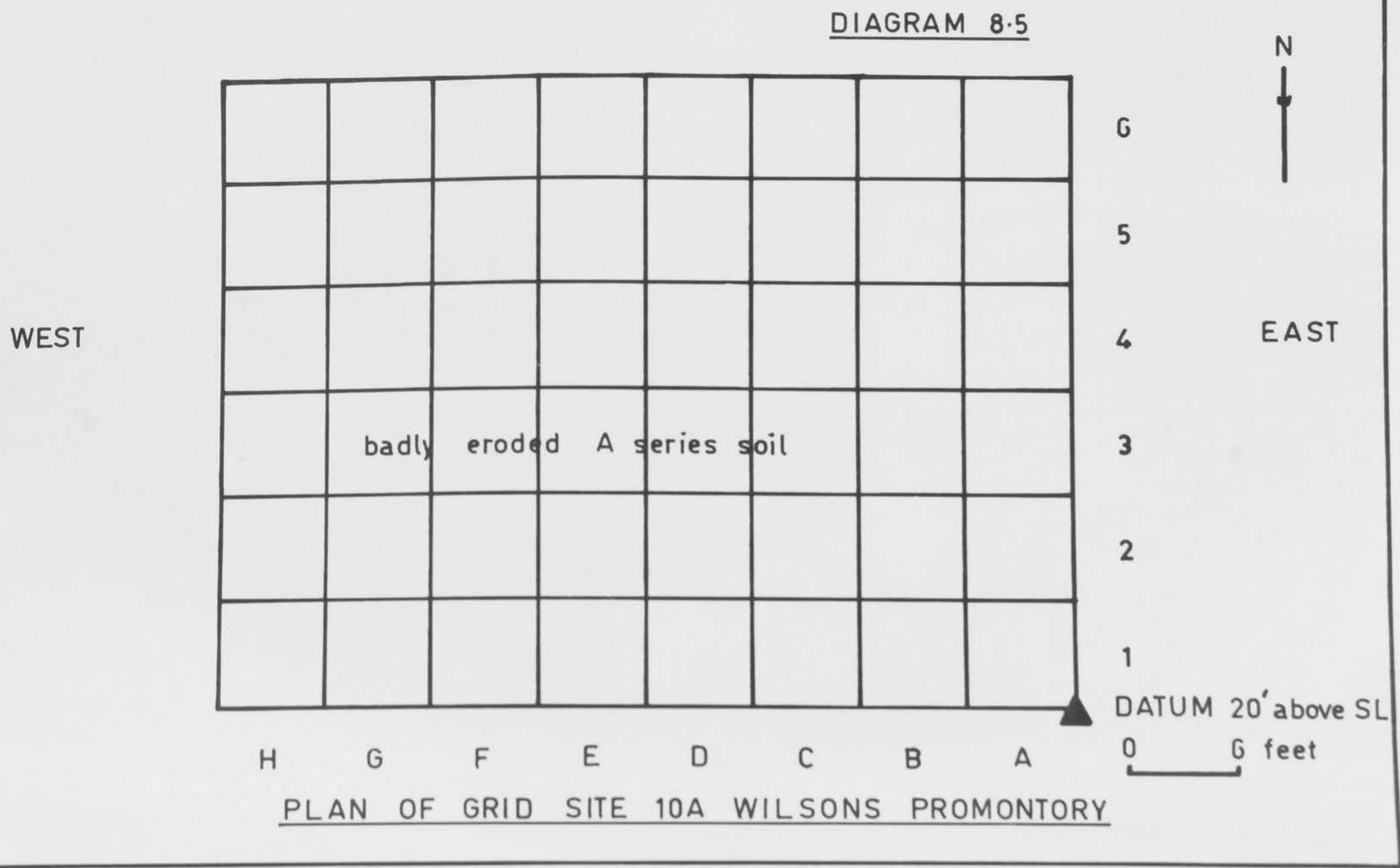


IHE AASHAFOLOO Of WILSONS PREMONTOAY

$$
\text { 1. }
$$

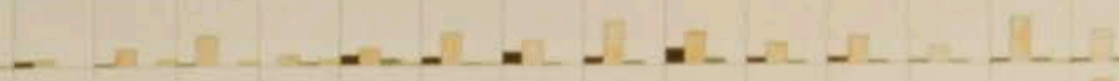


Jue archatelogy of WiLsons promontogr.

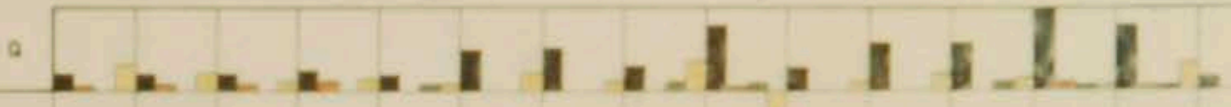

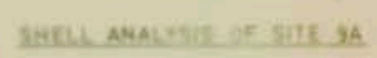

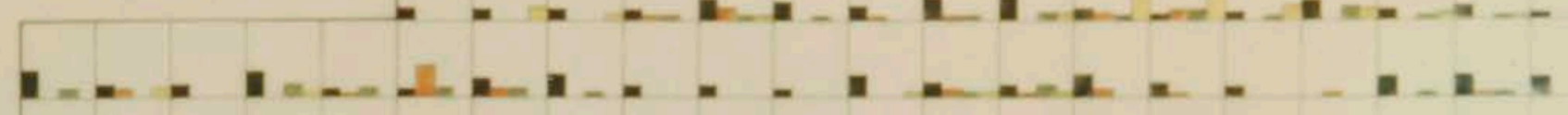

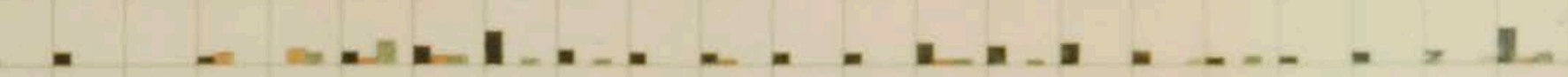

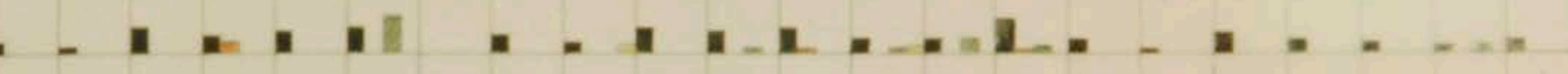

sutedyet $x$

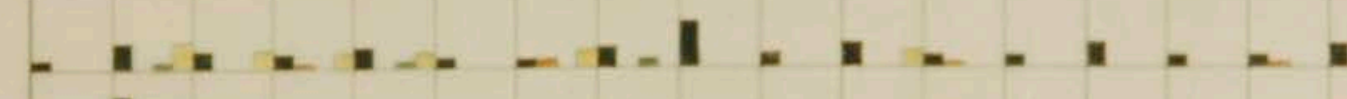

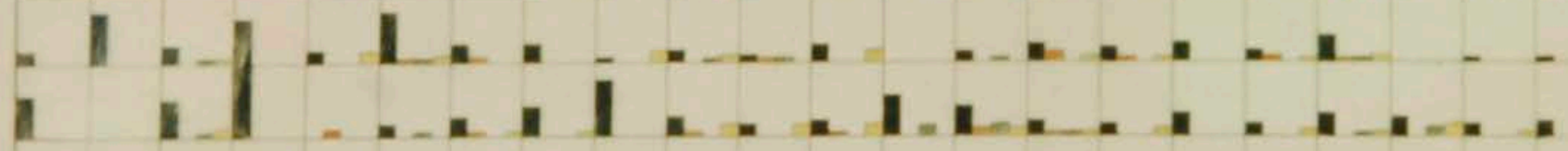

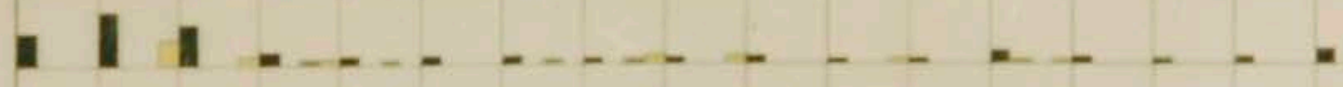

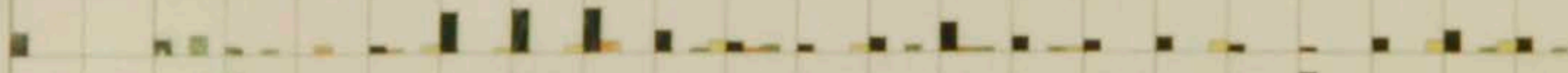

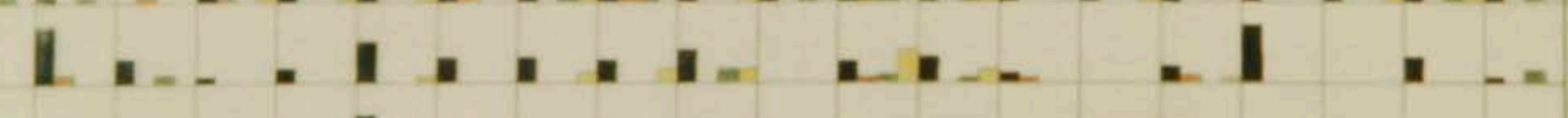




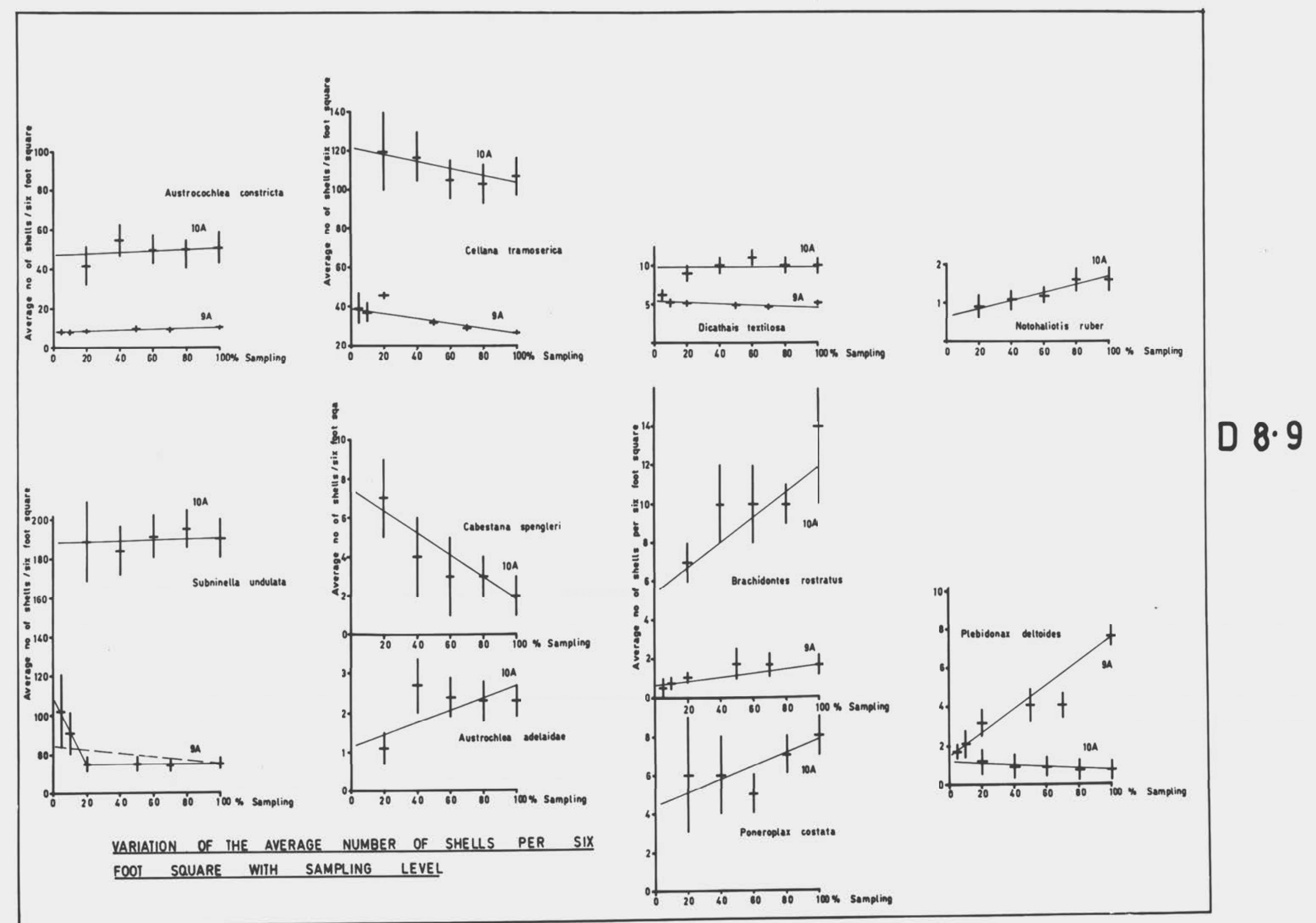




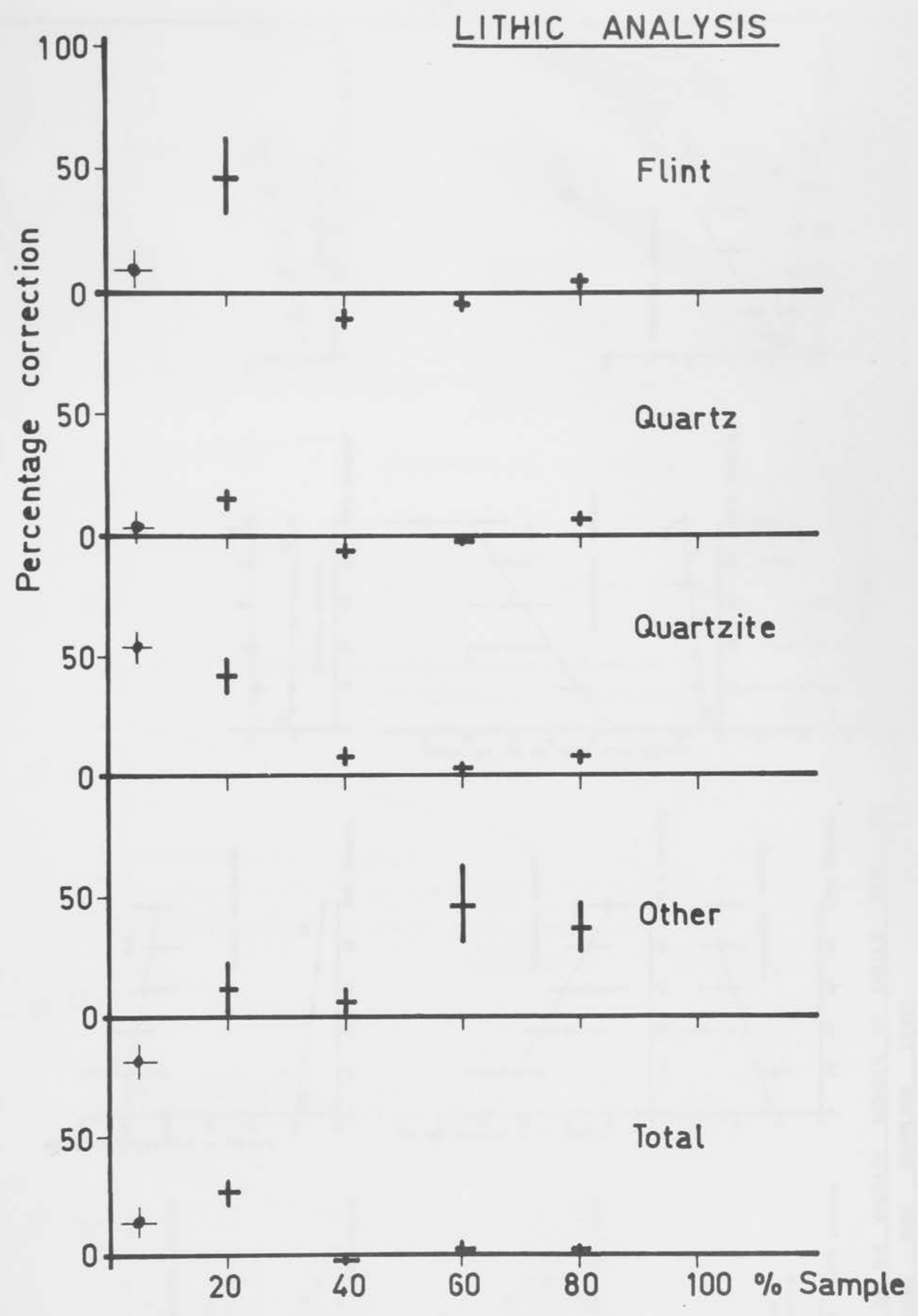

RANDOM SAMPLING OF MIDDEN SITES PERCENTAGE CORRECTION PER SAMPLING

- Site 9A LEVEL

+ Site $10 \mathrm{~A}$ 

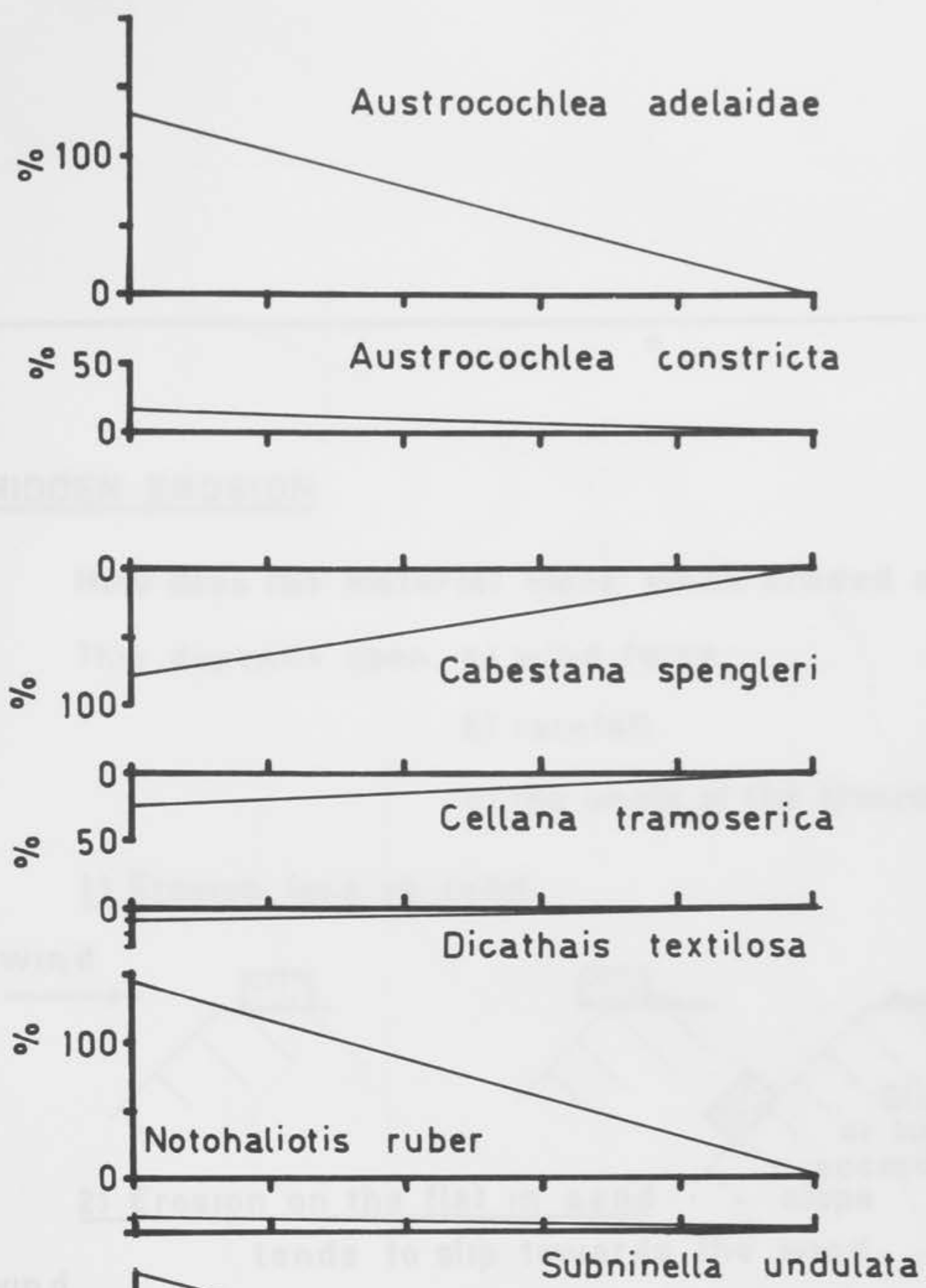

॰ 10
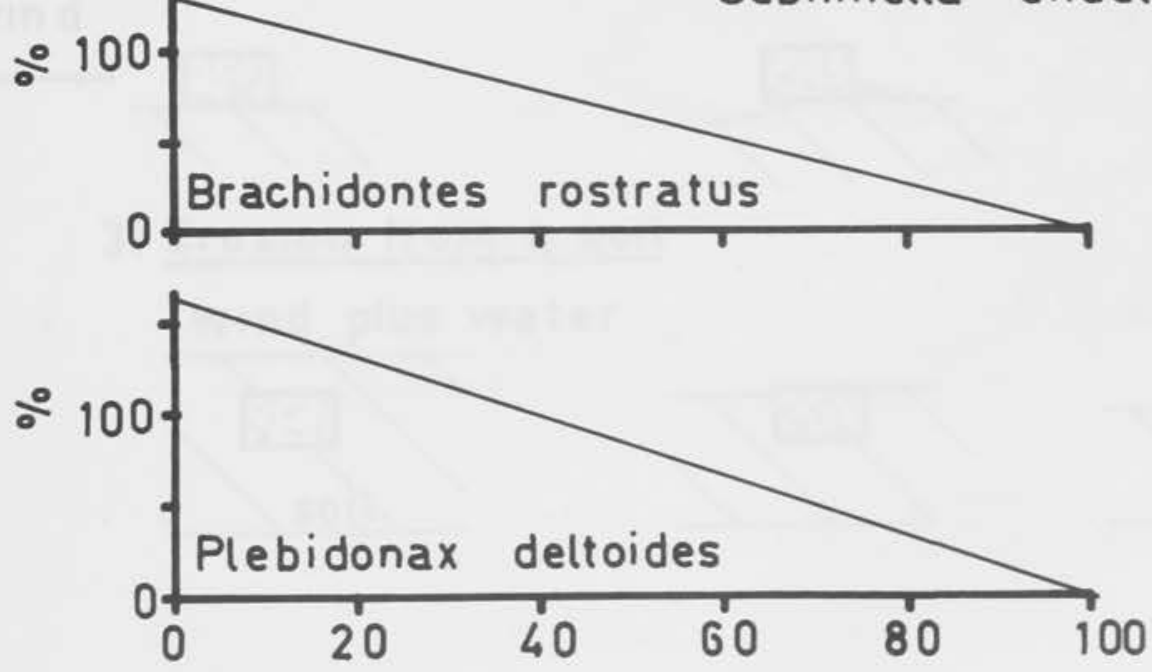

RANDOM SAMPLING OF MIDDENS

$\%$ Correction to average number

of shells per species per sampling 


\section{MIDDEN EROSION}

How does the material move when eroded out?

This depends upon a) wind force

b) rainfall

c) the angle of the erosion face

\section{1) Erosion face in sand}

wind

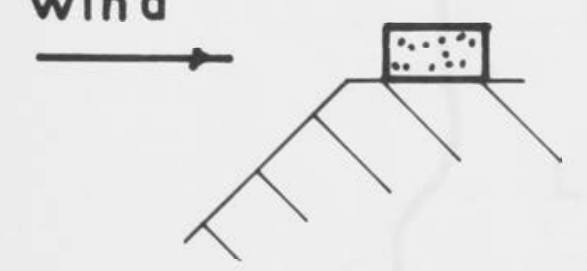

2) Erosion on the flat in sand
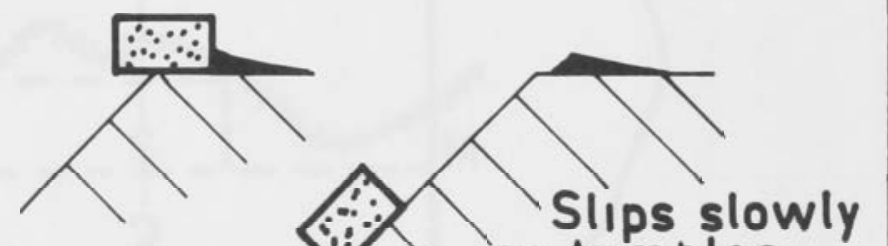

or tumbles

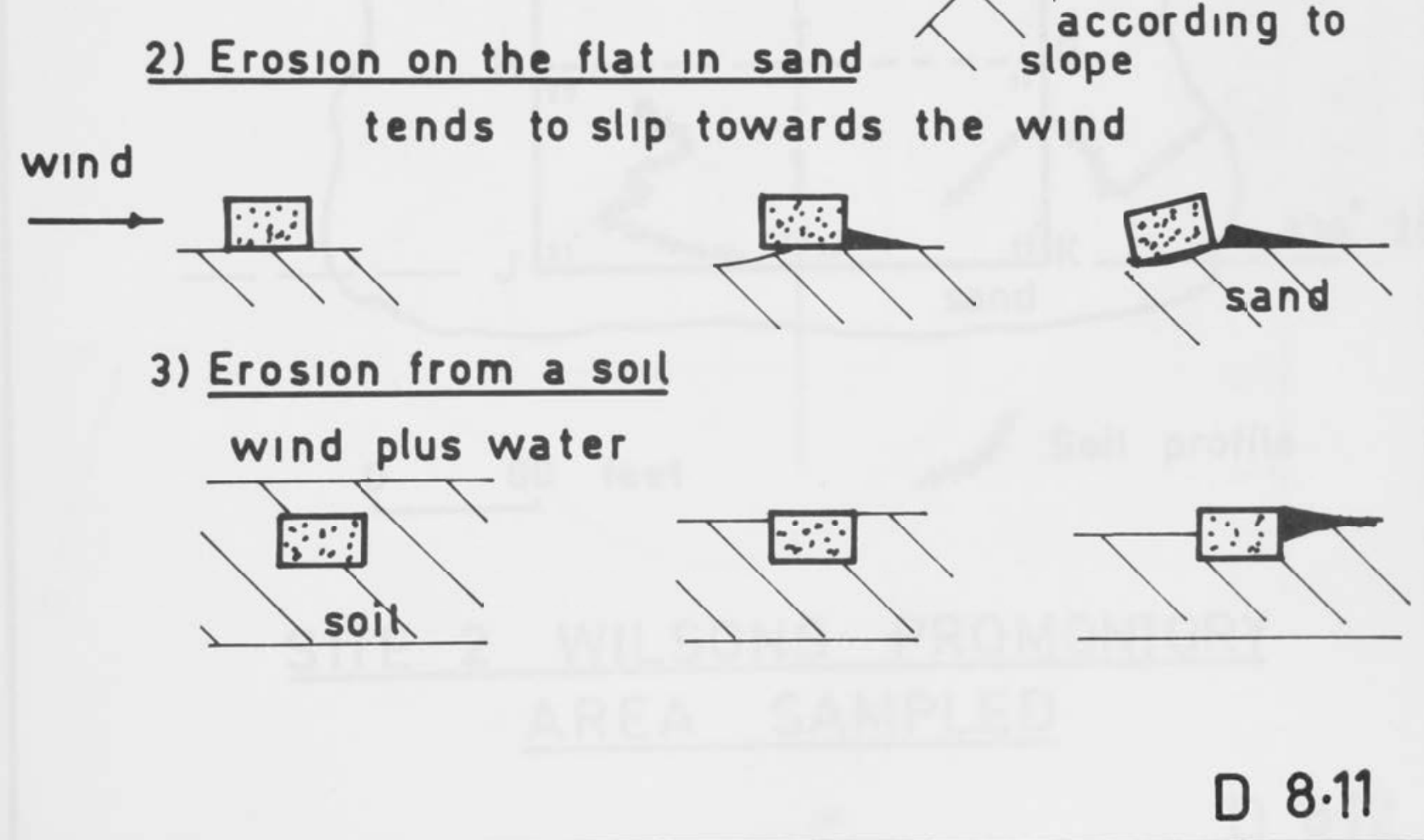




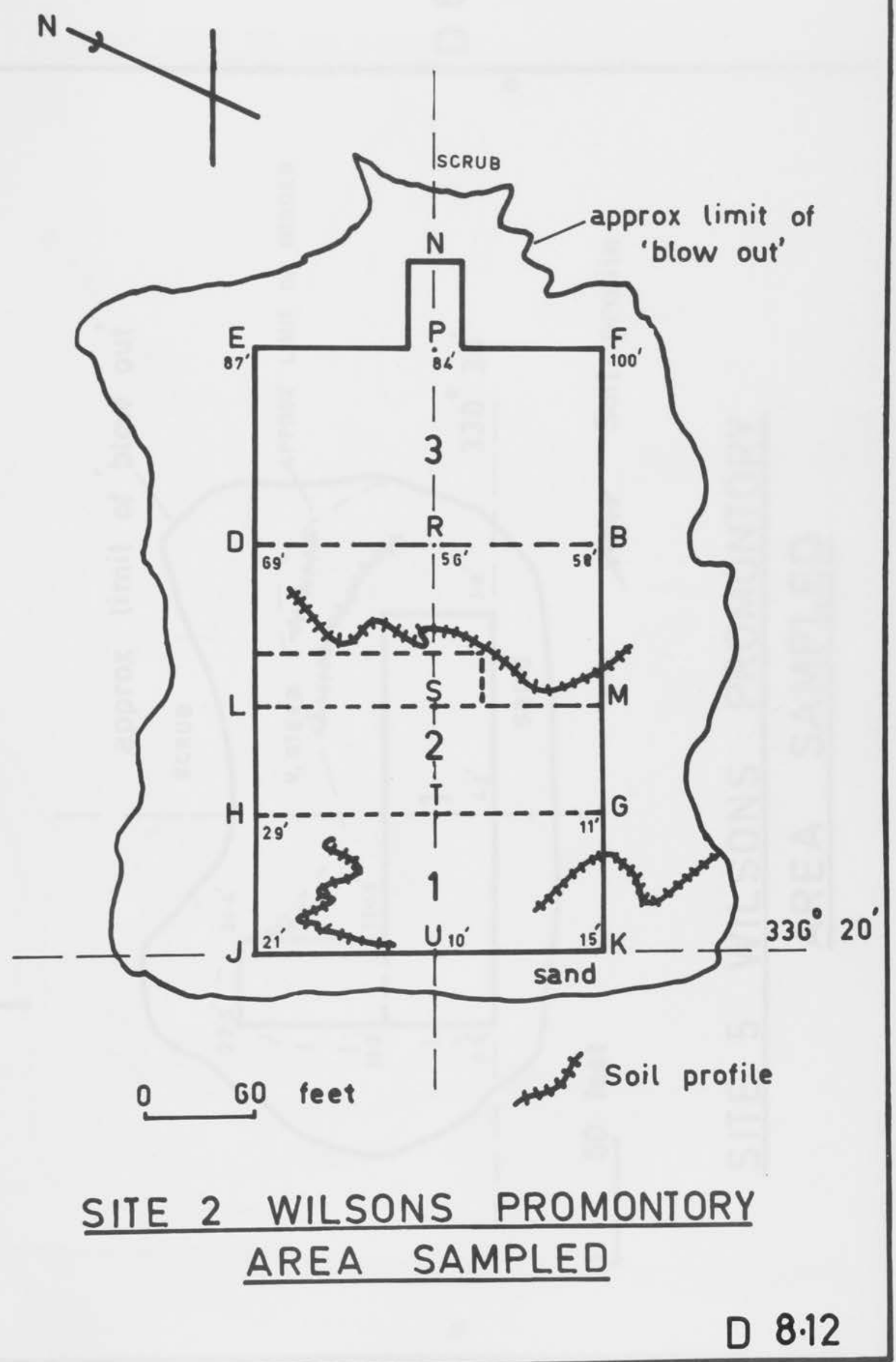




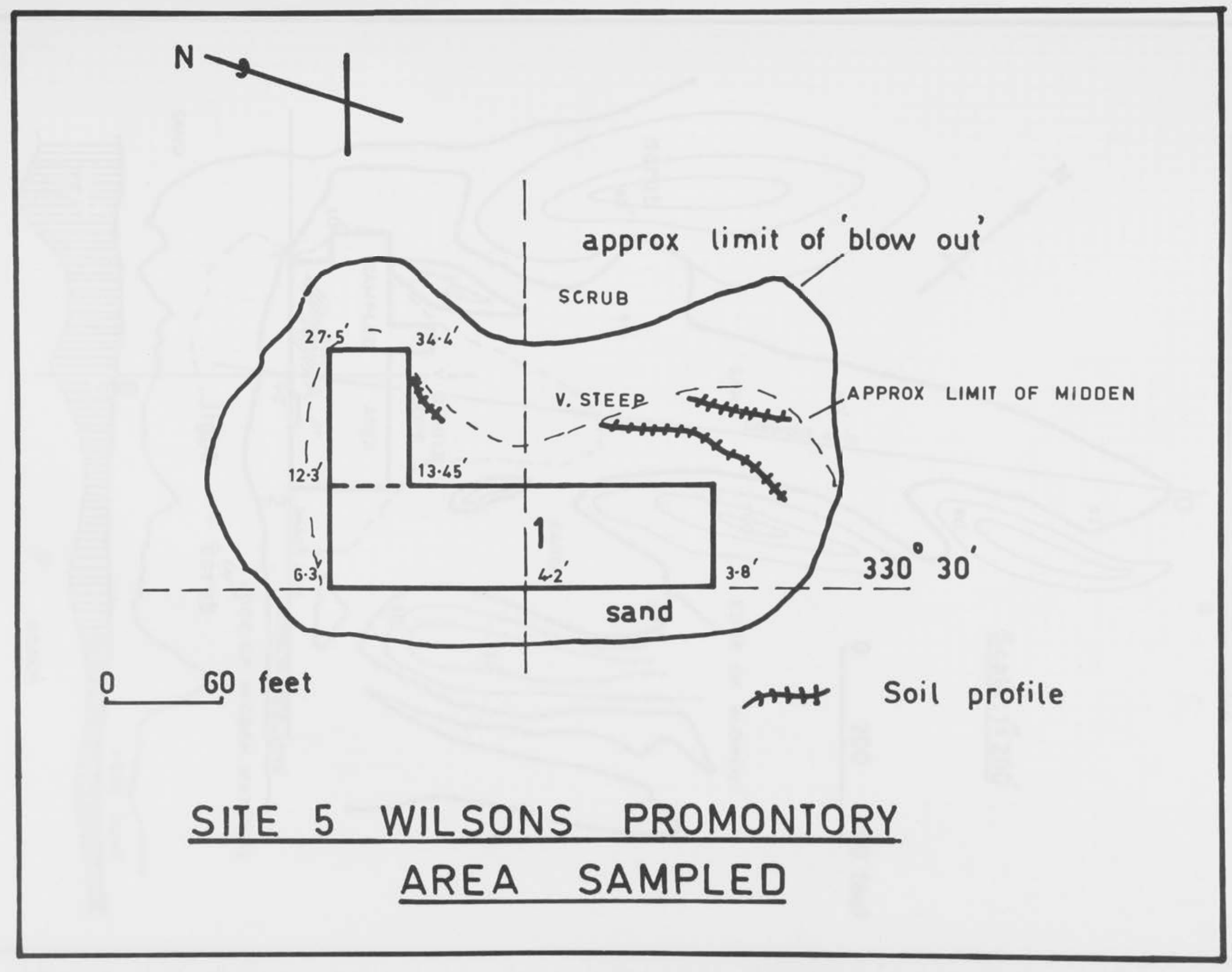

D 8.13 


\section{PLAN OF SITE 9D WILSONS PROMONTORY}

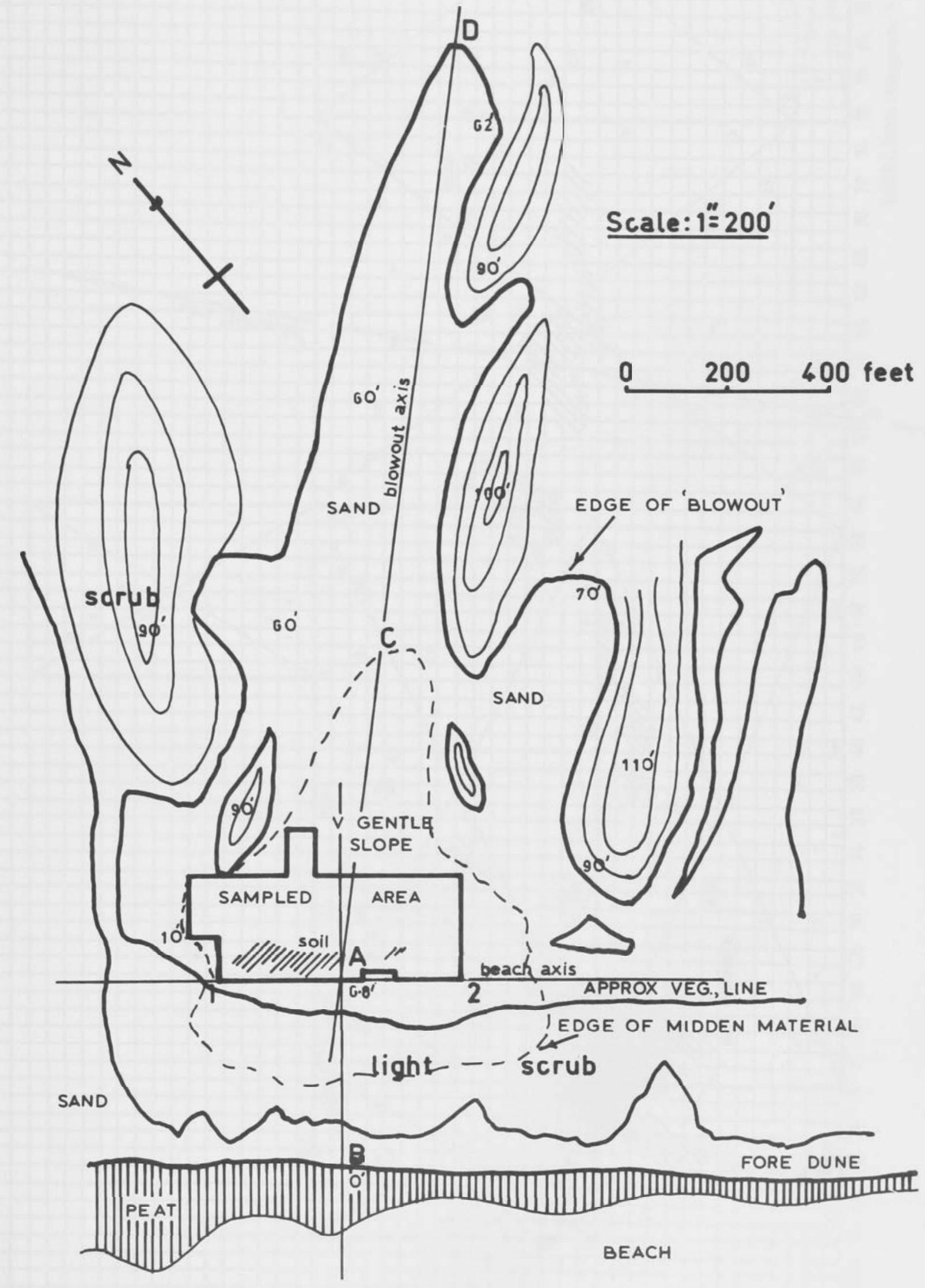

$\overline{M W} M$ 


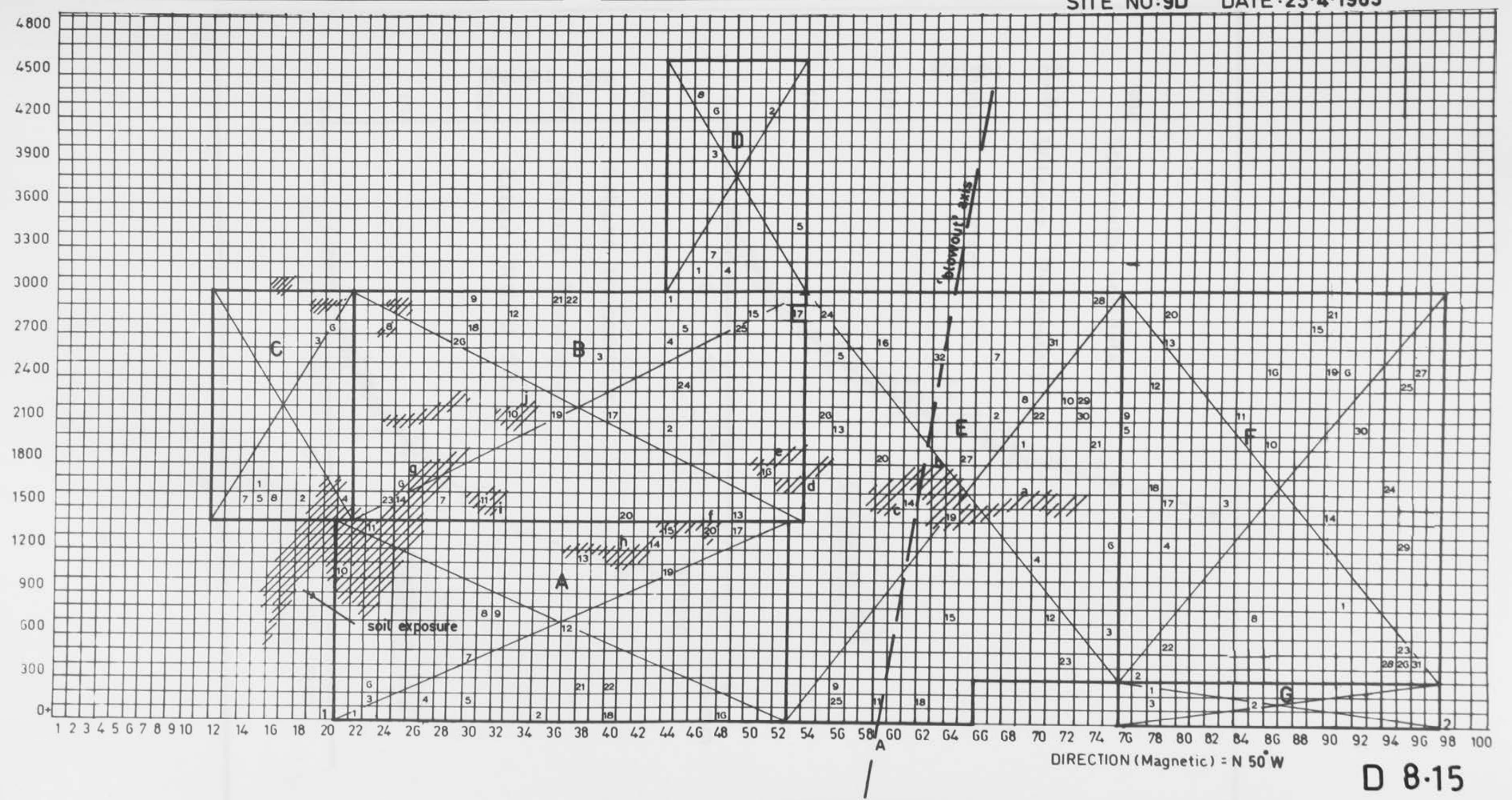




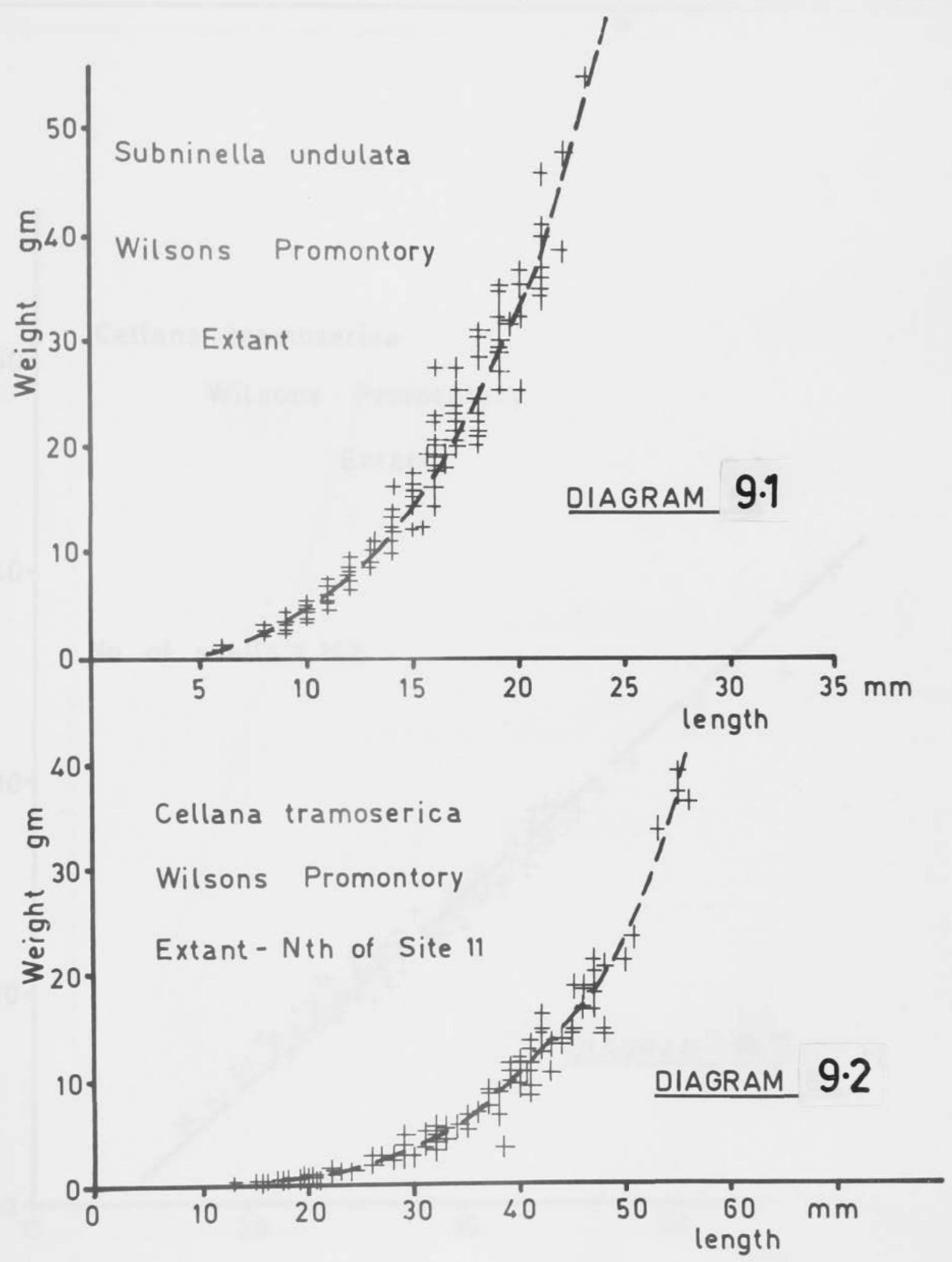




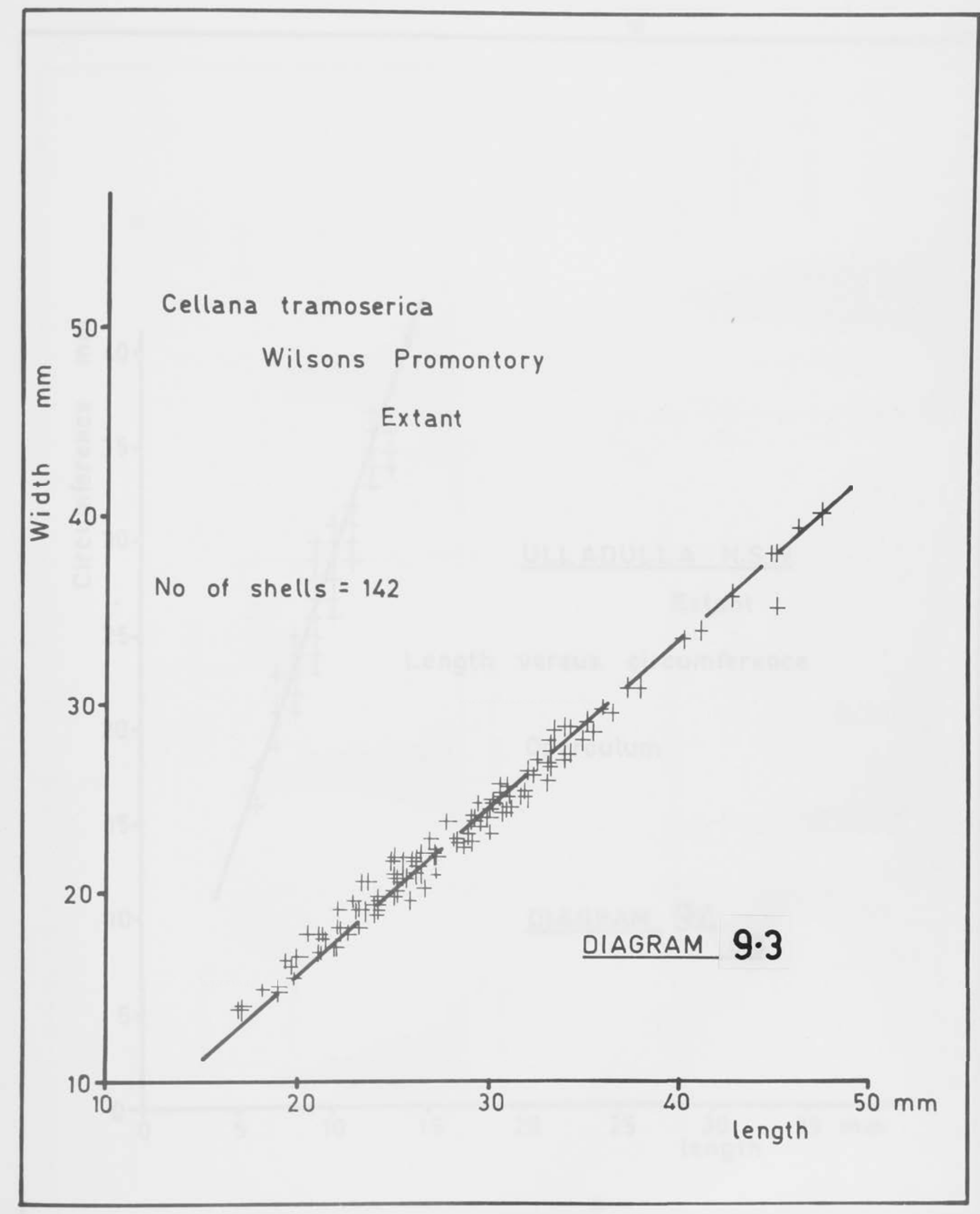




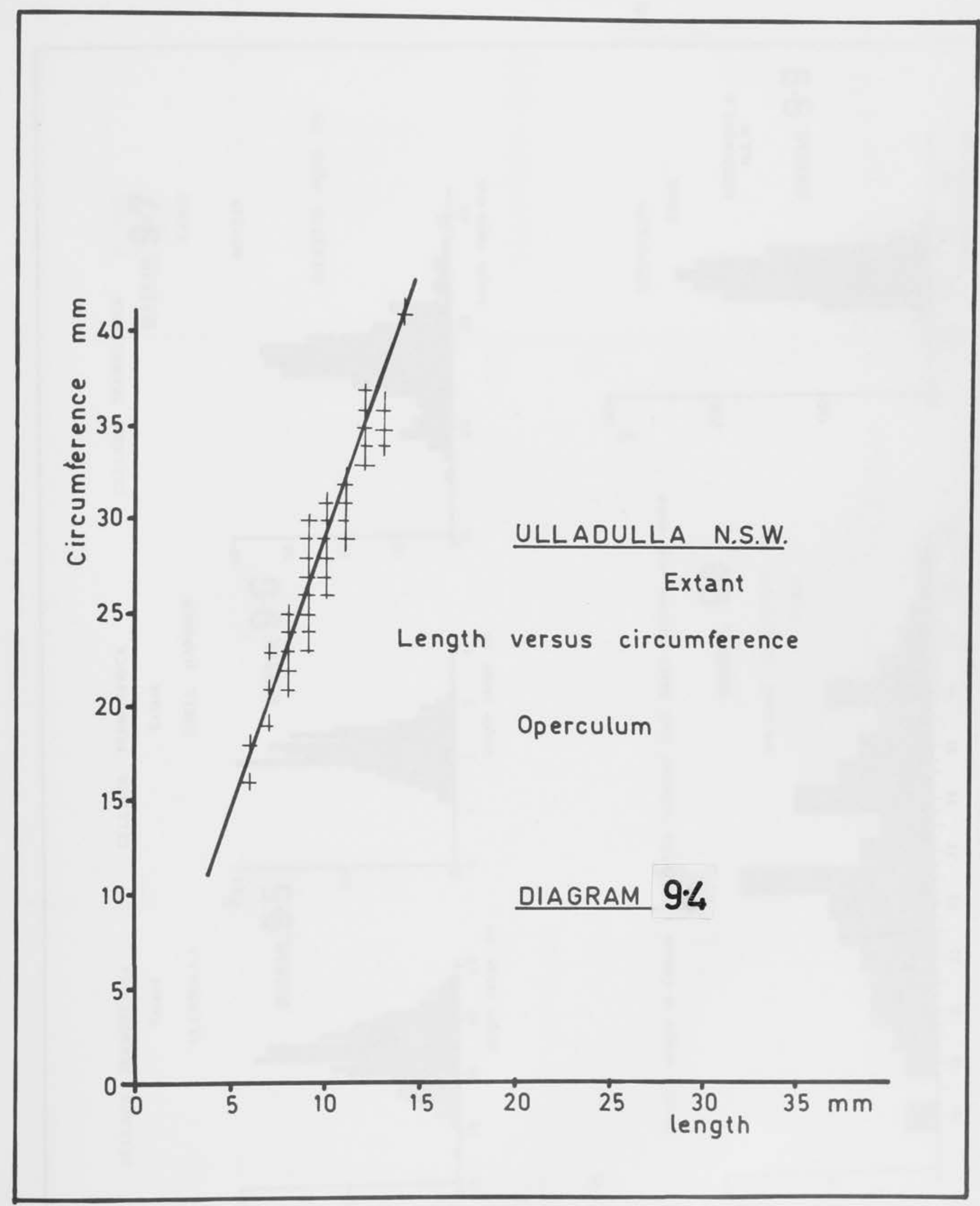




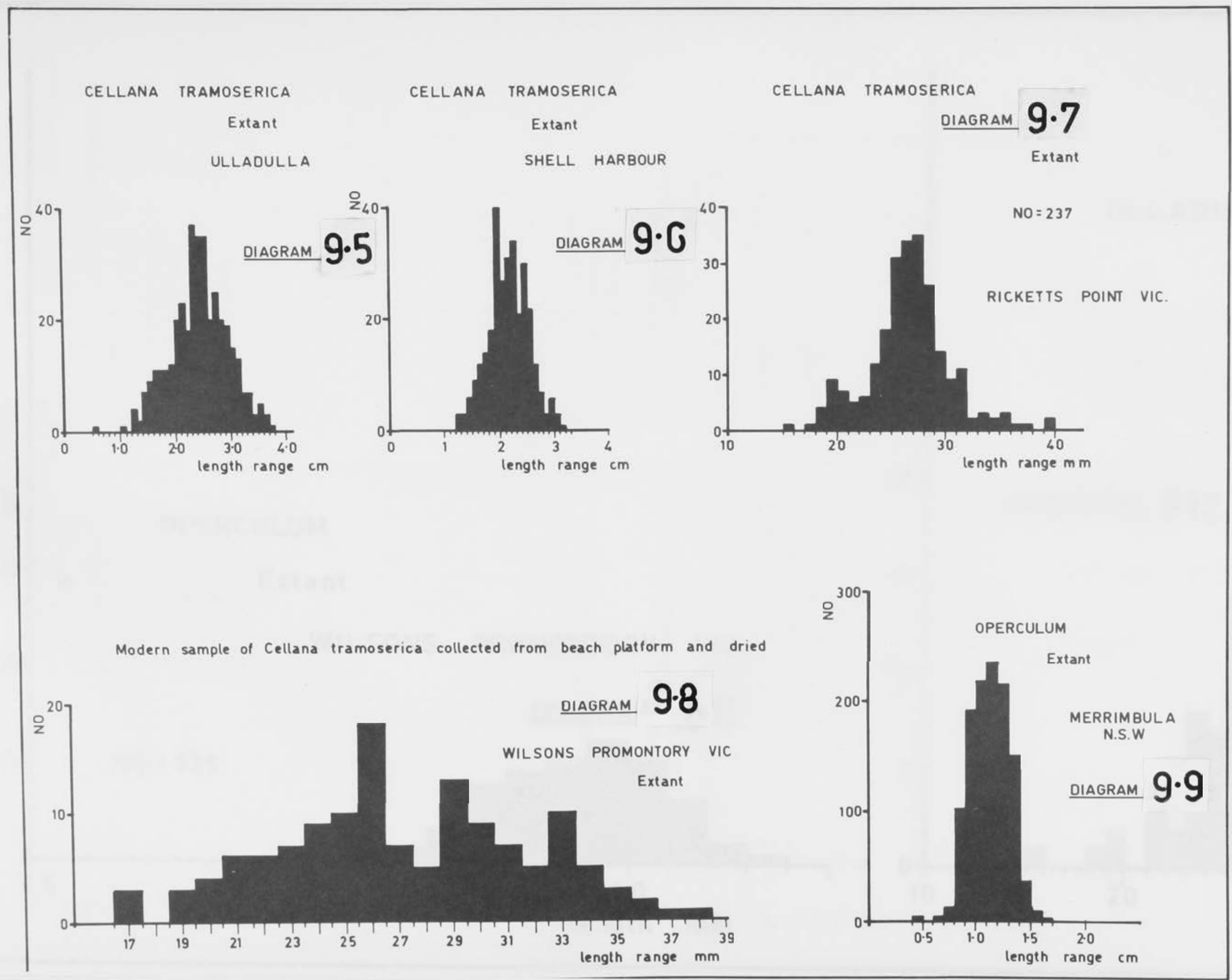




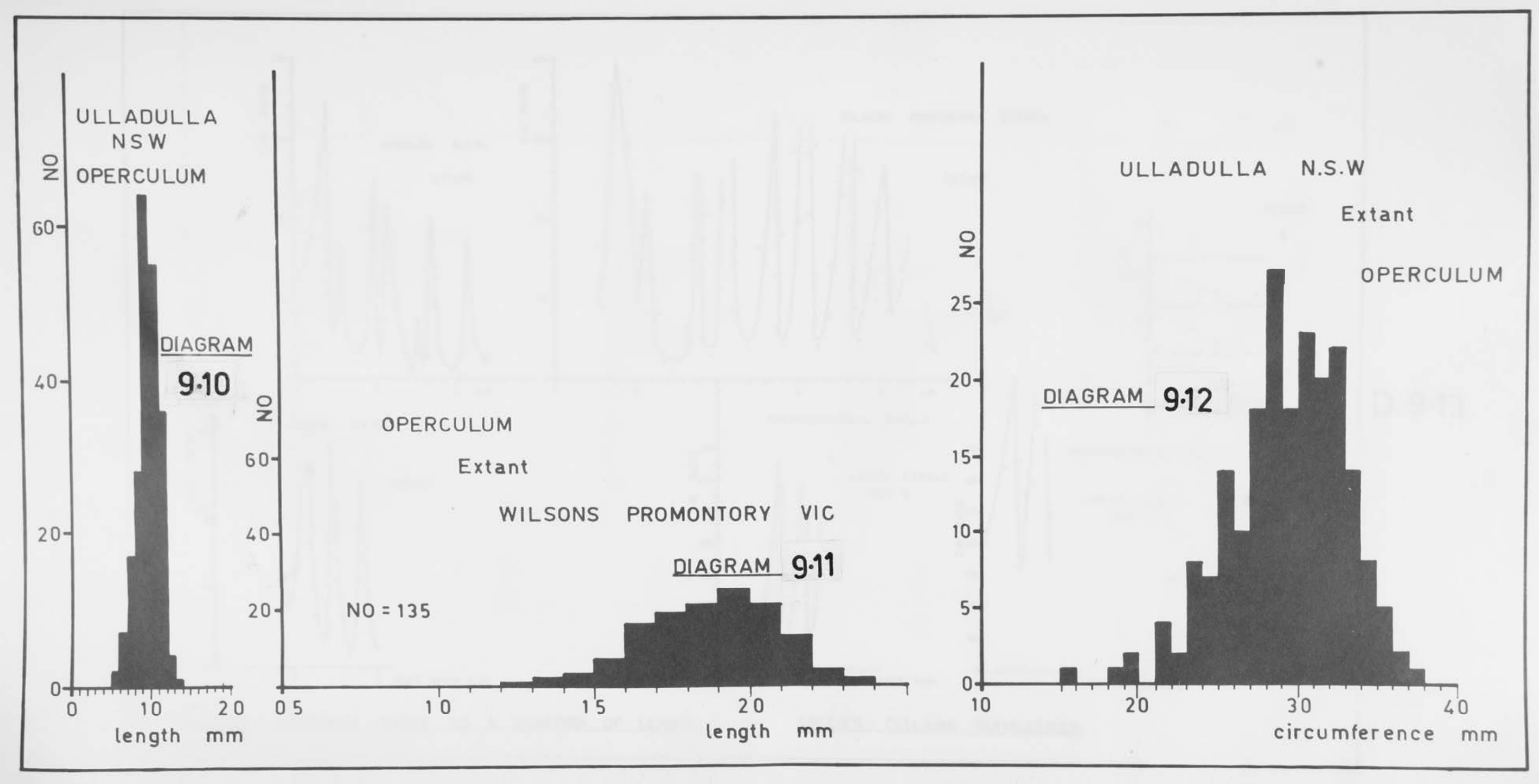




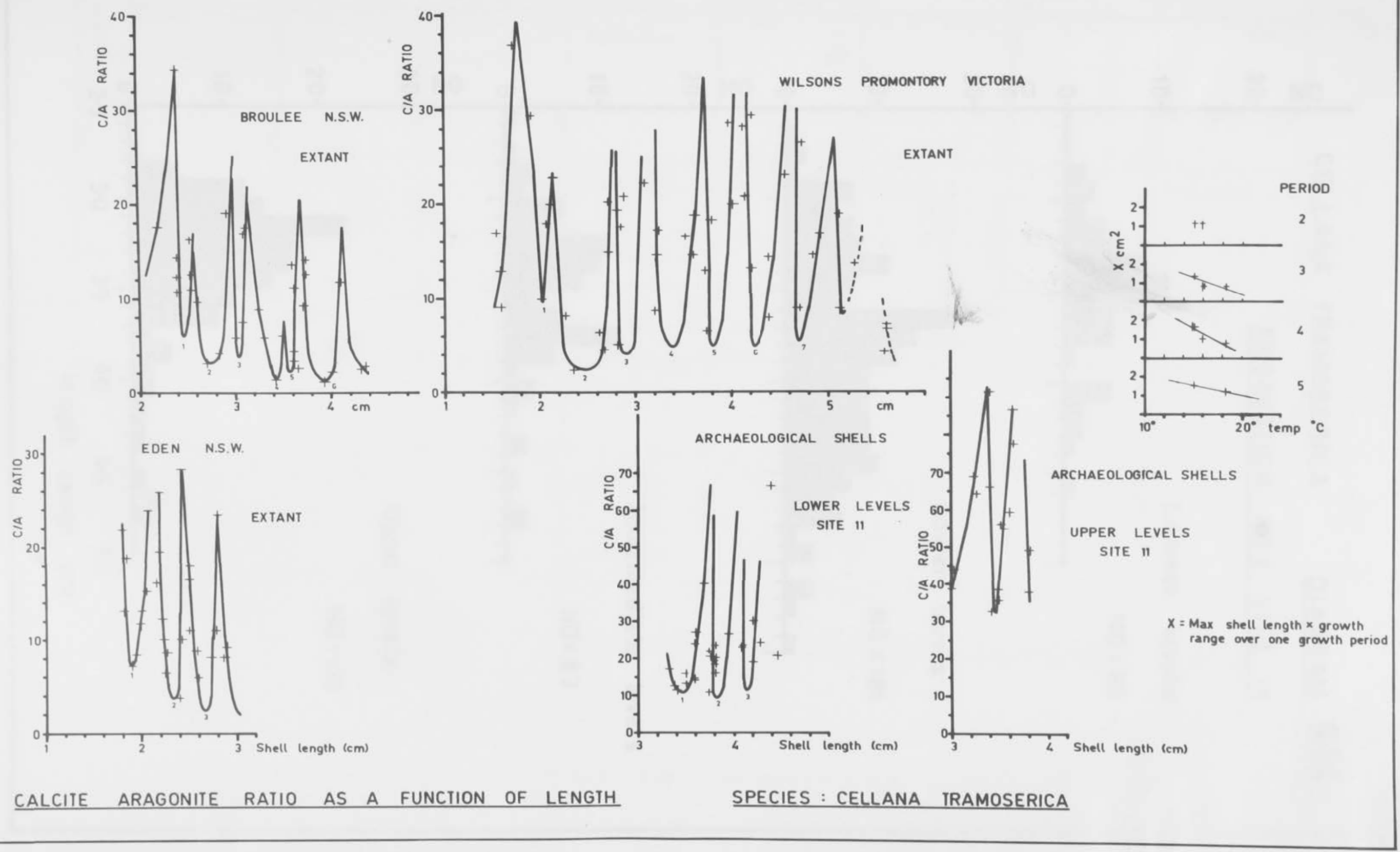

D 9.13 


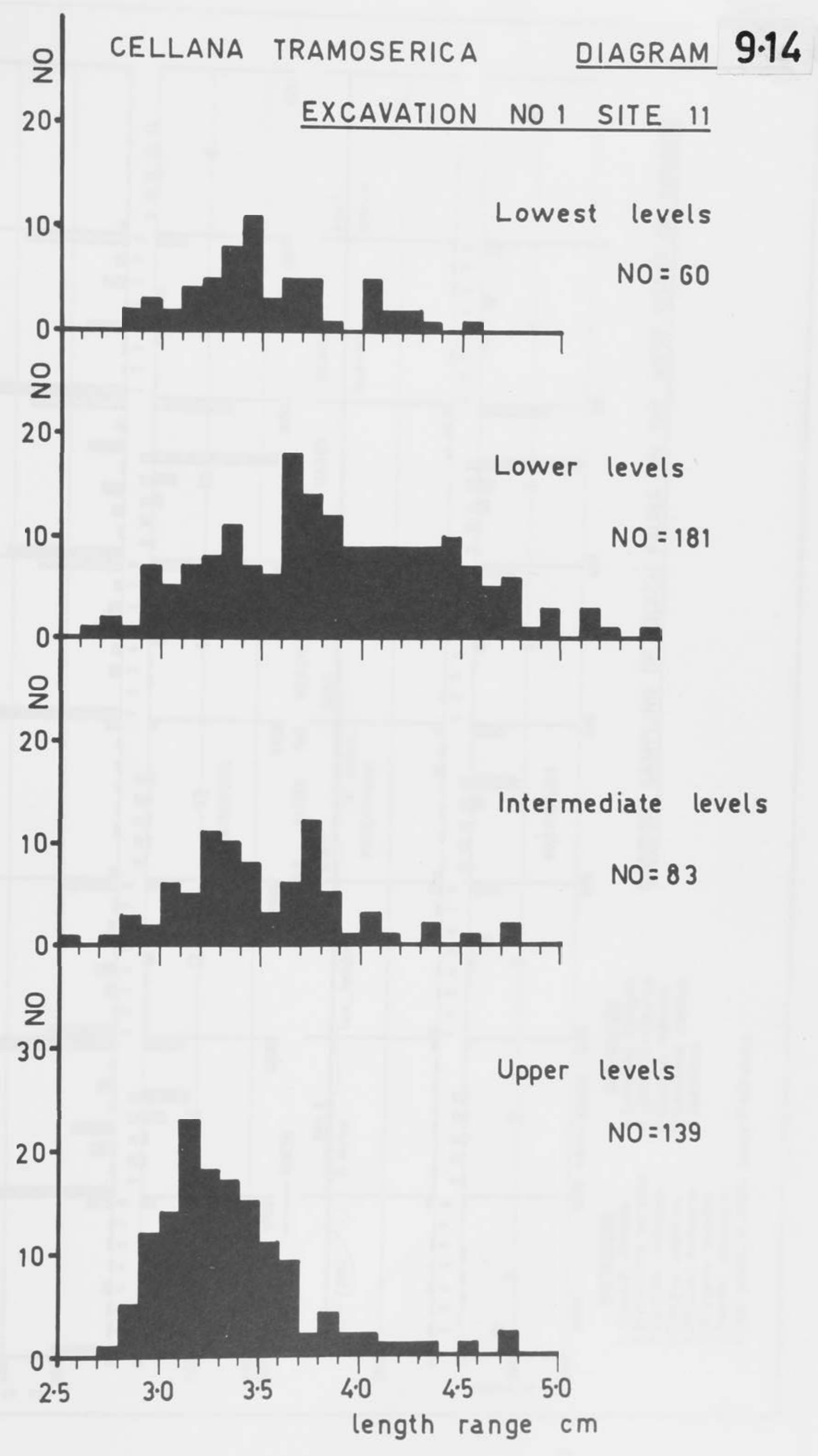




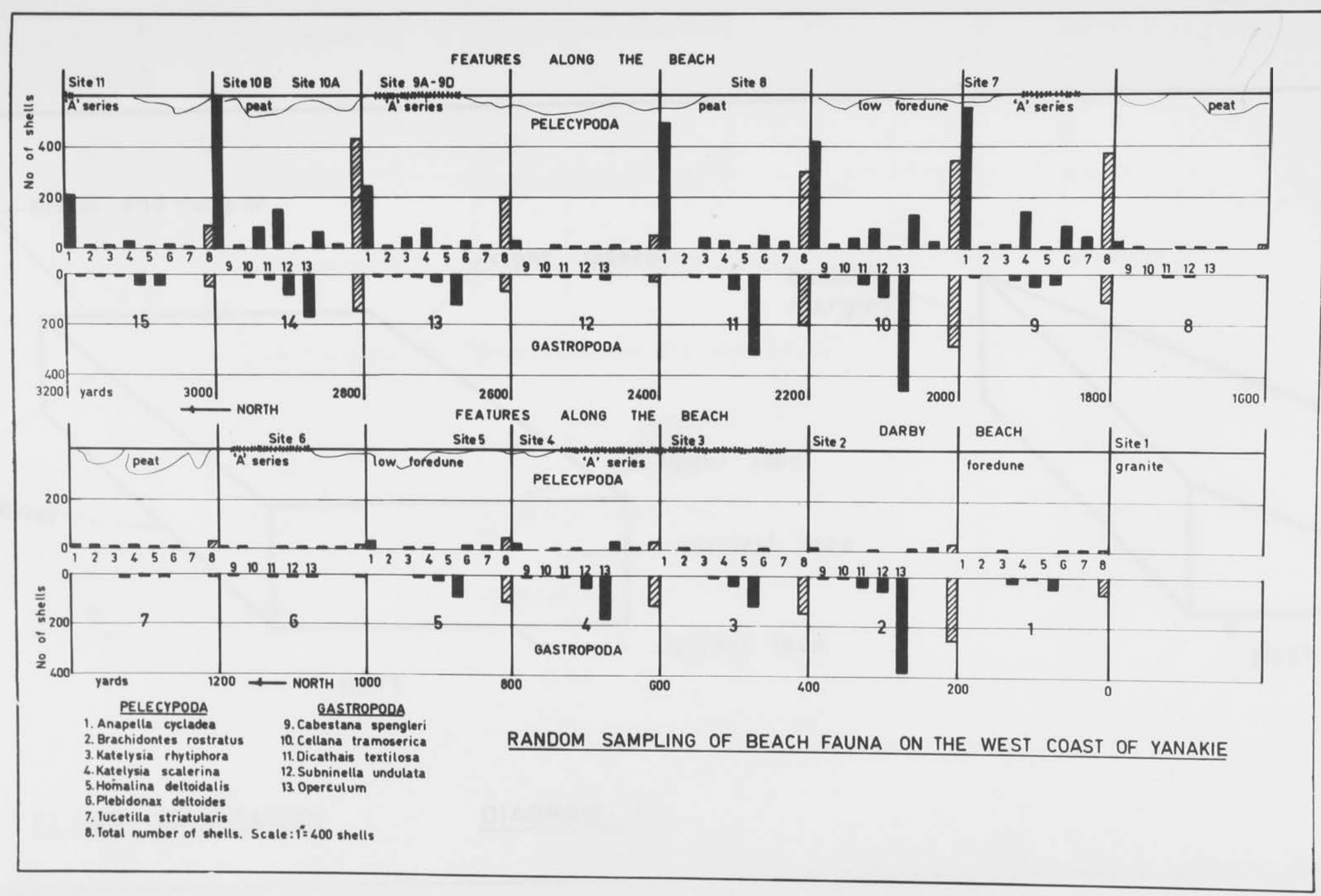

D 10.1 

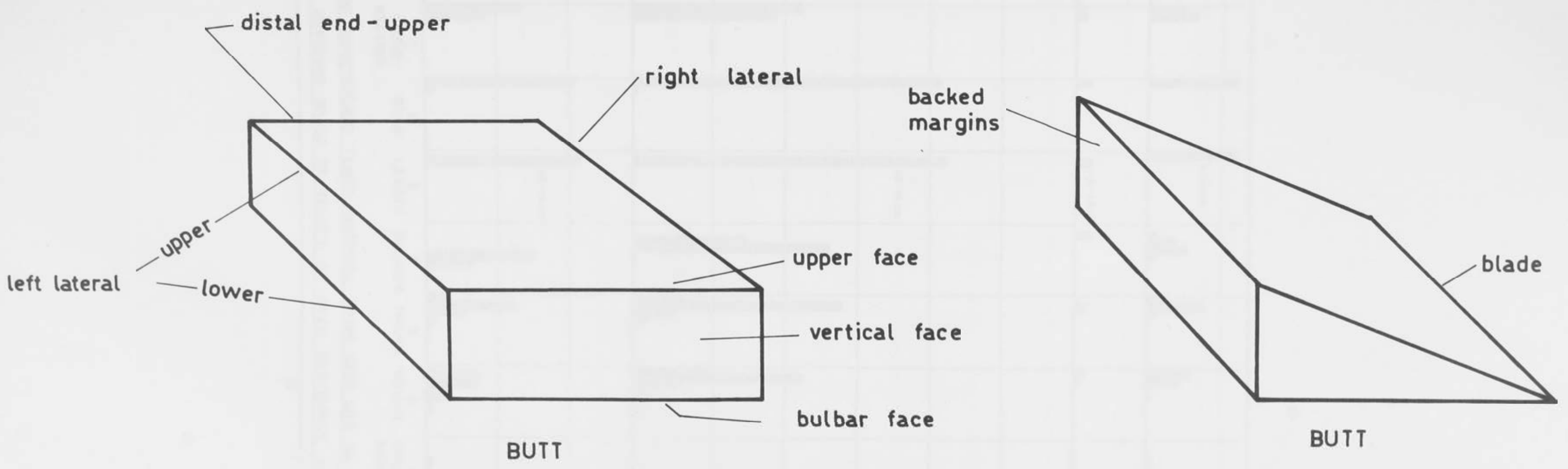


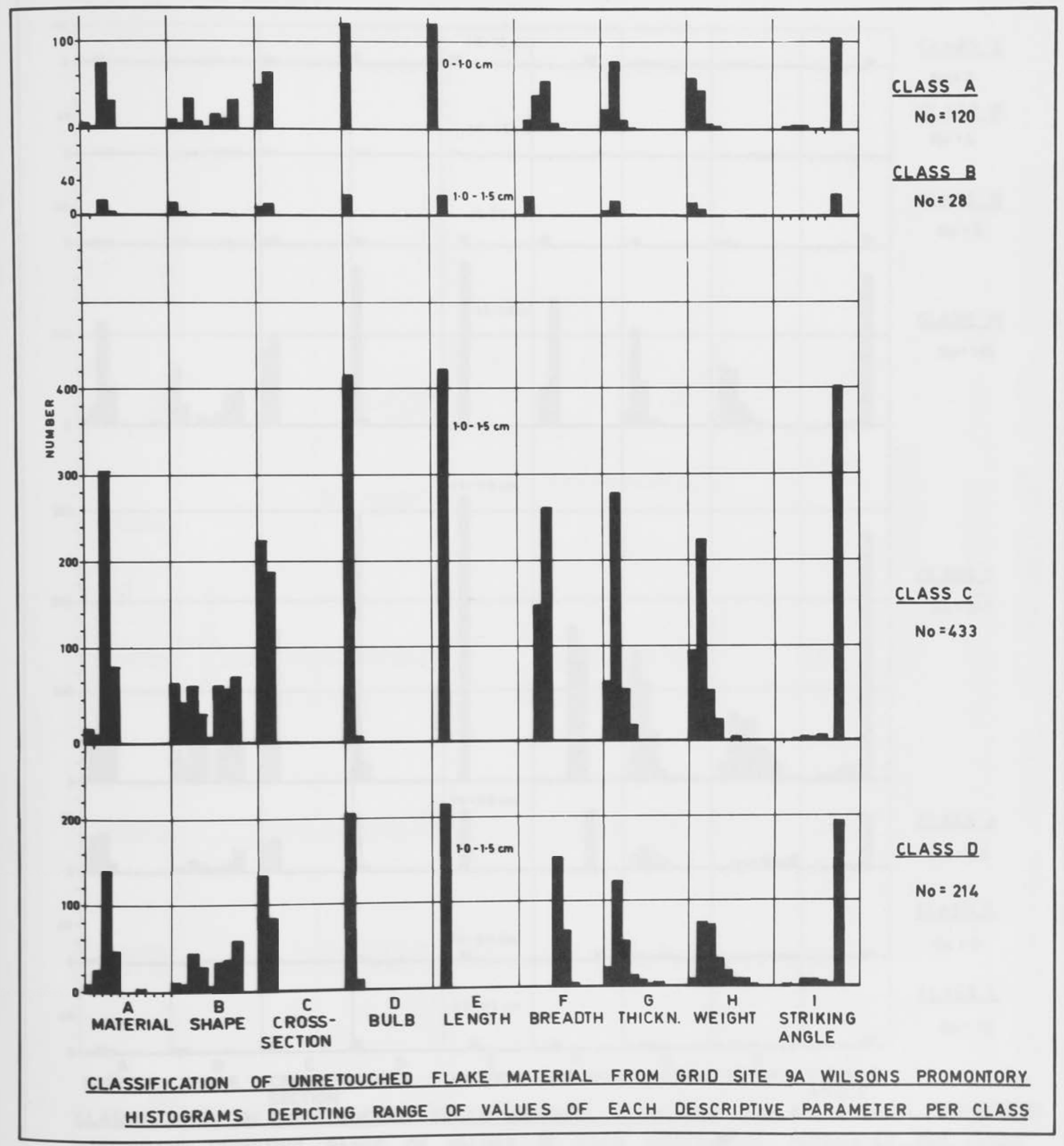

D 12.1 


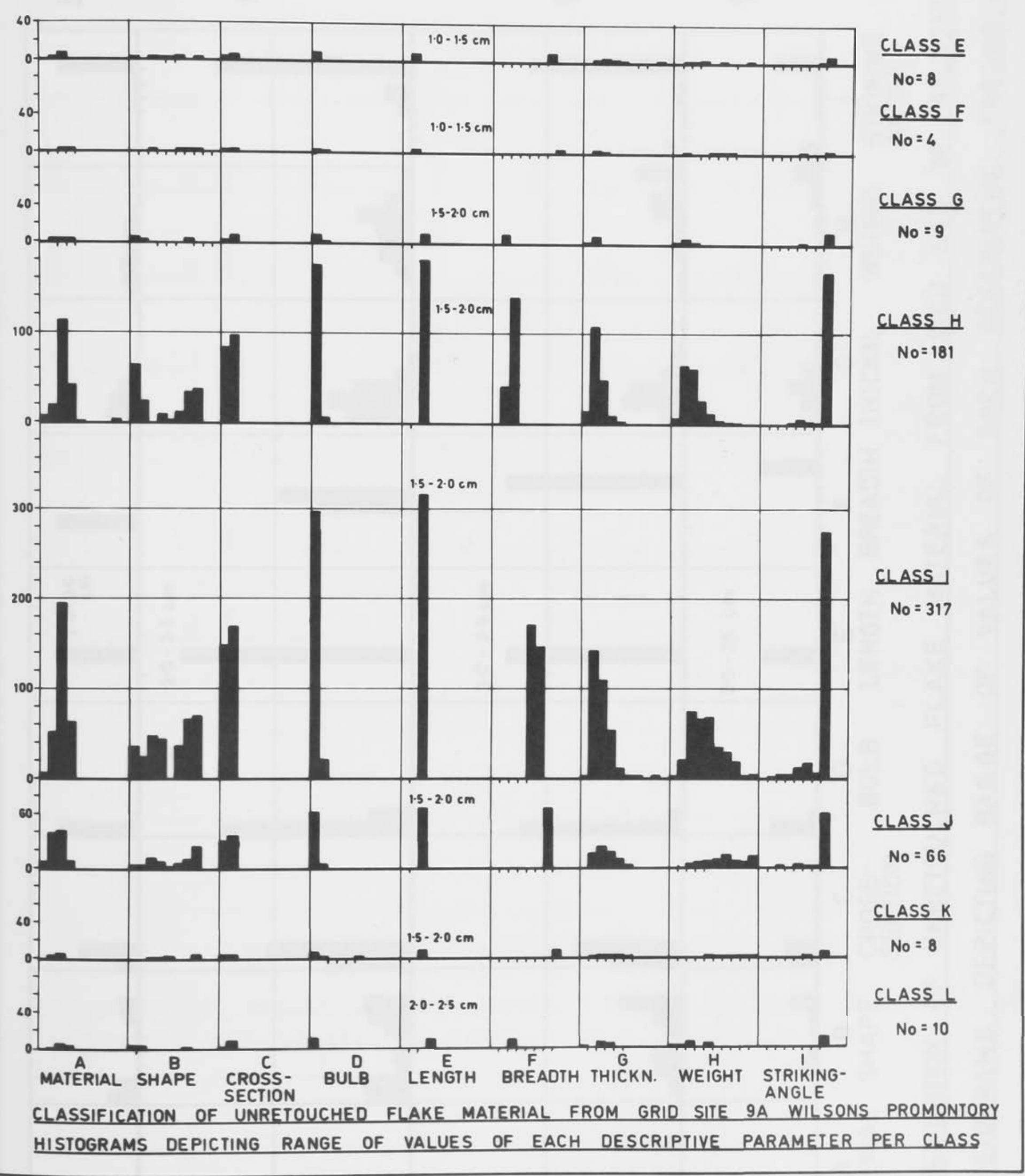

D 12.2 


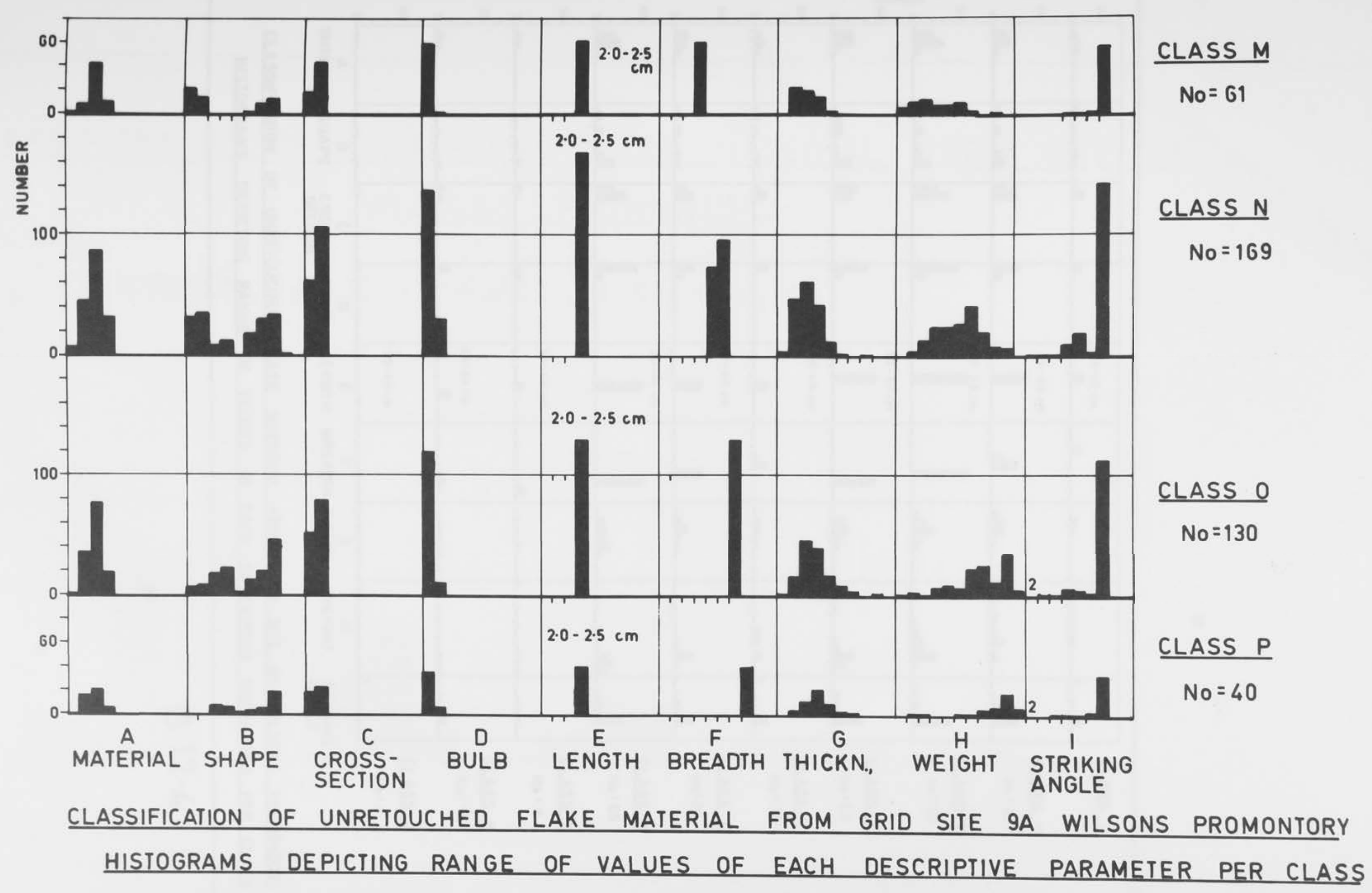

D $12 \cdot 3$ 


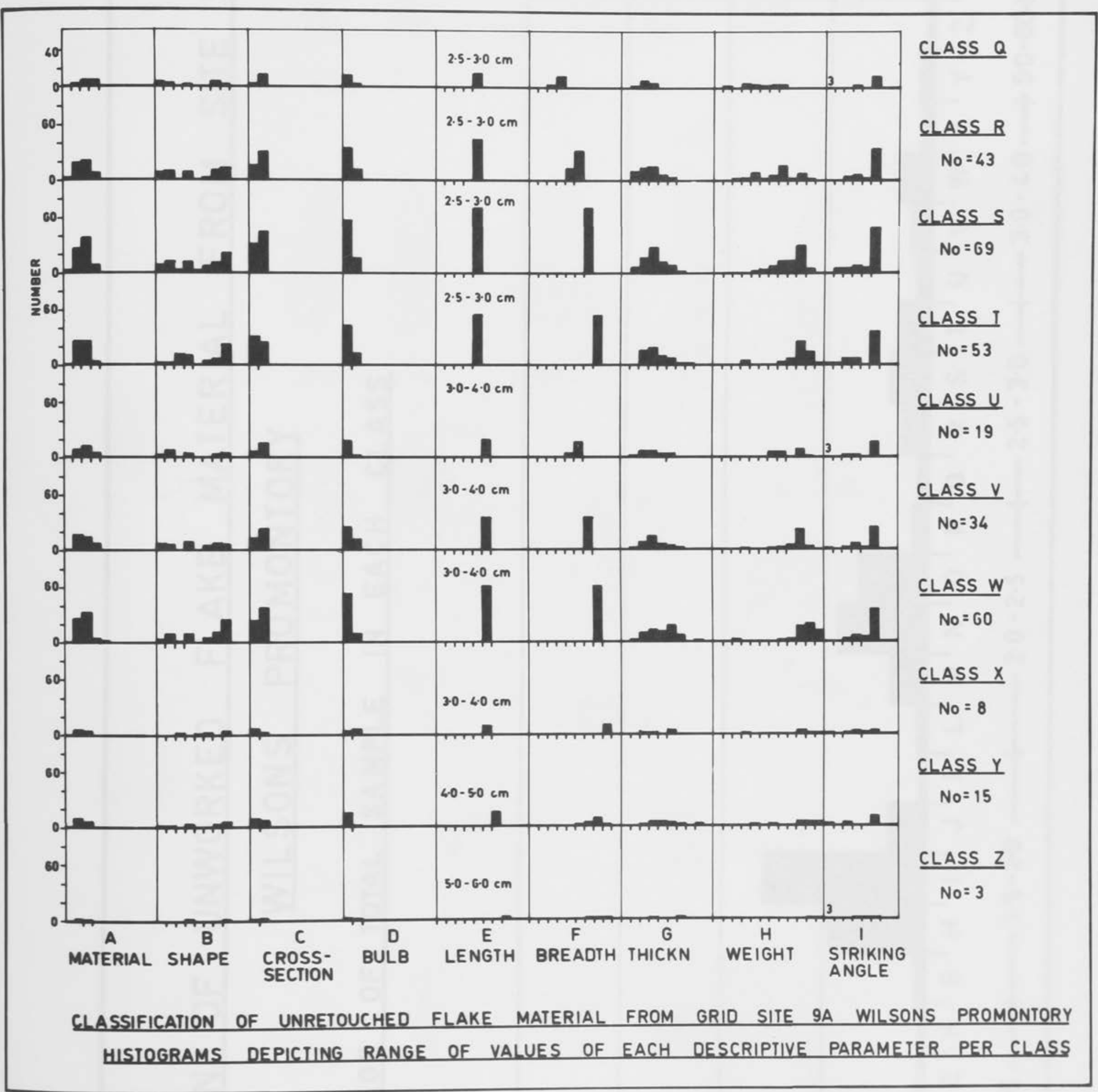

D $12 \cdot 4$ 


\section{CLASSIFICATION OF UNWORKED FLAKE MATERIAL FROM SITE 9A WILSONS PROMONTORY}

\section{PERCENTAGE OF TOTAL SAMPLE IN EACH CLASS}

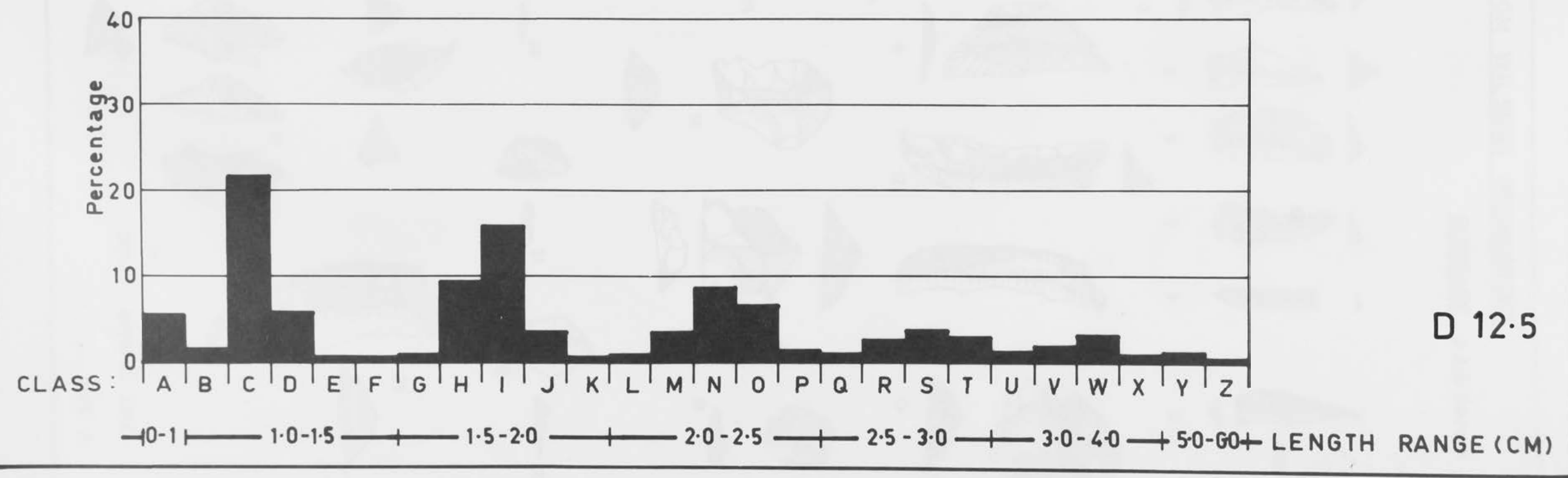


FLAKE MATERIAL FROM WILSONS PROMONTORY Diagram $12 \cdot 6$

SURFACE A\&B Series
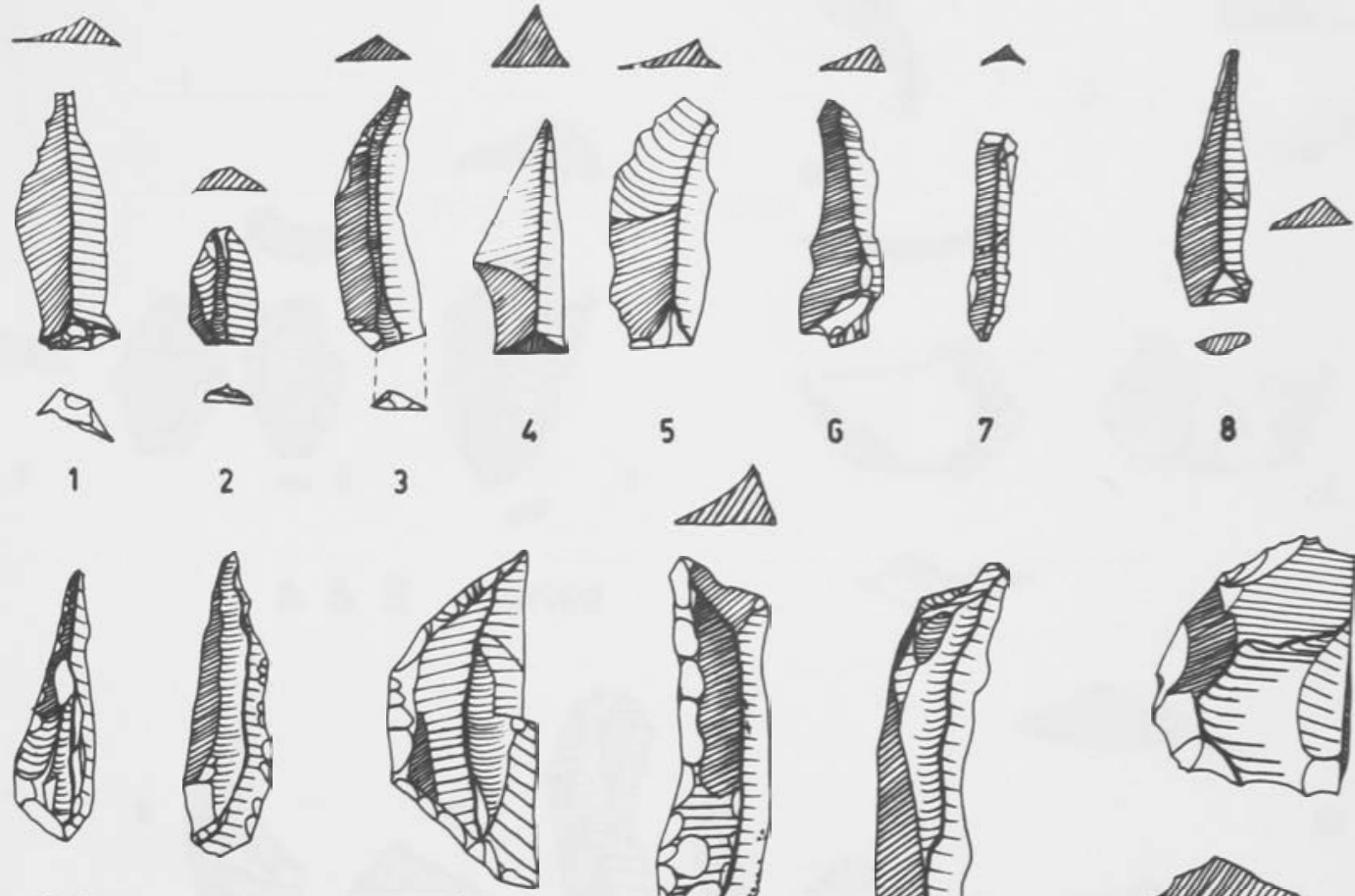

and

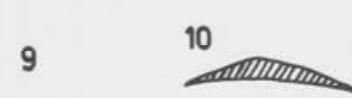

11
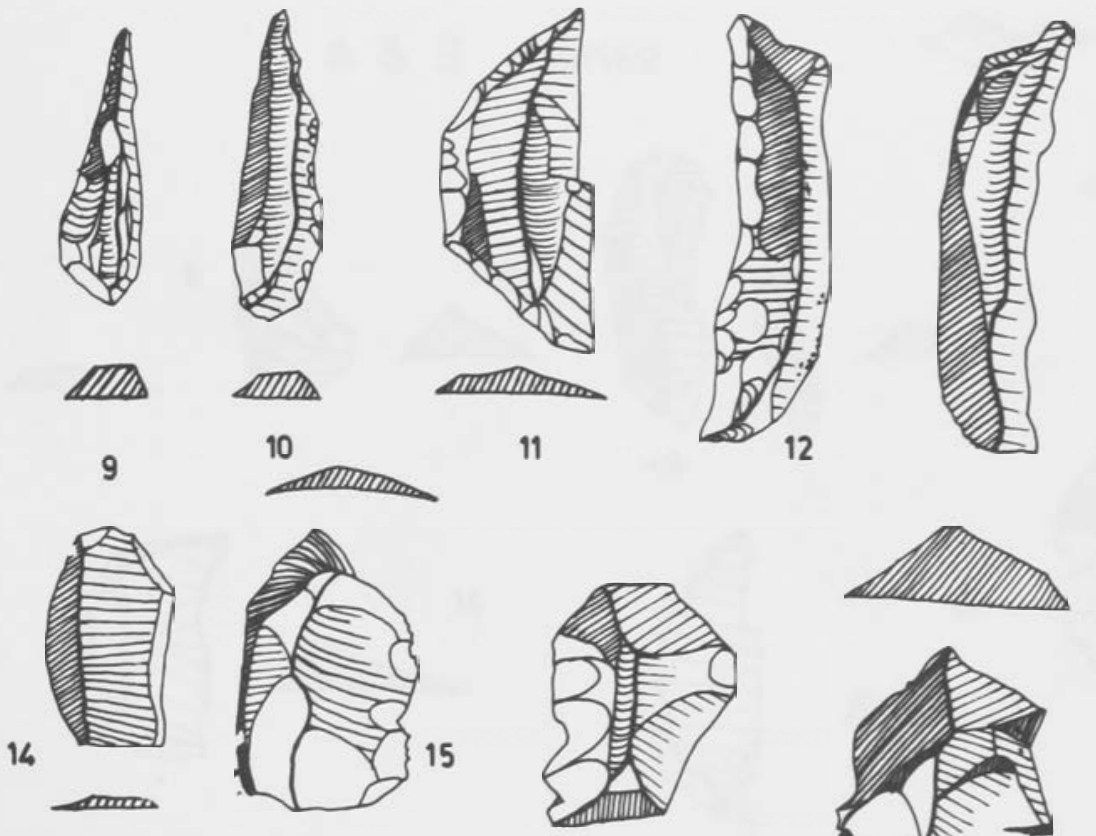

16
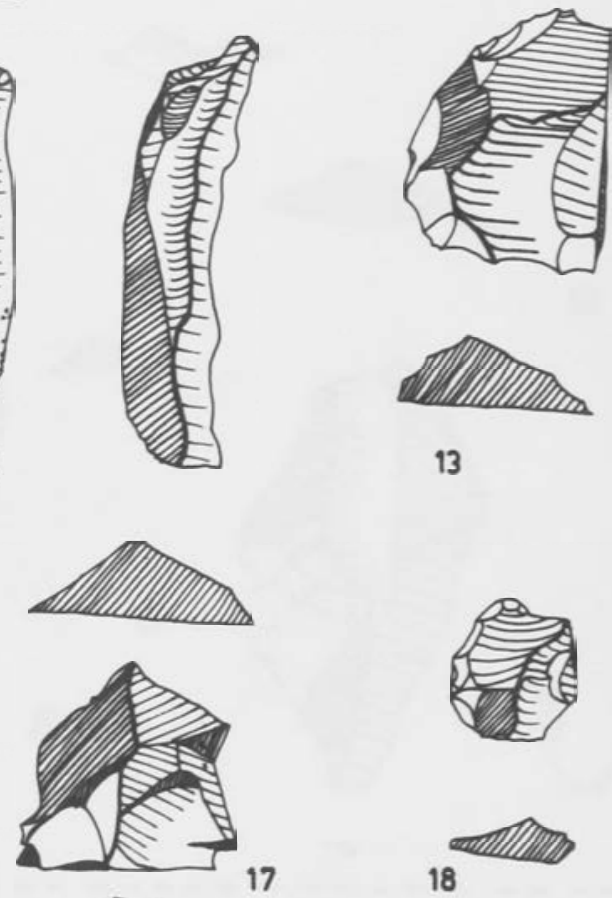

\%
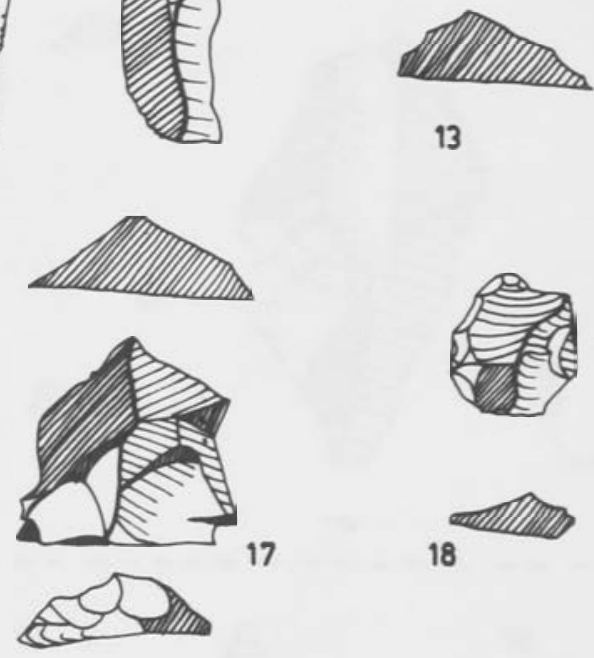

19

-
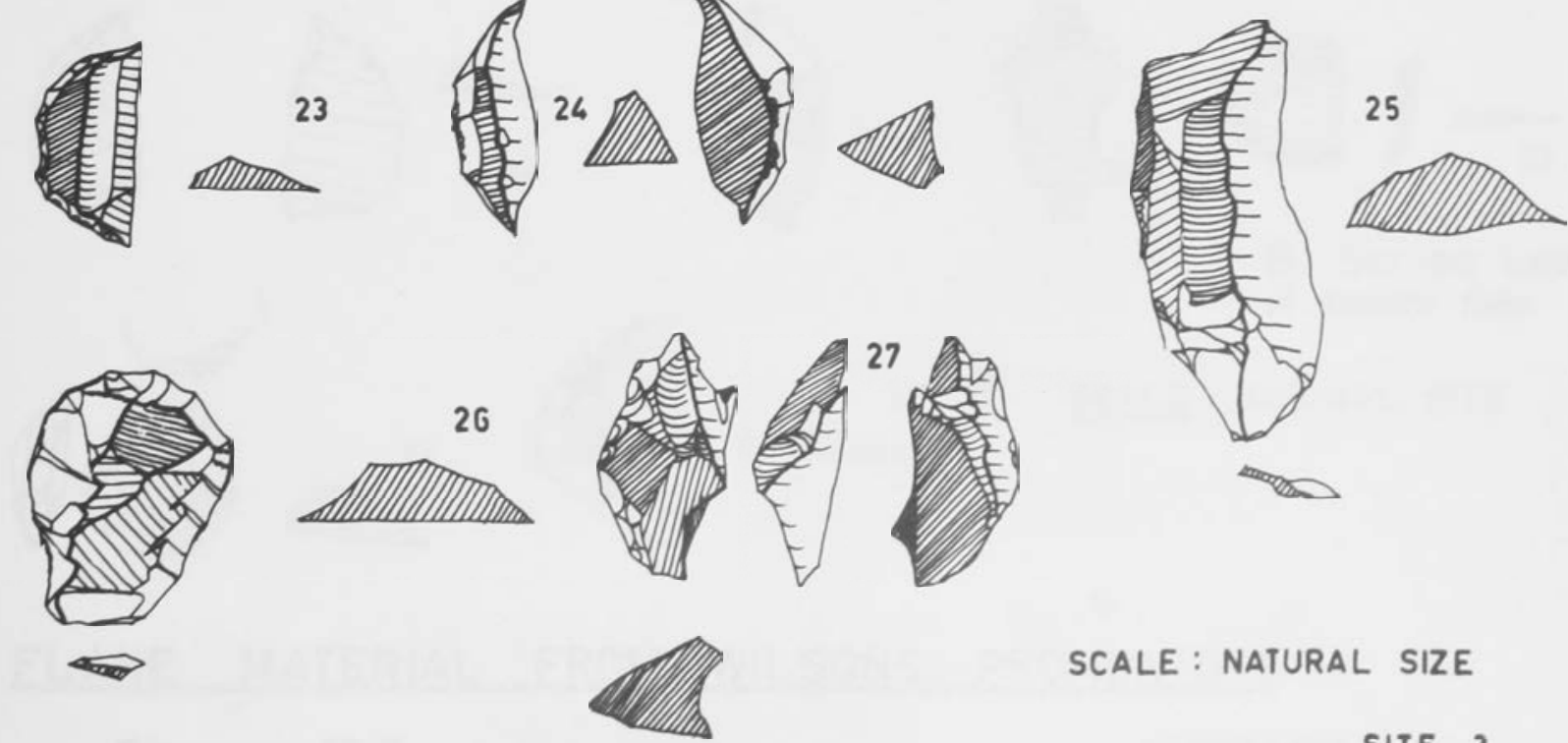

SCALE : NATURAL SIZE 


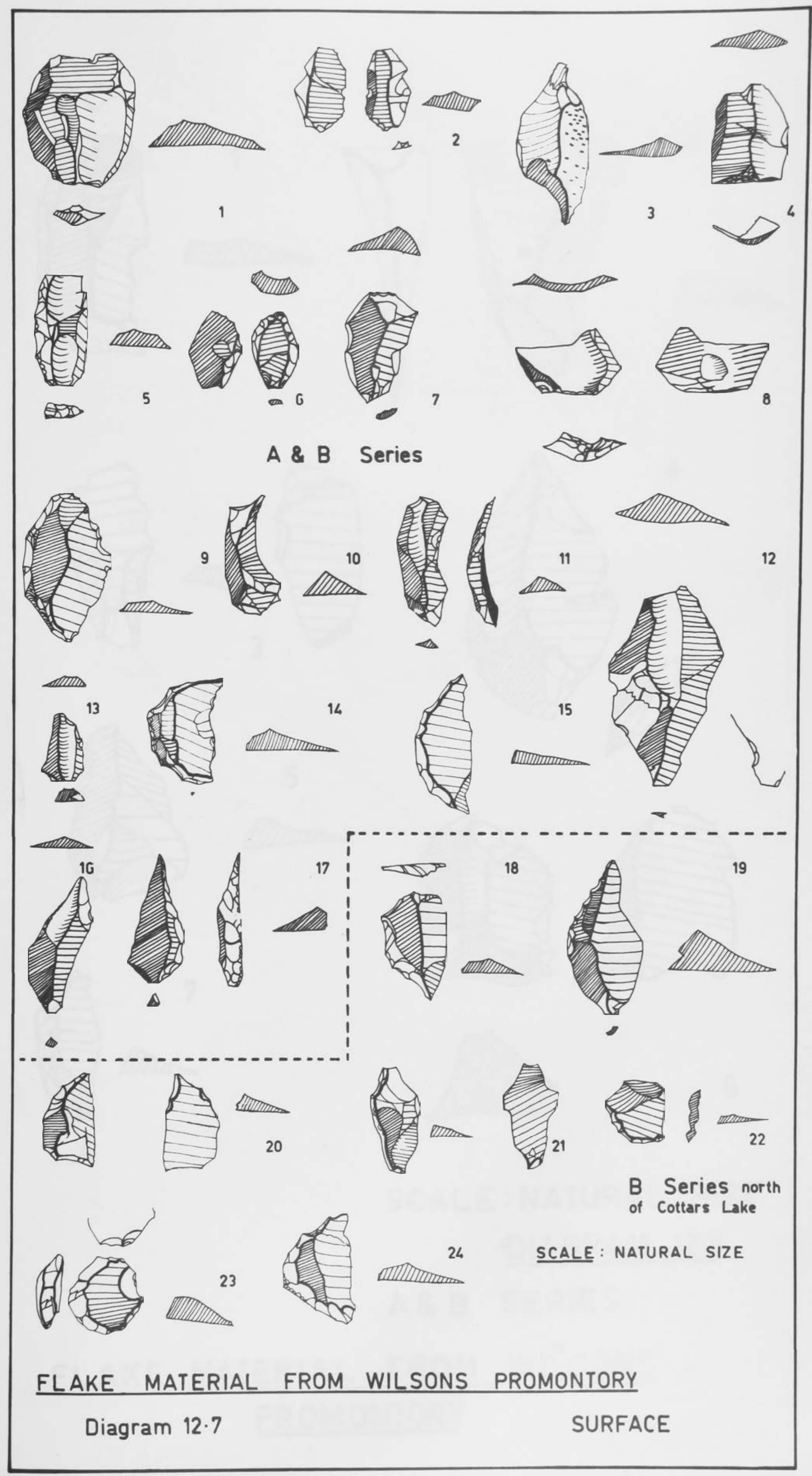



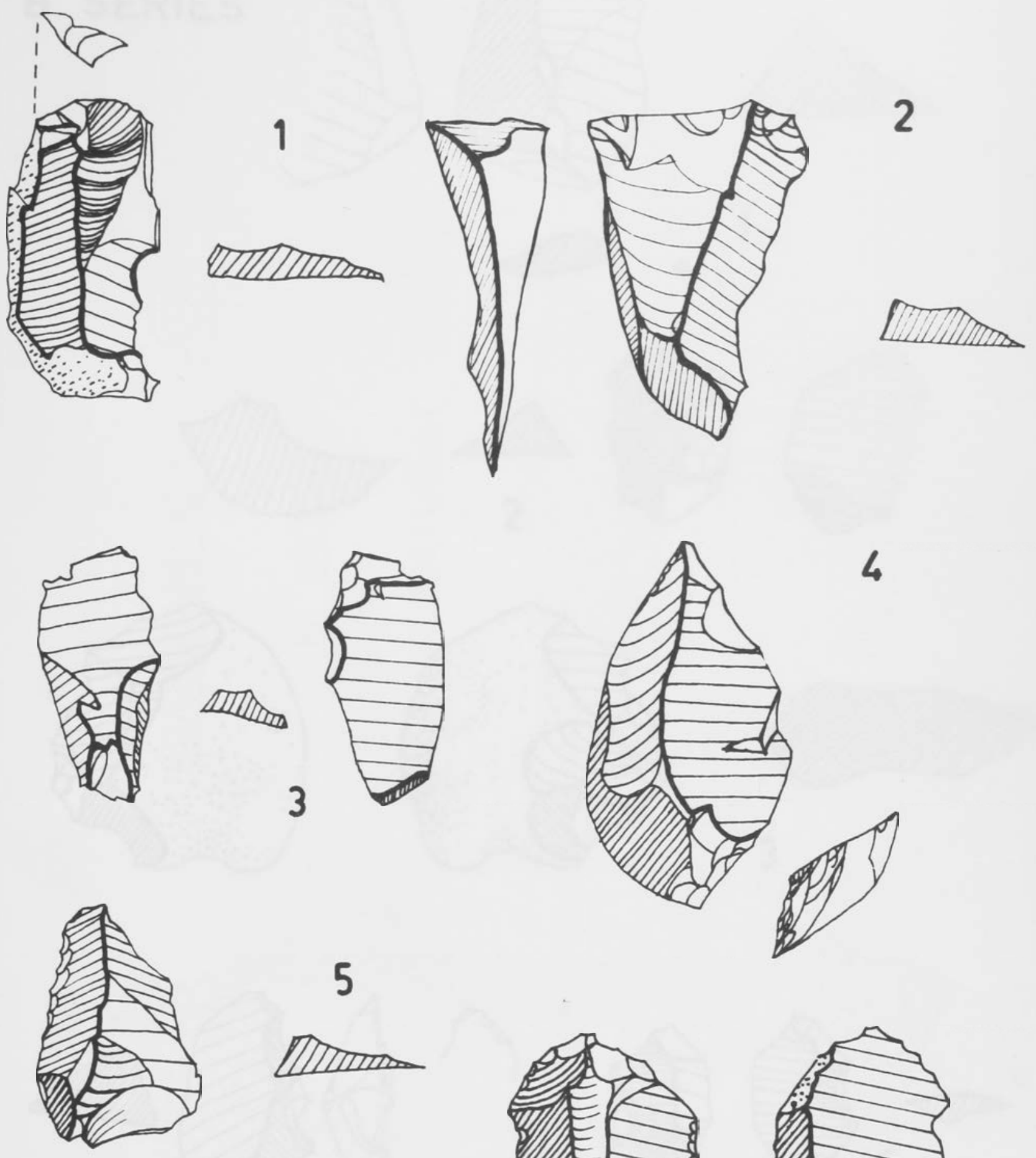

5

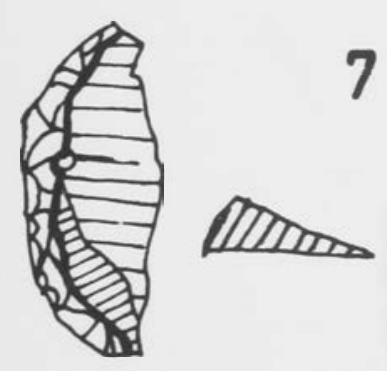

-

$\Delta$
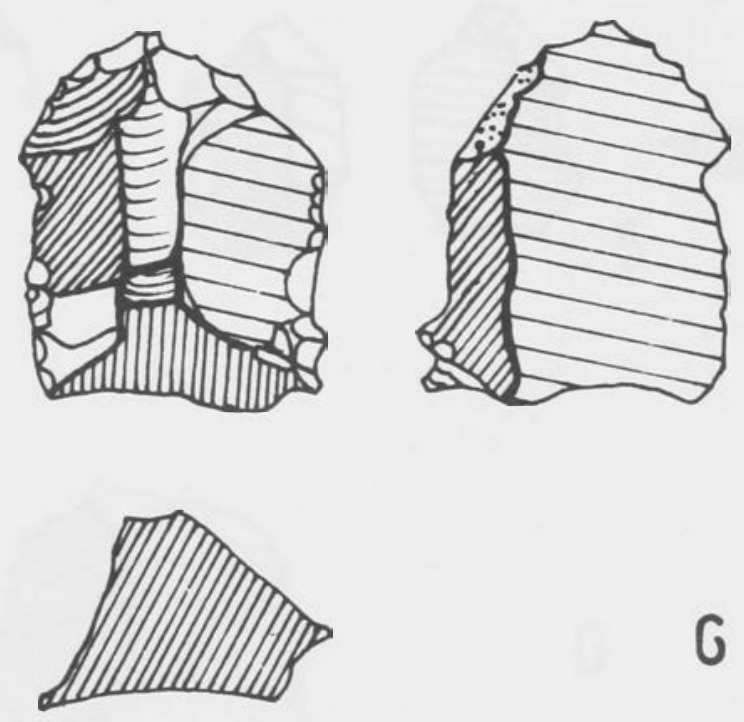

G

SCALE: NATURAL SIZE DIAGRAM 12.8

$A \& B$ SERIES

FLAKE MATERIAL FROM WILSONS PROMONTORY 

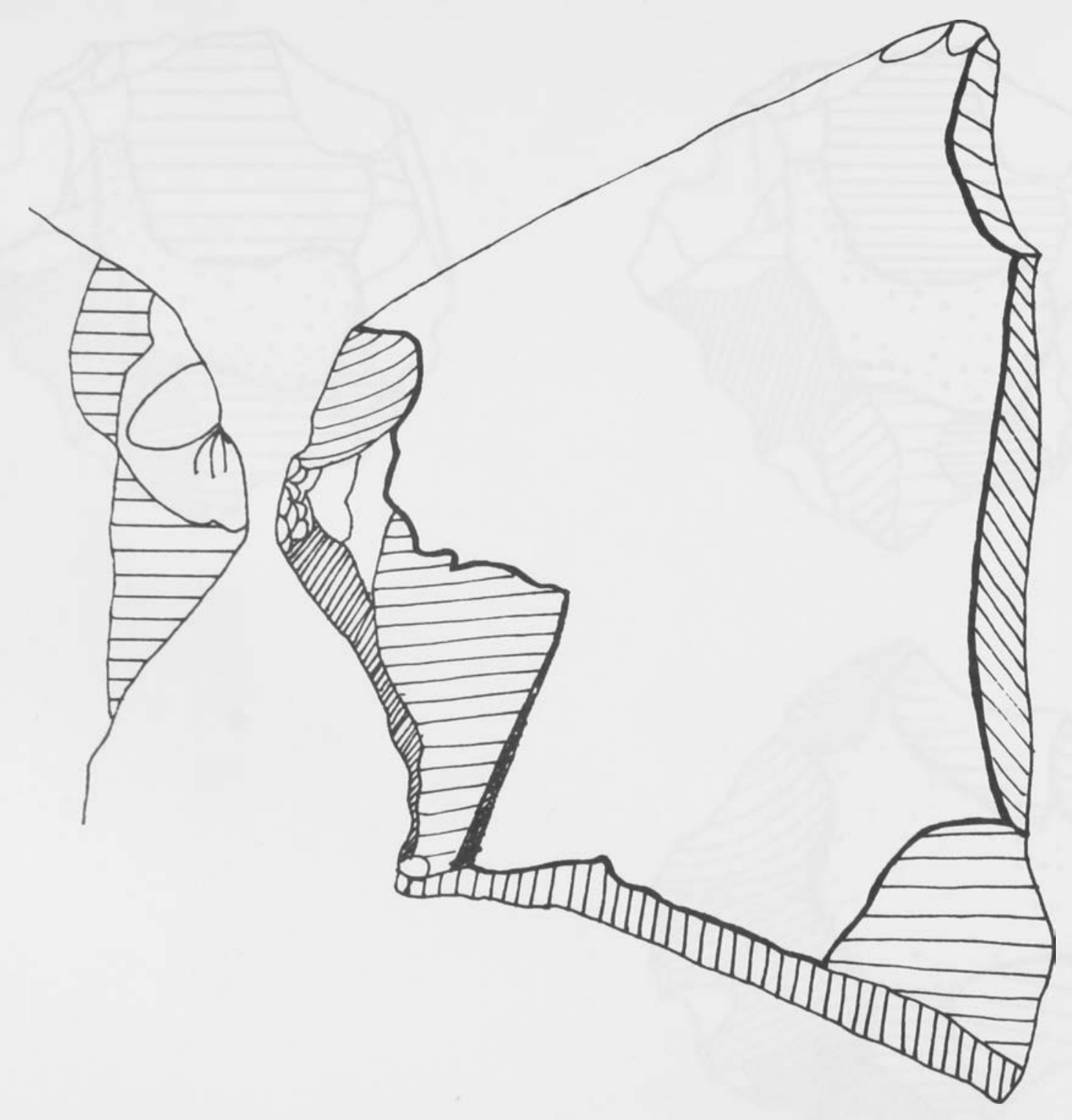

\section{DIAGRAM $12 \cdot 10$}

B SERIES

SCALE : NATURAL SIZE

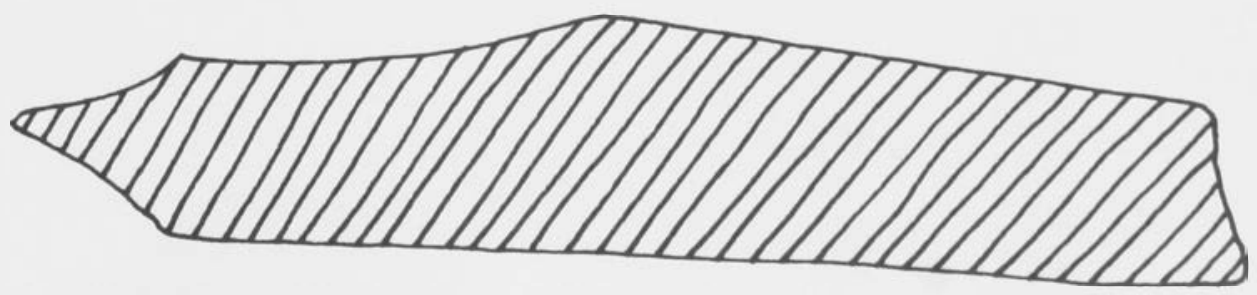



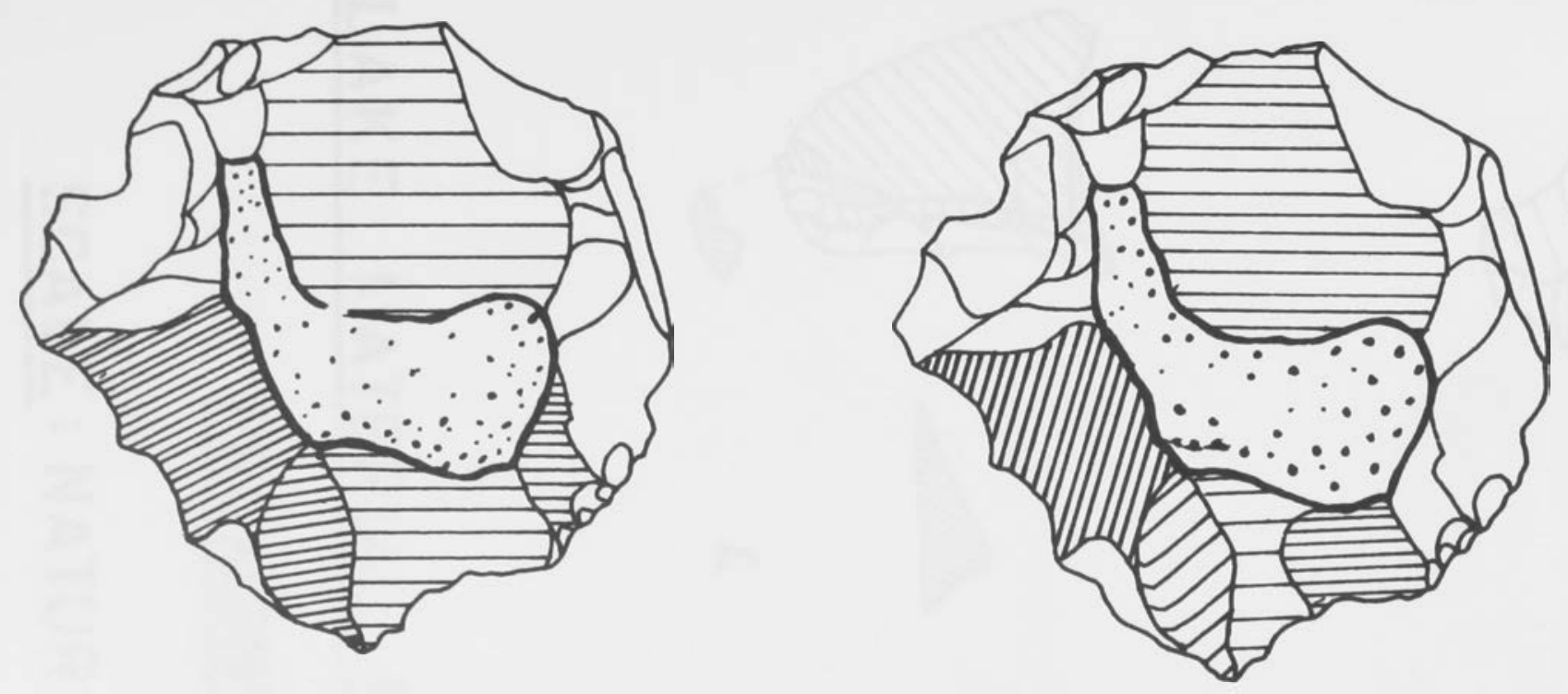

DIAGRAM 12.11

B SERIES

SCALE: NATURAL SIZE
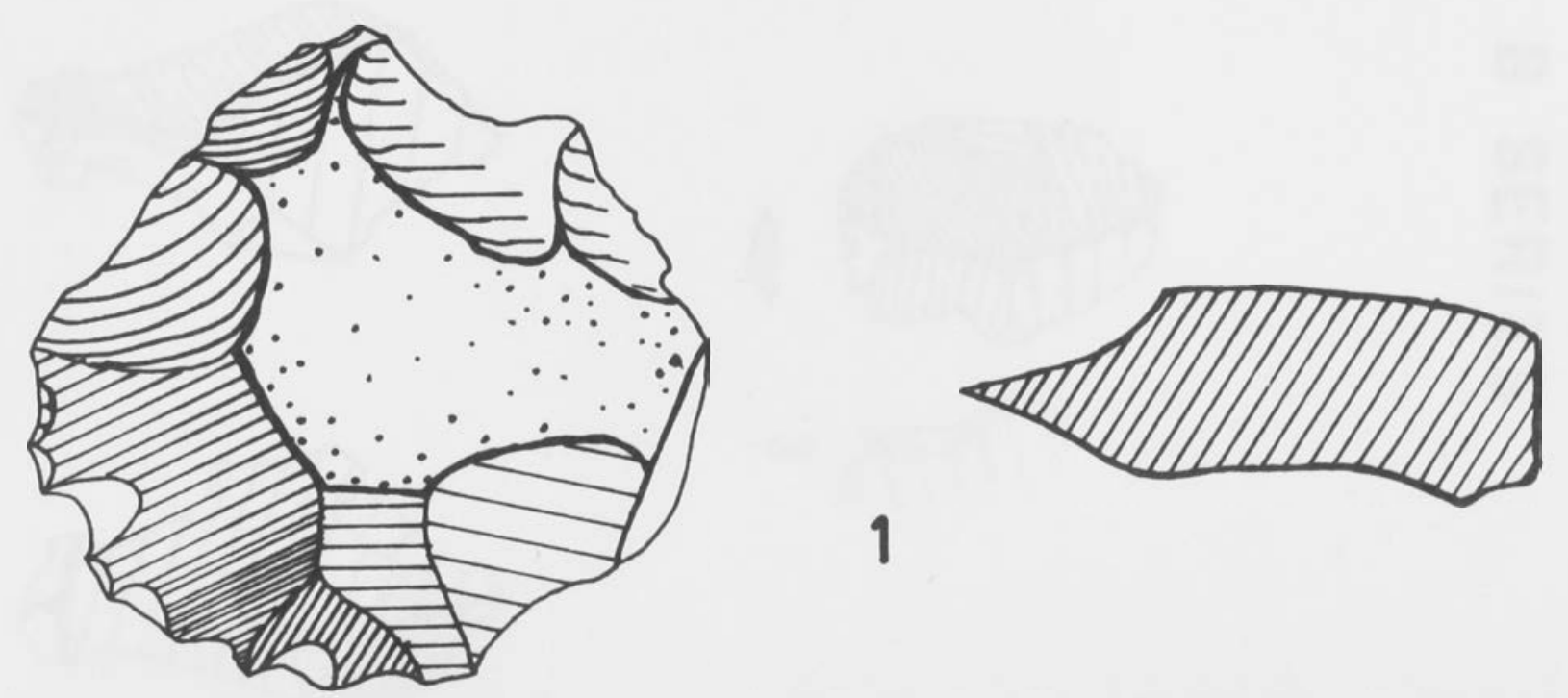


\section{DIAGRAM $12 \cdot 12$}

B SERIES
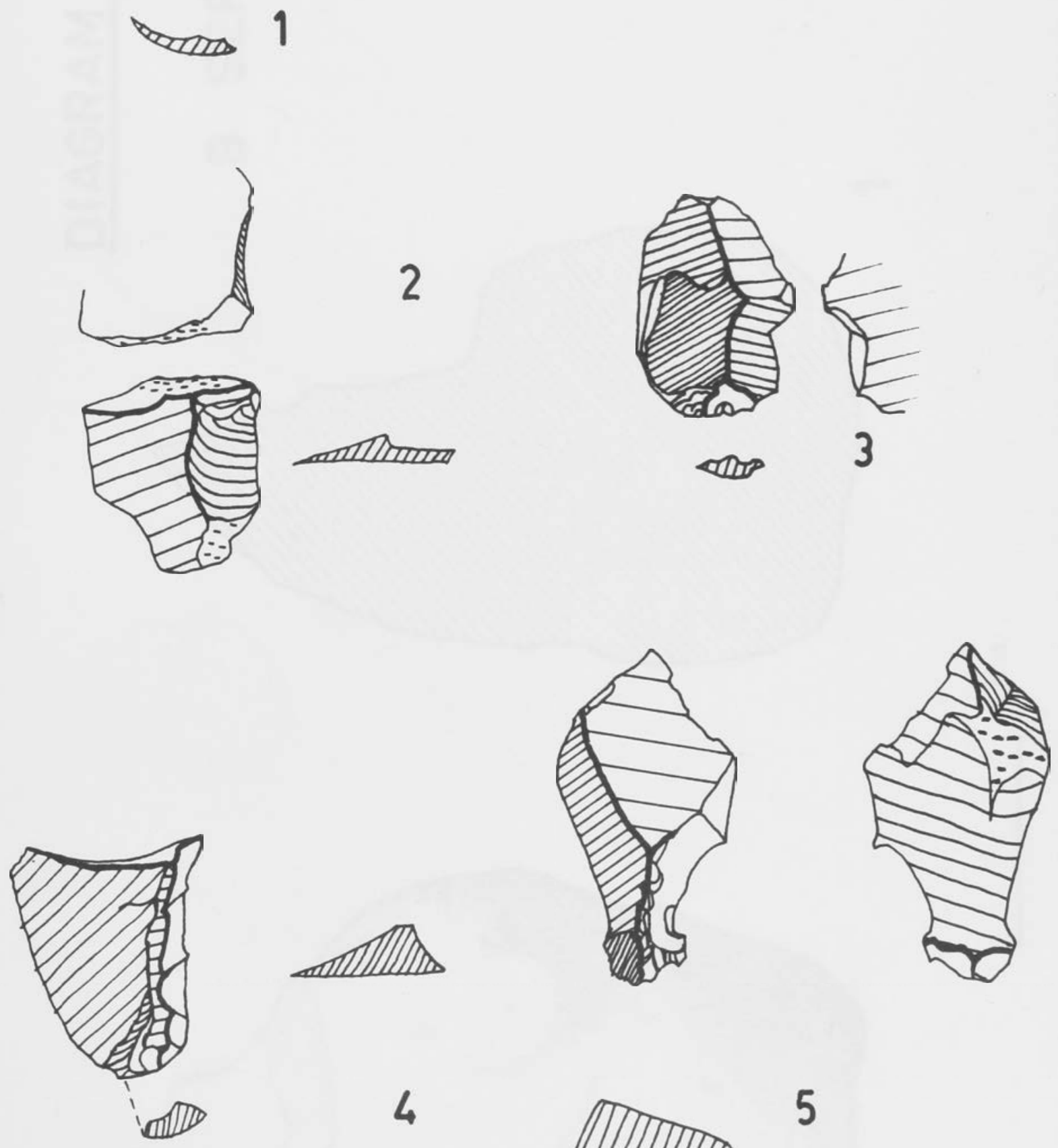

4

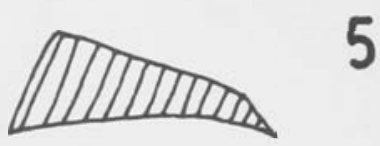

FLAKE MIATERIAL FROM WILSONS

PROMONTORY

SCALE: NATURAL SIZE 
SCALE: HALF NATURAL SIZE

DIAGRAM $12 \cdot 13$
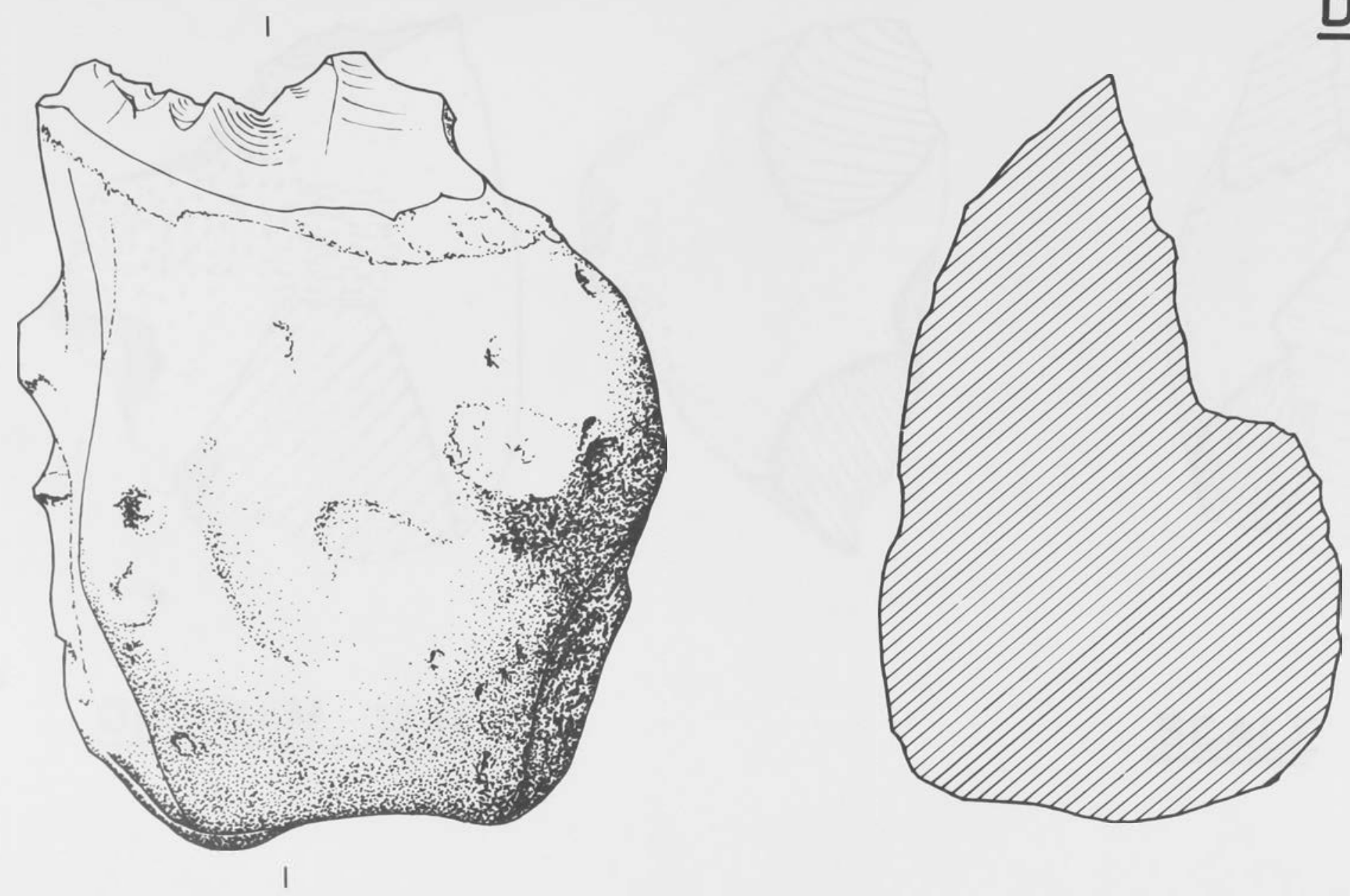

B SERIES

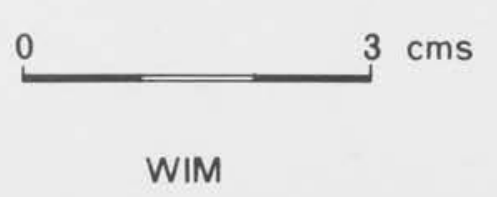



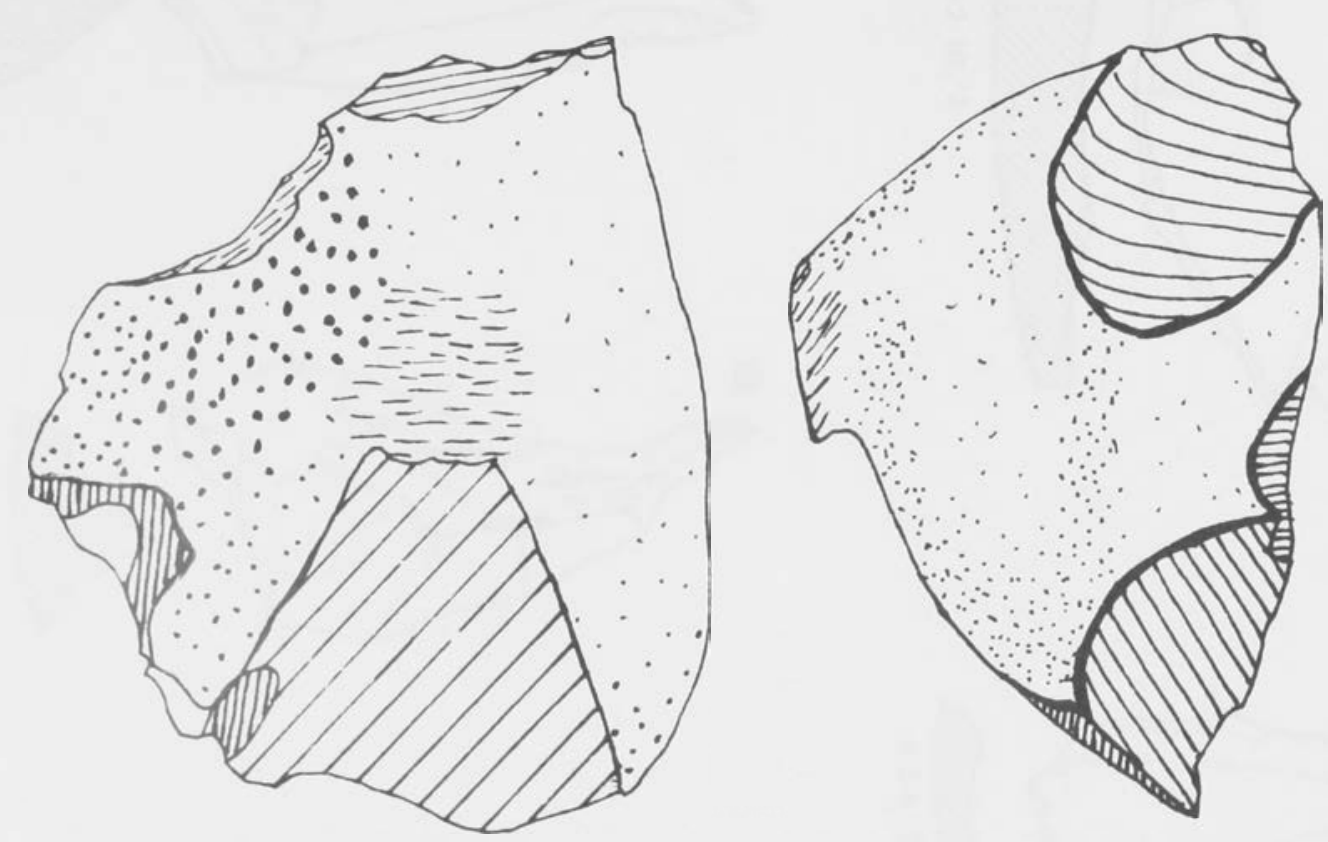

DIAGRAM $12 \cdot 14$

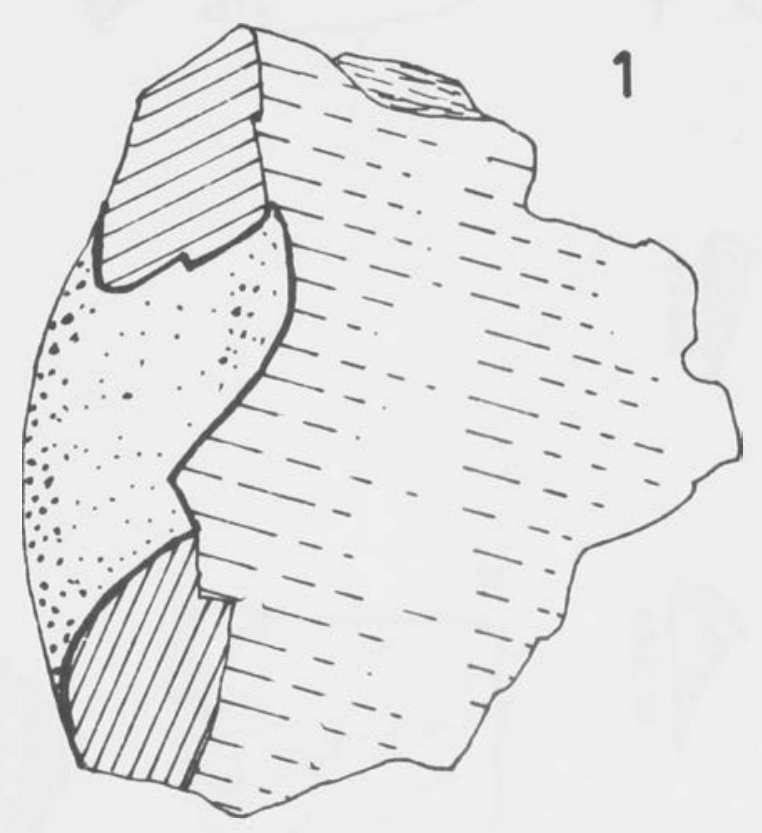

SCALE : NATURAL SIZE 
Flake material from Excavation 9A/6 Wilsons Promontory
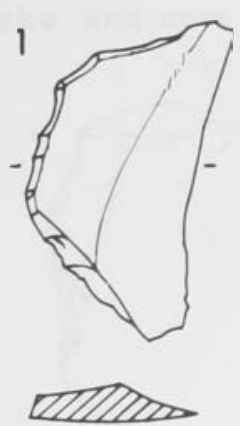

B. $3 \cdot 7 / 1$
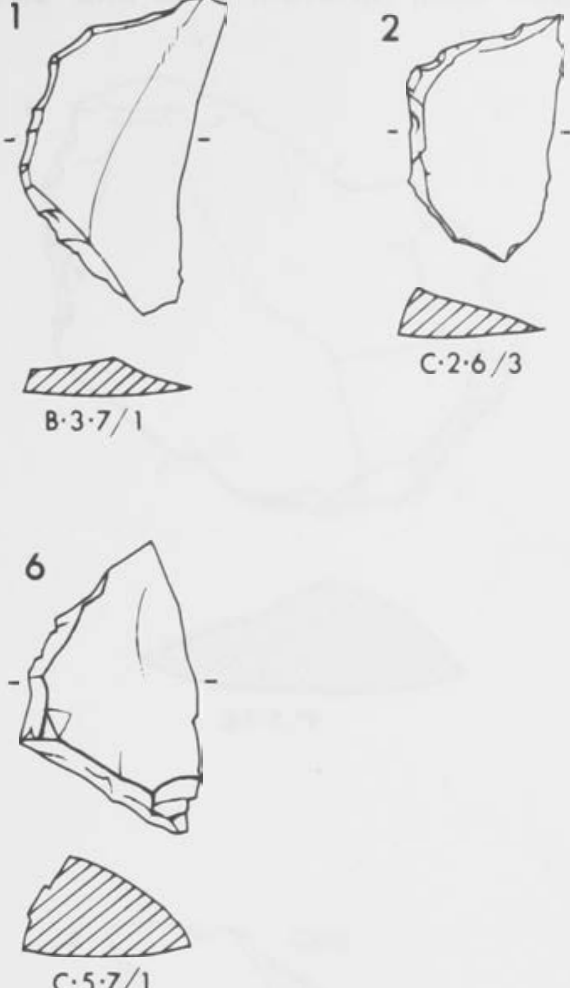

C. $5 \cdot 7$

9

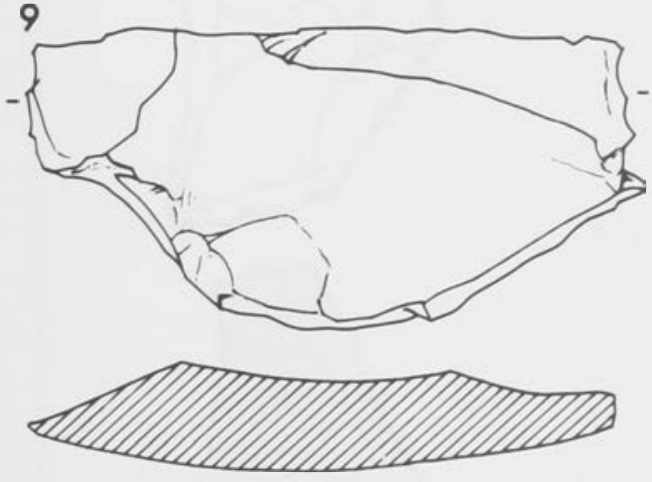

B. $2 \cdot 10 / 2$
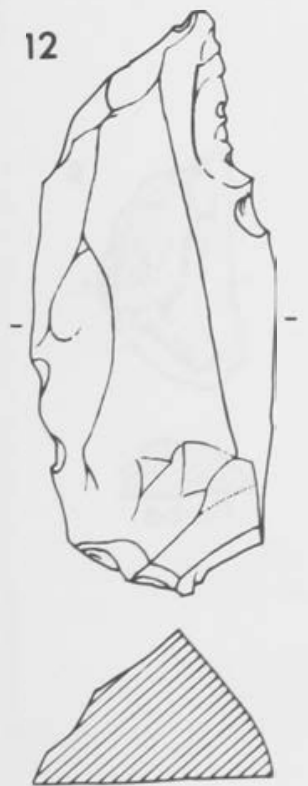

A.1 $1 / 1$
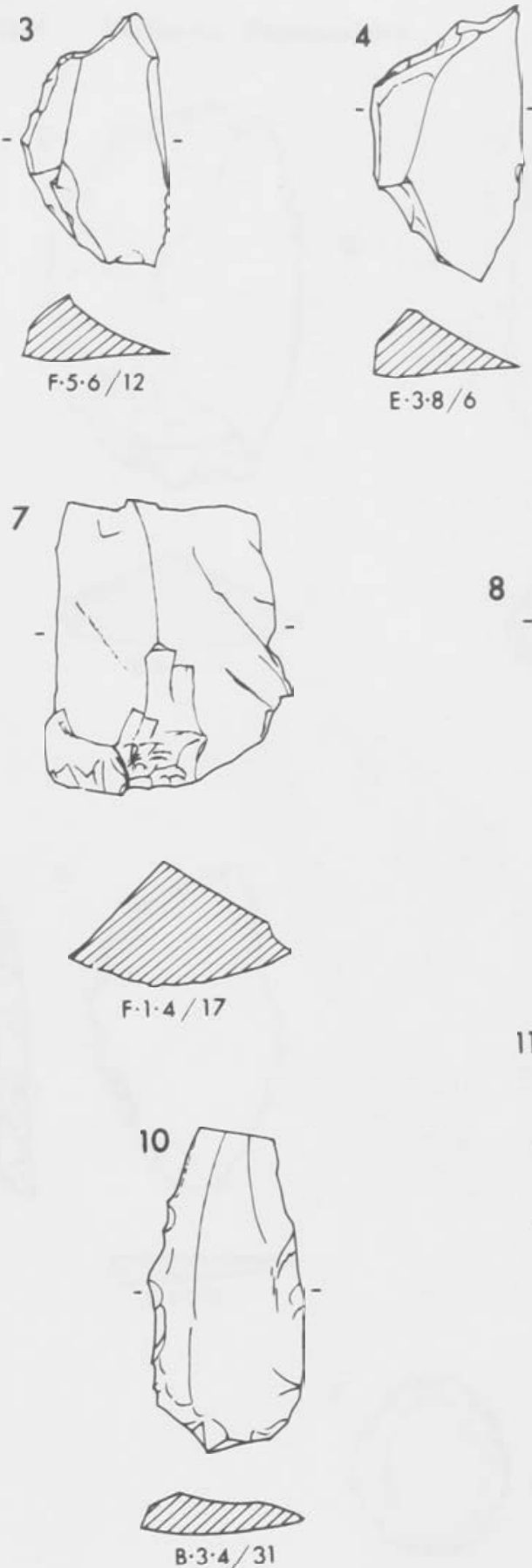

Diagram $12 \cdot 15$

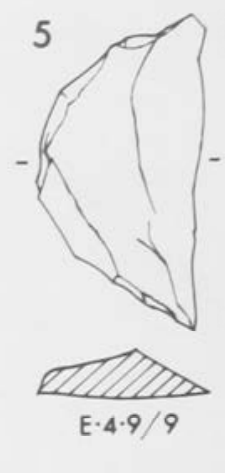

8
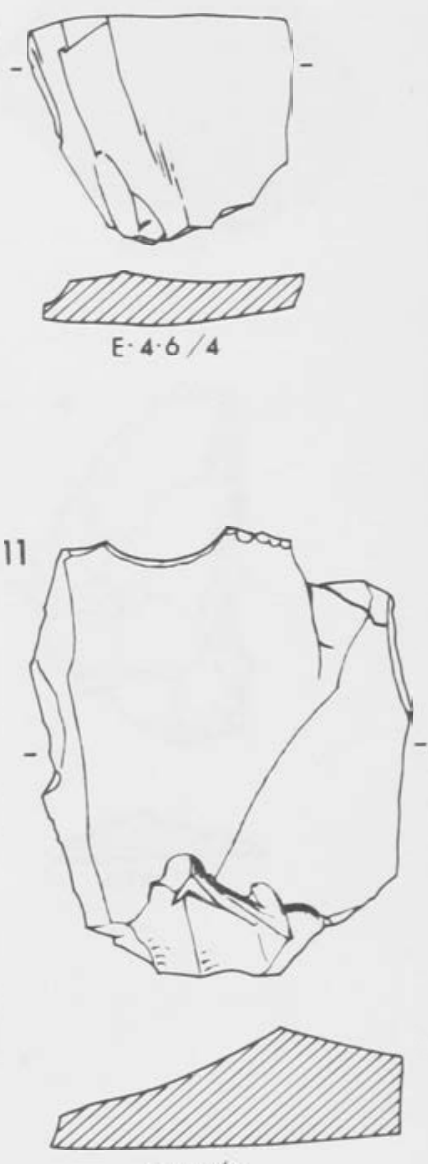

E. $4 \cdot 6 / 3$
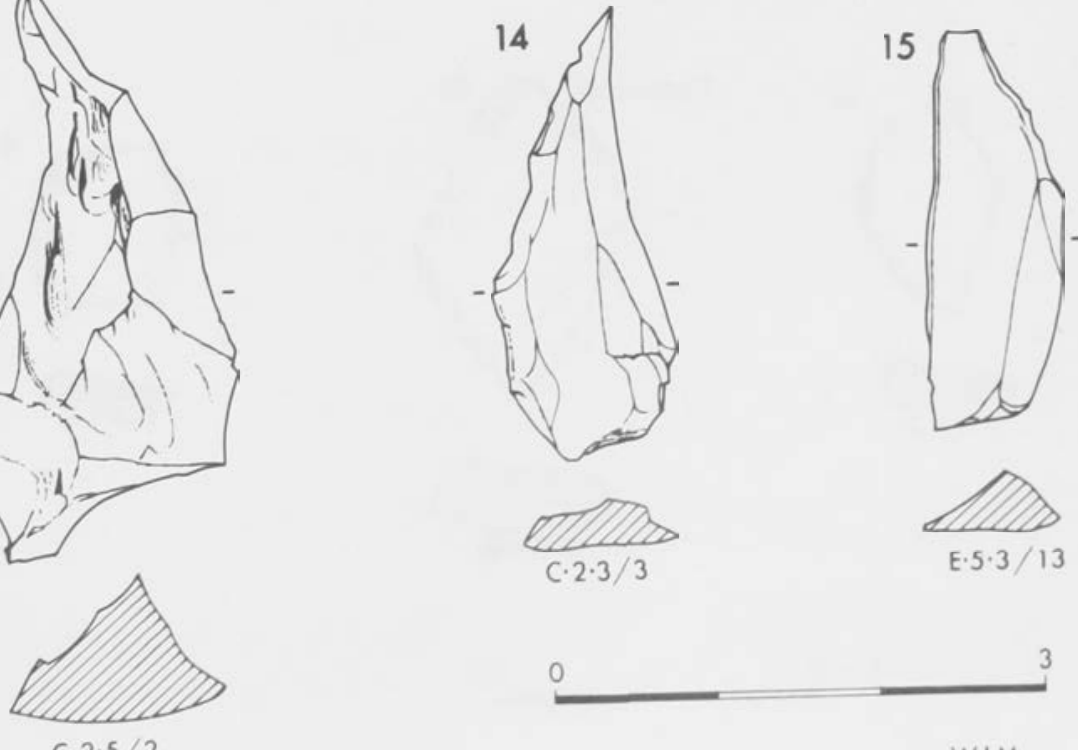

C. $2.5 / 2$ 
Flake and core material from Excavation 11/1 Wilsons Promontory
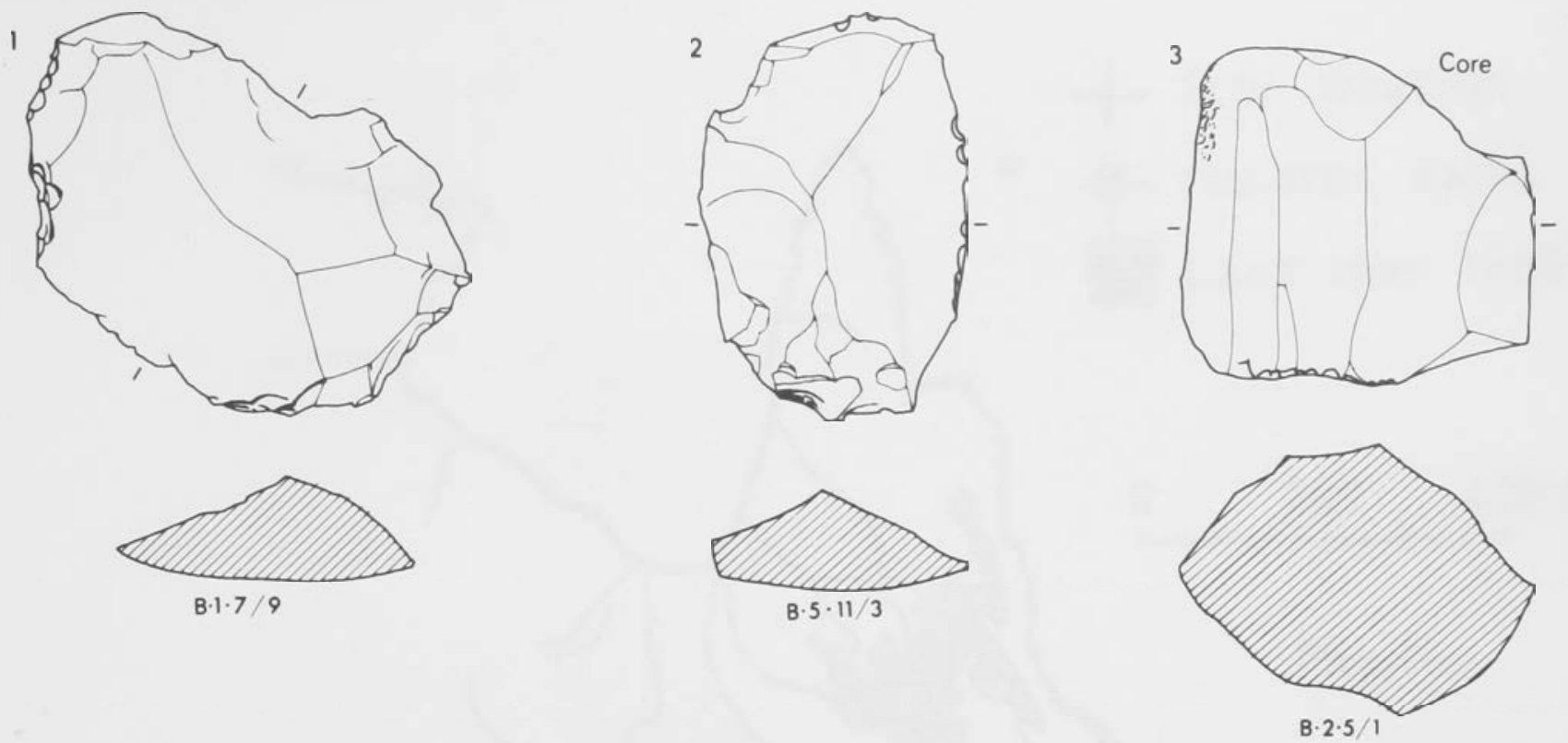

4
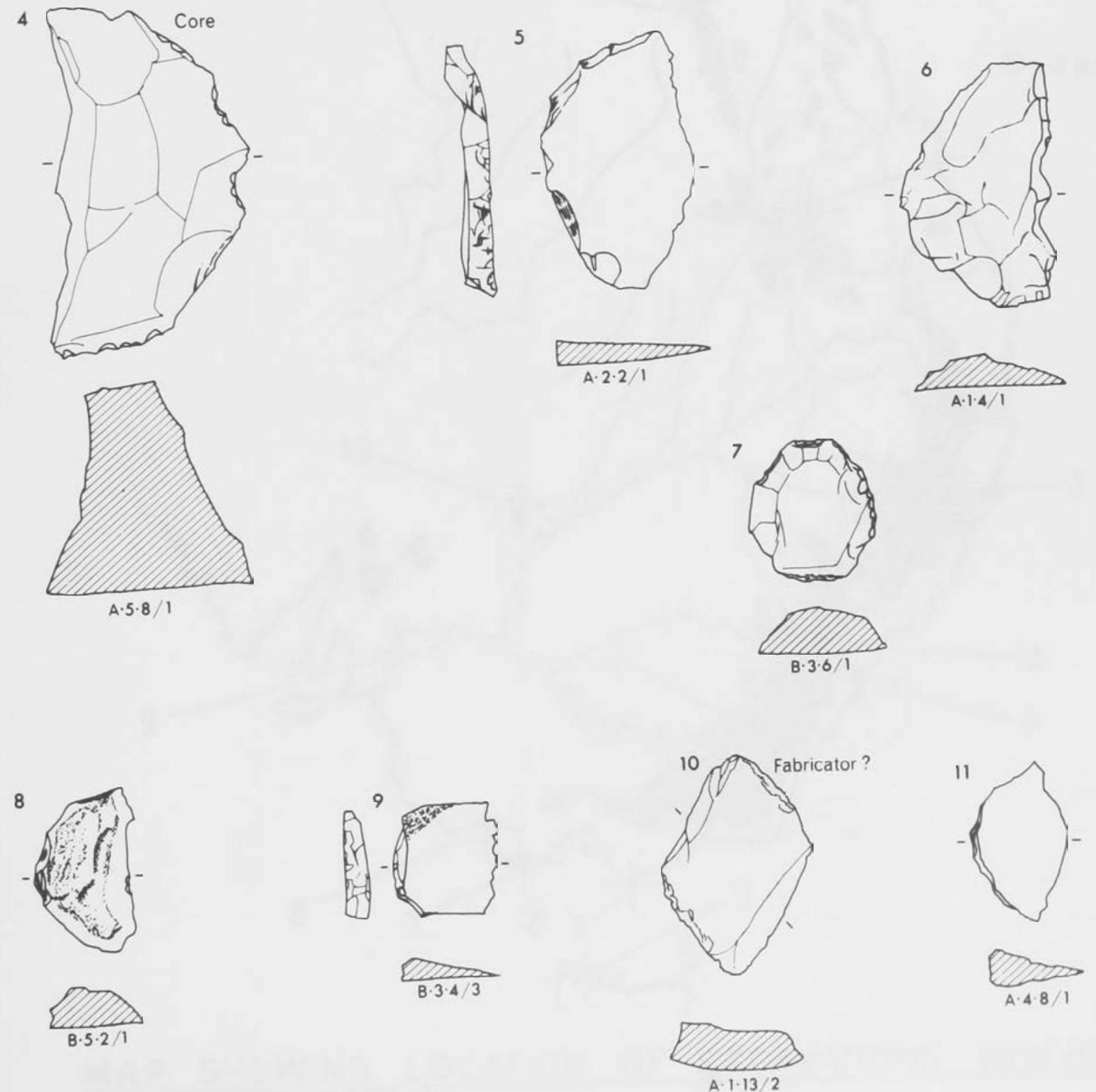


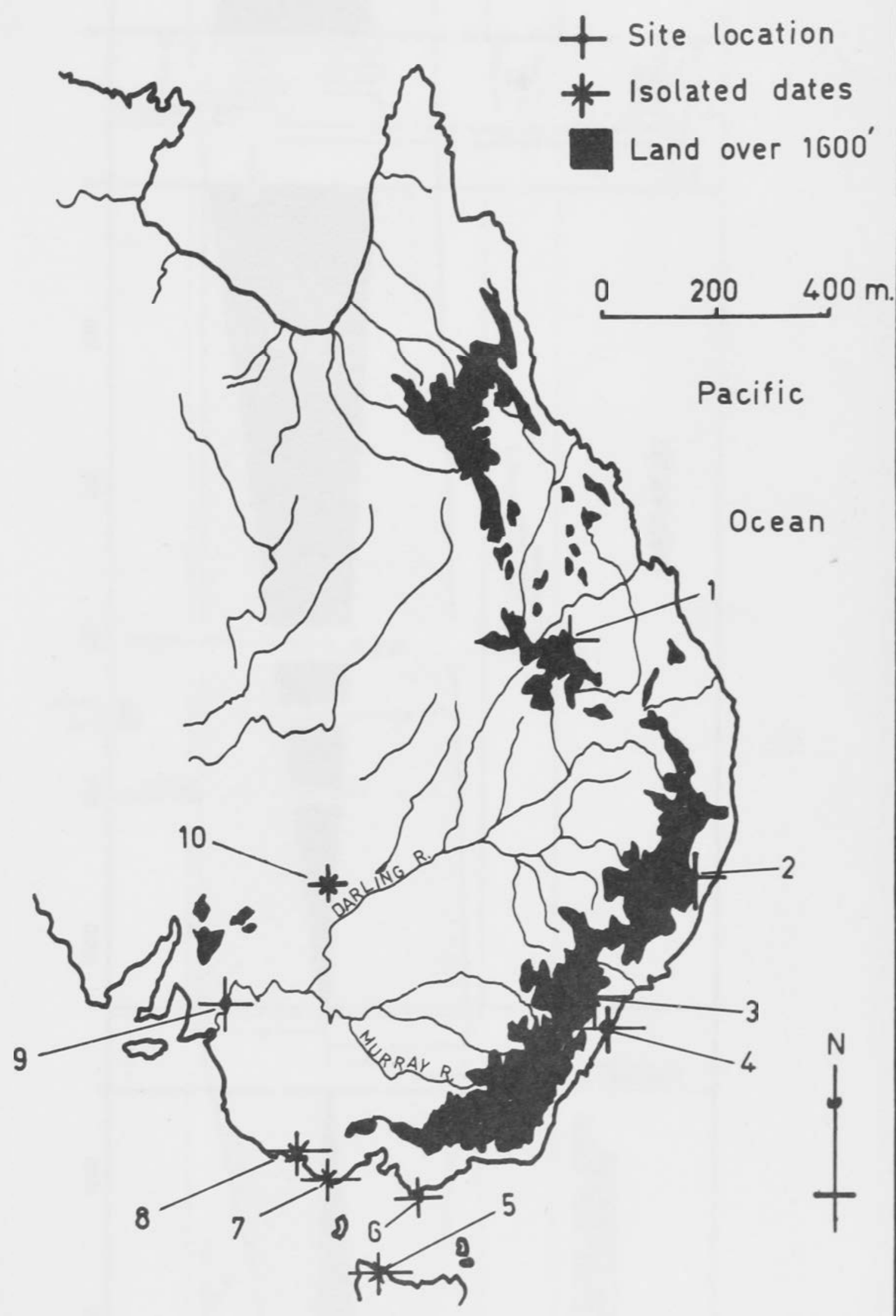

MAP SHOWING LOCATION OF EXCAVATIONS WHERE CARBON 14 DATES ARE AVAILABLE DIAGRAM 13.1 

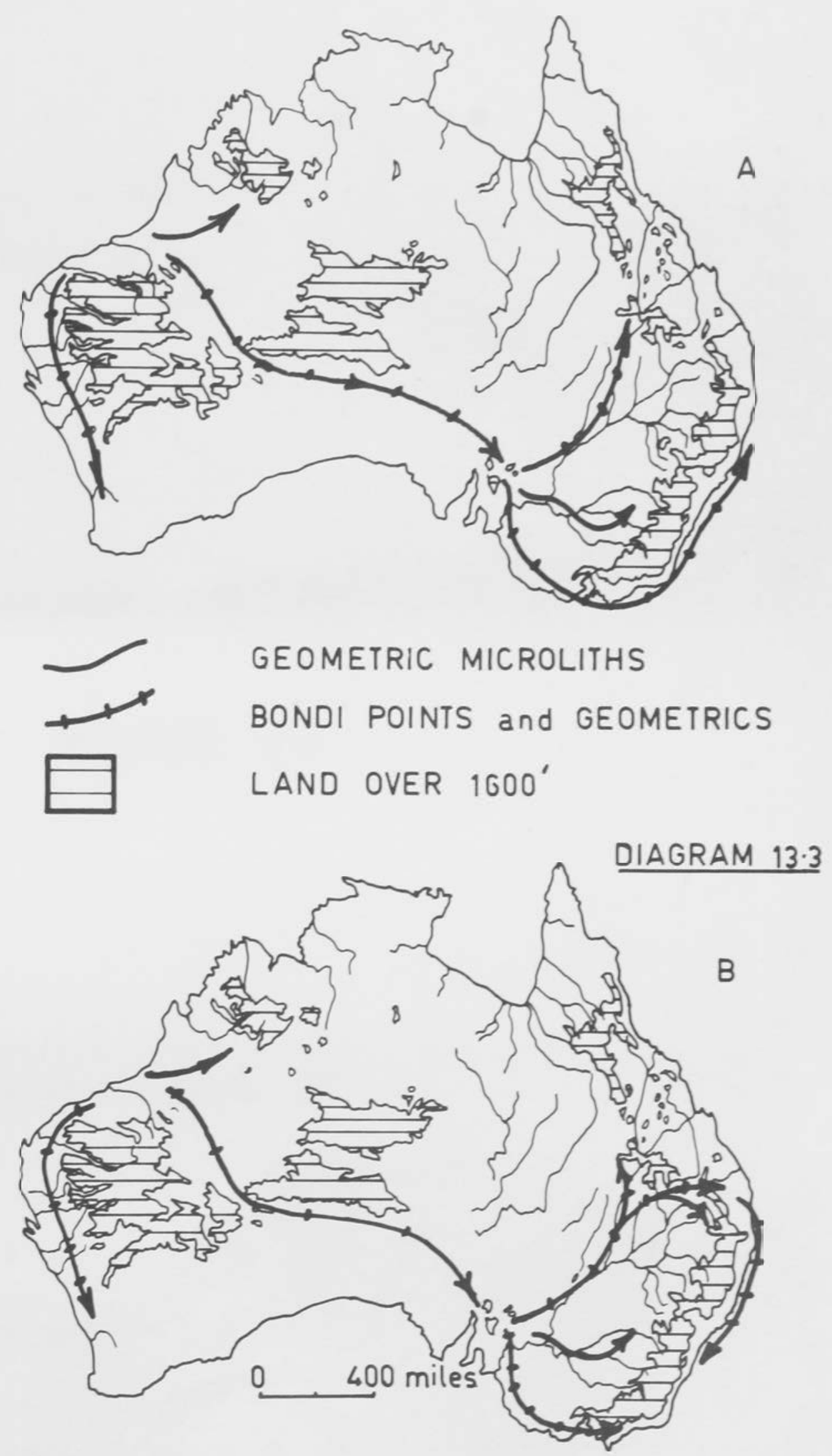

TWO POSSIBLE DIFFUSION ROUTES FOR BACKED BLADES IN AUSTRALIA 


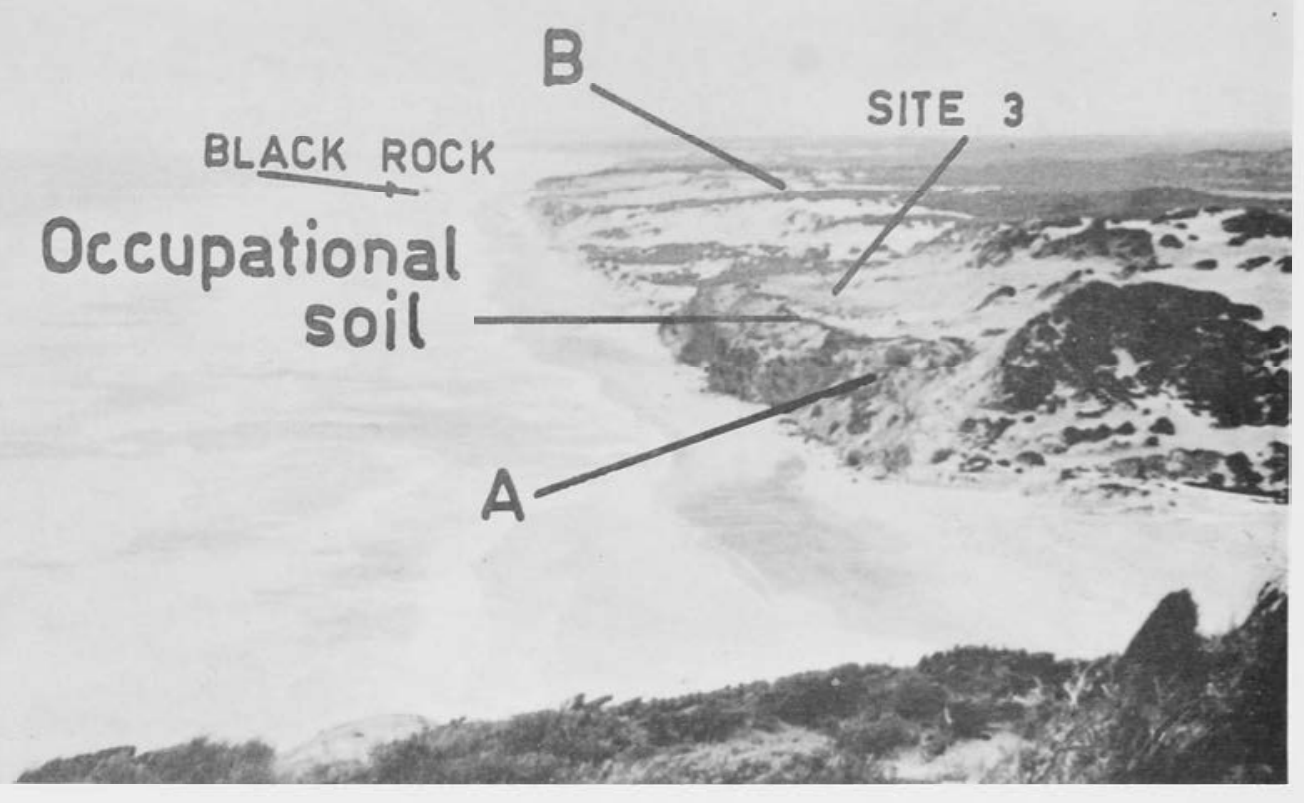

PLATE $3 \cdot 1$

\section{Occupational soil}

Site 3

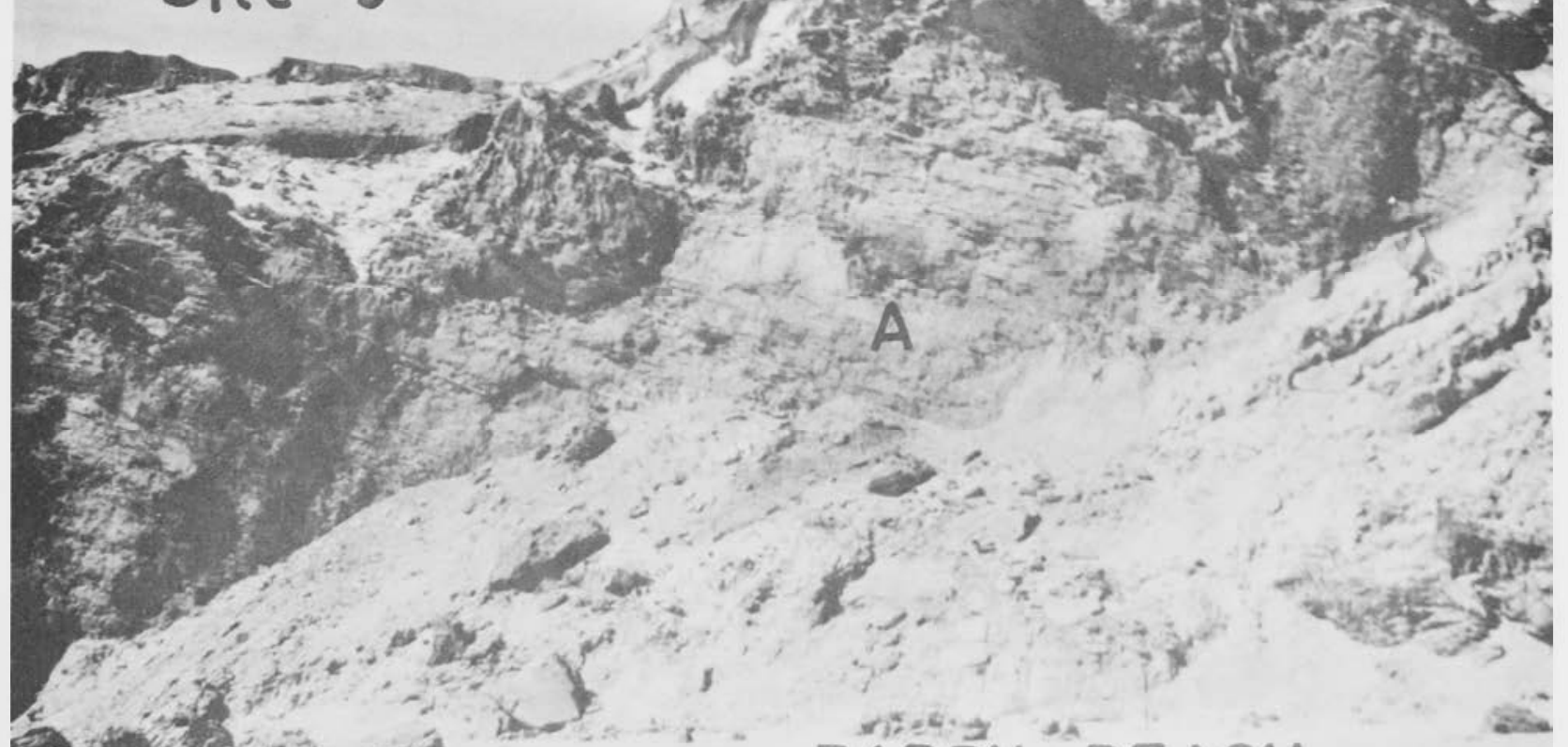

DARBY "BEACH 


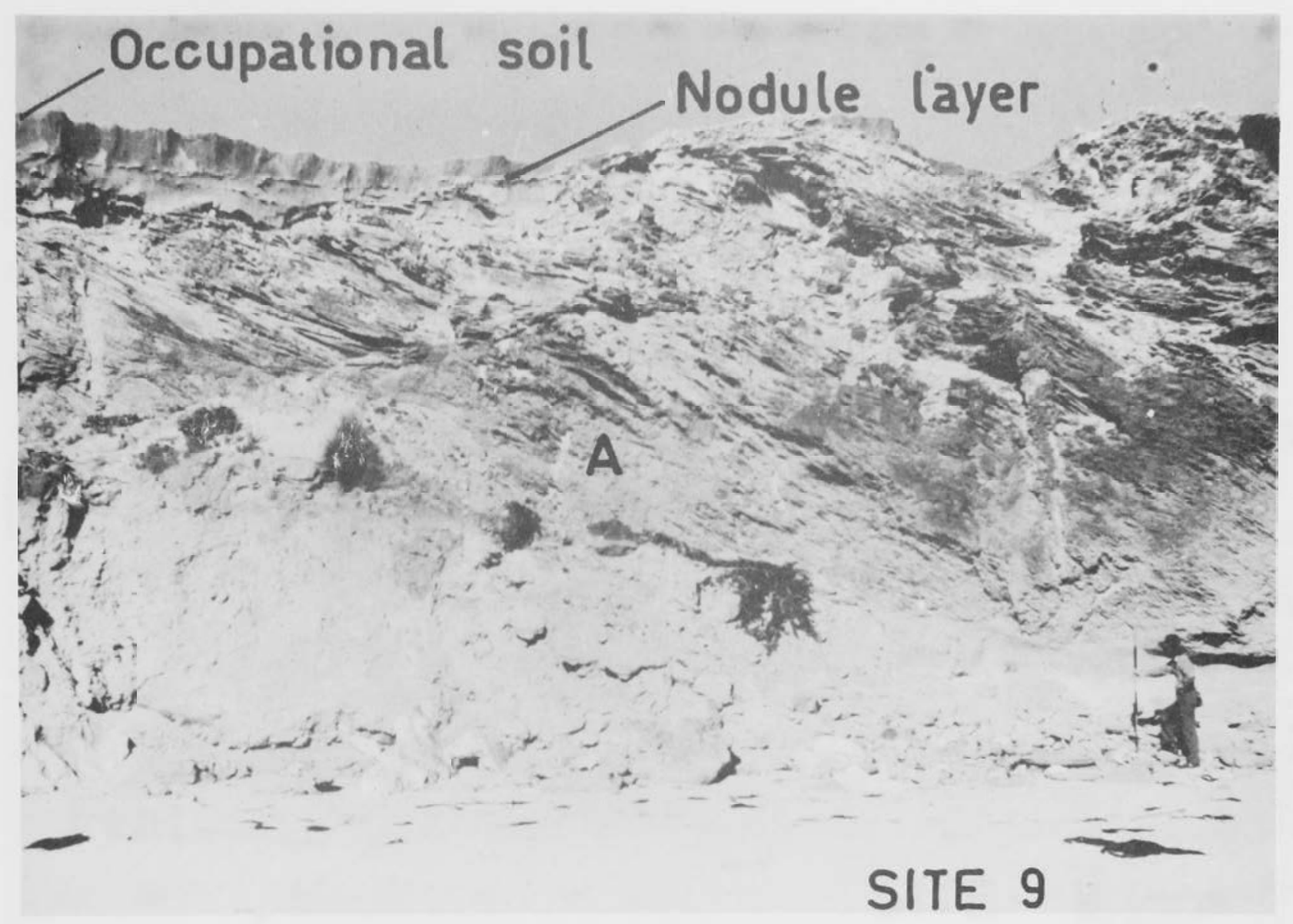

PLATE $3 \cdot 3$

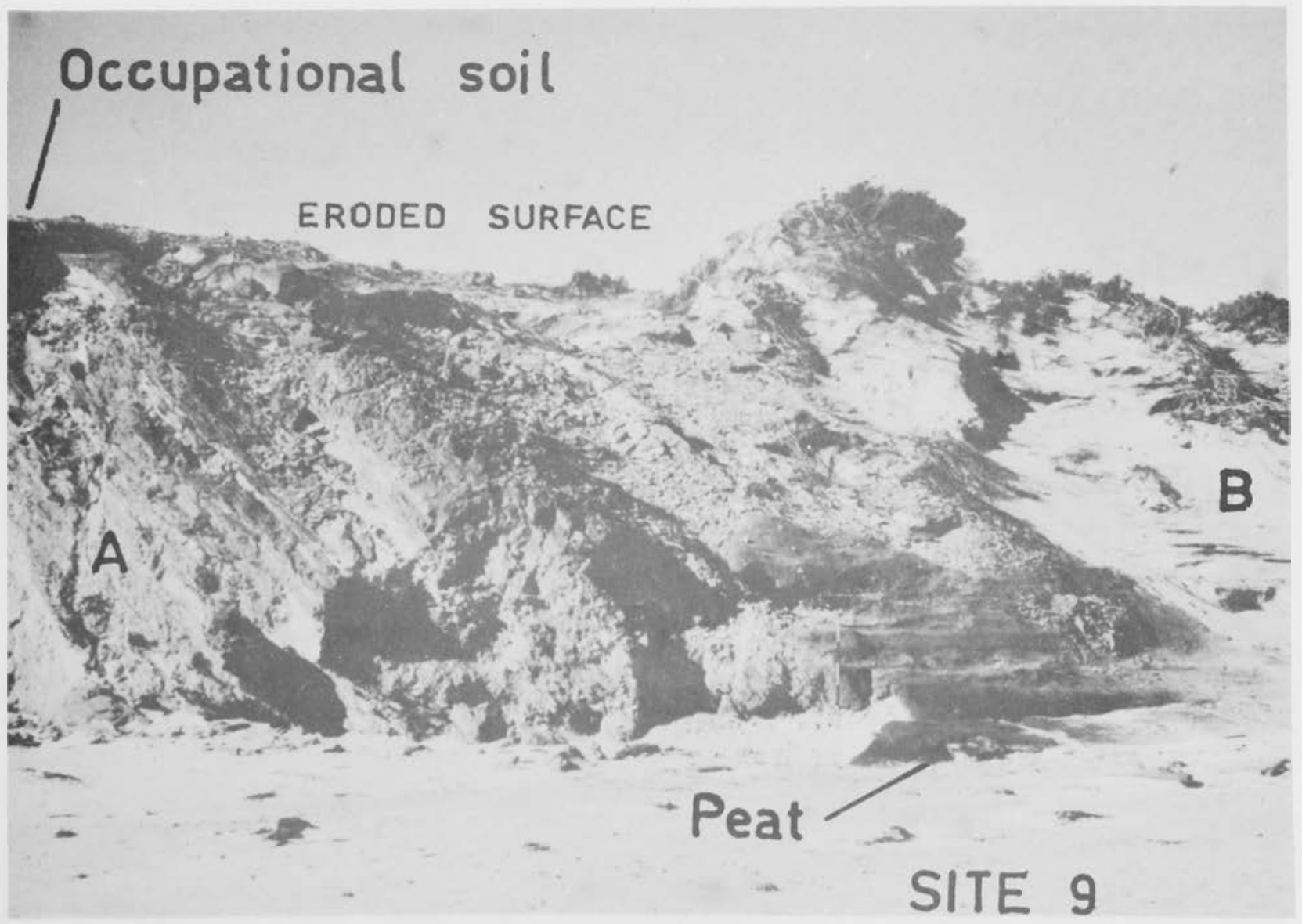




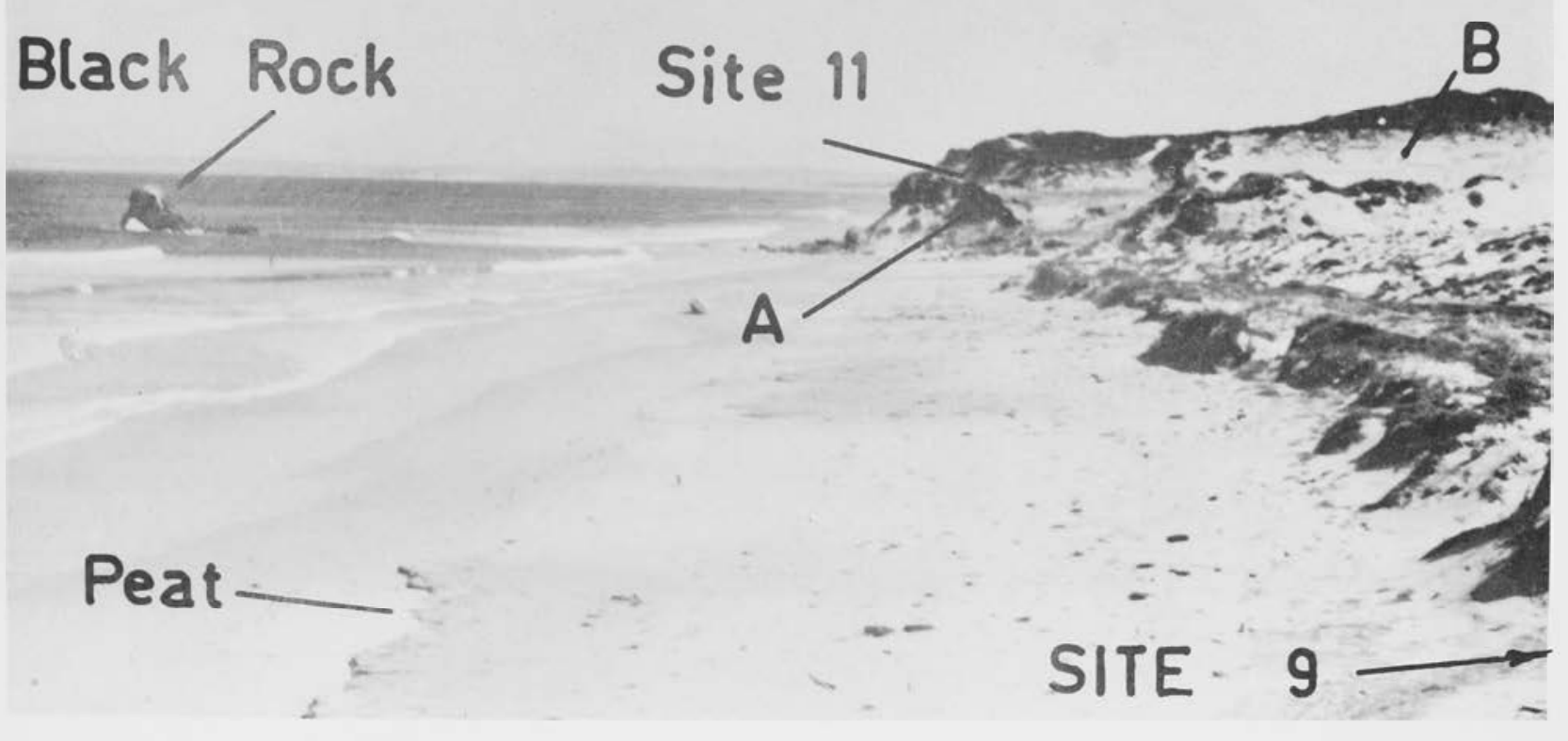

PLATE $\quad 3.5$

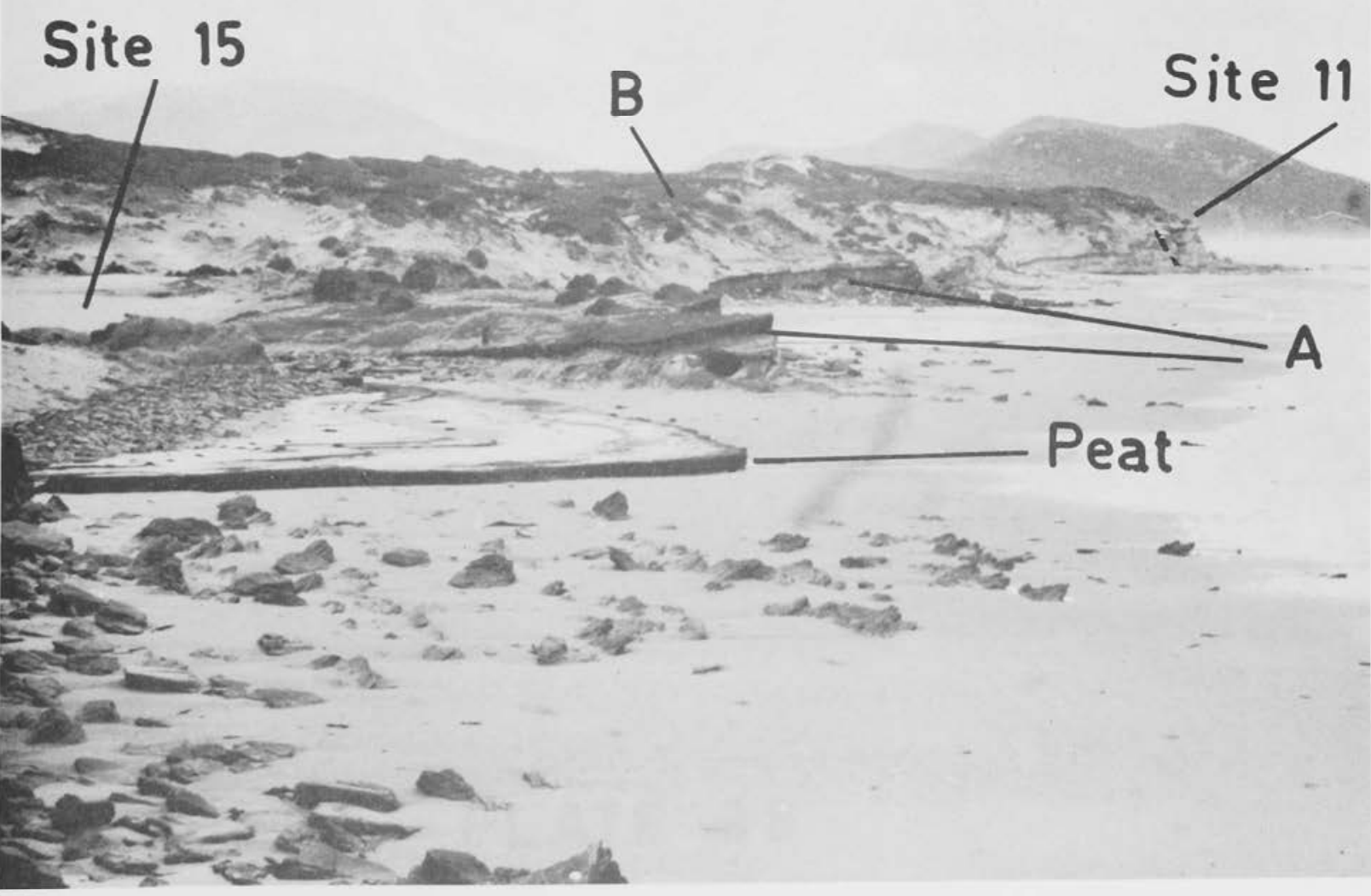




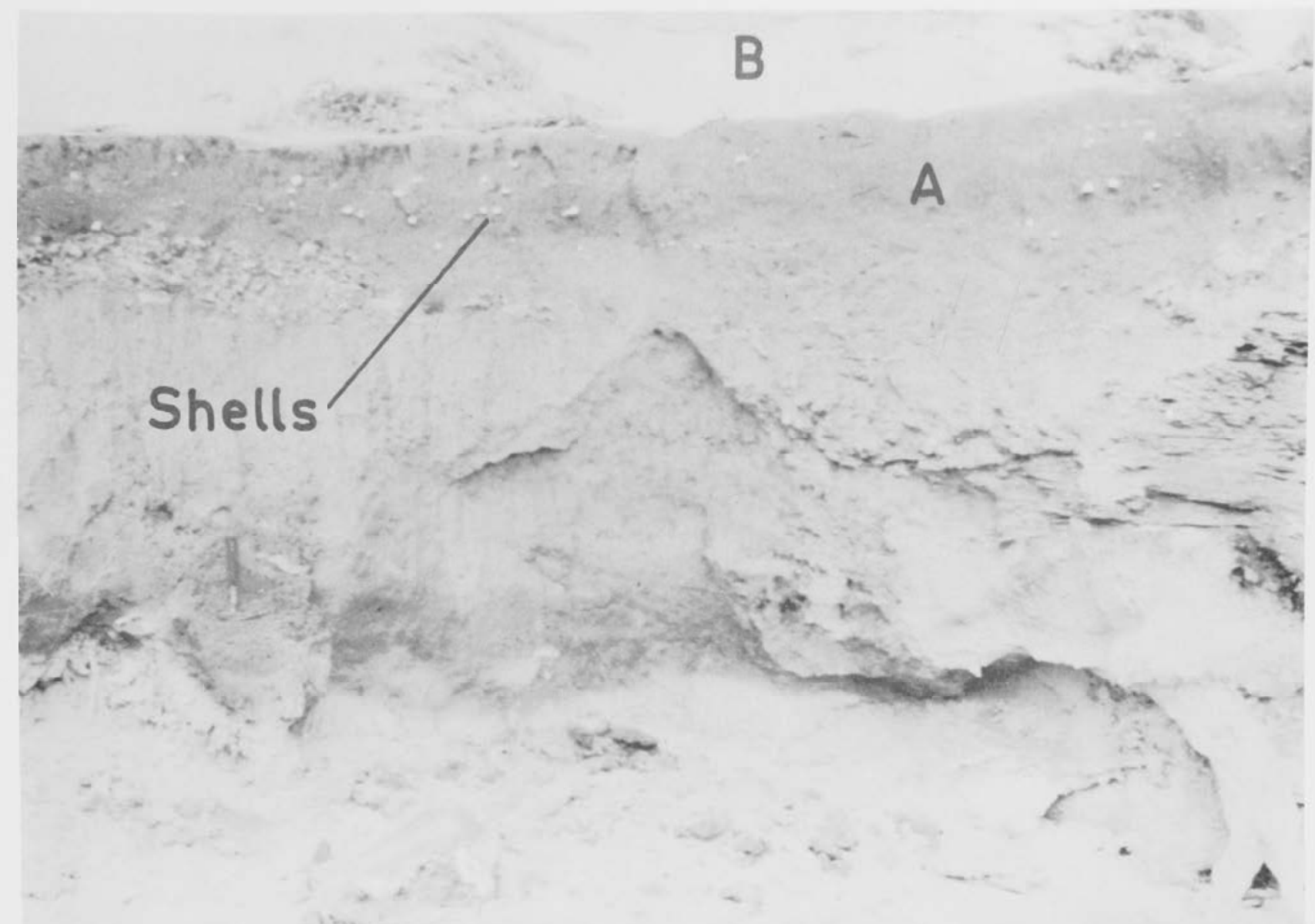

\section{PLATE $\quad 3.7$}

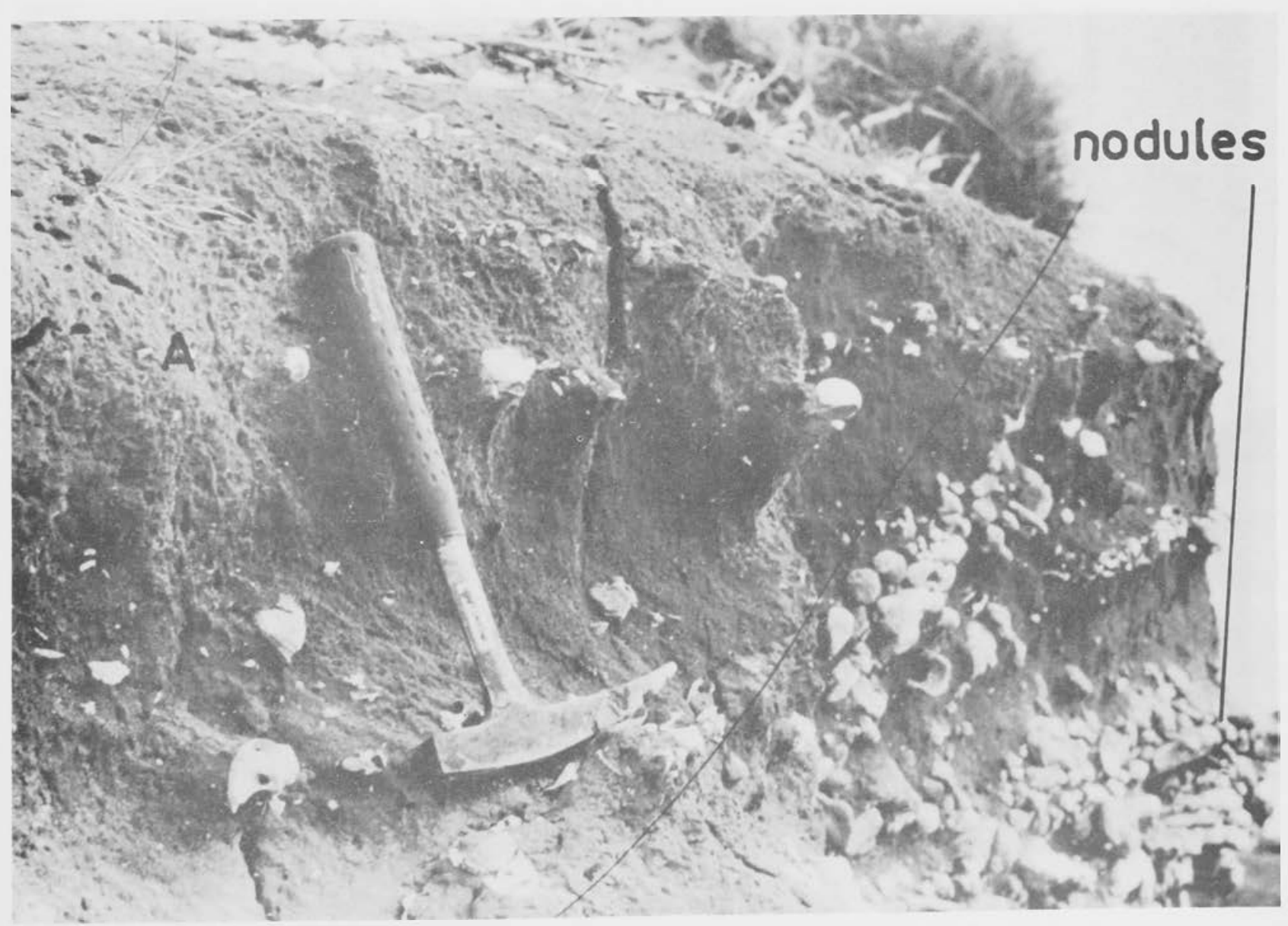




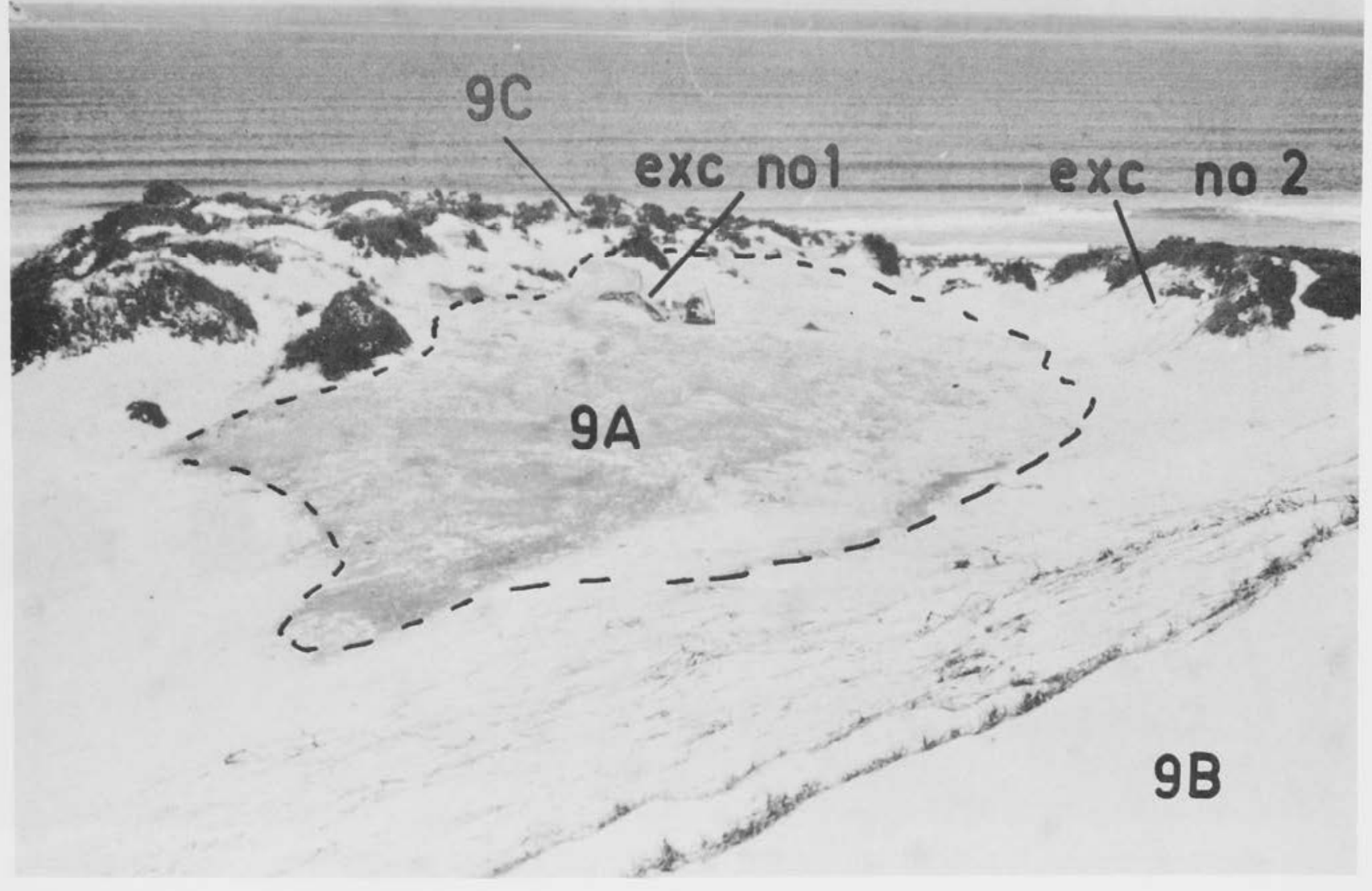

PLATE $4 \cdot 1$

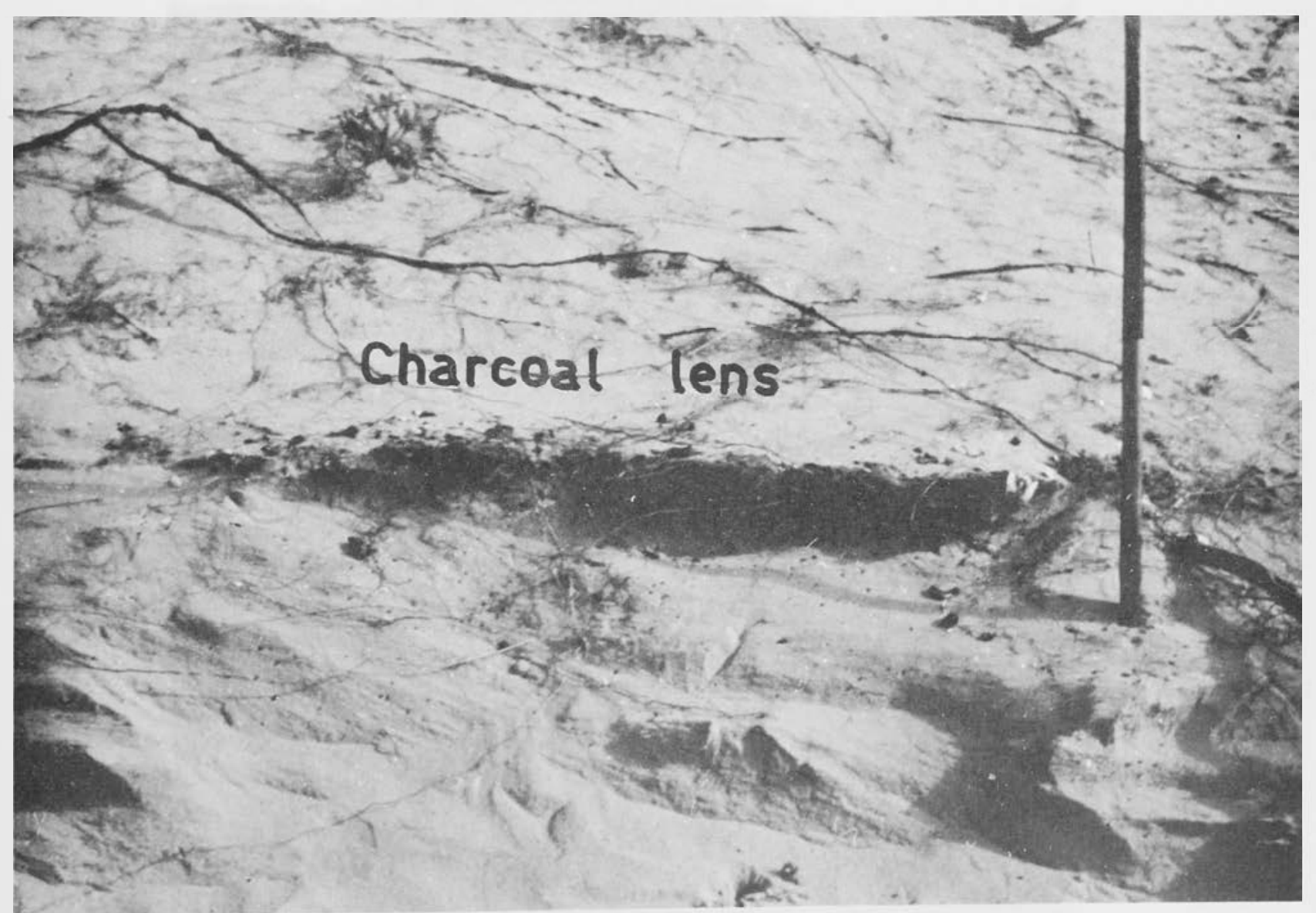

PLATE $\quad 4 \cdot 2$ 


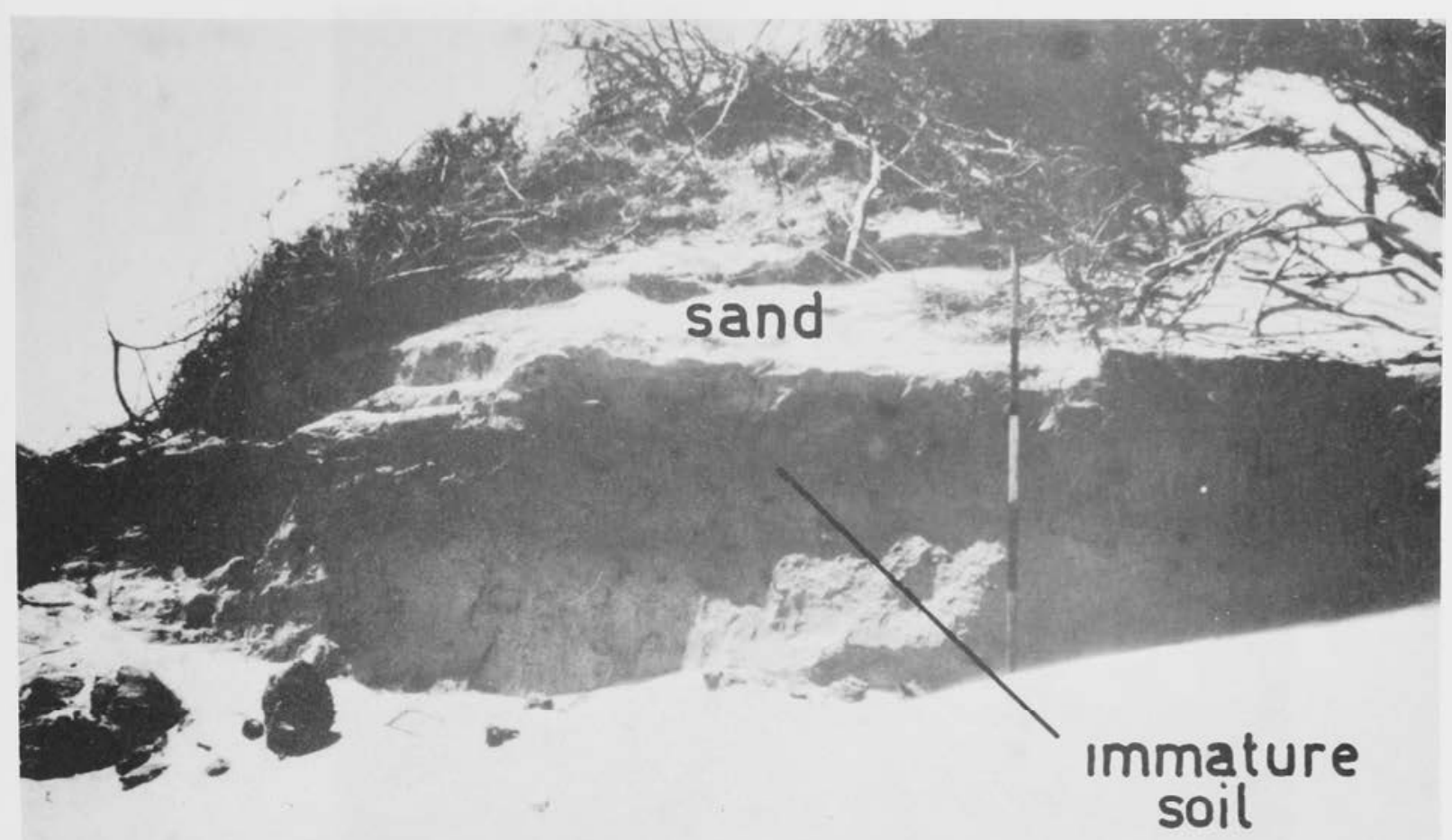

PLAte $\quad 4 \cdot 3$
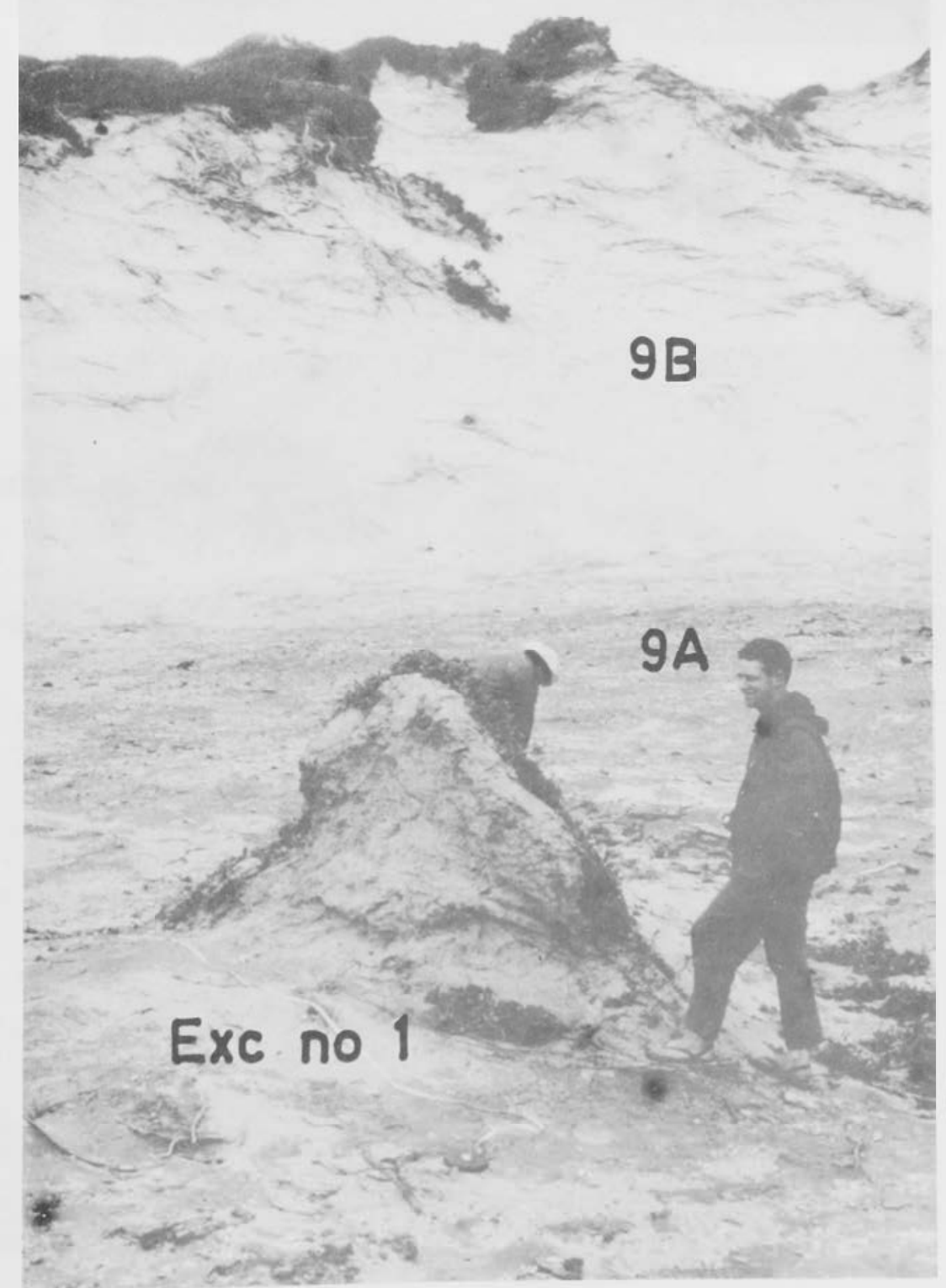

PLATE $4 \cdot 4$ 


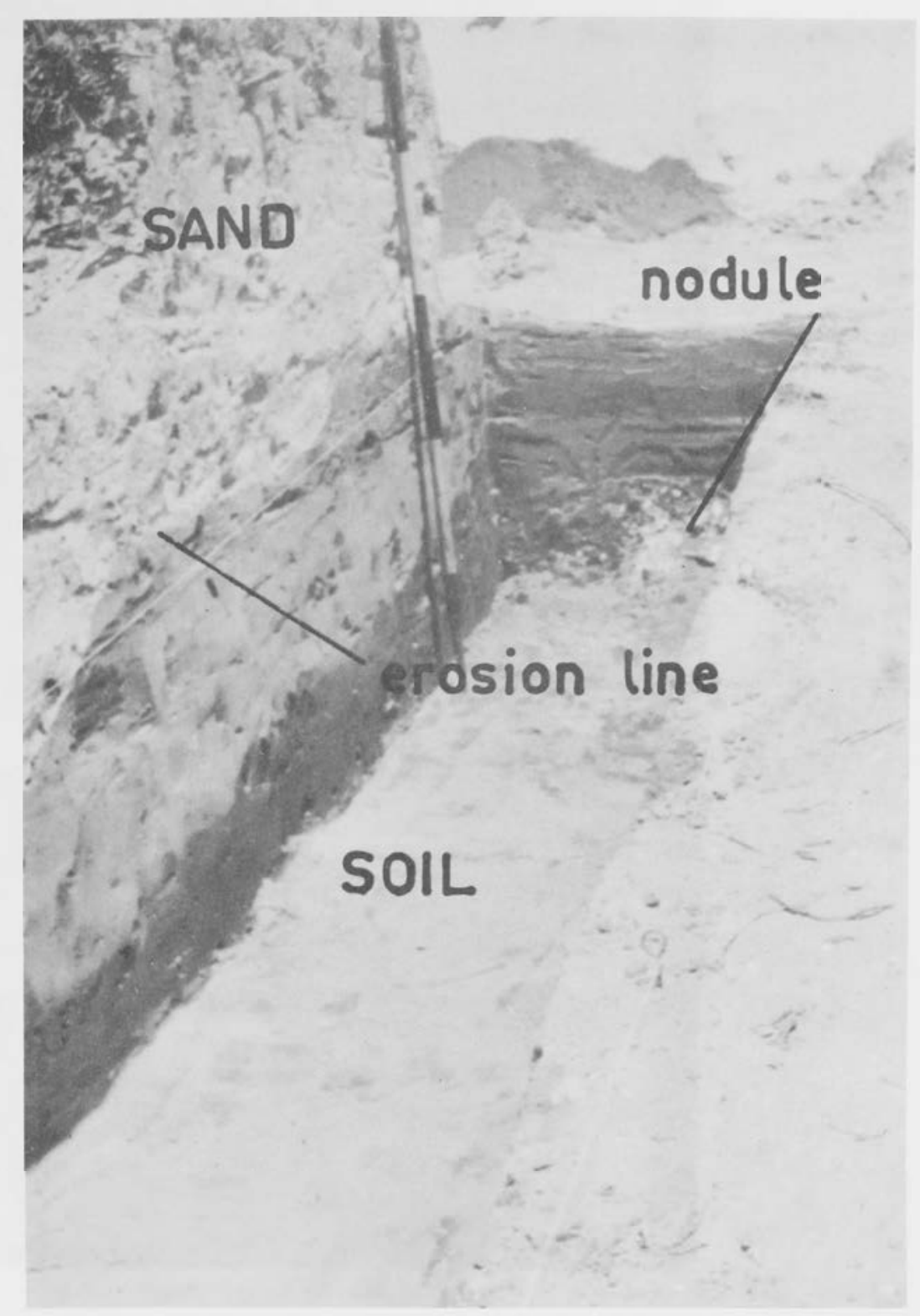

\section{PLATE 4.5}

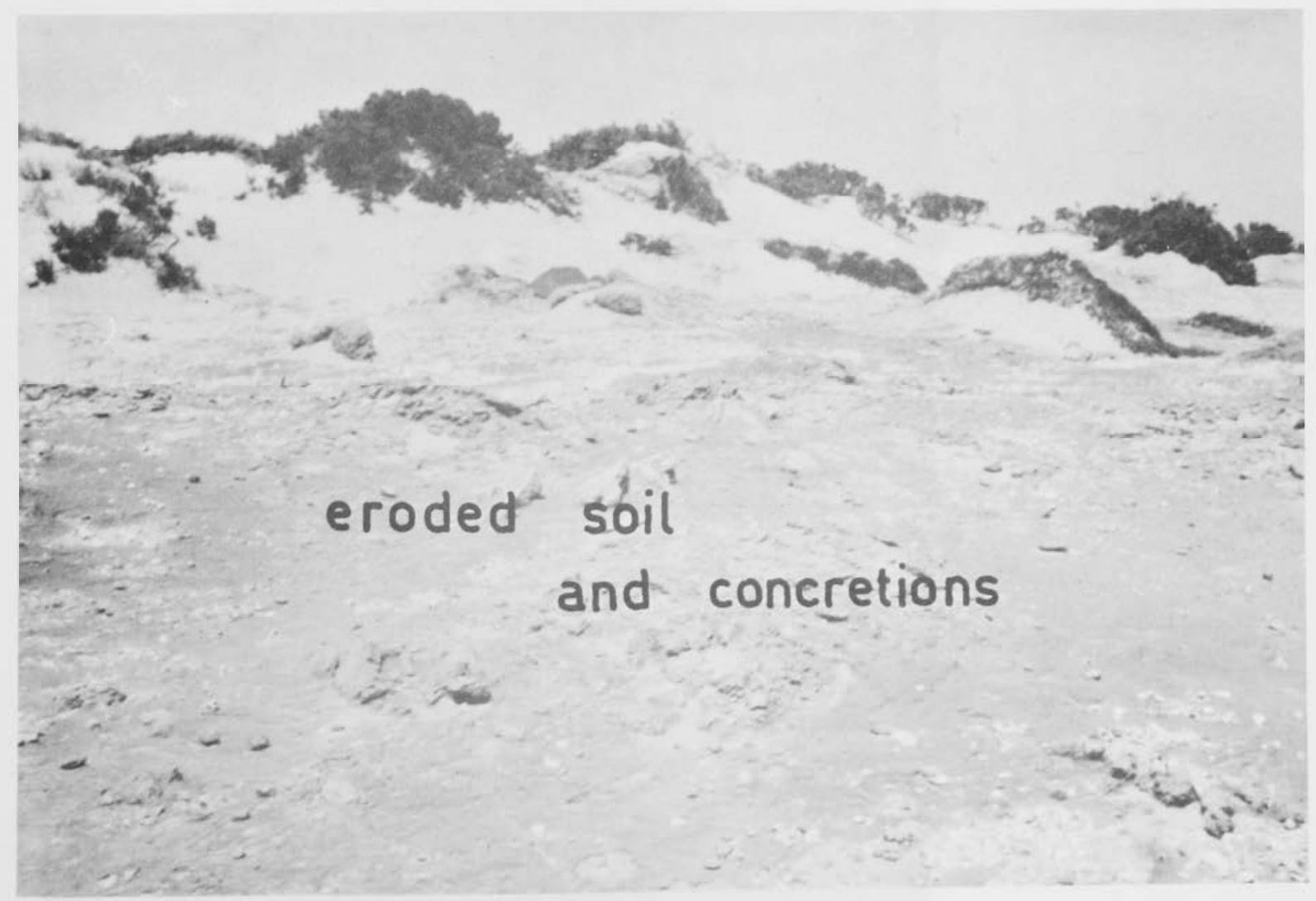

PLATE $4 \cdot 6$ 


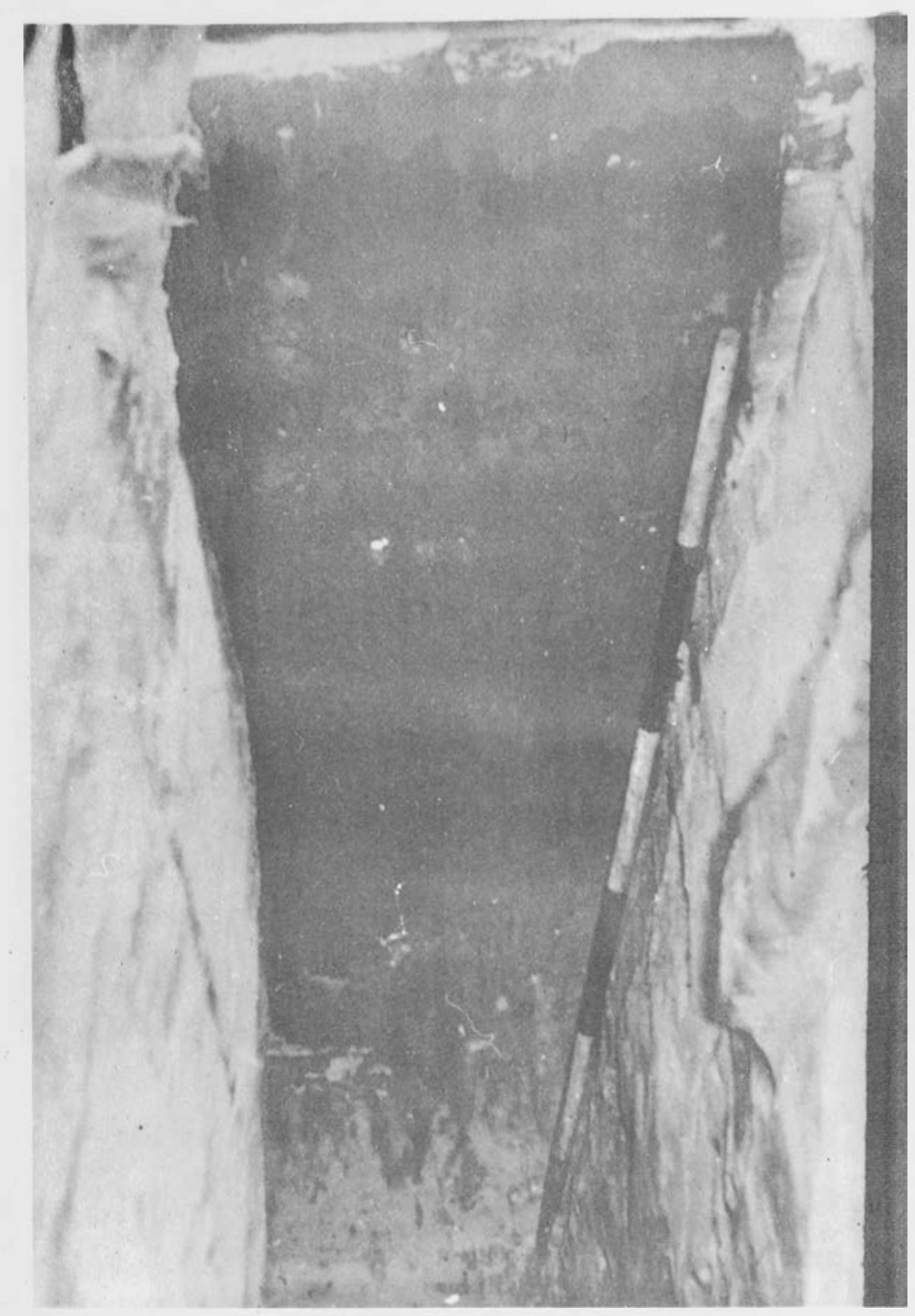

PLATE $\mathbf{4 \cdot 7}$

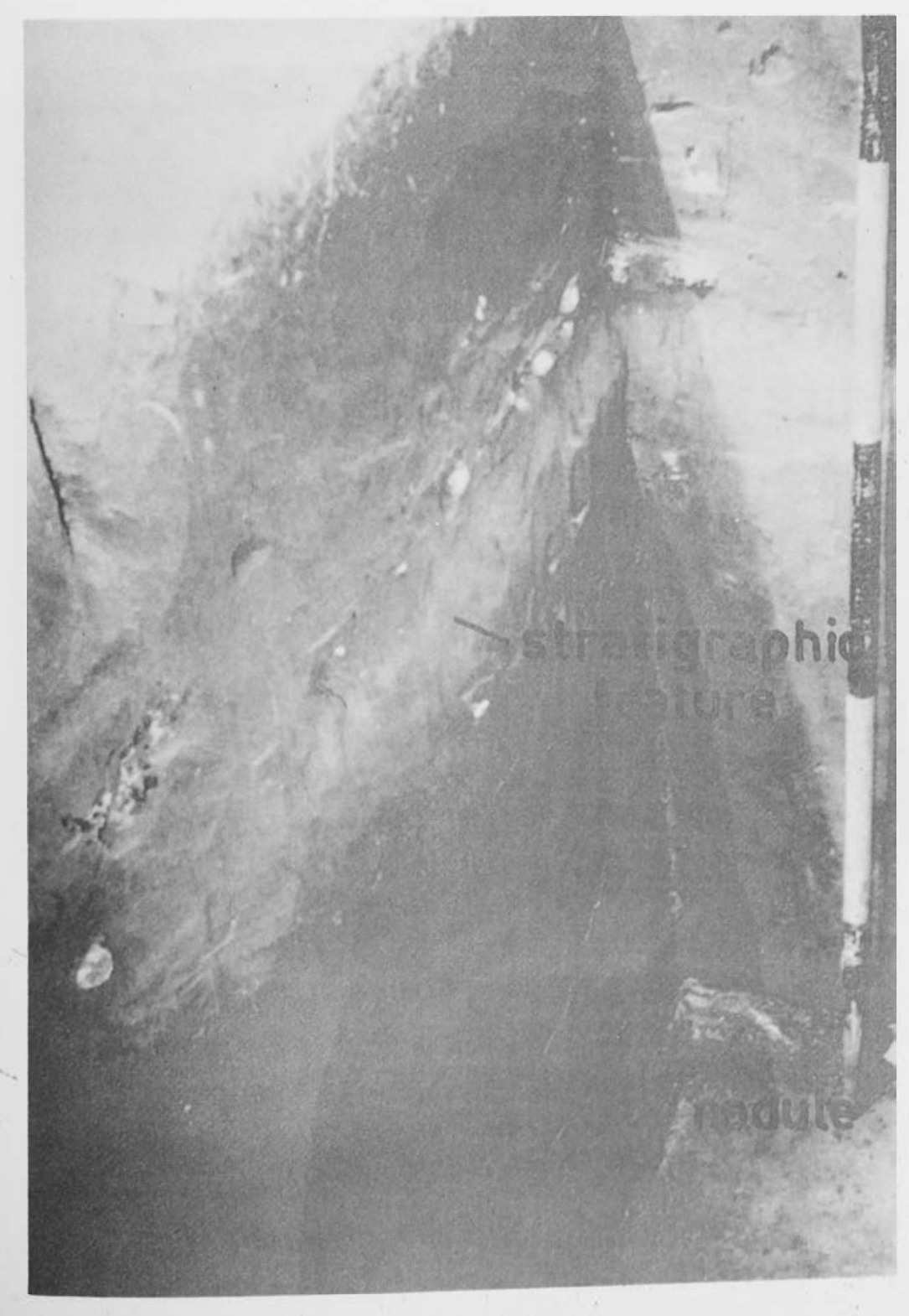

PLATE 4.8 


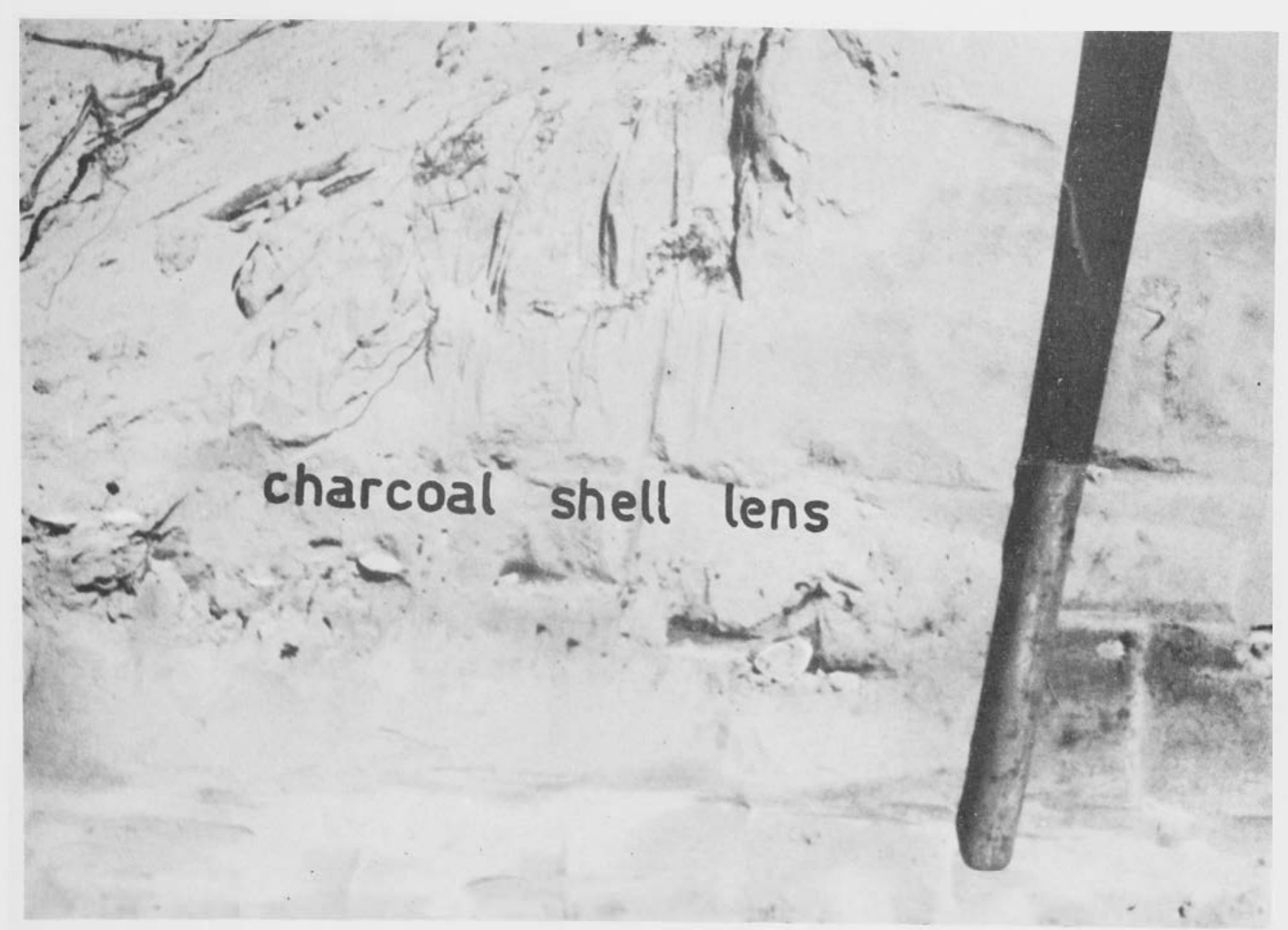

PLATE $4 \cdot 9$

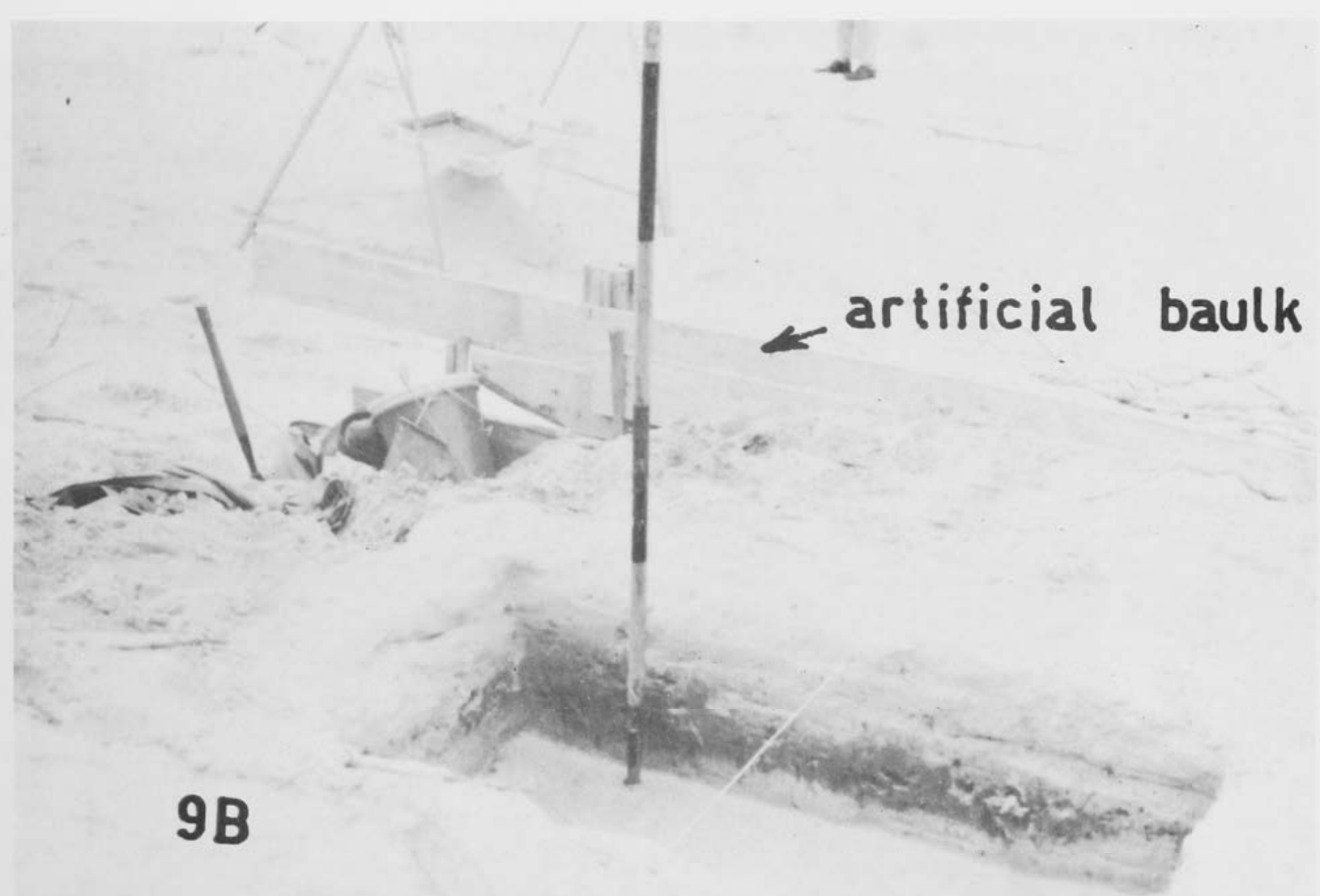




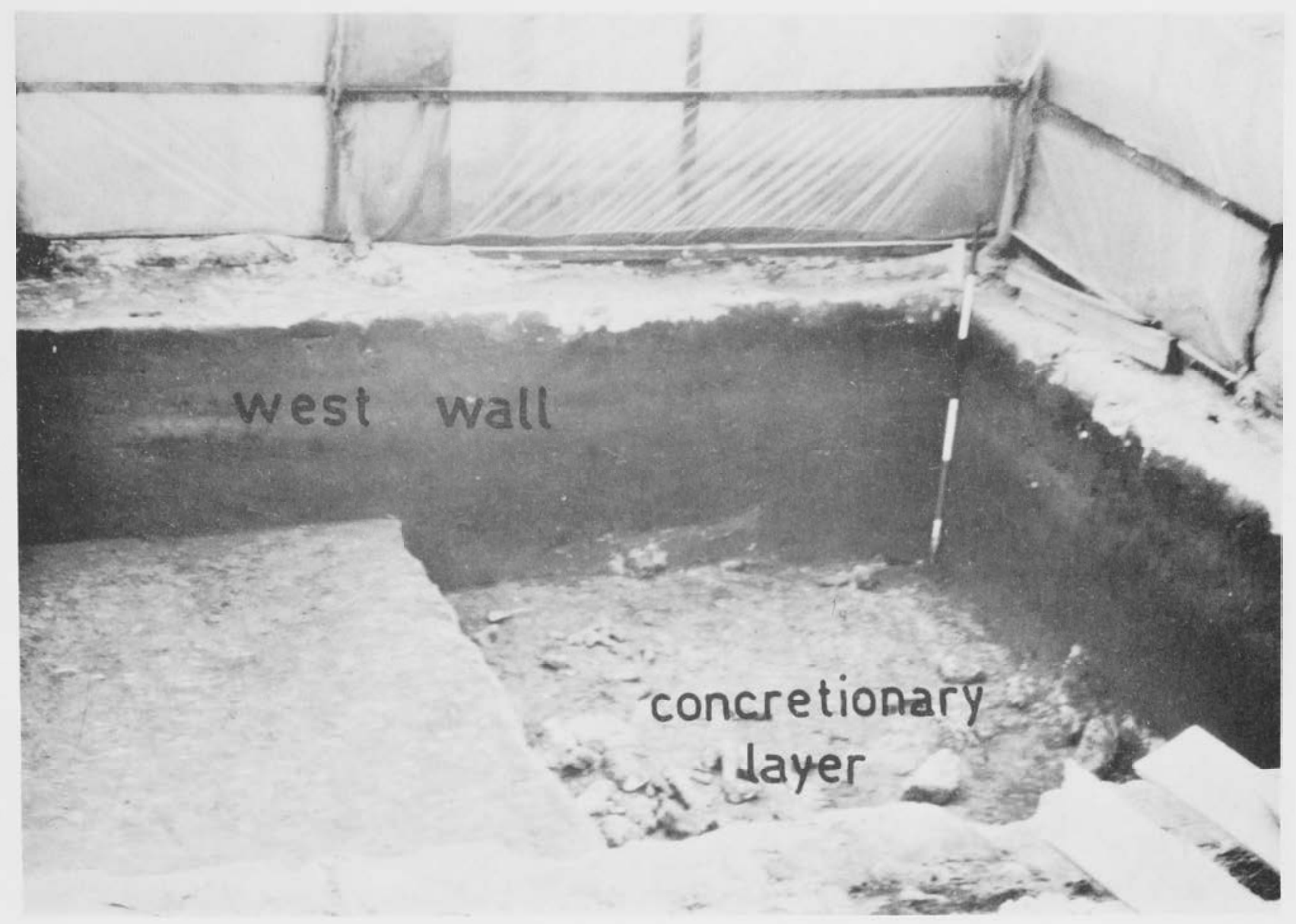

PLATE 4.13

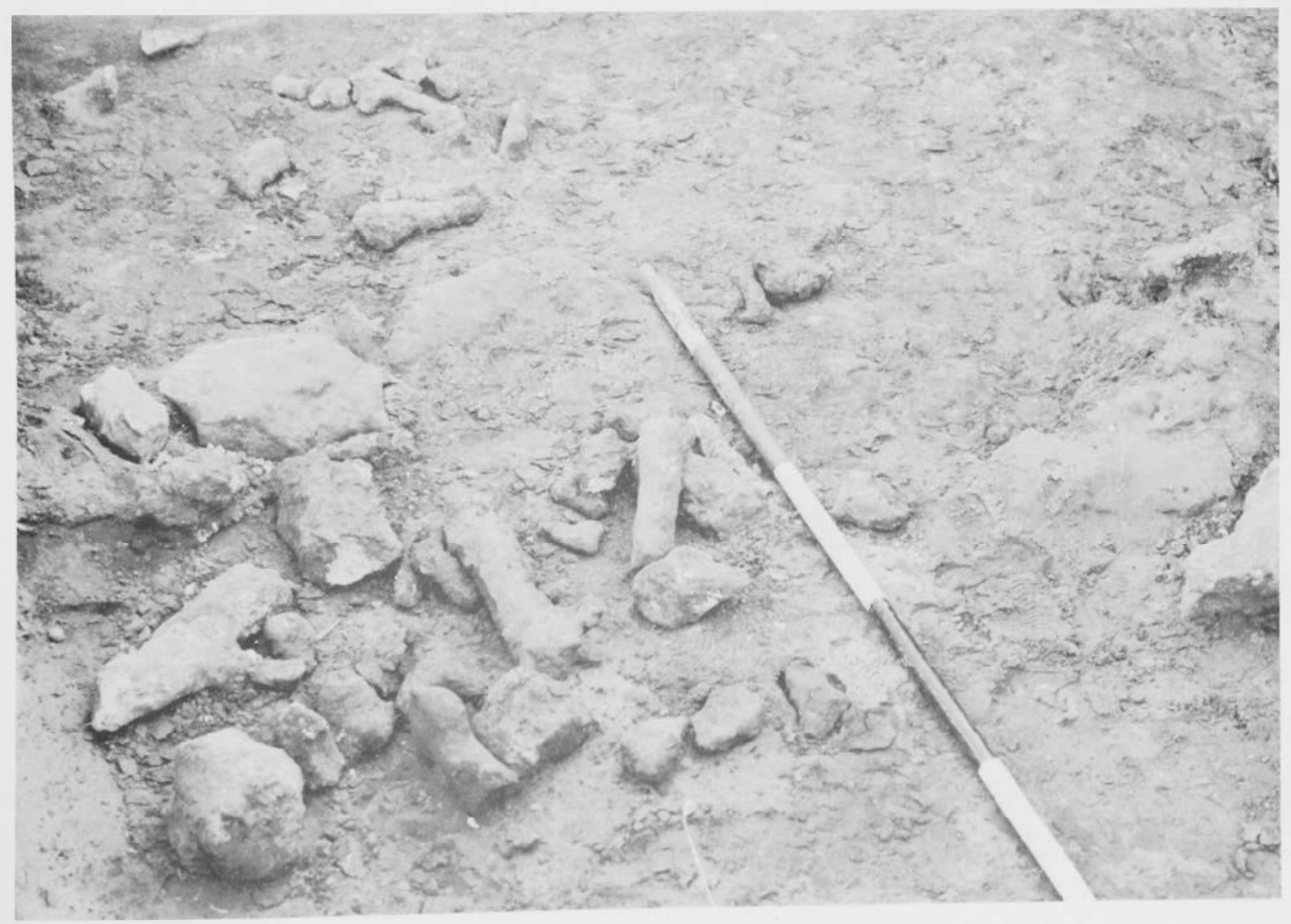

PLATE $4 \cdot 14$ 


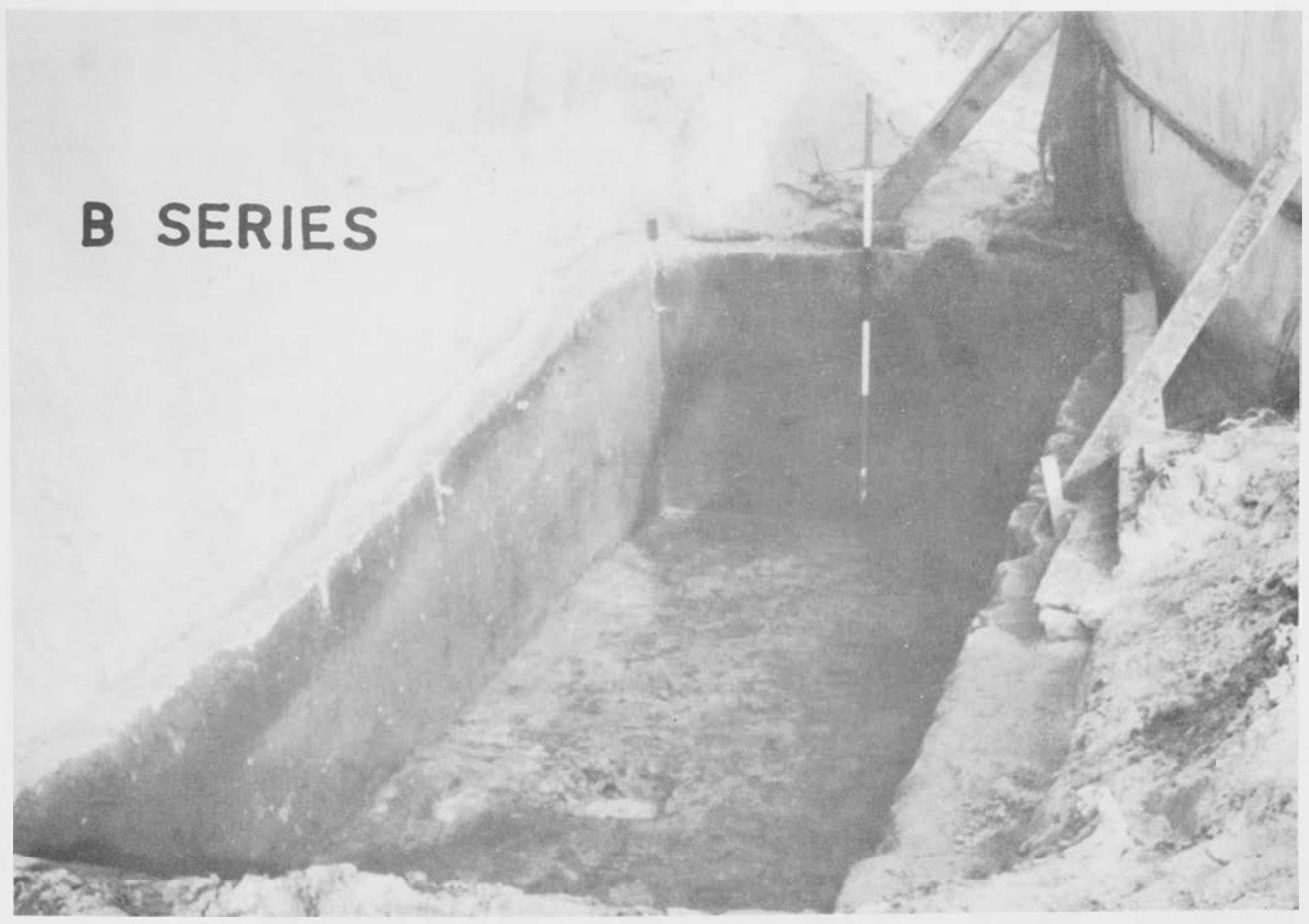

PLATE $\mathbf{4 . 1 5}$

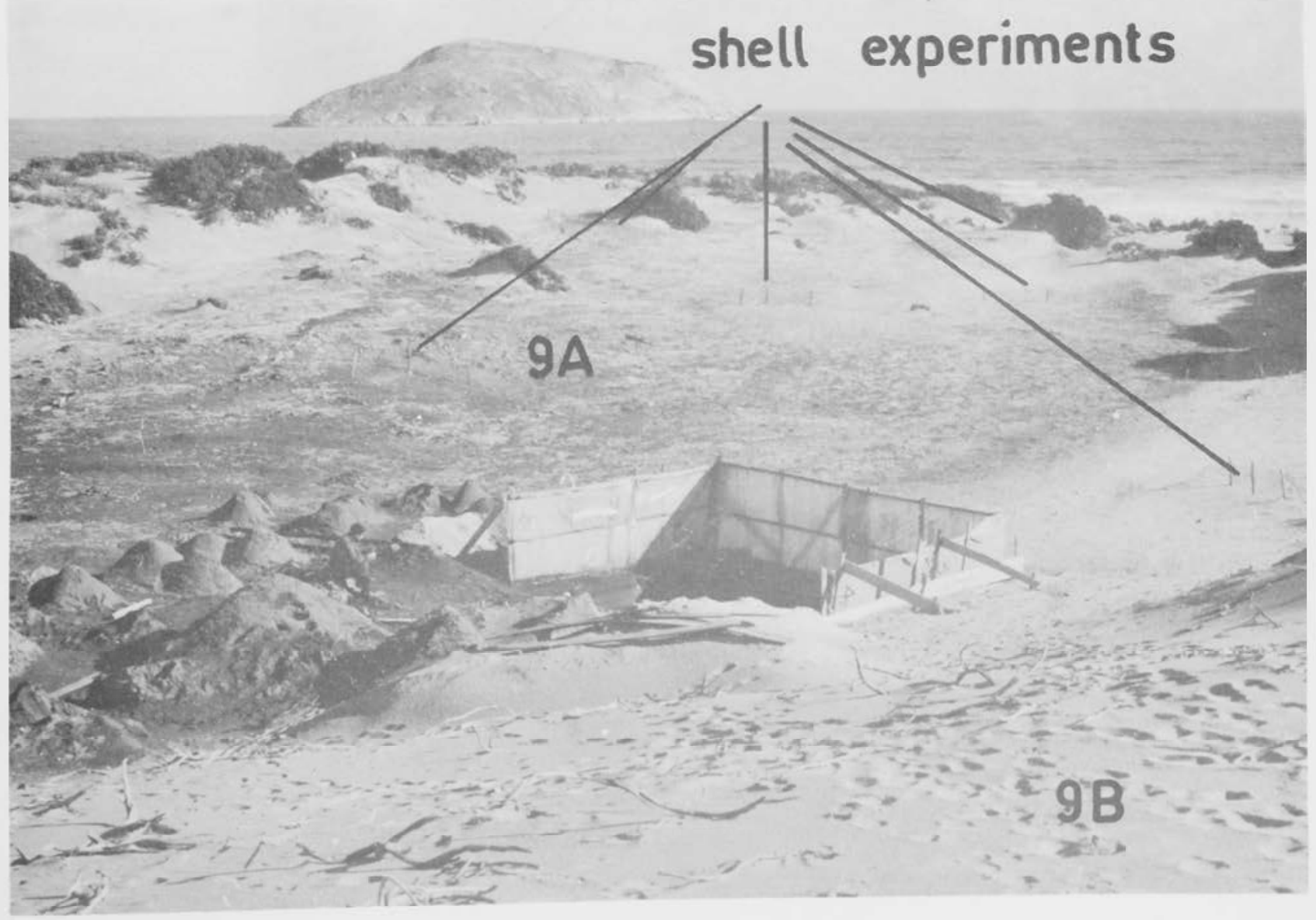

PLATE $\quad 4 \cdot 16$ 


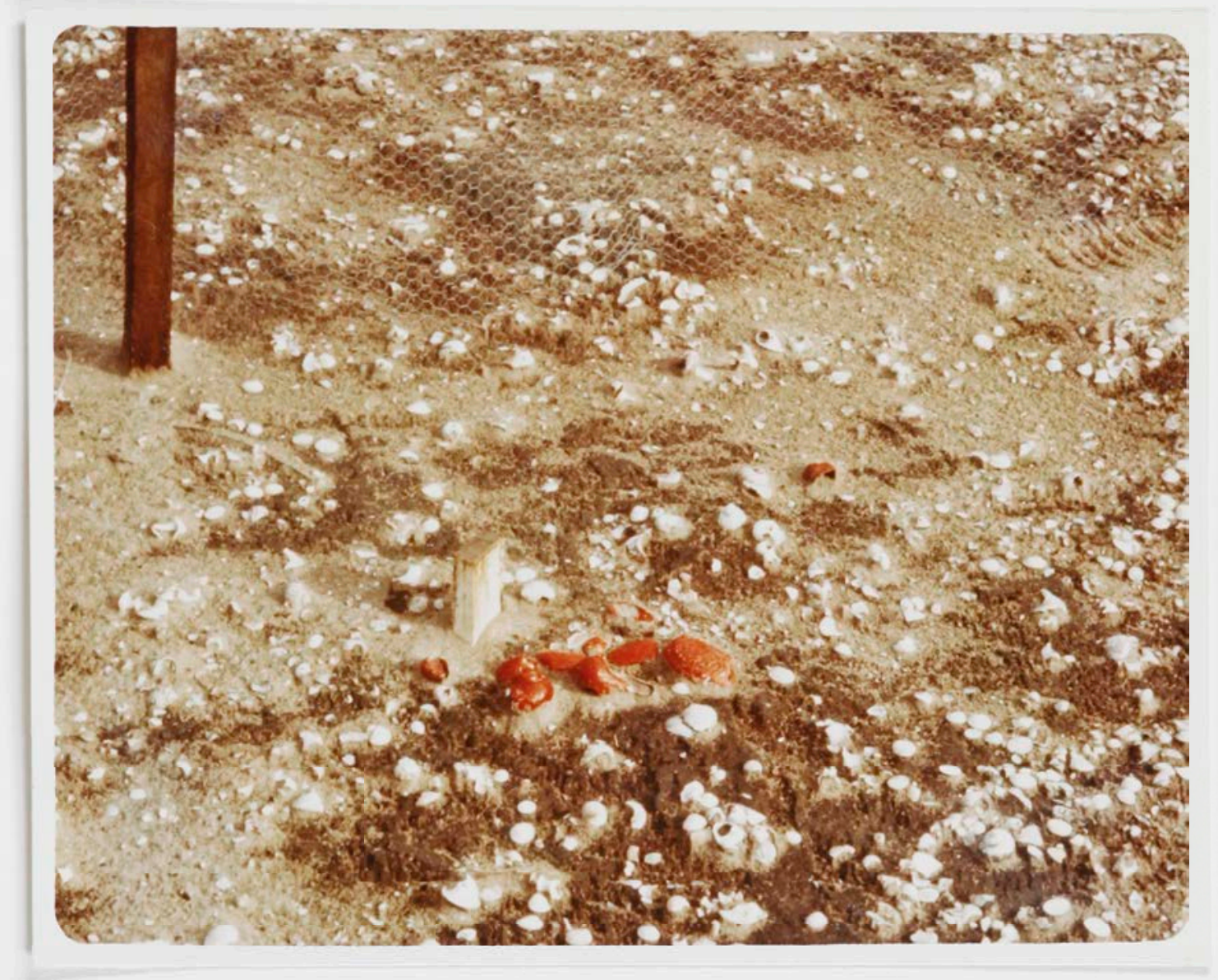

PLATE 0.1 


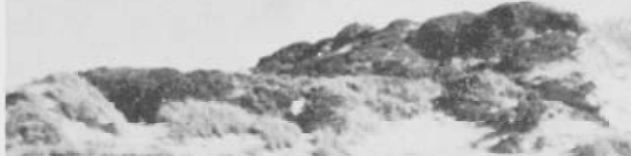

ateine

\section{Site 10A}

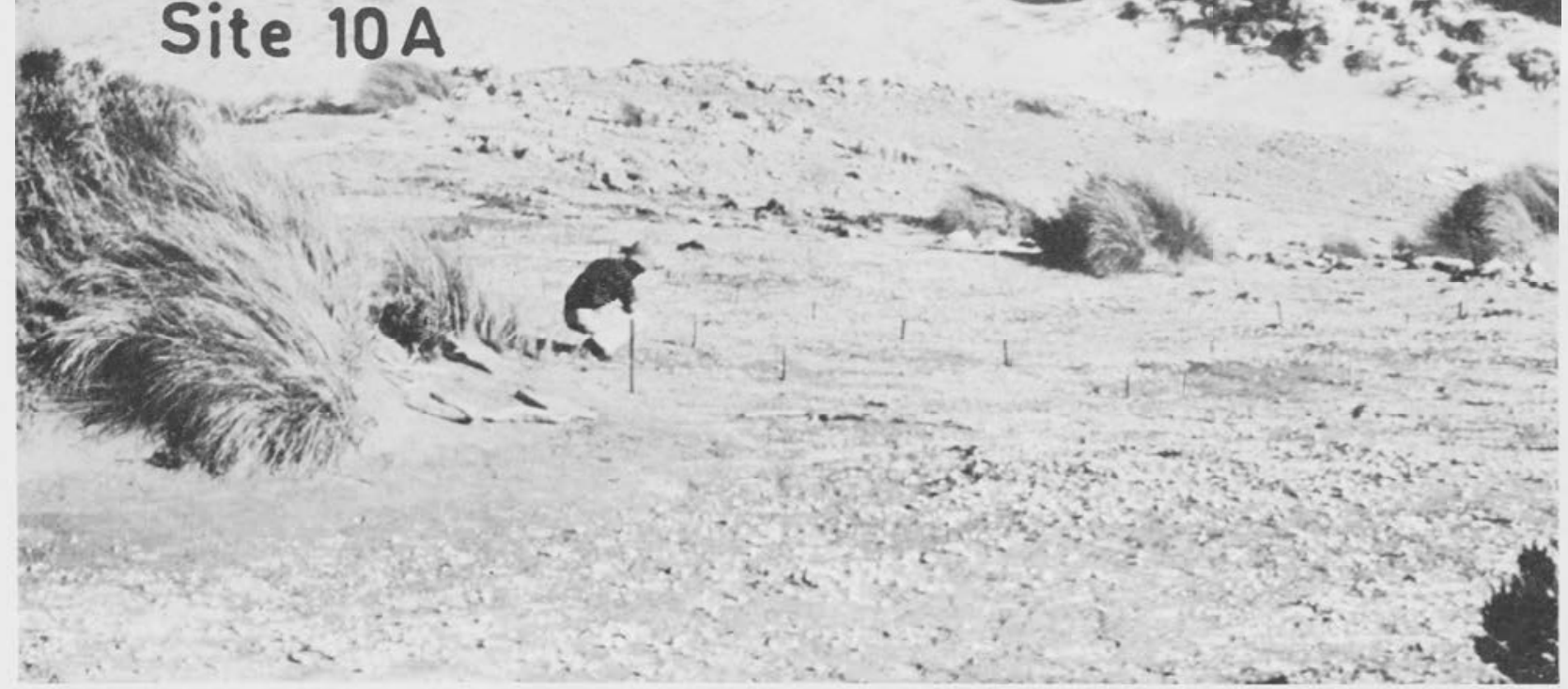

PLATE $8 \cdot 1$

N

exposed soils

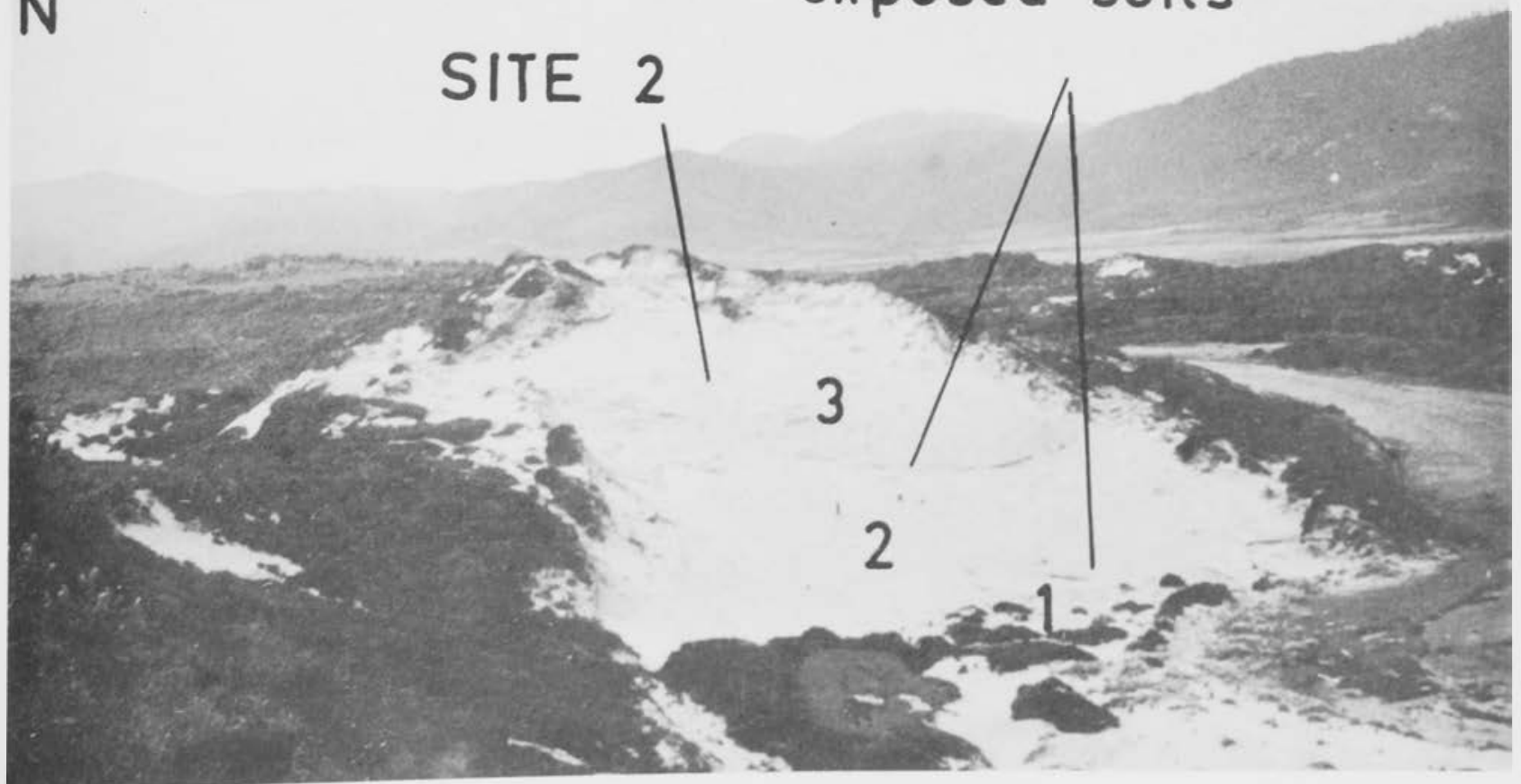




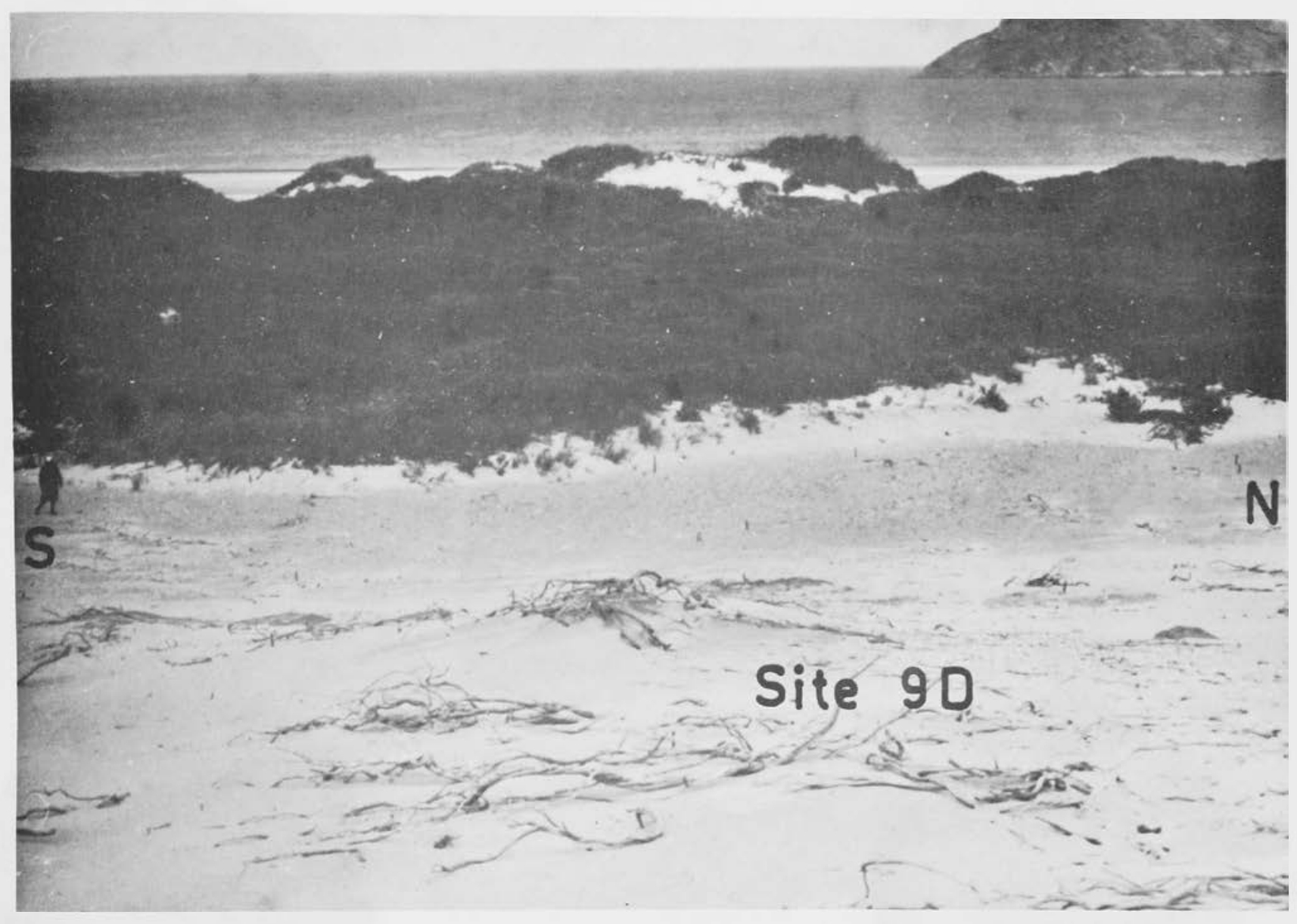

PLATE 8.3 

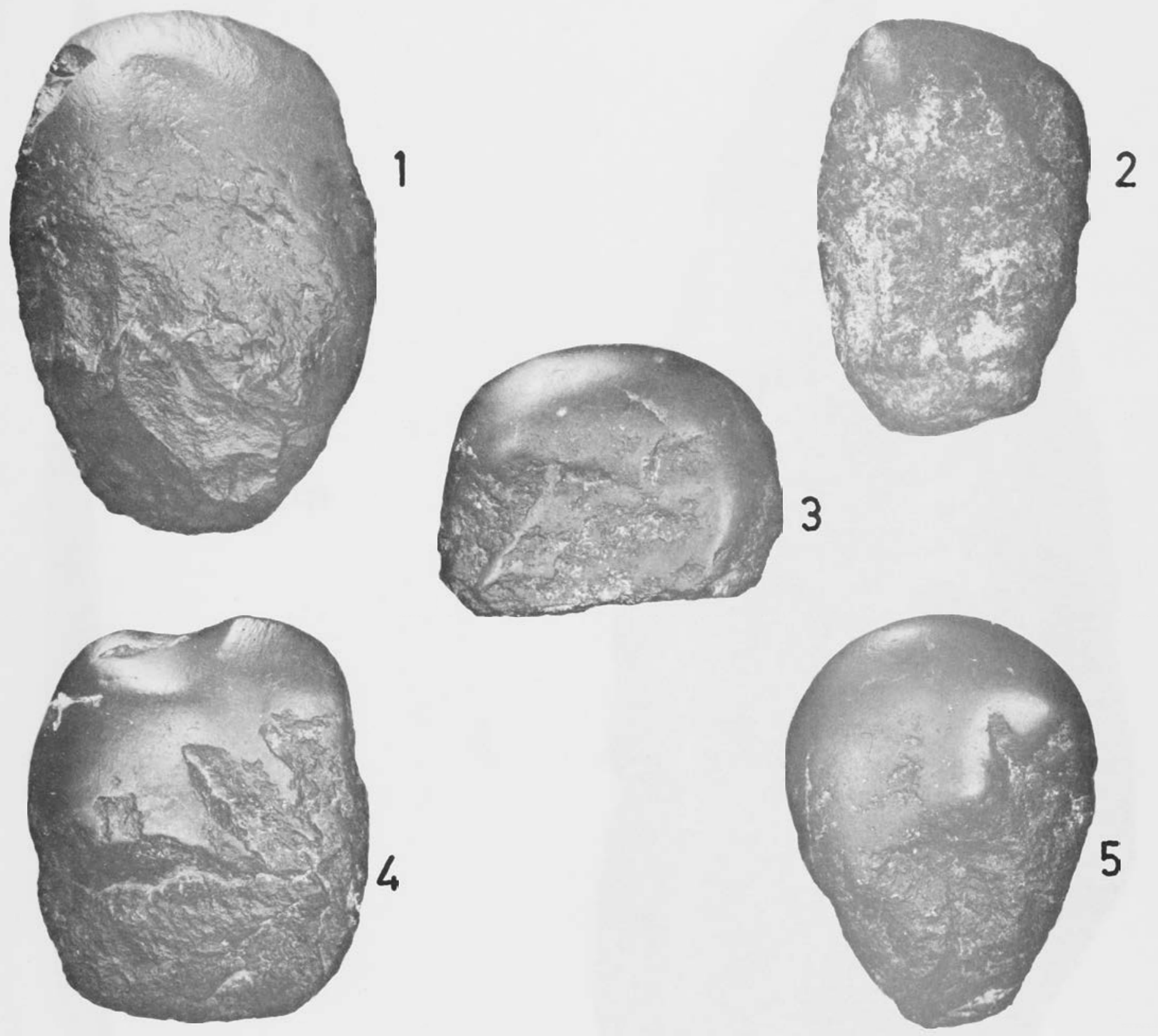

PLATE $12 \cdot 1$ 


\section{$0 \quad 1 \mathrm{~cm}$}

\section{0 $1 \mathrm{~cm}$}

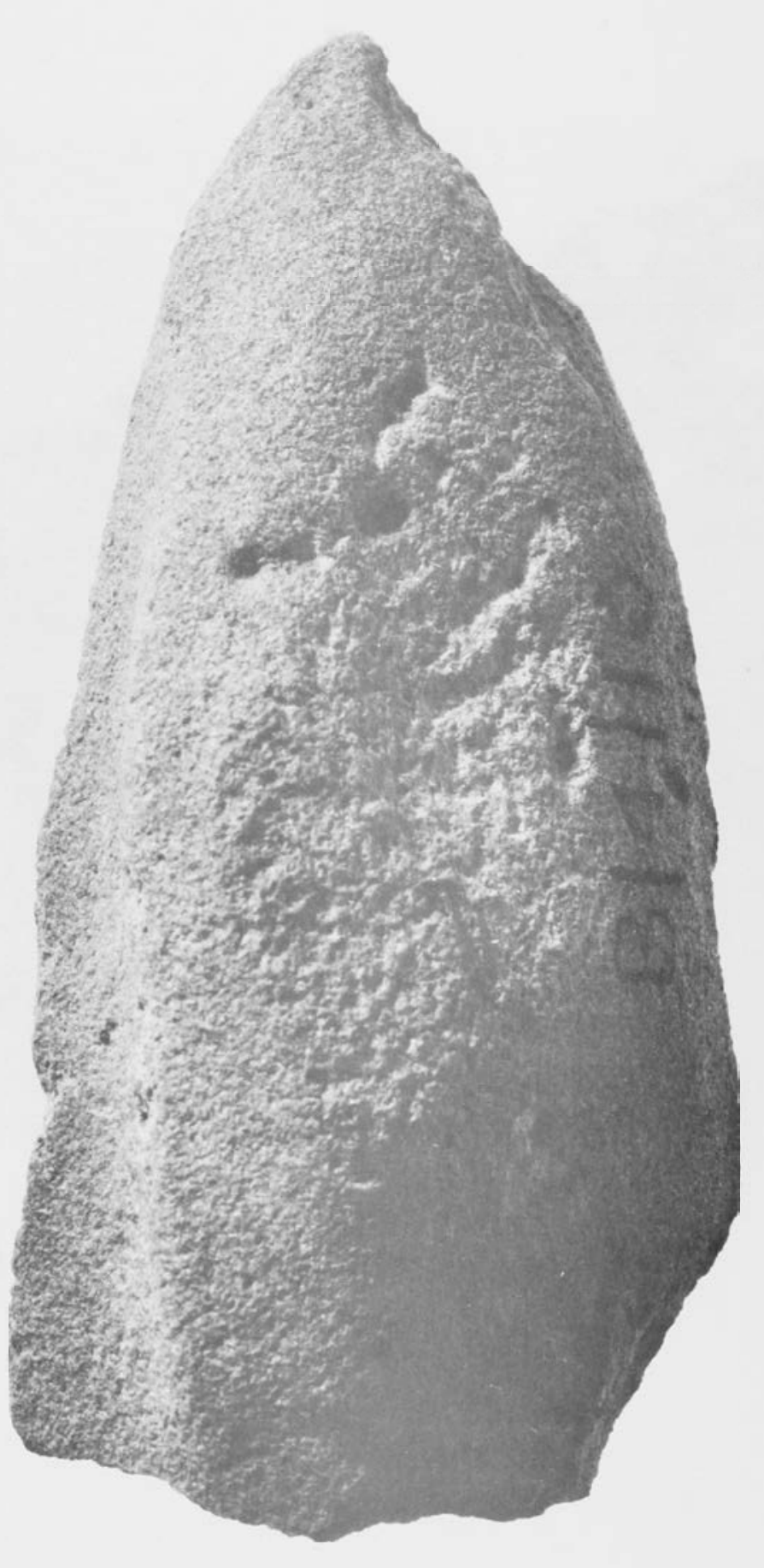

PLATE 12.2 


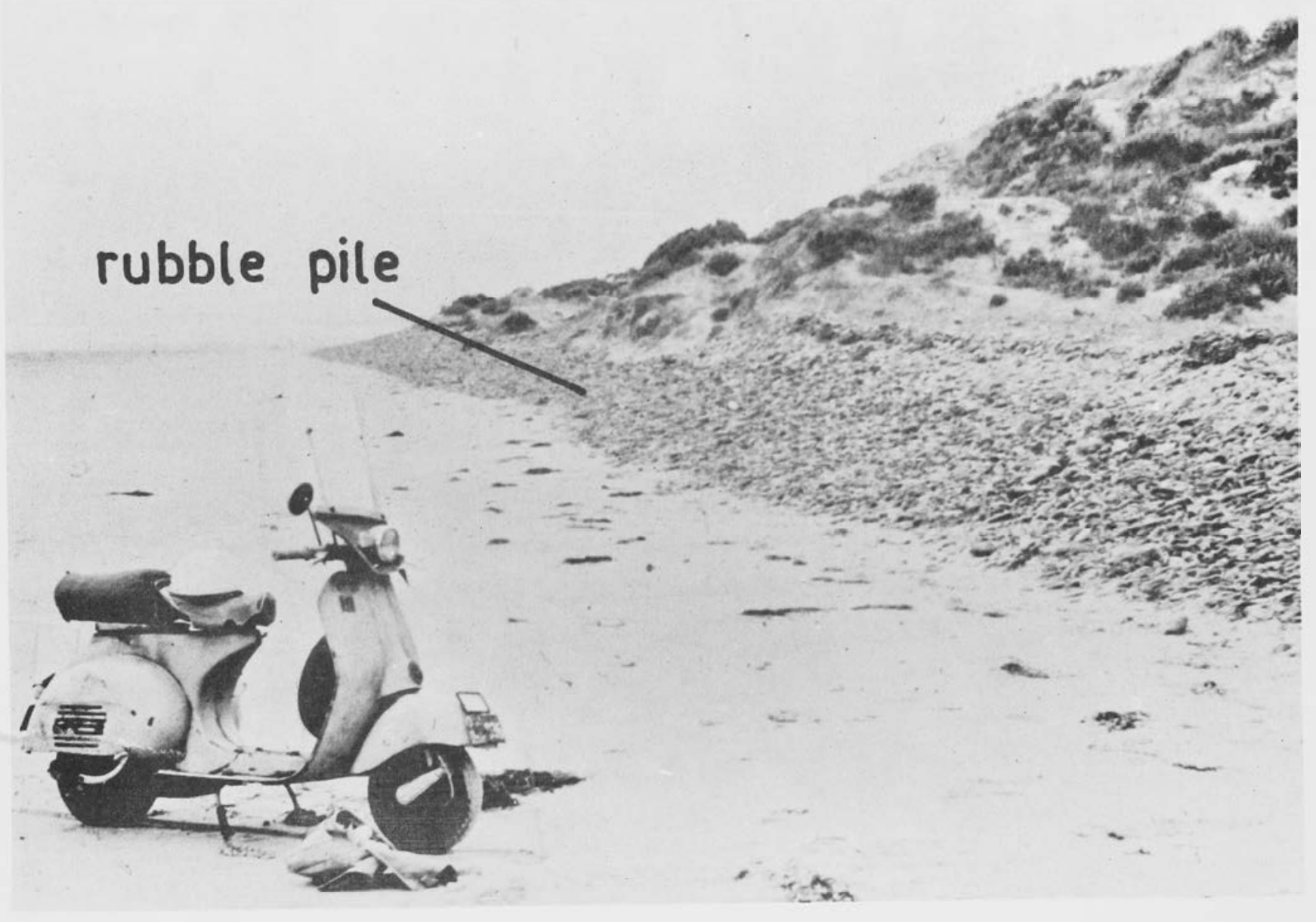

PLATE $\quad 12 \cdot 3$ 